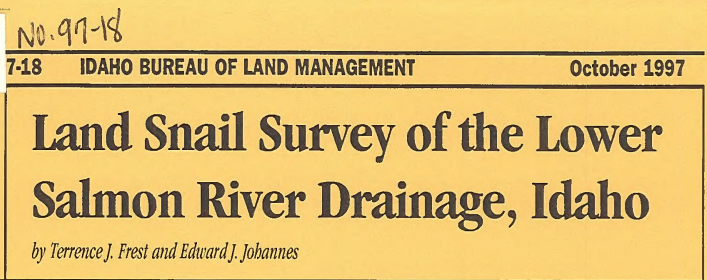




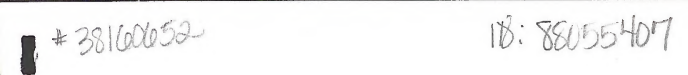

\title{
LAND SNAIL SURVEY OF THE LOWER SALMON RIVER DRAINAGE, IDAHO
}

\author{
Terrence J. Frest \\ Edward J. Johannes
}

Deixis Consultants

2517 NE 65th Street

Seattle, WA 98115-7125

revised September 15, 1995 
The universe is a more amazing puzzle than ever, as you glance along this bewildering series of animated forms---the hazy butterflies, the carved shells, the birds, beasts, fishes, insects, snakes, and the upheaving principle of life everywhere incipient, in the very rock aping organized forms. Not a form so grotesque, so savage, nor so beautiful but is an expression of some property inherent in man the observer---an occult relation between the very scorpions and man. I feel the centipede in me---cayman, carp, eagle, and fox. I am moved by strange sympathies; I say continually "I will be a naturalist."

-- Ralph Waldo Emerson, 1833

This wide ranging and plastic genus [Oreohelix] ....shows two centers of speciation. The most dramatic one is in the Salmon River Valley between Riggins and White Bird. Ten taxa of specific and subspecific rank are known from this restricted area, while the next greatest center, the entire northern part of Utah, has eleven races of five species distributed over a much wider area. This section of the Salmon River Valley is one of the best collected areas for land snails in western North America........This aggregation of taxa presents perhaps the most striking assemblage of monogeneric land snail local diversity in North America.

-- Alan Solem, 1974 


\section{TABLE OF CONTENTS}

INTRODUCTION-1.--

SCOPE AND METHODS -

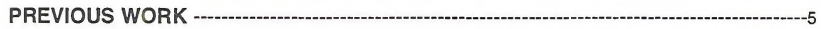

BACKGROUND - -

THE LOWER SALMON RIVER AREA

GEOLOGIC HISTORY-1.-1

BIOGEOGRAPHY-10

BACKGROUND - -

LOWER SALMON RIVER LAND SNAIL BIOGEOGRAPHY

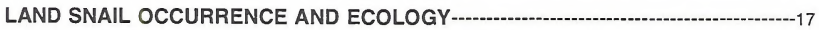

OCCURRENCE --_-18

ECOLOGY -

MOLLUSKS AS BIOLOGICAL INDICATORS---

SPECIES OF SPECIAL CONCERN-

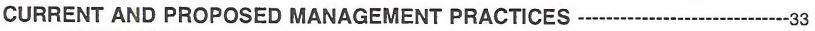

BACKGROUND --33

OVERVIEW --_-_--37

SPECIFIC PRACTICES -

SPECIES DISCUSSIONS--.--

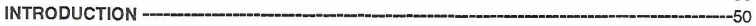

FORMAT - -

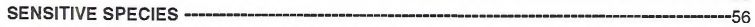

Allogona (Allogona) lombardii Smith, 1943 -56

Allogona (Allogona) ptychophora solida Vanatta, 1924 -

Crypiomastix (Bupiogona) popull (Vanatta, 1924) --_-59

Cryptomastix (Cryptomastix) harfordiana (Binney, 1878) -

Cryptomastix (Cryptomastix) mullani clappi (Hemphill, 1897) - -

Cryptomastix (Cryptomastix) mullani latilabris (Pilsbry, 1940) - 


\section{TABLE OF CONTENTS (cont.)}

\section{SENSITIVE SPECIES (CONT.)}

Cryptomastix (Cryptomastix) n. sp. 3 -

Cryptomastix (Cryptomastix) n. sp. 5 - 66

Cryptomastix (Cryptomastix) n. sp. 6 - 67

Discus marmorensis Baker, 1932- 68

Hemphillia camelus Pilsbry \& Vanatta, 1897--.--10

Ogaridiscus subrupicola (Dall, 1877) -

Oreohelix hammeri Fairbanks, 1984-72

Oreohelix haydeni hesperia Pilsbry, 1939--73

Oreohelix haydeni perplexa Pilsbry, 1939--74

Oreohelix idahoensis idahoensis (Newcomb, 1866) -

Oreohelix intersum (Hemphill, 1890) -

Oreohelixn. sp. 8 -

Oreohelix n. sp. 12 -

Oreohelixn. sp. 13 -

Oreohelix n. sp. 14 - -

Oreohelix n. sp. 15 -

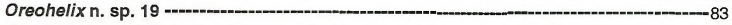

Oreohelix n. sp. 20 -

Oreohelix n. sp. 21 -

Oreohelix n. sp. 22 -

Oreohelixn. sp. 23 -

Oreohelix n. sp. 24 -

Oreohelix n. sp. 25 -

Oreohelix n. sp. 29 --

Oreohelix n. sp. 32 -

Oreohelix strigosa goniogyra Pilsbry, 1934 -

Oreohelix strigosa $\mathrm{n}$. subsp. 1 -

Oreohelix vortex Berry, 1932 -

Oreohelix waltoni Solem, 1975 -98

Pristiloma (Pristinopsis) idahoense (Pilsbry, 1902) -

WATCH LIST --

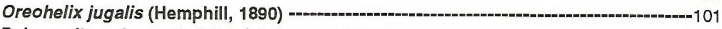

Polygyrella polygyrella (Bland \& Cooper, 1861) -

Radiodiscus (Radodiscus) abietum Baker, 1930 - 104

Zacoleus idahoensis Pilsbry, 1903 - 105

NONSENSITIVE SPECIES - -

Allogona(Allogona) ptychophora ptychophora (Brown, 1870) -

Anguispira kochi occidentalis (Von Martens, 1882) -

Cochlicopa Iubrica (Müller, 1774) - 107

Cryptomastix (Cryptomastix) mullani mullani (Bland \& Cooper, 1861-.......-_-108

Cryptomastix (Cryptomastix) mullani olneyae (Pilsbry, 1891)--108

Discus whitneyi (Newcomb, 1864) -

Euconulus fulvus alaskensis Pilsbry,1906 -

Hawaiia minuscula (Binney, 1840) -

Helicodiscus salmoneus Binney, 1886 - 


\section{TABLE OF CONTENTS (cont.)}

NONSENSITIVE SPECIES (CONT.)

Microphysula ingersolli ingersolli (Bland, 1874) -

Planogyra clappi (Pilsbry, 1898) -._-

Punctum (Toltecia) pusillum (Lowe, 1831) --_-_-

Pupilla hebes (Ancey, 1881) --_-

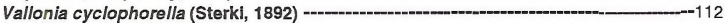

Vertigo concinnula Cockerell, 1897 -

Vitrina alaskana Dall, 1905 --_.--112

Zonitoides (Zonitoides) arboreus (Say, 1816) - -

SPECIES OF UNCERTAIN STATUS -

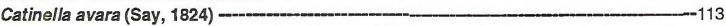

Cryptomastix (Cryptomastix) mullani hemphilli (Binney, 1886) --_-_-_-_-_-114

Deroceras sp. _-_ -114

Succinea stretchiana Bland, 1865--115

FRESHWATER TAXA -

FRESHWATER SNAILS - -

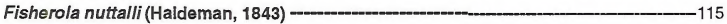

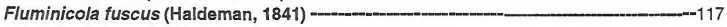

Pristinicola hemphilli (Pilsbry, 1907) -___-_-_-_-119

Stagnicola (Hinkleyia) montanensis (Baker, 1913) -_-___ -

Stagnicola (Stagnicola) idahoensis (Henderson, 1931) --_-_-____-_-121

Valvata n. sp. 1- -122

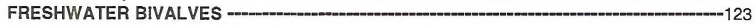

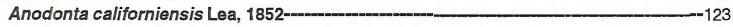

Gonidea angulata (Lea, 1838) -______________- 125

Margaritifera falcata (Gould, 1850) -_-__-_-_-_-__

ACKNOWLEDGEMENTS-

REFERENCES---:--

GLOSSARY-----:- 


\section{TABLES}

$\begin{array}{llc}\text { TABLE } & \text { TITLE } & \text { PAGES } \\ \text { 1. } & \text { MOLLUSKS OF THE LOWER SALMON RIVER VALLEY } & \text { T1-2 } \\ \text { 2. } & \text { STATUS OF LOWER SALMON RIVER VALLEY LAND MOLLUSKS } & \text { T3-4 } \\ \text { 3. } & \text { SITE FAUNAL LISTS } & \text { T5-58 } \\ \text { 4. } & \text { SPECIES SITE LISTS } & \text { T59-61 } \\ \text { 5. } & \text { SITE OWNERSHIP } & \text { T62 }\end{array}$

\section{FIGURES}

FIGURE TITLE

PAGE

1.

MAP OF THE LOWER SALMON RIVER VALLEY

$\mathrm{F} 2$

2.

LOWER SALMON RIVER OREOHELIXTYPE LOCALITIES

$\mathrm{F} 4$

3.

OTHER LOWER SALMON RIVER LAND SNAIL TYPE LOCALITIES

F6

4.

RANGES OF ENDEMIC OREOHELIX SPECIES

F8

5.

RANGES OF ENDEMIC POLYGYRID SPECIES

F10

6.

LOWER SALMON RIVER LAND SNAIL BIOGEOGRAPHY

F12

SPECIES/SITE RANKINGS

F14

LOWER SALMON RIVER LAND SNAIL SITE DIVERSITY

F16

NUMBER OF SENSITIVE AND CANDIDATE LOWER SALMON RIVER F18 LAND SNAIL SPECIES

10.

STATUS OF LOWER SALMON RIVER LAND SNAILS

$\mathrm{F} 20$

11. MOISTURE PREFERENCES OF LOWER SALMON RIVER LAND SNAILS

F22

12. ALTITUDE PREFERENCES OF LOWER SALMON RIVER LAND SNAILS

F24

13.

COVER PREFERENCES OF LOWER SALMON RIVER LAND SNAILS 
APPENDICES

APPENDIX TITLE

A.

B.

C.
SITE DESCRIPTIONS

SITE MAPS

SPECIES DISTRIBUTION MAPS
PAGES

A1-35

B1-39

C1-62

vii 


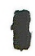

I

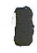

1

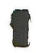

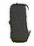

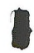

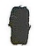

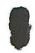

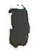

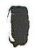

I

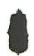

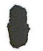

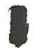

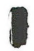

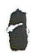

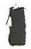

। 


\title{
LAND SNAIL SURVEY OF THE LOWER SALMON RIVER DRAINAGE, IDAHO
}

\author{
INTRODUCTION
}

The land snail fauna of the Lower Salmon River area has been famous among mollusk specialists (malacologists) since the 1860s. While land snails, with at least 30,000 species world wide (Solem, 1974), are relatively widespread, diversity here is exceptional, and a wide variety of forms are present. To date, at least 60 species have been reported (Table 1), more than half of the total for the entire state of Idaho. This number is quite remarkable for a North American state; and made even more so because of the prevalent habitat. High land snail diversity is generally associated with tropical islands and equatorial climes; at the very least, moist forested areas generally have much higher species diversity than semiarid areas such as western Idaho. In assessing the importance of the Lower Salmon River terrestrial malacofauna, we can do no better than to quote one of the preeminent land snail specialists of the century, the late G. Alan Solem in Solem \& Clarke, 1974): "This wide ranging and plastic genus [Oreohelix] ....shows two centers of speciation. The most dramatic one is in the Salmon River Valley between Riggins and White Bird. Ten taxa of specific and subspecific rank are known from this restricted area, while the next greatest center, the entire northern part of Utah, has eleven races of five species distributed over a much wider area.... This aggregation of taxa presents perhaps the most striking assemblage of monogeneric land snail local diversity in North America". Many of the taxa have unusual shell sculpture and are much sought after by collectors. Especially notable are such taxa as Oreohelix idahoensis idahoensis, Oreohelix haydeni perplexa, and Oreohelix strigosa goniogyra.

Apart from scientific and collectors' interests, these animals serve a vital function in the semiarid and forest ecosystems, being one of the primary groups responsible for recycling of dead plant matter and animal wastes. Moreover, a number of the taxa are very rare and local in distribution. Such considerations led to their proposed early inclusion on the first federal Endangered Species List. In the event, it was decided to survey for some of these taxa. The survey results (Solem \& Clarke, 1974) inspired placement of some seven Idaho taxa as listing candidates, a status maintained unchanged to the present (USFWS, 1994). Six of these taxa are Lower Salmon River endemics: Discus marmorensis Baker, 1932; Oreohelix idahoensis idahoensis (Newcomb, 1866); Oreohelix jugalis (Hemphill, 1890); Oreohelix strigosa goniogyra 
Pilsbry, 1934; Oreohelix vortex Berry, 1932; and Oreohelix waltoni Solem, 1975. Many of these taxa, and some others as well, are or were thought to be restricted largely or wholly to the Salmon River corridor. As much of the land here is public land owned and managed by the Bureau of Land Management, Nez Perce National Forest, or the State of Idaho, it was desirable to conduct a comprehensive survey of the Lower Salmon River corridor. This report is intended to be a comprehensive status survey of land snails on BLM holdings.

This report is organized as follows. We first discuss this survey's scope and range. The history of previous efforts by malacologists in this area is reviewed. We then discuss the region's geologic history; land snail biogeography, occurrence, and ecology; the role of mollusks as biological indicators; and some background information on sensitive taxa and status recommendations. We then provide an overview of the survey area's land snail fauna, as resulting from this study. A large section discusses individual taxon ecology, range, sites, and status. Finally, a few comments are made on the area's freshwater mollusk fauna. Details of site description and location and species maps are provided in the Appendices (A-C). To facilitate location in this somewhat long document, figures, tables, and appendices are placed in separate sections at the end of the report. In general, this report parallels the larger document prepared for the Interior Columbia Basin Ecosystem Management Project (Frest \& Johannes, 1995a). Further information and more complete regional context can generally be found in that document.

Accompanying this report is a smaller one specifically on the Lucile Caves ACEC mollusks.

\section{SCOPE AND METHODS}

As originally conceived, this survey was intended to concentrate on BLM property in the Lower Salmon River corridor from the Riggins area to the river's junction with the Snake in Hells Canyon. We extended the survey into the major Salmon River tributaries, including portions of the Little Salmon and Rapid rivers and all of the major creeks. Also covered is the mainstem Salmon River from French Creek (River of No Return) to Riggins (Figure 1). This was done for several reasons. First, we had already collected information on these areas as part of our own research, in the period from 1989-1993. Results of this work are incorporated in the report. Additionally, the BLM has substantial holdings in these areas. As well, some of the species, including certain of the candidate taxa, were known to range into these areas from past research, ours and others. Comprehensive assessment of their status was not possible without consideration of these sites, 
i.e. coverage of the taxa's full range. For the same reason, our sites were not necessarily confined to BLM lands, but included suitable snail habitat regardless of ownership.

Field work for this project was conducted between October 12 and October 24, 1993. Because of very low water conditions, jet boat usage on the Salmon River was restricted, and it was not possible to gain access to some portions of the area during the fall, 1993 field season. Accordingly, field work was continued into 1994, with most concentrated between April 24 and April 28, 1993. Timing of previous collecting trips included August, 1989; June, 1990; October, 1990; and June, 1993 (for details, see Appendix A). We collected a total of 213 land snail sites, some several times (Appendix A, Figure 1). The area between Riggins and White Bird, with most suitable habitat and relatively easy access, was covered heavily; but we also visited suitable habitat in the remainder of the area. Sites were placed to include 1) all definitely locatable historic sites; 2) all major lithologies in this geologically complex area (for rationale, see below); 3) all available habitat types, in rough proportion to their current prevalence in the survey area. Most of our sites were at low to moderately high elevations, in part because of considerations of ownership and access; but also because most of the species concerned do not occur at very high elevations. Nevertheless, we did sample some high elevation sites to ensure the accuracy of past reports.

Standard methods in malacology were use to conduct the survey (see Frest \& Johannes, 1995a and references therein). As the survey emphasized larger land snails, and as litter processing requires substantial time and effort, most sites were hand collected. However, a representative sample (about 20 ) were litter sampled also. The general lack of litter at most semiarid sites discouraged extensive sampling with this method; and such samples here were often disappointing, in that they added little to total diversity. This combination of methods was effective in approaching full actual diversity in the earlier Black Hills survey (Frest \& Johannes, 1993d). Live-collected material for later anatomic study was generally drowned in tepid water with a relaxant (a combination of menthol crystals and propylene phenoxytol) added. 24-36 hours was required for some taxa; and small snails and slugs were relaxed separately. Material from each site was fixed for $24-48$ hours in dilute (4-5\%) formalin and transferred to buffered $75 \%$ ethyl alcohol. In the lab, samples were cleaned and transferred to fresh alcohol. Samples were then picked, segregated by species, and identified as completely as possible without dissection. Finally, individual species' containers were filled with $75 \%$ ethyl alcohol with borax buffer and $10 \%$ glycerin for long-term storage.

Solem (1975) noted that new taxa had resulted from each major previous effort in this region and predicted that more would be found. We were nevertheless somewhat dismayed at the number of new forms represented in our collections. The prevalence of new taxa required considerable extra efforts at identification. We performed extensive dissections of many lots, using standard methods, i.e. removal of the shell and further fixation in Bouin's solution, followed 
by staining with hematoxylin and dissection under a binocular microscope in dilute Bouin's solution. Reproductive anatomy, both male and female, was most emphasized, as this has proved most useful in the past (e.g., Pilsbry ,1939; Solem, 1975). Solem's (1975) methodology and species criteria proved particularly useful for the genus Oreohelix. The methodology employed by Roth \& Miller (1993) and Emberton (1988) was especially suited to Cryptomastix. We also developed an extensive protocol for evaluating shell characters, finding that juvenile features as well as adult yielded taxonomically useful information. Many of the features used had been suggested earlier by Pilsbry $(1933,1939)$ but not applied systematically. The anatomical data are extensive, and will not be included except incidentally here. We suspect that characters useful in field identification will prove more useful in this context. Moreover, we found that there was a strong correlation between shell features and soft anatomy, such that species identified by attention to either could be distinguished by each. This is similar to the results noted by Emberton (1988) for the eastern North American Triodopsinae. Careful attention to details of shell morphology and good material is required, however.

We also found it very useful to review major museum collections for historic material. This was necessary to establish species morphology (here based particularly on the holotypes and not necessarily on literature discussion of the species' concept). We also made special efforts to collect topotypical material whenever possible. This was difficult in some cases, due to vague type localities and loss of historic sites. Museum material was also useful in determining past locations of taxa and the extent of environmental change in the region. Such material was one of the more important factors in determining species status. Most such museum work was done to further our own research interests and before initiation of this project. A little was done subsequently to round out species coverage. Institutions visited and timing of such visits is given below, as is the standard (Levinton et al., 1985) collection acronym. The latter is used widely in the species discussions. The amount of museum material from this area is quite large. Essentially ever major natural history museum in the world can be expected to have some, as do some private collections, including our own. Only the largest collections, i.e. those with much material and original localities, are listed here.

$\begin{array}{ll}\text { ANSP } & \text { Academy of Natural Sciences of Philadelphia, Philadelphia (1991) } \\ \text { CAS } & \text { California Academy of Sciences, San Francisco }(1991,1995) \\ \text { DMNH } & \text { Delaware Museum of Natural History, Wilmington (1991) } \\ \text { MCZ } & \begin{array}{l}\text { Museum of Comparative Zoology, Harvard University, Cambridge (1985, } \\ 1991)\end{array} \\ \text { FMNH } & \text { Field Museum of Natural History, Chicago (1985, 1991) } \\ \text { SBMNH } & \text { Santa Barbara Museum of Natural History, Santa Barbara (1995) } \\ \text { UCM } & \text { University of Colorado Museum, Boulder (1991) }\end{array}$


Aside from our own and museum collections, we also made use of those of varions private collectors, including that of Steve Welty, Dubois, Wyoming. We were assisted in the field at various times by a number of individuals (see ACKNOWLEDGEMENTS for details).

\section{PREVIOUS WORK}

\section{BACKGROUND}

Over 150 species of land snails and slugs have to date been ascribed to or described from eastern Washington and Oregon, Idaho, and western Montana. Large numbers of these were described during the classical period of U.S. malacology, i.e. from about 1860-1940. Major workers during this period included Henry Hemphill, who was active in Idaho, Washington, and Oregon from about 1860-1890; Henry Pilsbry and his collaborators (Vanatta, Ferriss), describing western U.S. forms from about 1910-1948; H. B. Baker, especially active in the West in the 1920 s and 30s; and Junius Henderson, working also in the period 1920-1940. Most of the earlier discoveries are summarized in Pilsbry's famous monograph (1939-48), still unsurpassed as a summary of knowledge concerning western U.S. land forms. After a time of relative quiescence marked by the publication of many smaller works, the pace of discovery and description of new forms has once again accelerated. It is quite likely that the land snail and slug fauna will eventually more than double, to approximately 300 forms. The slug fauna of about a dozen species is about half as large as that west of the Cascades, but still extraordinary. Many of the land snail genera occur only in western North America west of the Rocky Mountains; the fauna is thus sharply distinct from that of the rest of the U.S. As detailed below, endemicity is remarkable in certain genera, notably in the shelled genera Oreohelix and Cryptomastix and the slug Hemphillia. A number of distinct endemic clusters occur in various places (see Frest \& Johannes, 1995a, Tables $11-28$, for examples). Quite often, this endemicity is paralleled not only in mollusks, but in other animal and even plant groups as well. 


\section{THE LOWER SALMON RIVER AREA}

As noted above, this was one of the earliest areas in the western U.S. to be collected for land snails; and one in which particular effort was made. As a result, the land snail fauna here is better known than in some other areas in the western states. Perhaps the first, and certainly one of the more extensive, efforts were those of Henry Hemphill, particularly in the 1860s-1890s. Hemphill was an itinerant stone mason and tinker, who traveled over much of the Pacific Northwest and California from 1860 to his death in 1914 (Anon., 1914). Hemphill collected large series, which he offered for sale in privately printed catalogues, with the result that his material may be found in institutions throughout the world. He frequently revisited sites. Certain difficulties arise using his material (Coan \& Roth, 1987). Some lots may combine material from different sites. Moreover, his localities are sometimes imprecise, even by the standards of the time (as witness Pilsbry, 1940: "He was an outstanding collector, but weak on labeling his shells."; "Hemphill's vague localities are somewhat irritating.").

Hemphill is known to have collected this area in the 1860 s and again in the $1890 \mathrm{~s}$. He collected prodigiously, with some lots known to run into the hundreds. Hemphill specimens are distributed widely; but his personal collections, including unsold material and his own lots, came to rest at Stanford University, eventually being transferred to the CAS, where it remains. At about the same time, the pioneer naturalist J. G. Cooper is known to have collected in Idaho. E. H. Ashmun collected in this area in the early 1900s; much of his material is in the ANSP. H. B. Baker spent a considerable time working the region in the summer of 1930; this material is mostly in the ANSP. Allyn Smith visited this area in 1931 and again in 1941 (most material in CAS, with some in SBMNH). The noted private collector M. L. Walton made several trips to the Lower Salmon River area in the 1950s and in 1960; results of these trips are in the DMNH, with some material in the FMNH and ANSP also. In the 1960 field work, Walton was accompanied by Alan Solem. Solem and others did status survey work for the OES in this area in August, 1974, collecting over 100 sites. Much of the material from this survey is in the $\mathrm{FMNH}$, with some also in the Canadian National Museum of Natural History. Walter Miller has collected this area more than once, in the 1960 s and 1970s (material now in SBMNH). We have done extensive work in the region since 1989, culminating in field work in 1993-1994. As well, many private collectors have visited this region over the years. We are aware, for example, of several collecting trips by a total of six private collectors since 1990. Undoubtedly, there have been many more. As noted by Solem and Clarke (1974), professional malacologists have long known that many of the taxa here were rare and 
local, and hence feared that too much publicity in regard to site locations (or even descriptions of new taxa) could lead to their extirpation by over-zealous collectors. Thus, since Pilsbry very few detailed site descriptions have appeared in print. One result of this was that each new collector had to rework much of the region. Thus, it can safely be assumed that taxa which are known from few sites are genuinely rare. We have made extensive use of public and private information resources; and nobody else has found additional sites for these taxa.

The earliest formal descriptions of Lower Salmon River drainage land snails are those of Baird \& Cooper (1861-1862), Newcomb (1866), Binney (1874), Binney (1879, 1885, 1886), and Hemphill $(1890,1897)$. Baker (1932) and Smith (1943) are important succeeding works. Early literature was comprehensively summarized in Henderson (1924) and Pilsbry (1939-1948), who also added a substantial number of new taxa. Later contributions include those of Webb (1968, 1970a, 1970b); Solem (1975); and Fairbanks (1984). The most significant papers are listed in the REFERENCES and see also the equivalent section in Frest \& Johannes (1995a).

\section{GEOLOGIC HISTORY}

In explaining the extraordinary diversity of Lower Salmon River land snails, analysis of contemporary environments helps only partly. More probable causes are to be sought in the more distant past history of the area. For this reason, regional geologic history is touched on briefly here. For more complete overview and references to the geologic literature see Frest \& Johannes (1995a).

The Rocky Mountain geologic province, which includes western Idaho and in this state makes up its western boundary, made up a good part of the western edge of the North American continent from about 800 million years ago to about 100 million years ago. To the west of this area was the Pacific Ocean; to the east, a variety of interior seaways and the core continent, including the eastern and central U. S. The Rocky Mountains proper are the product of two major orogenic events, the first of which was initiated about 100 million years ago. The period of about 65-100 million years ago (YBP) was an era of intense geologic activity in western North America. Mountain building, vulcanism, and batholith emplacement occurred; and the last interior seaway dried up, linking the Rockies with the eastern part of the continent. Another series of mountain-building events took place in this area about 40 million YBP. Glaciation affected the region during the last 2.5 million years, with minor events (the Pinedale and Bull Lake) about 10,000 and 2,000 YBP 
respectively. The most severe ice age appears to have been the last major event of the Late Pleistocene, the 28,000-12,000 YBP Wisconsinan. Continental glaciation characterized the major Plio-Pleistocene episodes (perhaps 7), covering at least half of the region. Mountain glaciation was effective further south.

The general effect of glaciation would have been lowland displacement of land snail populations during glacials and isolation and fragmentation of populations, particularly on high peaks, during interglacials. Considerable drainage derangement and realignment also takes place during periods of glaciation. As stream corridors a major migration routes for active dispersal of land mollusks, the combined effects of glaciation on this region's land snails fauna must have been profound.

The rise of the Cascades and Olympics, perhaps beginning in the Oligocene but obvious during the Miocene (i.e., about 20 million YBP) and still ongoing, in essence made Washington and Oregon a permanent part of the continent. Vulcanism was initiated as early as the Eocene (perhaps 40 million YBP), and small islands or isolated land masses or island chains may have been present since the Cretaceous or even earlier. For about the last 100 million years, accretion of new blocks to the western edge of North America occurred sporadically. Major examples of such exotic blocks or accreted terrain were emplaced in the Blue Mountains and along the western border of Idaho, particularly in Hells Canyon and the Salmon River. Many of these may be part of the emplaced Wrangellian Terrain, a zone of activity stretching from Alaska to California and including the Lower Salmon River area. Similar emplacement occurred in the Olympics. Major emplacement of batholiths, as in Montana, occurred near the end of the Cretaceous, notably the Idaho and Kaniksu batholiths. Extensive volcanic sequences formed in Idaho during the Eocene. Aside from extensive mountain building, the Miocene also saw the initiation of flood basalts of the Columbia and Grande Ronde Groups in the interior of Washington and Oregon, many originating from the Blue Mountains. Such activity continued through the Pliocene. At about the end of the Miocene, downdrop of the Snake River Plain may have occurred. Major flood basalt activity, related to the progress of a diapire from northwestern Nevada and southeastern Oregon across southern Idaho, may have begun in the Miocene. As the diapire moved east and north across Idaho to its current position in Yellowstone National Park, it is accompanied by intense volcanic activity, producing younger and younger basalt flows. As with Montana, the northern portions of Washington and Oregon were affected by identically-timed Plio-Pleistocene glaciation, with effects being most pronounced in the western Cascades.

The Wrangellian heritage of this area is strong and very significant in terms of land snail distribution and speciation. In the eastern U.S. perhaps as many as half of the taxa are calciphiles (Hubricht, 1985). The Rocky Mountain flanks and great basin include a number of limestone units yielding especially suitable edaphic conditions for land snails; but these are mostly absent in 
Idaho, except for the southeastern portion. However, large emplaced blocks of limestone, limy schists, and other units yielding a calcicole-enhancing, high-calcium regolith, are concentrated in this portion of western Idaho. Areas to the west are mostly basalt, with comparatively few exotic blocks. Even where these are present, the comparative youth of this terrain limits the nuinber of possible species originations and migrations. Columbia and Grande Ronde Group basalts can yield good land snail terrain, and are much more suitable than certain igneous units, such as granites. Nevertheless, they are not generally as suitable as limestones. The Lower Salmon River area has a core of comparatively old terrain which includes significant carbonates, surrounded by younger basalts, thus with significant elements of both habitat suites. The only other comparable area, Hells Canyon, is actually part of the same system. Although incompletely explored, it is evident that high endemism, particularly in the genera Oreohelix and Cryptomastix, is present here also, with nearly complete large-snail turnover from north to south. There is some overlap: in the lowest portions of the Salmon River, Hells Canyon endemics are common (see below).

Large-scale geologic processes also strongly influence local climate. In general, the Rocky Mountain area seems to have had episodes of mild and moist tropical climate through the Miocene. This area would have been primarily coastal in position, with large mountain ranges to the east. Moist, mesic forests (with a much greater arboreal diversity than at present, including a stronger deciduous element) would have been the dominant vegetational regime. Such coastal areas remained warm and moist through the Eocene; but the rise of the Cascades meant that the interior areas eventually became comparatively dry, a condition probably initiated in the Miocene but more pronounced from the Pliocene to the Recent, except for interruptions of a sort by glacial periods. During the Pliocene and Pleistocene glacial advances, extensive pluvial lakes formed in interior Washington, Oregon, Utah, and Nevada, with interglacials, vulcanism, and other geologic activity causing periodic shifts in location of lakes, and their eventual near extinction; but also profoundly rearranging drainages in the Interior Columbia Basin.

These landscape-scale events had profound effects on the Interior Columbia Basin mollusk fauna. Relatively little is known of either freshwater or land forms for areas west of Idaho before the Eocene, as most of the area was marine. In the Rocky Mountain portions of the area was a rich freshwater fauna, which bears little relationship to more easterly faunas or to the modern malacofauna. Prevalent are large unionids, viviparids, pilids, and other families now either much reduced or extinct in the region (see LaRocque, 1960 and Taylor (1988a, b) for reviews). Viviparids extended as far west as the base of the Cascades during the Miocene (Taylor, 1985) The terrestrial fauna is more poorly understood. Certainly, some genera characteristic of the modern fauna were in place from the Cretaceous (notably Oreohelix). This exemplifies a common theme for continental mollusk faunas. For the most part, terrestrial faunas in North America seem to reflect a Gondwana distribution pattern, with most families present since the Paleozoic (Solem, 
1979 , 1981, 1984). For freshwater forms, this may be true of many families; but some later migration does take place (Taylor, 1985, 1988b). Reconnection of the Rocky Mountain area to eastern North America may be indicated by the finding of extralimital forms, suggestive of eastern affines and mixed mesophytic forests, in the Deep River Formation of Montana (Roth \& Emberton, 1994). Earliest common records for the western portion of the Interior Columbia Basin stem from the Eocene. Freshwater mollusk faunas of that period seem to show some relationship with the modem ones, and very little with the earlier Rocky Mountain faunas, save the persistence of Viviparidae for a short while. Land mollusks are comparatively poorly known, except for certain areas, such as the John Day Formation (Eocene) of Oregon. Generally, it would appear that some of the genera present today may have extended into the Rocky Mountain region in the early Tertiary. Late cooling and drying (Eocene-Oligocene) may have segregated some of the genera, with certain taxa remaining in the Rocky Mountains while others migrated westward or eastward (Roth, 1986b).

Unfortunately, there is essentially no Late Tertiary fossil record for the Lower Salmon River area. Indications from sites to the north and south are that the generalizations made above hold. The present fauna includes a wide variety of species adapted for semiarid environments and low-moderate elevations (see Figures 11-13). Geologic controls are evident from the high proportion of endemics (Figure 10a) and the narrow ranges of many taxa (Figures 4-5). As might be expected, a number of species have type localities here, including some present in other biogeographic regions. Considering just described forms, at least nine Oreohelix (Figure 2) and 5 other taxa (Figure 3) were first described from this rather circumscribed area. More detailed discussion of geologic and other influences on land snail distribution are deferred to the following sections.

\section{BIOGEOGRAPHY}

\section{BACKGROUND}

Many of the most characteristic land and freshwater mollusk (bivalve and snail) taxa currently living in the West Coast states have very limited geographic ranges. Part of the current freshwater snail fauna, for example, may consist of relatively recent (perhaps 65 million years B. P.) 
immigrants from Asia, or forms derived from Asian ancestors and not present elsewhere in the U.S. Most of North Amenica is generally separated into two faunal realms, the Eastern and Western Divisions (see Frest \& Johannes, 1995a, Figure 2). Faunas of these two areas are distinct even at the family level. For example, the Interior Columbia Basin (or ICB) families Helminthoglyptidae, Oreohelicidae, and Ammonitellidae do not range into the eastern Division. Even in such widespread farnilies as the Polygyridae, western forms are generally distinct at the generic level (e.g., Vespericola and Cryptomastix vs. Mesodon and Triodopsis). Characteristic coastal forms are different from those of the Rocky Mountains (e.g., Monadenia vs. Oreohelix), and California coastal forms are very distinct from those of most of Oregon, Washington, and British Columbia. In both cases, these differences involve not rare taxa, but the dominant and characteristic genera in the biogeographic unit. Many such taxa are confined to a coastal belt that extends only from the Cascades to the Pacific, and is believed to be of comparably recent origin geologically.

Within the Interior Columbia Basin, there are three distinct land snail provinces widely recognized by malacologists (Henderson, 1931b, Pilsbry, 1948, with modifications by Bequaert \& Miller, 1973: Figure 2 of Frest \& Johannes, 1995a), all in the Western North American Division. The Oregonian Province extends from coastal British Columbia just into extreme northern California. Notable are a number of species of the helminthoglyptid genus Monadenia and the polygyrid genus Vespericola. Also characteristic is the variety of slugs, notably in such genera as Hemphillia and Prophysaon. The Washingtonian Province extends east from the Cascades crest in southern British Columbia to the Idaho Panhandle and northwestern Montana, thence through much of eastern Washington and Oregon to the Cascades foothills north of Klamath Falls. In this province, Monadenia and Vespericola are present only at the western fringe, and Cryptomastix largely replaces Vespericola. Some genera, such as Polygyrella, Microphysula, Udosaryx, Zacoleus, and Magnipelta are provincial endemics. Oreohelix is present but sporadic, with only a few species in one or two lineages present. Some genera are common to the Oregonian and Washingtonian provinces but absent or rare elsewhere. Example include Prophysaon, Hemphillia, and Pristiloma. The large Rocky Mountain Province lies generally south of the Washingtonian, and includes southwestern Montana, southern Idaho, Wyoming, western Colorado, Utah, Nevada, and eastern and northeastern California. It is generally characterized by absences, such as those of many typical eastern genera and genera common to the other western provinces, such as Monadenia, Cryptomastix, Pristiloma, Microphysula, Radiodiscus, Hemphillia, Udosaryx, and Magnipelta. Particularly notable is the great number of species and morphologies in the genus Oreohelix. According to this scheme, the Lower Salmon River area lies solidly in the Washingtonian Province.

Provincial boundaries are fluid at best, and subject to modification by large-scale geologic events. Those discussed here apply best in the Late Tertiary-modern period, more specifically for 
the last 30 million years or so. Even at present, characterization of certain areas is not straightforward. The Columbia Gorge, because of its unique position and history, manages to maintain a disparate mix of elements, none of which is greatly speciose but many of which are endemic. Notable are species of Monadenia, Vespericola, Cryptomastix, and Oreohelix, mostly xerophiles and commonly co-occurring. The eastern Cascades in Washington may be another such area, featuring easternmost occurrences of Oregonian Province species with westernmost occurrences of Washingtonian Province taxa, along with a few unique elements.

Distribution of some especially important genera should be noted briefly. Oreohelix (see Frest \& Johannes, 1995a, Figure 9) [or more generally, the North American endemic family Oreohelicidae] is particularly characteristic of the Rocky Mountain and Washingtonian provinces in the Interior Columbia Basin. Note that most occurrences of the genus are in the eastern half of the area. In general, the western occurrences are sporadic and belong to just a few taxa. Substantial endemism is present in the genus in the Hells Canyon area, lower Salmon River valley, southeastern Idaho, Wasatch Range in Utah, and in the northwestern portions of Montana. The genus appears to be absent from large parts of the most arid portions of the ICB but continues with high diversity occurrences into the Rocky Mountains proper. The polygyrid Cryptomastix (Frest \& Johannes, 1995a, Figure 10) occurs mostly in the eastern portions of the Interior Columbia Basin; and also in the Oregonian Province. In this area, only 2 species are present, both quite different from the Washingtonian taxa. Areas of high endemicity are in Hells Canyon, the lower Salmon River valley, and the Clearwater River drainage. The genus does not occur in the far south areas of the ICB; nor in the Rocky Mountain Province areas. Diversity is low in the interior areas of both Washington and Oregon; and the genus appears to be absent from large areas in both states. The slug genus Hemphillia (Frest \& Johannes, 1995a, Figure 11) is typical of both the Washingtonian and Oregonian provinces. Its distribution pattern is similar to that of Cryptomastix, but more exaggerated, with major lobes into the mountainous regions of both provinces. As with the shelled polygyrids, species are very different in the west Cascades and Olympics, versus Idaho and Montana, although here higher diversity is in the Oregonian Province, not the Washingtonian. Many genera are distributed more or less uniformly in the Interior Columbia Basin assessment area (excepting the drier portions of the interior and some other special cases discussed before); but these tend to be the more cosmopolitan genera. A significant number of taxa have the more sporadic distribution suggestive of relict status. Examples in the Interior Columbia Basin include Polygyrella and Megomphix: see SPECIES DISCUSSIONS section in Frest \& Johannes, 1995a for details. 


\section{LOWER SALMON RIVER LAND SNAIL BIOGEOGRAPHY}

The Lower Salmon River areas is a part of the Washingtonian Province. As such, it would be expected to have substantial numbers of species in such genera as Oreohelix and Cryptomastix, and for such genera as Hemphillia and Polygyrella to be present. Overall, the fauna is typical for a Washingtonian area, in terms of genera present (Tables 1,2). Ecological considerations limit the occurrence of such genera as Polygyrella and Hemphillia (both tend to be notophiles or at least strong mesophiles). Still, both are present locally, though at few sites (Table 3). In most parts of North America, relatively cosmopolitan forms, i.e. those living in more than two mollusk provinces; particularly, those living in both Divisions, would be expected to make up a very large proportion of the total species diversity. Regional endemics, i.e., those present in more than one area in the host province (here, the Washingtonian) typically make up the next largest component. Finally, strict local endemics are usually a small but important part of any regional land snail fauna.

The Lower Salmon River area is not typical; and it is useful to use a slightly modified scheme to analyze land snail biogeography here (Table 1: illustrated diagrammatically in Figure 10a). Only some $7 \%$ of the 61 species reported to make up the malacofauna (here including Cryptomastix mullani hemphilli, even though it may now be locally extinct) are truly cosmopolitan forms. Regional taxa (for this purpose defined to embrace species occurring in more than one Washingtonian province) make up a rather small $38 \%$ of the taxa. In total, strong endemics constitute a surprising $55 \%$ of the total diversity. As noted previously, some of these are shared with the adjacent Hells Canyon drainage (a relatively small $7 \%$ ). This leaves nearly half of the malacofauna (44\%) as strict endemics occurring only in the Lower Salmon River drainage.

In such a situation, it is perhaps not surprising to find that ranges of individual taxa are often very limited. In this context it is most helpful to discuss Oreohelix and Cryptomastix, which two genera account for most of the endemic diversity (Table 1). None of the 24 taxa recognized here occur throughout. The most widely distributed form is perhaps Oreohelix jugalis (Appendix C32); but even this form is absent form significant portions of the region. Many taxa have distributions limited to stream corridors less than $10 \mathrm{mi}$. in length, and often narrower (Figure 4). Frequently, these ranges are non-overlapping. Ranges of the 10 taxa in Cryptomastix discriminated here are also rather narrow; but much less so typically than in Oreohelix (Figure 5). Ranges also are more likely to overlap.

Within Oreohelix it is possible to distinguish several groupings, possibly deserving separate taxonomic status, on the basis of parallel anatomical and conchological features. Some of these do not occur locally and are characteristic of other areas, such as the Rocky Mountain or 
Southwestern provinces. Lower Salmon River groupings and their distributions, both locally and regionally, are as follows:

1) Oreohelix jugalis group. Limited to the Washingtonian Province. Local members are Oreohelix jugalis and Oreohelix n. sp. 15. Other members are such taxa as Oreohelix junii (= type O. strigosa strigosa: see Frest \& Johannes, 1995a) and Oreohelix n. sp. 26 of Frest \& Johannes, 1995a. Species of this group occur in much of the area but appear to be absent from the lowermost Salmon River and Hells Canyon. The jugalis-type species are fairly broad in their habitat tolerances, tolerating the range from moderately xeric-moderately mesic situations. Many occur on basalts; but substrate preferences are broad generally.

2) Oreohelix haydeni group. Members of this distinctive assemblage occur scattered throughout the range of the genus, although absent from the western portion of the Washingtonian Province. Local members are Oreohelix haydeni hesperia, Oreohelix haydeni perplexa, Oreohelix n. sp. 8, and Oreohelix n. sp. 24. The range of the group is quite narrow, essentially the Salmon River drainage from Riggins to the mouth of Wet Gulch. There are other related forms in southern Hells Canyon. These snails are typically xericoles. Over the whole range, this group is found on a variety of substrates; but most often limestone (as locally).

3) Oreohelix idahoensis group. This very distinctive species group is limited to the Lower Salmon River-Hells Canyon area. Included are Oreohelix idahoensis idahoensis, Oreohelix waltoni, and Oreohelix n. sp. 20. Related forms are Oreohelix idahoensis baileyi and Oreohelix n. sp. 30 of Frest \& Johannes, 1995a. This set of species occupies a similar, rather limited, area to the last, but extended formerly to the White Bird area (currently to the Box Canyon area). The group is also quite limited geographically in Hells Canyon. These taxa are generally xericoles, and apparently are mostly or always calciphiles also.

4) Oreohelix intersum group. This set of taxa occurs only in the Lower Salmon River region. It is very restricted in distribution even here, essentially to a portion of the Rapid RiverLittle Salmon River drainage; individual taxa typically have ranges of a few miles. Member taxa are Oreohelix intersum; Oreohelix hammeri; Oreohelix n. sp. 12; Oreohelix n. sp. 13; Oreohelix n. sp. 14; and Oreohelix n. sp. 19. Several species are found only on limestone, but intersum itself has been noted from limestone, basalt, and schist regoliths.

5) Oreohelix vortex group. At the moment, this includes only Oreohelix vortex and Oreohelix n. sp. 32. The group occurs only from about Slate Creek to a point midway between the mouths of White Bird Creek and Rock Creek (Figure 4). Nothing closely comparable has yet been reported outside of the Lower Salmon River Valley. Nearly all Oreohelix vortex sites are on basalt. This taxon and Oreohelix n. sp. 32 prefer rather xeric settings, especially open basalt talus.

6) Oreohelix "strigosa" group. This species assemblage in the broad sense has been noted from most of the area of occurrence of the genus. It is probably too broad as presently 
conceived; in particular, the status of forms called strigosa depressa needs to be reassessed in detail. Here, we regard Oreohelix strigosa goniogyra, Oreohelix strigosa n. subsp. 1, Oreohelix n. sp. 21, Oreohelix n. sp. 22, and Oreohelix n. sp. 23 as members. These snails are generally large types preferring mesic, often well-forested settings; but a significant number prefer more xeric settings. Substrate preference is rather catholic, although certain species can be limited to limestones or other calcareous lithologies. Distribution locally is fairly broad, with the exception of the major tributaries, perhaps because of the limited occurrence of situations favoring mesocoles.

The smaller number of Cryptomastix species may be divided into perhaps three groups, also established on a combination of shell and soft part features (see SPECIES DISCUSSIONS for details):

1) the Bupiogona group is represented by a single species locally, Cryptomastix (Bupiogona) populi. This taxon is restricted in the Lower Salmon River survey area to the lower third of the river (Figure 4), and occurs also in part of Hells Canyon. Other species of this assemblage are found in Hells Canyon (Cryptomastix (Bupiogona) n. sp. 1 and Cryptomastix (Bupiogona) n. sp. 2 of Frest \& Johannes, 1995a). These snails prefer basalt substrate in rather strongly xeric settings. They are fairly large species with depressed spires and no apertural teeth; but best characterized anatomically.

2) the mullani group involves such taxa as Cryptomastix (Cryptomastix) mullani mullani and Cryptomastix (Cryptomastix) mullani olneyae, rather large forms with weakly developed apertural dentition. Other examples include Cryptomastix (Cryptomastix) mullani hemphilli (reported from this area) and Cryptomastix (Cryptomastix) mullani blandi. Cryptomastix (Cryptomastix) n. sp. 6, Cryptomastix (Cryptomastix) mullani latilabris, and Cryptomastix (Cryptomastix) mullani clappi likely also belong here; and are locally endemic. Most of these species are common in mesic settings, often forested, on a variety of substrates. Cryptomastix (Cryptomastix) mullani mullani is the most widely distributed and eurytopic species in the genus. Cryptomastix (Cryptomastix) n. sp. 6 and Cryptomastix (Cryptomastix) mullani clappi are unusual in that they are most common in xeric-semixeric settings, although also found at more mesic sites at low elevations.

3) the magnidentata group comprises small forms with parietal or palatal teeth generally well developed. Aside from the nominate form, such species as Cryptomastix (Cryptomastix) samburni and Cryptomastix (Cryptomastix) n. sp. 1 and 2 of Frest \& Johannes, 1995a are placed here. The group is widespread in Hells Canyon and the lower Salmon River area; and sporadic in the Clearwater drainage. Local members include Cryptomastix (Cryptomastix) harfordiana, Cryptomastix (Cryptomastix) n. sp. 3, and Cryptomastix (Cryptomastix) n. sp. 5. Two of these are strict local endemics; but Cryptomastix (Cryptomastix) n. sp. 3 is also found in the northern 
part of Hells Canyon. These taxa can occur on a variety of substrates, but are most frequent on basalt, and some may be restricted to it. The magnidentata group is characteristically xericole.

A prominent feature of land snail distribution is this region as a whole is the very different aspect to faunas collected only a few miles apart. Looking at the complete terrestrial malacofauna (for individual species maps see Appendix 3), five major groupings are evident. These are illustrated in Figure 6:

1) one fauna is characteristic of the region from a point midway between the mouths of White Bird and Rock Creeks to the river mouth. This same species association also occurs in part of hells Canyon, essentially the northern portion in WA and OR. Much of this area is typified by xeric habitat, especially basalt outcrops and taluses. Distinguishing taxa are Cryptomastix (Bupiogona) populi, Cryptomastix (Cryptomastix) n. sp. 5; Cryptomastix (Cryptomastix) n. sp. 3; Oreohelix n. sp. 25; and Oreohelix n. sp. 29.

2) the second species association is as much characterized by the absence of species of assemblages 1) and 3) as positively; but the rather ubiquitous occurrence of Oreohelix vortex is very evident. Cryptomastix is limited largely to harfordiana and $\mathrm{n}$. sp. 6 . The area involved stretches from a point midway between the mouths of Rock Creek and White Bird Creek to the lower reaches of Slate Creek. As before, xeric habitats and basalt substrates are typical.

3) the next species association ( 3 on Figure 6 ) is confined largely to the Salmon River corridor proper, from the mouth of Slate Creek to Riggins. In this region occur taxa of the idahoensis species group, as well as very local members of several others: idahoensis idahoensis; waltoni; Oreohelix n. sp. 20, n. sp. 21, n. sp. 23; and n. sp. 24. Among Cryptomastix species, harfordiana and n. sp. 5 are typical. Sites occur on a wide range of substrates, including metasedimentary lithologies, limestone, basalt, schist, and mixed boulder piles. Many localities are either xeric or semixeric in nature, and occur with a sage scrub plant community.

4) the penultimate species assemblage is typical of a very limited area along the lower Little Salmon River corridor (Figure 6). It is in this region that the various species of the intersum group are found. Cryptomastix occurrences are particularly sporadic; and none of the species are strict endemics. Substrate is variable, with limestone and basalt most evident; but schist and other lithologies may also be involved. Once again, most sites are in sage scrub and rather open and dry.

5) the last species assemblage is a feature of the River of No Return in the area from Riggins upstream to the mouth of French Creek (Figure 6). Characteristic taxa are Oreohelix n. sp. 15 and Cryptomastix (Cryptomastix) mullani clappi. Most of the other long-known endemic Lower Salmon River taxa are not found here; even Oreohelix jugalis is very rare. Substrate ranges from schist to granite; most sites are rather dry Ponderosa pine forest, i.e. most taxa are slight xerophiles-weak mesophiles. 
These species assemblages account for about $80 \%$ of the collected sites. The remainder are often those found at higher elevations and/or along major tributaries, such as Slate Creek or John Day Creek. Land snail communities at these sites are often every bit as distinctive (as witness, for example, those occurring on the large limestone exotic terrain block in the middle reaches of Slate Creek); but the small number of sites has rendered it inconvenient to formally define these as yet. Perhaps the most distinctive are those along middle Slate Creek, with Hemphillia camelus, Zacoleus idahoensis, Discus marmorensis, Allogona lombardii, Oreohelix strigosa n. subsp. 1, and Oreohelix n. sp. 22; and the related sites along John Day Creek, with Discus marmorensis, Cryptomastix (Cryptomastix) mullani latilabris, and Oreohelix haydeni hesperia. Interestingly, both groups involve high-diversity communities restricted to middle elevation moist, shaded, mesic mature forest sites with limestone substrate.

\section{LAND SNAIL OCCURRENCE AND ECOLOGY}

\section{OCCURRENCE}

Land snails can be found at any elevation and in all situations from coastal lowlands to arid deserts, if the area is relatively undisturbed. As a generality, land snails are most diverse in tropical regions and on certain Pacific islands (Solem, 1974, 1984); but temperate diversity on a site basis may be equal to that in more equatorial climes. Solem (1974), Solem, Climo, \& Roscoe (1981), Solem \& Climo (1985), and Emberton (1995) record sites from temperate New Zealand and Madagascar with land snail diversity exceeding 50 species. Some sites in eastern North America have more than 30 species (Emberton, 1995; Hubricht, unpub.), and Midwestern sites with 20 or more species are not unusual. On a world-wide basis, forested locales are generally most diverse, and the average overall is probably close to 20 (Solem, 1984). In the western U.S., sites with this diversity are less common, although quite possible in coastal sites, e.g. in the Olympics [Branson's (1977, 1980) and Branson \& Branson's (1984) sites are much less diverse because efforts were largely limited to hand collecting]. In our experience, litter and hand sampling of coastal fir forests in Washington, Oregon, and northern California, as well as mixed spruce, fir, or pine forests in northern Washington, northern Idaho, and western Montana, generally yields 10 15 species of shelled snails and slugs in relatively intact sites. Other things being equal, diversity 
declines at high latitudes; and these faunas typically consist mostly of small and widespread forms. Areas that are permanently frozen generally lack land snails. In this area, small land snails seem unusually rare, even in forest settings; and litter samples were relatively low in diversity also. As noted previously, large land snail diversity of the survey area as a whole is great; but that noted at any one site is comparatively low.

At the other end of the spectrum, truly arid regions ( $<6$ " of precipitation yearly) also often have low diversity land snail faunas or large regions with no land mollusks. On the other hand, relictual areas in such regions may have surprising diversity (often low abundance), and certain land snail families are specialized for arid regions. In North America, two examples are the Mexicansouthwestern Urocoptidae and Holospiridae. Semiarid areas ( $>6$ but $<12$ " annual precipitation) generally have land snail faunas, sometimes showing substantial diversity. Often, only one or two species will be found at a site, but regional endemics can be common. Hells Canyon (ID-OR-WA), the lower Salmon River valley (ID), and the Utah Wasatch Range are world-famous for their diverse semiarid land snail faunas. In the latter, site abundance is often quite high, even though per site diversity may be low. Quite often, families or smaller groupings will show physiological specialization for particular environments, e.g. for arid and semiarid areas. Factors influencing distribution and physiological modifications for land snails of such regions have been discussed by Schmidt-Nielsen et al. (1971). One example is the western U.S. endemic genus Oreohelix. Physiological adaptations for aestivation in this genus have been investigated by Rees \& Hand $(1990,1991,1993)$ and Rees et al. (1991). One obvious adaptation by Oreohelix is the practice of hatching eggs internally, instead of the typical pattern of laying them in favorable locations. Dessication of eggs and juveniles is perhaps the most common cause of land snail death world wide (Solem, 1984), and the problem is acute in arid areas. Hatching the eggs internally provides some insulation; additionally, adults seem to be able to delay release of juvenile if conditions warrant. Despite environment-tuned moisture tolerances, land snails and slugs prefer moist environments, with some taxa being restricted to and many preferring the more typically moist portions of the particular environment in which they occur. Thus, distinct xerophile, mesophile, and notophile species groups may characterize certain portions of any large geographic area. Sometimes, moisture preferences seem to characterize groupings even at the generic level. Vespericola, for example, is generally a strong notophile, as is the slug genus Hemphillia. Holospira seem to be a definite xerophile. The more speciose or more widespread genera often have species specialized for particular moisture regimes. Examples in the Interior Columbia Basin include the characteristic large genus Oreohelix and the widespread small genus Vertigo. In this area, the range of environments utilized by Oreohelix is quite broad, with particular species or species groups, as noted above, xeriphiles, mesophiles, or nearly notophiles. There are direct 
parallels in all three regimes in Cryptomastix also, as noted above and in the SPECIES DISCUSSIONS.

Just as land snail diversity (and often abundance) decreases in area with low effective moisture (be these cold xeric conditions such as tundra or warm xeric such as deseri), diversity (and often abundance) generally decreases with increasing altitude. High-altitude faunas often consist mostly of small taxa, many of which are not endemics; and site diversity often is 5 or less in the ICB. A few apparent true hypsiphile large taxa do occur in the Interior Columbia Basin. Examples include Oreohelix alpina, Oreohelix elrodi, and Discus brunsoni. True Oreohelix subrudis also seems to prefer such settings. True hypsiphiles may be lacking locally, although Oreohelix n. subsp. 1 seems to prefer higher sites, as does Oreohelix hammeri. Locally there seems no decrease in the proportion of large taxa with increasing altitude; but it must be borne in mind that high-elevation sites were mostly outside the scope of this project.

For other species, temperature preferences may be a more strongly determining factor limiting distribution. Most species in the Oreohelix haydeni group, for example, seem to prefer warm xeric settings. Certain taxa, such as Pristiloma arctica, Vertigo modesta, Vertigo alpestris, and Zoogenetes harpa, prefer cold environments. Such species as these become more common regionally to the north, where they may be widespread at low elevations, but are rare to the south, where they may be confined to mountain tops. An example among larger taxa is the Federal candidate species Discus shimeki (see, e.g. discussion in Bequaert \& Miller, 1973, and Frest \& Johannes, 1993d). The observed patterns for the region as a whole seems to hold true locally for those species or species groups common to both. Some of the more strongly endemic species groups here also seem to be stenotopic; in particular, to be restricted to more xeric locales. The Oreohelix idahoensis and Oreohelix intersum species groups provide examples; and Lower Salmon River haydeni group members are also generally xeric sage scrub inhabitants (Oreohelix haydeni hesperia may be a notable exception).

Size analyses of land snails indicate a strongly uneven distribution by height or volume. According to Burch \& Pearce (1990), there are four main groupings: 1) minute ( $<3 \mathrm{~mm}$ in longest (major) dimension); 2) small (3-10 mm major dimension); 3) medium (11-30 mm major dimension); and 4) (>30 mm major dimension). Emberton (1995) suggests a very similar arrangement. Quite useful locally is subdivision into three subgroupings: those $\leq 2 \mathrm{~mm}$ (which often make up half the diversity of a typical land snail fauna); those 2-10 mm (which may be termed medium-sized); and those $>10 \mathrm{~mm}$ (large). Small species, though seldom noticed, are most ubiquitous, as their small size makes concealment from predators and retirement in adverse conditions most practical. Viable populations of small forms may occupy very small areas. At the highest elevations (tundralike habitat), only small forms are found. Likely genera in the Interior Columbia Basin assessment 
area include Pristiloma, Pupilla, Vertigo, Vallonia, Cochlicopa, Punctum, and Euconulus among small forms; and Discus, Zonitoides, Retinella, and Radiodiscus among medium-sized.

As we emphasized earlier, the Lower Salmon River area is unusual in this respect. Small and medium- sized taxa are uncommon generally and not particularty diverse. Moreover, small forms do not appear to increase in either abundance or diversity here, if low and medium elevation sites are compared.

Generally, the larger genera are absent at high elevations; but such forms as Oreohelix alpina and Oreoehlix subrudis may be exceptions. Quite often some slugs (e.g., Udosarx, Deroceras) are present also. On the whole, the alpine land snail fauna is mostly rather widespread and eurytopic forms, many of which may be present at lower elevations as well (examples include Oreohelix subrudis, Cochlicopa lubrica; Discus whitneyi, Deroceras spp., Euconulus fulvus alaskensis, Punctum spp., and Zonitoides arboreus), or species which are present at lower elevations to the north (e.g., Zoogenetes harpa, Retinella wheatleyi). Only a few described taxa in the Interior Columbia Basin appear to be true alpine endemics (hypsiphiles). The best examples are the large Oreohelix alpina and small Pristiloma arcticum crateris. Forms which appear to be restricted to moderately high-high elevations are, however, quite common. Prominent examples in the assessment area include Oreohelix subrudis, Oreohelix idahoensis baileyi, Oreohelix hammeri, Oreohelix n. sp. 8, and Oreohelix strigosa n. subsp. 1. At lower elevations, substantial numbers from all three size groupings may be present. Generally, the large polygyrid land snail genera Allogona, Vespericola, and Cryptomastix occur only at low-moderate elevations. Few small to medium-sized forms seem as restricted, although diversity is generally higher in all three groups at lower elevations (if pristine sites are compared). Note that the survey area also appears exceptional in this regard; however, the current lack of low elevation, mesic forested sites here may preclude accurate comparison. Still, overall there is some suggestion of altitudinal speciation in some genera, but most is likely due more to responses to differences in effective precipitation and temperature than to height per se.

Despite the original, essentially ubiquitous distribution of terrestrial mollusks in the assessment area, the modern picture is somewhat different. Were one to, say, divide the whole area into $1 \mathrm{mi}$. grid squares and sample the corners, at least $80-90 \%$ or more of the samples would have no mollusks. Much of this is due to human modifications in the last 150 years; however, some is due to other factors. These include unfavorable substrate (e.g. granite); recent formation geologically (e.g. the eastern Snake River Plain); effects of Pleistocene glaciation (e.g. the northern Cascades); and effects of catastrophic geologic events (e.g. interior Washington, as a result of the Missoula Floods). Portions of interior WA and OR even before settlement had relatively few land snails due to the effects of the Pleistocene Bonneville and Missoula Floods. Some of these same areas and the eastern Snake River Plain, ID and upper Deschutes River 
drainage, $O R$ are volcanic terrain of relatively recent origin. The very patchy distribution of land snails in Yellowstone National Park is due to the same cause. Granitic terrain is generally unfavorable to mollusks; hence, they are rare in the Sawtooth Mountains and Idaho Batholith areas in ID, even though immediately adjacent regions in the same state are unusually diverse. $A$ local example is the drop in diversity experienced as one progresses upstream in the Salmon River from Riggins. Entering the western portion of the River of No Return (Riggins to French Creek), there is a substantial drop in species diversity. Above French Creek, i.e. in the Idaho Batholith outcrop area, large land snails of any kind are rare. A similar phenomenon takes place as one proceeds upstream in the Little Salmon River drainage from the mouth. The area near Riggins, with more diverse substrate, has larger faunas with several endemics. As the granite portions of the drainage are encountered, large land snails diversity quickly drops to about two species, both cosmopolitan and eurytopic forms. Northwestern WA has a comparatively small fauna due to Pleistocene glaciation. As was detailed above, provincial boundaries are also due in part to geologic history. Since the Miocene, areas between the Rocky Mountains and the Cascades have become relatively dry, and may lack land snails except locally. Such gaps in distribution are evident when plots of the distribution of the principal genera are compared (see Frest \& Johannes, 1995a, Figures 8-10).

In the Lower Salmon River survey area, occurrences cover a wide variety of habitats and elevations. Surprisingly for such a relatively arid area, a very large proportion of our sites had land snails (Figure 8). The general species/site rankings (Figure 7) had the expected negative logarithmic distribution, except that the right tail is unusually long (there are many species restricted to a few sites). This pattern is similar to that observed in the Upper Sacramento drainage study (Frest \& Johannes, 1995b), which involved another area with complex geology and drainage history and numerous narrow endemics. A third example is the Black Hills National Forest survey (Frest \& Johannes, 1993d). To generalize, over half of the taxa are comparatively rare, that is, occur at 10 sites or less and are classified even locally as very rare (Figure 7; Figure 10B). The rare species include many of the strict endemics; but more unusual is the fact that also in this category are a substantial number of the cosmopolitan forms. The five most common taxa are all regional or more narrow endemics.

Site diversity here is quite low also, with over half the sites having 3 or fewer species. Semiarid sites, which are most common by far, are especially low in diversity. The few sites with 8 or more species are mostly mature forest, mesic sites. This low site diversity is not necessarily typical either of semiarid regions studied elsewhere, or of areas with substantial relict faunas (Frest \& Johannes, 1993e; 1995b, c; and Frest (1991) provide examples). Many sites in the Lower Salmon survey area have faunas with one or two large land snails and little else. These are commonly species of Oreohelix and Cryptomastix. Even though many such are Sensitive species 
and include six federal listing candidates, the number of sites with several such taxa is not very great (Figure 9), in contrast with the situation observed in other high diversity, relict-rich faunas (Frest, 1991; Frest \& Johannes, 1995b, c). However, a large number of sites have 2-4 Sensitive taxa. These same sites often have rare or unusual floral elements as well, such as McFarlane's four-o'-clock.

\section{ECOLOGY}

Many areas favored by land snails share common features. Most significant are cover, effective moisture availability, and geologic history. Geologically distinctive regions (such as the Hells Canyon-lower Salmon River area of Idaho, eastern Oregon, and southeastern Washington: Frest \& Johannes, 1995a, Figures 4, 7; and see discussion above) often have high diversity and many endemics. This is partly due to mollusks' substrate preferences. For example, a large proportion of the eastern U.S. land snail fauna is calciphilous, found only on limestone, dolomite, and similar lithologies and soils derived from them (note listings in Hubricht, 1985). In the Interior Columbia Basin, many species of Oreohelix are thought to be calciphiles (Pilsbry, 1939). Examples include Oreohelix idahoensis baileyi, Oreohelix idahoensis idahoensis, Oreohelix haydeni hesperia, Oreohelix n. sp. 14, Oreohelix n. sp. 16 of Frest \& Johannes, 1995a, and Oreohelix n. sp. 20. Other land snails similarty limited include Discus marmorensis. In numerous other cases, highly endemic forms seem similarly limited (e.g., Oreohelix haydeni perplexa, Oreohelix elrodi, Oreohelix alpina, Oreohelix hammeri, Cryptomastix (Cryptomastix) magnidentata, Cryptomastix (Cryptomastix) mullani latilabris); but the limited geographic distribution of some of these sometimes makes interpretation of substrate preference equivocal. Almost as common is restriction to basalt and basalt-derived soils. Examples here include Cryptomastix (Cryptomastix) n. sp. 3, Monadenia fidelis minor, Vespericola columbiana depressa, Oreohelix variabilis, and Oreohelix vortex (see Frest \& Johannes, 1995a for taxa extralimital to the survey area). As with the limestone snails, small geographic range may obfuscate substrate preferences: Cryptomastix (Cryptomastix) mullani latilabris is a prime local example.

A few rock types seem more or less inimical to these animals. Land snails are often very rare, for example, on granitic terrains, and many of the core Rocky Mountain ranges with predominantly basement (basic igneous lithologies) rocks have reduced or no land snail faunas. The effect on slugs is not as great; but also quite evident. Examples of such ranges are the Idaho 
Sawtooths and the Tobacco Root Mountains of Montana. Even in these areas, certain more ubiquitous and broadly tolerant taxa are present. Quite often, the minute terrestrial species (e.g., species of Vertigo, Pupilla, and Euconulus) are least affected by substrate differences. However, some large forms are also quite catholic in substrate occurrence. Oreohelix jugalis, Oreohelix strigosa depressa, Oreohelix subrudis, and Allogona ptychophora ptychophora are prominent examples. Quite often, rock type is of more significance than plant community per se. Soil pH is thus a good measure of land snail abundance and diversity in the Columbia Basin. Compared to eastem U.S. (Appalachian) faunas, western snails can tolerate moderately acid conditions; but faunas are more diverse (and, often, individuals are more abundant) on soils with slightly alkaline $\mathrm{pH}$. Slugs do not require $\mathrm{CaCO}_{3}$ for their [reduced or absent] shells, and hence would not seem likely to be as restricted; however, alkaline soils are also preferred by many shell-less forms also.

In interpreting the influence of rock type, some caution should be exercised. While limestone, marble, and dolomite are obvious sources of $\mathrm{CaCO}_{3}$, as are many other sedimentary rocks, some igneous lithologies, such as carbonatites and certain granite types, may be quite adequate. Similarly, some metamorphic lithologies can vary widely in $\mathrm{CaCO}_{3}$ content, but are often eminently suitable for maintaining large faunas. Schists, serpentinites, and some metasedimentary terrains are common examples in the Columbia Basin. While having only a small percentage of calcareous matter per se, this readily becomes part of the soil, making them excellent regolith contributors from the point of view of mollusk diversity. Some schists in the Lower Salmon River area are unusually calcareous, and hence provide excellent mollusk substrate. The ability of some larger land snails to thrive on seemingly unsuitable soils is remarkable. Oreohelix n. sp. 27 of Frest \& Johannes, 1995a, for example, is confined to an Ordovician quartzite and is seemingly absent from bordering limestones. Several prominent geologic units in the Columbia Basin have exceptional land snail faunas associated with them in at least part of their outcrop area. Most notable are the Carboniferous Madison Limestone (and equivalents: Lodgepole, Mission Canyon) and Amsden Formation; the Permian Phosphoria Formation; and the Miocene-Pliocene basalts of the Columbia River Group. In the Lower Salmon River area, the Triassic Martin Bridge Limestone is an excellent example.

Edaphic conditions are likely primary controls for many western species as well. In general, diversity and abundance are highest in areas with persistent and considerable free moisture. Thus, moist forests, slope bases, north slopes, springs, and seeps, edges of floodplains, and rock taluses are areas of concentration. Shaded and well-vegetated locales are also typically areas with exceptional abundance and diversity. In semiarid regions, such as typify the Lower Salmon River region, these considerations are paramount. Large portions of such areas may lack land snails altogether, or have sparse faunas consisting of a few exceptionally xeric-tolerant forms (e.g., species of Vallonia, Pupilla, or Zonitoides). In such regions, mountainous and rocky areas, 
with common springs or taluses, may be islands of abundance and/or endemicity for terrestrial mollusks. Many of the dryland forms are specialized for such habitats, and cannot tolerate humidities and moisture levels typical for forest snails. In some cases, particular lineages may be specialized for such environments. Examples include Oreohelix haydeni and related forms, Oreohelix variabilis and related forms, Allogona ptychophora solida, Cryptomastix populi, Cryptomastix hendersoni, and Cryptomastix harfordiana and related forms. Even though the Lower Salmon River survey area has exceptional numbers of xeric-adapted species, it remains true that areas with some water, e.g. talus bases, seeps, springs, and partly shaded taluses, have more diverse and more abundant snail faunas. These moist area provide critical refuges for more mesic taxa in this region in particular. As might be expected, most slugs occur in moist environments: Hemphillia and Magnipelta are essentially restricted to them, and are clearly notophiles. Prophysaon is best characterized as a mesophile-moderate notophile. Though essentially mesophilic, some slug taxa, such as Deroceras spp., are quite widespread.

The biology and role of land snails and slugs in the varied Interior Columbia Basin ecosystems are closely similar to those of many arthropods (see Olson, 1992 for background). Land snails primarily consume decaying vegetation, dead leaves, and animal wastes. Slugs have similar food preferences, although some are more likely to be green vegetation and coprolite specialists. They thus perform a vital role in nutrient and detritus recycling, even in semiarid environments. Notable differences from insects are: 1) mollusk diversity is usually much less; and 2) insects are generally much more easily dispersed. Terrestrial mollusks can be considered analogous to flightless insects in several important respects. In general, land snails in this region (as elsewhere in North America) require relatively undisturbed vegetational cover appropriate to the habitat involved, which may range from closed canopy forest to sage scrub or open, rocky talus. Most are somewhat retiring, and avoid areas with strong insolation or exposure. Many cease activity and shelter during dry or exceptionally cold or hot periods. At some times in the year, land snails are most active from dusk to dawn. Genera such as Monadenia may be strongly eoan and/or crepuscular; others, such as Vespericola and many slugs, may be quite active in daylight. Locally Oreohelix and Cryptomastix may be quite active in daylight if moisture requirements are met. Species vary considerably in activity and in response to changed conditions. Allogona is very active and may emerge from aestivation even after very brief rains. Some of the more xeric taxa are much more cautious. Still, activity and visibility of all often increase markedly after rain storms. Many land snail taxa thrive in lowland to middle elevation moist (often riparian) forests and the areas around springs, bogs, or marshes. Generally stable rocky taluses or rockslides are another favorite habitat; these may be well-occupied regardless of cover, but the snails may be difficult to find except under special weather conditions. In this region, occurrences in basalt or limestone taluses are frequent. The semianid climate that is prevalent means that many species will aestivate for a 
major part of the year. Locally, the times of greatest activity are in early spring and late fall. Coastal areas, because of their relatively high humidity, are another favored area of occurrence. Minor differences in insolation, cover, or availability of moisture, even on the same slope, may result in very different land snail communities (e.g., Roth \& Eng, 1980). Thus, colonies can be very local.

Because terrestrial mollusks are relatively small, viable colonies may occupy surprisingly small areas. While the size of long-term viable populations is still somewhat a matter of dispute, examples are known of survival with as few as 1,500 adults in a colony (Frest, 1984). It is safe to say that only a few thousand individuals may be sufficient. For minute forms, colonies of only a few square feet seem to be viable in certain cases (Frest, 1991); however, somewhat larger buffer areas are evidently necessary to maintain such small sites in the long run. Even for larger species, colonies are not great in areal extent. The largest Oreohelix colony of which we are aware is about $1 \mathrm{mi}$. long and $1 / 4 \mathrm{mi}$. in width. One of the smaller we have observed is about 12 " in width and less than $20^{\prime}$ long; another is approximately $6^{\prime}$ in length and 2 ' in width. In both of these cases, the snail genera involved (Vertigo and Oreohelix) typically are dominants and have large standing populations. Other genera, e.g. Monadenia (Roth \& Eng, 1980) and Magnipelta are typically rather scattered in occurrence. As many as 20 adult Oreohelix may occur per $1 / 4 \mathrm{~m}$ quadrat square in such species as Oreohelix strigosa cooperi, Oreohelix haydeni hesperia, Oreohelix idahoensis idahoensis, and Oreohelix strigosa goniogyra. In some areas, such species appear to literally cover the ground, and are much more abundant than all co-occurring insects. Interestingly, all of these are xerophiles. Other species, such as Oreohelix elrodi and Oreohelix amariradix, may occur at densities of less than 1 adult per $1 \mathrm{~m}$ square. Some other environments may be equally productive in terms of biomass. The calcareous fens studied by Frest (1990) had up to 4,000 mollusks per $1 / 4 \mathrm{~m}$ square. In semiarid areas, large-sized snail species colonies may consist of millions of individuals. At rich sites, dead snail shells may litter the ground, outweighing even total live plant biomass. In semiarid areas such as the Lower Salmon River region, land snail mass may be astoundingly large. Sites with shells littering the ground, far outnumbering and outmassing remains of any other animal group, are not uncommon. Some of the best examples are on the Lucile Caves ACEC. Land snails may appear rare much of the year; but a visit to a seemingly dry and lifeless basalt talus in spring or after a major rainstorm is very instructive, even if no or few shells are evident on the surface.

Regardless of major habitat type, desiccation is the primary reason for land snail mortality even in undisturbed habitats (Solem, 1984). Snails and slugs in each major habitat type have evolved ways of dealing with the problem. Talus-dwellers are often cryptic for most of the year. Most snails shelter or aestivate even in dense forests in the typically dry period from JuneSeptember; many hibernate in winter. Snails and slugs frequently shelter under rocks, leaves, bark, litter, or logs. Some Monadenia and Prophysaon individuals shelter in moss on trees far 
above the ground. Even snails more tolerant of xeric conditions need rocks or loose plant material of some size and volume for diurnal and seasonal shelter. Suitable winter or long-term retreats (hibemaculae) are uncommon at any given site, and may be occupied over many years and by large numbers of individuals. Thus ready availability of coarse woody debris is very important for forest mollusks, as it is for many other forest-dwellers (see Harmon et al., 1986 for a general review; Spies, Franklin, \& Thomas, 1988 for Douglas fir forests). Most species seem to prefer to have relatively large debris pieces available, i.e. logs and major branches, although bark and smaller pieces should be present also. Large debris piles do not seem to constitute good mollusk shelter. Loose rock and talus and the root balls, radices, or bases of larger vascular plants serve the same function in and or semiarid areas, with particular plants (generally larger individuals) often considerably favored. Genera such as Balsamorrhiza, Celtus, Physocarpus, Prunus, Sorbus, Rhus, Urtica, Laportea, and Artemisia are very significant as shelter plants in semiarid environments.

Formerly, land snails were thought to occur only in vegetational communities in which deciduous trees or shrubs are an important element (Karlin, 1961). It soon became apparent that land snails occurred just as often in coniferous forests (Kralka, 1986); and that semiarid plants were as suitable as mollusk food resources as were trees of the Eastern Deciduous Forest biome. Still, it remains true that land snail diversity, and sometime abundance, are greatest in plant communities with a significant non-coniferous component. Certain forms, such as some Vertigo and other pupillid species, some succineids, some Oreohelix species, some slugs, and many others may be most abundant in pure coniferous stands, if these are relatively mature or moist. Branson (1977) made the important observation that the usually high slug diversity and endemism of western U.S. forests may relate to their comparative acidity. In many cases, soil pH is a much better determinant of abundance and diversity than plant community structure per se. In the northwestern states, land snails have been found in the following forest plant associations, listed in no particular order: Picea sitchensis, Sequoia sempervirens, Tsuga heterophylla, Pseudotsuga menziesii, Abies amabilis, Abies magnifica, Abies lasciocarpa, Tsuga mertensiana, Pseudotsuga/hardwood, Pinus ponderosa, Abies concolor, Abies grandis, Pinus contorta, Juniperus occidentalis, and Quercus garryana, as well as the various more open plant communities with Celtus occidentalis, various Artemisia species, etc. High-diversity associations are perhaps more likely to occur in the vicinity of Populus, Betula, Acer, Salix, Physocarpus, Cornus, or Tsuga. Particularly appealing tree or shrub species are Acer macrophyllum, Acer circinatum, Acer glabrum, Alnus rubrus, Alnus rhombifolia, Alnus sinuata, Amelanchier alnifolia, the larger Artemisia species, Betula papyrifera, Betula pumila, Betula occidentalis, Celtus occidentalis, Corylus cornuta, Cornus nuttalli, Cornus stolonifera, Populus tremuloides, Populus trichocarpa, Prunus virginiana, Prunus emarginata, and many species of Salix. Arbutus 
or Rhododendron seem less suitable than most, perhaps because these genera have rather tough leaves; a similar effect has been noted in Australian sclerophyl forests. Gaultheria stands may also be less diverse, although at least one coastal species, Pristiloma pilsbryi, has been found primarily in dense salal. Undoubtedly, there are a number of such associations in the Interior Columbia Basin. One treatment of land snaiVplant associations in western ecosystems is Frest \& Johannes (1993d); the works of Boag and various collaborators should also be consulted.

Slugs are a somewhat special case. The shell-less habitat has perhaps evolved independently at least 11 times on a world-wide basis (Solem, 1974). The lack of shells and special modifications of the slime enable slugs to shelter and move about more readily than most shelled forms. Specialized composition, and the ability to alter composition as required, enables slugs to use slime for protection from dessication, to enhance travel speeds, and to discourage predators. L. Deyrup-Olsen (University of Washington) has conducted many elegant studies of the ways in which slugs utilize and modify slime. The shell-less condition, as noted above, may be advantageous in dominantly coniferous forests, where usable calcium sources are usually scarce.

Land snails and slugs are mostly herbivores; a few will also consume animal matter of various kinds, and fewer still (Ancotrema, Haplotrema) are carnivores, particularly of other snails. Most taxa commonly ingest soil, and very many, in particular slugs, commonly ingest fecal matter of all sorts. Most local taxa prefer dead vegetation or even fungi in small amounts. Terrestrial mollusks thus contribute substantially to nutrient recycling and breakdown of plant detritus and animal wastes. Some forms will digest wood, or chew it into fibers to form suitable locations for egg-laying. A few slugs are characteristically found in decaying logs and appear to be feeding on partly decayed wood. The small forms generally eat soil, fecal matter, partly decayed leaves, and the small plants and fungi upon them. Leaves from deciduous trees and shrubs (e.g., Salix, Alnus, Populus, Acer, and Cornus) are particularly liked by some taxa. Some slugs and snails relish larger fungi. More often, green vegetation in the understory is preferred (examples include Heracleum, Rorippa, Rubrus, and even Urtica). Such shelled genera as Allogona and Vespericola, as well as many slugs, seem to commonly consume green vegetation; but all larger mollusks also eat fallen leaves, soil, and partly decayed matter in it. Some genera (e.g., Monadenia) prefer fallen leaves or inner bark layers. Juvenile and adult feeding preferences may differ (Roth \& Eng, 1980; personal obs.). Terrestrial mollusks are thus primary higher and lower plant and animal waste recyclers in both forested and more open situations. In turn, snails and slugs are consumed avidly by many small mammals (e.g., shrews, voles, shrew moles), amphibians, and by a number of birds. Various insects, including certain beetle, fly, and wasp families, either prey upon snails directly or parasitize them with their eggs and larvae. Snail shells are used for shelter, domiciles, or egg-laying sites by a variety of insect and other arthropod taxa. Certain of the larger land snails were even utilized as food by Native Americans. 
Life history of many taxa is strongly controlled by climate. Nearly all of the small species have one-year life spans and are semelparous. Breeding may take place in the spring, after snow melt, or somewhat later in the fall, especially September-October. Eggs hatch about one month after being laid, and some adults and many young survive the winter. Larger land snails are more variable. Intermediate-sized land snails, such as Discus, may commonly live for about 2 years. Some species of larger genera, such as Monadenia and Oreohelix, e.g., may live for at least 8-10 years; sexual maturity may be reached in these species in two to three years (Walton, 1970). It seems likely that Oreohelix species may vary as much in life history as do Ashmunella species. Xeric forms may be quite long-lived; while mesic forms may be essentially annual. Vespericola and Cryptomastix appear to have a much shorter life span, perhaps two years or less for most species. This point needs to be investigated further, particularly for the xeric Cryptomastix species, such as those that characterize the Lower Salmon River area. Life span may differ between talus dwellers and forest species in the same genus; this has not yet been carefully investigated, but xerophiles appear to have significantly longer life spans.

The land snail genera Allogona, Ancotrema, Cryptomastix, Haplotrema, Oreohelix, Polygyrella, and Monadenia have been observed copulating most frequently in the period from April to June. Eggs and juveniles of the same genera have been seen most often from May to July. Under suitable conditions, egg laying may also take place in some forms in fall. Certain taxa, such as Prophysaon, are most likely to reproduce in the period from September to October. Mortality is heavy in the summer and winter. Certain slugs and shelled forms have similar life cycles; however, at least some genera are iteroparous, and some have life spans greater than one year. As in freshwater mollusks, adults of small forms may die after laying eggs. The larger forms breed and lay eggs in much the same seasons as do the small species; but some genera appear to breed in only one season (or once per year), generally in the spring. In these taxa, adults need not commonly die from reproductive stress. Brood sizes may vary considerably from taxon to taxon. Seasonality of activity, including reproduction, is most strongly pronounced in openground, xeric, or talus habitats, and is much less so in perennially-moist environments. While available moisture at certain times is vital, species and genera vary widely in their moisture tolerances. Some forms (e.g., Vespericola, Prophysaon, and Hemphillia) are found only or largely in perpetually very moist areas, often riparian forests or spring and seep borders and are termed notophiles. Others (e.g., certain Monadenia and Oreohelix species that are mesophiles) avoid extremely moist situations. Acid habitats such as bogs often have relatively low diversity faunas, with few large taxa. High diversity is frequently associated with calcareous habitats. The xerophile habit is quite common in the ICB.

Land snail colonies are long-term, with some clearly in the same area since the end of the Pleistocene (i.e., for the last 10,000 years). One such was noted by Clarke \& Hovingh (1993); 
example are common in the semianid portions of the Interior Columbia Basin, in situations where preservation of Holocene and late Pleistocene fossils are likely. Local examples may include the Lucile Caves ACEC Oreohelix idahoensis idahoensis sites and the Oreohelix haydeni perplexa site in Twilegar Gulch. Certainly, most of the historic sites in the Lower Salmon River area can be recollected (if precisely known), unless human modification has extirpated them. Migration may be generally slow; the Oreohelix colony described by Clarke \& Hovingh, for example, has failed to reoccupy portions of a talus last inundated by Lake Bonneville. In other situations, stream transport of at least $1.5 \mathrm{mi}$., due to one event, has been noted (Roth, pers. comm. 1993). Most typically, spread occurs the hard way, by crawling; and land snails may typically journey only as far as a $20^{\prime}$ radius from their place of birth in a lifetime. Active dispersal in a semiarid area can be presumed to be even more slow than that typical for forests. Passive transport by stream or flooding or by animals, wind, etc. has been observed; but how typical and successful such events are in establishing long-term range changes needs more study. Here again, such events would seem inherently more unlikely to occur in semiarid or arid settings, such as the Lower Salmon River, simply because snails activity and exposure occurs less frequently here than in generally moist situations. Methods of transport and colony foundation have been reviewed by Davis (1982) for freshwater forms and by Taylor (1988b).

\section{MOLLUSKS AS BIOLOGICAL INDICATORS}

In many regards, mollusks are an especially practical group for use in assessing the general health of the terrestrial and aquatic ecosystem. They are present in some numbers in almost any environment. Certain species are eurytopic; however, many species are stenotopic and unusually sensitive to various kinds of disturbance or pollution. Most species respond quickly and obviously to disturbance. As almost all are relatively sessile and complete their life cycles in place, they are particularly convenient for site-specific assessments. Sampling procedures are relatively simple and can be readily quantified. As it happens, many of the Sensitive species dealt with here would be readily useful indicator species (e.g., the species of Cryptomastix and Oreohelix). Mollusk centers of diversity generally correlate well with those determined from other groups; examples are common from plants, fish, salamanders, and insects. Similarly, mollusk abundance tends to peak in particularly high diversity locales. 
The presence of a number of local endemics makes mollusks of unusual biogeographic significance. As compared to insects, there are relatively few taxa, many are comparatively large, taxonomy and morphology are comparatively comprehensible and straightforward, and most can be easily identified. About half of the total taxa in old growth forests have already been described, and relatively comprehensive identification manuals are now, or shortly will be, available for them. The shell of most is durable, making them both obvious and also quite likely to be preserved as fossils or subfossils. They are one-part animals, and most can be identified from the shell alone. The extensive fossil record of some provides a long-term background history unavailable with most groups. An extensive literature attempts to relate fossils to past and present climates, drainages, and large-scale geologic and ecological processes.

Freshwater mollusks are used extensively in the eastern and central parts of the U.S. as biological indicators and to monitor physical and chemical, as well as biotic changes of waters. Examples include Clarke (1979a, b). Bivalves have been used regularly to study uptake of various organic and inorganic pollutants, and are among the most sensitive organisms for such purposes; reviews include Fuller (1974), Imlay (1982) and McMahon (1990).

\section{SPECIES OF SPECIAL CONCERN}

Many of the taxa dealt with are Species of Special Concern in the definition of Frest \& Johannes (1993a, 1995a). Accordingly, background information from those works is incorporated, with some modification, here. In order to compile the species records listed below, the freshwater and land mollusk fauna of Washington, Oregon, Idaho, Montana, Wyoming, Nevada, and Utah was reviewed. Starting points were Pilsbry (1939-48), Burch (1989), Taylor (1975), and references therein, including Henderson (1924, 1929, 1936a, and 1936b). The periodical literature published subsequent to $1936-48$ was also reviewed, as were available consultant's reports and other "gray " material. We have collected freshwater and land mollusks in these states since 1986; where practical, such records were incorporated also. Information from private collectors and museums was also included, where such material was examined and verified by us. The present compilation is partially based on species lists in Frest \& Johannes (1991b, 1993c, 1993f, 1995a, and 1995b).

Tables 1-3 of Frest \& Johannes (1995a) listed a total of 190 mollusk species or subspecies herein regarded as Species of Special Concern (SOSC). These were evenly divided 
between terrestrial and land forms: 95 are terrestrial (87 snails and 8 slugs) and at least 95 freshwater (88 snails and 7 clams). All are currently known or likely to have ranges partly or wholly within the Interior Columbia Basin assessment area, as defined previously. One hundred seventytwo were regarded as Sensitive Species (Species of Special Concern in the usage of USFWS, 1992a, 1992b; critically sensitive species in imminent danger of extinction if present trends continue). While many are either present or potential candidates for Federal listing, only 5 are presently listed as Endangered or Threatened species. A substantial portion of these taxa occur in the Lower Salmon River region (see Tables 3 and 19 of Frest \& Johannes, 1995a: Table 2 herein). We currently regard a total of about 36 Lower Salmon River land snail taxa as Sensitive and recommend that these be treated similarty by USFS, BLM, and other federal and state agencies concerned with land management and wildlife. All of the taxa here defined as Sensitive should be regarded as priority species in USFWS usage (as above).

Four are Watch List species. These are also Sensitive species (as well as SOSC) in our usage, and should also be regarded as sensitive by USFS, BLM, and other federal and state agencies concerned with land management and wildlife. However, these taxa are not regarded as in imminent danger of extinction, and are not considered potential candidates for Federal listing at this time. Seventeen species appear to be in no local or region-wide danger of extinction and hence do not require protection. Finally, 4 species are taxa of uncertain status also discussed individually under the section entitled SPECIES DISCUSSIONS. These are not considered further here, although additional research may demonstrate that they are valid taxa and in need of special consideration.

The Species of Special Concern represent roughly $66 \%$ of the estimated actual diversity in the Lower Salmon River area. Five of the Sensitive species are listed as federal candidates (see Table 1 herein, USFWS, 1994). In general, land snail species are not on Idaho Threatened or Endangered lists although the Idaho Conservation Data Center does track the federal candidates. Malacologists have long been interested in the status of U.S. mollusks, particularly in the eastern and central U.S., and have held various symposia, etc. on them. The American Malacological Union holds regular symposia on mollusk conservation and has a standing Conservation Committee. Hence, some of the taxa discussed herein have been suggested for listing by malacologists previously (e.g. Smith, 1970; Solem \& Clarke, 1974a; Solem, 1975; Clarke, 1976a; Frest \& Johannes, 1991b, 1993c, 1993e, 1993f, 1995a; Frest \& Roth, 1995; and sendings to various federal and state agencies by us, 1988-1994).

Our lists and discussions differ from those made previously in that they: 1) are based on more recent information, including research and project collections by Deixis Consultants personnel (T. Frest, E. Johannes, J. Johannes) of many taxa from 1989-1994; 2) include some previously unknown or unconsidered species and subspecies; 3) exclude or recommend status 
changes for some taxa now known to be either more broadly distributed than earlier thought or taxonomically suspect; and 4) are restricted to forms known or likely to occur within the assessment area. As in Frest \& Johannes (1993c, 1995a) we have included undescribed taxa and specify known and suspected areas of endemism. Unlike some previous efforts, we have included taxa of uncertain status. The listing is conservative in that some taxa now regarded as either extinct or too poorly known for adequate range definition (i.e., occur in relatively unstudied areas; are too recently discovered to be fully evaluated; or occur in poorly studied microhabitats) are deliberately excluded. Further documentation of the species and subspecies listed in Tables $1-3$ is provided below in the form of short, referenced discussions of each.

Of the 61 mollusk species and subspecies listed on Tables 1-3, some are of especial concern. Important factors in assigning species to the critically Sensitive group were: extremely restricted current distribution or local endemism; occurrence solely or largely in particularly threatened habitat, such as old growth or late successional forest, low-elevation springs in semiarid or and locales; taluses, or the like; sensitivity; very limited or circumscribed habitat; loss of a majority of historic sites and habitat; or declining populations. Generally, all of the above factors apply to the species in this group. Within this classification, species known or likely to occur on BLM or Forest Service lands were favored strongly for consideration. Similarly, species known or thought to be old growth or mature forest associates, mature sage scrub associates, or riparian associates were given special emphasis in making selections for inclusion here; most taxa qualify under two criteria. Current candidates were automatically considered to be priority species.

In practice, our criteria closely mirror those used by Thomas et al. (1993, p. 261) for developing a "short list" from the much larger list of species that occur in old growth or late successional forests. These criteria are largely directly applicable to Interior Columbia Basin habitats and ecosystems in general and Lower Salmon River examples in particular. Most or all taxa considered here would qualify under a combination of two or more of the SAT short list's four criteria and nine factors. As can be seen from the SPECIES DISCUSSIONS, nearly all taxa were included for two or more of the reasons outlined above. The 36 high-priority taxa that meet these conditions are indicated in Table 2. It should be emphasized, however, that, due to lack of recent collections of at least one taxon, this listing is particularly conservative. It is likely that other taxa discussed herein are now, or soon will be, subject to similar problems. It is also highly likely that some taxa not discussed here should be included. This listing should thus be considered as somewhat tentative. As time and information growth demands, we hope to revise and reissue it.

Sensitive species comprise the largest single group of Lower Salmon River land snails, with 36 members occurring within the survey area (Tables 1-3). Six of the Sensitive species are Federal listing candidates; but none are Federally listed at this time (Table 2). We recommend listing of all but a few of these species as either Threatened or Endangered on present evidence; 
other species require further study. Most or all of these land snails are known or thought to be found on federal lands, particularly BLM holdings; others occur on state lands, private inholdings, or areas adjacent to public lands (Table 2). Of our 213 sites (Appendix A), at least 114, or some $54 \%$, are definitely on BLM lands (Table 5). Additional sites are known to be on Nez Perce National Forest or State of Idaho public lands. Many of the remainder are along the US 95 corridor and hence may also be at least in part on public lands. Limits of the present corridor and ownership of the old alignments of this and one or two other public roads were unclear in these cases, and needs to be checked further.

\section{CURRENT AND PROPOSED MANAGEMENT PRACTICES}

\section{BACKGROUND}

There is a wealth of generally neutrally-compiled information to demonstrate that current land management practices of the major public land management agencies, in the Interior Columbia Basin as elsewhere in the West, are inadequate. In response to congressional inquiry, the General Accounting Office (GAO) recently attempted to assess the effectiveness of current management practices of the USDA Forest Service and USDI Bureau of Land Management in protecting and sustaining wildlife on federal lands (GAO, 1991a). The Forest Management Act of 1976 requires the Forest Service to maintain viable populations of each native vertebrate species [or, by some interpretations, all native species] on each management unit. It is possible that this law could be enforced in the future, and extended to include land held by other government agencies. The GAO concluded that "consideration provided to wildlife is below that provided to consumptive uses such as livestock grazing, logging, and mining" (GAO, op. cit., p. 18). For example, the General Mining Law of 1872 gives mining primacy over other uses of federal lands. Analyses of the effects of mining and of the Law have generally concluded both that abuses were occurring and that the Law needs revision (GAO, 1986, 1989a). Even National Wild life Refuges, the only federal lands required by design to be managed primarily for the benefit of wildlife, are affected almost universally by secondary uses (GAO, 1989b). Such secondary and consumptive uses, at least as now practiced, are often directly inimical to species preservation. GAO (1991a) also noted the low levels of funding and staffing provided for wildlife programs. It concluded that, 
in cases of conflict, consumptive uses were often favored despite acknowledged negative impacts on wildlife. Moreover, most planned wildlife actions were demonstrably not actually being implemented by the managing agencies. Another report (GAO, 1991b) noted the necessity for better wildlife protection, as current enforcement is selective. Even on paper, wildlife protection or enhancement actions almost always are directed at species perceived as "glamorous" or as favored by the public -particularly the Three F species (furred, feathered, or finned)- often at the expense of other taxa. Quite often, recovery or conservation efforts for Three $F$ species are undertaken to the detriment of other forms. Most federal lands agency biologists specialize either in fish or in mammals; there are very few invertebrate specialists anywhere in the Forest Service, BLM, or even in USFWS.

The typical lack of even roughly complete species inventories of federal lands has been commented upon previously (Frest \& Johannes (1993c, 1995a). In general, there is little detailed knowledge about most invertebrate groups on public lands (Olson, 1992; Frest and Johannes, 1993c). A recent study (Stohlgren and Quinn, 1992) of the National Park system, for example, indicated that none had comprehensive biotic inventories, even of such relatively small and conspicuous groups as mollusks. Most western U.S. National Forests and BLM Districts have in the past few years completed Land and Resource Management Plans or equivalent documents; none that we have seen go much beyond Three F species; most do not mention any invertebrates. Recent proposals to conduct such inventories are a step in the right direction: but this step will require considerable time and resources to implement, and should not be pursued precipitously. The Forest Service's attempt to use an indicator species approach to monitor biodiversity on its holdings is a case in point. Planning regulations direct that several categories of species are to be represented among the taxa to be monitored. These are 1) endangered and threatened plant and animal species; 2) species with special habitat needs that may be influenced significantly by planned management actions; 3) species commonly hunted, fished, or trapped; and 4) non-game species of special interest. Predictably, category 2 has been emphasized to the point of near exclusion of the other categories. We are aware of no invertebrates so utilized on any unit; this despite the fact that invertebrate species [including mollusks] clearly qualify, minimally under categories $2 \& 4$, and often under 1) as well. Even with the Three-F bias, the GAO concluded that the monitoring approach appeared expensive and ineffective. Reasons cited were that 1) relationships between indicator species and the habitat characteristics they are supposed to predict are unknown; 2) observed changes may be natural and not require management action; 3 ) monitoring may be impractical due to personnel shortages during critical periods; and 4) selection of indicator species is "sometimes based on factors other than their biological or ecological representativeness, or their predictive value. Instead, some indicator species have been selected for socioeconomic or political reasons" (GAO, 1991c, p. 3). 
On average, even relatively development-restrictive agencies such as the National Park Service have made little progress in documenting or mitigating threats to their public holdings (GAO, 1987). In many of the National Forests, for example, it was impossible for outside examiners to determine the extent of resource deterioration in designated wilderness areas because basic information on conditions in many of them was lacking. However, site visits indicated that many wilderness areas showed signs of adverse impacts [even though these areas are legally mandated to be relatively free of disturbance, according to the Wilderness Act of 1964], and that funding for wilderness management was inadequate (GAO, 1989c).

Similar considerations apply to rangelands and grasslands. The GAO (1988a) found that adequate recent inventory information was often lacking, and condition of much of the public rangeland is not reliably known; but that over $50 \%$ of the public rangelands remained in either poor or fair condition. Another recent report (GAO, 1991d) indicated that the Forest Service is not performing needed monitoring of its grazing allotments, and that range managers themselves consider about $25 \%$ of the allotments to be in a declining condition and/or overstocked. A similar study found that the BLM likewise was not monitoring at all the status of about $50 \%$ of the grazing allotments covered by EISs (GAO, 1992). In many cases, BLM efforts to prevent unauthorized grazing are inadequate (GAO, 1990a): during any given year, "many grazing areas are inspected infrequently or not at all". Outside evaluations of federal grazing practices are generally scathing, as witness Horning (1994).

In the particularly vital riparian areas, both Forest Service and BLM efforts at restoration have recently been criticized (GAO, 1988b). This is particularly unfortunate, as another federal agency has recently concluded that riparian areas "are in the worst shape in history" (EPA, 1990). Even though both agencies have policies that endorse restoration of riparian areas, only limited numbers of riparian areas have been restored. Successes represent only a small amount of riparian area; support from management for such efforts has been weak; and some field staff claim that "management has taken reprisals against staff who tried to implement riparian management programs in areas with politically powerful permittees"; and in any case, existing inventories of riparian areas are incomplete.

We have commented previously (Frest \& Johannes, 1993c, 1995a, and above) upon the general lack of consideration given to all but a few "glamorous" species in federal agency management plans. Until recently, many BLM districts simply lacked resource management plans, 13 years after the passage of the Federal Land Policy and Management Act of 1976 (GAO, $1990 \mathrm{~b})$. The rush to complete such plans has, in our opinion, resulted in inadequate documents in many respects, and no expansion in species coverage. Even with the best of intentions [and we need not concede that those exist here], management is typically focused on a single-species approach, in which the species to be benefited is generally the domestic cow and, at best, 
unspecified "wildlife", with the unspoken presumption that these are large, huntable vertebrates. However, such species do not exist in isolation.

One minor example will suffice. "At the Snake River Resource Area in Idaho, one project consisted of making improvements [sic] to a spring so that more water was collected and available for livestock and wildlife. According to the environmental assessment included in the project file, the improvement would also make water available to wildlife when livestock were removed from the allotment" (GAO, 1993a). Readers of the ICB report (Frest \& Johannes, 1995a) will have noted that springs along the Snake River in Idaho harbor several federally listed taxa; and a variety of other sensitive species are known to inhabit such springs, including many narrow endemics. Most to all of the native fauna is extirpated from springs when they are "improved" in this way. The GAO chose to interpret this case as an example of not fully describing all resources benefiting from range improvements. We would take the opposite tack, and note that the BLM in Idaho seldom if ever knows what species are present in such habitats generally, let alone specifically; how rare; if listing issues are involved; or what the detriments to the native biota as a whole are [does not fully describe resources harmed", to use the proper jargon] from spring "improvements". It will not be surprising that "livestock grazing management was the primary objective of $71 \%$ of the range improvement projects completed in fiscal years 1990 and 1991 " (GAO, 1991d, p. 7). After all, what else is there?

This analysis merely skims the surface of the situation, and is perhaps overly generous. Studies by environmental groups tend to be more critical. We quote from one as an example (Losos et al., 1993):

"Natural resource extraction activities are wholly or partly responsible for endangering 62 to 68 percent of all species that are formally listed as at risk of extinction in this country".

"[These species] are at risk of extinction at least in part from hardrock mining, logging, livestock grazing, water development, and recreation".

"Water development projects - such as dams, flood control, water diversion, and dredging. have the most extensive impacts, affecting 29 to 33 percent of all listed species".

"Recreational activities - primarily off-road vehicle use and general recreation - damage 23 to 26 percent of federally listed species".

"Livestock grazing harms 19 to 20 percent of endangered and threatened species. Logging affects between 14 and 17 percent. Hardrock mining alone damages 4 to 6 percent, and when all mining activities are considered, the figure increases to 14 to 21 percent".

"Species whose ranges are on federal lands are generally harmed more by logging, livestock grazing, hardrock mining, and recreation -50 to 59 percent $\cdots$ than those inhabiting nonfederal lands -- 46 to 55 percent". 
Major changes in policy and management will be necessary to supplant and repair past actions. In the last few years, most of the Pacific Coast and Interior Columbia Basin states' National Forests and BLM Districts have completed Land and Resource Management Plans or their equivalents. So far, none of those we have seen have adequately addressed biodiversity concerns. Most, for example, go little beyond Three F species; none adequately address invertebrates; and most fail to even mention them. The controversy over the listing of the Northern Spotted OWl has brought such concerns considerable attention. The National Recovery Plan for the species (USFWS, 1992a, b) is one of the few to attempt to address ecosystem concerns, and could serve as a model for such efforts elsewhere. As the mandate for recovery was expanded to include other significant animal and plant species, it was also extended to other habitats, such as riparian zones, which support the bulk of western coniferous forest and arid to semi-arid land biodiversity. In making management recommendations for the Lower Salmon River mollusk SOSC, we will parallel some of the policies most likely to be implemented in federal lands within the range of the Northern Spotted Owl. Major references are Thomas et al. $(1990,1993)$ and Johnson et al. (1991).

\section{OVERVIEW}

In general, any modification of habitat that decreases available moisture or increases insolation is very strongly detrimental to land mollusks, and often id to freshwater species as well. Logging tends to increase insolation to the point that most species are extirpated. Burning of slash, physical disruption of habitat, and destruction of forage plants (often deciduous trees and shrubs and herbaceous forest understory) compounds the problem. Indirect effects, such as stream modification and destruction of springs, have removed much additional habitat, as has human settlement along the coast proper. Tree farms, like Midwest corn fields, are generally devoid of any native mollusks. Semi-arid lands with introduced grasses are in no way comparable to native sage communities in terms of biodiversity. Sometimes, only introduced species, like most commonly seen garden slugs on the West Coast, may thrive in such settings. In our study sites in western Washington, for example, relatively undisturbed sites had a mean diversity of 10 12 species. Recently clear-cut areas generally had no shelled species. Most areas that had been clear-cut 20-60 years ago regained no more than 2 shelled species. Often, the only mollusks seen alive in recent clear-cuts were found in very limited colonies under protected settings, such 
as missed trees or unburned debris piles. In our opinion, the long-term viability of such colonies is questionable, let alone their ability to serve as reservoirs to repopulate regrown forests. Generally, only one or two slug species were at all widespread in recent clearcuts or in reforested areas up to 40 years after cutting. Land and freshwater mollusks are also quite susceptible to the effects of forest spraying for pest and unwanted plant control.

Grazing is also a major factor causing extipation. Direct trampling is the major problem, but resulting vegetation changes and the usual reduction in plant biomass and effective cover are also significant. With as much as $90 \%$ of federal lands in the Interior Columbia Basin states allotted to livestock producers, this is an extremely severe problem. Certainly, this is one of if not the major impact on Lower Salmon River habitats. Most known sites for the genus Hemphillia and many other of the particularly unique Oregonian and Washingtonian endemics have been destroyed by logging of lowland old growth and mature forest; many species of special concern and Sensitive taxa seem to be specifically associated with such forests. Many species are now or were originally very limited in distribution. The Malone jumping slug, Hemphillia malonei, e.g., occurs only on the slopes of Mt. Hood. Many species of Oreohelix and Cryptomastix in the Interior Columbia Basin have strongly circumscribed ranges. The species dealt with here are especially strong cases in point. The genus Megomphix has similar problems; all known sites for hemphilli, e.g., were either in the Puget Sound region or in the more or less completely cut-over Willapa Hills, southwestern Washington. Both leutarius[in the ICB] and californicus [northern California] have very limited ranges. Very few sites for this genus have been found in recent years, and the whole family Megomphicidae is now quite rare; some southern Califomia species have been previously suggested as Federal listing candidates. Management of Pacific Coast and Interior Columbia Basin state forests should reflect such considerations if survival of the native land mollusk fauna is to be assured. Similarly, many freshwater endemics are very restricted in occurrence, sometimes to single sites: examples are numerous in Fluminicola, Pyrgulopsis, and Lyogyrus, among others. While this makes them very vulnerable to extinction, another consequence is that protection may be a relatively simple and inexpensive process, if it is deemed a worthwhile goal.

A recent study (Frest \& Johannes, 1993d) of one western National Forest may be instructive: the more extensive work that is available for Eastern Deciduous Forest land snail communities may not be as directly relevant. The Black Hills National Forest, South Dakota and Wyoming, is dominated by Ponderosa pine and spruce forests. Much of the area with pine cover has been logged recently, and very little intact riparian vegetation remains. Grazing is common on logged terrain and in lowland areas. Large areas were mined long ago, and some operations continue. Forest fires are common and destructive. Survey of 189 sites by a combination of litter sampling and live collecting yielded some interesting results. Thirty-six species were found to remain in the Forest. A few were new taxa; these included uncommon local endemics and habitat- 
restricted forms; but the bulk of the fauna was of forms widespread in North America. A number of species previously reported from the area were not found.

Heavily logged and grazed sites had a very small land snail and slug fauna consisting of about six widespread forms. Areas that had been clear-cut did not appear to recover their snail fauna, even after many years; upland areas were particularly hard-hit. Mined localities were similarly affected. Fires occurring before fire suppression was attempted seem to have had only local effects on the land snail fauna; modern fires effectively sterilize large areas of snails. The native freshwater mollusk fauna of the Forest appears to have been almost entirely extirpated, even from spring habitats. Even relatively widespread species have been extirpated from most or all of the Black Hills. The richest areas for diversity were the few remaining relatively intact niparian areas and limestone canyons with spruce cover, in part because logging of spruce does not take place. Such sites commonly had diversities of fifteen or more species. Well over half of the total number of species were confined to a small area in the northwest part of the Forest and occurred at only a few sites. Because of extensive habitat loss, several species were suggested for federal listing, and protection of the few remaining sites for most was strongly recommended.

A general observation resulting from this and other studies is that effects of single practices may be detrimental but bearable; but combinations are especially destructive. A common example in the Interior Columbia Basin forests is the logging, followed by grazing; sage brush removal is often followed by grass seeding and grazing in semi-arid lands. Logging in itself has a negative effect; but common site preparation practices thereafter administer the coup de gras, if one was needed. Spring "improvement", by trenching, piping, etc., followed by grazing, is another particularly common procedure, very effective in eliminating nonlivestock species.

Some general principles should be stated here first. Lumbering, especially clear-cuts, is essentially disastrous to the Species of Special Concern, as it is also in Douglas fir forests of the Pacific Northwest (Frest and Johannes, 1993c). Lumbering increases insolation; removes cover; increases ground temperature in summer; decreases effective ground temperature in winter (i.e., increases exposure); decreases available moisture and effective humidity; removes shelter, hibernation, and egg-laying sites; removes ground cover, including forage plants for many species; simplifies community structure; and decreases diversity. The removal of coarse woody debris and litter by logging (often followed by burning of slash) is particularly objectionable. Precise effects depend upon methodology, as will be detailed below; in general, clear-cuts are most disastrous; and some thinning may be necessary in forests in which natural fires have been suppressed. The best management technique is none at all, i.e. allowance of natural processes to continue, including fires. Barring this fire management techniques mimicking the natural process in each major plant communities much as possible (Agee, 1993) should be favored. In the fir forests of the Pacific Northwest, various rotations (of 50-200 years/cycle) have been 
suggested. These may or may not be adequate for relatively mobile species such as birds and mammals; but we doubt their efficacy for relatively sessile forms such as snails, or for species with limited geographic distributions (Olson, 1992; Frest and Johannes, 1993c, 1995a).

Talus disturbance is an especially significant problem in the Lower Salmon River area. The importance of stable rock talus to land snails, particularly in semiarid areas, cannot be overemphasized. Significant (sometimes the only) populations of land snails may occur in taluses of any lithology; locally, those of basalt, schist, and limestone are most prominent. Causes of disturbance include road building and grading, usage for fill or road metal, and mining for mineral commodities. Any substantial damage to a rock talus may render it wholly or partially unfit for snail occupation, and talus bases are most critical in this regard. Taluses may be occupied regardless of size; indeed, very large talus piles, or talus with very large liths, may be less suitable than smaller piles or taluses with less massive liths. In arid and semiarid areas, rock talus and boulder piles, which often have lower temperatures, more open space, and much greater available moisture than surrounding areas, provide a very significant refuge to a variety of animal taxa.

Similarly, mining may have drastic effects. Areas directly mined are of course generally sterile of land snails. Regeneration of such areas would be expected to take place rather slowly under the best of circumstances for many species. Likewise, there is little evidence that the Species of Special Concern can survive severe or sustained grazing. Grazing tends to simplify the plant community, resulting in loss of forage species. It tends to increase insolation, shrink or remove cover, litter, hibernation, and shelter sites, decrease winter ground temperature, increase summer ground temperature, decrease effective available moisture and humidity, compact soil, and physically destroy land snail individuals and colonies. Severe forest fires increase insolation, destroy ground cover and litter, increase soil erosion rates, acidify the soil, drastically alter the plant community, remove shelter, hibernation, and egg-laying sites, and alter the forest floor microclimate and soil composition.

In practice, the major human causes of habitat alteration have very similar effects. Land snails, as well as many other forest floor taxa, have relatively slow rates of migration. In the present, largely disturbed conditions typical of much of the Interior Columbia Basin, there remain relatively few population reservoirs for many species. Again, the Lower Salmon River species provide excellent examples, with narrow ranges being typical for most taxa (Figures 4-5) and most species being known from very few sites (Figures 7, 10B; Table 2). Surviving colonies are often geographically restricted and isolated, with large areas of unsuitable habitat intervening. Even comparatively mobile vertebrates have considerable difficulty maintaining populations in such a landscape (Stacey \& Taper, 1992); there is virtually no chance for migration or gene exchange between populations for the effectively sessile or slow-moving terrestrial and aquatic mollusks which require active or self-dispersal (the majority of taxa, including almost all endemics and 
sensitive species). Major disturbance of remaining sites for the very rare SOSC should not be countenanced, as recovery would be slow at best, and most likely would not take place at all at most localities. The best strategy for most of the SOSC is preservation of at least some of the now known sites essentially intact. In some instances, very carefully controlled thinning may be necessary to prevent severe forest fires; but such activities should be undertaken only with great care. Fortunately, land snails are generally most common in areas relatively marginal for large-scale lumbering operations. The tendency to concentrate in certain habitats, such as steep, rocky forested slopes, riparian woodlands, and around springs and seeps is notable for all of the SOSC. In most cases, viable land or freshwater mollusk colonies can be quite small. Discus shimeki and the Vertigo species may be present in large numbers in areas of only a few tens of square feet. Oreohelix colonies with lengths of a mile and widths of 1/4-1/2 mi. are known from several states. In the Hells Canyon and lower Salmon River regions, colonies are generally on the order of several hundred square feet in area. It would not seem unreasonable or unfeasible to carefully preserve undisturbed the relatively small number of parcels necessary to sustain these species.

Because of the small size of many land snail colonies and their current sporadic distribution, certain other activities, mostly related to human stock and recreational use, should also be addressed. In certain instances, development is compatible with many uses; however, these cases are often due to fortuitous physiographic and other features not inherently associated with the activity. Examples will be discussed below. As most land snail species have been extirpated from most of the public lands in the Interior Columbia Basin, and as the SOSC are geographically limited and occur in any case only in relatively unimpacted areas, the potential for conflicts in usage is not that great. However, there is a real potential for difficulties in certain limited areas, particularly in those that have not yet been subjected to intensive management. Ironically, the most attractive features of some areas, e.g. relatively undisturbed forests, deep valleys, and absence of large-scale consumptive operations, to humans for recreational uses coincide with their attractiveness to other species as well. In general, intense recreational usage will extirpate snail colonies. As before, no disturbance is the best policy. When conflicts arise, mitigation may be a viable alternative. However, there is little precedent with land snails, or more particularly with the Species of Special Concern here. Such activities are likely quite possible, relatively inexpensive and uncomplicated, and perhaps worth attempting in particular cases; but only if a core number of original sites have been completely secured in order to guarantee viability of the species concerned.

As the reader will have noted, mollusk diversity, whether of terrestrial or of aquatic forms, is concentrated in certain relatively small portions of the Interior Columbia Basin (Frest \& Johannes, 1995a). Even if the fauna of a single endemic region is considered in isolation, as with the Lower Salmon River malacofauna herein, the same principle holds. In particular, many species 
are confined to calcareous substrate (notably, such units as the Paleozoic Madison, Lodegpole, Mission Canyon, Amsden, and Phosphoria; or [locally] the Triassic Martin Bridge). Total outcrop areas of these units make up a small part of the total area of the Interior Columbia Basin. Even within the quite circumscribed outcrop area of these units, many species, particularly the Species of Special Concern, are limited to a small fraction of the total outcrop area. Certain drainages and narrowly circumscribed geographic areas are particularly significant to mollusk biodiversity, as outlined broadly under BIOGEOGRAPHY previously. Preeminent are portions of the Columbia Gorge, Hells Canyon, the lower Salmon River, the Clearwater, the Clark Fork, and the Bitterroot drainages. Conservation efforts for most of the significant taxa should be concentrated in this very small portion of the total Interior Columbia Basin area. In some instances, other sites are also very significant, such as a few localities with schist or limestone substrate in western and southeastern Idaho and in western Montana. Similarly, springs in the Upper Klamath Lake drainage, the Columbia Gorge, southeastern Idaho, and specific portions of the Oregon Interior Basins, western Wyoming, and the northern quarter of the Interior Columbia Basin. Specific sites are noted under the appropriate headings in the SPECIES DISCUSSIONS. As was made clear in the discussion of areas of endemism and of mollusk biogeography, it is not unusual for both terrestrial and aquatic mollusk SOSC to occur in the same narrow geographic areas- and often at the same sites. Conservation of specific limited habitats, such as taluses, cold springs and seeps, and riparian areas, will go far toward ensuring preservation of mollusk biodiversity on public lands. As well, many other rare species are present in sites with mollusk SOSC. Notable are many plant species (both vascular and nonvascular), insect taxa, and reptiles and amphibians.

One example will be cited to indicate the value of a habitat conservation approach to preserving mollusk biodiversity. Recent survey of the remaining sites for the Federally Endangered lowa Pleistocene Snail led to the discovery of sites for some 8 other mollusk taxa and at least $\mathbf{5 0}$ disjunct plant species, all representative of a glacial relict biota characteristic of the upper Midwest. At least 3 of the plants were themselves already listing candidates. It is suspected that many more rare plant and animal species occupy the same sites. Recovery plans for the biota as a whole envision protection of little more than 4,000 acres total, at a relatively minor cost (Frest, 1984, 1991), and the potential to delist most of the involved species. This is being implemented partly as a special USFWS unit, the Driftless Area National Wildlife Refuge. Similar plans would be relatively easy to apply to most of the species discussed herein. Co-occurrence of rare plants and mollusks may be the case locally as well: note Macfarlane's four-o'-clock and Oreohelix idahoensis idahoensis on the Lucile Caves ACEC and occurrence of the plant at Oreohelix vortex sites also.

The practical possibilities for such plans can be evaluated by scrutiny of the Black Hills National Forest mollusk survey (Frest \& Johannes, 1993d). As indicated above, preservation of very little of the Forest was recommended to maintain mollusk biodiversity, mostly some small 
tracts concentrated in the northwest comer of the Forest. Even within the area specified as of particular importance, it was demonstrated that certain specific microhabitats were especially important to Black Hills land snails, particularly the SOSC. These included rocky taluses, springs, seeps, slope bases, and north- and east-facing slopes, particularly if well-forested and shaded (closed or partial canopy). As discussed before, such settings, particularly if accompanied by intact Pinus ponderosa or Picea glauca series communities with a diverse understory (including some or most of such taxa as Linnaea borealis, Aconitum sp., Viola spp., including canadensis, Pyrola spp. (all), Moneses uniflora, Adoxa moschatellina, Gymnocarpium dryopteris, Betula spp., Salix spp., Cornus canadensis, Cornus stolonifera, Aralia spp., Circaea alpina, Rosa acicularis, and other taxa mentioned above), and some deciduous tree and shrub admixture (good examples are various species of Acer, Alnus, and Populus) are most likely to support diverse land snail faunas.

Many of the localities particularly favored were scheduled for special preservation efforts for other reasons. The importance of riparian areas to mollusks, particularly of riparian forests, shaded slope bases, and springs, seeps, and permanent streams in more arid regions has also been mentioned repeatedly above. Forest management has long recognized the importance of riparian buffers. However, the common past practice, of relatively intact $100 \mathrm{ft}$. wide corridors, seems to be inadequate to protect both streams and riparian-related species; and riparian zones in both federal lands and elsewhere generally now seem to be in the worst condition ever recorded (EPA, 1990). We prefer the definition employed by Thomas et al. (1993), namely of Riparian Habitat Conservation Areas extending "from the edges of the active stream channel to the top of the inner gorge, or to the outer edges of the 100-year floodplain, or to the outer edges of riparian vegetation, or to a distance equal to the height of two site-potential trees, or 300 feet horizontal distance (600 feet, including both sides of the stream channel), whichever is greatest" (op. cit., p. 447). The Spotted Owl controversy has stimulated a thorough reexamination of forest management practices, and the recommendations and evaluations made in Thomas et al. (1990, 1993) and in Johnson et al. (1991) should receive careful consideration here also, as forest communities in the ICB are closely analogous to those of the Pacific Northwest. Similarly, the Association of Forest Service Employees for Environmental Ethics has recently called for implementation of a policy of 100 yard buffer zones nationwide. 


\section{SPECIFIC PRACTICES}

In order to aid in the management of Lower Salmon River public lands, some specific comments will be made here in regard to some common management practices and activities. The same recommendations have been made previously in regard to the Interior Columbia Basin in general (Frest \& Johannes, 1995a). The order is not systematic; but hopefully it covers some of the major possibilities.

1) Hiking trail construction and maintenance, as well as use of such trails, is quite capable of extirpating snail colonies. One instance of human trail use destroying a population of the Endangered lowa Pleistocene snail has been documented (see Frest, 1984, 1991, and references therein). The disturbance-induced small size of colonies of, and limited distribution of, many of the SOSC must again be pointed out. Examples of snail colonies surviving trails across them can also be adduced; but conservative management should be the norm. Damage is particularly likely in arid or semi-arid settings, as human trails or points of particular interest for recreational, scenic, or archaeological purposes tend to be in areas particularly likely to have remaining mollusk colonies. Springs or other permanent water in such settings is also of extraordinary interest to humans as well as mollusks, and particularly likely to have developed trails.

2) Picnic area reconstruction. In general, snail colonies can survive low-use and lowimpact picnic areas; but increasing usage will cause extirpation. Colonies are unlikely to survive in such areas proper; and areas bordering picnic facilities will be impacted. Any considerable usage will be damaging.

3) Snow plowing on existing roads is likely to have little or no impact, unless road salting (with either sodium or calcium chloride) is carried out extensively in conjunction with it. Salt is notoriously harmful to land snails and can impact freshwater forms as well.

4) Road construction is generally disastrous, at least temporarily, if snails (especially SOSC) are present. Again, in the great majority of the ICB, the native mollusk fauna is extimated or much reduced, so that conflicts are unlikely. The overall effect on an existing colony is to extirpate in the roadway proper, and site preparation often extends the effects. If a sufficient population reservoir remains in the vicinity following construction, partial regeneration of the colony is quite possible; but colonies are already fragmented and much reduced in area and numbers; allowing continuing attrition is imprudent. Roads form essentialiy impassible barriers to terrestrial forms. Aside from direct construction effects, road building increases human traffic, including foot traffic; increases exposure and effective ground temperature; generally changes the local plant 
community; leads to introduction of disturbance plants and non-native and noxious plant and animal species; and stimulates damaging side effects, such as spraying.

5) Timber harvest has been dealt with in part above. Even the effects of selective cutting are likely to be extirpation of sensitive species, such as the SOSC. Very limiting coppicing, as has been practiced in the United Kingdom, can be compatible with survival of many land snail species; but most proposals for western U.S. forests leave ludicrously small numbers of trees. In Washington, some "forests" managed in this manner have one or two standing trees per acre: the result is grotesque as well as ineffective. As practiced in the U.S., the effects of the heavy equipment standard to most logging operations are much more severe than old-style European coppicing. Selective cutting as done in the area some 60-90 years ago, i.e. without use of heavy mechanical equipment, seems to have left the terrestrial mollusk fauna largely intact, at least in some sites in the Olympics and Cascades. Least damage is done if riparian areas are left intact, as well as areas around permanent springs and seeps, no matter how small. Similarly, retention of a small fraction of the landscape intact, such as slope bases, especially on north-facing slopes, should leave a sufficient population reservoir to prevent extirpation and allow recolonization of the uplands.

We believe that attempts to implement selective logging practices in the Douglas fir forests of the Interior Columbia Basin generally have been ineffective. Sloppy logging often results in fatal damage to the few trees left standing. Overstory removal increases insolation to a considerable extent, and often decreases effective moisture to the extent of exaggerating fires. We do not think that the SOSC would survive such a technique. As forests in these areas are already often somewhat more open and have comparatively thin soils and lesser amounts of debris, ground disturbance and site preparation may have even more severe effects than in Westside forests. In practice, the damage done to the understory is often severe; and the change in microclimate may be sufficiently severe as to eliminate snail colonies and drastically change the composition of the understory community.

Again, the importance of coarse woody debris to forest floor animal and plant communities should also be reemphasized. Larger pieces are most suitable as refuges or hibernaculae, and mechanical techniques which result in the production of mulch, (ground-up or small-sized debris only) are disastrous to mollusks, and many other more or less sedentary or slow-dispersing organisms. Patch cuts might be acceptable if the allowed rotation time were sufficient to allow migration of surrounding populations. However, most proposed rotation periods are completely inadequate. Moreover, the size of uncut areas often is much less than necessary to sustain more than a fraction of the original community.

There is a sizable literature on forest fragmentation. Even though much is focused on larger vertebrates and plants, it is clear that fairly sizable reserves are necessary to sustain 
biodiversity. Very few studies have been conducted on relatively immobile animal taxa, such as many forest floor invertebrates, as yet. Precommercial thinning, if a prelude to further lumbering, has bad effects but not as severe as timber "harvesting", and is comparatively irrelevant. One analogy might be machine-gunning an area prior to saturation bombing or shelling.

6) Site preparation is likely to completely extirpate any snails remaining in the area affected. Surviving deadfall and large debris pieces are generally removed or fragmented, destroying remaining shelter or hibernaculae; litter is often dispersed or removed totally to bare mineral soil, and further drying-out of the forest floor ensues. Burning of slash removes much or all of any mollusk fauna remaining. Ground preparation activities such as furrowing are undoubtedly nearly as effective here as they are in Midwest corn fields in creating monospecific communities. Spraying to kill or inhibit so-called competing plants, such as Arctostaphylos or Sorbus, would have the double effect of direct poisoning and indirect removal of any remaining or developing cover for mollusks. Both freshwater and terrestrial forms are sensitive to the usual range of herbicides, pesticides, and fertilizers employed, in particular organochlorides or acidifiers. We have no information as to the effects of use of Bacillus thuringensis or similar biocides on mollusks.

7) Spring development generally results in loss of all or many species. Effects include drying out of nearly all of the original spring area; disruption of soil, rock, and vegetational cover; encouragement of stock visits (see under grazing, above and below), with concomitant trampling effects and effects of "acidic" manure likely to accumulate in such settings. Unless some part of the source area is left intact and carefully protected, the effect of development is generally to completely extirpate the native freshwater mollusc fauna, as well as most of the diversity in other animal and plant groups. This is an extremely important issue in the Lower Salmon River area, as elsewhere in the Interior Columbia Basin. At least 3,500 springs have been "developed", often at public expense, in Idaho and Montana alone. Such development often fails in its primary function, that of making water more available to stock. Piping, etc. often disturbs the groundwater source or is so inexpertly done as to dry up the spring. Moreover, this activity tends to concentrate stock into an extremely limited area. Trampling and waste fouling effects are exaggerated, and compaction can also cause the spring source to fail more readily than with springs left in the natural state.

In much of the and and semi-arid portions of the Interior Columbia Basin, springs are not only vital sources of water to domestic animals and humans, but are the major locales for biodiversity. Spring development has thus tended to selectively extirpate the relatively few rich islands of plant and animal diversity in many of the more xeric lands in the Interior Columbia Basin. Perhaps the single most deleterious activity in arid and semi-arid ecosystems to both terrestrial 
and freshwater forms is development of springs. Reasons for this have been discussed above. We can do no better than to supply the following quote:

\section{"Range Improvements" - an Oxymoron}

"Range improvement projects are a major BLM management emphasis. These projects would be more accurately termed as livestock management facilities. One of the most common range improvement projects is to run water through a pipe from a natural spring to a watering trough. In Idaho and Montana alone, the BLM and livestock permittees have developed over 3,500 springs on public lands. Some BLM Districts have developed all known springs. Yet in desert ecosystems, natural springs are critical areas for maintaining biological diversity.

The BLM often states that the purpose of these spring developments is to improve riparian area condition. Yet the BLM does not monitor the effectiveness of these projects for riparian improvements. Diverting spring water to a trough results in a dewatered wetland or spring riparian area, and a net loss of wetlands acreage. This effect is not only inconsistent with the Bureau's publicized goals for wetland/riparian improvement, but is inconsistent with the national policy of no net loss of wetlands." (PEER, 1994).

8) Spring fencing in general causes little damage per se, and there is no irreparable harm. The benefits from fencing to the area protected on the whole far outweigh any negative effects. In practice, however, fencing is often relatively ineffective as a protective measure. To function properly, it must be done with some care; and field crews often do not exercise such care. Moreover, maintenance of such fences is often done inadequately or haphazardly, in our experience. As a mitigation technique, fencing can be done in such a manner as to preserve at least part of the local biodiversity but still make water available for other uses. Spring sources and a few hundred feet of the upper run should be rigorously protected. For many species, this will provide enough habitat to maintain a viable population.

9) Fencing of niparian areas and allotments generally suffers from the same drawbacks as spring fencing. In practice, a certain amount of deliberate sabotage and illegal grazing also takes place for various reasons, and is seldom corrected. An effective program is low-tech and could work well, if sufficient funding, motivation, and personnel are available.

10) Prescribed burning, if carefully conducted, should produce no permanent bad effects. In practice, however, much such is unnecessary, except in already disturbed settings. Mollusks seem able to survive natural fires, but not exceptionally severe fires or those resulting from the past practice of fire suppression. Complete incineration of forest floor litter and of even coarse woody debris appears to be uniformly disastrous for all terrestrial mollusk species. Practices mimicking the natural fire regime for each major plant community, as described, e.g. in Agee (1993) are strongly to be preferred. Fires in sage scrub or other arid or semi-arid plant 
relatively intact forests with considerable duff alongside medium-large streams, particularly at the edge of flood plains (slope base). Most sites have high understory diversity, as well as high land snail diversity. Moist valley, ravine, gorge, or talus sites are preferred, i.e. low on a slope and near permanent or persistent water, but not normally subject to regular or catastrophic flooding. Persistence of moisture is a desideratum. Noted associates include Allogona ptychophora ptychophora, Polygyrella polygyrella, Hemphillia camelus, Zacoleus idahoensis, Anguispira kochi occidentalis, Anguispira nimapuna, and several Cryptomastix species. A definite mesophile.

Lower Salmon River occurrences (see below) have similar associates (Allogona ptychophora ptychophora, Hemphillia camelus, Zacoleus idahoensis, Anguispira kochi occidentalis, and Cryptomastix mullani olneyae; plus Discus marmorensis, Oreohelix n. sp. 22, and (rarely) Oreohelix haydeni hesperia): see Tables 3-4 for details. The local ecology is likewise similar, except that all 3 sites are on limestone soils.

Original distribution: Typical populations occurred along the Lochsa, Selway, and uppermost Clearwater River and their major tributaries, northern ID (Clearwater Mountains). The original distribution was probably essentially continuous in this area.

This taxon has not previously been reported from the lower Salmon River area (Table 1). We found a few disjunct colonies (3) of uncertain status (possibly an undescribed form) along a small portion of the lower Salmon River drainage at moderate-high elevations (Slate Creek, John Day Creek: Table 4, Appendix C3). Pending further investigation, these are regarded as likely Allogona lombardii (see also discussion under Hemphillia camelus, below).

Current distribution: A few isolated populations survive in densely forested areas along the lower Lochsa and Selway River and one major Selway tributary. We have recently recollected the type locality and other sites in the previously known and likely range. It is not likely that later work will greatly expand either the range or number of sites. Current status of some sites (e.g. Branson, Sisk, \& McCoy, 1966) needs to be reevaluated.

The three sites in Slate Creek and John Day Creek are rather unusually intact mature moderate-elevation forest, a habitat type now quite rare in the Lower Salmon River valley.

Threats: Timber harvest and grazing have affected most of the original range. Highways (e.g., US 12) and parks, pullouts, and other such modifications are concentrated in its preferred habitat along much of the Lochsa and part of the Selway corridors. The species is not found in recently logged or heavily grazed areas.

The Lower Salmon River valley sites are in a habitat type now largely displaced by logging and grazing. Occurrence on a sizable isolated limestone block presents special problems, e.g. recent quarrying has removed much suitable habitat; and all three colonies are subject to further such damage. Logging is extensive and ongoing throughout the surrounding area. Grazing is conducted on much of the area; and the species is absent from grazed portions of the area. This species is currently very rare locally (Table 2) and is absent from many seemingly suitable upland forest sites in the vicinity, e.g. most of our John Day Mountain sites, upper Grave Creek sites, etc.

Criteria for inclusion: Regional (part of Washingtonian Province) endemic with rather specialized habitat requirements that has lost much of its original habitat; few known or likely sites; old growth and riparian associate. Much remaining is public land subject to logging, grazing, or other potentially imperiling human activities. Most known and former sites are on public land, including Clearwater National Forest, Nez Perce National Forest, and the Lochsa section of the Cleanwater Wild and Scenic River. This species appears to be declining throughout its limited range. Treated as a Sensitive species in Frest \& Johannes (1995a).

Recommended status: Currently this species has no special status. Minimally, it should be considered a sensitive species by the Forest Service, BLM, and state land and wildlife management agencies. There is sufficient recently-collected information, and recent survey work, 
to indicate that Federal and State (ID) listing as Threatened is warranted, due to limited distribution, loss of habitat, and threats to remaining habitat. The species is very rare locally (Tables 2-4).

References: Smith (1943); Pilsbry (1948); Webb (1968); Frest \& Johannes (1995a); Deixis 1989-94 collections.

\section{Allogona (Allogona) ptychophora solida Vanatta, 1924 APPENDIX C5}

\section{dry land forestsnail}

Type locality: Cottonwood Tree Canyon, along Snake River, 50 miles south of Lewiston, Nez Perce Co., ID; holotype ANSP 132476 (Vanatta, 1924). No location with exactly this name and description has been found; however, Cottonwood Creek in Hells Canyon, approximately 40 miles south of Lewiston, is the likely type locality.

Description: See Vanatta (1924) and Pilsbry (1940) for descriptions and comparisons. Limited material, consisting of shells only, was available to Vanatta and Pilsbry. Recent collections demonstrate that this is likely a full species, with distinctive anatomy and body and mantle pigmentation as well as shell features. As compared to the nominate subspecies, solida has a lower spire; the shell is generally greenish in color; the apertural margin is thicker and white in color; and the body is consistently dark gray. Ptychophora ptychophora is higher; the shell is generally tan, yellow-brown, or light reddish brown in color; it has a thin, generally tan apertural margin; and the body is generally light yellow-tan or pale tan in color.

Ecology: This moderately xerophilic taxon occurs most frequently in comparatively open and dry large basalt taluses, generally at lower elevations, along a limited portion of the northern Hells Canyon (Snake River) drainage, ID, WA, \& OR, the Lewiston and Clarkston area, ID \& WA, the lowermost Salmon River drainage, Idaho and Nez Perce cos., ID, plus the lowermost Clearwater River drainage, ID. Covering vegetation may include Celtus, Artemisia, Prunus, Balsamorrhiza, grasses, Seligeria, and some bryophytes. It is most frequent on N.-facing large taluses, often only at their base. While it is a xerophile as compared to the other Allogona species, it avoids the most dry sites, i.e. areas preferred by Oreohelix haydeni subspp. and Oreohelix idahoensis idahoensis.

Common land snail associates include several small Cryptomastix species (including magnidentata at one former site), Cryptomastix populi, Allogona ptychophora ptychophora, Oreohelix jugalis, and Oreohelix vortex. The species has been found occasionally on limestone or metasedimentary substrate. In the Lower Salmon area, essentially all sites are on basalts. Common associates, aside from the general ones just listed, here include Cryptomastix n. $\mathrm{sp} .3$ and n. sp. 6, as well as Oreohelix n. sp. 25 (see Table 3).

Original distribution: Probably comparatively frequent in the areas underlain by the Grande Ronde and Columbia River basalts, Snake River, Salmon River, and lower Clearwater River. For Lower Salmon River Valley distribution, see Appendix C5; note that the species only occurs from about the mouth of Skookumchuck Creek to the mouth of the Salmon River. Most colonies occur at slope base along the major river corridors, not in major tributaries.

This taxon is a Hells Canyon-Lower Salmon River endemic, found only in portions of both canyons (see distribution map). It is the most strongly xeric-adapted of the Allogona species, most of which are mesic forest snails, as the common name implies. 
Current distribution: This taxon now occurs as isolated colonies in relatively undisturbed portions of the original distribution, i.e. roadless areas in the lower Salmon and Hells Canyon. Clearwater and Mission Creek sites appear to be extipated. Much or all of the known and potential range has recently been surveyed in some detail (Frest \& Johannes, 1995a). There are currently about 21 Lower Salmon River Valley sites (Table 3). Other collectors and malacologists have also explored this area, from the 1860 s to the present (e.g., H. Hemphill, H. B. Baker, M. Walton, and A. Solem). It is not likely that later work will greatly expand either the range or number of sites.

Threats: Grazing occurs over much of the original habitat, and the species appears to be absent from heavily grazed areas. Roads are often located preferentially along the bases of large talus piles in the larger river corridors, e.g. US 95. Mining of basalt for road metal and for fill has extirpated colonies since 1990, e.g. near White Bird and Lewiston, ID. Roadside spraying is a problem for some colonies in both WA and ID. The species' total population size and number are declining. The Hammer Creek colony has been largely destroyed recently by road work (access to Forest Service recreational areas). Heavy grazing has limited and impacted about half of the known sites; this pressure is increasing, particularly in the White Bird area, about half of the Lower Salmon River range.

Criteria for inclusion: A Hells Canyon-Lower Salmon River endemic that has lost much of its rather specialized habitat. Remaining colonies are mostly on public lands, including BLM and Nez Perce National Forest properties. Very few sites known and substantial range expansion or finds are not likely. This species is declining throughout its limited range, and colony loss has been observed in recent years, particularly in the Hells Canyon part of the range. Treated as a Sensitive species in Frest \& Johannes (1995a).

Recommended status: To date, this species has no special status; it should be considered a sensitive species by the Forest Service, BLM, and state land and wildlife management agencies. There is sufficient recently-collected information, and recent survey work, to recommend Federal and State (ID, WA) listing as Threatened, and OR listing as Endangered, due to loss of habitat, some historic sites, and increasing human populations and usage of some or all of remaining habitat. Locally, it is a rare taxon, confined too a limited number of sites in only a portion of the survey area (Table 2, Appendix C5).

References: Vanatta (1924); Pilsbry (1940); Frest \& Johannes (1995a); Deixis collections, 199094.

\section{Cryptomastix (Bupiogona) populi (Vanatta, 1924) poplar oregonian APPENDIX C9}

Type locality: "Cottonwood Tree Canyon, on Snake River 50 miles south of Lewiston, Nez Perce Co., ID" (Vanatta, 1924); holotype ANSP 132939a. This is the same site as the type locality of Allogona ptychophora solida (q.v.) and is also a site for the rare Oreohelix n. sp. 18 (Limestone Point mountainsnail; see Frest \& Johannes, 1995a). We were unable to find a site with precisely this name and description on either current or old maps available to us. However, Cottonwood Creek in Hells Canyon, approximately $40 \mathrm{mi}$. south of Lewiston, is the likely type locality.

Description: See Pilsbry (1940). The species was based originally on 2 dead specimens only. Live material indicates that the dark blue-black body and wine-red shell color are quite distinctive among described species of Cryptomastix, as are the apertural features noted by Pilsbry. Anatomy of specimens of this species, collected by W. B. Miller from near Clarkston, WA, was 
described and illustrated by Webb $(1970 b, 1990)$ under the name Cryptomastix hendersoni. The unique features of the male anatomy were the basis for the new subgenus Bupiogona Webb, 1970. We have confirmed these features in recently collected Cryptomastix populi (compared with the type material at ANSP in 1991); by analogy with other triodopsinids (see, e.g., detailed studies of Emberton, 1988), they are unusual enough as to justify generic separation, as has been done recently in the related western genera Vespericola and Hochbergellus (Roth \& Miller, 1992, 1993). Two other Snake River forms (Cryptomastix (Bupiogona) n. sp. 1 and n. sp. 2 of Frest \& Johannes, 1995a) are similar in gross anatomy, but differ considerably and consistently in shell and soft part details. For anatomy of typical Cryptomastix (s.s.), see Pilsbry (1940) and Webb (1970a).

As noted above, it may be necessary to designate a new type species for Bupiogona, according to ICZN rules. However, this will not affect the status of this species, the logical choice for neogenotype. To resolve the situation it will be necessary to establish the nature of Webb's specimens and request a ruling under Articles 65B, 67I, and 70 (ICZN, 1985). Note that available courses of action do not affect the validity of either Cryptomastix hendersoni or Cryptomastix populi.

Ecology: This taxon, a moderate xerophile, is found mostly in rather open and dry, large-scale basalt taluses, generally at lower elevations, along a limited portion of the northern Hells Canyon (Snake River) drainage, ID, WA, \& OR, the Lewiston and Clarkston area, ID \& WA, and the lowermost few miles of the lower Salmon River canyon, Nez Perce Co., ID. The rather limited talus vegetation may include Celtus, Artemisia, Prunus, Balsamorrhiza, grasses, Seligeria, and some bryophytes. Surrounding vegetation is generally sage scrub. This species usually occurs in steep, N. or E.-facing taluses, often only at their base. It is a xerophile as compared to the other Allogona species, but avoids the most dry sites, i.e. areas preferred by Oreohelix haydeni subspp. and Oreohelix idahoensis idahoensis. Common land snail associates include Cryptomastix (Cryptomastix) species, Allogona ptychophora ptychophora, Allogona ptychophora solida, and various species of Oreohelix. This taxon has been found occasionally in metasedimentary taluses as well.

In the Lower Salmon River area, occurrences are rather typical. The substrate is basalt (generally talus); Cryptomastix species associated include n. sp. 3 and n. sp. 6; Oreohelix n. sp. 25 is frequently fund in the same sites, as well as the Allogona species mentioned above (see Table 3 for details).

Original distribution: Probably once comparatively frequent in the areas underlain by the Grande Ronde and Columbia River basalts, Snake River, Salmon River, and lower Clearwater River. Most colonies occur at slope bases along the major river corridors, not in major tributaries. These generalizations apply well to the local occurrences; all are on Grande Ronde basalts.

Current distribution: This taxon now occurs as isolated colonies in relatively undisturbed portions of the original distribution, i.e. roadless areas in the lower Salmon River canyon and northern Hells Canyon. It is replaced by related species in the central and southern parts of Hells Canyon. Clearwater sites appear to be extirpated. Much or all of the known and potential range has recently been surveyed in some detail (Frest \& Johannes, 1995a). The current range is largely coincident with that of Allogona ptychophora solida, except that the latter does not appear to range down the Snake as far as Clarkston, WA.

Several years ago, we believed this taxon to be much more widespread; but further collecting and elimination of certain sites within a few years of our first visits in the late 1980s has made us much less sanguine about chances for the species' survival.

All currently extant Lower Salmon River sites (10: Tables 3, 4) occur downstream from the mouth of Rock Creek, in a very limited area (Appendix C9). Not all are in the main canyon. The absence of this species from the upstream basalt outcrop area around White Bird, not to mention the less continuous outcrops between Riggins and White Bird, is interesting. 
Threats: Grazing is extensive in much of the original habitat, and the species appears to be absent from heavily grazed areas. The former colony at Lime Hill, near Rogersburg, WA, e.g., seems to be extirpated solely due to grazing. Roads are often located preferentially along the bases of large talus piles in the larger river corridors inhabited by the species, e.g. US 95; roadside spraying is a problem for some colonies. Mining of basalt for road metal and for fill has extirpated colonies since 1990, e.g. near White Bird and Lewiston, ID. Very large colonies along US $12 \mathrm{~W}$. of Clarkston have been extirpated by road realignment and maintenance in the last few years.

Criteria for inclusion: A Hells Canyon-Lower Salmon River endemic that has lost much of its rather specialized habitat. Remaining colonies are mostly on public lands, including BLM and Nez Perce National Forest properties. Very few sites are known or likely. This species is declining throughout its limited range, and colony loss has been observed in recent years. Treated as a Sensitive species in Frest \& Johannes (1995a).

Recommended status: Has none at present, but minimally should be considered a sensitive species by the Forest Service and BLM. There is sufficient recently-collected information, and recent survey work, to indicate that Federal and State (WA, OR, ID) listing as Threatened is warranted, due to loss of habitat and increasing human populations and usage of most or all of remaining habitat.

In the survey area, there are only 10 sites, many of which are small in extent. We regard Cryptomastix populi as uncommon locally and in need of protection.

References: Vanatta (1924); Pilsbry (1940); Frest \& Johannes (1995a); Deixis collections, 199094.

\section{Cryptomastix (Cryptomastix) harfordiana (Binney, 1879) Salmon oregonian APPENDIX C10}

Type locality: Salmon River (Hemphill); Pilsbry (1940, p. 870) states "probably somewhere north of Lucile", Idaho Co., D (lower Salmon River drainage). Holotype ANSP 11116. In view of the known distribution, there are a number of places from which Hemphill could have secured his material, and a need for explicit designation of a precise type locality (Figure 2).

Description: The tangled history of this name has been well reviewed by Pilsbry (1940), which work also has the best previous illustration and description of the shell. See also Frest \& Johannes (1995a). Live-collected specimens are generally very sparsely hirsute. Turgeon et al. (1988) regarded this species as of uncertain affinities; dissection indicates it is Cryptomastix s.l. Affinities are with Cryptomastix magnidentata and related species.

Ecology: This species is most often found in rock taluses (limestone, schist; more rarely basalt or granite) at low elevations. Most are comparatively dry and open, with scattered Celtus, grasses, and Rhus clumps. On occasion, the species is found in open to more sheltered stream side boulder piles, often with Salix, Cornus stolonifera, Rubrus, and bryophyte cover in part. Common associates include several species of Oreohelix, including idahoensis idahoensis, jugalis, and waltoni, plus Allogona ptychophora ptychophora, Helicodiscus salmoneus, Vitrina alaskana, and Vallonia cyclophorella. Cryptomastix harfordiana can occur in relatively strongly xeric sites, such as sage scrub; but it is usually rare in such settings; it is basically a moderate xerophile. 
Original distribution: Lower Salmon River valley between Riggins and Copperville, Idaho Co., ID; the whole range is in the survey area. This species was probably extremely abundant originally in its narrow area of occurrence, and is still often the dominant species of Cryptomastix locally, although quite rare at some sites.

Current distribution: Scattered sites within the original area of distribution (about 19: Tables 34). As many other malacologists and collectors, including H. Hemphill, H. B. Baker, A. Solem, and M. Walton, have explored this area, it is unlikely that the range or number of sites will be significantly expanded by future work.

Threats: Grazing over whole of range; talus mining and removal; gold and gravel mining operations; road building (e.g. US 95 corridor, which traverses roughly $50 \%$ of total range); human habitation; roadside spraying. The species tends to occur at the base of major slopes, which are also primary road and human habitation and recreation sites.

Criteria for inclusion: Strict local endemic (Table 1); loss of historic habitat; loss of colonies in recent years (declining number of sites and individuals); continuing heavy grazing in whole range; occurrence on public lands, including BLM and Nez Perce National Forest property; expanding recreational use of Salmon River corridor. The trends for the population as a whole (number of sites, number of individuals) are downward. Treated as a Sensitive species in Frest \& Johannes (1995a).

Recommended status: Currently has none. Should be considered a sensitive species by the Forest Service and BLM. There is sufficient recently-collected information, and recent survey work, to indicate that Federal and State (ID) listing as Endangered should be considered: the species is a local endemic with a very limited distribution. Preferred habitat is limited in occurrence and especially subject to human utilization. The species occurs partly on public lands.

References: Pilsbry (1940); Frest \& Johannes (1995a); Deixis collections, 1988-94.

$\begin{array}{cc}\text { Cryptomastix (Cryptomastix) mullani clappi (Hemphill, 1897) } & \text { River of No } \\ \text { Return oregonian } \\ \text { APPENDIX C11 }\end{array}$

Type locality: "Salmon River Mountains" (Hemphill); syntypes CAS 58821; ANSP 71479 [paratypes according to Baker (1964); possible syntypes according to Coan \& Roth (1987)]; USNM 46905; 58754 . As usual, Hemphill's locality citation is vague. The types likely came from the River of No Return area, east of Riggins and west of French Creek, ID (Figure 2).

Description: See Pilsbry (1940) for complete description and illustrations. The dark body color; dark mantle color; medium size; low subdiscoidal conch; relatively large umbilicus, barely or not at all covered by the columellar reflection; columellar insertion on the right side of the umbilicus; and fine, dense pelage distinguish the form (actually a full species) from related taxa. See descriptions of Cryptomastix harfordiana, n. sp. 5, and n. sp. 6 for comparisons.

Ecology: Found mostly at lower elevations in forested areas (mostly partly open Pinus ponderosa forest), on moist, north-facing slopes. Occasionally common in extensive mossy, north-facing metasedimentary taluses. Most sites have rich understory floras, including grasses, bryophytes, forbs, and shrubs. Moist valley, ravine, gorge, or talus sites are preferred, i.e. low on a slope and near permanent or persistent water, but not normally subject to regular or catastrophic 
flooding. Persistence of moisture is a desideratum. There are relatively few associated taxa; most often, these are Allogona ptychophora ptychophora and Oreohelix n. sp. 15 (Table 3). A mesophile species.

Original distribution: Confined to a narrow area on the south side of the River of No Return between Riggins and the mouth of French Creek (Appendix C11). Occurrences along the main Salmon from Riggins to Lucile, ID ascribed to this subspecies in Frest \& Johannes (1995a) (following Pilsbry (1940) are mostly Cryptomastix n. sp. 5, as defined herein. Specimens ascribed to White Bird and to Slate Creek (Henderson in Pilsbry, 1940), and found occasionally from near the mouth of John Day Creek downstream to site 158, are another taxon, Cryptomastix n. sp. 6 herein.

Current distribution: A few isolated colonies in the area cited above. This region was extensively surveyed in 1993-94. Many other collectors, including H. Hemphill, H. B. Baker, A. Solem, and M. Walton, have explored this area. It is unlikely that the range or number of sites will be significantly expanded by future work.

Threats: Gold mining and road building (e.g., French Creek Road) in narrow area occupied; talus removal; logging; major fires in 1994. This form is evidently declining; extinct colonies were noted in 1993-94, and habitat modification is extensive. Population trends (number of sites, number of individuals) are downward.

Criteria for inclusion: Very local endemic; decline in absolute numbers and number of sites; continued human activities in preferred habitat; habitat loss; association with relatively intact forest; occurrence on public lands (BLM, Payette and Nez Perce National Forests). The whole range is in a small part of the survey area. Treated as a Sensitive species in Frest \& Johannes (1995a), even with the more extensive range then accepted.

Recommended status: This taxon has none at present: it should be considered a sensitive species by the Forest Service and BLM. There is sufficient recently-collected information, and recent survey work, to indicate that Federal and State (ID) listing as Endangered is warranted. Many of the known sites have been negatively affected by grazing, logging, and other activities. The effects of the 1994 fires have not been evaluated but are predictably negative, especially in areas affected by other activities.

References: Pilsbry (1940); Frest \& Johannes (1995a); Deixis collections, 1989-1991, 19931994.

\author{
Cryptomastix (Cryptomastix) mullani latilabris (Pilsbry, 1940) wide-lipped \\ oregonian \\ APPENDIX C12
}

Type locality: Lower two or three miles of John Day Creek, lower Salmon River drainage, Idaho Co., ID; holotype ANSP 175777a. The precise locality is not certain; but this most likely refers to the vicinity of the Oreohelix haydeni hesperia type locality and the adjacent ravine to the north (Figure 2; see also Appendix A and B). Specimens in older collections, e.g. ANSP: Baker: early 1930 s, indicate that this species once occurred lower in the John Day Creek drainage; but it is now extinct in this highly modified area. 
Description: See Pilsbry (1940). This is a comparatively small (to $12 \mathrm{~mm}$ width) subspecies of Cryptomastix with a very broad, white, nonrevolute apertural lip. The parietal tooth is very prominent; the basal and palatal lamellae are stronger than in typical mullani, though not so strong as in forms like Cryptomastix harfordiana. Live specimens vary between reddish and yellowishred in color. Periostracal hairs are moderately sparse and short but persistent. The shell is typically depressed, rather low conic, with a somewhat convex base. The small size, color, periostracal hair, and apertural features distinguish the subspecies from mullani mullani.

Ecology: Found in moist and shady areas in relatively intact forest, generally on limestone substrate; occasionally in shaded and mossy limestone and schist talus, at moderate elevations, mostly near stream borders. Forest is Pinus ponderosa with strong forb and deciduous shrub understory, including Pyrola spp., Cornus canadensis, Linnaea borealis, Viola spp., and rich litter. Moist valley, ravine, gorge, or talus sites are preferred, i.e. low on a slope and near permanent or persistent water, but not normally subject to regular or catastrophic flooding. Persistence of moisture is a desideratum. Associated land snails include Oreohelix n. sp. 22 (Slate Creek mountainsnail), Oreohelix haydeni hesperia, Discus marmorensis, Anguispira kochi occidentalis, Allogona lombardii, Hemphillia camelus, Ogaridiscus subrupicola, and Pristiloma idahoensis. A mesophile, as are most Cryptomastix species.

Original distribution: Probably confined to rich forest at moderate to high elevations along a portion of the lower Salmon River, Idaho Co., ID. Pilsbry (1940) ascribes specimens from a site along the South Fork Clearwater River 3-4 mi. below Harpster to this species; but examination of the specimens indicates they are better assigned to mullani mullani. We revisited and recollected this site in 1991.

Current distribution: Found in 4 remnant colonies along a major creek tributary to the central lower Salmon River, Idaho Co., ID (John Day Creek); see Table 3 and Appendix 1 for details. The species is extinct at the type locality, and also at the reported site in sec. 35, T 26 N R 1 E, near Lucile. The species is absent from heavily grazed and clear-cut areas, such as lower John Day Creek. We surveyed the area of occurrence in 1990-94; and many other collectors, including $\mathrm{H}$. Hemphill, H. B. Baker, A. Solem, And M. Walton, have explored this area. It is unlikely that the range or number of sites will be significantly expanded by future work.

Threats: Road metal quarrying, past and present, along the lower and middle reaches of john Day Creek; lumbering in most of known and potential habitat; road building along critical stream corridor; heavy grazing in much of lumbered habitat.

Criteria for inclusion: Strict local endemic (Table 1); loss of habitat; ongoing threats; occurrence on public lands, including BLM and Nez Perce National Forest parcels; loss of historic sites, including the type locality. The species is definitely declining. Population trends (number of sites, number of individuals) are downward. Treated as a Sensitive species in Frest \& Johannes (1995a).

Recommended status: Has none at present: it should be considered a sensitive species by the Forest Service and BLM. Federal and State (ID) listing as Endangered is justified on current information, due to loss of historic sites and degradation of most of known and likely habitat: see above. We found the species very rare in the survey area in terms of number of sites ad total population; the whole range occupies a very small part of the survey area (Appendix C12).

References: Pilsbry (1940); Frest \& Johannes (1995a); Deixis collections, 1989-91, 93-94. 


\section{Cryptomastix (Cryptomastix) n. sp. 3 APPENDIX C15}

disc oregonian

Type locality: None as yet; undescribed taxon.

Description: This small Cryptomastix species has a nearly flat spire of $51 / 2$ rather closely spaced whorls. Maximum adult size is about $10 \mathrm{~mm}$; but most adults average about $8 \mathrm{~mm}$. The species lacks periostracal hair; is light yellow in color; and has a white, strongly tridentate aperture. The aperture is narrow, strongly inclined, strongly constricted immediately behind the lip, and has a prominent indentation in the area of the parietal tooth, causing the lip to appear L-shaped in side view. Most animals have the mantle lightly spotted with black, although 3 colonies in the vicinity of Lyons Bar consistently have darker mantles. The umbilicus elliptical and comparatively broad, $c a$. $3 / 4$ the full shell diameter in width. The lip is rather narrow, non revolute; the columellar insertion is mostly to the right of the umbilicus, which has only a small proportion covered by it. The shell base is comparatively flat.

This species can be distinguished from most related taxa by the color and flat, disc-like spire. Only the much-larger and quite distinct Cryptomastix sanburni has equally slowly expanding whorls. It is not represented in previous collections from the Lower Salmon River area.

Ecology: A strong xerophile. This species prefers dry, exposed taluses, most frequently basalt. Cover is limited to grasses, uncommon Seligeria and mosses, scattered Rhus horribilis or Sorbus clumps and occasional Celtus and Prunus. Commonly co-occurring land snails are Cryptomastix populi, Allogona ptychophora solida, Allogona ptychophora ptychophora, and several Oreohelix species, most often jugalis or vortex.

Original distribution: A regional endemic (Table 1), limited to a portion of the Lower Salmon River, Nez Perce and Idaho cos., ID, from approximately the mouth of Rock Creek to the confluence with the Snake River in Hells Canyon, thence downstream in the Snake (Nez Perce Co., ID; Wallowa Co., OR, and Asotin Co., WA) to a point a few miles west of Clarkston, WA.

Current distribution: Found in very small numbers in a small number of colonies in the region cited above. In the lower Salmon River area we located 7 sites (Table 3, Appendix C15), confined to a limited area of the main Salmon River corridor; we have collected the N. part of Hells Canyon and the Snake River in WA in the period 1989-1994. The Snake River corridor near Clarkston has also been collected recently by T. Burke (Wenatchee National Forest) and W. B. Miller (Santa Barbara Museum of Natural History). It is unlikely that many additional sites will be found.

Threats: Essentially all of the Salmon River habitat is grazed, much heavily; as is much of the Hells Canyon area. As with other species in this region, highway corridors are located along some of the suitable habitat, e.g. US 12 in WA. Talus mining and roadside spraying are problems for some colonies, particularly in the WA portion of the range. Some sites west of Clarkston and south of Lewiston collected in the late 1980s have been extirpated by road modification in the last three years; the species is declining in numbers and areal extent. Population trends (number of sites, number of individuals) are downward.

Criteria for inclusion: Local (part of Hells Canyon-Lower Salmon River) endemic; specialized and limited habitat; small number of known and potential sites; loss of historic sites; occurrence on public lands, including Hells Canyon National Recreation Area. Treated as a Sensitive species in Frest \& Johannes (1995a).

Recommended status: A newly recognized form with no status as yet. Should be considered a sensitive species by the Forest Service and BLM. There is sufficient recently-collected 
information, and recent survey work, to indicate that Federal and State (ID, WA, OR) listing as Endangered is warranted, due to habitat loss and decrease in historic sites, ongoing threats.

Lower Salmon River colonies are small in areal extent and the species is not common alive at any. We regard this species as very rare in the survey area (Table 2).

References: Frest \& Johannes (1995a); Deixis collections, 1989-94.

\section{Cryptomastix (Cryptomastix) n. sp. 5} APPENDIX C16
Lucile oregonian

Type locality: None as yet; undescribed taxon.

Description: This medium-sized Cryptomastix species has a low spire of $43 / 2-5$ whorls, moderately rapidly expanding. Maximum adult size is about $16 \mathrm{~mm}$, larger than harfordiana and roughly the same as clappi, but most adults average about $14 \mathrm{~mm}$. The species often lacks periostracal hair or has only traces (unlike clappi, which is distinctly and closely hirsute; or harfordiana, which generally lacks periostracal hair); color ranges from bluish gray to tan; and has a white, weakly tridentate aperture. The aperture is comparatively broad, weakly inclined, and has a whitish periphery, with the basal lamella and palatal tooth present but always weak. The parietal tooth is more distinct than that of clappi, but much less prominent than that of harfordiana. The umbilicus is similar in morphology to that of clappi. Most animals have the mantle lightly spotted with black. The lip is rather narrow, weakly revolute, broader than that of clappi; the columellar insertion is definitely above the umbilicus, which has a small proportion covered by it, similar to harfordiana and less open than that of clappi. The shell base is low convex.

This species is present in older collections from the Lucile area. Pilsbry (1940, p. 869, text and fig. 504 b-d) described it and illustrated it as "form intermediate between clappi and harfordiana" - an apt definition on shell morphology. With sizable quantities of live material of all three, the distinctness of this form becomes apparent. Comparisons with clappi and harfordiana have been made above; see also discussion of Cryptomastix $\mathrm{n}$. sp. 6 below.

Ecology: A moderate xerophile. This species prefers exposed taluses of varying lithology, including schist and limestone. Cover is often limited to grasses, uncommon Seligeria and mosses, scattered Rhus horribilis or Sorbus clumps and frequent Celtus and Prunus. Commonly co-occurring land snails are Allogona ptychophora ptychophora and several Oreohelix species, most often idahoensis idahoensis or jugalis.

Original distribution: A strict local endemic (Table 1), limited to a portion of the Lower Salmon River, Idaho Co., ID, from approximately Riggins to the mouth of White Bird Creek (Appendix C16). Almost all sites are in or very near to the Lower Salmon River itself.

Current distribution: This Cryptomastix is locally common (Table 2), being found at about 40 sites within its rather restricted total distribution (Table 3, Appendix C16), confined to a limited area of the main Salmon River corridor. Several of these sites may no longer represent living populations; and the taxon is rare live at most sites. It is unlikely that many additional sites will be found.

Threats: Essentially all of the Salmon River corridor is grazed, much heavily. As with other species in this region, highway corridors are located along some of the suitable habitat, in particular US 95. Talus mining and roadside spraying are problems for some colonies. Gold mining has impacted (and likely extipated) some sites. Certain localities collected in the late 1980 s have been 
extirpated by road modification in the last three years. Grazing has much reduced some sites, leading to extinction or near extinction of sites in the Lucile and Twilegar Gulch areas within the last 5 years. The species is declining in numbers and areal extent. Population trends (number of sites, number of individuals) are downward.

Criteria for inclusion: Strict local endemic; specialized and limited habitat and distribution; loss of historic sites; occurrence on public lands, including BLM tracts.

Recommended status: A newly recognized form with no status as yet. Should be considered a sensitive species by the Forest Service and BLM. There is sufficient recently-collected information, and recent survey work, to indicate that Federal and State (ID, WA, OR) listing as Threatened is warranted, due to habitat loss and decrease in historic sites, ongoing threats.

We regard this species as common in the part of the survey area in which it occurs (Table 2): but the total range is small and unfortunately concentrated in that part of the Lower Salmon River corridor most susceptible to human modification.

References: Deixis collections, 1989-94.

Cryptomastix (Cryptomastix) n. sp. 6 APPENDIX $\mathrm{C} 17$
White Bird oregonian

Type locality: None as yet; undescribed taxon.

Description: This medium-sized Cryptomastix species has a low spire of 4 t/ -5 whorls, moderately rapidly expanding. Maximum adult size is about $16 \mathrm{~mm}$, larger than Cryptomastix harfordiana and roughly the same as clappi, but most adults average about $14 \mathrm{~mm}$. The species often lacks periostracal hair or has only traces (unlike clappi, which is distinctly and closely hirsute; or harfordiana, which generally lacks periostracal hair); color is generally bluish gray; and has a white, very weakly tridentate aperture, often with the palatal lamella absent. The aperture is comparatively narrow, weakly inclined, and has a whitish periphery, with the basal lamella and palatal tooth present but nearly vestigial. The parietal tooth morphology is much like that of clappi and much less prominent than that of harfordiana. The umbilicus is similar in morphology to that of clappr, but typically narrower. Most animals have the mantle almost uniformly black. The lip is rather narrow, not revolute, and broader than that of clappi; the columellar insertion is definitely above the umbilicus, which has a small proportion covered by it, similar to harfordiana and Cryptomastix n. sp. 5 and less open than that of clappi. The shell base is low convex.

This species is present in older collections from the Lucile and White Bird areas. Comparisons with clappi and harfordiana have been made above; see also discussion of Cryptomastix n. sp. 5 above. The species most closely resembles clappi; but the anatomy is very distinct, and it differs consistently in several shell features as well.

Ecology: A strong-moderate xerophile. Cryptomastix n. sp. 6 prefers dry, exposed taluses, generally basalt. Cover is often limited to grasses, uncommon Seligeria and mosses, scattered Rhus horribilis or Sorbus clumps and uncommon Celtus and Prunus. Commonly co-occurring land snails are Allogona ptychophora ptychophora, Allogona ptychophora solida, and several Oreohelix species, most often $\mathrm{n}$. $\mathrm{sp}$. 25 or jugalis. This taxon occurs at much drier sites than clappi; but does not do well in the very dry taluses inhabited by Cryptomastix n. sp. 3. Cooccurrence with Cryptomastix harfordiana has been noted at several sites (Table 3). 
seem characterized by the latter morphology Specimens from Wet Gulch and vicinity seem characteristically small and high. We have not had enough opportunity to thoroughly examine the anatomy of all variants, in particular the Wet Gulch morph; and prefer to keep all known sites under this rubric pending further study. It is possible that a species complex is involved. The Wet Gulch form is nearly extinct.

Ecology: Generally found on limestone outcrops and limestone talus in rather open Pinus ponderosa forest, at moderate-high elevations. The type locality (site 184 or 185) is a comparatively open and dry large-scale talus with grasses, Sorbus, Amelanchier, and Rhus. Common large land snail associates are Cryptomastix mullani latilabris and Allogona ptychophora ptychophora. At forested sites, associates include other Cryptomastix spp., Anguipsira kochi occidentalis, and Allogona ptychophora ptychophora. At one site, Discus marmorensis was also found with this taxon. The forest sites are comparatively dry and open; in moist and niparian sites, this species is very rare or absent; a xerophile. This taxon occurs at a range of elevations, from nearly river side to mountain meadows.

Original distribution: Probably at one time widespread over several tributaries of the lower Salmon River (E. side only), in the vicinity of John Day Creek. Long-dead shells are still common at many sites in which live individuals were no longer present.

Current distribution: Restricted to a few remnant colonies in the area of its original distribution, on private, BLM, and Nez Perce National Forest lands. We found it at a total of ten sites (Appendix C28), generally on the west side of John Day Mountain and mostly in the John Day Creek drainage. Many other malacologists have collected in this area, both private and professional, beginning in the $1860 \mathrm{~s}$.

Threats: Logging, grazing, forest fires, and agricultural use of most of the original range. Areas heavily grazed and/or clearcut lack this species. Within the original range, literally millions of dead shells may be found in areas so treated, which now either lack the species entirely or have it restricted to fortuitous small rock outcrops. The species has probably lost more than $90 \%$ of its original range. Population trends (number of sites, number of individuals) are downward.

Criteria for inclusion: Strict local endemic (Table 1) found only in a small portion of the survey area; habitat loss, as detailed above and in Frest \& Johannes (1995a); occurrence on public lands. The species can be common where it occurs; but in view of the very limited geographic range and limited number of surviving sites, should even locally be regarded as rare (Table 2). Treated as a Sensitive species in Frest \& Johannes (1995a).

Recommended status: Currently this taxon has no special status; it should be considered a sensitive species by the Forest Service, BLM, and other land management agencies. Federal and State (ID) listing as Endangered, due to habitat loss, population declines, and other factors outlined above, should also be considered.

References: Pilsbry (1939); Frest \& Johannes (1995a); Deixis collections, 1989-1994.

Oreohelix haydeni perplexa Pilsbry, 1939

APPENDIX C29 enigmatic mountainsnail

Type locality: Twilegar Gulch, sec. 35 T 26 NR 1 E, Lucile quad., Idaho Co., ID, lower Salmon River drainage; holotype ANSP 174024a. For site map, see Figure 2 and Appendix B15. 
Description: See Pilsbry (1939) for description and illustrations. The unique (for Oreohelix) shell ornament with crossed, equally-strong spiral ribs and lirae (cancellate pattern) make it one of the most unusual U.S. land snails, and hence easily subject to overcollecting.

This species occurs near to colonies of Oreohelix idahoensis idahoensis and Oreohelix n. sp. 20 [Sheep Gulch mountainsnail]; however, its anatomy and juvenile sculpture demonstrate that it is a member of the haydeni complex, as Pilsbry (1939) surmised.

Ecology: Open, rather dry sage scrub with small-scale limestone talus (mostly W.-facing) and outcrops; grasses, Artemisia spp., Amelanchier, rare Opuntia, and Physocarpus. Associated land snails include Cryptomastix harfordiana, Helicodiscus salmoneus, and Allogona ptychophora ptychophora. The known site is at moderate elevations and is bordered on all sides by other Oreohelix spp. colonies. This taxon appears to be a moderate-strong xerophile, and could be a calciphile also.

Original distribution: A single extended colony in Twilegar Gulch. This colony is bordered on three sides by colonies of other Oreohelix species, notably Oreohelix idahoensis idahoensis and Oreoehelix n. sp. 20 [Sheep Gulch mountainsnail]. Scattered colonies of these species and Oreohelix jugalis occur below and on the other side of the Salmon River from Twilegar Gulch.

Current distribution: Small remnant colonies in protected areas within the limits of the original sites. Common dead shells indicate that at least $70 \%$ of the original site no longer has living individuals. Reduction in numbers and in area occupied has been observed during several visits, 1989-1994.

Threats: Heavy grazing; fires, which have occurred in the immediate area in recent years; overcollecting.

Criteria for inclusion: Extremely local strict endemic, still known from a single site despite extensive searches by us and several other malacologists since the 1930s; ongoing and past threats; observed decline in area occupied and live population size. Treated as a Sensitive species in Frest \& Johannes (1995a).

Recommended status: Surprisingly, this taxon has no special status at present. It should be considered a sensitive species by the Forest Service, BLM, and other land management agencies. Federal and State (ID) listing as Endangered, due to extremely limited geographic range and declining numbers and condition of habitat, should be undertaken. It is very rare live now [1994] even at the only known site.

References: Pilsbry (1939); Frest \& Johannes (1995a); Deixis collections, 1989-1994.

Oreohelix idahoensis idahoensis (Newcomb, 1866) APPENDIX $\mathrm{C} 30$ costate mountainsnail

Type locality: Specimens received from the original collector (Henry Hemphill) bear labels reading "between Idaho City and the Coeur d'Alene mining district [about 200 mi.]", "Lucile", and "Salmon River Mountains". As Hemphill collected extensively in the area about Lucile, lower Salmon River, Idaho Co., ID, it is generally accepted that this region is the source of Hemphill's specimens. Holotype ANSP 10857a. Probable paratypes (certainly topotypes) from Hemphill's collection are widely scattered in major U.S. and foreign museum and private collections, including 
our own. Solem (1975) accepted Lucile as the type locality, although a more explicit site should probably be designated. See Figure 2 and Appendices $B$ and $C$ for site locations.

Description: See Pilsbry (1939) for description and illustrations and Solem (1975) for modern dissection. This form may not actually be closely related to true idahoensis baileyi, although in the same species group. The higher spire, larger number of whorls, high, widely spaced white ribs and brown (bandless) ground color, small umbilicus, and deflected aperture are distinctive feature. Rib spacing in Oreohelix n. sp. 18 [Limestone Point mountainsnail] is closer (see Frest \& Johannes, 1995a for background on this species); transverse ribs are not as prominent; the spire is not as high; there is a distinct peripheral rib; there is little contrast in color between transverse ribs and interspaces; and the umbilicus is proportionately smaller. Oreohelix n. sp. 20 [Sheep Gulch mountainsnail] has a small, much more depressed spire, wide umbilicus, weak to absent peripheral keel, and fine, more closely spaced transverse ribs.

The only other taxon with any close resemblance is the final known member of the species group, the Pittsburg Landing mountainsnail, Oreohelix n. sp. 30 (see Frest \& Johannes, $1995 \mathrm{a}$, for information on this species). This species has a somewhat similar shell shape; however, the umbilicus is larger; spiral striation is not well developed; the radial ribs, though prominent, are narrower and more narrowly spaced, more as in Oreohelix peripherica newcombi than in the other idahoensis-group taxa; and the two typical color bands of Oreohelix (absent in idahoensis) are well developed. The Hells Canyon taxon also lacks any kind of peripheral keel, rib, or angulation.

Ecology: Restricted to low-middle elevation limestone and calcareous schist outcrops and talus, generally in sage scrub; typically in rather dry and open terrain with common Artemisia and grasses; less common Amelanchier, Celtus, Opuntia. Usually occurs in monospecific colonies (Table 3), occasionally with Cryptomastix harfordiana and "Catinella avara". Sites with this taxon are mostly W.-facing; the species is often locally abundant in the restricted area in which it occurs. A strongly xerophilic species and a calciphile.

Original distribution: A small area a few miles long on both sides of the lower Salmon River, Idaho Co., ID, in the vicinity of Lucile (Appendix $\mathrm{C}_{3}$, essentially from the mouth of Race Creek to the mouth of China Creek.

Current distribution: Restricted to a few colonies within the original area of distribution. We found the species at 20 sites, of which 4 are likely now extinct (Tables 3,4$)$. The area of known and likely occurrence has been visited many times by malacologists.

Threats: Grazing; gold mining; talus and limestone quarrying; range fires. One large colony is now near extinction due to a combination of grazing and recent fires. Dead shells mark an area more than 20 times the present live occurrence. Building in Lucile has also impacted sites. In one area, sheep grazing has eliminated most of one colony, while remnants on the opposite side of the road (protected from grazing) have abundant snails. Similar effects from grazing and other causes can be observed at all remaining sites. Apparently extinct colonies occur north of Riggins. The species is declining; the best remaining sites by far are concentrated on the Lucile ACEC (see separate report on this area). This species, termed by Pilsbry "one of our prettiest land shells", is also a favorite of collectors. Population trends (number of sites, number of individuals) are downward.

Criteria for inclusion: Strict local endemic (Figure 1) with specialized habitat; declining populations and area of occurrence; current and past threats; occurrence on federal (BLM ACEC) lands. Treated as a Sensitive species in Frest \& Johannes (1995a). Treated as a Sensitive species in Frest \& Johannes (1995a). 
Recommended status: We favor Federal State (ID) and listing as Threatened, if BLM Lucile ACEC sites can be thoroughly protected; otherwise Endangered. This species is currently a federal Category 2 candidate (USFWS, 1994). It should be considered a sensitive species by the Forest Service, BLM, and other land management agencies. Aside from this survey, many other malacologists and collectors have worked this area, including $\mathrm{H}$. Hemphill, H. B. Baker, A. Solem, and $\mathrm{M}$. Walton. It is unlikely that many additional sites will be found.

References: Pilsbry (1939); Solem (1975);Frest \& Johannes (1995a); Deixis collections, 19881994.

\section{Oreohelix intersum (Hemphill, 1890) deep slide mountainsnail APPENDIX C31}

Type locality: Stone piles at the foot of a steep bluff back some distance from the banks of the Little Salmon River, Pollock quad., Idaho Co., ID; Figure 2; lectotype SBMNH 33930; paralectotypes CAS 58867; 54557; 54558; 54561; USNM 363248; AMNH 61704; 61705. See Coan \& Roth (1987) for discussion of accurate lectotype designation for this species, vs. Hanna \& Smith (1939).

Description: Pilsbry (1939); regarded as a full species by Berry (1932), Hanna \& Smith (1939) and Solem (1975); see discussion in Solem (1975)). Dissection, both by Solem (1975) and us, indicates that this species is not particularly closely related to Oreohelix jugalis, as Pilsbry originally thought. Species with closely comparable anatomy have so far been noted by us only in the Little Salmon River-lower Salmon River area of ID and constitute a distinct species group.

Ecology: Found primarily in rather dry and open basalt and (rarely) schist talus slides, all at lower elevations; grasses, scattered clumps of Rhus horribilis and Sorbus; Celtus, and Amelanchier and Opuntia are the usual plant associates. Colonies are generally surrounded by sage scrub (Artemisia, Balsamorrhiza). Despite the common name, rock taluses with this species need not be large or deep. This taxon often is the only large land snail present at a site. A moderatelystrongly xerophilic taxon. This species is generally not common alive at any site. Wetter and forested sites nearby are inhabited by other members of this complex (see below).

Original distribution: Lower few miles of Little Salmon River drainage, including larger tributaries, Idaho Co., ID.

Current distribution: Scattered sites within area of original distribution; perhaps 4 live colonies currently. See Appendix C31 for map; see also Table 3.

Threats: Grazing; road construction, e.g. US 95 corridor; talus mining; irrigation system construction; roadside spraying for weed control. Each of the above has been observed to impact at least one colony in recent years. In heavily grazed areas, colonies are absent or limited to small areas protected by fortuitous circumstances. The species is declining, both in terms of absolute numbers and area occupied. Population trends (number of sites, number of individuals) are downward.

Criteria for inclusion: Occurrence on public lands (BLM); local endemic with rather specialized habitat; observed threats, declining numbers; habitat loss. This is a strict local endemic limited to a very small portion of the Little Salmon River drainage (Appendix C31). It should be noted that the upper portions of this drainage (beyond the survey area; but collected by us, 1989-1993) have a 
granite-derived regolith and are unsuitable foe most land snail species. Treated as a Sensitive species in Frest \& Johannes (1995a).

Recommended status: At present, this species has no special status. It should be considered a sensitive species by the Forest Service, BLM, and other land management agencies Federal and State of ID listing as Endangered is recommended for the reasons stated above. Comprehensive recent surveys of the lower Salmon, part of the Little Salmon, and Rapid River drainages for this and other land snail species were conducted by us (see Figure 1 for site distribution). Many other malacologists and collectors have worked this area, including H. Hemphill, H. B. Baker, A. Solem, and $\mathrm{M}$. Walton. It is unlikely that many additional sites will be found.

References: Pilsbry (1939); Hanna \& Smith (1939); Solem (1975); Frest \& Johannes (1995a); Deixis collections, 1988-1994.

\section{Oreohelix n. sp. 8 Squaw Creek mountainsnail APPENDIX C33}

Type locality: None at present; undescribed taxon.

Description: Medium-sized (to $14 \mathrm{~mm}$ ) species with up to 5 whorls. Shell weakly biconvex; upper surface almost flat; color greenish-yellow. Strong peripheral keel with periostracal fringe; other less pronounced periostracal wreaths on low lirae developed on lower surface only; upper with about 7-9 fine, closely spaced lirae; lower with 4-6 rather widely spaced fringed lirae. Growth lines strong on both surfaces; sutures barely impressed. Color bands absent. Umbilicus deep, wide, about $40 \%$ of shell diameter.

This species is a member of the haydenicomplex. It does not closely resemble any other Salmon River taxon. Among known forms, it is closest in shell characters to two species. The quartzite mountainsnail (see Frest \& Johannes , 1995a, for discussion) from SE ID is similar in color but that taxon has a larger shell, with flatter dorsal surface; fewer lirae, especially on the upper surface; and much less prominent periostracal fringes. Oreohelix barbata Pilsbry, 1905 has similar cuticular wreaths, but the bearded mountainsnail is brown, less broadly umbilicate, less depressed, and has a strongly oblique aperture. Internal anatomy of the Arizona-New Mexico Oreohelix barbata is similar in many respects to that of Radiocentrum species (Pilsbry, 1939), while that of this taxon is similar to members of the Oreohelix haydeni species group (which does not occur in Arizona or New Mexico).

Ecology: Found in dry, open, small to large-scale basalt talus, generally west-facing, generally near the talus base only, at moderate elevations; a moderate-strong xerophile. Associated plants include common Sorbus and grasses, less common Balsamorhiza, Celtus, and Artemisia. A small bryophyte component is sometimes present also. Most often, this is the only large land snail found. At one site rare dead Cryptomastix mullani olneyae were also noted; in general, land snails are rare in the taluses in this drainage, for unknown reasons. E.-facing and lower, more moist taluses in the same drainage lacked this species. A moderately xerophile species.

Original distribution: Probably confined to a portion of the Little Salmon River drainage, Idaho Co., ID.

Current distribution: Confined to a few small colonies along Squaw Creek (Appendix C33). Most basalt taluses in the area lack the species or have only long-dead shells; the species is rare at 
known sites, and evidently declining. Only one site has been demonstrated currently to have live individuals; and there are just 3 sites in total (Tables 3,4$)$.

Threats: Talus mining; road construction and maintenance (FS 517); grazing is heavy in the area despite the prevalence of moderately steep and poorly vegetated talus. Heavily disturbed and shallow taluses lacked live specimens, although long-dead shells indicated former occurrence in some areas.

Criteria for Inclusion: Very local endemic; habitat loss and continuing threats; occurrence on public lands (BLM and Nez Perce National Forest; see Appendices A and B for details). Comprehensive recent surveys of the lower Salmon and part of the Little Salmon and Rapid River drainages for this and other land snail species were conducted by us, and $\mathrm{m}$ other malacologists and collectors have worked this area, including H. Hernphill, H. B. Baker, A. Solem, and M. Walton. Population trends (number of sites, number of individuals) are downward. It is very unlikely that many additional sites will be found. Treated as a Sensitive species in Frest \& Johannes (1995a).

Recommended status: This species has no special status at present; it definitely should be considered sensitive by state and federal (e.g., BLM) land and wildlife managers. We suggest Federal and State (ID) listing as Endangered, due to current rarity, habitat loss, and continuing threats. We rate the species as very rare (Table 2); and the known and potential ranges are very limited.

References: Frest \& Johannes (1995a); Deixis collections, 1993-1994.

\section{Oreohelix n. sp. 12 hackberry mountainsnail APPENDIX C34}

Type locality: To be designated when species is described.

Description: Shell large for genus, to $22 \mathrm{~mm}$ at $5 \mathrm{w} / 2$ whorls (maximum adult size). Spire low conical, with somewhat convex whorls, weak peripheral keel, and slightly impressed sutures. Keel continues to aperture; aperture thin, not deflected; strongly oblique, rounded except on parietal wall; parietal callus thin. Umbilicus moderately deep, elliptical, 1/a-1/5 maximum shell diameter. Shell with large, low, slightly irregular transverse ribs, more or less evenly spaced. Ribs slightly stronger above shell periphery. Spiral striation absent. Color bands generally 2; thin; about equal above and below periphery; upper surface sometimes light brown; both surfaces occasionally with additional very thin color bands.

A large member of the Oreohelix intersum group, characterized by a large, rather high spire; large umbilicus; and ribbing that is more distinct on the upper surface.

Ecology: This strong xerophile lives on relatively open mixed alluvial and limestone talus slopes. All are dry and poorly vegetated (largely open), with grasses and Celtus the most common species. Colonies are almost monospecific, with occasional individuals of Allogona ptychophora ptychophora the only other large land snail.

Original distribution: Probably confined to a portion of the lower Rapid River valley, Little Salmon River drainage, Idaho Co., Idaho, E. side of the Seven Devils Mountains, and absent from high elevations and moist lowland situations. 
Current distribution: Known live from perhaps 4 colonies in the lower Rapid River drainage (Appendix C34); all are in close proximity. One or more appear to be on Nez Perce National Forest lands. See Appendices A \& B for site details.

Threats: The whole known range is heavily grazed, and colonies appear to be confined to fortuitously protected areas. Dead shells indicate former much more widespread occurrence. Colonies are on or near horse/foot trails into Rapid River back country; the slope with surviving sites has been sapped, possibly to provide material for an adjacent Idaho Power fish hatchery.

Criteria for inclusion: Very local strict endemic; impacts on all known sites. Population trends (number of sites, number of individuals) are downward. We regard this species as very rare. Treated as a Sensitive species in Frest \& Johannes (1995a).

Recommended status: To date, this species has no special status. We believe that it should minimally be regarded as sensitive by state, federal (e.g., Forest Service), and other land and wildlife managers as appropriate. We suggest Federal and State (ID) listing as Endangered, due to the limited area of occurrence, ongoing threats, reduced number and size of sites, and other threats discussed previously. Comprehensive recent surveys of the lower Salmon and part of the Little Salmon and Rapid River drainages for this and other land snail species were conducted by us and by the many other malacologists and collectors who worked this area previously, including H. Hemphill, H. B. Baker, A. Solem, and M. Walton. It is unlikely that many additional sites will be found.

References: Frest \& Johannes (1995a); Deixis collections, 1990-1994.

\section{Oreohelix n.sp. $13 \quad$ Rapid River mountainsnail APPENDIX C35}

Type locality: To be designated when the species is described.

Description: Shell in mid range for genus; diameter at 5-5 3/2 whorls (maximum adult size) about 16 $\mathrm{mm}$. Spire low, sutures moderately impressed; surface with coarse, broad, rather widely-spaced, and somewhat irregular ribs, equal on both shell surfaces. Color bands generally thin, equal; secondary thin bands sometimes present on both surfaces; upper whorls light brown except for ribs. Umbilicus rather deep, abrupt, somewhat well-like, about $1 / 3-1 / 3$ full shell diameter. Periphery distinctly angulate; angulation continues to aperture; aperture very strongly oblique.

A medium-sized member of the Oreohelix intersum group, characterized by a rather low spire; large umbilicus; distinct coarse ribbing on both surfaces. The nearest relative is Oreohelix $\mathrm{n}$. sp. 12 [hackberry mountainsnail]; aside from just-noted differences, the proportionately wider and less well-like umbilicus (lower whorls more evenly rounded) are distinctive.

Ecology: This strong xerophile lives on relatively open mixed alluvial and limestone talus slopes. The 3 known sites (Appendix C35; see also Appendices A and B) are dry and poorly vegetated (largely open), with grasses and Celtus the most common species. Colonies are almost monospecific, with occasional individuals of Allogona ptychophora ptychophora the only other large land snail.

Original distribution: Probably confined to a portion of the lower Rapid River valley, Little Salmon River drainage, Idaho Co., Idaho, E. side of the Seven Devils Mountains, and absent from high elevations and moist lowland situations. 
Current distribution: Known live from only 3 localities in a very limited portion of the lower Rapid River drainage. One or more appear to be on Nez Perce National Forest lands.

Threats: The whole known range and surrounding area is heavily grazed, and colonies appear to be confined to fortuitously protected areas. Dead shells indicate former much more widespread occurrence. Colonies are on or near horse and foot trails into Rapid River back country; the slope with surviving sites has been sapped, possibly to provide material for the adjacent Idaho Power fish hatchery.

Criteria for inclusion: Very local strict endemic; impacts to all known sites. Population trends (number of sites, number of individuals) are downward. This species is rare and very localized. Treated as a Sensitive species in Frest \& Johannes (1995a).

Recommended status: This species has no special status at present. tt should be regarded as sensitive by state, federal (e.g., Forest Service), or other land and wildlife Managers. We recommend Federal and State (ID) listing as Endangered, due to the limited area of occurrence, known and predictable future impacts to al known sites, and other reasons cited above. Comprehensive recent surveys of the lower Salmon River and part of the Little Salmon River and Rapid River drainage for this and other land snail species were conducted by us and by other malacologists and collectors, including H. Hemphill, H. B. Baker, A. Solem, and W. Walton. It is unlikely that many additional sites will be found.

References: Frest \& Johannes (1995a); Deixis collections, 1990-1994.

\section{Oreohelix n. sp. $14 \quad$ limestone mountainsnail}

\section{APPENDIX C36}

Type locality: To be designated when species is described.

Description: Shell small-medium sized; maximum diameter at adulthood $(5 \mathrm{w} / 2$ whorls) about 13 $\mathrm{mm}$; comparatively thin except for slightly thickened aperture. Spire very low, almost discoidal; whorls slightly convex; sutures deeply impressed; pronounced peripheral keel. Transverse ribs pronounced, widely spaced, cord-like, more or less regular; equal on both shell surfaces. Lower surface more convex; almost with basal angulation; umbilicus elliptical, well-like even though shallow and broad, about $1 / 3$ shell diameter. Color bands faint-absent; shell ranges from slightly brownish to off-white, with transverse ribs often slightly lighter in color than interspaces. Aperture oblique, almost trapezoidal, sometimes barely adnate.

This very striking species is a small member of the Oreohelix intersum group. Distinctive features are the low, almost discoidal shell; relatively prominent ribbing, strong peripheral keel, small size; and large umbilicus. Oreohelix hammeri, the only local snail with at all similar features, is much larger, has fewer, very large and low radial ribs; and a proportionately much smaller umbilicus.

Ecology: A strong xerophile living on relatively open limestone outcrops and talus slopes. Sites are dry and poorly vegetated (largely open), with grasses, Celtus, and Balsamorrhiza the most common species. Colonies typically have occasional individuals of Allogona ptychophora ptychophora, Oreohelix n. sp. 13 (Rapid River mountainsnail), and Cryptomastix spp. 
Original distribution: Probably confined to a portion of the lower Rapid River valley, Little Salmon River drainage, Idaho Co., Idaho, E. side of the Seven Devils Mountains, and absent from high elevations and moist lowland situations.

Current distribution: Known live from only 2 nearby colonies in the lower Rapid River drainage. One or perhaps both appear to be on Nez Perce National Forest lands. Occurrence on adjacent BLM lands is possible.

Threats: The whole known range is heavily grazed, and colonies appear to be confined to fortuitously protected areas. Dead shells indicate former, much more widespread occurrence. Colonies are on or near horse/foot trails into Rapid River back country. Live individuals are rare at both sites, one of which is a rockpile only a few feet in width.

Criteria for inclusion: Extremely local strict endemic; impacts on all known sites. Population trends (number of sites, number of individuals) are downward. Treated as a Sensitive species in Frest \& Johannes (1995a).

Recommended status: Currently, this species has no special status. Minimally, it should be regarded as sensitive by federal (e.g., Forest Service) or other land and wildlife managers. Federal and State (ID) listing as Endangered is needed, in our opinion, due to the very limited area of occurrence, ongoing threats to existing populations, and other factors discussed above. Comprehensive recent surveys of the lower Salmon River and part of the Little Salmon River and Rapid River drainages for this and other land snail species, as well as past explorations in the same areas by other malacologists and collectors such as H. Hemphill, H. B. Baker, A. Solem, and W. Walton, make it unlikely that many additional sites will be found.

References: Frest \& Johannes (1995a); Deixis collections, 1988-1994.

\section{Oreohelix n. sp. $15 \quad$ speckled mountainsnail} APPENDIX $\mathrm{C} 37$

Type locality: Will be designated when the species is formally described.

Description: A medium-large species, reaching a maximum diameter of $23 \mathrm{~mm}$ at $4 \mathrm{~s}-5$ whorls. Spire depressed, sutures slightly impressed; weak peripheral keel visible in side view but aperture well-rounded. Shell comparatively thin; aperture not thickened parietal callus very thin; aperture not jugate. Color bands weakly developed; subperipheral very thin; supraperipheral band wider; upper whorl with light pinkish brown background color and well-developed irregular small white spots and blotches, roughly paralleling growth lines; growth lines slightly raised into irregular, thin but distinct transverse ribs; ribs generally streaked with white. Lower shell surface white; both surfaces with moderately well-developed striae, slightly stronger on upper surface. Umbilicus shallow, well-rounded; small, diameter about $1 / 5$ maximum shell width.

A member of the jugalis species group, differing from its better-known Idaho congener in size, shell color; apertural morphology; and relative umbilicus size.

Ecology: This Oreohelix is a comparative mesophile, occurring in steep mixed schist/ or conglomerate/alluvial slopes and taluses. Sites are generally N.facing; may be perennially moist due to seeps or springs; and are mostly at comparatively low elevations. Partly open Pinus ponderosa forest, with common small deciduous trees and extensive moss and grass cover, is a desideratum for this species. It is absent from relatively dry sites, even when the canopy is 
comparatively extensive. The most frequent large land snails found with this taxon are Cryptomastix mullani clappi and Allogona ptychophora ptychophora. Small land snails, such as Vitrina alaskana, Discus whitneyi, and Helicodiscus salmoneus, are frequent also. See Table 3 and Appendix $A$ for site faunal lists and more details.

Original distribution: This species likely once was widespread in a limited portion of the River of No Return valley, from Riggins to the French Creek Bridge, Idaho Co., ID.

Current distribution: Survives at a few scattered colonies within the limits of its original range, mostly on the S. side of the River of No Return, within the limited stretch indicated above as far as the Lake Creek Bridge (Appendix C37). The species is rare live at all 6 sites, and common finds of long-dead shells suggest a former, much more extensive population much reduced in recent years. Some known sites are on BLM and Payette National Forest sites. Additional sites on the N. side of the River of No Return (Nez Perce National Forest and BLM public lands) are possible.

Threats: The French Creek Road has had major impact on all existing sites. Occasional long-dead shells can be found in the road berms for a distance of several miles beyond current live sites; but live colonies are very limited in area. Much of the area above the road has been heavily grazed, and snails generally survive only in the steepest and most unstable slope areas.

Criteria for inclusion: Local endemic; impacts to known sites; reduction in range and size of populations; occurrence on public lands. We regard this species as rare even within its limited known area of occurrence. Population trends (number of sites, number of individuals) are downward. Treated as a Sensitive species in Frest \& Johannes (1995a).

Recommended status: Comprehensive recent surveys of the lower Salmon River drainage for this and other land snail species were conducted by us, adding to previous such work by other malacologists and collectors, including $\mathrm{H}$. Hemphill, H. B. Baker, A. Solem, and W. Walton. Older collections mostly do not include specimens of this species. It is unlikely that many additional sites will be found. At present, this species has no special status; minimally, it should be regarded as sensitive by federal (e.g., Forest Service, BLM) or other land and wildlife managers. Federal and State (ID) listing as Endangered is needed, in our opinion, due to the limited area of occurrence, ongoing threats to existing populations, and other factors discussed above.

References: Frest \& Johannes (1995a); Deixis collections, 1989-1994.

Oreohelix n. sp. 19

Shingle Creek mountainsnail
Appendix $\mathrm{C} 38$

Type locality: Will be designated when the species is formally described.

Description: Shell small for genus; to $13 \mathrm{~mm}$ at 4,5 whorls (adult size); spire low conical; moderately impressed sutures; whorls convex; moderately distinct peripheral keel (but not a rib or pronounced); transverse ribs coarse, irregular, equally strong on both shell surfaces. Radial striation moderately developed on both sides. Color bands narrow but distinct, equal; small additional bands common on lower surface only; upper surface light reddish brown except for transverse ribs, which are generally white. Umbilicus moderately deep, somewhat well-like, about 2. maximum shell width.

Anatomically, this species is a member of the intersum species group. The shell features somewhat recall those of Oreohelix waltoni, but the juvenile sculpture differs considerably, as 
does the anatomy. The color pattern, rib spacing, and spire height of the two also consistently differ. This small Oreohelix is probably most closely related to Oreohelix intersum; but is much smaller, has a lower spire; coarser and more widely spaced transverse ribs; transverse ribs equally strongly developed on the base; and a proportionately larger and deeper umbilicus despite the lower spire. Known colonies are quite consistent in morphology.

Ecology: A comparative mesophile; found on rock (basalt) outcrops in shaded terrain at low elevations. Vegetation is rather moist Ponderosa pine forest with a well-developed understory, with grasses, bryophytes, and forbs diverse and common. Associated land snail species include Cryptomastix mullani mullani, Allogona ptychophora ptychophora, and Discus whitneyi.

Original distribution: Probably originally common in part of the Little Salmon River valley and major tributaries, Nez Perce National Forest, Idaho Co., ID.

Current distribution: Survives at 2 small colonies in Shingle Creek and on the lower Salmon River, Idaho Co., $\mathbb{D}$ (Appendix C38; see also Appendices $A$ and $B$ for site details). One site is believed to be on Nez Perce National Forest and State of Idaho lands.

Threats: Much of the surrounding area has been cleared and is heavily grazed by sheep. Lowelevation forest is now very rare in the Little Salmon and Lower Salmon drainages. Colonies have also been affected by road building (Rapid River Road). population trends, in terms of number of individuals and area occupied, are downward.

Criteria for inclusion: Local endemic, occurrence on public lands; past and ongoing threats. We regard the species as very rare even within its known range of occurrence. Treated as a Sensitive species in Frest \& Johannes (1995a).

Recommended status: This species has no special status at present. It should be considered a sensitive species by the Forest Service, BLM, and other land management and wildlife agencies. Federal and State (ID) listing as Endangered is appropriate for the reasons just cited. Comprehensive recent surveys of the lower Salmon and parts of the Little Salmon and Rapid River drainages for this and other land snail species are the result of work over many years by us and by other malacologists and collectors, such as H. Hemphill, H. B. Baker, A. Solem, and W. Walton. It is unlikely that many additional sites will be found.

References: Frest \& Johannes (1995a); Deixis collections, 1990-1993.

\section{Oreohelix n. sp. 20 Sheep Gulch mountainsnail APPENDIX C39}

Type locality: Has yet to be designated; taxon is undescribed.

Description: Shell low turbinate; whorls convex except for moderate peripheral angulation, rather narrow; 5-5 1/2 whorls in adult; last $1 / 2$ commonly strongly deflected, sometimes almost disjunct; sutures deeply impressed. Aperture periphery sometimes reinforced, especially across parietal margin; aperture oval, strongly oblique. Maximum diameter about $11 \mathrm{~mm}$. Shell moderatelystrongly ribbed, equally above and below; ribs somewhat irregular, spacing about half that of Oreohelix idahoensis idahoensis. Umbilicus well-like (periphery nearly angular), comparatively wide, about 1/4 maximum diameter. Shell unbanded; radial ribs whitish; interspaces brownish. Spiral striation weak as compared to Oreohelix idahoensis idahoensis. 
Shell shape and size in this taxon are somewhat similar to Oreohelix waltoni, but ribbing in that species is much less prominent; there is a distinct pigment pattem not present here; and waltoni is more depressed and has a much wider umbilicus. Comparisons with Oreohelix idahoensis idahoensis, the only other equally (or more) strongly-ribbed Lower Salmon River species have been made above; additionally shell shape and proportionate umbilical width are markedly different than in that species. Anatomically, this species is a member of the idahoensis species group.

Shells of this taxon are present (rather rarely) in old collections under the name Oreohelix idahoensis baileyi, Sheep Gulch examples were illustrated by Pilsbry (1939). For comparisons with true baileyi, an apparent Hells Canyon endemic, see Frest \& Johannes (1995).

Ecology: A strong xerophile, found in comparatively open areas with scattered limestone outcrops and talus; more rarely on limy schists. Associated vegetation includes grasses and Artemisia, with rare Celtus, common Opuntia, scattered buckbean. A probable calciphile. Associated land snails include rare Allogona ptychophora ptychophora and small Cryptomastix spp. Quite often, this species occurs alone. A medium-elevation species.

Original distribution: A small area (probably ca. $15 \mathrm{mi}^{2}{ }^{2}$ ) near the lower Salmon River NE, E., \& $\mathrm{SE}$ of Lucile. Colonies of this taxon generally occur at slightly higher elevations than nearby Oreohelix idahoensis idahoensis and Oreohelix haydeni perplexa. An old site which we have not recollected occurs on Nez Perce National Forest lands.

Current distribution: Found only in small areas of the original range well protected from grazing. There are 7 known populations, all of which appear to be quite small. Collection of live material for this species was difficult. The existing sites occupy a very small portion of the survey area (Appendix C39). Occurrence on State of Idaho lands, Nez Perce National Forest, and BLM lands is quite possible.

Threats: The whole range of this taxon is currently heavily grazed, and the snails survive only in areas too rocky to be completely grazed out. Dead shells indicate a former, much wider distribution, but only in the limited area cited above. One colony, that at site 204, seems to have been extirpated since its discovery in 1990 . This area also has scattered mines and prospects, and has been utilized for quarries and gravel pits also.

Criteria for inclusion: Strict local endemic with very limited range; narrow habitat requirements; loss of preferred habitat and range; ongoing threats. Population trends (number of sites, number of individuals) are downward. We regard the species as rare even within its very limited geographic range. Treated as a Sensitive species in Frest \& Johannes (1995a).

Recommended status: This species has no status at present. Minimally, it should be considered a sensitive species by appropriate federal, state, and other land management and wildlife agencies. Federal and State (ID) listing as Endangered should be undertaken, due to limited range and habitat loss. Comprehensive recent surveys of the lower Salmon River drainage for this and other land snail species were conducted by us and others, including H. Hemphill, H. B. Baker, A. Solem, and M. Walton, over many years. It is not likely that later work will greatly expand the range or result in location of substantial numbers of additional sites.

References: Pilsbry (1939); Frest \& Johannes (1995a); Deixis collections, 1988-1994. 


\section{Oreohelix n. sp. 21 Box Canyon mountainsnail APPENDIX C40}

Type locality: To be designated when the species is described formally.

Description: Shell small-medium in size (maximum at 4 k 5 whorls $18 \mathrm{~mm}$; some populations much smaller); low, depressed spire; whorls moderately convex; upper whorl surface often slightly stepped; moderately strong peripheral keel; sutures weakly impressed. Spiral striation strongly and consistently developed; growth lines distinct, regular, slightly raised, and fine on upper surface; lower surface much smoother. Lower color band thin but consistently present; upper band diffuse, sometimes not discernible; upper whorl often light brown; narrow white band on periphery. Aperture strongly oblique; often slightly deflected in last 1/8 whorl; commonly jugate; thickened; slightly flared al around except for parietal wall. Umbilicus moderately deep, round, with broadly rounded border; diameter about $1 / 3-\frac{1}{4}$ maximum shell diameter.

This species somewhat resembles a miniature Oreohelix n. sp. 23 (Lucile mountainsnail). However, it differs from that species in its smaller size, lack of a basal brown patch, angulate periphery, and prominent spiral striation, easily visible to the unaided eye. It was present in old collections (dating to Henry Hemphill) in very small numbers, either unidentified or confounded with Oreohelix jugalis. Anatomy has not been completely worked out; but it appears to be related to the "strigosa" species group, rather than to the jugalis group. The closest Idaho relative would be Oreohelix n. sp. 23.

Ecology: This species is found on metasedimentary outcrops and thin talus, generally at low elevations. A strong xerophile, it occurs in relatively open terrain, most often with grasses, Celtus, Opuntia, and local bryophytes and the common plant associates. Land snails which co-occur include Allogona ptychophora ptychophora, Cryptomastix harfordiana, and Helicodiscus salmoneus; at one site, Vallonia cyclophorella, Pupilla hebes, Cochlicopa lubrica, and Oreohelix waltoni are close associates. All known sites closely hug the Lower Salmon River corridor.

Original distribution: Probably relatively ubiquitous in the lower portions of a few ravines on the Salmon River, roughly from the mouth of Slate Creek to a point north of Riggins (Appendix C40) lower Salmon River drainage, Idaho Co., ID.

Current distribution: A few very small colonies in two disjunct area: 1) the immediate vicinity of Box Canyon; and 2) on the east side of the river north of the mouth of Race Creek. At least one site is on BLM lands. We did not find this species on the W. side of the river, even near Box Canyon. The current disjunct occurrence pattern is likely a result of recent habitat change. This species is rare at all known sites, and difficult to find alive.

Threats: Most of the range has been severely affected by talus removal and road building along the US 95 corridor. Much of the area above the highway itself has been heavily grazed. The snails occur only in the few areas which still have talus or are too rocky for most cattle to traverse frequently. Mining was formerly extensive in this area; and some prospects are still worked nearby. The best remaining site could easily be removed for road material or fill, as has happened recently in this area (see, e.g., entry for Oreohelix jugalis).

Criteria for inclusion: Very local strict endemic (Table 1); occurrence on public lands; decline in habitat and numbers; ongoing threats. Population trends (number of sites, number of individuals) are downward. Treated as a Sensitive species in Frest \& Johannes (1995a).

Recommended status: Currently, this species has no special status. Minimally, it should be considered a sensitive species by appropriate federal, state, and other land management and wildlife agencies. Federal and State (ID) listing as Endangered is needed, for the reasons cited 
above. Comprehensive recent surveys of the lower Salmon River drainage for this and other land snail species were conducted by many malacologists and collectors, including us, $H$. Hemphill, $H$. or number of sites.

References: Deixis collections, 1988-1994; Frest \& Johannes (1995a).

\section{Oreohelix n. sp. 22 Slate Creek mountainsnail}

Type locality: Will be designated when the species is formally described.

Description: Shell turbinate; low dome-shaped in first three whorls, more rapidly expanding and taller in final two whorls; adults (5-5 $\frac{1}{4}$ whorls) medium-sized, to $20 \mathrm{~mm}$ diameter. Shell moderately thick; ornamented with numerous fine, closely spaced, raised, slightly irregular growth lines (transverse ribs), often slightly coarser on upper surface. Spiral striation well-developed, evenly spaced, strong on both surfaces, intersecting transverse ribs to give shell finely beaded several irregularty spaced very thin band; the two peripheral bands thin, often not present; pattern; these bands often interrupteds on both upper and lower surfaces the most common often with purplish brown tinge througted or broken into mottles, purplish brown; upper surface less than 1/5-1/6 full shell diameter, deout, stronger where bands intersect. Umbilicus narrow, oblique, deflected slightly in last $1 / 8$ whop, with well- rounded border. Aperture circular, slightly contact with earlier whorls.

This species somewhat resembles the Utah-SE Idaho peripherica species group in general appearance. Anatomically, however, it appears instead related to the "strigosa" species group. The low dome-shaped early whorls, later change in coiling parameters, and regular, narrowly-sized and -spaced radial ribs are distinctive features not shared with other "strigosa"
group taxa.

Ecology: This species is most common on moist, high-diversity Pinus ponderosa forest, with limestone outcrops and substrate but also with a well-developed duff layer. It occurs more sparingly in moist limestone and limy schist talus. Forests have a strong deciduous component, such understory plants as Cornus canadensera, and other small trees and shrubs, as well as Asarum. Persistence of moisture is a desidensis, Pyrola spp., Linnaea, Viola, bryophytes, and mountainsnail also appears to be a calciphiletum. This species is a mesophile. The Slate Creek "exotic terrain" limestone block (other suchile, confined to areas on or in the vicinity of a single and have their own very distinctiver such blocks in drainages to the $\mathrm{N}$. and $\mathrm{S}$. lack this species larger mollusks include Anguispire kochi mullani subsp., Discus marmorensis, Discus "whitneyi", Allogona cf. lombardii, Cryptomastix from those portions of Slate Creek with basalt substrate.

Original distribution: Probably confined originally to a limited area (essentially, the outcrop area of one large exotic (accreted terrain) limestone block) in the middle Slate Creek drainage, lower
Salmon River, Idaho Co., ID.

Current distribution: Restricted to 4 relatively unimpacted areas in the middle elevations of the middle Slate Creek drainage, including sites on Nez Perce National Forest, and probably on adjoining BLM lands as well (Appendix $\mathrm{C} 41$ ). This taxon is rare at two sites and common at the 
remaining two; we regard it as rare within its limited area of occurrence. Dead shells suggest an original (and fairly recent) continuous distribution now reduced to isolated colonies.

Threats: Heavy grazing in lower part of the middle Slate Creek drainage, where now confined to less cow-friendly talus; limestone quarrying, which has continued episodically to the present, with one recent round just concluded in the last 2 years; road building (Forest Service campground and Slate Creek access road). Dead shells indicate nearly ubiquitous former occurrence in the middle Slate Creek area; but heavily impacted areas, regardless of cause, have long-dead shells only; and this applies to the majority of the former range.

Criteria for inclusion: Very limited, strict local endemic; specialized habitat; occurrence on public lands; declining numbers and habitat; past and ongoing threats. Population trends (number of sites, number of individuals) are downward. Treated as a Sensitive species in Frest \& Johannes (1995a).

Recommended status: At present, this species has no status; minimally, it should be considered a sensitive species by appropriate federal (Nez Perce National Forest, BLM) and state land management and wildlife agencies. Federal and State (ID) listing as Endangered is recommended. A local endemic now much reduced in numbers and area occupied and with continuing, clear threats. Collectively, mollusk surveys of the lower Salmon River drainage for this and other land snail species by us and by many other malacologists and collectors, including $\mathrm{H}$. Hemphill, H. B. Baker, A. Solem, and W. Walton, make it unlikely that later work will greatly expand either the range or number of sites.

References: Deixis collections, 1990-1994; Frest \& Johannes (1995a).

\section{Oreohelix n. sp. $23 \quad$ Lucile mountainsnail \\ APPENDIX C42}

Type locality: To be designated when species is formally described.

Description: Shell large for genus, to $25 \mathrm{~mm}$ diameter at full adult size (5-5 $1 / 2$ whorls); moderately thick; comparatively tall for the genus, conic. Growth lines thin, irregular, fine, slightly stronger on upper surface; striation patchy, sometimes prominent for short stretches, often absent; surface overall rather smooth for the genus. Whorls slightly angular except for last; last whorl wellrounded, slightly inflated; deflected slightly as aperture approached; aperture slightly flared, thickened, commonly jugate, very oblique. Umbilicus moderate-sized, somewhat deep; wellrounded border; diameter about $1 / 3$ maximum shell width. Color bands well-developed, subequal; brown patch on lower surface at border of umbilicus; upper surface slightly brownish; typically extra bands seldom developed on either surface.

This species is among the early finds of Henry Hemphill, but has been overlooked in collections, largely because of lack of specific locality data but also due to confusion with Oreohelix jugalis (one of Binney's (1885) figures of "jugalis" is this species). It is more closely related anatomically to the "strigosa" species group than to the jugalis species group. It differs in shell features from the latter in that it is much taller; larger; more closely coiled, has an angular periphery; and has a brown pigment patch on the base. The only closely similar ldaho taxon is the Box Canyon mountainsnail (q.v.); but that taxon differs in several obvious features (see discussion under Oreohelix n. sp. 21 above). The very broad umbilicus and tall spire are unusual features for "strigosa" species group taxa. 
Ecology: This species occurs primarily near and in metasedimentary outcrops and small-scale talus, and occasionally in boulder piles above the high water mark. It is a relatively mesophilic taxon. Common plants are grasses, Rhus horribilis, Celtus, Sorbus, and Balsamorhiza. Land snails noted at the same sites as this species include Cryptomastix harfordiana, Allogona ptychophora ptychophora, Helicodiscus salmoneus, and Oreohelix jugalis. The Lucile mountainsnail once ranged onto the same alluvial slope as Oreohelix waltoni at the Lucile colony; but is now extinct at this site. The species is not found on limestone substrate (common near Lucile) or in very dry areas, and hence does not occur, e.g., in areas occupied by Oreohelix idahoensis idahoensis or Oreohelix haydeni perplexa very near Lucile, although it can occur in nearby boulder piles. Co-occurrence with other Oreohelix species is typical.

Original distribution: Found on both sides of the lower Salmon River for several miles $\mathrm{N}$. and $\mathrm{S}$. of Lucile, roughly between the mouths of Race Creek and John Day Creek, on private and BLM lands, Idaho Co., ID. For details, see Appendices A and B; and map 42 in Appendix C.

Current distribution: Restricted to a few colonies in less-impacted area within the original range. There are about 9 live populations (Appendix C41; Table 4). Sites on BLM lands remain viable. See above for further information. This species is rare at most sites and we regard it as rare in
general throughout its limited area of occurrence.

Threats: Heavy grazing in much of area of occurrence; gold mining; road and human habitation construction along the US 95 corridor; talus and gravel mining. The snail is absent from heavily grazed areas. At least one mining claim within a colony's boundaries was being worked in 19921994. Dead shells from former colonies are common along US 95 near Lucile. Mining operations have disturbed or removed many of the boulder-cobble areas along the banks of the lower Salmon River, while creating others. The mining discard piles, though some are quite old, have
not been re-inhabited by this species.

Criteria for inclusion: Strict local endemic; occurrence on public lands; definable and ongoing threats; decline in habitat area and in numbers. Population trends (number of sites, number of individuals) are downward. Treated as a Sensitive species in Frest \& Johannes (1995a).

Recommended status: As yet, this species has no special status. Minimally, it should be considered a sensitive species by appropriate federal (e.g., BLM) and state land management and wildlife agencies. Federal and State (ID) listing as Endangered is suggested, for the reasons outlined above. Comprehensive recent surveys of the lower Salmon River drainage for this and other land snail species were conducted by various workers from the 1860 s onward, including us, H. Hemphill, H. B. Baker, A. Solem, and M. Walton. It is not likely that later work will greatly expand
either the range or number of sites.

References: Deixis collections, 1988-1994; Frest \& Johannes (1995a)

\section{Oreohelix n. sp. 24 Wet Gulch mountainsnail}

Type locality: To be designated when species is described.

Description: Shell with low depressed spire, sometimes sublenticular; small (to $10 \mathrm{~mm}$ ); generally 5 is rather narrow whorls as adult; whorls with slightly convex sides; upper whorl surfaces somewhat stepped; sutures deeply impressed; periphery slightly angular and with distinct but 
narrow rib. Growth lines faint; moderately prominent, low, somewhat irregular transverse ribs on both surfaces, equally prominent on lower; fine raised spiral ribs (generally 5-7 on both upper and lower surfaces; spiral striation even faint but consistent over whorl surfaces. Shell thin; aperture moderately oblique, not thickened, not flared, slightly deflected in final 1/16 whorl. Color bands faint; peripheral bands sometimes absent; several faint bands sometimes present on either or both whorl surfaces, whole shell often very light tan, with several narrow white bands and thin, darker brown bands. Umbilicus about $1 / 4$ shell diameter, deep, with well-rounded border; slightly elliptical.

This species, because of its small size, convex whorls, low spire, and large umbilicus, somewhat resembles Oreohelix waltoni. However, that species has very different juvenile sculpture and anatomy; prominent radial ribs; and lacks transverse ribs. Waltoni is a member of the idahoensis species group; while anatomy indicates links between this species and the haydeni
species group.

Ecology: This moderate xerophile is found on a largely open, dry, and exposed schist ridge and talus. Vegetation is sparse; but includes Celtus and grasses. This is the only large land snail found live, although recently dead specimens of Allogona ptychophora ptychophora and Cryptomastix harfordiana occur in the vicinity. Long-dead Oreohelix haydeni hesperia were also noted; but these could be wash-down from farther up Wet Gulch, although these were the typical, large flat form and not the smaller high Wet Gulch morph.

Original distribution: Only known from one site [31] as yet, near the mouth of Wet Gulch, lower Salmon River, Idaho Co., Idaho. See Appendix C42 and Appendices A and B for additional
information.

\section{Current distribution: Same as above.}

Threats: This area has been heavily grazed, and live snails are confined to a narrow area protected by steep rocky terrain and the location of a fence line (the species is not found live on the other side of the fence line). The area has been damaged by fence line placement and is subject to landslides. Ownership is unclear; it may be within the US 95 right-of-way.

Criteria for inclusion: Extremely local strict Lower Salmon River endemic; past and ongoing threats, reduced colony size and numbers. Population trends (size and condition of site, number of individuals) are downward. Treated as a Sensitive species in Frest \& Johannes (1995a).

Recommended status: Currently this species has no special status; minimally, it should be considered a sensitive species by appropriate federal (e.g., BLM) and state land management and wildlife agencies. Federal and State (ID) listing as Endangered is suggested, for the reasons outlined above. Comprehensive recent surveys of the Lower Salmon River drainage for this and other land snail species were conducted by us between 1990-1994. Many other collectors have worked this area, including H. Hemphill, H. B. Baker, A. Solem, and M. Walton, without finding other sites for this species. It is not likely that later work will greatly expand either the range or
number of sites.

References: Frest \& Johannes (1995a); Deixis collections, 1994. 


\section{Oreohelix n. sp. $25 \quad$ Stites mountainsnail}

APPENDIX C44

Type locality: Designation is deferred to the time when the species is formally described.

Description: Shell low dome-shaped, with faintly angular periphery and moderately convex sides; medium-sized, with up to 6 whorls, diameter to $20 \mathrm{~mm}$. Aperture obliquely rounded, moderately oblique, slightly thickened; minor flare in last 1/16 whorl; slightly deflected typically. Shell moderately thick; principal color bands faint, sometimes interrupted; both whorl surfaces with varying amounts of purple-brown suffusion, but stronger on upper surface. Growth lines and spiral striation rather faint and irregular, equal above ad below periphery. Umbilicus, small, wellrounded border, deep, about $1 / 5=1 / 6$ maximum shell diameter, slightly elliptical.

Anatomy of this species has been well described by Solem (1975) under the name Oreohelix strigosa strigosa. The Stites mountainsnail is characterized by a combination of size, spire shape, and the general rufous tint noted by Solem (1975). Comparisons between this taxon and sometimes co-occurring Oreohelix vortex were discussed at length by Solem (1975), who established beyond doubt that both are separate species.

Ecology: This species is a moderate to weak xerophile, found typically in somewhat dry, open basalt taluses, often at low elevations. Balsamorhiza, Celtus, grasses, and Sorbus are common associates; but other taxa, such as Salix. Populus, Sambucus, Rhus, Urtica, and various composites occur at some sites. The most frequent co-occurring land snail is Allogona ptychophora ptychophora; but small Cryptomastix spp. and Cryptomastix mullani mullani may be common in the same taluses also; Polygyrella polygyrella and Oreohelix vortex were noted at one or more sites with this taxon.

Original distribution: Probably once one of the more common land snail species in the lower portions of the drainage of the South Fork Clearwater River and N. of Lucile in the lower Salmon River valley, where these have basalt talus or substrate. This form has not been noted in the $N$. portion of Hells Canyon, which also has extensive basalt outcroppings and rock piles, nor in the lower Salmon River valley S. of Riggins (also basalt substrate). The species is confined in the Salmon River area to the stretch from near the mouth of Skookumchuck Creek to the vicinity of Eagle Creek (Appendix C44).

Current distribution: Sporadically distributed within the original range. Many basalt taluses in the same general area have other species of Oreohelix, such as jugalis or vortex. We have this species from a total of 28 sites (Appendix C44); it is relatively common locally within its rather limited range, and is not completely restricted to the main river corridor.

Threats: Talus mining and road improvements (one such, near White Bird in 1994, has almost completely destroyed perhaps the largest known site, and long-term survival here is unlikely);
grazing; location of human habitations and roads.

Criteria for inclusion: Local endemic; past and ongoing threats; occurrence on public lands, including BLM, Nez Perce National Forest, and Nez Perce Tribe parcels. Population trends (number of sites, number of individuals) are downward. Treated as a Sensitive species in Frest \&
Johannes (1995a).

Recommended status: Presently, this species has no special status; minimally, it should be considered a sensitive species by appropriate federal (e.g., BLM) and state land management and wildlife agencies. Federal and State (ID) listing as Threatened is suggested, for the reasons outlined above. Comprehensive recent surveys of the lower Salmon River drainage and adjacent parts of the lower Clearwater R. drainage for this and other land snail species were conducted by 
us; and many other collectors (both professional and private) have worked this area, including $\mathrm{H}$. Hemphill, H. B. Baker, A. Solem, and M. Walton. It is not likely that later exploration will greatly expand either the range or number of sites.

References: Solem (1975); Frest \& Johannes (1995a); Deixis collections, 1989-1994.

Oreohelix n. sp. 29

Hells Canyon mountainsnail APPENDIX C45

Type locality: Will be designated when the species is described.

Description: Shell medium-sized for genus, to $20 \mathrm{~mm}$; adult with $4 \mathrm{~b} / 5 \mathrm{~b} / \mathrm{z}$ worls; low turbinate in shape, slowly expanding, with low, almost fiat, initial whorls. Shell moderately thin; aperture definitely reinforced, slightly deflected, not strongly oblique; distinctly flared, and slightly reflected over umbilicus. Growth lines faint on adult whorls, low, widely spaced, irregular; lower surface almost smooth; spiral striation absent on mature whorls; surface dull or with slight sheen. Two principal color bands thin but almost always present; secondary bands uncommon; shell generally chalky off-white, except for faint brown suffusion above upper color band. Umbilicus small, deep, well-rounded border; elliptical; diameter about 1/5-1/6 total shell width.

This medium-sized species somewhat resembles taxa from other parts of the range ascribed by Pilsbry (1939) to Oreohelix strigosa depressa. It differs from type material and other lots from $\mathrm{CO}$ in that it is higher; has fewer and more convex whorls; has a smaller umbilicus; and generally lacks spiral striation. Anatomically, it is a member of the "strigosa" species group.

Ecology: A strong xerophile, found on several lithologies in sage scrub; but particularly common on limestone. Most colonies occur in small-scale, N.-facing talus or rock piles. Common associates include Artemisia, Balsamorrhiza, grasses, Celtus, Opuntia, and Rhus. More frequent large land snails found with this species include Allogona ptychophora ptychophora, Cryptomastix populi, and additional small Cryptomastix species. This species generally occurs at lower elevations in major stream valleys.

Original distribution: Probably quite common along the middle and northern parts of Hells Canyon, the Snake River Canyon to a point a few miles W. of Clarkston, WA; and along the lower few miles of the Grande Ronde River. In the southern portion of Hells Canyon, i.e. Seven Devils Mountains and S., this species is replaced by others. This taxon appears to have been utilized as a food resource by early aboriginal peoples in Hells Canyon.

In the Lower Salmon River area, this species is very sporadic in its distribution. The probable complete range here is from the mouth of Skookumchuck Creek to the Snake River.

Current distribution: Scattered sites within the original range, including Nez Perce National Forest (e.g., the vicinity of Pittsburg Landing), Wallowa-Whitman National Forest, Hells Canyon National Recreation Area, and Snake Wild and Scenic River: narrow portions of Idaho and Nez Perce cos., ID; Asotin and Whitman cos., WA; and Wallowa Co., OR. Locally, there are 4 live sites (Appendix C45), in 2 areas near the mouth of Rock Creek and in the vicinity of the mouth of China Creek. We regard the species as common herein (e.g., Table 2) largely because of its more frequent occurrence in the north portion of Hells Canyon; it is rare and sporadic, as far as presently known, in the Lower Salmon River area. There is a good possibility of additional sites in the lowermost 20 miles of the Salmon River. 
Threats: Trail and road development in the Pittsburg Landing area; heavy grazing in most of its maintenance in the Clarkston areang in the northern Hells Canyon area; road building and years); expansion of Clarkston. WA and colonies along US 12 have been extirpated in the last few absolute numbers and number, range or number of sites.

Criteria for inclusion: Local (Hells Canyon-Lower Salmon River) endemic; past and current threats (as outlined above); loss of historic sites; declining numbers; occurrence on public lands.
Treated as a Sensitive species in Frest \& Johannes (1995a).

Recommended status: This taxon has no special status at present. Minimally, it should be regarded as a sensitive species by the relevant Forest Service, BLM, and state land management reasons discussed previously. References: Frest \& Johannes (1995a); Deixis collections, 1989-1994. Old specimens of this
taxon are in museum collections (e.g. ANSP).

\section{Oreohelix n. sp. 32}

\section{Skookumchuck mountainsnail
APPENDIX C46}

Type locality: Will be designated when the species is formally described; it is currently known
form a single site.

Description: A small (to $12 \mathrm{~mm}$ diameter), low, convex domed-shaped species characterized by weak color bands. The species 5 s/2 evenly expanding whorls; unpigmented upper surface; and open umbilicus; but is smaller, has a close relative of Oreohelix vortex (q.v.), with a similar large lacks beaded wreaths; and has a peculiar, rough shell whorls, lacks pigment on the upper surface; defined is quite variable, there is no other, rough shell surface. Even though 0 . vortex as currently interesting to note that co-occurring large land snail known to us closely resembling this one. It is We have not yet dissected this recently discriminated species.

Ecology: A xerophile, restricted to a large-scale basalt talus. The site is rather dry and open. in a part of the talus. Associas Balsamorhiza, Artemisia, Celtus, Rhus, and Sorbus. It occurs low Oreohelix n. sp. 25, and Cryptomastix n. sp. 6 .

Original distribution: Uncertain. Identical habitat occurs in the northern portion of the lower Salmon River valley, roughly from Slate Creek to the river mouth. This species is seemingly absent from basalt terrain of similar age, physiography, and history in the lower Clearwater River valley, Current distribution: A single site (150: see Appendices A and B for details) in the middle
portion of Skookumchuck Creek (Appendix C46). The region in general has been recently
surveyed (Figure 1) and has been visited repeatedly by malacologists since the 1860 . unlikely that future finds will substantially increasedly by malacologists since the $1860 \mathrm{~s}$. It is very colonies. 
Threats: Heavy grazing in much of its range; talus mining in the lower Salmon River valley; road construction and maintenance. Talus along this creek has been quarried repeatedly for road metal, generally completely destroying or greatly diminishing snail colonies. This particular talus has been impacted by material removal and by road building, and the snail occurs only in certain areas of the remainder.

Criteria for inclusion: Strict local endemic limited to a single site; past and ongoing threats.

Recommended status: This taxon has no special status at present, although the very closely related Oreohelix vortex is a Federal C2 candidate (USFWS, 1994),. Minimally, it should be considered a sensitive species by BLM, Forest Service, and other land management agencies. Federal and State (D) listing as Endangered is appropriate, in our opinion. It is very uncommon even in the limited portion of the single talus in which it occurs. Comprehensive recent surveys of the lower Salmon River drainage for this and other land snail species were conducted by us between 1989 and 1994. Many other collectors have worked this area for over 130 years, including $\mathrm{H}$. Hemphill, H. B. Baker, A. Solem, and M. Walton. It is very unlikely that substantial expansion of whether range or number of live sites will occur from future work.

References: Deixis collections, 1989-1994.

\section{Oreohelix strigosa goniogyra Pilsbry, 1934 striate mountainsnail APPENDIX C47}

Type locality: "On lower Race Creek below forest, $\frac{1}{4}$ mile from the mouth and 2 miles north of Riggins, Idaho" (Pilsbry, 1939); holotype ANSP 158421a. Pilsbry (1939) cites the original description as dating from 1933; but the cover of separates include the line "Published March 3 , 1934". For type locality, see Figure 2 and Appendices A and B. Strictly speaking, the colony 14 mile from the mouth of Race Creek is now extirpated (in a well-used horse pasture); however, the "adjoining" colony below, collected by Walton, Solem and by us, is still extant, and might be considered to have been originally continuous with the Baker site, simply overlooked.

Description: See Pilsbry $(1934,1939)$ for description of both shell and anatomy. This is a rather large taxon with a prominent peripheral keel and very obvious but fine striation on both surfaces, quite visible to the naked eye. The peripheral bands are typically developed. No other species in the "strigosa" species group has a strongly carinate adult shell with prominent spiral lines. This species superficially somewhat resembles the bicarinate mountainsnail (Oreohelix $\mathrm{n}$. sp. 17); but the basal carina, fine ribs rather than incised lines, and haydeni species group anatomy are obvious differentiae.

Note that we at present recognize two sets of colonies, one on Race Creek and its tributaries and the second near the mouth of Lake Creek. This latter group has not yet been investigated anatomically, and could be a conchologically convergent form. The Selway River sites also need to be reinvestigated; we were unable to get anatomical material of this species in a recent visit.

Ecology: This snail is found mostly on forested outcrops (Pinus ponderosa forest), with lithologies ranging from greenish schist to limestone. Commonly, sites have a partly-completely closed canopy and diverse fort and deciduous understory. Reported colonies have substantial faunas, including Polygyrella polygyrella, Cryptomastix mullani mullani, Allogona ptychophora ptychophora, Anguispira nimapuna, and Hemphillia camelus. One site supposedly with this 
taxon is also the type locality for Allogona lombardii. The elevation range for this species is
considerable.

Original distribution: Originally reported from the Race Creek drainage, Lower Salmon River Subsequently, Smith Idaho; also found in the Lake Creek drainage, River of No Return. drainage. We have been collections. Taxonomy of specime locate Smith's Selway specimens in either the CAS or SBMNH

Current distribution: May be limited to a few remnant colonies in the Race Creek and Lake Creek nearby, presuma the locality has been grazed out (now in a horse pasture); but a colony remains collectors have revisited 5 ic (BLM) lands and protected on one side by a fence We and private but did not find this species. there are 6 Lower Salmon drainages (Appendix C46).

Threats: Grazing; logging in both the Selway and Lower Salmon valleys, road location and modifications; forest fires. The colonies along the upper part of the Race Creek drainage were huge, judging by dead shells, which number in the millions. Relatively recent clearcutting and fire have reduced these sites in Nez Perce National Forest to small remnants, with the snail mostly surviving in rocky areas offering some refuge from summer desiccation. Population trends (number of sites, number of individuals) are downward.

Criteria for inclusion: We regard this subspecies as a strict local endemic, discounting the Selway reports; past and continued threats, as noted above; occurrence on public (National Treated as a Sensitive lt is generally rare, even in its quite limited area of known occurrence.

Recommended status: At present this taxon is a federal C2 candidate (USFWS, 1994). It should at least be considered a sensitive species by Forest Service and other federal and state land and wildlife agencies. We recommend Federal and State (ID) listing of this taxon as Endangered. As comprehensive recent surveys of the Lower Saimon River drainage for this and other land snail species were conducted by us and also by other malacologists, both professional and amateur, including H. Hemphill, H. B. Baker, A. Solem, and M. Walton, it is not likely that later work will greatly expand either the range or number of sites.

References: Pilsbry (1934, 1939); Smith (1943); USFWS (1994); Frest \& Johannes (1995a);
Deixis collections, 1989-1993.

\section{Oreohelix strigosa n. subsp. 1 Nez Perce mountainsnail
APPENDIX C48}

Type locality: To be established when the species is formally described.

Description: Shell large, low, depressed, 5-6 whorls, diameter to $30 \mathrm{~mm}$; moderately thick; whoris convex, sutures only slightly impressed; slight peripheral keel occasionally; accentuated in last half whorl only. Growth lines very fine, low, moderately regular, crowded; spiral striation strong, striae moderately widely spaced, crossing growth lines to produce finely reticulate pattern not visible to naked eye; surface appears somewhat smooth. Aperture rounded, not reinforced, 
moderately oblique. Umbilicus moderate in size and depth, border well-rounded, circular, about 1/3 maximum shell diameter. Color bands generally present; subsidiary bands variable in size and position; shell ground color off-white, generally with varying amounts of purple-brown or purplered suffusion or mottles or both, especially on top surface.

This large-sized taxon appears from shell and anatomical features to be a member of the "strigosa" species group. Distinguishing features are the low spire, fine growth lines, and prominent and consistent but very fine (difficult to see with the naked eye) spiral striae.

Ecology: This mesophilic taxon is found exclusively in moderate-high elevation Pinus ponderosa forests, generally in areas with some rock exposure. It has been noted primarily on limestone; but occasionally on basalt as well. Moist valley, ravine, gorge, or talus sites are preferred, i.e. low on a slope and near permanent or persistent water, but not normally subject to regular or catastrophic flooding. Persistence of moisture is a desideratum. Common associates are Physocarpus, Prunus, soapberry, and bryophytes. Sometimes found with such taxa as Allogona ptychophora ptychophora, Anguispira kochi occidentalis, Cryptomastix mullani mullani, and Radiodiscus abietum. This species is not as sensitive to disturbance as, e.g., Hemphillia camelus; but is absent from severely grazed or otherwise heavily disturbed areas. It does not seem to prefer talus situations, although sometimes found there.

Original distribution: Probably very widespread in medium-high elevations in the Seven Devils Mountains area, Nez Perce and Payette National Forest; in undisturbed sites it is the most frequently encountered large land snail. It is now absent from the vast majority of its range, where long-dead shells often still attest to its former occurrence.

Current distribution: Restricted to relatively undisturbed sites in Nez Perce National Forest; particularly those with limestone or other calcium-rich substrate. See Appendices A and B and Appendix $\mathrm{C} 48$ for some specifics; we found this taxon at 6 sites and regard it as generally uncommon. It is probably rare-very rare at lower elevations, i.e. most BLM tracts in this region. The Lower Salmon River sites are on major tributaries only, in two areas: 1) Papoose Creek drainage, Little Salmon River; and 2) Slate Creek drainage, Lower Salmon River (Appendix C48).

This species was mostly overlooked by earlier collectors, because of access problems in high portions of the Hells Canyon-lower Salmon River area. Still, at least one historic low site (along Squaw Creek) is known to have been extirpated. This locality was collected by H. B. Baker in the 1930s and is referred to by Pilsbry (1939); specimens are in the ANSP collections.

Threats: Severe grazing; logging; severe forest fires; road building and maintenance.

Criteria for inclusion: Local (part of the Washingtonian Province) endemic; habitat reduction and possible site loss throughout range. Population trends (number of sites, number of individuals) are downward. It is not likely that later work will greatly expand either the range or number of sites. Treated as a Sensitive species in Frest \& Johannes (1995a).

Recommended status: This taxon has no special status at present; it should at least be considered a sensitive species by Forest Service and other federal and state land and wildlife agencies. We recommend consideration of federal and State (ID) listing of this taxon as Threatened. Extensive surveys of the lower Salmon River drainage for this and other land snail species were conducted by many previous workers, including H. Hemphill, H. B. Baker, A. Solem, and $M$. Walton, from the 1860 s; not to mention our own more recent work. A few old records indicate widespread former occurrence in this area.

References: Frest \& Johannes (1995a); Deixis collections, 1990-1994. 


\section{Oreohelix vortex Berry, 1932
Appendix C49}

Type locality: "Salmon River, White Bird, Idaho, Co., Idaho"; holotype Berry collection 7283 ; paratypes Berry collection 4655; holotype of Oreohelix flammulifer Berry, 1932, a synonym, of this site, see Solem (1975). Berry collection 4656 (same type locality). For probable location was collected later by Walton, Solem, Miller, relocated the taxon at a site near White Bird, which likely type locality (Figure 2).

Description: The best shell description and illustration are by Pilsbry (1939); but see also anatomy and illustrations in Solem (1975). This species, another Hemphill discovery, does not [Skookumchuck mountainsalmon River Oreohelix species, except possibly Oreohelix n. sp. 32 periostracum-fringed lirae, impressed sutures shell features are the rather close coiling, fine same period as many other Sased sutures, and wide umbilicus. It was first discovered in the undescribed until much later. Pilmon River species (1860-1880); but, like many, remained nomen nudum); other such specimens specimens of this species at ANSP under abavia (a

subspecies of jugalis: anatomich flammulifer and regarded this taxon as a information, it is clear that vortex is a full not available for any of the three. With this additional flammulifer is a synonym, as Pilsbry surmised (Sol particularly closely related to jugalis; while variable taxon. Certain populations, such ed (Solem, 1975). As recognized herein, vortex is a drainages, and some of those along the as those of lower Skookumchuck Creek and adjacent consistent morphology varying some Lower Salmon (e.g., north of Lyons Bar), appear to have that more detailed study will necessitate from that of the type area at White Bird. It is possible Oreohelix $\mathrm{n} . \mathrm{sp} .32$ and retain a broad definition of vortex. Thus far, we take this step only with

Ecology: A xerophile, restricted mostly to large-scale basalt taluses. Sites are typically rather dry and open. Most common vegetation is grasses; at some sites, Balsamorhiza, Artemisia, Celtus, Rhus, and Sorbus may be locally common. The species prefers low to medium elevations in large stream valleys. Generally, it occurs low in the larger taluses. Common associates among larger land Snails are Allogona ptychophora ptychophora and ptychophora solida, Oreohelix jugalis, and

Original distribution: Probably quite widespread in the northern portion of the lower Salmon River valley, roughly from Slate Creek to an area north of White Bird Creek. This species is absent from basalt terrain of similar age, physiography, and history in the lower Clearwater River valley, northern Hells Canyon, and northern Little Salmon River valley. Its apparent absence from the lower part of the Grande Ronde Group basalt outcrop area along the lowermost 60 miles of the

Current distribution: Remains in up to 22 isolated colonies in the most undisturbed parts of its original range, particularty along a short stretch of the lowermost Salmon River and lower parts of two of its larger creek tributaries, i.e., between Slate Creek and a point midway between White has been visited Rock Creek (Appendix C49). The range has been recently surveyed by us and will substantially repeatedly by malacologists since the $1860 \mathrm{~s}$. It is very unlikely that future finds public lands (BLM). The original status range or number of viable colonies. Many sites are on Threatened (Solem \& Clarke, 1974). are downward. 
Threats: Heavy grazing in much of its range; talus mining in the lower Salmon River valley, which has recently destroyed some old sites; highway construction and maintenance, including US 95 and smaller roads in the vicinity of White Bird. Sites affected by highway construction along old US 95 many years ago have still not recovered. One largely destroyed site was used as a quarry, and the colony persists only as small remnant patches. Talus mining is extensive in most of its range. While the species is quite characteristic of a part of the Lower Salmon River area, the total range is rather small (Appendix C49). We regard the species in general as uncommon even within its limited known geographic range.

Criteria for inclusion: Local endemic; occurrence on pubic lands; past and ongoing threats. Treated as a Sensitive species in Frest \& Johannes (1995a).

Recommended status: This taxon, although a Federal C2 candidate (USFWS, 1994), has no special status at present. Minimally, it should be considered a sensitive species by BLM, Forest Service, and other land management agencies. Federal and State (ID) listing as Threatened is appropriate, in our opinion. Considering that, in aggregate, comprehensive surveys of the lower Salmon River drainage for this and other land snail species were conducted by many malacologists over the past 130 years, including H. Hemphill, H. B. Baker, A. Solem, and M. Watton; and more recently by Solem and Clarke and by us, it is very unlikely that substantial increase of either range or number of live sites will accrue from future work.

References: Berry (1932); Pilsbry (1939); Solem (1975); USFWS (1994); Frest \& Johannes (1995a); Deixis collections, 1989-1994.

\section{Oreohelix waltoni Solem, $1975 \quad$ lava rock mountainsnail APPENDIX C50}

Type locality: "Idaho, Idaho Co., more than $1.6 \mathrm{~km}$ up John Day Creek from the Salmon River, north of Lucile"; holotype FMNH 182000; paratypes FMNH 98141, 98151, 170711, 170741; NMC 72060; others in DMNH (unnumbered). For more precise location of the type locality, see Appendices $\mathrm{A}$ and $\mathrm{B}$ and Figure 2.

Description: Solem (1975) provides excellent illustrations and descriptions of both shell and anatomy. This species was overlooked by earlier collectors, largely because of its rarity. Unusual features are the small, flattened shell, broad umbilicus; prominent ribs; and juvenile sculpture. It is a member of the Oreohelix idahoensis idahoensis species group, as defined above. Some members of the Oreohelix intersum species group (q.v.) superficially resemble this taxon (notably the Shingle Creek mountainsnail, Oreohelix n. sp. 19); but the coarse ribs and juvenile sculpture, together with lesser characters such as its shell color pattern (discussed by Frest \& Johannes, 1995a), distinguish this species. The Wet Gulch mountainsnail (Oreohelix n. sp. 24) is superficially similar also; but this species is a member of the haydeni species group, with weaker radial ribs and equally prominent lirae, as well as a juvenile typical of its species group.

Ecology: This species is a typical xerophile, found in rather dry, open areas in sage scrub vegetation. The common name suggests association with basalts; this is true of the type locality, but other sites are on mixed schist/alluvium. Most commonly associated plants are grasses, Artemisia, and Celtus; Sorbus, Prunus, and Physocarpus occur locally. This taxon is the dominant at most sites; but co-occurrence with Oreohelix jugalis and Oreohelix n. sp. 21 (Box Canyon mountainsnail) was noted at one site each. More frequent associates are Allogona ptychophora ptychophora and Cryptomastix harfordiana. 
Original distribution: The lava rock mountainsnail may once have been common in the central part of the lower Salmon River, i.e. between Riggins and White Bird, on suitable substrate.

Current distribution: We found the lava rock mountainsnail at a total of 8 sites (Appendix C50). Unfortunately, at least 3 of these are now [1994] believed extirpated (Table 4). This species survives in perhaps 5 sites in the vicinity of Lucile and John Day Creek, less than half of the historic range. The type locality has been much affected by cattle grazing, and the species is currently very rare and found in only a limited part of the talus. The second colony mentioned by Solem (1975) may be extinct, as we have been unable to find live individuals there in the last 2 years (last seen live at this site in 1990). At least one locality is on BLM lands.

Finds of recently dead material by us and by S. Welty (pers. comm., 1993) in 1990 and 1991 along the White Bird Creek road indicated the possible presence of a colony in this area (alluded to also by Solem, 1975); however, this area was massively modified for grade improvement and for a home site in 1994, and there is no chance of survival at this site. We searched the relevant portion of the White Bird Creek valley in 1993 and again in 1994 anyway, unsuccessfully. Most sites (except the type locality) are along the main river corridor (Appendix C50).

Threats: All known sites are impacted by grazing; the Lucile colony may have been extirpated by sheep grazing; the type locality has been heavily grazed by cattle. The other sites are similarly affected. Road construction and maintenance have considerably reduced the sites along US 95. Talus mining, especially for basalt gravel, has affected taluses in the immediate vicinity of all sites. Gold mining and prospecting impacts sites in schist lithologies. Population trends (number of sites, number of individuals) are very clearly downward.

Criteria for inclusion: Very local strict endemic; small number of sites; historic site loss and population decline in recent years; occurrence on public lands. Treated as a Sensitive species in Frest \& Johannes (1995a).

Recommended status: Currently, this species is a Federal C2 candidate (USFWS, 1994). It should minimally be considered a sensitive species by BLM, Forest Service, and other land management agencies. Comprehensive recent surveys of the lower Salmon River drainage for this and other land snail species, as conducted by us and by Solem and Clarke, as well as earlier efforts by numerous other workers, including $\mathrm{H}$. Hemphill, H. B. Baker, A. Solem, and M. Walton, make it is very unlikely that later work will greatly expand either the range or number of sites for this species. Status surveys for Oreohelix species (specifically including this one) were first conducted in this area in 1973-1974 (Solem \& Clarke, 1974); listing was recommended at that time (Solem \& Clarke, 1974; Solem, 1975). We strongly recommend Federal and State (ID) listing as Endangered.

References: Solem \& Clarke (1974); Solem (1974, 1975); USFWS (1994); Frest \& Johannes (1995a); Deixis collections, 1990-1994.

\section{Pristiloma (Pristinopsis) idahoense (Pilsbry, 1902) thinlip tightcoil} APPENDIX $\mathrm{C} 53$

Type locality: Stevens Ranch, Weiser Canyon (Weiser River), Adams Co., ID. Holotype ANSP 82353. 
Description: The best summary description and illustration are in Pilsbry (1946); see also Baker (1931). As regards shell features, the close coiling and yellowish vitreous shell color distinguish this species from the related Pristiloma lansingiand Pristiloma arcticum.

Ecology: A somewhat mesophilic species occurring generally in rather open-largely closedcanopy Ponderosa pine-Douglas fir forests, at rather low elevations, on a variety of substrates. In general, moist valley, ravine, gorge, or talus sites are preferred, i.e. low on a slope and near permanent or persistent water, but not normally subject to regular or catastrophic flooding. Persistence of moisture for at least part of the year is a desideratum. Land snail associates include species of Cryptomastix (especially mullani mullani) and Allogona, Radiodiscus abietum, Microphysula ingersolli, and some more widespread forms (Baker, 1932). On occasion, this species has been found with such rare taxa as Megomphix lutarius, Polygyrella polygyrella, Oreohelix haydeni hesperia, Pristiloma subrupicola, and Cryptomastix mullani latilabris.

Original distribution: A Washingtonian Province taxon; but mostly in the eastern part of this province. Reported formerly from the following $\mathbb{D}$ counties: Adams, Boise, Benewah, Boise, Clearwater, Idaho, Kootenai, and Shoshone. Included are sites currently in Payette, Nez Perce, Clearwater, and the Idaho Panhandle National Forests.

Current distribution: Uncertain; we have not found this taxon at many of the old sites; nor has Brunson (pers. comm., 1993) at his western MT sites. T. Burke (pers. comm., 1994) has collected this species in eastern Washington. S. Welty (pers. comm., 1994) has also repeatedly tried unsuccessfully to recollect this species at some of the old sites, e.g. Rabbit Creek.

The thinlip tightcoil has been noted during this survey at only one site, which is also the sole locality for Ogaridiscus subrupicola (Appendix C53). No live specimens were collected, in part due to fieldwork timing. Local associates also include Oreohelix haydeni hesperia and Cryptomastix mullani latilabris.

Threats: Most of the former range has been logged and is now grazed. Other sites are part of the Coeur d'Alene-Kingston mining district. Some of this area has been severely affected by smelter emissions and mining wastes. Certainly, population trends (in number of sites and number of individuals) are downward.

Locally, the preferred mesophilic habitat is rare, due to logging and settlement in the lower reaches of major Salmon River tributaries. Grazing and clearing have affected much former habitat. We have not found this species in some areas expected, e.g. the moist forests along the middle portion of Slate Creek or our upland Nez Perce National Forest sites.

Criteria for inclusion: A regional endemic, reported from a small number of widely scattered sites; lack of recent collections; threats in areas of known past occurrence; occurrence on public lands. Treated as a Sensitive species in Frest \& Johannes (1995a).

Recommended status: This taxon has no special status at present. It should be considered a sensitive species by the Forest Service, BLM, and other land management and wildlife agencies. Federal and State (ID) listing as Threatened may be appropriate for the reasons cited above. Locally, the species is evidently very rare and in need of protection.

References: Pilsbry (1902, 1946); Baker (1932); Frest \& Johannes (1995a); Deixis collections, 1990. 


\section{WATCH LIST: SENSITIVE, BUT NOT CRITICALLY}

Under this heading are discussed taxa which are known or have been reported to occur in the Interior Columbia Basin; are known to have lost much of their range; and are regarded as sensitive species, i.e. especially associated with mature, relatively undisturbed forests; riparian areas; springs; and/or some combination of specialized or especially impacted habitat. However, these taxa may have had a comparatively broad range originally; or may be species which currently known or thought to be common outside the area of assessment elsewhere in the U.S. or in adjacent countries. These taxa are not regarded as in imminent danger of extinction without protection currently (although this may change rapidly, depending upon the management strategy adapted for public lands, and upon the effectiveness of its implementation).

These taxa should be regarded as sensitive by land management and wildlife planners, and their status should be carefully and periodically reviewed. Complacency in regard to their status and needs is not suggested.

\section{Oreohelix jugalis (Hemphill, 1890) boulder pile mountainsnail}

APPENDIX C

Type locality: "Salmon River Mountains, Idaho"; lectotype ANSP 62372a; for possible paralectotypes, see Coan \& Roth (1987) and Frest \& Johannes (1995a). Hemphill's lots often contained specimens of what we here term Oreohelix $\mathrm{n} . \mathrm{sp} .23$.

Description: The best previous description and illustrations are those of Pilsbry (1939); but see also Solem (1975) for anatomy and Frest \& Johannes (1995a).

Ecology: This species occurs at low elevations in rock taluses (schist; basalt; metasediments; limestone) and boulder piles (mixed lithologies). This is a rather tolerant species, occupying the range from slightly mesophile to moderately-strongly xerophile. Sites are open, vary in exposure, and can be seasonally dry. Plant associates include Celtus, Rhus, Salix, Sorbus, and Cornus stolonifera, as well as grasses and a few bryophytes. Common associates include Allogona ptychophora ptychophora, Allogona ptychophora solida, Cryptomastix harfordiana, and such Oreohelix species as Oreohelix vortex. The species is found occasionally with such species as Oreohelix waltoni and several of the new taxa described above.

Original distribution: Limited to the area along the lower Salmon River from Riggins to about RM 20, mostly in Idaho Co., ID.

Current distribution: Still survives at a fair number of sites in the original range, including some on BLM lands. See Frest \& Johannes(1995a) for a recent assessment. 
Threats: Nearly all known sites are impacted by grazing; sheep, horses, and cattle have considerably reduced or even extipated sites. Road construction and maintenance have considerably reduced sites along US 95 , and probably extirpated the species from much of the corridor, judging by still-common dead shells. Talus mining, especially for basalt gravel and alluvium, has affected taluses in the immediate vicinity of all sites. Large sites near White Bird have been completely eliminated (in 1991 and 1994) from talus mining and road improvements. Road corridors are selectively located in preferred habitat of this species. Gold mining and prospecting impacts sites in schist lithologies. Boulder piles along the Salmon River are mostly disturbed by gold mining, and there is little indication that this species has reoccupied mining discard heaps and similar sites, even though some are quite old. Population trends (number of sites, number of individuals) are very clearly downward.

Criteria for inclusion: Local endemic; occurrence on public lands; habitat decline; loss of historic sites. Treated as a Watch List species in Frest \& Johannes (1995a).

Recommended status: At present, this species is a C2 federal candidate (USFWS, 1994). With thorough survey, it has been noted as more common than originally expected, even though quite limited and though it has suffered considerable range and site loss (Frest \& Johannes, 1995a). Assuming that sites for other, more rare species in the same corridor can be protected, it is possible that this species will be included on enough as to not warrant listing. The species should minimally be considered sensitive by the Forest Service, BLM, and other appropriate land management and wildlife agencies. If other species associated with jugalis are not protected then this taxon should be federally listed as Threatened.

References: Hemphill (1890); Pilsbry (1939); Solem (1975); USFWS (1994); Frest \& Johannes (1995a); Deixis collections, 1988-1994.

\section{Polygyrella polygyrella (Bland \& Cooper, 1861) APPENDIX C52}

humped coin

Type locality: Eastem slope of the Coeur d'Alene Mountains, Sanders Co., MT (likely in Lolo National Forest currently). Location of holotype uncertain; Bland specimens in USNM.

Description: For best descriptions and illustrations, see Pilsbry (1939); see also illustration in Burch \& Pearce (1990).

Ecology: Found generally in moist Douglas fir and spruce forests, often in association with rock outcrops. Substrate is quite variable, and can include basalt, schist, and limestone. Partly open forest with a rich understory, including diverse forbs, mosses, and deciduous shrubs, is common; the best colonies occur in forested taluses. Moist valley, ravine, gorge, or talus sites are preferred, i.e. low on a slope and near permanent or persistent water, but not normally subject to regular or catastrophic flooding. Persistence of moisture is a desideratum. Land snail associates include such forms as Allogona ptychophora ptychophora; Allogona lombardit, mesophile-slight xerophile Oreohelix species; mesophile Cryptomastix species, including mullani mullani; Zacoleus idahoensis, and Hemphillia camelus. This species is a mesophile, but can tolerate moderately xerophilic conditions in rock taluses. This species often occurs with quite rare and endemic mesophile-weakly xerophile taxa, such as Anguispira nimapuna and Cryptomastix magnidentata.

Local ecology is similar, with the species being found in moist, shaded and forested sites, with diverse land snail faunas. Here, the few known localities are on basalt substrate. Associates 
include Oreohelix vortex, Oreohelix n. sp. 25, Allogona ptychophora ptychophora, and Cryptomastix mullani olneyae.

Original distribution: In MT, generally in the Clark Fork River drainage, Bitterroot Range and Coeur d'Alene Mountains; in ID, in the Coeur d'Alene River drainage (Kootenai Co.); the Clearwater, Lochsa, and Selway drainages (Nez Perce, Idaho cos.); and also in the Blue Mountains (Walla Walla Co., WA; Umatilla Co., OR). Generally a Washingtonian Province species; but absent from the western portions of this province.

Current distribution: T. Burke (pers. comm., 1994) has not found this species in NE WA; nor have we. Recent attempts to recollect the Blue Mountain localities were also unsuccessful. This species is known from very few MT sites (R. B. Brunson, pers. comm., 1993). Old sites were in Clearwater National Forest, Nez Perce National Forest, Nez Perce Tribe lands, Lolo National Forest, possibly Kaniksu National Forest; and the Panhandle National Forests. We have (1991, 1994) unsuccessfully tried the old sites in the vicinity of Coeur d' Alene, Cataldo, and Old Mission. The Mission Creek site is still viable, though threatened by quarry expansion (see discussion under Cryptomastix magnidentata in Frest \& Johannes, 1995). For another old site, see Branson, Sisk, \& McCoy (1966).

In the Lower Salmon River survey area, we have noted the species at only 3 sites; one of these (102) was likely extirpated in 1994. All three sites are along White Bird Creek (Appendix C52). The species is uncommon at the 2 remaining sites. Similar habitat elsewhere in the area (e.g., along Rock Creek and its upper tributaries; along Papoose Creek or Squaw Creek) lack the taxon; and we have not found it as yet at higher elevation sites in Nez Perce National Forest.

Threats: Logging and grazing over most of known and potential range; the species is restricted to rather moist sites, generally in exceptionally botanically diverse and intact forests. Logging of relatively intact moderate-elevation Douglas fir forest; grazing of much of the logged terrain; highway construction and other river right-of-way impacts; severe forest fires. This species was probably once very common and widespread. It has lost most of its habitat and most historic sites; but a fair number of other sites probably remain viable. We have found it only very locally abundant.

Threats to local sites include road grading construction and expansion of White Bird (responsible for the demise of 1 site in 1994), logging, and brush clearing. One of the White Bird sites is the putative type locality for Oreohelix vortex (q.v.).

Criteria for inclusion: This regional endemic species is definitely declining in terms of remaining habitat and population size. Some old sites are known to be extirpated. Most historic sites are on federal lands, including Nez Perce National Forest, Clearwater National Forest, the Idaho Panhandle National Forests, and Umatilla National Forest. Sites occur on Nez Perce Tribe and BLM lands as well. Because this taxon originally had a rather extensive range, and because we have not had the opportunity to recheck all old sites, we are not recommending listing at present. One should note, however, that the whole family or subfamily to which it belongs (Ammonitellinae) is rare and thought to have a relict distribution. Several members of this group are either federal listing candidates or have been suggested for listing, including members of all other ammonitellinid genera (Megomphix, Ammonitella, Polygyroidea, and Glyptostoma). Treated as a Watch List species in Frest \& Johannes (1995a).

Recommended status: We do not recommend federal or State (WA, OR, ID, MT) listing at this juncture; however, it should be regarded as a sensitive species by Forest Service, BLM, and other land management and wildlife agencies. Locally, it is very rare (Table 4) and in some danger of extipation.

References: Pilsbry (1939); Frest \& Johannes (1995a); Deixis collections, 1988-1994. 


\section{Radiodiscus (Radiodomus) abietum Baker, 1930 fir pinwhe日l APPENDIX C56}

Type locality: Near the mouth of the East Fork of the Weiser River, on Stevens Ranch, Adams Co., ID. Holotype ANSP 149979a; paratypes 149979.

Description: See Baker (1930) and Pilsbry (1948) for description and illustrations. This mediumsized species is much larger and has a comparatively smaller umbilicus than the Southwestern Province Radiodiscus millicostatus. Anatomy of the two nominal subgenera is rather different, and each is monotypic.

Ecology: Generally found in rather moist, rocky forested terrain, at medium-high elevations. Most often, the dominant vegetation is Pseudotsuga menziesii forest, with a rich understory including many forbs, deciduous shrubs, and bryophytes. The species has also been found in Thuja stands. Moist valley, ravine, gorge, or talus sites are preferred, i.e. low on a slope and near permanent or persistent water, but not normally subject to regular or catastrophic flooding. Persistence of moisture is a desideratum. The regolith is variable, ranging from basalt to schist to limestone. Common associates include Allogona ptychophora ptychophora, Cryptomastix mullani subspp. and other Cryptomastix spp., larger mesophile Oreohelix spp., Polygyrella polygyrella, and slugs such as Hemphillia camelus and Zacoleus idahoensis. A mesophile species, apparently feeding on partly decayed leaves and organic debris in soil. The Lower Salmon River occurrence seems more or less typical in ecology and associates (for latter, see Table 3); Oreohelix strigosa n. subsp. 1 is present at the site.

Original distribution: Old sites for this species included the Blue Mountains, WA and OR; a string of western ID and D Panhandle counties (Bonner, Kootenai, Shoshone, Clearwater, Nez Perce, Idaho, and Adams); extreme NE WA (Ferry Co.: T. Burke, pers. comm., 1994); and part of NW MT (Lincoln, Sanders, Lake, Mineral, Ravalli, \& Missoula cos.; Brunson \& Russell, 1967). River valleys involved included the upper Weiser, Little Salmon, Salmon, Hells Canyon, Coeur d'Alene, St. Joe, Clearwater, Lochsa, Selway [all Snake tributaries), Flathead, Kootenai, Clark Fork, and Bitterroot. Sites on public lands include ones in Payette, Nez Perce, Clearwater, and the Panhandle National Forests. Some notion of relative rarity can be gauged from this study ; we found this species at a single site.

Current distribution: Known to survive at several sites in NE WA (T. Burke, pers. comm., 1994); we have unsuccessfully rechecked most of the old ID sites, finding it extirpated in all but one. On the other hand, we have collected this species in several sites recently; mostly remnant moist forest patches at moderate elevations.

Thus far, we have noted this species at only one Lower Salmon River drainage site, at moderate elevation in the Papoose Creek drainage (site 180: Appendix C56; see also Appendices $A$ and $B$ ). It is thus very rare locally, although other sites, particularly in Nez Perce National Forest, are possible. The species was absent at several seemingly suitable sites in this area, however.

Threats: Logging of relatively intact moderate-elevation Douglas fir forest; grazing of much of the logged terrain; highway construction and other river right-of-way impacts; severe forest fires. This species was probably once very common and widespread. It has lost most of its habitat and most historic sites; but a fair number of other sites probably remain viable. We have found it nowhere 
abundant. The only local site has been largely logged; and this species was found only in a small rocky area not completely clear-cut.

Criteria for inclusion: Regional (primarily eastem portion of the Washingtonian Province and a very limited area of the Rocky Mountain Province) endemic; mature forest species; occurrence on public lands; riparian associate. Treated as a Watch List species in Frest \& Johannes (1995a).

Recommended status: Formal Federal or State (WA, OR, ID, MT) listing is probably unnecessary at this point. However, this species should be considered sensitive by Forest Service, BLM, and other appropriate federal and state land management and wildlife agencies. It is likely very rare on BLM lands in the area, and should probably be afforded protection.

References: Baker (1930); Pilsbry (1948); Brunson \& Russell (1967); Frest \& Johannes (1995a); Deixis collections, 1988-1994.

\section{Zacoleus idahoensis Pilsbry, $1903 \quad$ sheathed slug APPENDIX C61}

Type locality: Meadows, Washington Co., Idaho; holotype ANSP 87493a.

Description: See Pilsbry $(1903,1948)$ for best description and illustrations; see also illustration in Burch \& Pearce (1990).

Ecology: This species is a moderate mesophile-notophile, which can sometimes be found also in somewhat more xeric sites. Most sites are in relatively intact and florally diverse forests, generally Douglas fir, spruce, or Ponderosa pine, with a rich understory including many forbs and bryophytes. It most often occurs at moderate-high elevations. At high elevation sites, forests may be more open, and nonvascular plants a more significant component of the flora. Moist valley, ravine, gorge, or talus sites are preferred, i.e. low on a slope and near permanent or persistent water, but not normally subject to regular or catastrophic flooding. Persistence of moisture is a desideratum. It has been noted with many other land snail and slug species, including Hemphillia camelus, Magnipelta mycophaga, Allogona ptychophora ptychophora, Allogona lombardii, Polygyrella polygyrella, various Cryptomastix species, including mullani mullani, Anguispira kochi occidentalis; and Anguispira nimapuna.

The local occurrences are typical, with high-diversity land snail faunas (Table 3 ) in wellforested situations with a nearly closed canopy and persistent moisture. Limestone is the substrate here; but the taxon is not so restricted elsewhere in its range.

Original distribution: Lower Salmon-Little Salmon River drainage, Clearwater (including Lochsa and Selway) River drainage, Coeur d'Alene (including St. Joe) River drainage, Washington, Adams, Idaho, Bonner, Kootenai, Shoshone, and Clearwater cos., ID; Clark Fork River drainage, Sanders Co., MT. Old sites are in the Idaho Panhandle National Forests, Clearwater National Forest, Nez Perce National Forest, Payette National Forest, and Lolo National Forest, as well as on BLM and other lands in this same region.

Current distribution: Still occurs at scattered sites in the original distribution. Collected recently (1989-1994) at a few sites in the Lolo Pass area; Coeur d'Alene drainage; and Clearwater drainage. During this survey, the species was noted at 2 sites in the middle Slate Creek drainage (Appendix C61). We did not find it at our Little Salmon River sites, although it has been recorded from this drainage previously. 
Threats: Logging and grazing over most of known and potential range; the species is restricted to rather moist sites, generally in exceptionally botanically diverse and intact forests. Logging of relatively intact moderate-elevation Douglas fir forest; grazing of much of the logged terrain; highway construction and other river right-of-way impacts; severe forest fires. This species was probably once very common and widespread. It has lost most of its habitat and most historic sites; but a fair number of other sites probably remain viable. We have found it only very locally abundant. It is less sensitive than the more clearly notophile slug genera, such as Prophysaon and Hemphillia.

Threats to local sites are similar, and include road building and maintenance, limestone quarrying, and grazing. Much of the potential habitat area has been logged and is now grazed; the species is absent from such sites. Historic sites along the little Salmon River and lower John Day Creek appear to have been extirpated. We consider the taxon locally to be very rare and in need of protection.

Criteria for inclusion: Local endemic; occurrence on public lands; loss of historic sites; loss of most habitat. Treated as a Watch List species in Frest \& Johannes (1995a).

Recommended status: This slug has none at present. It should be considered a sensitive species by the Forest Service, BLM, and other federal and state land management and wildife agencies, e.g. in $\mathrm{D}$ and $\mathrm{MT}$. However, enough sites are likely to exist as to not require federal listing at this time.

References: Pilsbry (1903, 1948); Frest \& Johannes (1995a); Deixis collections, 1990-1994.

\section{NONSENSITIVE SPECIES}

Discussed below are those land snail species encountered during this survey which are not regarded as Sensitive or Watch List species in the sense employed herein, i.e. rare or seriously declining, with some palpable danger of extinction throughout the Interior Columbia Basin. These taxa are generally widely distributed (often cosmopolitan or regional endemic [Washingtonian Province] and currently are in no serious danger of complete extinction. Local status of these taxa (within the survey area) may differ considerably. Accordingly, a discussion of each is included here, in much condensed format as compared to the foregoing. Local status is emphasized; for more comprehensive discussions of the geographic range of these taxa, and their distribution and ecology, consult the literature. 
This taxon is still widely distributed in eastern WA, northern ID, eastern OR, and western MT. It is also the most commonly encountered larger land taxon in the Lower Salmon River Valley, with over 79 sites (Table 3; Appendix C4) scattered through the survey area. While a number of deadonly sites were noted (Table 4) and considerable site loss has occurred, here as elsewhere, this taxon is in no present danger of local extinction. Although this subspecies does prefer somewhat xeric habitats, the most xeric are inhabited by the subspecies solida (q.v.) and the species is common in dry-moderately wet forested sites as well. No substrate preference is obvious; and talus piles are especially good habitat, particularly if springs or seeps are nearby. A wide variety of plant taxa were noted at sites with this species; and it occurs through a broad elevation range.

Considerable variation was noted in Lower Salmon populations in terms in shell morphology, body color, and anatomy; and it is quite possible that the nominate subspecies is actually a species complex; this point requires further investigation. Montana populations (which include the type locality) are seemingly not as variable.

\section{Anguispira kochi occidentalls (Von Martens, 1882) suggest western giobe APPENDIX C6}

no common name: we

This taxon is widely distributed in the Rocky Mountain and Washingtonian provinces, with isolated Oregonian occurrences as well. Most typically, it is a mesic land snail particularty characteristic of moderate-high elevation coniferous and mixed coniferous-deciduous forests. No substrate preference is evident. The more xeric occurrences, e.g. in the Columbia Gorge, OR-WA have been termed Anguispira kochi eyerdami, a taxon which could be valid, based on present knowledge. Local sites are similar in ecology and few in number ( 5 only: see Table 4 and Appendix C6). Common associates generally are other mesic forest snails, such as Cryptomastix mullani mullani and mullani olneyae; Allogona lombardii, and such species as Oreohelix subrudis and Hemphillia camelus. In the Lower Salmon River area, occurrences are similar in associates and ecology; but may include local endemics such as Cryptomastix mullani latilabris, Oreohelix haydeni hesperia, or Oreohelix n. sp. 22.

As might be expected, forest habitat with this species is currently quite limited in the Lower Salmon River area; and occurrences are at higher elevations or in relict, mature forest areas. This taxon is in no danger of extinction generally; but is rare locally, and could be extirpated in this region if care is not taken with existing sites. Most surviving sites are likely at moderate elevations on Forest Service lands.

\section{Cochlicopa lubrica (Müller, 1774) APPENDIX C8}

glossy pillar

This small land snail is Holarctic in distribution. In many areas, it is a synanthromorph (e. g., western WA) and is found in a variety of habitats, covering a broad range of substrates and elevation. Locally, it has been noted from 12 sites (fairly frequently for a small species), mostly rather xeric or mesic. These localities are fairly scattered over the survey area along the main Salmon River 
corridor (Appendix C8). It is associated with a variety of large and small taxa (Table 3), making succinct faunal characterization difficult. The glossy pillar is also widely distributed in the Oregonian, Washingtonian, and Rocky Mountain provinces, as well as in eastern North America. There is no danger of regional extinction and little of local extirpation, and we regard the species as locally common.

\section{Cryptomastix (Cryptomastix) mullani mullani (Bland \& Cooper, 1861) Coeur d'Alene oregonian APPENDIX $\mathrm{C13}$}

This regional endemic (Washingtonian and Rocky Mountain provinces) is still common in scattered sites within the historic range and is in no danger of extinction currently, despite the loss of some historic sites and widespread environmental modifications through much of its known area of occurrence. It is not, however, particularly widespread in the survey area (4 sites [Table 3)), although locally common. We regard it as rare in the Lower Salmon River Valley, and most likely to be found at moist mature forest sites at moderate to high elevations.

This mesophile taxon is often found associated with Oreohelix strigosa depressa and related forms; Anguispira kochi occidentalis; and Allogona ptychophora ptychophora. As such sites are now rare in the survey area, we do not expect large numbers of additional sites on BLM lands, although populations on National Forest holdings are quite possible.

\section{Cryptomastix mullani olneyae (Pilsbry, 1891) Spokane oregonian \\ no common name: we suggest APPENDIX C14}

Like the foregoing taxon, this subspecies of mullani is a common and widespread regional endemic, characteristic of somewhat mesic-slightly xeric, often forested sites in the Washingtonian and Rocky Mountain provinces. It has been reported previously from the survey area. We found it at 22 sites scattered loosely over the whole survey area (Appendix C14); most colonies are on major tributaries, rather than very near to the mainstem Salmon River. Land snail associates are much more varied locally than typical for sites with the subspecies and include numerous mesic species of Oreohelix and Cryptomastix, plus such taxa as Allogona ptychophora ptychophora and Anguispira kochi occidentalis (Table 3). As with localities elsewhere, the regolith is varied, and the taxon has been reported from a wide range of elevations.

We regard this subspecies as locally common and in no present danger of extinction, here or in most of its historic range (Table 2). 


\section{Discus whitneyi (Newcomb, 1864) forest disc APPENDIX C20}

This species is recorded in the literature almost invariably as Discus cronkhitei (Newcomb, 1865); the current species concept is due to Roth (1987). This taxon is Holarctic and widely distributed in the eastern U.S. (Hubricht, 1985). it is less frequent in the western U.S., but still widespread and in no danger of extirpation.

Despite the common name, this species is found in a wide range of habitats, including swamp and floodplain edges and prairies, as well as forests. Generally, it is found in relatively moist places. We found it to be very rare in the Lower Salmon Valley (2 sites: Tables 2- 4). Both were at moderate elevations, in relatively moist situations, and some distance from the mainstem Salmon River (Appendix C20). We think it is very likely that many other sites exist at higher elevations in the study area, so that local extipation is not likely to be a problem. However, three things should be noted about Lower Salmon River populations. The first is the species' apparent absence from the many spring-associated sites we collected at lower elevations. The second is the lack of $D$. whitneyi in litter samples from the area (see Table 3 and Appendix 1). Finally, live specimens from the Slate Creek drainage (site 176) appear to differ in shell morphology and body color from any other lots we have seen, and our ascription of material from this site to Discus whitneyi is only tentative. The local status of this species requires further investigation.

\section{Euconulus fulvus alaskensis Pilsbry, 1906 no common name: we suggest western hive APPENDIX C21}

The western hive is widely distributed and locally common in the Oregonian, Washingtonian, and Rocky Mountain provinces. Often overlooked in the literature, this taxon is readily distinguished by the fine but distinct radial ribbing on the upper half of the shell. Most literature references to Euconulus fulvus in the coastal Pacific states refer to this taxon; and the nominate subspecies is rare in the Rocky Mountain states, in our experience.

This subspecies, like most Euconulus, occurs in moist leaf litter in forests, floodplain edges, and prairies and meadows at a wide range of elevations. We found it at only 5 sites (Tables 3-4) in the survey area, from which it had not been previously reported (Table 1). Sites are along main tributaries as well as the Salmon River proper (Appendix C21). More detailed litter sampling would probably tum up additional sites, particularly at higher elevations. We regard it as uncommon in the Lower Salmon River area, but as likely in no danger of local extinction. The subspecies' subpopulations appear healthy throughout most of its range.

\section{Hawalia minuscula (Binney, 1840) minute gem APPENDIX C22}

While this small species is quite widespread geographically, and something of a synanthromorph, it is not particularty abundant or common in western U.S. sites (see, e.g., Branson, 1977, 1980; Branson \& Branson, 1984). Locally, we found it rarely at a total of 8 sites (Tables 3,4). Locality distribution was sporadic through the central part of the survey area, with sites both along the mainstem Salmon River and major tributary streams (Appendix C22). The habitat ranges from 
rather dry talus to moist forested situations; and this species was probably overlooked at some sites because of its small size.

Hubricht (1985) regards it as a species of bare ground situations and did not find it in leaf litter. We have found it in such samples quite frequently, both in forest and prairie situations, both in the Midwest and westem U.S. While in toto, it is ranked as very rare locally (Table 2), it is unlikely to be extirpated by human activities and should not be regarded as a Sensitive species.

\section{Helicodiscus salmoneus Binney, 1886} APPENDIX C23

Salmon coil

This is the most widespread of the smaller land snail species in the Lower Salmon River Valley. As the name implies, the type locality is in the Lower Salmon River valley, and it has long been regarded as characteristic of this area. No very precise site has yet been designated (Figure 2); although there is a need to do so. We found it at 34 sites (Table 3), rather impartially distributed through the survey area (Appendix C23), in terms of both elevation and stream size. This species seems to be more distinctly xerophile in its habitat preferences than are many of the eastern U.S. species. Most sites were in taluses or rock outcrops at low to moderate elevations; typically, localities were comparatively dry and open and in sage scrub.

East of the Mississippi a number of Helicodiscus species occupy the Cumberland and Interior provinces; diversity of the Helicodiscidae is quite limited in the western U.S., with this species and Speleodiscoides spirellum the only native taxa. Helicodiscus salmoneus is widespread in the eastern part of the Washingtonian mollusk province; and this regional endemic is probably currently in no danger of extinction, regionally or locally.

\section{Microphysula ingersolli ingersolll (Bland, 1874) APPENDIX C25}

spruce snail

This small taxon is of scattered but relatively common occurrence in part of the western U.S., especially the Washingtonian Province. The genus as a whole is characteristic of the Western Division provinces. The subspecies is most often found in talus and rocky area, often forested but somewhat dry- the taxon is best characterized as a mesophile-slight xerophile. Its Oregonian Province counterpart, $M$. cookei, appears to be a forest mesophile. Perhaps because of the scarcity of such habitats in the Lower Salmon River area, the species is very rare locally (Table 2). We found it at only 3 sites, situated between Riggins and Slate Creek and off the Salmon River proper.

We see little danger of complete extipation of this taxon; but local extinction is a distinct possibility unless known or other sites are protected. 
This is primarily a species of the Oregonian and Washingtonian provinces, only recently reported from northern California (Roth, 1987) and not previously known from this area. This small taxon is mostly a forest snail, especially common in moist lowland areas and frequently encountered in litter samples. Its preferred habitat is rare in the Lower Salmon River Valley; and the western flatcoil is thus predictably rare locally. We found it live at a single site (Appendix C51). This site is also the only local locality for Punctum pusillum (q.v., below).

On a broad scale, much suitable habitat remains for this species even though the majority of forest in its range has been logged, and the species is not currently in danger of extinction. Local extirpation, however, is quite possible. We expect that sites remain on Nez Perce National Forest holdings, although our sites there so far have not had this species.

\section{Punctum (Toltecia) pusillum (Lowe, 1831) striate spot APPENDIX C54}

This is the taxon that, until the recent work of Roth (1986a), was known as Punctum conspectum (Bland, 1865). Roth presents strong reasons for regarding the West Coast specimens as examples of the European species. Most typically, this very small species is found in moist and shaded forest environments in the Pacific Northwest. It is most easily collected in numbers in litter samples. While the striate spot has lost most of its habitat, it is currently in no danger of extinction, in part because of its status as a regional endemic with a comparatively broad areal distribution.

It nevertheless is very rare locally. We found the species live at a single site (41: see Appendix A and B, Appendix C54 for details), associated with Planogyra clappi, Cryptomastix harfordiana, and Allogona ptychophora ptychophora (Table 3). The locality is unusually moist and mossy for a lowland Salmon River site; most such previously existing have been cleared or otherwise modified. Partly as a result of wholesale habitat change, we regard it as very rare locally and in real danger of extinction on BLM lands. Interestingly, we have not found it on higher elevation forested sites in Nez Perce National Forest as yet.

\section{Pupilla hebes (Ancey, 1881) crestless column APPENDIX C55}

This small pupillid is a regional endemic, especially characteristic of the eastem part of the Washingtonian Province and portions of the Rocky Mountain Province. It is most typically found in somewhat open, dry, and rocky habitats, generally at lower elevations; but is absent from very dry sites. It sometimes occurs in mountain meadows. Little substrate preference is evident. Associates may include a variety of small and large taxa, such as Vallonia cyclophorella, Cochlicopa Iubrica, Helicodiscus salmoneus, Vertigo spp. such as modesta, various Oreohelix spp., Allogona ptychophora ptychophora, etc. Local occurrences with Cryptomastix harfordiana and Cryptomastix n. sp. 5 are frequent.

Lower Salmon River occurrences are fairly typical, although the genus Vertigo is very rare locally. This taxon was noted at 9 sites in the area from the mouth of the Rapid River north to a point between the mouths of Rock Creek and White Bird Creek (Appendix C55). It is uncommon 
in the region generally (Table 2), but is in no substantive danger of local extipation. Sites are mostly on the Lower Salmon River proper; but sites at moderate elevations in major tributaries are known also.

\author{
Vallonia cyclophorella (Sterki, 1892) silky vallonia \\ APPENDIX C58
}

This very small taxon is typical of certain of the Westem Division Provinces, in particular the Rocky Mountain and Washingtonian. The species can tolerate rather strongly xeric and open situations, and is found frequently in talus, in rocky areas, on floodplain edges, and in grasslands. It is associated with a range of small and large taxa (for associates here, see Table 3), including Pupilla hebes, Cochlicopa lubrica, Discus whitneyi, Allogona spp., and various Cryptomastix and Oreohelix species. It is particularly likely to be found along edges on boulders and rock faces and at the base of rock taluses.

This was one of the more common taxa encountered during our study. The 14 sites are scattered through most of the survey area, especially but not exclusively along the mainstem Salmon River (Appendix C58). This species is in good condition generally throughout its range, as it is here also, and in no need of special protection.

\title{
Vertigo concinnula Cockerell, 1897 mitered vertigo APPENDIX C59
}

The mitered vertigo is a significant regional endemic, particular to portions of the Washingtonian, Southwestern, and Rocky Mountain Province. This species is associated with springs and seeps in drier areas and does not seem to be a forest species. Most Vertigo species are mesophiles or notophiles; some, like this one, can tolerate comparatively dry and open habitats if sufficient moisture is available. Although there are a number of springs in the survey area, we did not find it at most; however, the 2 known occurrences (Appendix C59) in the Rock Creek drainage are
rather typical occurrences.

We have collected this species at a scattering of sites across its old range. While most formerly favorable habitat has been lost, due to a combination of grazing, spring modification or diversion for agricultural and stock usage, and other human activities, it seems unlikely that this species is currently in any danger of extinction. Locally, however, it seems very rare; both known sites have been impacted by road construction and grazing; and local extipation is quite possible.

\section{Vitrina alaskana Dall, 1905 western glass-snail APPENDIX C60}

This thin-shelled semislug is listed under the European Vitrina pellucida (Müller, 1774) in Turgeon et al. (1988). This may be reasonable; but we prefer to maintain traditional usage for the time being. Rather cosmopolitan in western North America, this taxon has been reported from a variety of habitats, ranging from muskeg and near-tundra situations to fairly xeric habitats. No easy 
characterization of associates is possible. Locally, most sites are quite open and xeric, with rock (especially basalt) talus being especially common; and vegetation ranging from nearly none to grasses and sage scrub. It also occurs locally on rather moist, north-facing slopes in partly open Ponderosa pine forests.

The westem glass-snail is usually seen in small numbers at particular sites. Its life history is unusual, with activity sometimes continuing into winter. We see most specimens in early spring. It is locally common; the 17 occurrences noted (Tables 3,4) are widely distributed through the survey area, with nearly all, however, at sites along the mainstem Salmon River (Appendix C60). This taxon is relatively secure throughout its range, as far as we are aware.

\section{Zonitoides arboreus (Say, 1816) quick gloss
APPENDIX C62}

This cosmopolitan taxon is perhaps the most widely distributed land snail species in North America. It is considerably less frequent in the western U.S. than in the east; but has been recorded from all of the western states, generally at a number of sites (Hubricht, 1985, p. 32, 137). The quick gloss has been recorded from a variety of habitats. In the western states, it is something of a synanthromorph but also found in open woods, along floodplains, and in swampy areas or near springs

Zonitoides arboreus seems to be very rare in the survey area. It was noted at a single site, a spring on a north-facing slope, east of Riggins (Appendix C62). This species is probably one of the most secure native land snail taxa in the United States. its rarity in this area was surprising, particularly its absence from litter samples.

\section{SPECIES OF UNCERTAIN STATUS}

We here deal with a few taxa whose taxonomic affinities and/or occurrence in the survey area could not be resolved during this survey. Typically, such taxa belong to poorly-studied families such as the Succineidae.

\section{Catinella avara (Say, 1824) suboval ambersnail APPENDIX C7}

Snails ascribed to this very widespread taxon [e.g., see Hubricht (1985)] are known locally from about 8 sites (Table 4), mostly limited to the river stretch between Riggins and the mouth of Slate Creek (Appendix C7). At all of these sites, the species was rare; and at most it was represented by dead specimens only. This succineid elsewhere is typically found in low, wet situations, such as edges of marshes, swamps, and floodplains; these can range from quite open to heavily shaded. The local occurrences are in quite xeric taluses, on ether basalt or limestone regoliths, and 
typically very open. We ascribe the material collected so far to this taxon with strong reservations; the shell characters are similar, but only one or two live specimens were collected. The ecology suggests that this is almost certainly another species. Unfortunately, western U.S. succineids are very poorly studied. This taxon is likely a local endemic. Most eastern U.S. succineids occur in similar habitats, i.e. are notophiles; but xeric forms are quite widespread in the western U.S., as in Hawaii.

This taxon is very rare bcally; and while listing status cannot be resolved on present information, it is obviously in some need of protection in the Lower Salmon River corridor. Common associates here are such species as Oreohelix idahoensis idahoensis and Cryptomastix harfordiana.

\section{Cryptomastix (Cryptomastix) mullani hemphilli (Binney, 1886) no common} name: we suggest Hemphill oregonian

This subspecies was ascribed to the survey area by Pilsbry (1940). We were unable to collect this taxon locally, either at the reported site or elsewhere in the survey area. Examination of museum lots indicates that at least some sites have populations characterized by a nearly completely covered umbilicus, and it is quite likely that this subspecies is valid; however, other localities accepted by Pilsbry are essentially indistinguishable from mullani olneyae.

We have inadequate material at hand from sites elsewhere in the reported range to resolve the status of this subspecies; but doubt its continued presence in the Lower Salmon region, except perhaps very rarely. Should a live site be discovered, the colony should be protected.

Deroceras sp.

no common name: fieldslug APPENDIX $\mathrm{C} 18$

Slugs belonging to this genus are in need of revision in the western U.S. Several species have been ascribed to the area; while we are able to eliminate most, the small number of live specimens collected during this survey has precluded definitive species-level identification. The 4 occurrences (Table 3) are clumped into two disjunct areas (Appendix C18), one on the Lower Salmon River itself near the mouth of Slate Creek (Horseshoe Bend area) and the other on a tributary of Rock Creek. The two areas have in common the presence of springs and unusually moist habitat at comparatively low elevations.

Most western species of Deroceras are not in any imminent danger of extinction, with the possible exception of Deroceras monentolophus and D. hesperium (for the latter, see Frest \& Johannes, 1993; for the former, Pilsbry, 1948). However, the genus is evidently very rare locally, in part due to lack of suitable habitat; and the status of the Lower Salmon River examples needs further study to resolve species identity and distribution. 


\section{Succinea stretchiana Bland, 1865 Sierra ambersnail \\ APPENDIX C57}

This moderate-sized western U.S. succineid was classified as Catinella in Turgeon et al. (1988); we prefer to retain Pilsbry's (1948) assignment for the time being. The is one of a group of poorly understood western succineids which are more or less characteristic of semi-xeric habitats. Pilsbry reports various sites from Wyoming, Nevada, Utah, Idaho, and California, with most localities in the latter. Reexamination and anatomical characterization of this taxon, and more particularly of non-Califomia lots, is highly desirable. The unusual ranges suggests that more than one taxon is involved.

We have not seen material definitely attributable to this species elsewhere in Idaho. It seems to be very rare in the Lower Salmon River area, and was not recorded here previously. We found it at 2 sites only (Appendix C57), in the Slate Creek-John Day Creek portion of the mainstem river corridor. Both sites had dead specimens only. Both were strongly xeric locales, dry, open, and rocky, with sage scrub vegetation. We are unable to confirm live occurrence of this taxon presently.

\section{FRESHWATER TAXA}

Freshwater mollusks were beyond the scope of our contract. Nevertheless, we have collected these from time to time in the survey area recently; and this drainage has been a source of freshwater material for the same period of time as it has been for the better-known terrestrial mollusks. Moreover, there are several endemic or rare taxa present in the Lower Salmon River drainage. Certain of these taxa are current federal listing candidates, o should be considered for formal federal listing, and have been recommended for such listing previously. Hence, while we do not consider our results definitive or complete, some observations are made here on a number of species. We do not include specific site information or maps here except occasionally. For further information, see Frest \& Johannes $(1993,1995 \mathrm{a})$ or individual species references.

\section{FRESHWATER SNAILS}

\section{Fisherola nuttalli (Haldeman, 1843) shortface lanx}

Type locality: "Lower Columbia River" near the old mouth of the Willamette River near Portland, Multnomah Co., OR (could have been from the Willamette River itself also: see Frest \& Neitzel (in 
press, a)); Holotype of Ancylus crassus=Fisherola nuttalli ANSP 124320; paratype of Ancylus crassus ANSP 350079 (both said to be from Spokane River, WA); other Nuttall specimens USNM 169958 , from the Willamette River near Portland, OR.

Description: The best description and illustrations are those of Frest \& Neitzel (in press, a); see also Burch (1989).

Ecology: Generally found in unpolluted swift-flowing, highly oxygenated cold water on stable boulder-gravel substrate, often in the vicinity of rapids, in small to large rivers. Macrophytes are generally rare to absent at sites with this species, as are epiphytic algae. This species sometimes occurs with Fluminicola columbiana. For details, see Frest \& Neitzel (in press, a).

Original distribution: Formerly widespread in the lower Columbia River, Snake River, and a few major tributaries, WA-OR-ID-MT-BC. For details, see Frest \& Neitzel (in press, a). Most of the old sites are known to be extirpated, e.g. Frest \& Johannes (1993); Neitzel \& Frest, 1989, 1993; Frest \& Neitzel (in press, a).

Current distribution: The lower Columbia River populations are largely extinct due to habitat modification caused by Bonneville Power Administration [BPA] dams and impoundments, although one occurrence is known near Bonneville Dam (from NMFS collections, 1990) and another near the mouth of the Columbia: still survives in the Hanford Reach, WA; the lower Deschutes River and the John Day River, OR; part of the Snake River (middle Snake, ID; Hells Canyon, OR-ID); the Salmon River, ID, and the Methow and Okanogan rivers, WA; see Neitzel \& Frest $(1989,1992,1993)$, Frest \& Neitzel (in press, a), and Frest \& Johannes (1991a, b; 1993c) for details. Many of these areas are on (or influenced by management practices on) federal lands, e.g. Hanford Site (DOE), Deschutes Wild and Scenic River, Hells Canyon National Recreation Area; Okanogan National Forest; Gifford Pinchot National Forest; Mt. Hood National Forest; and Bonneville Power Administration.

This taxon locally is confined to the lower Salmon River . it does not occur in the Rapid River, Little Salmon River, or Salmon tributaries. In the Salmon, we have not found it beyond the western portion of the River of No Return. East of Riggins, it is very sporadic; but colonies are found in major rapids areas, such as Music Bar and Ruby Bar. The species is (or was) more generally distributed in gravel and cobble areas from above Riggins to the river mouth. It is absent from sites that have been dredged, subjected to hydraulic gold mining, or have bedrock substrate.

Threats: Impoundment and damming of much of the original habitat; sedimentation; orchard runoff; nutrient enrichment due to agricultural practices; pulp mill effluents; metal smelting residues and discharges. In addition, gravel and gold mining are significant local threats.

Criteria for inclusion: Riparian associate; current federal candidate; occurs on public lands. Treated as a Sensitive species in Frest \& Johannes (1995a).

Recommended status: This species has no special status at present. It should be considered a sensitive species by the Forest Service, BLM, and other land management and wildlife agencies. NPS (1994) seems barely aware of this taxon. Recommended as Federally Threatened; Threatened in WA; Threatened in OR; Endangered in MT; and Endangered in ID. Note extensive recent surveys specifically for this taxon. Currently (and inexplicably only) a Category 3 Federal candidate USFWS, 1994). Recommended for listing by Frest \& Johannes (1991b, 1993c, $1995 a)$. USFWS recently rejected a petition to upgrade the status of this species.

References: Taylor (1982a); Neitzel \& Frest (1989, 1990, 1992, 1993); USFWS (1991, 1994); Frest \& Neitzel (in press, a); Frest \& Johannes (1991a, b; 1993b, c, 1995a); Deixis collections, 1987-1994. 
Type locality: Type not located with certainty; type locality "Oregon"; claimed (Baker, 1964) holotype and paratypes (ANSP 27772, 27774) may not be (see Hershler \& Frest (in press); lectotype and paralectotypes of Amnicola hindsi Baird, 1863, type locality "River Kootanie" [sic. Kootenay River, British Columbia], BMNH 1863.2.4.17A, 1863.2.4.17, to be designated by Hershler \& Frest (in press); lectotype of Fluminicola columbiana Hemphill in Pilsbry, 1899 ANSP 27767; type locality Columbia River, probably at Wallula, Wala Walla Co., WA. Coan (1985) and Coan \& Roth (1987) ascribe the species to Keep (1887) as Fluminicola nuttalliana columbiana Keep, 1887, unlike essentially all other authors. They may be technically correct (ICZN, 1985, Articles 10-12, 50), for even though the name is first mentioned in Hemphill (1881), it was there unaccompanied by a description, definition, or indication; and a short description is supplied in Keep (1887). However, the situation for this and other Hemphill and Carpenter species described under similar circumstances may not be so straightforward.

Contra Coan \& Roth $(1987$, p. 327$)$, there is no compelling reason to believe that Fluminicola nuttalliana columbiana Keep, 1887 is the same as Fluminicola columbiana Hemphill in Pilsbry, 1899 [more properly, Fluminicola columbiana Pilsbry, 1899, according to ICZN (1985) rules, if it is assumed that the description in Pilsbry (1899) was written by Pilsbry and not derived from communications with Hemphill; in the latter case, the traditional usage would be correct], even if both were derived from Hemphill lots. According to Coan \& Roth (1987, p. 322) Hemphill "lumped together under a single locality specimens from numerous stations". If this is so, the only way to be even reasonably certain that the specimens in Keep's collection were the same taxon as other Hemphill specimens ascribed by Hemphill to the same taxon, let alone from the same locality, would be by direct comparison. Moreover, the types for the 1887 names would have to be drawn from the material in Keep's possession, e.g. "if, on the other hand, a name was made available by "Pilsbry, ex Hemphill MS", or the like, then the converse is the case: supposed Hemphill syntypes have no standing: the type material is only that which Pilsbry (or some other author) consulted" (Coan \& Roth, 1987, p. 324). We agree that this follows from Coan \& Roth's assumptions; but in this case, much of the type material accepted by Coan \& Roth (1987) is incongruent with their choice of author and date for the involved taxa. As far as we can determine, no Keep types for these taxa were originally designated; nor are Keep type lots, from which valid subsequent designations could be made, known to exist (Coan, 1985); this is not surprising, as Keep was not a taxonomist. It is also quite possible that the description used by Keep (1887) derives from Hemphill; in which case the only real addition by Keep is publication. Under such circumstances, the name would be validated; but as Hemphill in Keep, 1887. Further, the descriptions in Keep (1887) are very brief, so much so as to be only dubiously adequate. Again, Keep's intent should be borne in mind; it was not to provide a scientifically credible description. If the descriptions are inadequate, as sometimes stated by Coan (1985), then the Keep names should at best be considered nomina dubia, or at worst unrecognizable.

It is also questionable that Keep can be considered "alone responsible both for the name and for satisfying the criteria of availability other than publication" (ICZN, 1985, p. 91 [Article 50 (a)]). Keep himself ascribes the names to other authors; and the sources of these names, which include Hemphill (1881), Hemphill labels, Carpenter labels, and a Carpenter ms. [and may well also have included personal correspondence], are known. The same consideration also applies to Pilsbry (1899) in regard to Fluminicola columbiana Hemphill in Pilsbry, 1899. If it may equally be doubted that the ascribed authors, rather than the authors responsible for publication, in these cases satisfy the requirements for availability, this does not particularly enhance the case for ascription to the publication authors, but rather that for considering the names dubious, unavailable at that point, or unrecognizable. 
Keep was essentially a popularizer, not a taxonomist, as his whole published corpus makes dear (Coan, 1985). It is evident that he did not intend to formally describe as new Fluminicola columbiana or any of the other taxa in Keep (1887) whose names are ascribed to him by Coan (1985). The work involved is very obviously intended as a popular-level treatment of already-named taxa. Keep himself ascribed these taxa to other authors; and later workers, almost without exception, did so likewise [note, e.g. that Burch, 1982 assigned Fluminicola columbiana to Hemphill, not Keep as asserted by Coan (1985); this is consistent with Burch \& Tottenham, 1980 and Burch, 1989]. We think that, in the meaning of Article 50, it is clear that responsibility for the Keep (1887) names themselves, other than publication, is due to other authors; hence the species are properly ascribed to these authors, not to Keep. Under these circumstances, it is perhaps better either to 1) retain traditional usage and consider the Keep name for each as a nomen nudum, nomen dubium or species inquirenda; or alternatively 2) to ascribe the names to the original authors as "--.-- in Keep, 1887". If conservation of the "-...-.-- in Keep, 1887" name is desirable, then consideration of either 1) designation of a neotype from material labeled as type material by the species author [not Keep] or reasonably believed to be such; or 2) restriction of the 1887 name to the [missing or nonexistent] Keep types, e.g. as done by Paul (1971) for missing S. A. Miller cystoid holotypes may be preferable.

In short, we argue that the names in question originate with Hemphill or Carpenter; Keep's specimens came from Hemphill or Carpenter; Keep was not a taxonomist; Keep (1887) is not a taxonomic work but a popular work listing what Keep evidently thought were described species; and Keep himself ascribed the species to Hemphill or Carpenter. The first published descriptions of these taxa, which occur in Keep (1887), are so brief as to make it difficult to recognize the species involved, and their authorship is not clear. If the descriptions are inadequate, then Keep's use of the names at best creates a nomen dubium, and traditional usage is correct. The critical question, if the descriptions are accepted as adequate, is their source. If they derive from Hemphill or Carpenter (e.g., letters or mss., such as the one later published as Hemphill (1890)), then publication is the only contribution of Keep to the names; and they should therefore be credited to Hemphill or Carpenter in the format " in Keep, 1887" under the provisions of Article 50 (ICZN, 1985). We regard the descriptions in Keep (1887) as inadequate and clearly not intended to describe new taxa but merely to differentiate them from other described taxa; and would prefer not to recognize the names as validated in the 1887 publication. Much of the justification for the few former usages of Keep names, e.g. Palmer (1958); Ponder (1985); and Coan (1985), in our view derives from usage of the earlier version of the Code (ICZN, 1964), in which the wording of Article 50 is somewhat different.

Description: See Hershler \& Frest (in press) for shell and anatomy. This species until very recently was confused with several other taxa, and most commonly is cited as Fluminicola columbiana Hemphill in Pilsbry, 1899. Fluminicola nuttalliana columbiana Keep, 1891, Fluminicola columbiana (Pilsbry, 1899), and Fluminicola hindsi (Baird, 1863) have been demonstrated to be synonyms (Hershler \& Frest, in press). Cited as Fluminicola columbiana Hemphill in Pilsbry, 1899 in Frest \& Johannes (1993c).

At least one other species of Fluminicola occurs in the Lower Salmon River (Hershler \& Frest, in press). In most cases, the rather flat-sided final whorl, channeled suture, and simple columella of fuscus are sufficient differentiae; but anatomical characters are useful also.

Ecology: Restricted to small-large rivers, in switt current on stable gravel to boulder substrate in cold, unpolluted, highly oxygenated water, generally in areas with few aquatic macrophytes or epiphytic algae. A lithophile and perilithon grazer; and also an amniphile. Sometimes co-occurs with Fisherola nuttalli. For detailed discussion, see Frest \& Neitzel (in press, b). Local ecology is the same; and this species commonly occurs with Fisherola nuttalli in the mainstem Salmon River.

Original distribution: Lower Columbia River and a few of its major tributaries in WA, OR, ID, and BC (and probably MT as well). For details, see Frest \& Neitzel (in press, b). The record in Branson, Sisk, \& McCoy (1966) is erroneous. 
This species probably originally occurred continuously in the mainstem Lower Salmon River from about Ruby Bar to its mouth. Fluminicola in the upstream portions of the Salmon system and in the Little Salmon River are best ascribed to other taxa.

Current distribution: Possibly extinct in the lower Columbia River, WA-OR, and definitely extinct in most of the middle and upper Columbia River, WA, MT, and British Columbia; and in the Payette River, ID; still survives in the Okanogan and Methow rivers, WA; the Hanford Reach, WA; and a limited portion of the Snake River and possibly a few of its tributaries (Frest \& Neitzel, in press, b). Many of the remaining sites are on, or influenced by management practices on, federal lands, e.g. Hanford Site (DOE), Hells Canyon National Recreation Area; Okanogan National Forest; Gifford Pinchot National Forest; Mt. Hood National Forest; and Bonneville Power Administration. Lower Columbia River rocky and free-flowing lotic habitat largely has been eliminated by BPA dams and impoundments; sittation in this area has also been affected by agricultural practices and by clearcutting on adjacent National Forests.

The Columbia pebblesnail is sporadic in its current occurrence in the Lower Salmon River, being confined mostly to undisturbed cobble and boulder bars.

Threats: Impoundment and damming of much of the original habitat; sedimentation; orchard runoff; nutrient enrichment due to agricultural practices; pulp mill effluents; metal smelting residues and discharges. Locally, gravel and gold mining are serious problems.

Criteria for inclusion: Current federal candidate; occurrence on public lands; riparian associate.

Recommended status: Currently a Federal Category 2 candidate (USFWS, 1994). At present has no special or protected status; minimally, this species should be considered sensitive by Forest Service, BLM, and other appropriate land management and wildlife personnel. It should be considered Endangered Federally and in WA, OR, and ID (Frest \& Neitzel, in press). No recommendation is possible for MT at this time. Note extensive recent surveys specifically for this taxon. Recommended for listing by Frest \& Johannes (1991b, 1993a, 1995a). USFWS recently rejected a petition to upgrade the status of this species.

References: Pilsbry (1899); Taylor (1982b); Neitzel \& Frest (1989, 1990, 1992, 1993); USFWS (1991, 1994); Frest \& Johannes (1991b, 1993c, 1995a); Frest \& Neitzel (in press, b).

Type locality: Uncertain, and probably extinct in any case; Kentucky Ferry [sic], Snake River, WA; for information on the likely location of this Hemphill site, see Henderson $(1929,1936 \mathrm{~b})$ and Hershler et al. (1994). Lectotype ANSP 31176; paralectotypes ANSP 368405.

Description: See Hershler et al. (1994) for detailed anatomy and shell description and illustrations. The small, elongate, Bythinella-like conch is unique in western North America. As presently construed, the taxon embraces a wide range of shell morphology. With further study, Pristinicola may prove to be a species group, rather than a monospecific genus. This lithoglyphinid does not appear to be closely related to typical western North American taxa, such as Fluminicola (s.l.).

Ecology: Occurs mostly in very small springs and seeps; sometimes in larger springs, spring runs, or strongly spring-influenced small streams. A crenophile taxon, generally a perilithon grazer and lithophile. Substrate is usually coarse; Rorippa, Mimulus, and bryophytes are the commonly 
associated plants. Most sites are in semiarid areas, in low-medium elevation sage scrub; but Cascades sites are in faity dense Douglas fir forests at low-medium elevations. Often this is the only common freshwater mollusk at a site; the most frequent associates are Pisidium insigne and Fossaria spp. At some sites, this taxon occurs with Lyogyrus spp., Juga spp., or Fluminicola spp. Sites are generally very shallow; very cold, clear; have slow-moderate flow; and are relatively undisturbed. Local occurrences are typical. Most known sites, here and elsewhere, have a basalt regolith.

Original distribution: Scattered sites in part of the Columbia Basin, including a few large tributaries; and $\mathrm{S}$. in the Willamette and possibly coastal OR. Absent from northern WA; interior OR except for the Blue Mountains and Deschutes River drainage; and from all except western ID (not in the Snake system above the Weiser area). The eastemmost presently known occurrences are in the Lower Salmon system.

Current distribution: See Hershler et al. (1994) for detailed site descriptions known through 1993. Surviving sites are often on public lands, including BLM (Baker District); Hells Canyon National Scenic Area; the Grand Coulee area (Bureau of Reclamation); Gifford Pinchot National Forest; state and federal fish hatcheries in the Columbia Gorge, etc.

Here, there are only a few widely scattered sites, in such areas as the John Day, Rock, and Papoose Creek drainages.

Threats: The small semiarid springs and seeps preferred by this species are very readily subject to modification and destruction from a variety of causes. Recently extinct sites of which we are aware were extipated by road building and maintenance (WA 14; 1-84), grazing (Baker District BLM), dam construction and maintenance (Hells Canyon Dam, John Day Dam); and diversion and capping for campground, hatchery, stock, and domestic water supply (Columbia Gorge area). in the range as a whole, grazing is probably the biggest single problem. In some areas, nutrientenriched groundwater is a problem also, e.g. Grant Co., WA. Grazing and diversion are the major impacts in the Lower Salmon River area.

Criteria for inclusion: Local endemic; occurrence on public lands; loss of historic sites and habitat loss and threats to the remaining localities. Treated as a Watch List species in Frest \& Johannes (1995a).

Recommended status: None at present; there are about 50 sites presently known, some of which could be secure. The species should be regarded as sensitive by the BLM, Forest Service, and other appropriate land management and wildlife agencies. With further study, there is some possibility that this taxon will be divided into several species, each of which would then possibly require protection. At present, this taxon should not be listed in WA or OR; but as there are few sites in ID, state listing as Threatened may be appropriate. References: Henderson (1929, 1936b); Hershler et al. (1994); Frest \& Johannes (1995a); Deixis
collections, 1987-1994.

\section{Stagnicola (Hinkleyia) montanensis (Baker, 1913) mountain marshsnail}

Type locality: Hayes Creek, Bitterroot Mountains, near Ward, MT; types in UMMZ (76196); see Taylor, Walter, \& Burch (1963) for discussion of both types and type locality. 
Description: The best description is Taylor, Walter, \& Burch (1963); see this and Burch (1989) for illustrations. See also Baker (1913).

Ecology: Found mostly in small, perennial, very cold streams and spring outflows; unlike many Stagnicola, never found in seasonal ponds, stagnant or muddy water bodies, or (unlike many Lymnaea) in larger clear-water bodies, such as large perennial rivers and lakes. Substrate varies from mud to cobbles; aquatic macrophytes are generally rather uncommon or absent; Rorippa and bryophytes are most common. Most site with this species have flow, but minor volume and shallow depth. Elevation varies; but moderate to higher-elevation sites are either more common or more likely to have survived to the present.

Original distribution: Eastern Columbia Basin and western Great Plains; about 21 sites in NV, ID, MT, WY, and UT, with most sites in SE ID and adjacent parts of WY and UT; see Taylor, Walter, \& Burch (1963) for map and discussion; see also Taylor (1977, unpub.). No sites have been noted previously in the Lower Salmon River drainage; but presence of localities to the north, south, and west (as well as east) suggest that the species should occur here.

Current distribution: Survives at some of the original sites; some of the $\mathbb{D}$ and UT sites are now extipated. As we are currently surveying SE ID for spningsnails (1991-1994), along with R. Hershler et al. (1993-1994), significant range extension or discovery of sizable numbers of new sites for individual taxa are not to be expected from future work in this area. Some portions of the range, i.e. in WY and MT, need much additional survey work. Survey of springs in the Lower Salmon River drainage might also be productive.

Threats: The small drainages and spring outflows preferred by this species are particularly vulnerable to grazing. Small semiarid springs and seeps preferred by this species are very readily subject to modification and destruction from a variety of causes. Among these are road building and maintenance; dam construction and maintenance; location of housing and industrial buildings; and diversion and capping for campground, hatchery, stock, and domestic water supply. In the range as a whole, grazing is probably the biggest single problem. In some areas, nutrient-enriched groundwater is a problem also.

Criteria for inclusion: Local endemic; loss of historic sites and range; very specialized habitat. Treated as a Watch List species in Frest \& Johannes (1995a).

Recommended status: No formal status at present, although the species should be regarded as sensitive by the BLM, Forest Service, and other appropriate land management and wildife agencies. Further exploration in its limited habitat may show that this species is in need of Federal ESA or equivalent State (ID, MT, WY, NV, UT) protection.

References: Taylor, Walter, \& Burch (1963); Taylor (1977, unpub.); Burch (1989); Frest \& Johannes (1995a); Deixis collections, 1988-1994.

\section{Stagnicola (Stagnicola) idahoensis (Henderson, 1931) shortspire pondsnail}

Type locality: Little Salmon River, $16 \mathrm{mi}$. N. of New Meadows [i.e., near Pinehurst, Adams/ldaho cos., ID]; holotype UCM 17486a; paratypes 17486, 174896b. See Wu \& Brandauer (1982) for UCM types. 
Description: See Henderson (1931a) and Burch (1989). The only western species at all like this one in morphology is the lower Columbia River (WA, OR) Stagnicola apicina[?=Stagnicola solida Lea, according to Taylor, 1977, unpub.]. This species has a shorter spire; and the brown shell color and dark body are also distinctive field characters.

Taylor (1977, unpub.) and Taylor \& Bright (1987) regard only snails from a portion of the Little Salmon River as idahoensis, while treating those from the lower Little Salmon and from the Salmon itself as solida. We regard the lower Columbia apicina as distinct, following Burch (1989), and Salmon River occurrences of this species complex are disjunct and perhaps better regarded as idahoensis.

Ecology: This taxon is one of a small group of species with atypical habitat as compared to more widespread lymnaeids. It is a stenothermal amniphile, found in larger, relatively swift, cold, oligotrophic streams with coarse (gravel to boulder) but stable substrate. This species appears to be largely a perilithon grazer and lithophile (also atypical for the family). Other species with similar habits (and also with limited geographic ranges) are Stagnicola apicina (q.v.) and Stagnicola hinkleyi (q.v.). We have not found this taxon in the more typical stagnicolid habitats of backwaters, ditches, ponds, small streams, or streams with slow flow and other lotic characters. Common associates are Gonidea angulata, Fisherola nuttalli [Salmon River only], and Fluminicola fuscus [Salmon River only]. The taxon avoids areas with sand, mud, or bedrock substrate. Generally, macrophytes or epiphytic algae are rare or absent at sites with this species.

Original distribution: Lower portions of Little Salmon River, Idaho and Adams cos., and lower Salmon River from about French Creek Bridge to White Bird, Idaho Co., ID.

Current distribution: Still survives in parts of the original range. We did not find this species in the lowermost Salmon River, the Salmon River east of the River of No Return, uppermost half of the Little Salmon River, or in Hells Canyon. Sites with this species are on BLM and Payette and Nez Perce National Forest lands.

Threats: Disturbance of the substrate for hydraulic gold mining, dredging for gravel, and changes brought about by bridge and highway construction (e.g. in the vicinity of Riggins and of White Bird) are the primary problems. Jet boating may also be a problem.

Criteria for inclusion: Local endemic; continuing and ongoing threats; loss of much of range to human activities. Treated as a Sensitive species in Frest \& Johannes (1995a).

Recommended status: Currently has none. It should be considered a sensitive species by the Forest Service, BLM, and other land management and wildife agencies. Sufficient survey work has been done in recent years (e.g., Neitzel \& Frest, 1989, 1993) to indicate that this species should be Federal and State (ID) Threatened.

References: Henderson (1931a); Taylor (1977, unpub.); Taylor \& Bright (1987); Frest \& Johannes (1995a); Deixis collections, 1990, 1991, 1994.

Valvata n.sp. $1 \quad$ Salmon valvata

Type locality: None as yet; will be designated when the species is formally described.

Description: This small species has a low, glossy shell, with a depressed spire, somewhat as in Valvata perdepressa. It is smaller than Valvata humeralis, more depressed; the snout and 
tentacles are gray; and the mantle is black. The only taxon at all similar is an undescribed species known from a single NV site.

Ecology: A crenocole species, found in relatively unimpacted to pristine large seeps to mediumsized cold springs. Commonly, the substrate is mud, with minor amounts of sand, gravel, or larger particles; bedrock may be either basalt or limestone. Few other mollusks, other than Pristinicola hemphilli and Pisidium insigne, co-occur. Springs with this taxon have been noted at low-medium elevations; the only commonly occurring macrophyte is Rorippa. This species has been found mostly in soft sediment, which suggests detritivore habits like those of other species in this genus.

Original distribution: Lower Salmon River drainage, Idaho Co., ID. We have looked for this species in the Snake River canyon elsewhere in ID (Hells Canyon), OR, and WA to the mouth; and also in the upper part of the Salmon River system, ID, without success.

Current distribution: Found at a few sites in the lower Salmon River drainage. Notable are the drainages of Papoose Creek and of Rock Creek. We have collected mollusks in this area since 1988 , and heavily since 1990; many other collectors have done likewise since the $1860 \mathrm{~s}$. Future large range extensions or finds of sizable numbers of new sites are very unlikely. Known sites are on Nez Perce National Forest, BLM, and private lands. Most springs we have collected in the area lack this taxon.

Threats: There are very few remaining relatively undisturbed low to medium elevation springs in the lower Salmon River drainage. Most springs are subject to heavy gazing; many others have been capped or diverted for stock water supply. Others have been damaged or destroyed by road construction and maintenance. Others have been diverted or capped for domestic water supply, campgrounds, etc.

Criteria for inclusion: Very local endemic; heavy human impact on all of range; continuing and ongoing threats.

Recommended status: This newly discovered taxon currently has no special status. It minimally should be considered a sensitive species by the Forest Service, BLM, and other land management and wildife agencies. Should be Federal and State (ID) Endangered.

References: Frest \& Johannes (1995a); Deixis collections, 1994.

\section{FRESHWATER BIVALVES}

\section{Anodonta californiensis Lea, 1852 California floater}

Type locality: "'Rio Colorado," actually a former distributary of the river, approximately New River, Imperial County, Califomia. " (Taylor, 1981, p. 142).

Description: For best description and illustrations, see Burch $(1973,1975 b)$. This form does not closely resemble other described western anodontids, except for Anodonta wahlametensis [see Frest \& Johannes, 1995a, for discussion.]. That species has a much more conspicuous wing and 
different beak sculpture. The California floater has been confused in the literature with Anodonta nuttalliana nuttalliana and with Anodonta nuttalliana idahoensis. The best treatment is that of Taylor (1977, unpub.; 1981), who regards Anodonta nuttalliana nuttalliana as a synonym of Anodonta wahlametensis and Anodonta nuttalliana idahoensis as a synonym of Anodonta californiensis. It should be noted that the lectotype of Anodonta nuttalliana idahoensis was fixed by Johnson \& Baker (1973), according to ICZN (1985), Article 74 b, c; and treatment of type material by Coan \& Roth (1987, p. 324) is thus incorrect. As noted by Taylor (1981), there is some chance that Anodonta californiensis is a composite species; this needs to be carefully studied. One implication would be that protection is more justified, in that all component taxa would have limited ranges, and the whole group is already known to have been much reduced in range and abundance. This species was cited also in Frest \& Johannes (1991b, 1993c).

Ecology: "Lakes and slow rivers" (Taylor, 1981, p. 142), generally on soft substrates (mud-sand), in fairly large streams and lakes only, in relatively slow current. A low elevation species, found in both lakes and lake-like stream environments; basically a limnophile. A filter-feeder, as are all unionaceans. The host fish for the glochidial stage of this bivalve is (are?) unknown; note that the
fate of the fish larval host(s) also limits and determines the distribution of this species.

Original distribution: Lower Willamette and lower Columbia rivers in OR and WA from The Dalles to the mouth. In larger slow streams of northern CA as far south as the northern San Joaquin Valley. The former range includes Wahkiakum, Cowlitz, Clark, Skamania, and Klickitat cos., WA; Clatsop, Columbia, Multnomah, Hood River, and Wasco cos., OR; and Siskiyou, Shasta, Lassen, Modoc, and Tehama cos., CA. Upper Columbia system into British Columbia and in the Snake River as far as Wyoming; Green River, Wyoming; Humboldt River, NV; northern Utah; sporadic in
Arizona.

Records in the Lower Salmon River are likely.

Current distribution: Taylor (1981) reports that this species is probably eradicated over much of its original range. We have not found living specimens in the Willamette and lower Columbia River in searches from 1988-1990. Still survives in the Fall River and Pit River, Shasta Co., CA (1991); upper Sacramento River Also survives in Roosevelt Lake, Ferry Co., WA (pers. comm., T. Burkenogan River, Chelan Co., WA, Parts of This species was likely heavily impacted by th. Turke, 1994), and Curlew Lake, Ferry Co., WA. under Physella columbiana. Of the nearly 500 BPA dams and impoundments; see comments (in press a, b; see also Neitzel \& Frest, 1993) Columbia Basin sites surveyed by Frest \& Neitzel this species. It is clearly declining in numbers only three had live or recently dead specimens of species appears to be extinct or nearly extinct in in area occupied throughout its range. The and is very limited in distribution extinct in UT and NV (see, e.g., Clarke \& Hovingh, 1993) circumscribed, but may be the best extant (Frest middle Snake River populations are much Salmon River; but a systematic search has not been conducted.

Threats: Extensive diversion of CA rivers for irnigation, hydroelectric, and water supply projects has much reduced the CA range of this species. This species can tolerate some water pollution;
but not heavy nutrient enhancement or similar problems. Much of the middle Snake River in ID is rapidly becoming eutropified, due to agricultural
runoff, trout farms, and urbanization along the river corridor. Much of the river is impounded
behind a series of small dams; this is also detrimental The area has been declared water-quality detrimental for cold-water species such as this taxon. influx, generally from the same causes, is alted by EPA and the State of Idaho. Fine sediment impacted some of the historic sites. Introduction a major problem. A recent (1994) landslide also be a factor in the species' decline. Springs in this axtic mollusk species (Bowler, 1991) may pollution from agricultural and dairy operations; 
diverted for stock, domestic, industrial, and piscicultural water supply; heavily grazed; and dried due to groundwater drawdown.

In the lower Columbia River region threats include impoundments; continued siltation and other impacts on the few remaining sites with habitat characteristics approximating preimpoundment conditions on the lower Columbia. Harbor and channel "improvements" in the vicinity of Portland, The Dalles, and John Day Dam; nutrient enrichment of the lower Columbia due to agricultural run off. The Lower Granite Reservoir, WA population noted by Frest \& Johannes (1992) appears to have been extipated by the 1992 drawdown. Declines in numbers and/or distribution of the fish host(s) may also be involved.

This taxon is declining, in terms of area occupied and number of sites and individuals. if present still in the Salmon River, it would appear to be very rare.

Criteria for inclusion: Current $\mathrm{C} 2$ Federal candidate; occurrence on public lands; affected by federal projects; current and ongoing threats. The survey area is within the historic range. Treated as a Sensitive species in Frest \& Johannes (1995a).

Recommended status: Currently this species is a C2 candidate (USFWS, 1994). It minimally should be considered a sensitive species by the Forest Service, BLM, and other land management and wildlife agencies. Sufficient recent survey work has been done to demonstrate that this species should be Federal and State (OR, ID, WA, AZ, UT, WY, and CA) Threatened.

References: Burch (1973, 1975b); Taylor (1981); Frest (1992); Frest \& Johannes, 1992; 1993a, . 1993b, 1995a; Neitzel \& Frest (1993); Frest \& Neitzel (in press a, b); Deixis Consultants, 19881994.

Type locality: "Lewis's River" [Snake River], Idaho; types not seen.

Description: See Burch $(1973,1975 b)$ for best short description and illustration. This taxon is very distinctive.

Ecology: Found mostly in creeks and rivers of all sizes; rarely in lakes or reservoirs unless with substantial flow. This amniphile, filter-feeding taxon can live on firm mud substrate as well as on more coarse materials (which are more typical). More pollution-tolerant than some unionids; but still absent from highly polluted areas and places with unstable or very soft substrate. The host fish for the glochidia of this species is (are?) unknown.

Original distribution: "Southern British Columbia to southern Califomia, eastward to southern Idaho and northern Nevada" (Taylor, 1981). It should be noted that the species had a limited distribution W. of the Cascades, particularly in WA and OR, where most sites N. of SW OR are doubtful.

Current distribution: Uncertain. Known to be extirpated from many of the old sites, including much of the Snake system; but still common in some areas. Still occurs sporadically in some major tributaries to the Columbia and Snake, such as the Okanogan River (WA) and Clearwater River, Hells Canyon, and middle Snake River (ID). Formerly in Little Granite Reservoir (Frest \& Johannes, 1992); but this population is believed to have been extirpated by the 1993 drawdown. 
Substantial populations still occur sporadically in the Lower Salmon River from Riggins to the mouth, and in the lower Little Salmon River.

Threats: Extensive diversion of CA rivers for irrigation, hydroelectric, and water supply projects has much reduced the $\mathrm{CA}$ range of this species. This species can tolerate some water pollution; but not heavy nutrient enhancement or similar problems. For some recent records, see Taylor (1981), Frest \& Johannes (1991a, 1992, 1993e, 1994, 1995c).

Much of the middle Snake River in ID is rapidly becoming eutropified, due to agricultural runoff, fish farms, and urbanization along the river corridor. Much of the river is impounded behind a series of small darns; this is also detrimental for cold-water species such as this taxon. The area has been declared water-quality limited by EPA and the State of Idaho. Fine sediment influx, generally from the same causes, is also a major problem. A recent (1994) landslide impacted some of the historic sites. For some recent $\mathbb{D}$ sites for this species, see references under Frest \& Johannes (in part).

In the lower Columbia River region threats include impoundments; continued siltation and other impacts on the few remaining sites with habitat characteristics approximating preimpoundment conditions on the lower Columbia. Harbor and channel "improvements" in the vicinity of Portland, The Dalles, and John Day Dam; nutrient enrichment of the lower Columbia due to agricultural run-off. Locally, gravel and gold dredging of the river, past and present, are substantial problems.

This taxon is declining, in terms of area occupied and number of sites and individuals. Note that the fate of the fish larval host(s) also limits and determines the distribution of this species.

Criteria for inclusion: Regional endemic; loss of historic sites; human modification throughout range; concentration of human activities within preferred habitat; occurrence on public owned or regulated lands. Treated as a Watch List species in Frest \& Johannes (1995a).

Recommended status: We do not recommend Federal or State (WA, OR, ID) listing as this point, although the species minimally should be considered sensitive by the BLM, Forest Service, and other appropriate land management and wildlife agencies. More survey work needs to be done on this species, particularly in OR.

References: Burch (1973, 1975b); Taylor (1981); Frest \& Johannes (1995a); Deixis collections, 1987-1994.

$$
\text { Margaritifera falcata (Gould, 1850) western pearlshell }
$$

Type locality: "Puget Sound, Oregon" [sic: now Washington]; holotype USNM 5893, according to Johnson (1964).

Description: For best short description and illustration see Burch $(1973,1975 \mathrm{~b})$. The generally purple nacre and hermaphroditic condition are distinctive as compared to Margaritifera margaritifera, the most closely related species. See also discussion in Taylor (1988a).

Ecology: Primanily an amniphile species; medium-sized streams are preferable, although sometimes found in streams considerably narrower than $1 \mathrm{~m}$ (contra Clarke, 1981); rarely, in lakes with stream-like conditions. Generally in fast, clear, very cold areas with coarse substrate. In undisturbed streams, this species may cover the bottom. Host fish for the glochidia include 
chinook salmon, rainbow trout, brown trout, brook trout, speckled dace, Lahontan redside, and Tahoe sucker (Clarke, 1981).

Original distribution: "Southern Alaska to central Califomia, eastward to western Montana, westem Wyoming, and northern Utah" (Taylor, 1981). The range includes the survey area.

Current distribution: Extinct in most of the Snake system (except for upper tributaries, including the Blackfoot River (ID) and some major creeks in ID and WY); extinct from many of the coastal streams, in which it was once ubiquitous. Status of interior populations needs further work; extinct in the Okanogan River, e.g., many populations do not appear to have reproduced for many years. Populations persist locally in parts of the Coeur d'Alene system, including the Coeur d'Alene River and St. Maries River.

In the Lower Salmon River, populations now seem to be extremely sporadic. There are unusually large populations locally in the Little Salmon River. At least one of these shows regular reproduction.

Threats: Extensive diversion of rivers for irrigation, hydroelectric, and water supply projects has much reduced the WA, OR, ID, and CA range of this species. This species is not as tolerant of water pollution as Gonidea angulata and Anodonta kennerlyr, heavy nutrient enhancement, sittation, unstable substrate, or similar problems extipate populations. For some recent records, see Taylor (1981), and Frest \& Johannes (1991a, 1992, 1993e, 1994, 1995c).

Much of the middle Snake River in $\mathbb{D}$ is rapidly becoming eutropified, due to agricultural runoff, fish farms, and urbanization along the river corridor. Much of the river is impounded behind a series of small dams; this is also detrimental for cold-water species such as this taxon. The area has been declared water-quality limited by EPA and the State of Idaho. Fine sediment influx, generally from the same causes, is also a major problem. A recent (1994) landslide impacted some of the historic sites. For some recent ID sites for this species, see references under Frest \& Johannes (in part). Conditions in the Snake are typical for many of the rivers in this species' range. We have seen no live specimens from the mainstem Snake recently.

In the lower Columbia River region threats include impoundments; continued siltation and other impacts on the few remaining sites with habitat characteristics approximating preimpoundment conditions on the lower Columbia. Harbor and channel "improvements" in the vicinity of The Dalles and John Day Dam; nutrient enrichment of the lower Columbia due to agricultural run-off. We have seen no live specimens from the mainstem Columbia recently.

Threats in the Lower Salmon River and Little Salmon River are similar. Additionally, effects of gravel and hydraulic gold mining need to be considered.

This taxon is declining, in terms of area occupied and number of sites and individuals. Note that the fate of the fish larval host(s) also limits and determines the distribution of this species.

Criteria for inclusion: Regional endemic; loss of most historic sites; human modification of habitat throughout the range; occurrence on public lands. Treated as a Watch List species in Frest \& Johannes (1995a).

Recommended status: We do not recommend formal Federal or State (WA, OR, ID, MT, WY, NV, $\&$ UT) listing at this point, although the species should be considered sensitive by the BLM, Forest Service, National Park Service, and other land management, wildlife, and water regulatory agencies. Further work needs to be dome to document range changes. it should be noted, however, that populations showing repeated reproduction (at least several age classes) are now the exception rather than the rule.

References: Burch (1973, 1975b); Taylor (1981); Frest \& Johannes (1995a); Deixis collections, 1987-1994. 


\section{ACKNOWLEDGEMENTS}

We thank Craig Johnson (BLM-Cottonwood District) for his continuing interest in this project. R. B. Brunson (Missoula, Montana) was extremely generous with both information and specimens gathered during his 40 years of collecting experience. Thomas Burke (USDAWenatchee National Forest) very generously shared with us the results of many years of collecting and researching Washington terrestrial mollusks. Special thanks to Steve Welty (Dubois, Wyoming) for information and allowing us to review his extensive recent collections from Wyoming, Idaho, Washington, and other states.

For access to collections and facilities under their control, we thank the following: $G$. Davis, Academy of Natural Sciences of Philadelphia; Robert Van Syoc and E. Kools, California Academy of Sciences; Eric Hochberg, Santa Barbara Museum of Natural History; A. Chadwick, Delaware Museum of Natural History; S. K. Wu, University of Colorado Museum; D. Eernisse, University of Michigan Museum of Zoology; R. Hershler and P. Greenhall, Smithsonian Institution, National Museum of Natural History.

Assistance with fieldwork over the last seven years has been provided by many; we especially acknowledge the contributions of M. Frest (University of Washington), S. Nelson (Seattle, Washington), S. Welty (Dubois, WY), and G. Holm (Vancouver, British Columbia).

Opinions expressed herein are those of the authors and do not necessarily reflect those of the contract sponsors. 


\section{REFERENCES}

AFS. 1991. The Effects of Livestock Grazing on Riparian and Stream Ecosystems. Fisheries 16 7-11. [AFS position statement drafted by C. L. Armour, D. A. Duff, \& W. Elmore]

Agee, J. K. 1993. Fire Ecology of Pacific Northwest Forests. Island Press, Washington, D. C. $493 \mathrm{pp}$.

Anon., 1914. In memoriam - Henry Hemphill. Transactions of the San Diego Society of Natural History, 2: 58-60.

Baker, F. C. 1913. A new Lymnaea from Montana. The Nautilus 26: 115-116.

Baker, H. B. 1925. Anatomy of Lanx, a limpet-like lymnaeid mollusk. Proceedings, California Academy of Sciences 14: 143-169 1930. New and problematic west American land-snails. The Nautilus 43: 95-128. 1931. Nearctic vitreine land snails. Proceedings, Academy of Natural Sciences of Philadelphia 73: 85-117.

1932. New land snails from Idaho and eastern Oregon. The Nautilus 45: 82-87.

1964. Type land Snails in the Academy of Natural Sciences of Philadelphia. Part III. Limnophile and Thalassophile Pulmonata. Part IV. Land and Fresh-water Prosobranchia. Proceedings, Academy of Natural Sciences of Philadelphia 116: 149-193.

Bequaert, J. C. \& W. B. Miller. 1973. The Mollusks of the Arid Southwest. University of Arizona Press. $271 \mathrm{pp}$.

Berry, S. S. 1932. Three New Mountain Snails from Idaho and Nevada. Joumal of Entomology \& Zoology 24: 57-63.

Bieler, R. 1993. Gastropod phylogeny and systematics. Annual Review of Ecology and Systematics 23: 311-338.

Bowler, P. A. 1991. The Rapid Spread of the Freshwater Hydrobiid Snail Potamopyrgus antipodarum and its Impacts on the Native Snail Fauna in the Middle Snake River, Southern Idaho. ProceedingsDesert Fishes Council, 21: 173-182.

Branson, B. A. 1972. Hemphillia dromedarius, a new arionid slug from Washington. The Nautilus 85: 100-106.

1977. Freshwater and Terrestrial Mollusca of the Olympic Peninsula, Washington.

The Veliger 19: 310-330.

1980. Collections of gastropods from the Cascade Mountains of Washington.

The Veliger 23: 171-176.

\& R. M. Branson. 1984. Distributional Records for Terrestrial and Freshwater

Mollusca of the Cascade and Coast Ranges, Oregon. The Veliger 26: 248-257. 
M. E. Sisk, \& C. J. McCoy. 1966. Observations on and Distribution of Some Western and Southwestern Mollusks. The Veliger 9: 145-151.

Brunson, R. B. \& R. H. Russell. 1967. Radiodiscus, new to molluscan fauna of Montana. The Nautilus 81: 18-22.

Burch, J. B. 1962. How to Know the Eastern Land Snails. W. C. Brown, Dubuque, lowa. 214 pp. 1972. Freshwater Sphaeriacean Clams (Mollusca: Pelecypoda) of North America. [Biota of Freshwater Ecosystems Identification Manual 3]. U. S. EPA EP1.16:18050 ELD03/72/no. 3, $31 \mathrm{pp}$.

1973. Freshwater Unionacean Clams (Mollusca: Pelecypoda) of North America. [Biota of Freshwater Ecosystems Identification Manual 11]. U. S. EPA EP1.16:18050 ELD03/73/no. 11, 176 pp.

1975a. Freshwater Sphaeriacean Clams (Mollusca: Pelecypoda) of North America. Malacological Publications, Hamburg, MI. xi + 96 pp.

1975b. Freshwater Unionacean Clams (Mollusca: Pelecypoda) of North America. Malacological Publications, Hamburg, MI. xviii + 206 pp.

1982. Freshwater Snails (Mollusca: Gastropoda) of North America. Environmental Monitoring and Support Laboratory, Office of Research and Development, U.S. Environmental Protection Agency, Cincinnati, Ohio. NTIS PB82-207168, 294 pp.

. 1989. North American Freshwater Snails. Malacological Publications, Hamburg, MI. $365 \mathrm{pp}$.

\& T. A. Pearce. 1990. Terrestrial Gastropoda, pp. 201-309, in D. L. Dindal (ed.), Soil Biology Guide. J. Wiley, NY. 1359 pp.

, \& J. Tottenham. 1980. North American Freshwater Snails. Transactions of the POETS Society, 1(3): 81-215.

Chamberlin, R. V. \& D. T. Jones. 1929. A descriptive illustrated catalog of the Mollusca of Utah. University of Utah Bulletins 19(4) [biological series 1(1)], ix $+203 \mathrm{pp}$.

Clarke, A. H. 1979a. Gastropods as indicators of trophic lake stages. The Nautilus: 94: 138-142. 1979b. Sphaeriidae as indicators of trophic lake stages. The Nautilus: $94: 178-184$. 1981. The Freshwater Molluscs of Canada. National Museum of Natural History, National Museums of Canada. $446 \mathrm{pp}$.

\& P. Hovingh. 1991. Status Survey of Selected Land and Freshwater Gastropods in Utah. Draft Report, Contract \#14-16-0006-89-021, USDI Fish \& Wildlife Service. Ecosearch, Inc., Portland Texas. 70 pp. + appendices.

1993. Status Survey of Fifteen Species and Subspecies of Aquatic and Terrestrial Mollusks from Utah, Colorado, and Montana. Final Report, Contract \#1416-0006-91-046, USDI Fish \& Wildlife Service. Ecosearch, Inc., Portland Texas. 77 pp. + appendices. 
Coan, E. 1985. A bibliography and list of molluscan names of Josiah Keep. The Veliger 28: 211215.

Coan, E. \& B. Roth 1987. The malacological taxa of Henry Hemphill. The Veliger 29: 322-339.

Dall, W. H. 1877.[Hyalina subrupicola, n. s.], pp. 163-164, in A. S. Packard, On a new cave fauna from Utah. Bulletin, U. S. Geological and Geographical Survey of the Territories, 3: 157169.

Davis, G. M. 1982. Historical and Ecological Factors in the Evolution, Adaptive Radiation, and Biogeography of Freshwater Mollusks. American Zoologist 22: 375-395.

EFS. 1993. Interim protection for late-successional forests, fisheries, and watersheds. Executive summary. Eastside Forests Scientific Society Panel.

Emberton, K. C. 1988. The Genitalic, Allozymic, and Conchological Evolution of the Eastern North American Triodopsinae (Pulmonata: Stylommatophora: Polygyridae). Malacologia 28: 159-273.

1991. The Genitalic, Allozymic, and Conchological Evolution of the Tribe Mesodontini (Gastropoda: Pulmonata: Polygyridae). Malacologia 33: 71-178.

1995. Land-Snail Community Morphologies of the Highest Diversity Sites of Madagascar, North America, and New Zealand, with Recommended Altematives to Height-DiameterPlots. Malacologia 36: 67-78.

G. S. Kuncio, G. M. Davis, S. M. Philips, K. M. Monderewicz, \& Y. H. Guo. 1990. Comparison of recent Classifications of Stylommatophoran Land-Snail Families, and Evaluation of Large-Ribosomal-RNA Sequencing for their Phylogenetics. Malacologia 31: 327-352.

EPA. 1990. Livestock grazing on westem riparian areas. U. S. Environmental Protection Agency, Denver, Colorado.

Fairbanks, H. L. 1984. A new Species of Oreohelix (Gastropoda: Pulmonata: Oreohelicidae) from the Seven Devils Mountains, Idaho. Proceedings, Biological Society of Washington 97: 179-185.

FEMAT, 1993. Forest Ecosystem Management: An Ecological, Economic, and Social Assessment. U. S. Department of Agriculture, Forest Service, Portland, Oregon. $x i+729$ pp. appendices.

Fleischner, T. L. 1994. Ecological Costs of Livestock Grazing in Western North America. Conservation Biology 8: 629-644.

Frest, T. J. 1984. National Recovery Plan for lowa Pleistocene Snail (Discus macclintocki (Baker)). USDI Fish \& Wildlife Service. 24 pp. + appendix.

1990. Field Survey of lowa Spring Fens. Final Report to lowa Preserves and Ecological Services Bureau, lowa DNR. 84 pp.

1991. Summary Status Reports on Eight Species of Candidate Land Snails from the Driftless Area (Paleozoic Plateau), Upper Midwest. Final Report, Contract \#30181-01366, 
USDI Fish \& Wildlife Service. Deixis Consultants, Seattle, Washington. iii + 54 pp.

1992. Mollusc Fauna in the Vicinity of Three Proposed Hydroelectric Projects on the Middle Snake River, Central Idaho. Supplemental Report on the California floater Anodonta californiensis Lea, 1852. Final Report to Don Chapman Consultants, Inc., Boise, Idaho. Deixis Consultants, Seattle, Washington. 4 pp.

1995. A Review of the North American Freshwater Snail Genus Pyrgulopsis

(Hydrobiidae), by R. Hershler [review]. The Veliger 38: 77-78.

\& E. J. Johannes. 1991a. Mollusc Fauna in the Vicinity of Three Proposed Hydroelectric Projects on the Middle Snake River, Central Idaho. Final Report to Don Chapman Consultants, Inc., Boise, Idaho. Deixis Consultants, Seattle, Washington. 60 pp.

1991b. Present and Potential Candidate Molluscs Occurring Within the Range of the Northern Spotted Owl. Final Report to Northern Spotted Owl Recovery Team, Portland, Oregon. Deixis Consultants, Seattle, Washington. 30 pp.

1992. Effects of the March, 1992 Drawdown on the Freshwater Molluscs of the Lower Granite Lake area, Snake River, SE WA and W. ID. Final Report to US Army Corps of Engineers, Walla Walla District. Deixis Consultants, Seattle, Washington. $\mathrm{i}+11 \mathrm{pp}$.

1993a. Mollusc Survey of the Auger Falls Project (FERC \#4794) Reach of the Middle Snake River, Idaho. Final Report to Idaho DEQ and EPA Region 10. Deixis Consultants, Seattle, Washington. ii +35 pp.

1993b. Mollusc Survey of the Minidoka Dam area, upper Snake River, Idaho. Final Report to USDI Bureau of Reclamation. Deixis Consultants, Seattle, WA. ii +36 pp.

1993c. Mollusc Species of Special Concern Within the Range of the Northern Spotted Owl. Final Report to Forest Ecosystem Management Working Group, USDA Forest Service. Deixis Consultants, Seattle, Washington. 98 pp.

1993d. Land Snail Survey of the Black Hills National Forest, South Dakota and Wyoming. Final Report to USDA Forest Service and USDI Fish \& Wildlife Service. Deixis Consultants, Seattle, Washington. 156 pp. + appendix.

1993e. Freshwater Molluscs of the Upper Sacramento System, California, with Particular Reference to the Cantara Spill. 1992 yearly report to California Department of Fish \& Game. Deixis Consultants, Seattle, Washington. iv + 101 pp., appendices.

1993f. Freshwater Mollusks in the Vicinity of Three Proposed ITD Projects, Middle and Upper Snake River, Idaho. Final Report to Idaho Transportation Department. Deixis Consultants, Seattle, Washington. 40 pp.

1994. Freshwater Molluscs of the Upper Sacramento System, California, with Particular Reference to the Cantara Spill. 1993 yearly report to California Department of Fish \& Game. Deixis Consultants, Seattle, Washington, ii + 58 pp., appendices. 
. 1995a. Interior Columbia Basin Mollusk Species of Special Concern. Report ot Interior Columbia Basin Ecosystem Management Project. Deixis Consultants, Seattle, Washington. $x i+362 \mathrm{pp}$.

. 1995b. Fresh Water Mollusks of the Upper Klamath Lake Drainage, Oregon. 1994 yearly report to Oregon Natural Heritage Program. Deixis Consultants, Seattle, Washington.

.1995c. Freshwater Mollusks of the Upper Sacramento System, California, with Particular Reference to the Cantara Spill. 1995 final report to California Department of Fish \& Game. Deixis Consultants, Seattle, Washington. iii + 175 pp., appendices.

\& D. Neitzel. [in press, a]. Notes on the distribution and biology of Fisherola nuttalli (Haldeman, 1843), the shortface lanx (Gastropoda: Pulmonata: Lancidae). The Veliger.

, \& D. Neitzel. [in press, b]. Notes on the distribution and biology of Fluminicola fuscus (Haldeman, 1841), the Columbia pebblesnail (Gastropoda: Prosobranchia: Hydrobiidae). The Veliger.

Fuller, S. L. H. 1974. Clams and Mussels (Mollusca: Bivalvia), pp. 215-273. In C. W. Hart, jr. \& S. L. $\mathrm{H}$. Fuller (eds.), Pollution ecology of freshwater invertebrates. Academic Press, New York.

GAO. 1986. Public Lands: Interior Should Ensure Against Abuses Form Hardrock Mining. General Accounting Office, GAO/RCED-86-48, 50 pp.

1987. Parks and Recreation: Limited Progress Made in Documenting and Mitigating Threats to the Parks. General Accounting Office, GAO/RCED-87-36, $71 \mathrm{pp}$.

. 1988a. Rangeland Management: More Emphasis Needed on Declining and Overstocked Grazing Allotments. General Accounting Office, GAO/RCED-88-80, 71 pp.

1988b. Public Rangelands: Some Riparian Areas Restores but Widespread Improvement Will Be Slow. General Accounting Office, GAO/RCED-88-105, 85 pp.

1989a. Federal Land Management: The Mining Law of 1872 Needs Revision. General Accounting Office, GAO/RCED-89-72. $47 \mathrm{pp}$.

1989b. National Wildlife Refuges: Continuing Problems With Incompatible Uses Call for Bold Action. General Accounting Office, GAO/RCED-89-196. 84 pp.

1989c. Wilderness Preservation: Problems in Some National Forests Should Be Addressed. General Accounting Office, GAO/RCED-89-202. 91 pp.

1990a. Rangeland Management: BLM Efforts to Prevent Unauthorized Livestock Grazing Need Strengthening. General Accounting Office, GAO/RCED-91-17, 16 pp.

1990b. Public Lands: Limited Progress in Resource Management Planning. General Accounting Office, GAO/RCED-90-225, 35 pp.

1991 a. Public Land Management: Attention to Wildlife is Limited. General Accounting Office, GAO/RCED-91-64, $52 \mathrm{pp}$. 
. 1991b. Wildlife Protection: Enforcement of Federal Laws Could Be Strengthened. General Accounting Office, GAO/RCED-91-44, 48 pp.

1991c. Wildlife Management: Problems Being Experienced With Current Monitoring Approach. General Accounting Office, GAO/RCED-91-123, 8 pp.

1991d. Rangeland Management: Forest Service Not Performing Needed Monitoring of Grazing Allotments. General Accounting Office, GAO/RCED-91-148, 8 pp.

1992. Rangeland Management: Interior's Monitoring Has Fallen Short of Agency Requirements. General Accounting Office, GAO/RCED-92-51, 53 pp.

1993a. Rangeland Management: BLM's Range Improvement Project Data Base Is Incomplete and Inaccurate. General Accounting Office, GAO/RCED-93-92, 18 pp.

Gould, S. J., \& D. S. Woodruff. 1986. Evolution and Systematics of Cerion (Mollusca: Pulmonata) on New Providence Island: a radical revision. Bulletin, American Museum of Natural History 182: $389-490$.

Hanna, G. D., \& A. G. Smith. 1939. Notes on some forms of Oreohelix strigosa. Proceedings, California Academy of Sciences 23: 381-392.

Harmon, M. E., J. F. Franklin, F. J. Swanson, P. Sollins, S. V. Gregory, J. D. Lattin, N. H. Anderson, S. P.Cline, N. G. Aumen, J. R. Sedell, G. W. Lienkaemper, K. Cromack, jr., \& K. W. Cummins. 1986. Ecology of coarse woody debris in temperate ecosystems. Advances in Ecological Research 15: 133-302.

Hemphill, H. 1881. New catalogue of the shells of California and adjacent states. San Diego, California; privately published. $12 \mathrm{pp}$.

. 1890. Descriptions of new varieties of North American land shells. The Nautilus 3: 133-135.

Henderson, J. 1924. Mollusca of Colorado, Utah, Montana, Idaho and Wyoming. University of Colorado Studies 13: 65-223.

1929. The Non-marine Mollusca of Oregon and Washington. University of Colorado Studies 17: 47-190.

1931a. A new lymnaeid from Idaho. The Nautilus 44: 75-77.

1931b. Molluscan provinces in the western United States. University of Colorado Studies 18: 177-186.

1936a. The Mollusca of Colorado, Utah, Montana, Idaho and Wyoming.

Supplement. University of Colorado Studies 23: 81--145.

.1936b. The Non-marine Mollusca of Oregon and Washington. Supplement.

University of Colorado Studies 23: 251--280.

Hershler, R. 1994. A Review of the North American Freshwater Snail Genus Pyrgulopsis

(Hydrobiidae). Smithsonian Contributions to Zoology no. 554, iv +121 pp. 
, \& T. J. Frest [in press]. A Review of the North American Freshwater Snail Genus Fluminicola (Hydrobiidae). Smithsonian Contributions to Zoology.

T. J. Frest, E. J. Johannes, P. A. Bowler, \& F. G. Thompson. 1994. Two New Genera of Hydrobiid Snails (Prosobranchia: Rissooidea) from the Northwestern United States. The Veliger 37: 221-243.

Horning, J. 1994. Grazing to Extinction: Endangered, Threatened and Candidate Species Imperiled byLivestock Grazing on Western Public Lands. National Wildlife Federation, Washington, DC. 68 pp.

Hubricht, L. 1985. The Distributions of the Native Land Mollusks of the Eastern United States. Fieldiana: Zoology, new series 24 (pub. 1359), 191 pp.

ICZN. 1964. International Code of Zoological Nomenclature. 176 pp. International Trust for Zoological Nomenclature, London.

1985. International Code of Zoological Nomenclature. 338 pp. International Trust for Zoological Nomenclature, London.

Imlay, M. J. 1982. Use of shells of freshwater mussels in monitoring heavy metals and environmental stresses: a review. Malacological Review 15: 1-14.

Johnson, K. N., J. F. Franklin, J. W. Thomas, \& J. Gordon. 1991. Alternatives for Management of Late-Successional Forests of the Pacific Northwest. U. S. Dept. of Agriculture, Forest Service, Portland, OR. 59 pp.

Johnson, R. I. 1964. The Recent Mollusca of Augustus Addison Gould. U. S. National Museum Bull. 239, $182 \mathrm{pp}$.

\& H. B. Baker. 1973. The types of Unionacea (Mollusca: Bivalvia) in the Academy of Natural Sciences of Philadelphia. Proceedings, Academy of Natural Sciences of Philadelphia 125: 145-186.

Kabat, A. R. \& R. H. Hershler. 1993. The Prosobranch Snail Family Hydrobiidae (Gastropoda: Rissooidea): Review of Classification and Supraspecific Taxa. Smithsonian Contributions to Zoology, no. 547 , iii +94 pp.

Karlin, E. J. 1961. Ecological Relationships Between Vegetation and the Distribution of Land Snails in Montana, Colorado, and New Mexico. American Midland Naturalist 65: 60-66.

Keep, J. 1887. West coast shells. A familiar description of the marine, fresh water, and land mollusks of the United States, found west of the Rocky Mountains. Bancroft Bros., San Francisco, Califomia. $230 \mathrm{pp}$.

Kralka, A. A. 1986. Population characteristics of terrestrial gastropods in boreal forest habitats. American Midland Naturalist 115: 156-164.

LaRocque, A. 1960. Molluscan faunas of the Flagstaff Formation. Geological Society of America, Memoir 78, $100 \mathrm{pp}$.

Leviton, A. E., R. H. Gibbs, jr., Heal, E., \& C. E. Dawson. 1985. Standards in Herpetology and Ichthyology: Part I. Standard Symbolic Codes for Institutional Resource Collections in Herpetology and Ichthyology. Copeia 1985: 802-832. 
Losos, E., J. Hayes, A. Phillips, C. Alkire, \& D. Wilcove. 1993. Taxpayers' Double Burden. Federal Resource Subsidies and Endangered Species. The Wilderness Society, Washington, DC. viii + 66 pp., appendices.

McMahon, R. F. 1991. Mollusca: Bivalvia, pp. 315-399. In Thorp, J. \& A. Covich (eds.). 1991. Ecology and Classification of North American Freshwater Invertebrates. Academic Press. $911 \mathrm{pp}$.

Neitzel, D. \& T. Frest. 1989. Survey of Columbia River Basin for Giant Columbia River Spire Snail Fluminicola columbiana and Great Columbia River Limpet Fisherola nuttalli. Battelle Pacific Northwest Laboratory PNL-7103. $x \dot{x}+34$ pp.

1990. Survey of Columbia River Basin Streams for Columbia Pebblesnail and Shortface Lanx. Fisheries 15: 2-3.

. 1992. Survey of Columbia River Basin Streams for Columbia Pebblesnail Fluminicola columbiana and Shortface Lanx Fisherola nuttalli. Battelle Pacific Northwest Laboratory PNL-8229. ix +29 pp., appendices. [draft]

1993. Survey of Columbia River Basin Streams for Columbia Pebblesnail Fluminicola columbiana and Shortface Lanx Fisherola nuttalli. Battelle Pacific Northwest Laboratory PNL-8229. ix + 29 pp., appendices.

Olson, D. 1992. The Northern Spotted Owl Conservation Strategy: Implications for Pacific Northwest Forest Invertebrates and Associated Ecosystem Processes. The Xerces Society, Portland, Oregon. $50 \mathrm{pp}$.

Palmer, K, V. W. 1958. Type Specimens of Marine Mollusca described by P. P. Carpenter from the West Coast (San Diego to British Columbia). Geological Society of America, Memoir 76. $376 \mathrm{pp}$.

Paul, C. R. C. 1971. Revision of the Holocystites Fauna (Diploporita) of North America. Fieldiana: Geology 24, 166 pp.

PEER. 1994. Public trust betrayed: employee critique of Bureau of Land Management rangeland management. Public Employees for Environmental Responsibility, Washington, DC. $v+25 \mathrm{pp}$.

Pilsbry, H. A. 1899. Catalogue of the Amnicolidae of the western United States. The Nautilus 12: 121-127. 1902. New American land shells. The Nautilus 16: 30-33.

1903. A new American genus of Arionidae. Proceedings, Academy of Natural Sciences of Philadelphia 55: 626-629.

1934. Notes on the anatomy of Oreohelix, -III, with description of new species and subspecies. Proceedings, Academy of Natural Sciences of Philadelphia 85: 383-410.

1939. Land Mollusca of North America (North of Mexico), vol. 1 pt. 1. Academy of Natural Sciences of Philadelphia Monograph 3 (1): 1-574.

1940. Land Mollusca of North America (North of Mexico), vol. 1 pt. 2. Academy of 
Natural Sciences of Philadelphia Monograph 3 (1): 575-994.

1946. Land Mollusca of North America (North of Mexico), vol. 2 pt. 1. Academy of Natural Sciences of Philadelphia Monograph 3 (2): 1-520.

1948. Land Mollusca of North America (North of Mexico), vol. 2. pt. 2. Academy of Natural Sciences of Philadelphia Monograph 3 (2): 521-1113.

, \& E. G. Vanatta. 1897. A new species of Hemphillia. The Nautilus 11: 44.

1898. Revision of the North American slugs: Binneya, Hemphillia,

Hesperarion, Prophysaon and Anadenulus. Proceedings, Academy of Natural Sciences of Philadelphia 50: 219-261.

Ponder, W. F. 1985. A review of the genera of the family Rissoidae (Mollusca:

Mesogastropoda: Rissoacea). Australian Museum, Records (Supplements) 4. 221 pp.

Rees, B. B. \& S. C. Hand. 1990. Heat Dissipation, Gas Exchange and Acid-Base Status in the Land Snail Oreohelix During Short-term Estivation, Journal of experimental Biology 152: 77-92.

1991. Regulation of glycolysis in the land snail Oreohelix during estivation and artificial hypercapnia. Journal of Comparative Physiology B 161: 237-246.

1993. Biochemical Correlates of Estivation Tolerance in the Mountainsnail Oreohelix (Pulmonata: Oreohelicidae). Biological Bulletins 184: 230-242.

, D. Malhotra, J. I. Shapiro, \& S. C. Hand. 1991. Intracellular pH Decreases During Entry Into Estivation in the Land Snail Oreohelix strigosa. Journal of experimental Biology 159: 525-530.

Riedel, A. 1980. Genera Zonitidarum. W. Backhuys, Rotterdam. 197 pp.

Roth, B. 1986a. Notes on Three European Land Mollusks Introduced to California. Bulletins, Southern California Academy of Sciences, 85: 22-28.

. 1986b. Land Mollusks (Gastropoda: Pulmonata) from early Tertiary Bozeman Group, Montana. Proceedings of the California Academy of Sciences 44: 237-267.

1987. Identities of two Californian land snails. Malacological Review, 20: 129-132.

. 1993. Critical Review of Terrestrial Mollusks Associated with Late-Successional and OldGrowth Forests in the Range of the Northem Spotted Owl. B. Roth, San Francisco, Califomia. $42 \mathrm{pp}$.

\& K. C. Emberton. 1994. "Extralimital" Land Mollusks (Gastropoda) from the Deep River Formation, Montana: Evidence for Mesic Medial Tertiary Climate. Proceedings of the Academy of Natural Sciences of Philadelphia 145: 93-106.

\& L. Eng. 1980. Distribution, ecology, and reproductive anatomy of a rare land snail, Monadenia setosa Talmadge. California Fish and Game 66: 4-16.

\& W. Miller. 1992. A new genus and species of polygyrid land snail (Gastropoda:

Pulmonata) from Oregon. The Veliger 35: 222-225. 
1993. Polygyrid land snails, Vespericola (Gastropoda: Pulmonata). 1.

Species and populations formerly referred to Vespericola columbianus (Lea) in

California. The Veliger 36: 134-144.

Schmidt-Nielsen, K., C. R. Taylor, \& A. Shkolnik. 1971. Desert Snails: Problems of Heat, Water and Food. Journal of experimental Biology 55: 385-398.

Smith, A. G. 1943. Mollusks of the Clearwater Mountains, Idaho. Proceedings, Califomia Academy of Sciences, series $4: 23: 537-554$.

1970. Western Land Snails, pp. 39-46. In Clarke, A. H. (ed.) Papers on the Rare and Endangered Mollusks of North America. Malacologia 10: 1-56.

Solem, A. 1974. The Shell Makers. Introducing Mollusks. Wiley-Interscience, New York. 289 pp.

1975. Notes on Salmon River oreohelicid land snails, with description of Oreohelix waltoni. Veliger 18: 16-30.

1979. Biogeographic Significance of Land Snails, Paleozoic to Recent, pp. 277-287.

In J. Gray \& A. J. Boucot (eds.) Historical Biogeography, Plate Tectonics, and the Changing Environment. Oregon State University Press, Corvallis, Oregon. 767 pp.

1981. Land-Snail Biogeography: A True Snail's Pace of Change, pp. 197-237. In G. Nelson \& D. E. Rosen (eds.) Vicariance Biogeography: A Critique. Columbia University Press, New York. 563 pp.

1984. A world model of land snail diversity and abundance, pp. 181-213. In A. Solem \&

A. C. Van Bruggen (eds.) World-wide Land Snails. E. J. Brill, Leiden. 363 pp.

\& A. H. Clarke. 1974. Report on status survey for Salmon River Valley land snails. Office Endangered Species, Washington, DC. 12 pp. [unpub. letter dated August 23, 1974]

\& F. M. Climo. 1985. Structure and Habitat Correlations of Sympatric New Zealand Land Snail Species. Malacologia 26: 1-30.

\& D. J. Roscoe. 1981. Sympatric species diversity of New Zealand land snails. New Zealand Journal of Zoology 8: 453-485.

Spies, T. A., J. F. Franklin, \& T. B. Thomas. 1988. Coarse woody debris in Douglas-fir forests of western Oregon and Washington. Ecology 69: 1689-1702.

Stacey, P. B., \& M. Taper. 1992. Environmental variation and the persistence of small populations. Ecological Applications 2: 18-29.

Stohlgren, T. J. \& J. F. Quinn. 1992. An Assessment of Biotic Inventories in Western U.S. National Parks. Natural Areas Journal, 12: 145-154.

Taylor, D. W. 1977. Rocky Mountain and Intermountain Freshwater Molluscs: an Annotated List. $40 \mathrm{pp}$. [unpub. ms.] 1981. Freshwater mollusks of California: a distributional checklist. Califomia Fish \& Game 67(3): 140-163. 
1982a. Status report on the Giant Columbia River Limpet in southwestem Idaho. Unpublished rept. to BLM. 7 pp.

1982b. Status report on the Great Columbia River Spire Snail in southern Idaho.

Unpublished rept. to BLM. 9 pp.

1985. Evolution of freshwater drainages and molluscs in western North America, pp. 265-321. In Smiley, C. J. (ed.), Late Cenozoic History of the Pacific Northwest. Pacific Division AAAS and Califormia Academy of Science, San Francisco. 417 pp.

1988a. Aspects of Freshwater Mollusc Ecological Biogeography. Palaeogeography, Palaeoclimatology, Palaeoecology 62: 511-576.

1988b. Phylum: Mollusca, pp. 33-57. In J. Gray, Evolution of the freshwater ecosystem: the fossil record. Palaeogeography, Palaeoclimatology, Palaeoecology 62: 1 214.

\& R. C. Bright. 1987. Drainage History of the Bonneville Basin, pp. 239-256, in R. S. Kopp \& R. E. Cohenour (eds.), Cenozoic Geology of Western Utah. Sites for Precious Metal and Hydrocarbon Accumulations. Utah Geological Association Publication 16, $684 \mathrm{pp}$.

, H. J. Walter, \& J. B. Burch. 1963. Freshwater snails of the subgenus Hinkleyia (Lymnaeidae: Stagnicola) from the western United States. Malacologia 1: 237-281.

Thomas, J. W., E. D. Forsman, J. B. Lint, E. C. Meslow, B. R. Noon, \& J. Verner. 1990. A Conservation Strategy for the Northern Spotted OwI. U.S. Dept. of Agriculture, Forest Service, Portland, OR. 427 pp.

, M. G. Raphael, R. G. Anthony, E. D. Forsman, A. G. Gunderson, R. S. Holthausen, B. G. Marcot, G. H. Reeves, J. R. Sedell, \& D. M. Solis. 1993. Viability Assessments and Management Considerations for Species Associated with Late-Successional and OldGrowth Forests of the Pacific Northwest. U. S. Dept. of Agriculture, Forest Service, Portland, OR. 530 pp.

Turgeon, D. D. et al. 1988. Common and Scientific Names of Aquatic Invertebrates from the United States and Canada. Mollusks. American Fisheries Society, Special Publication 16, 277 pp.

Uminski, T. 1963. Taxonomy of Anguispira (?) marmorensis (H. B. Baker, 1932) with notes on the taxonomy of the genera Anguispira Morse and Discus Fitzinger (Gastropoda, Endodontidae). Polska Akademia Nauk Instytut Zoologiczny Annales Zoologici 21: 8191.

USFWS. 1991. Endangered and Threatened Wildlife and Plants: Animal Candidate Review for Listing as Endangered or Threatened Species, Proposed Rule. Federal Register 56: 58804-58836.

. 1992a. Recovery Plan for the Northern Spotted OwI-DRAFT. 662 pp.

. 1992b. Recovery Plan for the Northern Spotted Owl- FINAL DRAFT. 2 vols., 332 pp. 490 pp.

1994. Endangered and Threatened Wildlife and Plants: Animal Candidate Review for 
Listing as Endangered or Threatened Species; Proposed Rule. Federal Register 56: 58982-59028.

Vagvolgyi, J. 1968. Systematics and Evolution of the Genus Triodopsis (Mollusca: Pulmonata: Polygyridae) Harvard University Museum of Comparative Zoology, Bull. 136 (7): 14-254.

Vanatta, E. G. 1924. Descriptions of four new American shells. Proceedings, Academy of Natural Sciences of Philadelphia 76: 25-27.

Vaught, K. C. 1989. A Classification of the Living Mollusca. American Malacologists, Inc., Melbourne, FL. 189 pp.

Walton, M. L. 1970. Longevity in Ashmunella, Monadenia, and Sonorella. The Nautilus 83: 109112.

Webb, G. F. 1968. The Ashmunellinae: Sexological Notes on Allogona. Gastropodia 1(7): 70-72

1970a. Sexological Notes on Cryptomastix mullani (Bland and Cooper). Gastropodia 1(8): 73-75, 78 (PI. 35, figs. 13. 14).

1970b. Fragmentary Observations on Sexology of Cryptomastix hendersoni Pilsbry and $C$. magnidentata Pilsbry and a new subgenus (Pulmonata, Polygyridae, Ashmunellinae). Gastropodia 1(8): 77-78.

1990. Photographs of the Copulation of Cryptomastix (Bupiogona) hendersoni. Gastropodia 2(3): 22.

Wu, Shi-Kuei, \& N. E. Brandauer. 1982. Type specimens of Recent Mollusca in the University of Colorado Museum. University of Colorado Museum, Natural History Inventory of Colorado no. 7: $47 \mathrm{pp}$. 


\section{GLOSSARY}

$$
\begin{aligned}
& \text { amniphile (n.) } \\
& \text { aufwuchs (n.) } \\
& \text { calciphile (n.) } \\
& \text { crenocole (n.) } \\
& \text { crenophile (n.) } \\
& \text { detritivore (n.) } \\
& \text { edaphic (adj.) } \\
& \text { epiphyte (n.) } \\
& \text { eoan (adj.) } \\
& \text { genotype (n.) } \\
& \text { holotype (n.) }
\end{aligned}
$$$$
\text { hypsiphile (n.) }
$$$$
\text { insolation (n.) }
$$$$
\text { iteroparous (adj.) }
$$$$
\text { lectotype (n.) }
$$$$
\text { mesocole (n.) }
$$$$
\text { mesophile (n.) }
$$$$
\text { metasedimentary (adj.) }
$$$$
\text { monospecific (adj.) }
$$

preferring stream environments.; amniphilic is the adjective.

the organic coating on stones or other underwater surfaces in permanent water bodies; consists of diatoms, protozoans, small algal epiphytes; fungi; and bacteria. The major food resource for lithophile taxa, and for perilithon and periphyton feeders (q.v.).

a species requiring relatively large amounts of free calcium ions for its shell or for other physiology- or metabolism-related reasons; used here for certain land snail and slug species; there are calciphile plants as well.

organism living only in spring environments; spring dweller.

preferring spring environments; crenophilic is the adjective.

aqueous taxon feeding on organic particles in sediment.

pertaining to soil conditions, such as composition, $\mathrm{pH}$, zone, etc.

(small) organism living attached to a (larger) substrate particle or other organism; өpiphytic is the adjective.

becoming active, or appearing, in the twilight.

formally designated type species of a genus-level taxon.

formally designated type specimen for a species-level taxon, as established at the time of the original description or by valid subsequent action.

taxon restricted to or liking high elevations: refers to certain land and freshwater mollusk taxa; hypsiphilic is the adjective.

the amount of sunlight striking the ground.

brreding more than once in a lifetime.

a subsequently designated holotype.

organism restricted or largely restricted to moderately moist habitats.

a species tolerant of or requiring relatively moist [but not extremely moist] conditions for at least part of its life, such as occur in forests or other areas shielded from continual insolation. The adjective is mesophilic.

rock type of difficult to characterize lithology derived from the metamorphosis of a sedimentary unit.

single species; used in two senses: 1) a genus with but one species; 2) a species assemblage or community with but one species. 


\begin{abstract}
monotypic (adj.)
nomen dubium $(\mathrm{n}$.)

notophile (n.)

having a single species-level taxon; generally applied to a genus.

a species-level name of questionable validity.

a species tolerant of or requining very moist conditions for at least part of its life, such as occur alongside permanent streams, seeps or springs; used here for certain land snail and slug species. The adjective is notophilic.
\end{abstract}

paratype (n.)

pelophile (n.)

perilithon (n.)

periphyton (n.)

regolith (n.)

semelparous (n.)

s.s.

s.l.

species inquirenda (n.)

synanthromorph (n.)

syntype (n.)

xerocole (n.)

xerophile (n.)

all members of the type suite for a species-level taxon, other than the holotype.

preferring muddy environments; polophilic is the adjective.

those organisms growing on stones; usually refers to the smaller (near to microscopic, and consisting of just one or a few cells per individual) and inconspicuous epiphytic algae, diatoms, protozoans, bacteria and fungi, rather than to larger organisms or plants; aufwuchs, in part.

those organisms growing on submerged stems and other parts of aquatic macrophytes; usually refers to the smaller (near to microscopic, and consisting of just one or a few cells per individual) and inconspicuous epiphytic algae, diatoms, protozoans, bacteria and fungi, rather than to larger organisms or plants; aufwuchs, in part.

the parent rock from which the soil in an area is derived; or that lithology most influencing edaphic conditions.

breeding only once in a lifetime.

abbreviation for sensu stricto (Latin), in the strict sense.

abbreviation for sensu lato (Latin), in a loose sense.

species whose validity needs further investigation.

species which does well in or around human-inhabited areas.

all members of a type suite for a species-level taxon for which a holotype and paratypes have not yet been designated.

species limited to or essentially limited to dry (arid or semisrid) habitats

a species tolerant of or requiring relatively dry (arid or semianid) conditions for at least part of its life; used here for certain land snail and slug species. The adjective is xerophilic. 


\section{TABLES}

TABLE TITLE PAGES
TA

1. MOLLUSKS OF THE LOWER SALMON RIVER VALLEY T1-2

2. STATUS OF LOWER SALMON RIVER VALLEY LAND MOLLUSKS T3-4

$\begin{array}{ll}3 . & \text { SITE FAUNAL LISTS }\end{array}$

4. SPECIES STTE LISTS

T59-61

5.

SITE OWNERSHIP

T62 
1

1

1

1

I

I

I

I

I

I

I

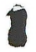

I

I

I

I

I

I

1 
TABLE 1. MOLLUSKS OF THE LOWER SALMON RIVER VALLEY.

\begin{tabular}{|c|c|c|c|}
\hline 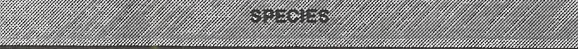 & 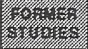 & 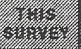 & 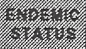 \\
\hline Allogona (Allogona) lombardii Smith, 1943 & - & $\mathrm{X}$ & $\mathrm{R}$ \\
\hline Allogona (Allogona) ptychophora ptychophora (Brown, 1870) & $\mathrm{x}$ & $\mathrm{X}$ & $R$ \\
\hline Allogona (Allogona) ptychophora solida Vanatta, 1924 & - & $\mathrm{x}$ & $\mathrm{H}$ \\
\hline Anguispira kochi occidentalis (Von Martens, 1882) & - & $\mathrm{x}$ & $R$ \\
\hline Catinella avara (Say, 1824) & $\mathrm{x}$ & $\mathrm{x}$ & $\mathrm{C}$ \\
\hline Cochlicopa lubrica (Müller, 1774) & $\bar{x}$ & $\mathrm{X}$ & $\mathrm{C}$ \\
\hline Cryptomastix (Bupiogona) populi (Vanatta, 1924) & - & $\mathrm{x}$ & $\mathrm{H}$ \\
\hline Cryptomastix (Cryptomastix) harfordiana (Binney, 1878) & $\mathrm{X}$ & $\mathrm{x}$ & $\mathrm{L}$ \\
\hline Cryptomastix (Cryptomastix) mullani clappi (Hemphill, 1897) & $x$ & $\bar{x}$ & $\mathrm{~L}$ \\
\hline Cryptomastix (Cryptomastix) mullani hemphilli (Binney, 1886) & $\mathrm{x}$ & - & $R$ \\
\hline Cryptomastix (C.) mullani latilabris (Pilsbry, 1940) & $\mathrm{x}$ & $\mathrm{x}$ & L \\
\hline Cryptomastix (Cryptomastix) mullani mullani (Bland \& Cooper, 1861) & $x$ & $\mathrm{x}$ & $\mathrm{R}$ \\
\hline Cryptomastix (Cryptomastix) mullani olneyae (Pilsbry, 1891) & $\mathrm{x}$ & $\mathrm{x}$ & $\mathrm{R}$ \\
\hline Cryptomastix (Cryptomastix) n. sp. 3 & - & $x$ & $\mathrm{H}$ \\
\hline Cryptomastix (Cryptomastix) n. sp. $5^{1}$ & $\mathrm{U}$ & $\mathrm{x}$ & $\mathrm{L}$ \\
\hline Cryptomastix (Cryptomastix) n. sp. $6^{1}$ & $\mathrm{U}$ & $\mathrm{X}$ & $\mathrm{L}$ \\
\hline Deroceras sp. & $\mathrm{x}$ & $\mathrm{x}$ & $\mathrm{C}$ \\
\hline Discus marmorensis Baker, 1932 & $x$ & $\mathrm{x}$ & $\mathrm{L}$ \\
\hline Discus whitneyi (Newcomb, 1864) ${ }^{2}$ & $\mathrm{x}$ & $x$ & $\mathrm{C}$ \\
\hline Euconulus fulvus alaskensis Pilsbry. 1906 & - & $\mathrm{x}$ & $R$ \\
\hline Hawaiia minuscula (Binney, 1840) & $x$ & $\mathrm{x}$ & $\mathrm{C}$ \\
\hline Helicodiscus salmoneus Binney, 1886 & $\mathrm{x}$ & $\mathrm{x}$ & $\mathrm{R}$ \\
\hline Hemphillia camelus Pilsbry \& Vanatta, 1897 & $\mathrm{x}$ & $\mathrm{x}$ & $\mathrm{R}$ \\
\hline Microphysula ingersolli ingersolli (Bland, 1874) & $\mathrm{x}$ & $\mathrm{X}$ & $R$ \\
\hline Ogaridiscus subrupicola (Dall, 1877) & $\mathrm{x}$ & $\mathrm{x}$ & $R$ \\
\hline Oreohelix hammeri Fairbanks, 1984 & {$[\mathrm{X}]$} & {$[\mathrm{X}]$} & $\mathrm{L}$ \\
\hline Oreohelix haydeni hesperia Pilsbry, 1939 & $\mathrm{x}$ & $\mathrm{x}$ & $\mathrm{L}$ \\
\hline Oreohelix haydeni perplexa Pilsbry, 1939 & $\mathrm{x}$ & $\mathrm{x}$ & $\mathrm{L}$ \\
\hline Oreohelix idahoensis idahoensis (Newcomb, 1866) & $\mathrm{x}$ & $x$ & L \\
\hline Oreohelix intersum (Hemphill, 1890) & $\mathrm{x}$ & $x$ & L \\
\hline Oreohelix jugalis (Hemphill, 1890) & $\mathrm{X}$ & $x$ & $\mathrm{~L}$ \\
\hline Oreohelix n. sp. 8 & - & $x$ & $L$ \\
\hline Oreohelix n. sp. 12 & - & $\mathrm{x}$ & $\mathrm{L}$ \\
\hline Oreohelix n. sp. 13 & $\mathrm{U}$ & $\mathrm{x}$ & $L$ \\
\hline Oreohelix n. sp. 14 & - & $x$ & $\mathrm{~L}$ \\
\hline Oreohelix n. sp. 15 & $\mathrm{U}$ & $x$ & $L$ \\
\hline Oreohelix ni. sp. 19 & - & $x$ & $L$ \\
\hline Oreohelix n. sp. $20^{3}$ & - & $x$ & $L$ \\
\hline Oreohelix n. sp. 21 & $\mathrm{U}$ & $x$ & $L$ \\
\hline Oreohelix n. sp. 22 & - & $x$ & L \\
\hline Oreohelix n. sp. $23^{4}$ & $\mathrm{U}$ & $x$ & $\mathrm{~L}$ \\
\hline Oreohelix n. sp. 24 & - & $x$ & $L$ \\
\hline
\end{tabular}


TABLE 1. MOLLUSKS OF THE LOWER SALMON RIVER VALLEY. (cont.)

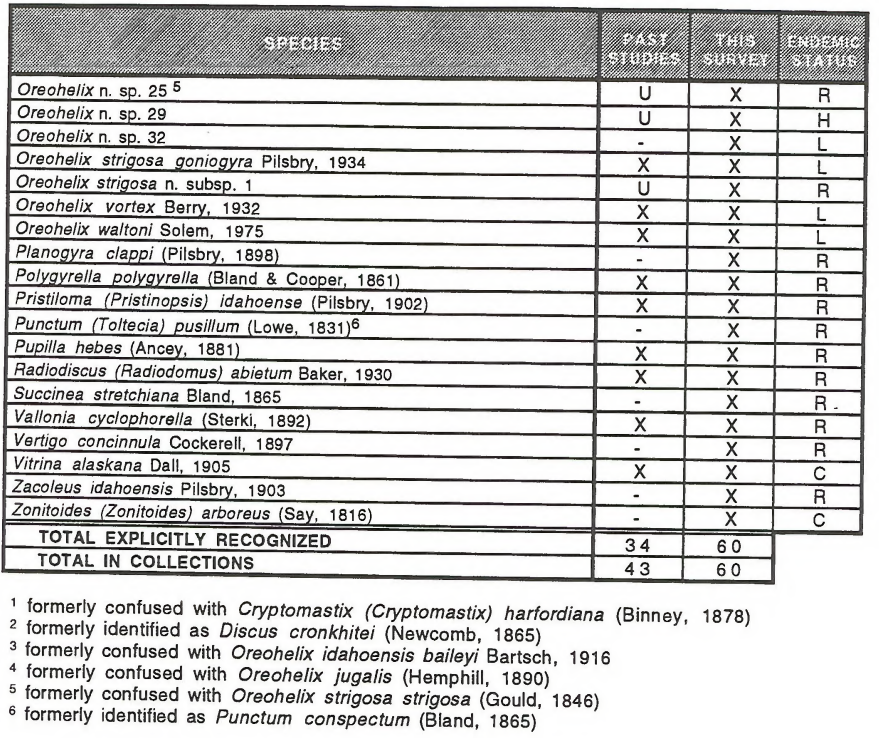

$L=\quad$ lower Salmon River endemic

$\mathrm{H}=$ Hells Canyon and lower Salmon River endemic

$\mathrm{R}=$ regional endemic (Washingtonian Province)

$\mathrm{C}=$ present widely in two or more mollusk provinces; cosmopolitan

$X=$ present and verified

$U=$ present in museum collections but identified as another taxon; undescribed

[ ] = present but not collected 


\section{TABLE 2. STATUS OF LOWER SALMON RIVER VALLEY LAND MOLLUSKS.}

\begin{tabular}{|c|c|c|c|}
\hline \multirow{2}{*}{ 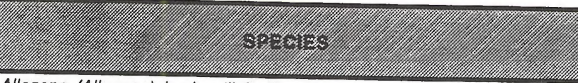 } & \multicolumn{2}{|c|}{ 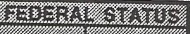 } & \multirow{2}{*}{ 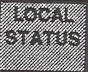 } \\
\hline & 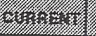 & 佂 & \\
\hline Allogona (Allogona) lombardii Smith, 1943 & $\mathrm{~N}$ & $\mathrm{~T}$ & VR \\
\hline Allogona (Allogona) ptychophora ptychophora (Brown, 1870) & $\mathrm{N}$ & $\mathrm{N}$ & $A$ \\
\hline Allogona (Allogona) ptychophora solida Vanatta, 1924 & $\mathrm{~N}$ & $T$ & $\mathrm{R}$ \\
\hline Anquispira kochi occidentalis (Von Martens, 1882) & $\mathrm{N}$ & $\mathrm{N}$ & VR \\
\hline Catinella avara (Say, 1824) & $\mathrm{N}$ & $\mathrm{N}$ & VR \\
\hline Cochlicopa lubrica (Müller, 1774) & $\mathrm{N}$ & $\mathrm{N}$ & $\mathrm{C}$ \\
\hline Cryptomastix (Bupiogona) populi (Vanatta, 1924) & $\mathrm{N}$ & $T$ & $w$ \\
\hline Cryptomastix (Cryptomastix) harfordiana (Binney, 1878) & $\mathrm{N}$ & $E$ & $\mathrm{C}$ \\
\hline Cryptomastix (Cryptomastix) mullani clappi (Hemphill, 1897) & $\mathrm{N}$ & $E$ & 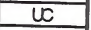 \\
\hline Cryptomastix (Cryptomastix) mullani hemphilli (Binney, 1886) & $\mathrm{N}$ & $\mathrm{U}$ & $\theta ?$ \\
\hline Cryptomastix (C.) mullani latilabris (Pilsbry, 1940) & $\mathrm{N}$ & $E$ & VR \\
\hline Cryptomastix (Cryptomastix) mullani mullani (Bland \& Cooper, 1861) & $\mathrm{N}$ & $\mathrm{N}$ & $\mathrm{R}$ \\
\hline Cryptomastix (Cryptomastix) mullani olneyae (Pilsbry, 1891) & $\mathrm{N}$ & $\mathrm{N}$ & $\mathrm{C}$ \\
\hline Cryptomastix (Cryptomastix) n. sp. 3 & $\mathrm{~N}$ & $E$ & VR \\
\hline Cryptomastix (Cryptomastix) n. sp. $5^{1}$ & $\mathrm{~N}$ & $\mathrm{~T}$ & $\mathrm{C}$ \\
\hline Cryptomastix (Cryptomastix) n. sp. $6^{1}$ & $\mathrm{~N}$ & $\mathrm{~T}$ & $\mathrm{C}$ \\
\hline Deroceras sp. & $\mathrm{N}$ & $\mathrm{N}$ & VR \\
\hline Discus marmorensis Baker, 1932 & $\mathrm{C}$ & $E$ & $\mathrm{R}$ \\
\hline Discus whitneyi (Newcomb, 1864) 2 & $\mathrm{~N}$ & $\mathrm{~N}$ & VR \\
\hline Euconulus fulvus alaskensis Pilsbry, 1906 & $\mathrm{~N}$ & $\mathrm{~N}$ & UC \\
\hline Hawaiia minuscula (Binney, 1840) & $\mathrm{N}$ & $\mathrm{N}$ & VR \\
\hline Helicodiscus salmoneus Binney, 1886 & $\mathrm{~N}$ & $\mathrm{~N}$ & $C$ \\
\hline Hemphillia camelus Pilsbry \& Vanatta, 1897 & $\mathrm{~N}$ & $T$ & VR \\
\hline Microphysula ingersolli (Bland, 1874) & $\mathrm{N}$ & $\mathrm{N}$ & VR \\
\hline Dgaridiscus subrupicola (Dall, 1877) & $\mathrm{N}$ & $\mathrm{T}$ & VR \\
\hline Preohelix hammeri Fairbanks, 1984 & $\mathrm{~N}$ & $E$ & VR \\
\hline Oreohelix haydeni hesperia Pilsbry, 1939 & $\mathrm{~N}$ & $E$ & $\mathrm{R}$ \\
\hline Dreohelix haydeni perplexa Pilsbry, 1939 & $\mathrm{~N}$ & $\mathrm{E}$ & VR \\
\hline Dreohelix idahoensis idahoensis (Newcomb, 1866) & $C$ & T? & $w$ \\
\hline Dreohelix intersum (Hemphill, 1890) & $\mathrm{N}$ & $E$ & $\mathrm{R}$ \\
\hline Preohelix jugalis (Hemphill, 1890) & $\mathrm{C}$ & T? & $C$ \\
\hline Oreohelix n. sp. 8 & $\mathrm{~N}$ & $\mathrm{E}$ & VR \\
\hline Oreohelix n. sp. 12 & $\mathrm{~N}$ & $E$ & VR \\
\hline Oreohelix n. sp. 13 & $\mathrm{~N}$ & $E$ & VR \\
\hline Oreohelix n. sp. 14 & $\mathrm{~N}$ & $E$ & VR \\
\hline Oreohelix n. sp. 15 & $\mathrm{~N}$ & $E$ & $R$ \\
\hline Oreohelix n. sp. 19 & $\mathrm{~N}$ & $\bar{E}$ & VR \\
\hline Oreohelix n. sp. $20^{3}$ & $\mathrm{~N}$ & $E$ & $\mathrm{R}$ \\
\hline Oreohelix n. sp. 21 & $\mathrm{~N}$ & $\bar{E}$ & $\mathrm{R}$ \\
\hline Oreohelix n. sp. 22 & $\mathrm{~N}$ & $E$ & $\mathrm{R}$ \\
\hline Oreohelix n. sp. $23^{4}$ & $\mathrm{~N}$ & $E$ & $\mathrm{R}$ \\
\hline Preohelix n. sp. 24 & $\mathrm{~N}$ & $E$ & VR \\
\hline
\end{tabular}


TABLE 2. STATUS OF LOWER SALMON RIVER VALLEY LAND MOLLUSKS. (cont.)

\begin{tabular}{|c|c|c|c|}
\hline \multirow{2}{*}{ 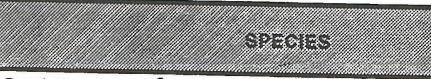 } & \multicolumn{2}{|c|}{ 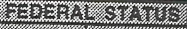 } & \multirow{2}{*}{ Y } \\
\hline & (oving & 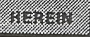 & \\
\hline Oreohelix n. sp. 255 & $\mathrm{~N}$ & $\mathrm{~T}$ & $\mathrm{C}$ \\
\hline Oreohelix n. sp. 29 & $\mathrm{~N}$ & $T$ & $\mathrm{C}$ \\
\hline Oreohelix n. sp. 32 & $\mathrm{~N}$ & $E$ & $\sqrt{R}$ \\
\hline Oreohelix strigosa goniogyra Pilsbry, 1934 & $\mathrm{C}$ & $E$ & $R$ \\
\hline Oreohelix strigosa n. subsp. 1 & $\mathrm{~N}$ & $T$ & Uc \\
\hline Oreohelix vortex Berry, 1932 & $\mathrm{C}$ & $T$ & Uc \\
\hline Oreohelix waltoni Solem, 1975 & $\mathrm{C}$ & $E$ & VR \\
\hline Planogyra clappi (Pilsbry, 1898) & $\mathrm{N}$ & $\mathrm{N}$ & VR \\
\hline Polygyrella polygyrella (Bland \& Cooper, 1861) & $\mathrm{N}$ & $\mathrm{S}$ & VR \\
\hline Pristiloma (Pristinopsis) idahoense (Pilsbry, 1902) & $\mathrm{N}$ & $T$ & VR \\
\hline Punctum pusillum (Lowe, 1831$)^{6}$ & $\mathrm{~N}$ & $\mathrm{~N}$ & VR \\
\hline Pupilla hebes (Ancey, 1881) & $\mathrm{N}$ & $\mathrm{N}$ & UC \\
\hline Radiodiscus (Radiodomus) abietum Baker, 1930 & $\mathrm{~N}$ & $\mathrm{~s}$ & VR \\
\hline Succinea stretchiana Bland, 1865 & $\mathrm{~N}$ & $\mathrm{~N}$ & $\mathrm{VR}^{+}$ \\
\hline Vallonia cyclophorella (Sterki, 1892) & $\mathrm{N}$ & $\mathrm{N}$ & $\mathrm{C}$ \\
\hline Vertigo concinnula Cockerell, 1897 & $\mathrm{~N}$ & $\mathrm{~N}$ & VR \\
\hline Vitrina alaskana Dall, 1905 & $\mathrm{~N}$ & $\mathrm{~N}$ & $\mathrm{C}$ \\
\hline Zacoleus idahoensis Pilsbry, 1903 & $\mathrm{~N}$ & $\mathrm{~S}$ & VR \\
\hline Zonitoides (Zonitoides) arboreus (Say, 1816) & $\mathrm{N}$ & $\mathrm{N}$ & VR \\
\hline
\end{tabular}

1 formerly confused with Cryptomastix (Cryptomastix) harfordiana (Binney, 1878)

2 formerly identified as Discus cronkhitei (Newcomb, 1865)

${ }^{3}$ formerly confused with Oreohelix idahoensis baileyi Bartsch, 1916

4 formerly confused with Oreohelix jugalis (Hemphill, 1890)

5 formerly confused with Oreohelix strigosa strigosa (Gould, 1846)

${ }^{6}$ formerly identified as Punctum conspectum (Bland, 1865)

\section{ABBREVIATIONS:}

$\mathrm{N}=$ no current special status

$\mathrm{C}=$ current federal candidate

$\mathrm{S}=\quad$ sensitive species; see Frest \& Johannes (1995a)

$\mathrm{T}=$ federal listing as Threatened

$E=$ federal listing as Endangered

$A=$ abundant

$\mathrm{C}=$ common

$\mathrm{UC}=$ uncommon

$\mathrm{R}=$ rare

$\mathrm{VR}=$ very rare

$\mathrm{e}=$ possibly extinct 
TABLE 3. SITE FAUNAL LISTS.

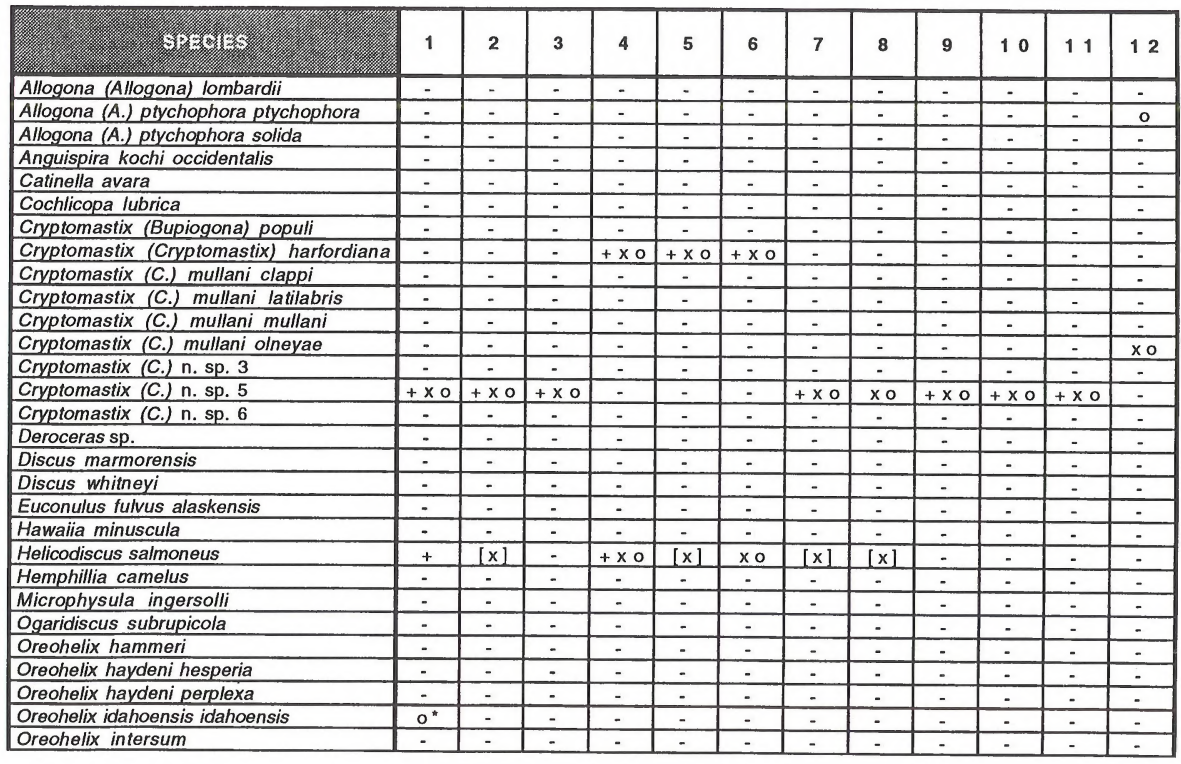

"= colony may be extinct 
TABLE 3. SITE FAUNAL LISTS. (cont.)

\begin{tabular}{|c|c|c|c|c|c|c|c|c|c|c|c|c|}
\hline 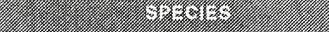 & 1 & 2 & 3 & 4 & 5 & 6 & 7 & 8 & 9 & 10 & 11 & 12 \\
\hline Oreohelix jugalis & - & - & - & - & - & - & - & - & - & - & - & $+x 0$ \\
\hline Oreohelix n. sp. 8 & - & - & - & - & - & - & - & - & - & - & - & - \\
\hline Oreohelix n. sp. 12 & - & - & - & - & - & - & - & - & - & - & - & - \\
\hline Oreohelix n. sp. 13 & - & - & - & - & - & - & - & - & - & - & - & - \\
\hline Oreohelix n. sp. 14 & - & - & - & - & - & - & - & - & - & - & - & - \\
\hline Oreohelix n. sp. 15 & - & $=$ & - & - & - & - & - & - & - & - & - & - \\
\hline Oreohelix n. sp. 19 & - & - & - & - & - & - & - & - & - & - & - & - \\
\hline Oreohelix n. sp. 20 & - & - & - & - & - & - & - & - & - & - & - & - \\
\hline Oreohelix n. sp. 21 & - & - & - & $+\times 0$ & - & - & $+\times 0$ & - & xo & - & - & - \\
\hline Oreohelix n. sp. 22 & - & - & - & - & - & - & - & - & - & - & - & - \\
\hline Oreohelix n. sp. 23 & - & - & - & - & - & $+\times 0$ & - & $+\times 0$ & - & $+x 0$ & $+\times 0$ & - \\
\hline Oreohelix n. sp. 24 & - & - & - & - & - & - & - & - & - & - & - & - \\
\hline Oreohelix n. sp. 25 & - & - & - & - & - & - & - & - & - & - & - & - \\
\hline Oreohelix n. sp. 29 & - & - & - & - & - & - & - & - & - & - & - & - \\
\hline Oreohelix n. sp. 32 & - & - & - & - & - & - & - & - & - & - & - & - \\
\hline Oreohelix strigosa goniogyra & - & - & - & - & - & - & - & - & - & - & - & - \\
\hline Oreohelix strigosa n. subsp. 1 & - & - & - & - & - & - & - & - & - & - & - & - \\
\hline Oreohelix vortex & - & - & - & - & - & - & - & - & - & - & - & - \\
\hline Oreohelix waltoni & - & - & - & - & - & - & - & - & - & - & - & - \\
\hline Planogyra clappi & - & - & - & - & - & - & - & - & - & - & - & - \\
\hline Polygyrella polygyrella & - & - & - & - & - & - & - & - & - & - & - & - \\
\hline Pristiloma (Pristinopsis) idahoense & - & - & - & - & - & - & - & - & - & - & - & - \\
\hline Punctum pusillum & - & - & - & - & - & - & - & - & - & - & - & - \\
\hline Pupilla hebes & - & - & - & - & - & - & - & - & - & - & - & - \\
\hline Radiodiscus (Radiodomus) abietum & - & - & - & - & - & - & - & - & - & - & - & - \\
\hline Succinea stretchiana & - & - & - & - & - & - & - & - & - & - & - & - \\
\hline Vallonia cyclophorella & - & {$[\mathrm{x}]$} & - & $\mathrm{x}$ & - & - & - & - & - & - & - & - \\
\hline Vertigo concinnula & - & - & - & - & - & - & - & - & - & - & - & - \\
\hline
\end{tabular}


TABLE 3. SITE FAUNAL LISTS. (cont.)

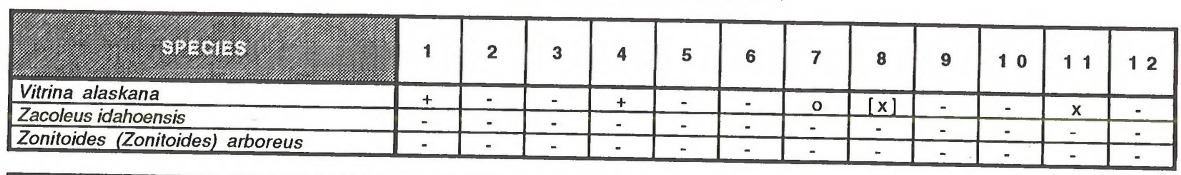

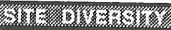

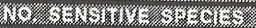

368:

\begin{tabular}{|c|c|c|c|c|c|c|c|c|c|c|c|}
\hline 3 & 3 & 1 & 5 & 2 & 3 & 4 & 4 & 2 & 2 & 2 & 3 \\
\hline $2 ?$ & 1 & 1 & 2 & 1 & 2 & 2 & 2 & 2 & 2 & 2 & 1 \\
\hline $1 ?$ & 0 & 0 & 0 & 0 & 0 & 0 & 0 & 0 & 0 & 0 & 1 \\
\hline
\end{tabular}
$+=$ live collection
$\mathrm{x}=$ recently dead
$\mathrm{o}=$ long-dead
[ ]= not collected 
TABLE 3. SITE FAUNAL LISTS. (cont.)

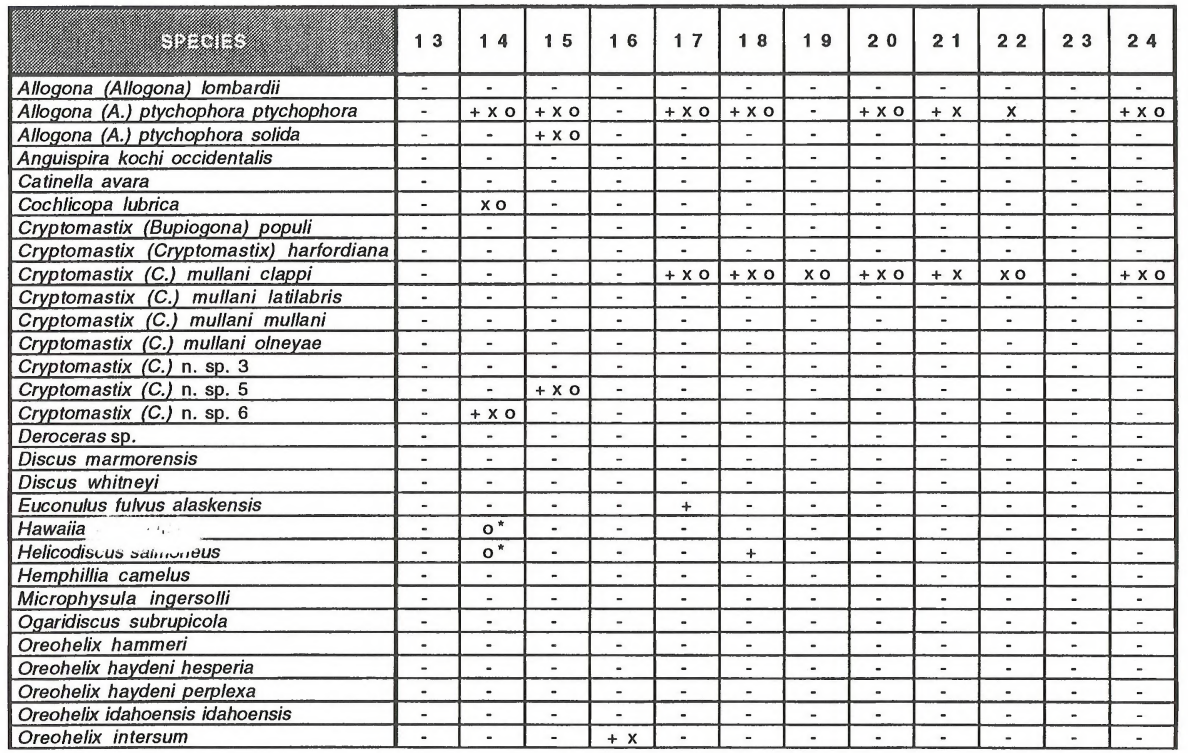

* = colony may be extinct 
TABLE 3. SITE FAUNAL LISTS. (cont.)

\begin{tabular}{|c|c|c|c|c|c|c|c|c|c|c|c|c|}
\hline 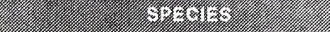 & 13 & 14 & 15 & 16 & 17 & 18 & 19 & 20 & 21 & 22 & 23 & 24 \\
\hline Oreohelix jugalis & - & + & $+\times 0$ & - & $0^{*}$ & - & - & - & $+\times 0$ & - & - & $\sim$ \\
\hline Oreohelix n. sp. 8 & - & - & - & - & - & - & - & - & - & - & - & - \\
\hline Oreohelix n. sp. 12 & - & - & - & - & - & - & - & - & - & - & - & - \\
\hline Oreohelix n. sp. 13 & - & - & - & - & - & - & - & - & - & - & - & - \\
\hline Oreohelix n. sp. 14 & - & - & - & - & - & - & - & - & - & - & - & - \\
\hline Oreohelix n. sp. 15 & - & - & - & - & $+\times 0$ & $+\times 0$ & - & $+x$ & - & - & - & - \\
\hline Oreohelix n. sp. 19 & - & - & - & - & - & - & - & - & - & - & - & - \\
\hline Oreohelix n. sp. 20 & - & - & - & - & - & - & - & - & - & - & - & - \\
\hline Oreohelix n. sp. 21 & - & - & - & - & - & - & - & - & - & - & - & - \\
\hline Oreohelix n. sp. 22 & - & - & - & - & - & - & - & - & - & - & - & - \\
\hline Oreohelix n. sp. 23 & - & - & - & - & - & - & - & - & - & - & - & - \\
\hline Oreohelix n. sp. 24 & - & - & - & - & - & - & - & - & - & - & - & - \\
\hline Oreohelix n. sp. 25 & - & - & - & - & - & - & - & - & - & - & - & - \\
\hline Oreohelix n. sp. 29 & - & - & - & - & - & - & - & - & - & - & - & - \\
\hline Oreohelix n. sp. 32 & - & - & - & - & - & - & - & - & - & - & - & - \\
\hline Oreohelix strigosa goniogyra & - & - & - & - & - & - & - & $+\times 0$ & - & - & - & - \\
\hline Oreohelix strigosa n. subsp. 1 & - & - & - & - & - & - & - & - & - & - & - & - \\
\hline Oreohelix vortex & - & $+\times 0$ & $+\times 0$ & - & - & - & - & - & - & - & - & - \\
\hline Oreohelix waltoni & - & - & - & - & - & - & - & - & - & - & - & - \\
\hline Planogyra clappi & - & - & - & - & - & - & - & - & - & - & - & - \\
\hline Polygyrella polygyrella & - & - & - & - & - & - & - & - & - & - & - & - \\
\hline Pristiloma (Pristinopsis) idahoense & - & - & - & - & - & - & - & - & - & - & - & - \\
\hline Punctum pusillum & - & - & - & - & - & - & - & - & - & - & - & - \\
\hline Pupilla hebes & - & xo & - & - & - & - & - & - & - & - & - & - \\
\hline Radiodiscus (Radiodomus) abietum & - & - & - & - & - & - & - & - & - & - & - & - \\
\hline Succinea stretchiana & - & - & - & - & - & - & - & - & - & - & - & - \\
\hline Vallonia cyclophorella & - & xo & - & - & - & - & - & - & - & - & - & - \\
\hline Vertigo concinnula & - & - & - & - & - & - & - & - & - & - & - & - \\
\hline
\end{tabular}

" = colony may now be extirpated 
TABLE 3. SITE FAUNAL LISTS. (cont.)

\begin{tabular}{|c|c|c|c|c|c|c|c|c|c|c|c|c|}
\hline \multicolumn{13}{|l|}{ 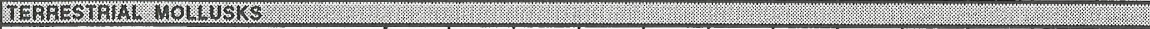 } \\
\hline Zacoleus idahoensis & - & - & - & - & - & - & - & - & - & - & - & - \\
\hline Zonitoides (Zonitoides) arboreus & - & - & - & - & - & - & - & - & - & - & - & - \\
\hline
\end{tabular}

\begin{tabular}{|l|l|l|l|l|l|l|l|l|l|l|l|l|}
\hline$x_{3}$ & 0 & 10 & 5 & 2 & 5 & 3 & 1 & 4 & 3 & 3 & 0 & 2 \\
\hline
\end{tabular}
$+=$ live collection
$x=$ recently dead
$\mathrm{o}=$ long-dead
[ ] = not collected
${ }^{*}$ = colony may be extirpated 
TABLE 3. SITE FAUNAL. LISTS. (cont.)

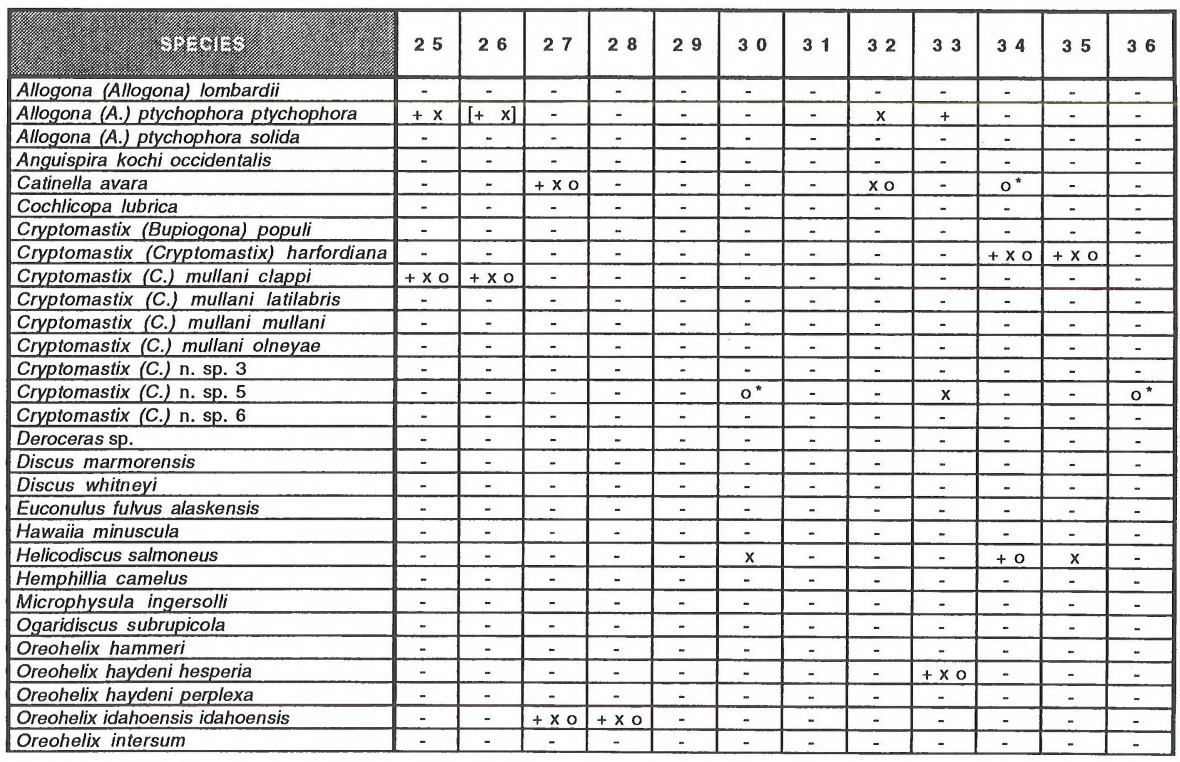

* = colony may be extirpated 
TABLE 3. SITE FAUNAL LISTS. (cont.)

\begin{tabular}{|c|c|c|c|c|c|c|c|c|c|c|c|c|}
\hline 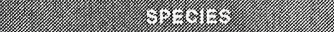 & 25 & 26 & 27 & 28 & 29 & 30 & 31 & 32 & 33 & 34 & 35 & 36 \\
\hline Oreohelix jugalis & - & - & - & - & - & - & - & $+\times 0$ & - & - & - & $0^{*}$ \\
\hline Oreohelix n. sp. 8 & - & - & - & - & - & - & - & - & - & - & - & - \\
\hline Oreohelix n. sp. 12 & - & - & - & - & - & - & - & - & - & - & - & - \\
\hline Oreohelix n. sp. 13 & - & - & - & - & - & - & - & - & - & - & - & - \\
\hline Oreohelix n. sp. 14 & - & - & - & - & - & - & - & - & - & - & - & - \\
\hline Oreohelix n. sp. 15 & - & - & - & - & - & - & - & - & - & - & - & - \\
\hline Oreohelix n. sp. 19 & - & - & - & - & - & - & - & - & - & - & - & - \\
\hline Oreohelix n. sp. 20 & - & - & - & - & - & - & - & - & - & - & - & - \\
\hline Oreohelix n. sp. 21 & - & - & - & - & - & - & - & - & - & - & - & - \\
\hline Oreohelix n. sp. 22 & - & - & - & - & - & - & - & - & - & - & - & - \\
\hline Oreohelix n. sp. 23 & - & - & - & - & $+\times 0$ & - & - & - & - & - & $+x 0$ & - \\
\hline Oreohelix n. sp. 24 & - & - & - & - & - & - & $+\times 0$ & - & - & - & - & - \\
\hline Oreohelix n. sp. 25 & - & - & - & - & - & - & - & - & $=$ & - & - & - \\
\hline Oreohelix n. sp. 29 & - & - & - & - & - & - & - & - & - & - & - & - \\
\hline Oreohelix n. sp. 32 & - & - & - & - & - & - & - & - & - & - & - & - \\
\hline Oreohelix strigosa goniogyra & - & - & - & - & - & - & - & - & - & - & - & - \\
\hline Oreohelix strigosa n. subsp. 1 & - & - & - & - & - & - & - & - & - & - & - & - \\
\hline Oreohelix vortex & - & - & - & - & - & - & - & - & - & - & - & - \\
\hline Oreohelix waltoni & - & - & - & - & - & $0^{*}$ & - & - & - & $0^{*}$ & - & - \\
\hline Planogyra clappi & - & - & - & - & - & - & - & - & - & - & - & - \\
\hline Polygyrella polygyrella & - & - & - & - & - & - & - & - & - & - & - & - \\
\hline Pristiloma (Pristinopsis) idahoense & - & - & - & - & - & - & $\therefore$ & - & - & - & - & - \\
\hline Punctum pusillum & - & - & - & - & - & - & - & - & - & - & - & - \\
\hline Pupilla he & - & - & $\mathrm{x}$ & - & - & - & - & - & - & - & - & - \\
\hline Radiodiscus (riadiodomus) abietum & - & - & - & - & - & - & - & - & - & - & - & - \\
\hline Succinea stretchiana & - & - & - & - & - & - & - & - & - & $\mathrm{O}^{\star}$ & - & - \\
\hline Vallonia cyclophorella & - & - & - & - & - & - & - & - & - & - & - & - \\
\hline Vertigo concinnula & - & - & - & - & - & - & - & - & - & - & - & - \\
\hline
\end{tabular}

*formerly $+\mathrm{x}$ o: recently extirpated colony or colony that may be extirpated 

TABLE 3. SITE FAUNAL LISTS. (cont.)

\begin{tabular}{|c|c|c|c|c|c|c|c|c|c|c|c|c|}
\hline 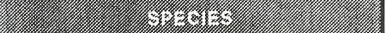 & 37 & 38 & 39 & 40 & 41 & 42 & 43 & 44 & 45 & 46 & 47 & 48 \\
\hline Allogona (Allogona) lombardii & - & - & - & - & - & - & - & - & - & - & $+\times 0$ & - \\
\hline Allogona (A.) ptychophora ptychophora & $+\times 0$ & $0^{*}$ & $0^{*}$ & - & $+\times 0$ & xo & $+\times 0$ & - & - & $x$ & - & $+x$ \\
\hline Allogona (A.) ptychophora solida & - & - & - & - & - & - & - & - & - & - & - & - \\
\hline Anguispira kochi occidentalis & - & - & - & - & - & - & - & - & - & - & - & - \\
\hline Catinella avara & - & $0^{*}$ & - & - & $\mathrm{O}^{*}$ & - & - & - & - & - & - & - \\
\hline Cochlicopa lubrica & - & - & - & - & - & - & - & - & - & - & - & - \\
\hline Cryptomastix (Bupiogona) populi & - & - & - & - & - & - & - & - & - & - & - & - \\
\hline Cryptomastix (Cryptomastix) harfordiana & - & - & $+\times 0$ & $+\times 0$ & $+\times 0$ & - & - & - & - & - & - & - \\
\hline Cryptomastix (C.) mullani clappi & - & - & - & - & - & - & - & - & - & - & - & - \\
\hline Cryptomastix (C.) mullani latilabris & - & - & - & - & - & - & $+\times 0$ & - & - & xo & $+\times 0$ & - \\
\hline Cryptomastix (C.) mullani mullani & - & - & - & - & - & - & - & - & - & - & - & - \\
\hline Cryptomastix (C.) mullani olneyae & - & - & - & - & - & - & - & - & - & - & - & $0^{*}$ \\
\hline Cryptomastix (C.) n. sp. 3 & - & - & - & - & - & - & - & - & - & - & - & - \\
\hline Cryptomastix (C.) n. sp. 5 & $+\times 0$ & $+\times 0$ & - & - & - & $0^{*}$ & - & - & - & - & - & - \\
\hline Cryptomastix (C.) n. sp. 6 & - & - & - & - & - & - & - & - & - & - & - & - \\
\hline Deroceras sp. & - & - & - & - & $+x$ & $+x$ & - & - & - & - & - & - \\
\hline Discus marmorensis & - & - & - & - & - & - & + & - & - & $\mathrm{x}$ & $+\times 0$ & - \\
\hline Discus whitneyi & - & - & - & - & - & - & - & - & - & - & - & - \\
\hline Euconulus fulvus alaskensis & - & - & - & - & - & - & - & - & - & - & - & - \\
\hline Hawaiia minuscula & - & - & - & - & - & - & - & - & - & - & - & - \\
\hline Helicodiscus salmoneus & - & - & - & $x$ & - & - & - & - & - & - & - & - \\
\hline Hemphillia camelus & - & - & - & - & - & - & - & - & - & - & - & - \\
\hline Microphysula ingersolli & - & - & - & - & - & - & - & - & - & - & $\mathrm{x}$ & - \\
\hline Ogaridiscus subrupicola & - & - & - & - & - & - & - & - & - & - & - & - \\
\hline Oreohelix hammeri & - & - & - & - & - & - & - & - & - & - & - & - \\
\hline Oreohelix haydeni hesperia & - & - & - & $\dot{-}$ & - & - & $+x o$ & - & - & - & $+\times 0$ & $+\times 0$ \\
\hline Oreohelix haydeni perplexa & - & - & - & - & - & - & - & - & - & - & - & - \\
\hline Oreohelix idahoensis idahoensis & - & - & - & - & - & - & - & - & - & - & - & - \\
\hline Oreohelix intersum & - & - & - & - & - & - & - & - & - & - & - & - \\
\hline
\end{tabular}

* = colony may now be extirpated 
TABLE 3. SITE FAUNAL LISTS. (cont.)

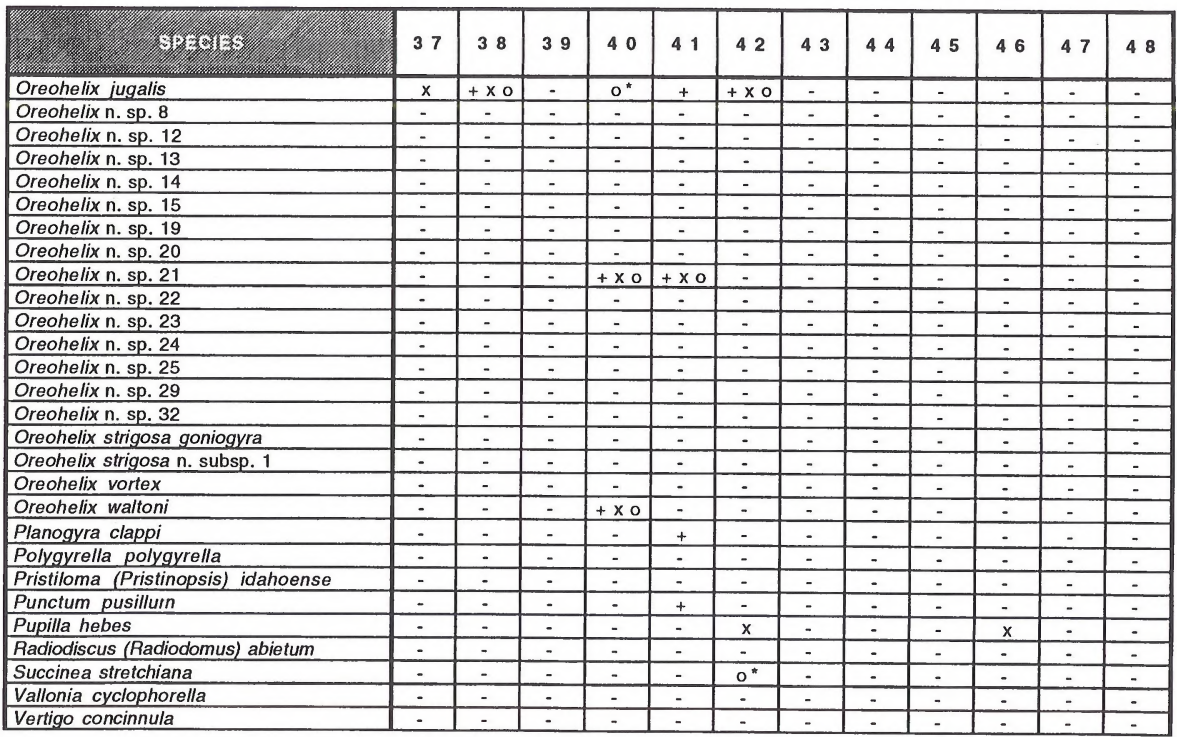

" = colony may now be extirpated 
TABLE 3. SITE FAUNAL LISTS. (cont.)

\begin{tabular}{|l|l|l|l|l|l|l|l|l|l|l|c|c|}
\hline Vitrina alaskana & 37 & 38 & 39 & 40 & 41 & 42 & 43 & 44 & 45 & 46 & 47 & 48 \\
\hline Zacoleus idahoensis & - & - & - & - & - & $x$ & - & - & - & $x$ & - & - \\
\hline Zonitoides (Zonitoides) arboreus & - & - & - & - & - & - & - & - & - & - & - & - \\
\hline
\end{tabular}

\begin{tabular}{|c|c|c|c|c|c|c|c|c|c|c|c|c|}
\hline 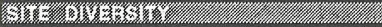 & 3 & 4 & 2 & 4 & 7 & 7 & 4 & 0 & 0 & 5 & 5 & 3 \\
\hline 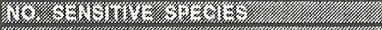 & 2 & 2 & 1 & 3 & 4 & [2?] & 3 & 0 & 0 & 2 & 4 & 2?] \\
\hline 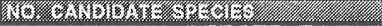 & 1 & 1 & 0 & [2?] & 1 & 1 & 1 & 0 & 0 & 1 & 1 & 0 \\
\hline
\end{tabular}

$+=$ live collection

$x=$ recently dead

$0=$ long-dead

[ ] = not collected

* = colony may now be extirpated 
TABLE 3. SITE FAUNAL LISTS. (cont.)

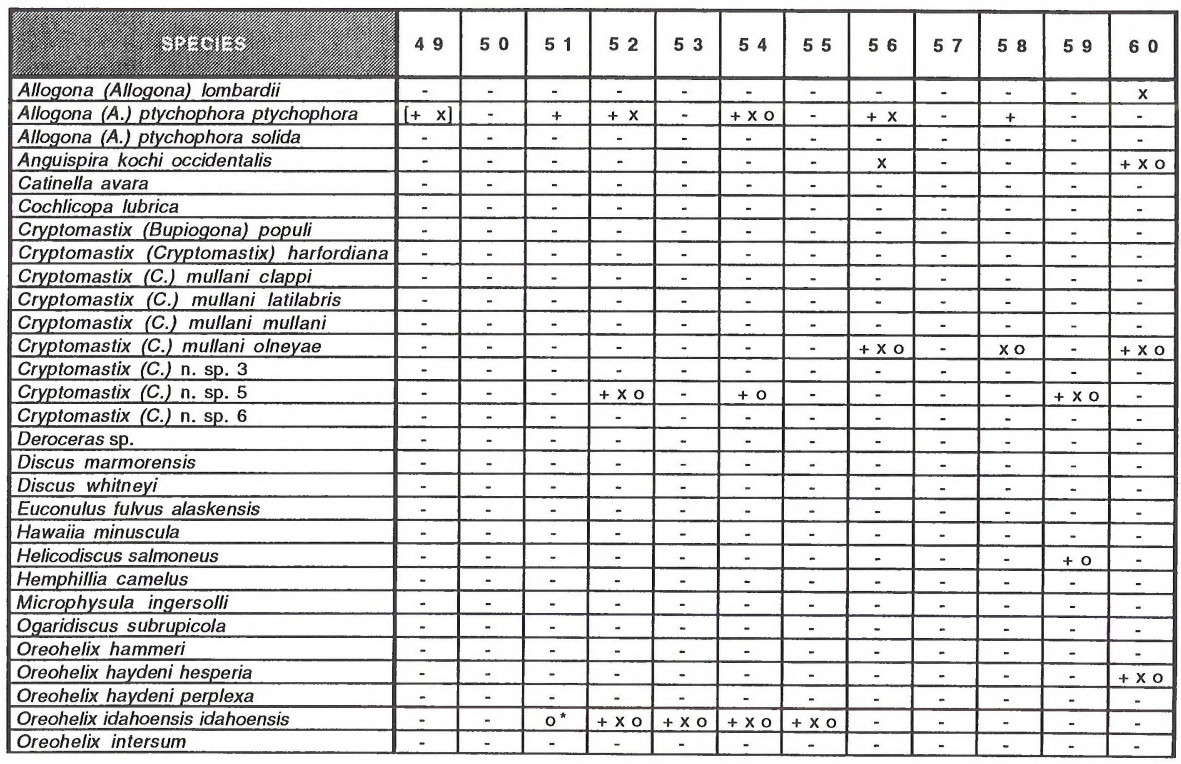

* = colony may now be extirpated 
TABLE 3. SITE FAUNAL LISTS. (cont.)

\begin{tabular}{|c|c|c|c|c|c|c|c|c|c|c|c|c|}
\hline 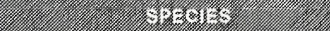 & 49 & 50 & 51 & 52 & 53 & 54 & 55 & 56 & 57 & 58 & 59 & 60 \\
\hline Oreohelix jugalis & - & - & - & - & - & - & - & - & - & - & - & - \\
\hline Oreohelix n. sp. 12 & - & - & - & $=$ & - & - & - & - & - & - & - & - \\
\hline Oreohelix n. sp. 13 & - & - & - & - & - & - & - & - & - & - & - & - \\
\hline Oreohelix n. sp. 14 & - & - & - & - & - & - & - & - & - & - & - & - \\
\hline Oreohelix n. sp. 20 & - & - & - & - & - & - & - & - & - & - & $+x 0$ & - \\
\hline Oreohelix n. sp. 21 & - & - & - & - & - & - & - & - & - & - & - & - \\
\hline Oreohelix n. sp. 22 & - & - & - & - & - & - & - & - & - & - & - & - \\
\hline Oreohelix n. sp. 23 & - & - & - & - & - & - & - & - & - & - & - & - \\
\hline Oreohelix n. sp. 24 & - & - & - & - & - & - & - & - & - & - & - & - \\
\hline Oreohelix n. sp. 25 & - & - & - & - & - & - & - & - & - & - & $=$ & - \\
\hline Oreohelix vortex & - & - & - & - & - & - & - & - & - & - & - & - \\
\hline Oreohelix waltoni & - & - & $=$ & - & - & - & - & - & - & - & - & - \\
\hline Planogyra clappi & - & - & - & - & - & - & - & - & - & - & - & - \\
\hline Polygyrella polygyrella & - & - & - & - & - & - & - & - & - & - & - & - \\
\hline Pristiloma (Pristinopsis) idahoense & - & - & - & - & - & - & - & - & - & - & - & - \\
\hline Punctum pusillum & - & - & - & - & - & - & - & - & - & - & - & - \\
\hline Pupilla hebes & - & - & - & - & - & - & - & $\mathbf{x}$ & - & - & - & - \\
\hline Radiodiscus (Radiodomus) abielum & - & - & - & - & - & - & - & - & - & - & - & - \\
\hline Succinea strelchiana & - & - & - & - & - & - & - & - & - & - & - & - \\
\hline Vallonia cyclophorella & - & - & - & - & - & - & - & - & - & - & - & - \\
\hline Vertigo concinnula & - & - & - & - & - & - & - & - & - & - & - & - \\
\hline
\end{tabular}

${ }^{*}$ = colony may now be extirpated 
TABLE 3. SITE FAUNAL LISTS. (cont.)

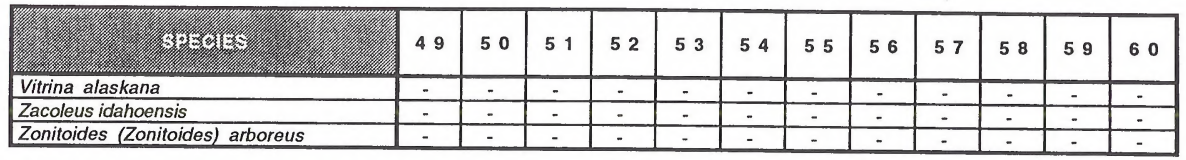

\begin{tabular}{|c|c|c|c|c|c|c|c|c|c|c|c|c|}
\hline Y & 1 & 0 & 2 & 3 & 1 & 3 & 1 & 5 & 1 & 3 & 3 & 4 \\
\hline 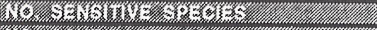 & 0 & 0 & [1?] & 2 & 1 & 2 & 1 & 1 & 1 & [1?] & 2 & 2 \\
\hline 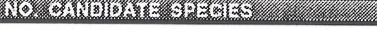 & 0 & 0 & [1?] & 1 & 1 & 1 & 1 & 0 & 0 & 0 & 0 & 0 \\
\hline
\end{tabular}

$+=$ live collection

$x=$ recently dead

$0=$ long-dead

[ ] = not collected

" = colony may now be extirpated 
TABLE 3. SITE FAUNAL LISTS. (cont.)

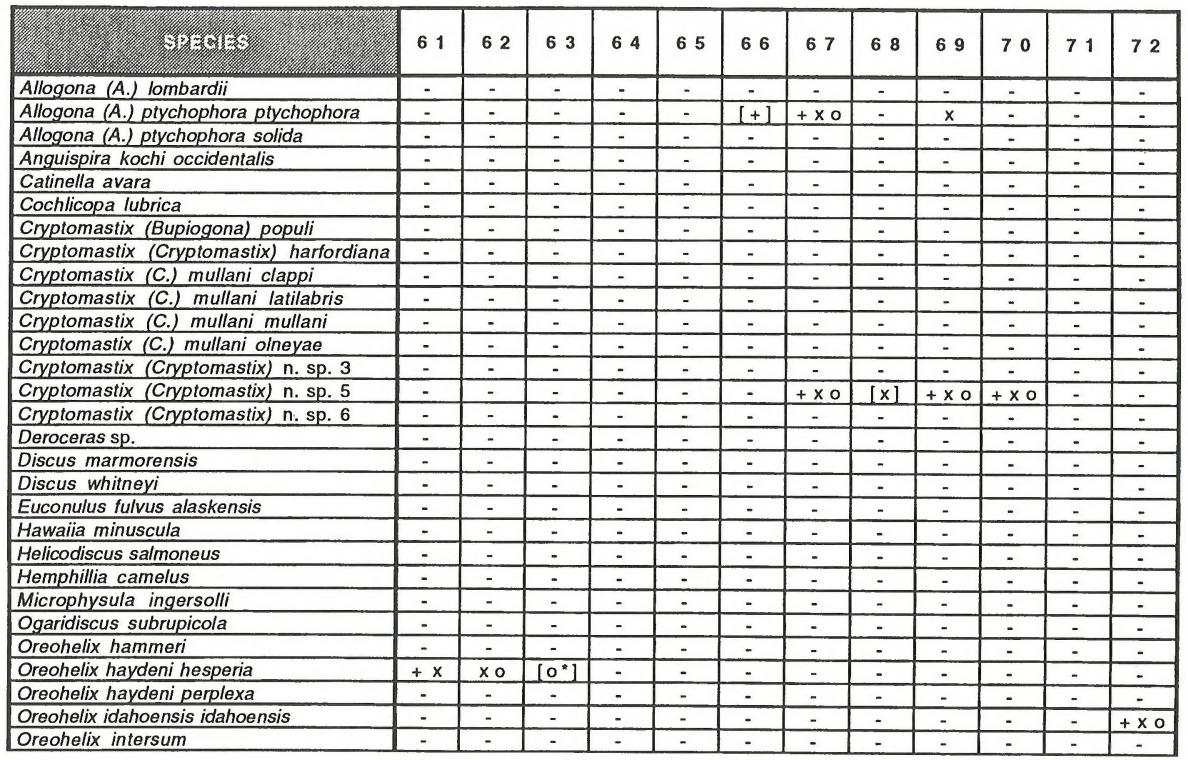

" $=$ formerly $+\mathrm{x}$ o; recently extirpated colony 
TABLE 3. SITE FAUNAL LISTS. (cont.)

\begin{tabular}{|c|c|c|c|c|c|c|c|c|c|c|c|c|}
\hline 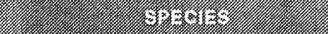 & 61 & 62 & 63 & 64 & 65 & 66 & 67 & 68 & 69 & 70 & 71 & 72 \\
\hline Oreohelix jugalis & - & - & - & - & - & - & +0 & - & + & - & - & - \\
\hline Oreohelix n. sp. 8 & - & - & - & - & - & - & - & - & - & - & - & - \\
\hline Oreohelix n. sp. 12 & - & - & - & - & - & - & - & - & - & - & - & - \\
\hline Oreohelix n. sp. 13 & - & - & - & - & - & - & - & - & - & - & - & - \\
\hline Oreohelix n. sp. 14 & - & - & - & - & - & - & - & - & - & - & - & - \\
\hline Oreohelix n. sp. 15 & - & - & - & - & - & - & - & - & - & - & - & - \\
\hline Oreohelix n. sp. 19 & - & - & - & - & - & - & - & - & - & - & - & - \\
\hline Oreohelix n. sp. 20 & - & - & - & $+\times 0$ & - & - & - & - & - & - & - & - \\
\hline Oreohelix n. sp. 21 & - & - & - & - & - & - & - & - & - & - & - & - \\
\hline Oreohelix n. sp. 22 & - & - & - & - & - & - & - & - & - & - & - & - \\
\hline Oreohelix n. sp. 23 & - & - & - & - & - & - & - & - & - & - & - & - \\
\hline Oreohelix n. sp. 24 & - & - & - & - & - & - & - & - & - & - & - & - \\
\hline Oreohelix n. sp. 25 & - & - & - & - & - & - & - & - & - & - & - & - \\
\hline Oreohelix n. sp. 29 & - & - & - & - & - & - & - & - & - & - & - & - \\
\hline Oreohelix n. sp. 32 & - & - & - & - & - & - & - & - & - & - & - & - \\
\hline Oreohelix strigosa goniogyra & - & - & - & - & - & - & - & - & - & - & - & - \\
\hline Oreohelix strigosa n. subsp. 1 & - & - & - & - & - & - & - & - & - & - & - & - \\
\hline Oreohelix vortex & - & - & - & - & - & - & - & - & $+\times 0$ & $+\times 0$ & - & - \\
\hline Oreohelix waltoni & - & - & - & - & - & - & - & - & - & - & - & - \\
\hline Planogyra clappi & - & - & - & - & - & - & - & - & - & - & - & - \\
\hline Polygyrella polygyrella & - & - & - & - & - & - & - & - & - & - & - & - \\
\hline Pristiloma (Pristinopsis) idahoense & - & - & - & - & - & - & - & - & - & - & - & - \\
\hline Punctum pusillum & - & - & - & - & - & - & - & - & - & - & - & - \\
\hline Pupilla hebes & - & - & - & - & - & - & - & - & - & - & - & - \\
\hline Radiodiscus (Radiodomus) abietum & - & - & - & - & - & - & - & - & - & - & - & - \\
\hline Succinea stretchiana & - & - & $\cdots$ & - & - & - & - & - & - & - & - & - \\
\hline Vallonia cyclophorella & - & - & - & - & - & - & + & - & - & - & - & - \\
\hline Vertigo concinnula & - & - & - & - & - & - & - & - & - & - & - & - \\
\hline
\end{tabular}


TABLE 3. SITE FAUNAL LISTS. (cont.)

\begin{tabular}{|l|c|c|c|c|c|c|c|c|c|c|c|c|}
\hline Vitrina alaskana & 61 & 62 & 63 & 64 & 65 & 66 & 67 & 68 & 69 & 70 & 71 & 72 \\
\hline Zacoleus idahoensis & - & - & - & - & - & - & - & - & - & - & - & - \\
\hline Zonitoides (Zonitoides) arboreus & - & - & - & - & - & - & - & - & - & - & - & - \\
\hline
\end{tabular}

\begin{tabular}{|c|c|c|c|c|c|c|c|c|c|c|c|c|}
\hline 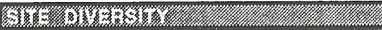 & 1 & 1 & 2 & 1 & 0 & 1 & 4 & 1 & 4 & 2 & 0 & 1 \\
\hline (y) & 1 & 1 & 2 & 1 & 0 & 0 & 2 & 0 & 3 & 2 & 0 & 1 \\
\hline 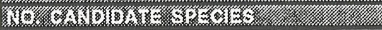 & 0 & 0 & 0 & 0 & 0 & 0 & 1 & 0 & 2 & 1 & 0 & 1 \\
\hline
\end{tabular}

$\begin{array}{ll}+= & \text { live collection } \\ x= & \text { recently dead } \\ 0= & \text { long-dead } \\ {[]=} & \text { not collected }\end{array}$


TABLE 3. SITE FAUNAL LISTS. (cont.)

\begin{tabular}{|c|c|c|c|c|c|c|c|c|c|c|c|c|}
\hline 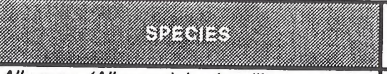 & 73 & 74 & 75 & 76 & 77 & 78 & 79 & 80 & 81 & 82 & 83 & 84 \\
\hline Allogona (Allogona) lombardii & - & - & - & - & - & - & - & - & - & - & - & - \\
\hline Allogona (A.) ptychophora ptychophora & - & - & xo & $+\times 0$ & - & $+\times 0$ & - & $\mathrm{x}$ & - & - & - & - \\
\hline Allogona (A.) ptychophora solida & - & - & - & - & - & - & $+\times 0$ & - & $+\times 0$ & - & $+\times 0$ & $+\times 0$ \\
\hline Anguispira kochi occidentalis & - & - & - & - & - & - & - & - & - & - & - & - \\
\hline Catinella avara & - & $0^{*}$ & - & - & - & - & - & - & - & - & - & - \\
\hline Cochlicopa lubrica & - & - & - & - & - & - & - & - & - & - & - & - \\
\hline Cryptomastix (Bupiogona) populi & - & - & - & - & - & - & - & - & - & - & - & - \\
\hline Cryptomastix (Cryptomastix) harfordiana & - & - & - & - & - & - & - & - & - & - & - & - \\
\hline Cryptomastix (C.) mullani clappi & - & - & - & - & - & - & - & - & - & - & - & - \\
\hline Cryptomastix (C.) mullani latilabris & - & - & - & - & - & - & - & - & - & - & - & - \\
\hline Cryptomastix (C.) mullani mullani & - & - & - & - & - & - & - & - & - & - & - & - \\
\hline Cryptomastix (C.) mullani olneyae & - & - & - & - & - & - & - & - & - & - & - & - \\
\hline Cryptomastix (C.) n. sp. 3 & - & - & - & - & - & - & - & - & - & - & $+\times 0$ & - \\
\hline Cryptomastix (C.) n. sp. 5 & - & - & xo & - & - & - & - & - & - & - & - & - \\
\hline Cryptomastix (C.) n. sp. 6 & - & - & - & - & - & $+\times 0$ & +0 & $+\times 0$ & $+\times 0$ & - & - & - \\
\hline Deroceras sp. & - & - & - & - & - & - & - & - & - & - & - & - \\
\hline Discus marmorensis & - & - & - & - & - & - & - & - & - & - & - & - \\
\hline Discus whitneyi & - & - & - & - & - & - & - & - & - & - & - & - \\
\hline Euconulus fulvus alaskensis & - & - & - & - & - & - & - & - & - & - & - & - \\
\hline Hawaiia minuscula & - & - & - & - & - & - & - & - & - & - & - & - \\
\hline Helicodiscus salmoneus & - & $0^{*}$ & - & - & - & - & - & - & - & - & - & - \\
\hline Hemphillia camelus & - & - & - & - & - & - & - & - & - & - & - & - \\
\hline Microphysula ingersolli & - & - & - & - & - & - & - & - & - & - & - & - \\
\hline Ogaridiscus subrupicola & - & - & - & - & - & - & - & - & - & - & - & - \\
\hline Oreohelix hammeri & - & $=$ & - & - & - & - & - & - & - & - & - & - \\
\hline Oreohelix haydeni hesperia & - & - & - & - & - & - & - & - & - & - & - & - \\
\hline Oreohelix haydeni perplexa & - & - & - & - & - & - & - & - & - & - & - & - \\
\hline Oreohelix idahoensis idahoensis & $+\times 0$ & $+\times 0$ & {$\left[0^{*}\right]$} & $0^{*}$ & $+\times 0$ & - & - & - & - & - & - & - \\
\hline Oreohelix intersum & - & - & - & - & - & - & - & - & - & - & - & - \\
\hline
\end{tabular}

" = colony may be extirpated 
TABLE 3. SITE FAUNAL LISTS. (cont.)

\begin{tabular}{|c|c|c|c|c|c|c|c|c|c|c|c|c|}
\hline 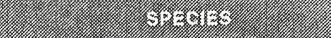 & 73 & 74 & 75 & 76 & 77 & 78 & 79 & 80 & 81 & 82 & 83 & 84 \\
\hline Oreohelix jugalis & - & - & - & - & - & - & - & - & - & - & - & - \\
\hline Oreohelix n. sp. 8 & - & - & - & - & - & - & - & $=$ & - & - & - & - \\
\hline Oreohelix n. sp. 12 & - & - & - & - & - & - & - & - & - & - & - & - \\
\hline Oreohelix n. sp. 13 & - & - & - & - & - & - & - & - & - & - & - & - \\
\hline Oreohelix n. sp. 14 & - & - & - & - & - & - & - & - & - & - & - & - \\
\hline Oreohelix n. sp. 15 & - & - & - & - & - & - & - & - & - & - & - & - \\
\hline Oreohelix n. sp. 19 & - & - & - & - & - & - & - & - & - & - & - & - \\
\hline Oreohelix n. sp. 20 & - & - & - & - & - & - & - & - & - & - & - & - \\
\hline Oreohelix n. sp. 21 & - & - & - & - & - & - & - & - & - & - & - & - \\
\hline Oreohelix n. sp. 22 & - & - & - & - & - & - & - & - & - & - & - & - \\
\hline Oreohelix n. sp. 23 & - & - & - & - & - & - & - & - & - & - & - & - \\
\hline Oreohelix n. sp. 24 & - & - & - & - & - & - & - & - & - & - & - & - \\
\hline Oreohelix n. sp. 25 & - & - & - & - & - & $+\times 0$ & $+\times 0$ & $+x$ & + & - & $+x$ & - \\
\hline Oreohelix n. sp. 29 & - & - & - & - & - & - & - & - & - & - & - & - \\
\hline Oreohelix n. sp. 32 & - & - & - & - & - & - & - & - & - & - & - & - \\
\hline Oreohelix strigosa goniogyra & - & - & - & - & - & - & - & - & - & - & - & - \\
\hline Oreohelix strigosa $\mathrm{n}$. subsp. 1 & - & - & - & - & - & - & - & - & - & - & - & - \\
\hline Oreohelix vortex & - & - & - & - & - & - & - & - & - & - & - & - \\
\hline Oreohelix waltoni & - & - & - & - & - & - & - & - & - & - & - & - \\
\hline Planogyra clappi & - & - & - & - & - & - & - & - & - & - & - & - \\
\hline Polygyrella polygyrella & - & - & - & - & - & - & - & - & - & - & - & - \\
\hline Pristiloma (Pristinopsis) idahoense & - & - & - & - & - & - & - & - & - & - & - & - \\
\hline Punctum pusillum & - & - & - & - & - & - & - & - & - & - & - & - \\
\hline Pupilla hebes & - & xo & - & - & - & - & - & - & - & - & - & - \\
\hline Radiodiscus (Radiodomus) abietum & - & - & - & - & - & - & - & - & - & - & - & - \\
\hline Succinea stretchiana & - & - & - & - & - & - & - & - & - & - & - & - \\
\hline Vallonia cyclophorella & - & $\times 0$ & - & - & - & - & - & $=$ & - & - & - & - \\
\hline Vertigo concinnula & - & - & - & - & - & - & - & - & - & - & - & - \\
\hline
\end{tabular}


TABLE 3. SITE FAUNAL LISTS. (cont.)

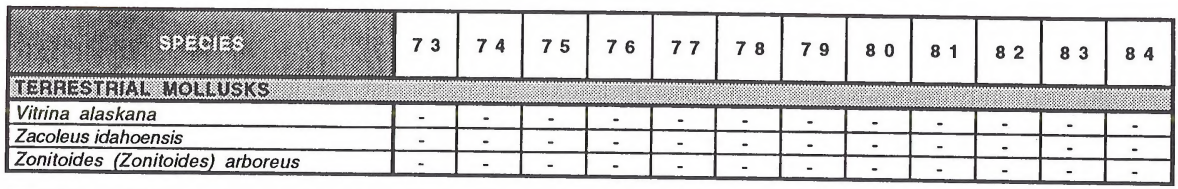

\begin{tabular}{|c|c|c|c|c|c|c|c|c|c|c|c|c|}
\hline $858=8$ B & 1 & 5 & 3 & 2 & 1 & 3 & 3 & 3 & 3 & 0 & 3 & 1 \\
\hline 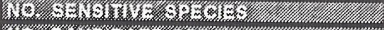 & 1 & 1 & [2?] & 1 & 1 & 2 & 3 & 2 & 3 & 0 & 3 & 1 \\
\hline 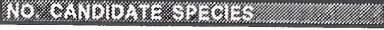 & 1 & 1 & [1?] & 1 & 1 & 0 & 0 & 0 & 0 & 0 & 0 & 0 \\
\hline
\end{tabular}
$+=$ live collection
$x=$ recently dead
$\mathrm{o}=$ long-dead
[ ] = not collected 
TABLE 3. SITE FAUNAL LISTS. (cont.)

\begin{tabular}{|c|c|c|c|c|c|c|c|c|c|c|c|c|}
\hline $47=y_{1}^{2}=$ & 85 & 86 & 87 & 88 & 89 & 90 & 91 & 92 & 93 & 94 & 95 & 96 \\
\hline Allogona (Allogona) lombardii & - & - & - & - & - & - & - & - & - & - & - & - \\
\hline Allogona (A.) ptychophora ptychophora & {$\left[0^{*}\right]$} & - & - & - & - & - & - & - & {$\left[0^{*}\right]$} & - & - & - \\
\hline Allogona (A.) ptychophora solida & - & $+x 0$ & $x$ & $+x$ & $x$ & $+x$ & - & - & - & - & - & - \\
\hline Anguispira kochi occidentalis & - & - & - & - & - & - & - & - & - & - & - & - \\
\hline Catinella avara & - & - & - & - & - & - & - & - & - & - & $0^{*}$ & - \\
\hline Cochlicopa lubrica & - & - & - & - & - & - & - & - & - & - & - & - \\
\hline Cryptomastix (Bupiogona) populi & - & - & $x 0$ & $x 0$ & $x 0$ & $+x 0$ & - & - & - & - & - & - \\
\hline Cryptomastix (Cryptomastix) harfordiana & - & - & - & - & - & - & - & - & - & - & - & - \\
\hline Cryptomastix (C.) mullani clappi & - & - & - & - & - & - & - & - & - & - & - & - \\
\hline Cryptomastix (C.) mullani latilabris & - & - & - & - & - & - & - & - & - & - & - & - \\
\hline Cryptomastix (C.) mullani mullani & - & - & $+x 0$ & - & - & - & - & - & - & - & - & - \\
\hline Cryptomastix (C.) mullani olneyae & - & - & - & - & - & - & - & - & - & - & xo & - \\
\hline Cryptomastix (C.) n. sp. 3 & - & $0^{*}$ & - & - & - & - & - & - & - & - & - & - \\
\hline Cryptomastix (C.) n. sp. 5 & - & - & - & - & - & - & $+x 0$ & - & - & - & - & - \\
\hline Cryptomastix (C.) n. sp. 6 & - & $+x$ & - & - & - & - & - & - & - & - & - & - \\
\hline Deroceras sp. & - & - & - & - & - & - & - & - & - & - & - & - \\
\hline Discus marmorensis & - & - & - & - & - & - & - & - & - & - & - & - \\
\hline Discus whitneyi & - & - & + & - & - & - & - & - & - & - & - & - \\
\hline Euconulus fulvus alaskensis & - & - & - & - & - & - & - & - & - & - & - & - \\
\hline Hawaiia minuscula & - & - & - & - & - & - & - & - & - & - & - & - \\
\hline Helicodiscus salmoneus & - & - & 0 & - & - & - & - & $+x$ & - & - & - & - \\
\hline Hemphillia camelus & - & - & - & - & - & - & - & - & - & - & - & - \\
\hline Microphysula ingersolli & - & - & - & - & - & - & - & - & - & - & $0^{*}$ & - \\
\hline Ogaridiscus subrupicola & - & - & - & - & - & - & - & - & - & - & - & - \\
\hline Oreohelix hammeri & - & - & - & - & - & - & - & - & - & - & - & - \\
\hline Oreohelix haydeni hesperia & - & - & - & - & - & - & - & - & - & - & - & - \\
\hline Oreohelix haydeni perplexa & $=$ & - & - & - & - & - & - & - & - & - & - & - \\
\hline Oreohelix idahoensis idahoensis & - & - & - & - & - & - & - & - & - & - & $+x 0$ & $+x 0$ \\
\hline Oreohelix intersum & - & - & - & - & - & - & - & - & - & - & - & - \\
\hline
\end{tabular}

* = colony may now be extirpated 
TABLE 3. SITE FAUNAL LISTS .(cont.)

\begin{tabular}{|c|c|c|c|c|c|c|c|c|c|c|c|c|}
\hline 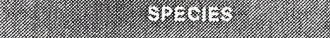 & 85 & 86 & 87 & 88 & 89 & 90 & 91 & 92 & 93 & 94 & 95 & 96 \\
\hline \multicolumn{13}{|l|}{ 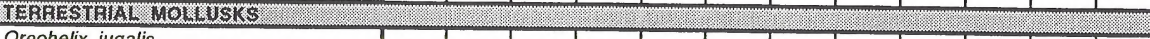 } \\
\hline Oreohelix jugalis & - & - & - & - & - & - & - & - & - & - & - & - \\
\hline Oreohelix n. sp. 8 & - & - & - & - & - & - & - & - & - & - & - & - \\
\hline Oreohelix n. sp. 12 & - & - & - & - & - & - & - & - & - & - & $=$ & - \\
\hline Oreohelix n. sp. 13 & - & - & - & - & - & - & - & - & - & - & - & - \\
\hline Oreohelix n. sp. 14 & - & - & - & - & - & - & - & - & - & - & - & - \\
\hline Oreohelix n. sp. 15 & - & - & - & - & - & - & - & - & - & - & - & - \\
\hline Oreohelix n. sp. 19 & - & - & - & - & - & - & - & - & - & - & - & - \\
\hline Oreohelix n. sp. 20 & - & - & - & - & - & - & - & - & - & - & - & - \\
\hline Oreohelix n. sp. 21 & - & - & - & - & - & - & - & - & - & - & - & - \\
\hline Oreohelix n. sp. 22 & - & - & - & - & - & - & - & - & - & - & - & - \\
\hline Oreohelix n. sp. 23 & - & - & - & - & - & - & $+\times 0$ & - & - & - & - & - \\
\hline Oreohelix n. sp. 24 & - & - & - & - & - & - & - & - & - & - & - & - \\
\hline Oreohelix n. sp. 25 & - & - & $+\times 0$ & - & - & - & - & - & - & - & - & - \\
\hline Oreohelix n. sp. 29 & - & $+x$ & - & $+x$ & $x$ & $x$ & - & - & - & - & - & - \\
\hline Oreohelix n. sp. 32 & - & - & - & - & - & - & - & - & - & - & - & - \\
\hline Oreohelix strigosa goniogyra & - & - & - & - & - & - & - & - & - & $+\times 0$ & - & - \\
\hline Oreohelix strigosa n. subsp. 1 & - & - & - & - & - & - & - & - & - & - & - & - \\
\hline Oreohelix vortex & - & - & - & - & - & - & - & - & - & - & - & - \\
\hline Oreohelix waltoni & - & - & - & - & - & - & - & - & - & - & - & - \\
\hline Planogyra clappi & - & - & - & - & - & - & - & - & - & - & - & - \\
\hline Polygyrella polygyrella & - & - & - & - & - & - & - & - & - & - & - & - \\
\hline Pristiloma (Pristinopsis) idahoense & - & - & - & - & - & - & - & - & - & - & - & - \\
\hline Punctum pusillum & - & - & - & - & - & - & - & - & - & - & - & - \\
\hline Pupilla hebes & - & - & - & - & - & - & - & - & - & - & - & - \\
\hline Radiodiscus (Radiodomus) abietum & - & - & - & - & - & - & - & - & - & - & - & - \\
\hline Succinea stretchiana & - & - & - & - & - & - & - & - & - & - & - & - \\
\hline Vallonia cyclophorella & - & - & + & - & - & - & - & + & - & - & - & - \\
\hline Vertigo concinnula & - & - & - & - & - & - & - & - & - & - & - & - \\
\hline
\end{tabular}


TABLE 3. SITE FAUNAL LISTS. (cont.)

\begin{tabular}{|l|c|c|c|c|c|c|c|c|c|c|c|c|}
\hline Vitrina alaskana & 85 & 86 & 87 & 88 & 89 & 90 & 91 & 92 & 93 & 94 & 95 & 96 \\
\hline Zacoleus idahoensis & - & $\mathrm{x}$ & - & - & - & - & - & - & - & - & - & - \\
\hline Zonitoides (Zonitoides) arboreus & - & - & - & - & - & - & - & - & - & - & - & - \\
\hline
\end{tabular}

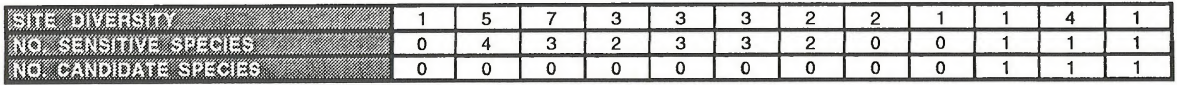

$+=$ live collection

$x=$ recently dead

$0=$ long-dead

[]$=$ not collected 
TABLE 3. SITE FAUNAL LISTS. (cont.)

\begin{tabular}{|c|c|c|c|c|c|c|c|c|c|c|c|c|}
\hline$-y^{\prime}=1$ & 97 & 98 & 99 & 100 & 101 & 102 & 103 & 104 & 105 & 106 & 107 & 108 \\
\hline Allogona (Allogona) lombardii & - & - & - & - & - & - & - & - & - & - & - & - \\
\hline Allogona (A.) ptychophora ptychophora & - & $+x$ & $+\times 0$ & - & - & $+\times 0$ & $+\times 0$ & - & - & $+\times 0$ & $+\times 0$ & $+\times 0$ \\
\hline Allogona (A.) ptychophora solida & - & - & - & $+\times 0$ & $+\times 0$ & - & - & - & - & - & - & - \\
\hline Anguispira kochi occidentalis & - & - & - & - & - & - & - & - & - & - & - & - \\
\hline Catinella avara & - & - & - & - & - & - & - & - & - & - & - & - \\
\hline Cochlicopa lubrica & - & - & - & - & - & - & - & - & - & - & - & - \\
\hline Cypptomastix (Bupiogona) populi & - & - & - & - & - & - & - & - & - & - & - & - \\
\hline Cryptomastix (Cryptomastix) harfordiana & - & - & - & - & - & - & - & - & - & $+\times 0$ & $+\times 0$ & $+\times 0$ \\
\hline Cryptomastix (C.) mullani clappi & - & - & - & - & - & - & - & - & - & - & - & - \\
\hline Cryptomastix (C.) mullani latilabris & - & - & - & - & - & - & - & - & - & - & - & - \\
\hline Cryptomastix (C.) mullani mullani & - & - & - & - & - & - & - & - & - & - & - & - \\
\hline Cryptomastix (C.) mullani olneyae & - & $+\times 0$ & - & - & - & $+\times 0$ & $+\times 0$ & - & - & - & - & - \\
\hline Cryptomastix (C.) n. sp. 3 & - & - & - & - & - & - & - & - & - & - & - & - \\
\hline Cryptomastix (C.) n. sp. 5 & $+\times 0$ & - & - & $+\times 0$ & $+\times 0$ & - & - & - & - & - & - & - \\
\hline Cryptomastix (C.) n. sp. 6 & - & - & - & - & - & - & - & $\mathrm{x}$ & - & - & - & - \\
\hline Deroceras sp. & - & - & - & - & - & - & - & - & - & - & - & - \\
\hline Discus marmorensis & - & - & - & - & - & - & - & - & - & - & - & - \\
\hline Discus whitneyi & - & - & - & - & - & $=$ & - & - & - & - & - & - \\
\hline Euconulus fulvus alaskensis & - & - & - & - & - & - & - & - & - & - & - & - \\
\hline Hawaiia minuscula & - & - & - & - & - & - & - & - & - & - & - & - \\
\hline Helicodiscus salmoneus & - & - & - & - & - & - & - & - & - & - & - & - \\
\hline Hemphillia camelus & - & - & - & - & - & - & - & - & - & - & - & - \\
\hline Microphysula ingersolli & - & - & - & - & - & - & - & - & - & - & - & - \\
\hline Ogaridiscus subrupicola & - & - & - & - & - & - & - & - & - & - & - & - \\
\hline Oreohelix hammeri & - & - & - & - & - & - & - & - & - & - & - & - \\
\hline Oreohelix haydeni hesperia & - & - & - & - & - & - & - & - & - & - & - & - \\
\hline Oreohelix haydeni perplexa & - & - & - & - & - & - & - & - & - & - & - & - \\
\hline Oreohelix idahoensis idahoensis & - & - & - & - & - & - & - & - & - & - & - & - \\
\hline Oreohelix intersum & - & - & - & - & - & - & - & - & - & - & - & - \\
\hline
\end{tabular}


TABLE 3. SITE FAUNAL LISTS. (cont.)

\begin{tabular}{|c|c|c|c|c|c|c|c|c|c|c|c|c|}
\hline 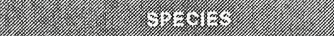 & 97 & 98 & 99 & 100 & 101 & 102 & 103 & 104 & 105 & 106 & 107 & 108 \\
\hline Oreohelix jugalis & $=$ & - & - & $+\times 0$ & - & - & - & $+\times 0$ & $+\times 0$ & $+\times 0$ & - & - \\
\hline Oreohelix n. sp. 8 & - & - & - & - & - & - & - & - & - & - & - & - \\
\hline Oreohelix n. sp. 12 & - & - & - & - & - & - & - & - & - & - & - & - \\
\hline Oreohelix n. sp. 13 & - & - & - & - & - & - & - & - & - & - & - & - \\
\hline Oreohelix n. sp. 14 & - & - & - & - & - & - & - & - & - & - & - & - \\
\hline Oreohelix n. sp. 15 & - & - & - & - & - & - & - & - & - & - & - & - \\
\hline Oreohelix n. sp. 19 & - & - & - & - & - & - & - & - & - & - & - & - \\
\hline Oreohelix n. sp. 20 & - & - & - & - & - & - & - & - & - & - & - & - \\
\hline Oreohelix n. sp. 21 & - & - & - & - & - & - & - & - & - & - & - & - \\
\hline Oreohelix n. sp. 22 & - & - & - & - & - & - & - & - & - & - & - & - \\
\hline Oreohelix n. sp. 23 & $+\times 0$ & - & $=$ & - & - & - & - & - & - & - & - & - \\
\hline Oreohelix n. sp. 24 & - & - & - & - & - & - & - & - & - & - & - & - \\
\hline Oreohelix n. sp. 25 & - & $+\times 0$ & $+\times 0$ & - & - & $+\times 0$ & - & - & - & - & $+\times 0$ & $+x 0$ \\
\hline Oreohelix n. sp. 29 & - & - & - & - & - & - & - & - & - & - & - & - \\
\hline Oreohelix n. sp. 32 & - & - & - & - & - & - & - & - & - & - & - & - \\
\hline Oreohelix strigosa goniogyra & - & - & - & - & - & - & - & - & - & - & - & - \\
\hline Oreohelix strigosa n. subsp. 1 & - & - & - & - & - & - & - & - & - & - & - & - \\
\hline Oreohelix vortex & - & $+\times 0$ & - & - & - & $+x$ & $+\times 0$ & - & - & $+\times 0$ & - & - \\
\hline Oreohelix waltoni & - & - & $0^{*}$ & - & - & - & - & - & - & - & - & - \\
\hline Planogyra clappi & - & - & - & - & - & - & - & - & - & - & - & - \\
\hline Polygyrella polygyrella & - & - & $0^{*}$ & - & - & $+\times 0$ & $+\times 0$ & - & - & - & - & - \\
\hline Pristiloma (Pristinopsis) idahoense & - & - & - & - & - & - & - & - & - & - & - & - \\
\hline Punctum pusillum & - & 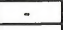 & - & - & - & - & - & - & - & - & - & 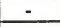 \\
\hline Pupilla hebes & - & - & - & - & - & - & - & - & - & - & - & - \\
\hline Radiodiscus (Radiodomus) abietum & - & - & - & - & - & - & - & - & - & - & - & - \\
\hline Succinea stretchiana & - & - & - & - & - & - & - & - & - & - & - & - \\
\hline Vallonia cyclophorella & - & - & - & - & - & - & - & - & - & - & - & - \\
\hline Vertigo concinnula & - & - & - & - & - & - & - & - & - & - & - & - \\
\hline
\end{tabular}

* $=$ formerly $+\mathrm{x}$ o or $\mathrm{x} 0$; colony now likely extinct. 

TABLE 3. SITE FAUNAL LISTS. (cont.)

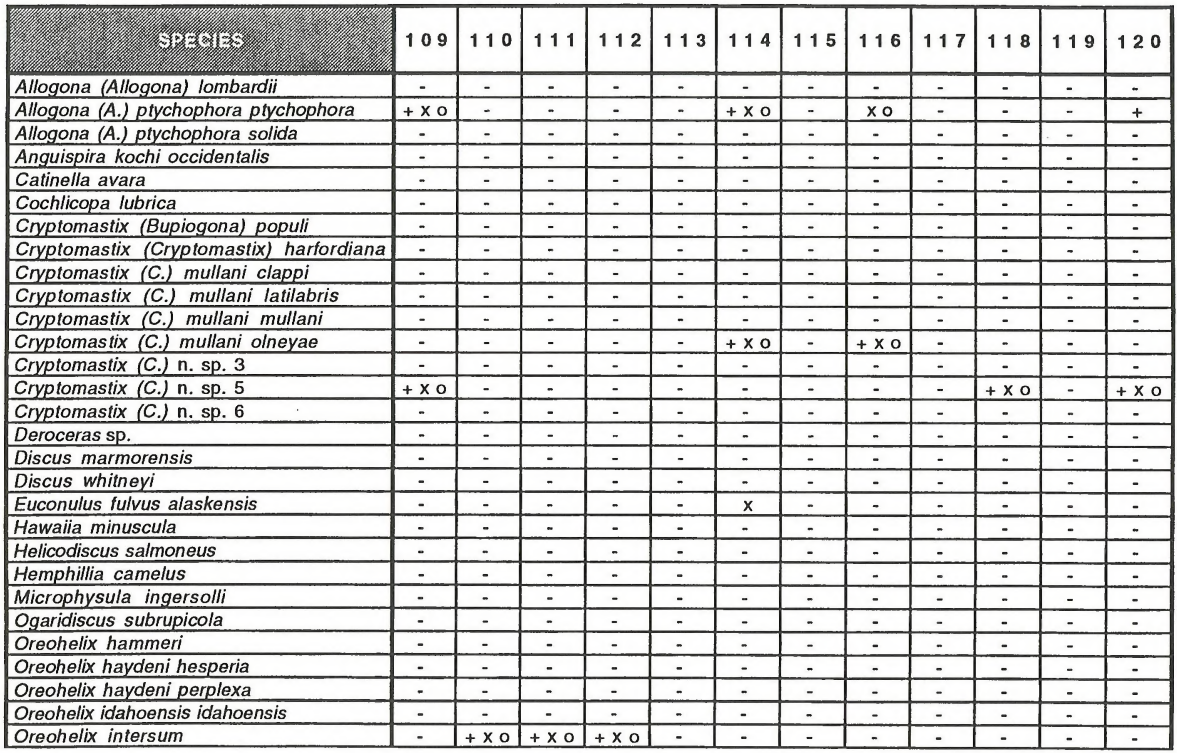


TABLE 3. SITE FAUNAL LISTS. (cont.)

\begin{tabular}{|c|c|c|c|c|c|c|c|c|c|c|c|c|}
\hline 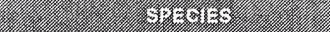 & 109 & 110 & 111 & 112 & 113 & 114 & 115 & 116 & 117 & 118 & 119 & 120 \\
\hline Oreohelix jugalis & $+\times 0$ & - & - & - & - & - & - & - & $+\times 0$ & - & - & - \\
\hline Oreohelix n. sp. 8 & - & - & - & - & - & - & - & - & - & - & - & - \\
\hline Oreohelix n. sp. 12 & - & - & - & - & $+\times 0$ & $+\times 0$ & $+\times 0$ & $+\times 0$ & - & - & - & - \\
\hline Oreohelix n. sp. 13 & - & - & - & - & - & - & - & - & - & - & - & - \\
\hline Oreohelix n. sp. 14 & - & - & - & - & - & $+\times 0$ & $+x 0$ & - & - & - & - & - \\
\hline Oreohelix n. sp. 15 & - & - & - & - & - & - & - & - & - & - & - & - \\
\hline Oreohelix n. sp. 19 & - & - & - & - & - & - & - & - & - & - & - & - \\
\hline Oreohelix n. sp. 20 & - & - & - & - & - & - & - & - & - & - & - & - \\
\hline Oreohelix n. sp. 21 & - & - & - & - & - & - & - & - & - & - & - & - \\
\hline Oreohelix n. sp. 22 & - & - & - & - & - & - & - & - & - & - & - & - \\
\hline Oreohelix n. sp. 23 & - & - & - & - & - & - & - & - & - & - & - & - \\
\hline Oreohelix n. sp. 24 & - & - & - & - & - & - & - & - & - & - & - & - \\
\hline Oreohelix n. sp. 25 & - & - & - & - & - & - & - & - & - & - & - & - \\
\hline Oreohelix n. sp. 29 & - & - & - & - & - & - & - & - & - & - & - & - \\
\hline Oreohelix n. sp. 32 & - & - & - & - & - & - & - & - & - & - & - & - \\
\hline Oreohelix strigosa goniogyra & - & - & - & - & - & - & - & - & - & - & - & - \\
\hline Oreohelix strigosa n. subsp. 1 & - & - & - & - & - & - & - & - & - & - & - & - \\
\hline Oreohelix vortex & $+\times 0$ & - & - & - & - & - & - & - & - & $+\times 0$ & $+\times 0$ & $+\times 0$ \\
\hline Oreohelix waltoni & - & - & - & - & - & - & - & - & - & - & - & - \\
\hline Planogyra clappi & - & - & - & - & - & - & - & - & - & - & - & - \\
\hline Polygyrella polygyrella & - & - & - & - & - & - & - & - & - & - & - & - \\
\hline Pristiloma (Pristinopsis) idahoense & - & - & - & - & - & - & - & - & - & - & - & - \\
\hline Punctum pusillum & - & - & - & - & - & - & - & - & - & - & - & - \\
\hline Pupilla hebes & - & - & - & - & - & - & - & - & - & - & - & - \\
\hline Radiodiscus (Radiodomus) abietum & - & - & - & - & - & - & - & - & - & - & - & - \\
\hline Succinea stretchiana & - & - & - & - & - & - & - & - & - & - & - & - \\
\hline Vallonia cyclophorella & - & - & - & - & - & - & - & - & - & - & - & - \\
\hline Vertigo concinnula & - & - & - & - & - & - & - & - & - & - & - & - \\
\hline
\end{tabular}


TABLE 3. SITE FAUNAL LISTS. (cont.)

\begin{tabular}{|l|c|c|c|c|c|c|c|c|c|c|c|c|}
\hline Vitrina alaskana & 109 & 110 & 111 & 112 & 113 & 114 & 115 & 116 & 117 & 118 & 119 & 120 \\
\hline Zacoleus idahoensis & - & - & - & - & - & - & - & - & - & - & - & - \\
\hline Zonitoides (Zonitoides) arboreus & - & - & - & - & - & - & - & - & - & - & - & - \\
\hline
\end{tabular}

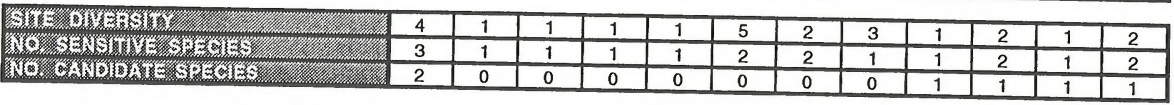

$\begin{array}{ll}+= & \text { live collection } \\ x= & \text { recently dead } \\ 0= & \text { long-dead } \\ {[]=} & \text { not collected }\end{array}$


TABLE 3. SITE FAUNAL LISTS. (cont.)

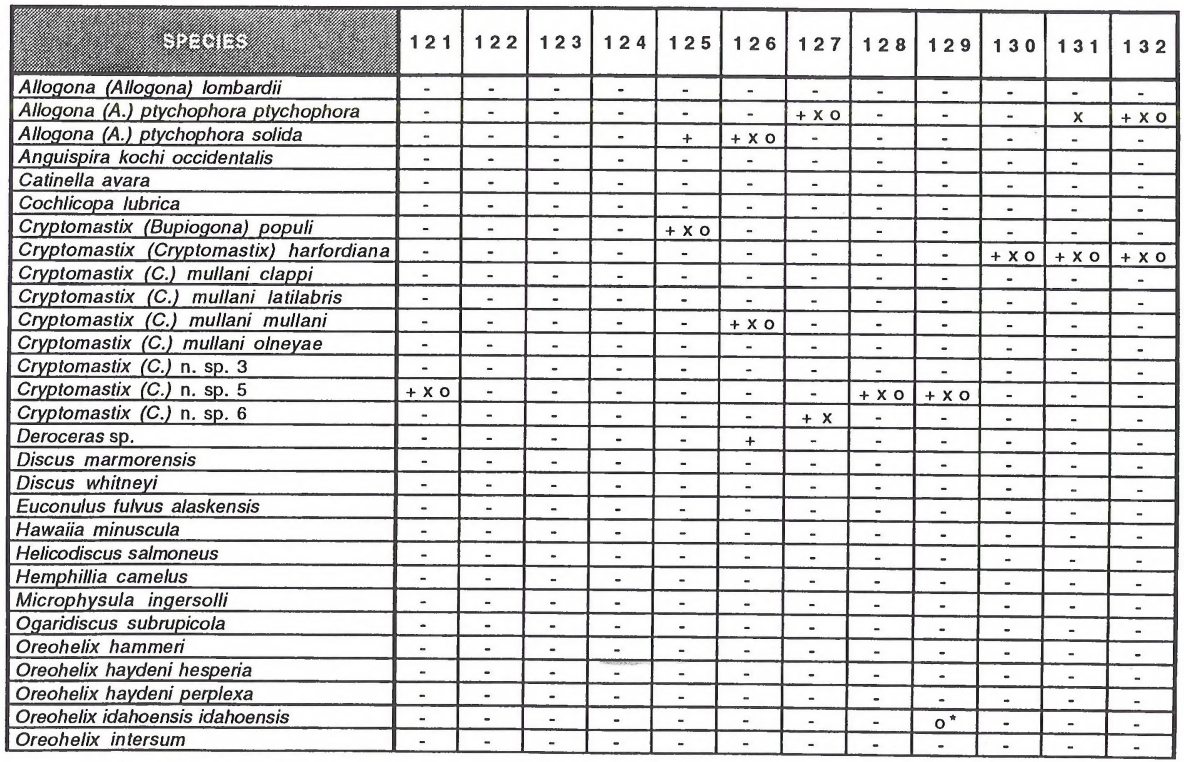

" = colony may now be extinct 
TABLE 3. SITE FAUNAL LISTS. (cont.)

\begin{tabular}{|c|c|c|c|c|c|c|c|c|c|c|c|c|}
\hline 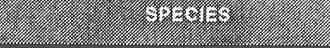 & 121 & 122 & 123 & 124 & 125 & 126 & 127 & 128 & 129 & 130 & 131 & 132 \\
\hline Oreohelix jugalis & - & - & - & - & - & - & $+\times 0$ & - & - & - & - & - \\
\hline Oreohelix n. sp. 8 & - & - & - & - & - & - & - & - & - & - & - & - \\
\hline Oreohelix n. sp. 12 & - & - & - & - & - & - & - & - & - & - & - & - \\
\hline Oreohelix n. sp. 13 & - & - & - & - & - & - & - & - & - & - & - & - \\
\hline Oreohelix n. sp. 14 & - & - & - & $=$ & - & - & - & - & - & - & - & - \\
\hline Oreohelix n. sp. 15 & - & - & - & - & - & - & - & - & - & - & - & - \\
\hline Oreohelix n. sp. 19 & - & - & - & - & - & - & - & - & - & - & - & - \\
\hline Oreohelix n. sp. 20 & - & - & - & - & - & - & - & - & - & - & - & - \\
\hline Oreohelix n. sp. 21 & - & - & - & - & - & - & - & - & - & $+\times 0$ & $+\times 0$ & - \\
\hline Oreohelix n. sp. 22 & - & - & - & - & - & - & - & - & - & - & - & - \\
\hline Oreohelix n. sp. 23 & - & - & - & - & - & - & - & - & - & - & - & $+\times 0$ \\
\hline Oreohelix n. sp. 24 & - & - & - & - & - & - & - & - & - & - & - & - \\
\hline Oreohelix n. sp. 25 & - & - & - & - & $+?$ & - & - & - & - & - & - & - \\
\hline Oreohelix n. sp. 29 & - & - & - & $\sim$ & - & - & - & - & - & - & - & - \\
\hline Oreohelix n. sp. 32 & - & - & - & - & - & $\approx$ & - & - & - & - & - & - \\
\hline Oreohelix strigosa goniogyra & - & - & - & - & - & - & - & - & - & - & - & - \\
\hline Oreohelix strigosa n. subsp. 1 & - & - & - & - & - & - & - & - & - & - & - & - \\
\hline Oreohelix vortex & $+\times 0$ & - & - & - & - & - & - & - & - & - & - & - \\
\hline Oreohelix waltoni & - & - & - & - & - & - & - & - & - & - & - & - \\
\hline Planogyra clappi & - & - & - & - & - & - & - & - & - & - & - & - \\
\hline Polygyrella polygyrella & - & - & - & - & - & - & - & - & - & - & - & - \\
\hline Pristiloma (Pristinopsis) idahoense & - & - & - & - & - & - & - & - & - & - & - & - \\
\hline Punctum pusillum & - & - & - & - & - & - & - & - & - & - & - & - \\
\hline Pupilla hebes & - & - & - & - & - & - & - & - & - & - & - & - \\
\hline Radiodiscus (Radiodomus) abietum & - & - & - & - & - & - & - & - & - & - & - & - \\
\hline Succinea stretchiana & - & - & - & - & - & - & - & - & - & - & - & - \\
\hline Vallonia cyclophorella & - & - & - & - & - & - & - & - & - & - & - & - \\
\hline Vertigo concinnula & - & - & - & - & - & $+\times 0$ & - & - & - & - & $=$ & - \\
\hline
\end{tabular}


TABLE 3. SITE FAUNAL LISTS. (cont.)

\begin{tabular}{|l|c|c|c|c|c|c|c|c|c|c|c|c|}
\hline (3). & 121 & 122 & 123 & 124 & 125 & 126 & 127 & 128 & 129 & 130 & 131 & 132 \\
\hline Vitrina alaskana & - & - & - & - & - & - & - & - & - & - & - & - \\
\hline Zacoleus idahoensis & - & - & - & - & - & - & - & - & - & - & - & - \\
\hline Zonitoides (Zonitoides) arboreus & - & - & - & - & - & - & - & - & - & - & - & - \\
\hline
\end{tabular}

\begin{tabular}{|c|c|c|c|c|c|c|c|c|c|c|c|c|}
\hline 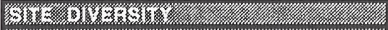 & 2 & 0 & 0 & 0 & 2 & 4 & 3 & 1 & 2 & 2 & 3 & 3 \\
\hline 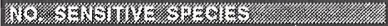 & 2 & 0 & 0 & 0 & 2 & 1 & 2 & 1 & 2 & 2 & 2 & 2 \\
\hline 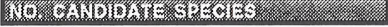 & 1 & 0 & 0 & 0 & 0 & 0 & 1 & 0 & $1 ?$ & 0 & 0 & 0 \\
\hline
\end{tabular}

$+=\quad$ live collection

$\mathrm{x}=$ recently dead

$0=$ long-dead

[ ] = not collected 
TABLE 3. SITE FAUNAL LISTS. (cont.)

\begin{tabular}{|c|c|c|c|c|c|c|c|c|c|c|c|c|}
\hline 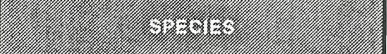 & 133 & 134 & 135 & 136 & 137 & 138 & 139 & 140 & 141 & 142 & 143 & 144 \\
\hline Allogona (Allogona) lombardii & - & - & - & - & - & - & - & - & - & - & - & - \\
\hline Allogona (A.) ptychophora ptychophora & - & - & - & + & $\therefore$ & - & $+\times 0$ & - & $+x$ & {$\left[0^{*}\right]$} & $+\times 0$ & $+\times 0$ \\
\hline Allogona (A.) ptychophora solida & - & - & - & - & - & - & - & - & - & - & - & - \\
\hline Anguispira kochi occidentalis & - & - & - & - & - & - & - & - & - & - & - & - \\
\hline Catinella avara & - & - & - & - & - & - & - & - & - & - & - & - \\
\hline Cochlicopa lubrica & - & - & - & - & - & - & - & + & xo & - & $\mathrm{x}$ & - \\
\hline Cryptomastix (Bupiogona) populi & - & - & - & - & - & - & - & - & - & - & - & - \\
\hline Cryptomastix (Cryptomastix) harfordiana & - & - & - & $+\times 0$ & - & - & - & - & - & - & $+\times 0$ & - \\
\hline Cryptomastix (C.) mullani clappi & - & - & - & - & - & - & - & - & - & - & - & - \\
\hline Cryptomastix (C.) mullani latilabris & - & - & - & - & - & - & - & - & - & - & - & - \\
\hline Cryptomastix (C.) mullani mullani & - & - & - & - & - & - & - & - & - & - & - & - \\
\hline Cryptomastix (C.) mullani olneyae & - & - & - & - & - & - & - & - & - & - & - & - \\
\hline Cryptomastix (C.) n. sp. 3 & - & - & - & - & - & - & - & - & - & - & - & - \\
\hline Cryptomastix (C.) n. sp. 5 & $+\times 0$ & $+\times 0$ & - & - & - & - & - & - & - & - & - & - \\
\hline Cryptomastix (C.) n. sp. 6 & - & - & - & - & + & 0 & $+\times 0$ & $+\times 0$ & $+\times 0$ & - & - & $+\times 0$ \\
\hline Deroceras sp. & - & - & - & - & - & - & - & - & - & - & - & - \\
\hline Discus marmorensis & - & - & - & - & - & - & - & - & - & - & - & - \\
\hline Discus whitneyi & - & - & - & - & - & - & - & - & - & - & - & - \\
\hline Euconulus fulvus alaskensis & - & - & - & - & - & - & - & - & - & - & - & - \\
\hline Hawaiia minuscula & - & - & - & - & - & - & - & - & - & - & - & - \\
\hline Helicodiscus salmoneus & +0 & - & - & $+\times 0$ & + & - & - & - & $+x$ & - & + & - \\
\hline Hemphillia camelus & - & - & - & - & - & - & - & - & - & - & - & - \\
\hline Microphysula ingersolli & - & - & - & - & - & - & - & - & - & - & - & - \\
\hline Ogaridiscus subrupicola & - & - & - & - & - & - & - & - & - & - & - & - \\
\hline Oreohelix hammeri & - & - & - & - & - & - & - & - & - & - & - & - \\
\hline Oreohelix haydeni hesperia & - & - & - & - & - & - & - & - & - & - & - & - \\
\hline Oreohelix haydeni perplexa & 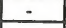 & - & - & - & - & - & - & - & - & - & $=$ & - \\
\hline Oreohelix idahoensis idahoensis & - & - & - & - & - & - & - & - & - & - & - & - \\
\hline Oreohelix intersum & - & - & - & - & - & - & - & - & - & - & - & - \\
\hline
\end{tabular}

* = colony may now be extinct 
TABLE 3. SITE FAUNAL LISTS. (cont.)

\begin{tabular}{|c|c|c|c|c|c|c|c|c|c|c|c|c|}
\hline 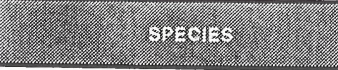 & 133 & 134 & 135 & 136 & 137 & 138 & 139 & 140 & 141 & 142 & 143 & 144 \\
\hline Oreohelix jugalis & - & - & $+\times 0$ & $+\times 0$ & $+\times 0$ & $+x 0$ & $+\times 0$ & + & - & - & - & $+\times 0$ \\
\hline Oreohelix n. sp. 8 & - & - & - & - & - & - & - & - & - & - & - & - \\
\hline Oreohelix n. sp. 12 & - & - & - & - & - & - & - & - & - & - & - & - \\
\hline Oreohelix n. sp. 13 & - & - & - & - & - & - & - & - & - & - & - & - \\
\hline Oreohelix n. sp. 14 & - & - & - & - & - & - & - & - & - & - & - & - \\
\hline Oreohelix n. sp. 15 & - & - & - & - & - & - & - & - & - & - & - & - \\
\hline Oreohelix n. sp. 19 & - & - & - & - & - & - & - & - & - & - & - & - \\
\hline Oreohelix n. sp. 20 & - & $+\times 0$ & - & - & - & - & - & - & - & - & - & - \\
\hline Oreohelix n. sp. 21 & - & - & - & - & - & - & - & - & - & - & - & - \\
\hline Oreohelix n. sp. 22 & - & - & - & - & - & - & - & - & - & - & - & - \\
\hline Oreohelix n. sp. 23 & - & - & - & - & - & - & - & - & - & - & - & - \\
\hline Oreohelix n. sp. 24 & - & - & - & - & - & - & - & - & - & - & - & - \\
\hline Oreohelix n. sp. 25 & - & - & - & - & - & - & - & - & $+\times 0$ & - & - & - \\
\hline Oreohelix n. sp. 29 & - & - & - & - & - & - & - & - & - & - & - & - \\
\hline Oreohelix n. sp. 32 & - & - & - & - & - & - & - & - & - & - & - & - \\
\hline Oreohelix strigosa goniogyra & - & - & - & - & - & - & - & - & - & - & - & - \\
\hline Oreohelix strigosa n. subsp. 1 & - & - & - & - & - & - & - & - & - & - & - & - \\
\hline Oreohelix vortex & - & - & - & - & - & - & - & $+\times 0$ & - & - & $+x o$ & - \\
\hline Oreohelix waltoni & - & - & $+\times 0$ & $+\times 0$ & - & - & - & - & - & - & - & - \\
\hline Planogyra clappi & - & - & - & - & - & - & - & - & - & - & - & - \\
\hline Polygyrella polygyrella & - & - & - & - & - & - & - & - & - & - & - & - \\
\hline Pristiloma (Pristinopsis) idahoense & - & - & - & - & - & - & - & - & - & - & - & - \\
\hline Punctum pusillum & - & - & - & - & - & - & - & - & - & - & - & - \\
\hline Pupilla hebes & - & - & - & - & - & - & - & - & xo & - & + & - \\
\hline Radiodiscus (Radiodomus) abietum & - & - & - & - & - & - & - & - & - & - & - & - \\
\hline Succinea stretchiana & - & - & - & - & - & - & - & - & - & - & - & - \\
\hline Vallonia cyclophorella & - & - & - & - & - & - & - & - & + & - & - & - \\
\hline Vertigo concinnula & - & - & - & - & - & - & - & - & - & - & - & - \\
\hline
\end{tabular}


TABLE 3. SITE FAUNAL LISTS. (cont.)

\begin{tabular}{|l|c|c|c|c|c|c|c|c|c|c|c|c|}
\hline Vitrina alaskana & 133 & 134 & 135 & 136 & 137 & 138 & 139 & 140 & 141 & 142 & 143 & 144 \\
\hline Zacoleus idahoensis & - & - & - & - & - & - & - & $+\times$ & - & - & - & - \\
\hline Zonitoides (Zonitoides) arboreus & - & - & - & - & - & - & - & - & - & - & - & - \\
\hline
\end{tabular}

\begin{tabular}{|c|c|c|c|c|c|c|c|c|c|c|c|c|}
\hline 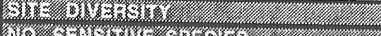 & 2 & 2 & 2 & 5 & 3 & 2 & 3 & 5 & 7 & 1 & 6 & 3 \\
\hline Ho & 1 & 2 & 2 & 3 & 2 & 2 & 2 & 3 & 2 & 0 & 2 & 2 \\
\hline 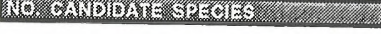 & 0 & 0 & 2 & 2 & 1 & 1 & 1 & 2 & 0 & 0 & 1 & 1 \\
\hline
\end{tabular}

$+=$ live collection

$x=$ recently dead

$\mathrm{O}=$ long-dead

$[$ ] = not collected 
TABLE 3. SITE FAUNAL LISTS. (cont.)

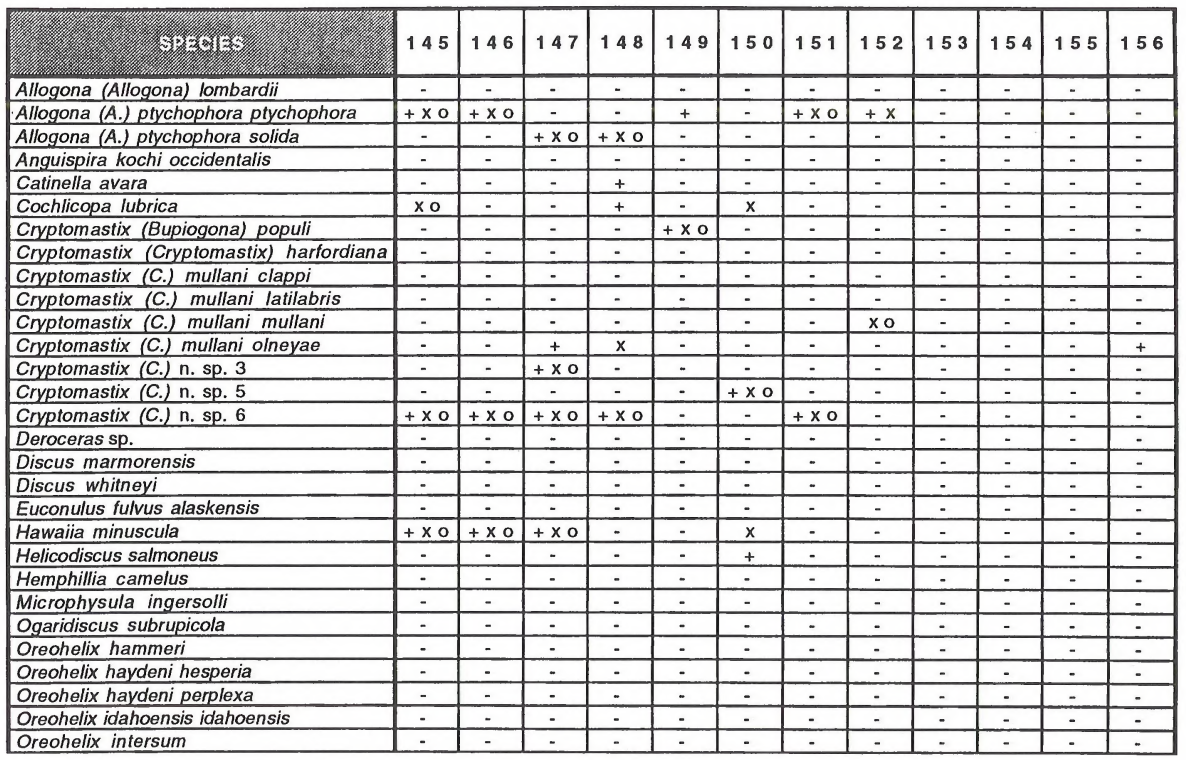


TABLE 3. SITE FAUNAL LISTS. (cont.)

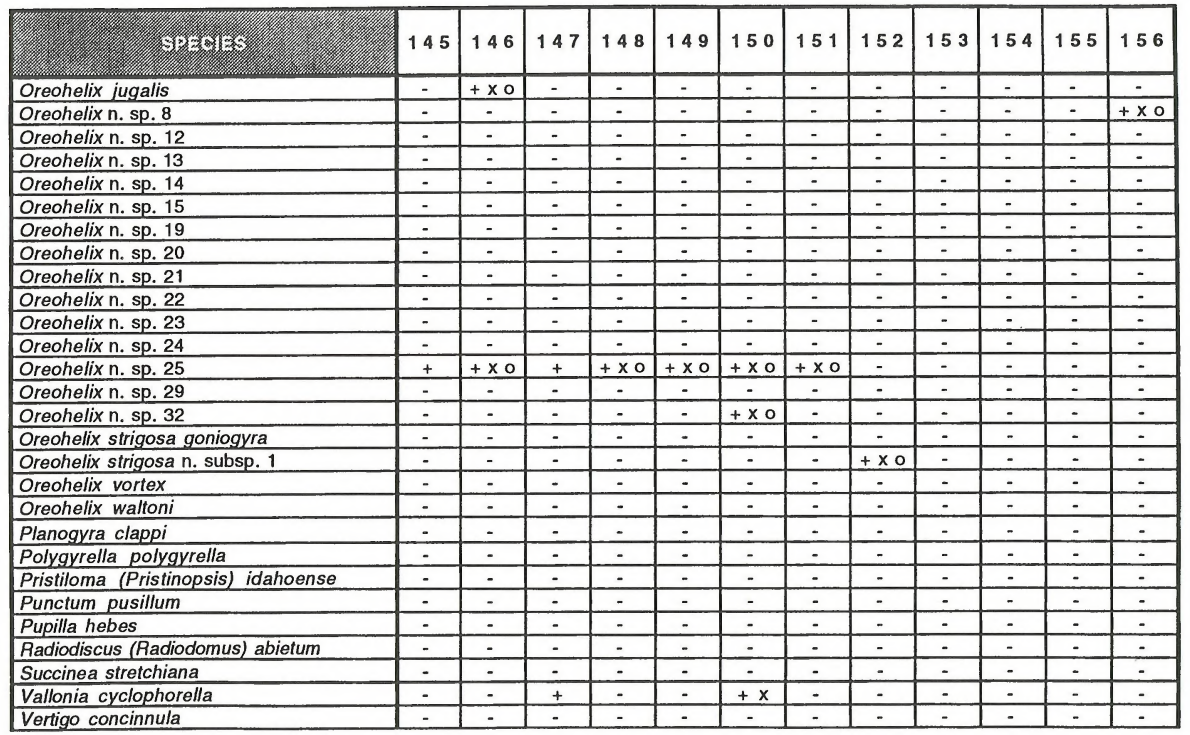



TABLE 3. SITE FAUNAL LISTS. (cont.)

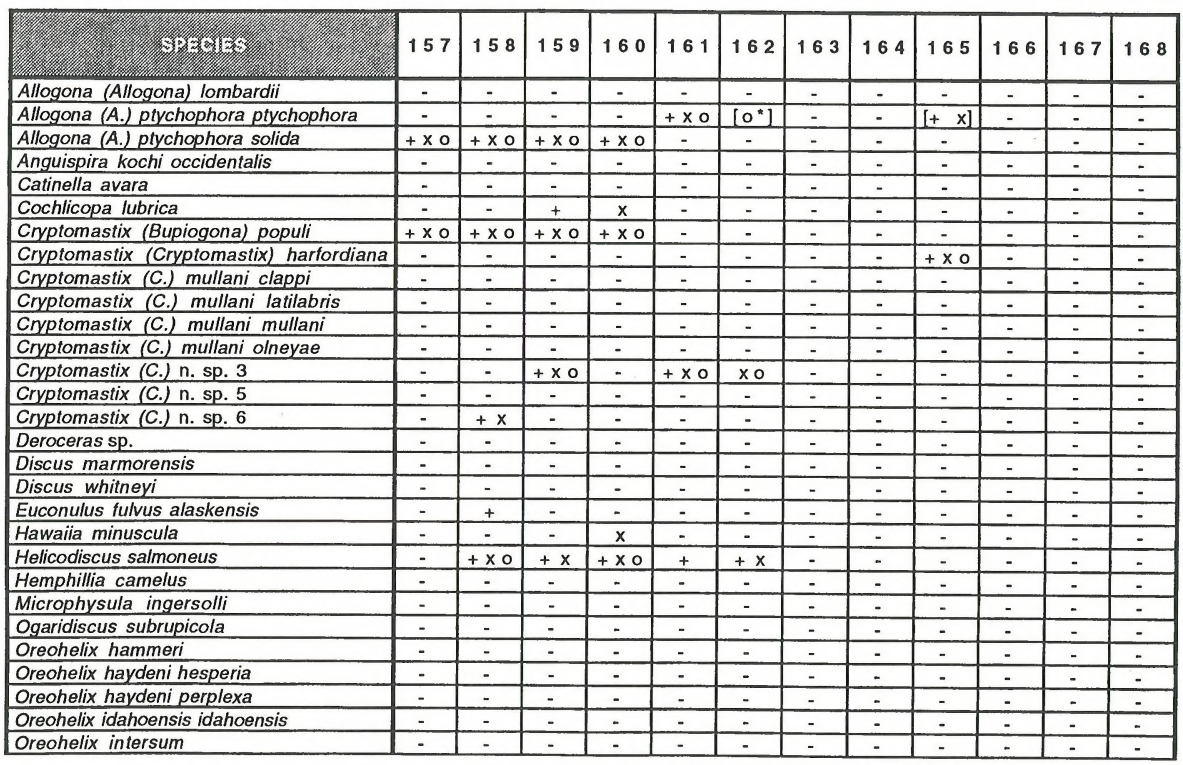

${ }^{\star}=$ colony may be extirpated 
TABLE 3. SITE FAUNAL LISTS. (cont.)

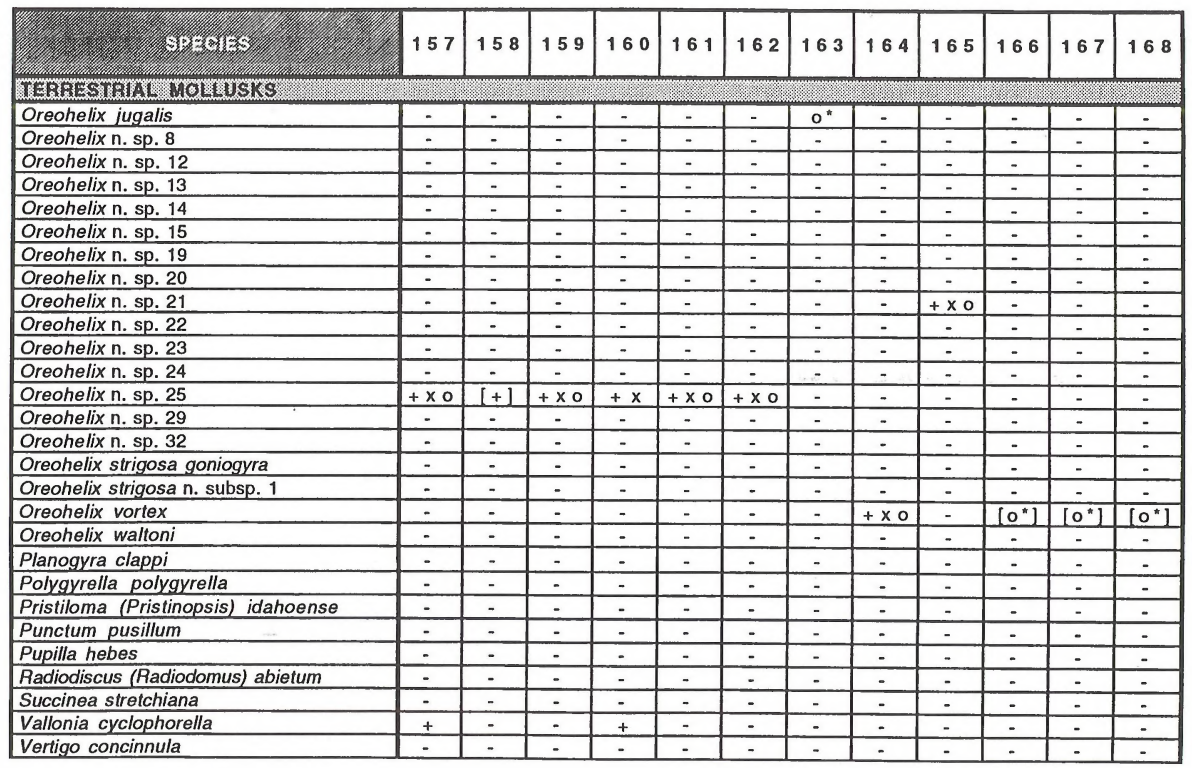

* $=$ formerly $+\mathrm{x}$ o; population now extinct 
TABLE 3. SITE FAUNAL LISTS. (cont.)

\begin{tabular}{|l|c|c|c|c|c|c|c|c|c|c|c|c|}
\hline \hline Vitrina alaskana & 157 & 158 & 159 & 160 & 161 & 162 & 163 & 164 & 165 & 166 & 167 & 168 \\
\hline Zacoleus idahoensis & $\mathrm{X}$ & $\mathrm{X}$ & - & - & - & - & - & - & - & - & - & - \\
\hline Zonitoides (Zonitoides) arboreus & - & - & - & - & - & - & - & - & - & - & - & - \\
\hline
\end{tabular}

\begin{tabular}{|c|c|c|c|c|c|c|c|c|c|c|c|c|}
\hline STI & 5 & 7 & 5 & 7 & 5 & 4 & $1 ?$ & 1 & 3 & [1?] & [1?] & [1?] \\
\hline Hes & 3 & 4 & 4 & 3 & 3 & 2 & $1 ?$ & 1 & 2 & [1?] & [1?] & [1?] \\
\hline 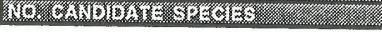 & 0 & 0 & 0 & 0 & 0 & 0 & $1 ?$ & 1 & 0 & [1?] & [1?] & [1?] \\
\hline
\end{tabular}

\footnotetext{
$+=$ live collection

$x=\quad$ recently dead

$0=$ long-dead

[ ] = not collected
} 
TABLE 3. SITE FAUNAL LISTS. (cont.)

\begin{tabular}{|c|c|c|c|c|c|c|c|c|c|c|c|c|}
\hline 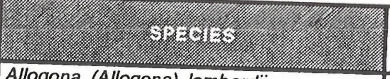 & 169 & 170 & 171 & 172 & 173 & 174 & 175 & 176 & 177 & 178 & 179 & 180 \\
\hline Allogona (Allogona) lombardii & - & - & - & - & - & - & - & $+\times 0$ & - & - & - & - \\
\hline $\begin{array}{l}\text { Allogona (A.) ptychophora ptychophora } \\
\text { Allogona (A.) ptychophora solida }\end{array}$ & - & - & - & $+x$ & - & + & $+x$ & $+\times 0$ & $+\times 0$ & + & $+\times 0$ & - \\
\hline $\begin{array}{l}\text { Allogona (A.) ptychophora solida } \\
\text { Anguispira kochi occidentalis }\end{array}$ & - & - & - & - & - & - & - & - & - & - & - & - \\
\hline $\begin{array}{l}\text { Anguispira kochi occidentalis } \\
\text { Catinella avara }\end{array}$ & - & - & - & - & - & - & - & $+\times 0$ & $+\times 0$ & - & - & - \\
\hline $\begin{array}{l}\text { Catinella avara } \\
\text { Cochlicopa lubrica }\end{array}$ & - & - & - & - & - & - & - & - & - & - & - & - \\
\hline $\begin{array}{l}\text { Cochlicopa lubrica } \\
\text { Cryptomastix (Bupiogona) populi }\end{array}$ & - & - & $x$ & - & - & - & - & - & - & - & - & - \\
\hline $\begin{array}{l}\text { Cryptomastix (Bupiogona) populi } \\
\text { Cryptomastix (Cryptomastix) harfordiana }\end{array}$ & - & - & - & - & - & - & - & - & - & - & - & - \\
\hline $\begin{array}{l}\text { Cryptomastix (Cryptomastix) harfordiana } \\
\text { Cryptomastix (C.) mullani clappi }\end{array}$ & - & - & - & - & $+\times 0$ & - & - & - & - & - & - & - \\
\hline $\begin{array}{l}\text { Cryptomastix (C.) mullani clappi } \\
\text { Cryptomastix (C.) mullani latilabris }\end{array}$ & $=$ & - & - & - & - & - & - & - & - & - & - & $=$ \\
\hline $\begin{array}{l}\text { Cryptomastix (C.) mullani latilabris } \\
\text { Cryptomastix (C.) mullani mullani }\end{array}$ & - & - & - & - & - & - & $=$ & - & - & - & - & - \\
\hline $\begin{array}{l}\text { Cryptomastix (C.) mullani mullani } \\
\text { Cryptomastix (C.) mullani olneyae }\end{array}$ & - & - & - & - & $=$ & - & - & - & - & - & - & - \\
\hline $\begin{array}{l}\text { Cryptomastix (C.) mullani olneyae } \\
\text { Cryptomastix (C.) n. sp. } 3\end{array}$ & - & - & + & - & - & - & $+\times 0$ & $+\times 0$ & $+\times 0$ & $+\times 0$ & $+x$ & - \\
\hline $\begin{array}{l}\text { Cryptomastix (C.) n. sp. } 3 \\
\text { Cryptomastix (C.) n. sp. } 5\end{array}$ & - & - & - & - & - & - & - & - & - & - & - & - \\
\hline $\begin{array}{l}\text { Cryptomastix (C.) n. sp. } 5 \\
\text { Cryptomastix (C.) n. sp. } 6\end{array}$ & - & - & - & - & - & $+\times 0$ & - & - & - & - & - & - \\
\hline Deroceras sp. & - & - & - & - & - & - & - & - & - & - & - & - \\
\hline Discus marmorensis & - & - & - & - & - & - & - & - & - & - & - & - \\
\hline Discus whitneyi & - & - & - & - & - & - & $+x$ & $+x$ & $+x$ & $+x$ & - & - \\
\hline Euconulus fulvus alaskensis & - & - & - & - & $=$ & - & - & $+\times 0$ & - & - & - & - \\
\hline Hawaiia minuscula & - & - & - & - & - & - & + & - & - & - & - & - \\
\hline Helicodiscus salmoneus & $=$ & - & $x$ & - & - & - & - & - & - & - & - & - \\
\hline Hemphillia camelus & - & - & xo & $+\times 0$ & - & - & $+x$ & - & - & - & - & - \\
\hline Microphysula ingersolli & - & - & - & - & - & - & - & - & + & - & - & - \\
\hline Ogaridiscus subrupicola & - & - & - & $+\times 0$ & - & - & $=$ & - & - & - & - & - \\
\hline Oreohelix hammeri & - & - & - & - & - & - & - & - & - & - & - & - \\
\hline Oreohelix haydeni hesperia & - & - & - & - & - & - & - & - & - & - & - & - \\
\hline Treohelix haydeni perplexa & - & - & - & - & - & - & - & - & - & - & - & - \\
\hline Preohelix idahoensis idahoensis & - & - & - & - & - & - & $=$ & $=$ & - & - & - & - \\
\hline Dreohelix intersum & - & - & - & - & - & - & - & - & - & - & - & $=$ \\
\hline & - & - & - & - & - & - & - & - & - & - & - & - \\
\hline
\end{tabular}


TABLE 3. SITE FAUNAL LISTS. (cont.)

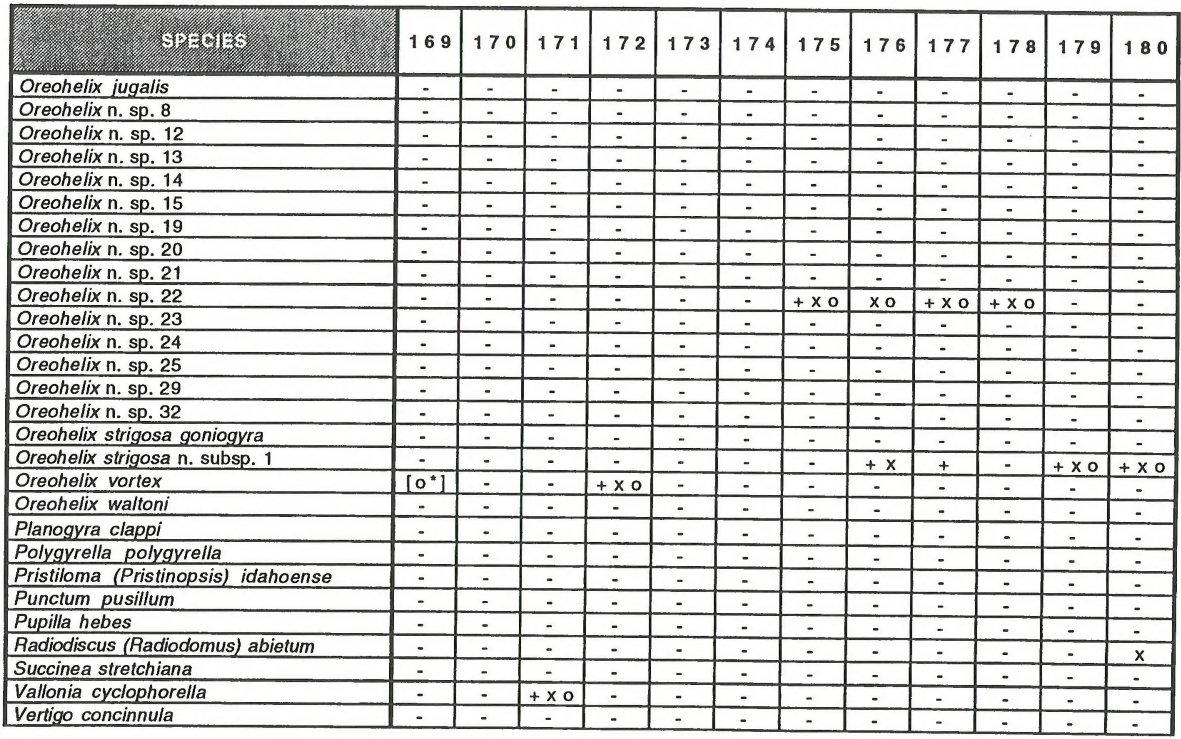

"= population now extinct 
TABLE 3. SITE FAUNAL LISTS. (cont.)

\begin{tabular}{|l|c|c|c|c|c|c|c|c|c|c|c|c|}
\hline $8(v)$ & 169 & 170 & 171 & 172 & 173 & 174 & 175 & 176 & 177 & 178 & 179 & 180 \\
\hline Vitrina alaskana & - & - & - & - & - & - & - & - & - & - & - & - \\
\hline Zacoleus idahoensis & - & - & - & $\mathrm{X}$ & - & - & + & - & - & - & - & - \\
\hline Zonitoides (Zonitoides) arboreus & - & - & - & - & - & - & - & - & - & - & - & - \\
\hline
\end{tabular}

\begin{tabular}{|c|c|c|c|c|c|c|c|c|c|c|c|c|}
\hline 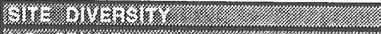 & [1] & 0 & 5 & 5 & 1 & 1 & 8 & 8 & 6 & 4 & 3 & 2 \\
\hline 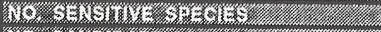 & [1] & 0 & 0 & 2 & 0 & 1 & 4 & 4 & 2 & 2 & 2 & 2 \\
\hline 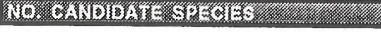 & {$[1]$} & 0 & 0 & 1 & 0 & 0 & 1 & 1 & 1 & 1 & 1 & 0 \\
\hline
\end{tabular}
$+=$ live collection
$x=$ recently dead
$0=$ long-dead
[]$=$ not collected 
TABLE 3. SITE FAUNAL LISTS. (cont.)

\begin{tabular}{|c|c|c|c|c|c|c|c|c|c|c|c|c|}
\hline 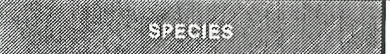 & 181 & 182 & 183 & 184 & 185 & 186 & 187 & 188 & 189 & 190 & 191 & 192 \\
\hline Allogona (Allogona) lombardii & - & - & - & - & - & - & - & - & - & - & - & - \\
\hline Allogona (A.) ptychophora ptychophora & - & - & - & $+\times 0$ & $+\times 0$ & - & - & - & - & xo & - & {$\left[\begin{array}{ll}x & 0\end{array}\right]$} \\
\hline Allogona (A.) ptychophora solida & - & - & - & - & - & - & - & - & - & - & - & - \\
\hline Anguispira kochi occidentalis & - & - & - & - & - & xo & - & - & - & - & - & - \\
\hline Catinella avara & - & - & - & - & - & - & - & - & - & - & - & - \\
\hline Cochlicopa lubrica & - & - & - & - & +0 & - & +0 & - & - & - & - & - \\
\hline Cryptomastix (Bupiogona) populi & - & - & - & - & - & - & - & - & - & - & - & - \\
\hline Cryptomastix (Cryptomastix) harfordiana & - & - & - & - & - & - & $+\times 0$ & - & - & - & - & - \\
\hline Cryptomastix (C.) mullani clappi & - & - & - & - & - & - & - & - & - & - & - & $+\times 0$ \\
\hline Cryptomastix (C.) mullani latilabris & - & - & - & - & $+\times 0$ & - & - & - & - & - & - & - \\
\hline Cryptomastix (C.) mullani mullani & - & - & - & - & - & - & - & - & - & - & - & - \\
\hline Cryptomastix (C.) mullani olneyae & - & - & - & - & - & $x$ & - & - & - & - & - & - \\
\hline Cryptomastix (C.) n. sp. 3 & - & - & - & - & - & - & - & - & - & - & $+x 0$ & - \\
\hline Cryptomastix (C.) n. sp. 5 & - & - & $=$ & - & - & - & - & $\times 0$ & - & - & - & - \\
\hline Cryptomastix (C.) n. sp. 6 & - & - & - & - & - & - & - & - & - & - & - & - \\
\hline Deroceras sp. & - & - & - & - & - & - & - & - & $=$ & - & - & - \\
\hline Discus marmorensis & - & - & - & - & - & - & $=$ & - & - & - & - & - \\
\hline Discus whitneyi & - & - & - & - & - & - & - & - & - & - & - & - \\
\hline Euconulus fulvus alaskensis & - & - & - & - & +0 & - & - & - & - & - & - & - \\
\hline Hawaiia minuscula & - & - & - & - & - & - & +0 & - & - & - & - & - \\
\hline Helicodiscus salmoneus & - & - & - & - & +0 & - & +0 & - & - & - & - & - \\
\hline Hemphillia camelus & - & - & - & - & - & - & - & - & - & - & - & - \\
\hline Microphysula ingersolli & - & - & - & - & - & - & - & - & - & - & - & - \\
\hline Ogaridiscus subrupicola & - & - & - & - & 0 & - & - & - & - & - & - & - \\
\hline Oreohelix hammeri & - & - & - & - & - & - & - & - & - & - & - & - \\
\hline Oreohelix haydeni hesperia & - & - & - & $+\times 0$ & $+\times 0$ & - & - & - & - & - & - & - \\
\hline Oreohelix haydeni perplexa & - & - & - & - & - & - & - & - & - & - & - & - \\
\hline Oreohelix idahoensis idahoensis & - & - & - & - & - & - & - & - & - & - & - & - \\
\hline Oreohelix intersum & - & - & - & - & - & - & - & - & - & - & - & - \\
\hline
\end{tabular}


TABLE 3. SITE FAUNAL LISTS. (cont.)

\begin{tabular}{|c|c|c|c|c|c|c|c|c|c|c|c|c|}
\hline 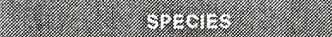 & 181 & 182 & 183 & 184 & 185 & 186 & 187 & 188 & 189 & 190 & 191 & 192 \\
\hline Oreohelix jugalis & - & - & - & - & - & xo & - & - & - & $+\times 0$ & - & - \\
\hline Oreohelix n. sp. 8 & - & - & - & - & - & - & - & - & - & - & - & - \\
\hline Oreohelix n. sp. 12 & - & - & - & - & - & - & - & - & - & - & - & - \\
\hline Oreohelix n. sp. 13 & - & - & - & - & - & - & - & - & - & - & - & - \\
\hline Oreohelix n. sp. 14 & - & - & - & - & - & - & - & - & - & - & - & - \\
\hline Oreohelix n. sp. 15 & - & - & - & - & - & - & - & - & - & - & - & $+\times 0$ \\
\hline Oreohelix n. sp. 19 & - & - & - & - & - & - & - & - & - & - & - & - \\
\hline Oreohelix n. sp. 20 & - & - & - & - & - & - & - & - & - & - & - & - \\
\hline Oreohelix n. sp. 21 & - & - & $\therefore$ & - & - & - & $+\times 0$ & xo & - & - & - & - \\
\hline Oreohelix n. sp. 22 & - & - & - & - & - & - & - & - & - & - & - & - \\
\hline Oreohelix n. sp. 23 & - & - & - & - & - & - & - & - & - & - & - & - \\
\hline Oreohelix n. sp. 24 & - & - & - & - & - & - & - & - & - & - & - & - \\
\hline Oreohelix n. sp. 25 & - & - & - & - & - & - & - & - & - & - & $+x 0$ & - \\
\hline Oreohelix n. sp. 29 & - & - & - & - & - & - & - & - & - & - & - & - \\
\hline Oreohelix n. sp. 32 & - & - & - & - & - & - & - & - & - & - & - & - \\
\hline Oreohelix strigosa goniogyra & $+\times 0$ & $+\times 0$ & $+\times 0$ & - & - & - & - & - & - & - & - & - \\
\hline Oreohelix strigosa n. subsp. 1 & - & - & - & - & - & - & - & - & - & - & - & - \\
\hline Oreohelix vortex & - & - & - & - & - & - & - & - & $=$ & - & - & - \\
\hline Oreohelix waltoni & - & - & - & - & - & $+\times 0$ & $+\times 0$ & - & - & - & - & - \\
\hline Planogyra clappi & - & - & - & - & - & - & - & - & - & - & - & - \\
\hline Polygyrella polygyrella & - & - & - & - & - & - & - & - & - & - & - & - \\
\hline Pristiloma (Pristinopsis) idahoense & - & - & - & - & xo & - & - & - & - & - & - & - \\
\hline Punctum pusillum & - & - & - & - & - & - & - & - & - & - & - & - \\
\hline Pupilla hebes & - & - & - & - & - & - & +0 & - & - & - & - & - \\
\hline Radiodiscus (Radiodomus) abietum & - & - & - & - & - & - & - & 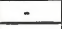 & - & - & - & - \\
\hline Succinea stretchiana & - & - & - & - & - & - & - & - & - & - & - & - \\
\hline Vallonia cyclophorella & - & - & - & - & - & - & +0 & - & - & - & - & $\therefore$ \\
\hline Vertigo concinnula & - & - & - & - & - & - & - & - & - & - & - & - \\
\hline
\end{tabular}


TABLE 3. SITE FAUNAL LISTS. (cont.)

\begin{tabular}{|l|c|c|c|c|c|c|c|c|c|c|c|c|c|}
\hline Vitrina alaskana & 181 & 182 & 183 & 184 & 185 & 186 & 187 & 188 & 189 & 190 & 191 & 192 \\
\hline Zacoleus idahoensis & - & - & - & - & +0 & - & - & - & - & - & - & - \\
\hline Zonitoides (Zonitoides) arboreus & - & - & - & - & - & - & - & - & - & - & - & - \\
\hline
\end{tabular}

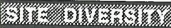

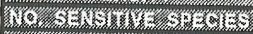

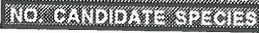

\begin{tabular}{|c|c|c|c|c|c|c|c|c|c|c|c|}
\hline 1 & 1 & 1 & 2 & 9 & 4 & 8 & 2 & 0 & 2 & 2 & 3 \\
\hline 1 & 1 & 1 & 1 & 3 & 2 & 3 & 2 & 0 & 1 & 1 & 3 \\
\hline 1 & 1 & 1 & 0 & 0 & 2 & 1 & 0 & 0 & 1 & 0 & 0 \\
\hline
\end{tabular}

$+=$ live collection

$\mathrm{x}=$ recently dead

$\mathrm{o}=$ long-dead 
TABLE 3. SITE FAUNAL LISTS. (cont.)

\begin{tabular}{|c|c|c|c|c|c|c|c|c|c|c|c|c|}
\hline 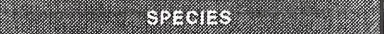 & 193 & 194 & 195 & 196 & 197 & 198 & 199 & 200 & 201 & 202 & 203 & 204 \\
\hline Allogona (Allogona) lombardii & - & - & - & - & - & - & - & - & - & - & - & - \\
\hline Allogona (A.) ptychophora ptychophora & $+\times 0$ & - & - & - & $+\times 0$ & {$\left[0^{*}\right]$} & - & - & - & - & - & - \\
\hline Allogona (A.) ptychophora solida & - & - & - & - & - & - & - & - & - & - & - & - \\
\hline Anguispira kochi occidentalis & - & - & - & - & - & - & - & - & - & - & - & - \\
\hline Catinella avara & - & - & - & - & - & - & - & - & - & - & - & - \\
\hline Cochlicopa lubrica & - & - & - & - & - & - & - & - & - & - & - & - \\
\hline Cryptomastix (Bupiogona) populi & - & - & - & - & - & - & - & - & - & - & - & - \\
\hline Cryptomastix (Cryptomastix) harfordiana & - & - & - & - & - & - & - & - & - & - & - & $\therefore$ \\
\hline Cryptomastix (C.) mullani clappi & [0"] & $+x$ & - & - & - & - & - & - & - & - & - & - \\
\hline Cryptomastix (C.) mullani latilabris & - & - & - & - & - & - & - & - & - & - & - & - \\
\hline Cryptomastix (C.) mullani mullani & - & - & - & - & - & - & - & - & - & - & - & - \\
\hline Cryptomastix (C.) mullani olneyae & - & - & - & - & $+\times 0$ & - & - & - & - & - & - & - \\
\hline Cryptomastix (C.) n. sp. 3 & - & - & - & - & - & - & - & - & - & - & - & - \\
\hline Cryptomastix (C.) n. sp. 5 & - & - & $+\times 0$ & - & - & - & - & - & - & - & - & - \\
\hline Cryptomastix (C.) n. sp. 6 & - & - & - & - & - & - & - & - & - & - & - & - \\
\hline Deroceras sp. & - & - & - & - & - & - & - & - & - & - & - & - \\
\hline Discus marmorensis & - & - & - & - & - & - & - & - & - & - & - & - \\
\hline Discus whitneyi & - & - & - & - & - & - & - & - & - & - & - & - \\
\hline Euconulus fulvus alaskensis & - & - & - & - & - & - & - & - & - & - & - & - \\
\hline Hawaiia minuscula & - & - & - & - & - & - & - & - & - & - & - & - \\
\hline Helicodiscus salmoneus & +0 & - & - & - & - & - & - & - & - & - & - & - \\
\hline Hemphillia camelus & - & - & - & - & - & - & - & - & - & - & - & - \\
\hline Microphysula ingersolli & - & - & - & - & - & - & - & - & - & - & - & - \\
\hline Ogaridiscus subrupicola & - & - & - & - & - & - & - & - & - & - & - & - \\
\hline Oreohelix hammeri & - & - & - & - & - & - & - & - & - & - & - & - \\
\hline Oreohelix havdeni hesperia & - & - & - & - & - & - & - & - & - & - & - & - \\
\hline Oreohelix haydeni perplexa & - & - & $+\times 0$ & - & - & - & - & - & - & - & - & - \\
\hline Oreohelix idahoensis idahoensis & - & - & - & - & - & - & - & - & - & $+\times 0$ & - & - \\
\hline Oreohelix intersum & - & - & - & - & - & - & - & - & - & - & - & - \\
\hline
\end{tabular}


TABLE 3. SITE FAUNAL LISTS. (cont.)

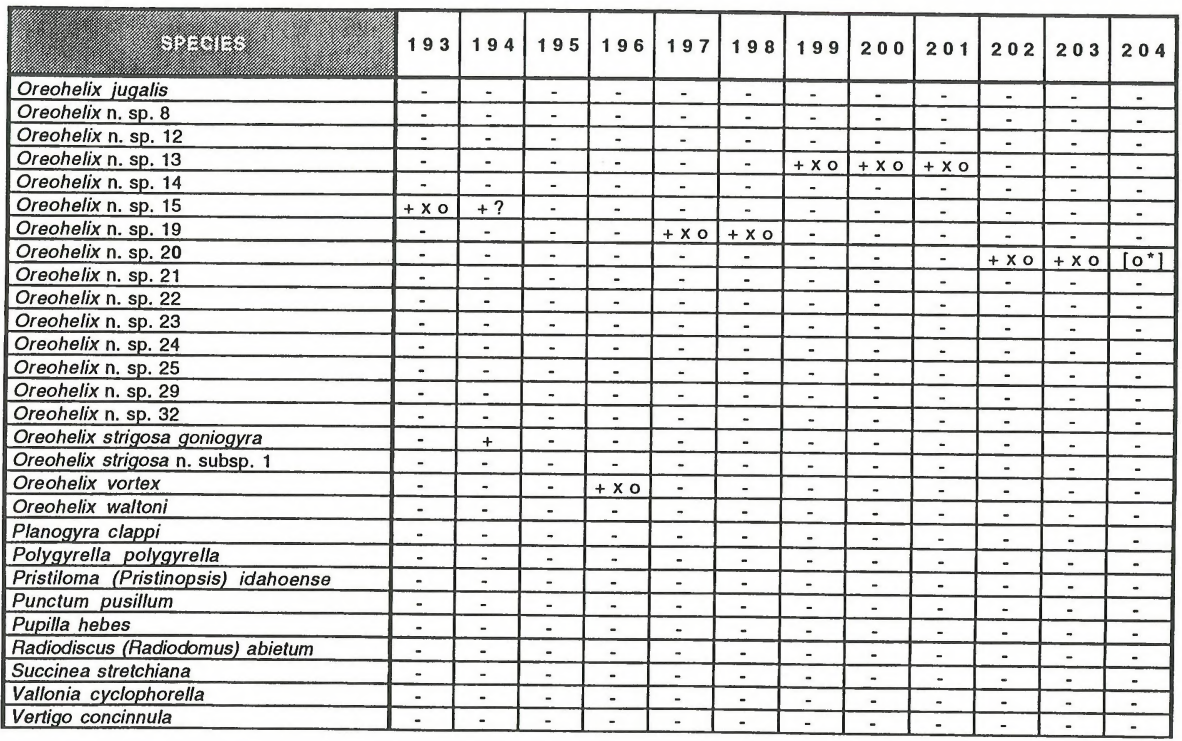

"= colony now extinct 
TABLE 3. SITE FAUNAL LISTS. (cont.)

\begin{tabular}{|l|r|c|c|c|c|c|c|c|c|c|c|c|}
\hline Vitrina alaskana & 193 & 194 & 195 & 196 & 197 & 198 & 199 & 200 & 201 & 202 & 203 & 204 \\
\hline Zacoleus idahoensis & - & - & - & - & - & - & - & - & - & - & - & - \\
\hline Zonitoides (Zonitoides) arboreus & - & - & - & - & - & - & - & - & - & - & - & - \\
\hline
\end{tabular}

\begin{tabular}{|l|l|l|l|l|l|l|l|l|l|l|l|l|}
\hline 5 & 5 & 3 & 2 & 1 & 3 & 2 & 1 & 1 & 1 & 2 & 1 & 1 \\
\hline Ka. & 2 & 3 & 2 & 1 & 1 & 1 & 1 & 1 & 1 & 2 & 1 & $1 ?$ \\
\hline
\end{tabular}

$+=$ live collection

$\mathrm{x}=$ recently dead

$o=$ long-dead 
TABLE 3. SITE FAUNAL LISTS. (cont.)

\begin{tabular}{|c|c|c|c|c|c|c|c|c|c|c|}
\hline (-) & 205 & 206 & 207 & 208 & 209 & 210 & 211 & 212 & 213 & (1) \\
\hline Allogona (Allogona) lombardii & - & - & - & - & - & - & - & - & - & 3 \\
\hline Allogona (A.) ptychophora ptychophora & - & - & - & - & - & $+x$ & - & - & - & 79 \\
\hline Allogona (A.) ptychophora solida & - & - & - & - & - & $+x$ & - & - & - & 21 \\
\hline Anguispira kochi occidentalis & - & - & - & - & - & - & - & - & - & 5 \\
\hline Catinella avara & - & - & - & - & - & - & - & - & - & 8 \\
\hline Cochlicopa lubrica & - & - & - & - & - & - & - & - & - & 12 \\
\hline Cryptomastix (Bupiogona) populi & - & - & - & - & - & - & - & - & - & 10 \\
\hline Cryptomastix (Cryptomastix) harfordiana & - & - & - & - & - & - & - & - & - & 19 \\
\hline Cryptomastix (C.) mullani clappi & - & - & - & - & - & - & + & - & - & 13 \\
\hline Cryptomastix (C.) mullani latilabris & - & - & - & - & - & - & - & - & - & 4 \\
\hline Cryptomastix (C.) mullani mullani & - & - & - & - & - & + & - & - & - & 4 \\
\hline Cryptomastix (C.) mullani olneyae & - & - & - & - & - & - & - & - & - & 22 \\
\hline Cryptomastix (C.) n. sp. 3 & - & - & - & - & - & - & - & - & - & 7 \\
\hline Cryptomastix (C.) n. sp. 5 & - & - & o & - & - & - & - & - & - & 40 \\
\hline Cryplomastix (C.) n. sp. 6 & - & - & - & - & - & - & - & - & - & 23 \\
\hline Deroceras sp. & - & - & - & - & - & + & - & - & - & 4 \\
\hline Discus marmorensis & - & - & - & - & - & - & - & - & - & 7 \\
\hline Discus whitneyi & - & - & - & - & - & - & - & - & - & 2 \\
\hline Euconulus fulvus alaskensis & - & - & - & - & - & - & - & - & - & 5 \\
\hline Hawaiia minuscula & - & - & - & - & - & - & - & - & - & 8 \\
\hline Helicodiscus salmoneus & - & - & - & - & - & - & - & - & - & 34 \\
\hline Hemphillia camelus & - & - & - & - & - & - & - & - & - & 1 \\
\hline Microphysula ingersolli & - & - & - & - & - & - & - & - & - & 3 \\
\hline Ogaridiscus subrupicola & - & - & - & - & - & - & - & - & - & 1 \\
\hline Oreohelix hammeri & - & - & - & - & - & - & - & - & - & [1] \\
\hline Oreohelix haydeni hesperia & - & - & - & - & - & - & - & - & - & 10 \\
\hline Oreohelix haydeni perplexa & - & - & - & - & - & - & - & - & - & 1 \\
\hline Oreohelix idahoensis idahoensis & - & - & $+\times 0$ & $\times 0$ & - & - & - & - & - & 20 \\
\hline Oreohelix intersum & - & - & - & - & - & - & - & - & - & 4 \\
\hline
\end{tabular}




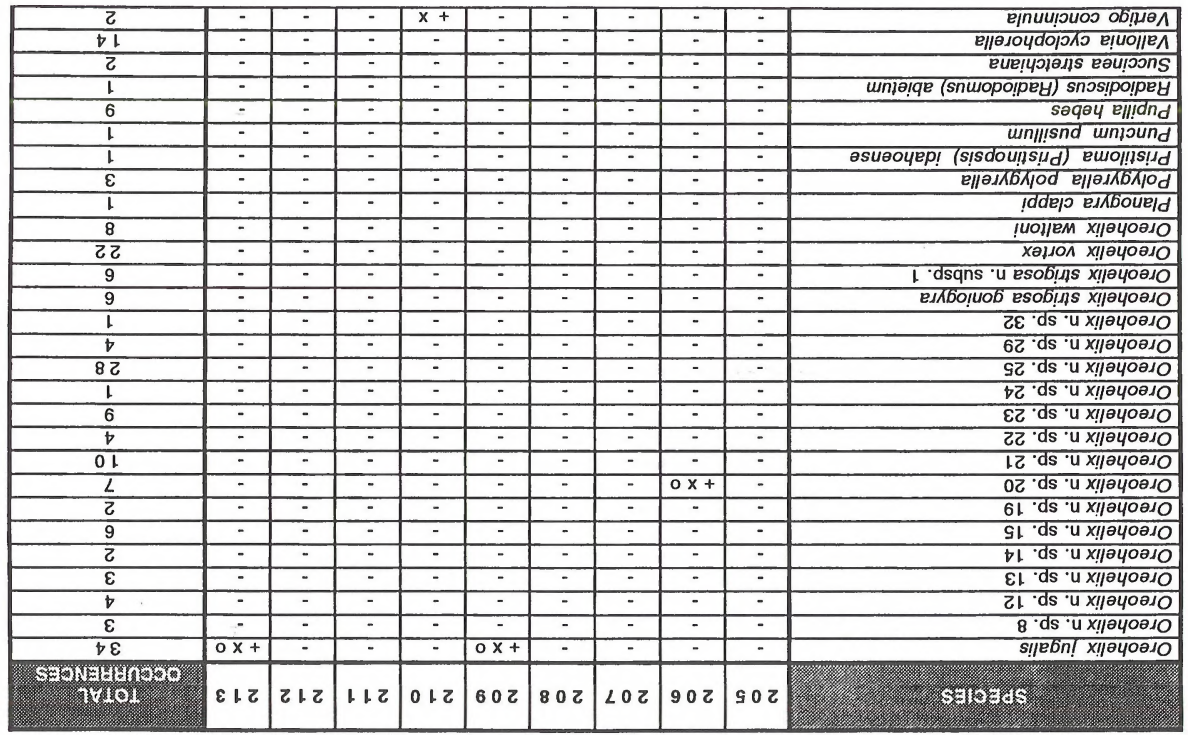

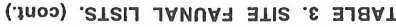




\begin{tabular}{|c|c|c|c|c|c|c|c|c|c|}
\hline I & 0 & 0 & 0 & 1 & 1 & 0 & 0 & 0 & 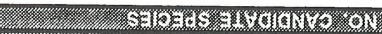 \\
\hline 1 & 0 & 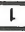 & 1 & 1 & $I$ & $i z$ & $t$ & 0 & (2) $\xi$ \& \\
\hline I & 0 & 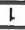 & $\mathrm{G}$ & I & 1 & 2 & $I$ & 0 & 1. \\
\hline
\end{tabular}

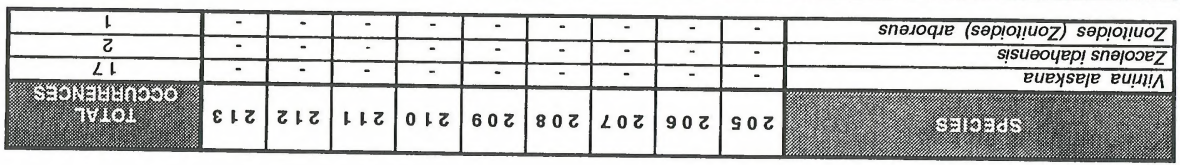

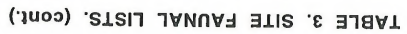




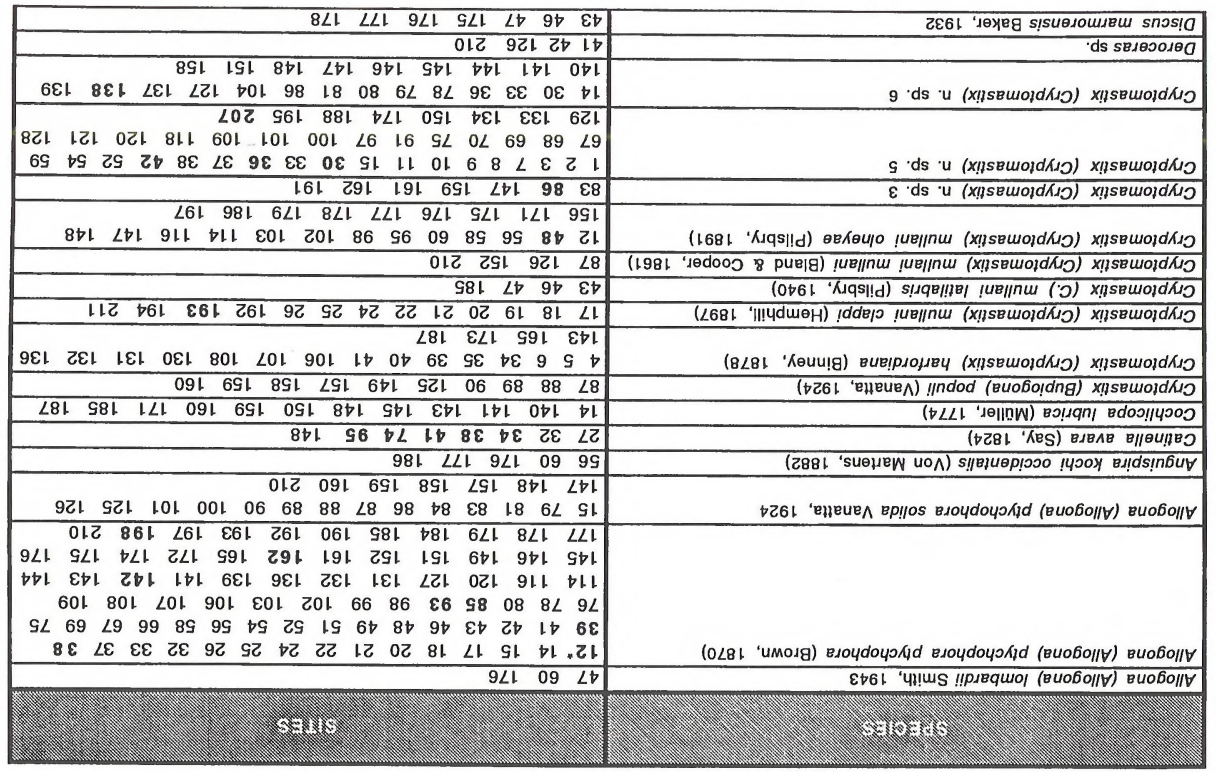

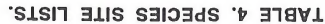




\begin{tabular}{|c|c|}
\hline 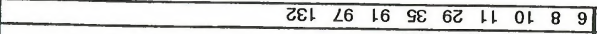 & $\varepsilon 己$ ds $\mathrm{u} x \| \theta 40010$ \\
\hline $8 \angle L \quad \angle L L \quad 9 \angle L \quad G \angle L$ & $22 \cdot d s \cdot u x ! \mid \theta 40 \theta 10$ \\
\hline 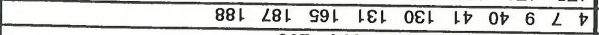 & 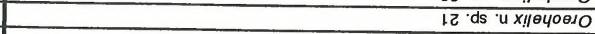 \\
\hline 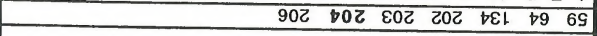 & 02 ds u $x ! \mid \theta 40 \theta i O$ \\
\hline $861 \quad \angle 61$ & 61 ds $\mathrm{u} x ! / \theta 40 \theta \lambda O$ \\
\hline $761 \quad \varepsilon 61 \quad 261 \quad 02 \quad 81 \quad \angle L$ & St ds $\mathrm{u} x ! \mid \theta 40010$ \\
\hline SII $\quad 011$ & Dt ds a $x ! / 040010$ \\
\hline 102002661 & 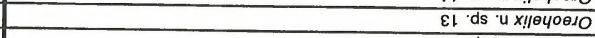 \\
\hline 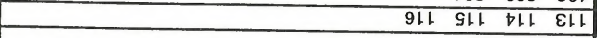 & $\mathrm{Cl} \cdot \mathrm{ds} \cdot \mathrm{u} x ! \operatorname{\theta i} 40 \theta \lambda O$ \\
\hline $991 \quad 89 \angle 9$ & 8 ds $\mathrm{u} x ! \mid \theta 40 \theta / O$ \\
\hline 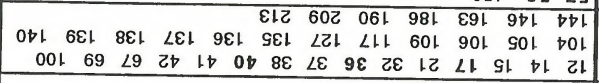 & (068! 'I!पdwөн) s!|в6n! х!|өчовло \\
\hline ZL। & 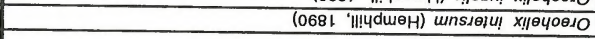 \\
\hline 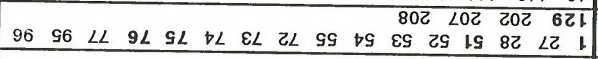 & 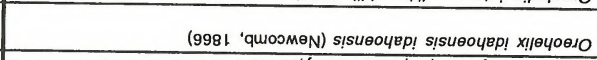 \\
\hline 961 & 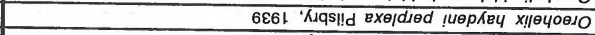 \\
\hline $\begin{array}{lllllllllll}981 & b 81 & \varepsilon 9 & 29 & 19 & 09 & 81 & \angle b & \varepsilon b & \varepsilon \varepsilon\end{array}$ & $6 \varepsilon 6$ เ 'Mqs!!d $8 ! \mu \theta d s \theta 4$ ! \\
\hline 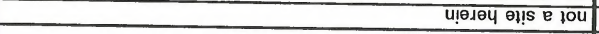 & t86! 'syuequ!e \\
\hline 981 & 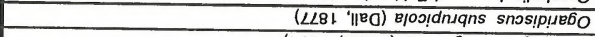 \\
\hline $96 \angle b$ & 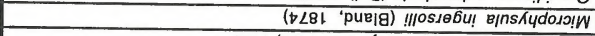 \\
\hline$\angle L 1$ & 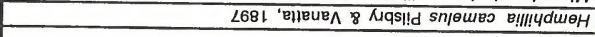 \\
\hline 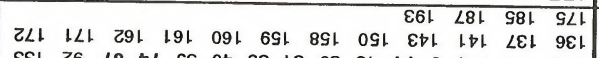 & \\
\hline 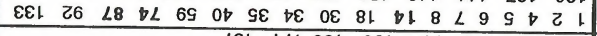 & 9881 'Kouu!g sneuoujes snos!poग!|өH \\
\hline$\angle 81 \quad 1 \angle L \quad 091 \quad 091 \quad \angle D L \quad 901 \quad S \$ 1 \quad 01$ & (0†8! 'Kөuu!g) e/nosnu!u в!!вмвH \\
\hline 981 SLI $891 \quad D L L \quad \angle L$ & 906! 'Kus!!d s!sueyseje snajny snjnuoon $\exists$ \\
\hline $9 \angle 1 \quad \angle 8$ & 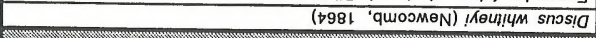 \\
\hline 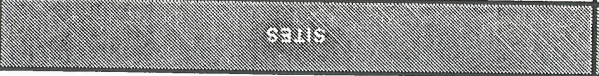 & \\
\hline
\end{tabular}

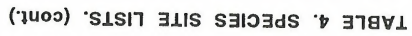


TABLE 4. SPECIES SITE LISTS. (cont.)

\begin{tabular}{|c|c|}
\hline Oreohelix n. sp. 24 & 31 \\
\hline Oreohelix n. sp. 25 & $\begin{array}{|lccccccccccccc|}78 & 79 & 80 & 81 & 83 & 87 & 98 & 99 & 102 & 103 & 107 & 108 & 125 & 141 \\
145 & 146 & 147 & 148 & 149 & 150 & 151 & 157 & 158 & 159 & 160 & 161 \\
162 & 191 & & & & & & & & & & & \\
\end{array}$ \\
\hline Oreohelix n. sp. 29 & $\begin{array}{lllll}86 & 88 & 89 & 90 \\
\end{array}$ \\
\hline Oreohelix n. sp. 32 & 150 \\
\hline Oreohelix strigosa goniogyra Pilsbry, 1934 & \begin{tabular}{llllll|}
20 & 94 & 181 & 182 & 183 & 194 \\
\end{tabular} \\
\hline Oreohelix strigosa n. subsp. 1 & \begin{tabular}{|llllll}
56 & 152 & 176 & 177 & 179 & 180 \\
\end{tabular} \\
\hline Oreohelix vortex Berry, 1932 & \begin{tabular}{|lrrrrrrrrrrrr}
14 & 15 & 69 & 70 & 98 & 102 & 103 & 106 & 109 & 118 & 119 & 120 & 121 \\
140 & 143 & 164 & 166 & 167 & 168 & 169 & 172 & 196 & & \\
\end{tabular} \\
\hline Oreohelix waltoni Solem, 1975 & \begin{tabular}{|llllllll}
30 & 34 & 40 & 99 & 135 & 136 & 186 & 187 \\
\end{tabular} \\
\hline Planogyra clappi (Pilsbry, 1898) & 41 \\
\hline Polygyrella polygyrella (Bland \& Cooper, 1861) & $99 \quad 102$ \\
\hline Pristiloma (Pristinopsis) idahoense (Pilsbry, 1902) & 185 \\
\hline Punctum pusillum (Lowe, 1831) & 41 \\
\hline Pupilla hebes (Ancey, 1881) & $\begin{array}{|lllllllll|}14 & 27 & 42 & 46 & 56 & 74 & 141 & 143 & 187 \\
\end{array}$ \\
\hline Radiodiscus (Radiodomus) abietum Baker, 1930 & 180 \\
\hline Succinea strotchiana Bland, 1865 & 3442 \\
\hline Vallonia cyclophorella (Sterki, 1892) & \begin{tabular}{|llllllllllllll}
2 & 4 & 14 & 67 & 74 & 87 & 92 & 141 & 147 & 150 & 157 & 160 & 171 & 187 \\
\end{tabular} \\
\hline Vertigo concinnula Cockerell, 1897 & $126 \quad 210$ \\
\hline Vitrina alaskana Dall, 1905 & $\begin{array}{|llllllllllllllll|}1 & 4 & 7 & 8 & 11 & 14 & 16 & 22 & 25 & 42 & 46 & 86 & 140 & 148 & 157 & 158 \\
185 & & & & & & & & & & & & & & \\
\end{array}$ \\
\hline Zacoleus idahoensis Pilsbry, 1903 & $172 \quad 175$ \\
\hline Zonitoides (Zonitoides) arboreus (Say, 1816) & 193 \\
\hline
\end{tabular}

"Bold face numbers indicate long-dead specimens only (colony often recently extirpated) 
TABLE 5. SITE OWNERSHIP.

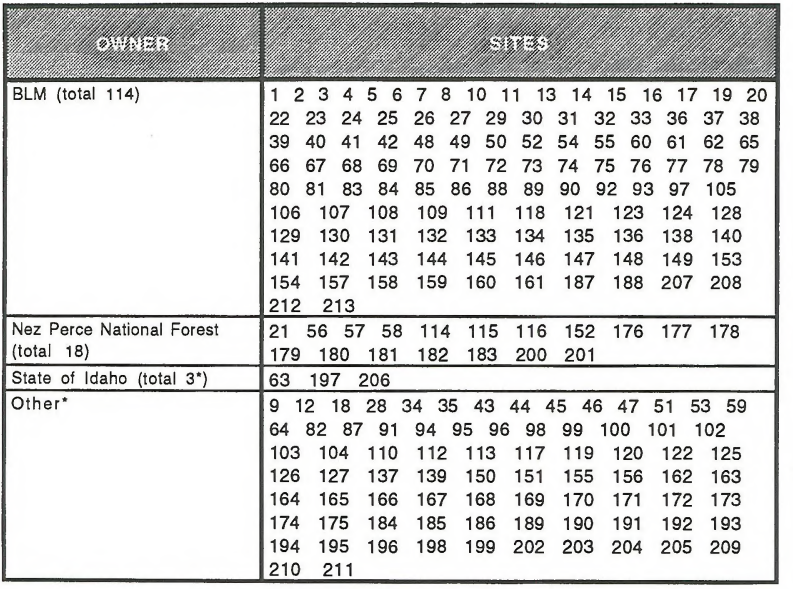

note that many of these sites are wholly or in part in the US95 corridor and hence also publicly owned. In many cases, the extent of the highway right-of way was unclear. One or more sites may be owned by Payette National Forest. 


\section{FIGURES}

FIGURE TITLE

PAGE

1.

MAP OF THE LOWER SALMON RIVER VALLEY

F2

2. LOWER SALMON RIVER OREOHELIX TYPE LOCALITIES

F4

3.

OTHER LOWER SALMON RIVER LAND SNAIL TYPE LOCALITIES

F6

4.

RANGES OF ENDEMIC OREOHELIX SPECIES

F8

5.

RANGES OF ENDEMIC POLYGYRID SPECIES

F10

6.

LOWER SALMON RIVER LAND SNAIL BIOGEOGRAPHY

F12

7.

SPECIES/SITE RANKINGS

F14

8.

LOWER SALMON RIVER LAND SNAIL SITE DIVERSITY

F16

9.

NUMBER OF SENSITIVE AND CANDIDATE LOWER SALMON RIVER LAND SNAIL SPECIES

10.

STATUS OF LOWER SALMON RIVER LAND SNAILS

F20

11.

MOISTURE PREFERENCES OF LOWER SALMON RIVER LAND SNAILS

F22

12.

ALTITUDE PREFERENCES OF LOWER SALMON RIVER LAND SNAILS

F24

13.

COVER PREFERENCES OF LOWER SALMON RIVER LAND SNAILS

F26 


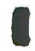

1

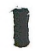

I

I

I

I

I

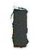

1

1

I

1

1

1 


\section{FIGURE 1. MAP OF THE LOWER SALMON RIVER VALLEY.}

Map of survey area in the Lower Salmon River Valley, in portions of Idaho, Lewis, and Nez Perce Cos., Idaho. Some pertinent BLM holdings are shown as dotted areas. Collecting sites indicated by numbers and black dots, type locality of Oreohelix hammeri by star. See Appendix A for site descriptions and Appendix B for more detailed site maps. Inset shows location of survey area in respect to state boundaries. Scale of Figures 1-6 is the same, but only indicated on Figure 1. 
1

1

I

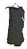

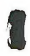

I

1

$I$

I

I

I

I

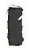

1

1

I

1

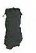

I 
FIGURE 2. LOWER SALMON RIVER OREOHELIX TYPE LOCALITIES.

\begin{abstract}
Map of survey area in the Lower Salmon River Valley, showing locations of type localities for described species of the important land snail genus Oreohelix. Many of these sites are on BLM public lands. Tentatively chosen type localities for many of the new Oreohelix taxa discussed herein will also be on BLM public lands. Note concentration of sites in the Riggins-White Bird corridor. For detailed discussion of locations, see text; see also Figure 1 and Appendices A-C.
\end{abstract}




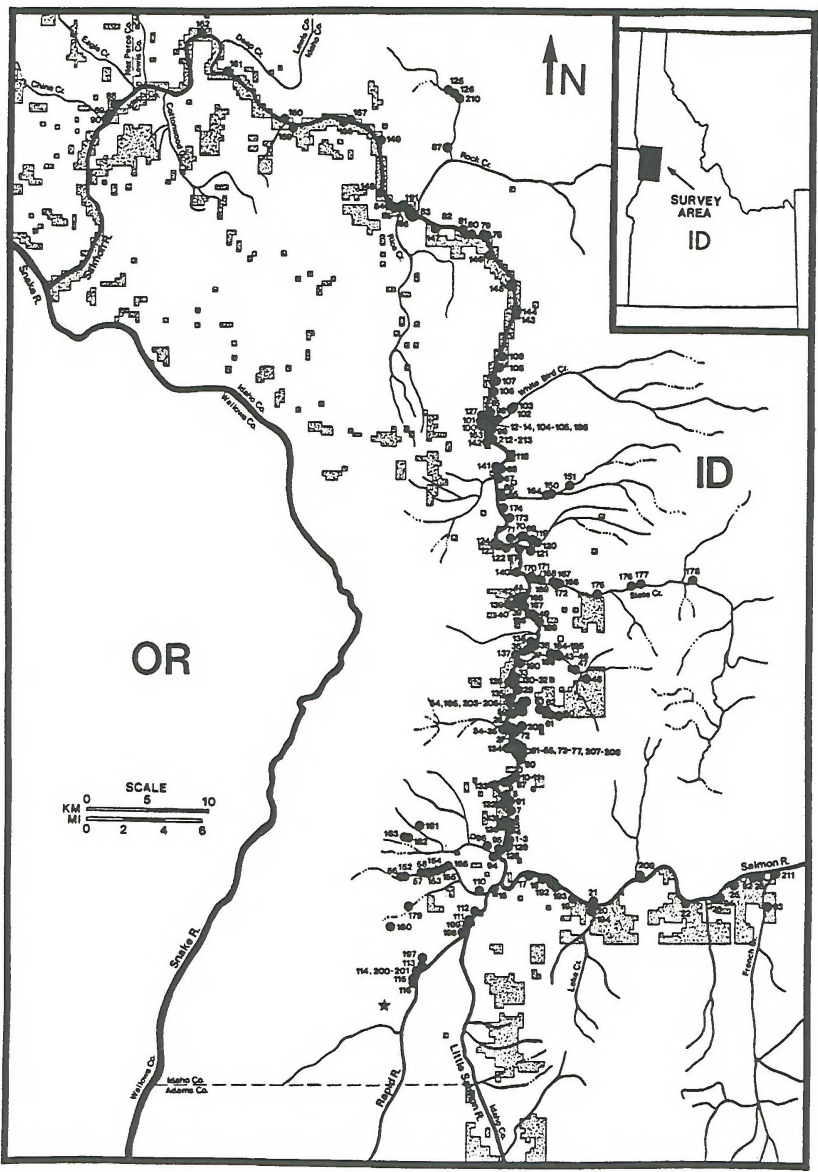

$F_{2}$ 
FIGURE 3. OTHER LOWER SALMON RIVER LAND SNAIL TYPE LOCALITIES.

Map of survey area in the Lower Salmon River Valley, showing locations of type localities for described land snail species aside from Oreohelix. Certain of these sites are on BLM public lands. Tentatively chosen type localities for some new non-Oreohelix taxa discussed herein will also be on BLM public lands. Note concentration of sites in the Riggins-White Bird corridor. Two species, Cryptomastix harfordiana and Helicodiscus salmoneus, currently have the unacceptably vague type locality "Lower Salmon River"; subsequent workers will desginate more precise type localities. Possible extirpation of Cryptomastix clappi and Discus marmorensis at their type localities for may necessitate degination of another site. For detailed discussion of locations, see text; see also Figure 1 and Appendices A-C. 
Oreohellx type localltles

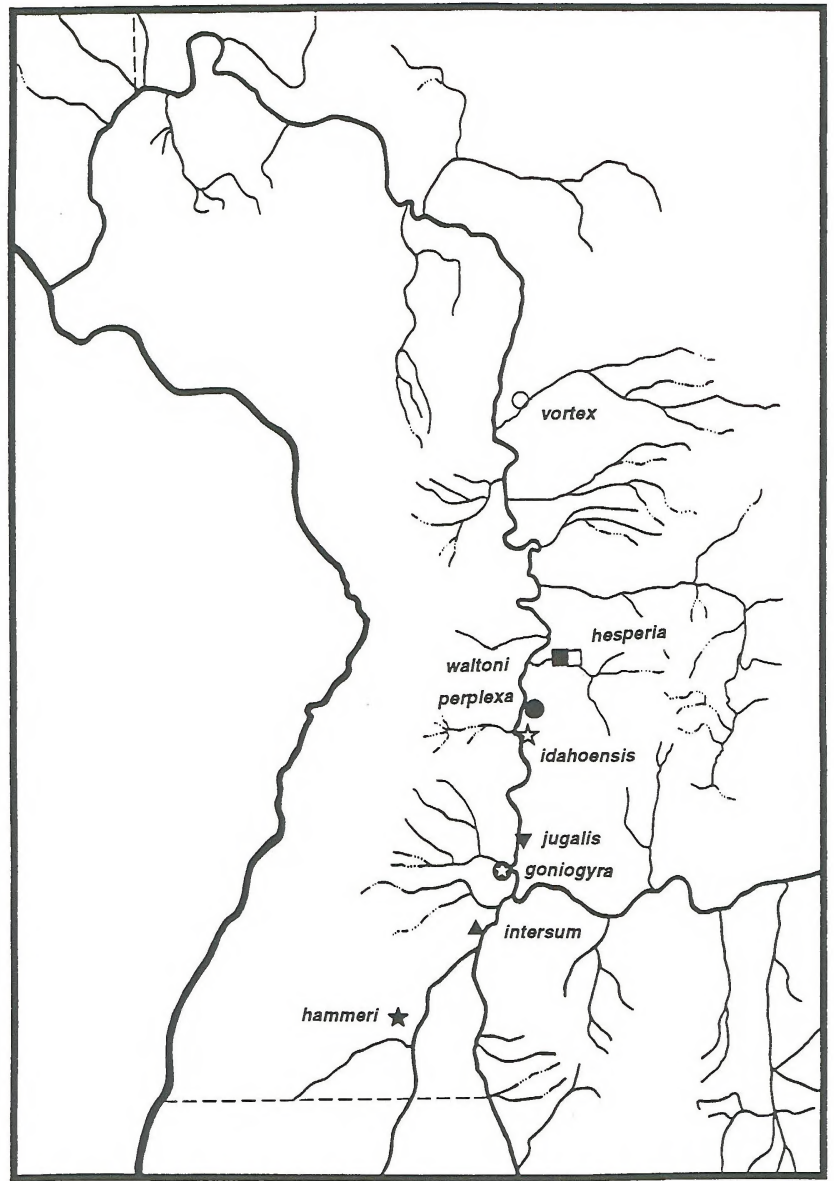




\section{FIGURE 4. RANGES OF ENDEMIC LOWER SALMON RIVER OREOHELIX SPECIES.}

Map of survey area in the Lower Salmon River Valley, showing currently known ranges for certain endemic Lower Salmon River Oreohelix species. Very restricted ranges are characteristic of many taxa. Note concentration of ranges in the Riggins-White Bird corridor of the Salmon proper, as well as several main tributaries (Rapid River, John Day Creek, Slate Creek, etc.). For detailed discussion of locations, see text; see also Figure 1 and Appendices A-C. 
Other land snall type localitles

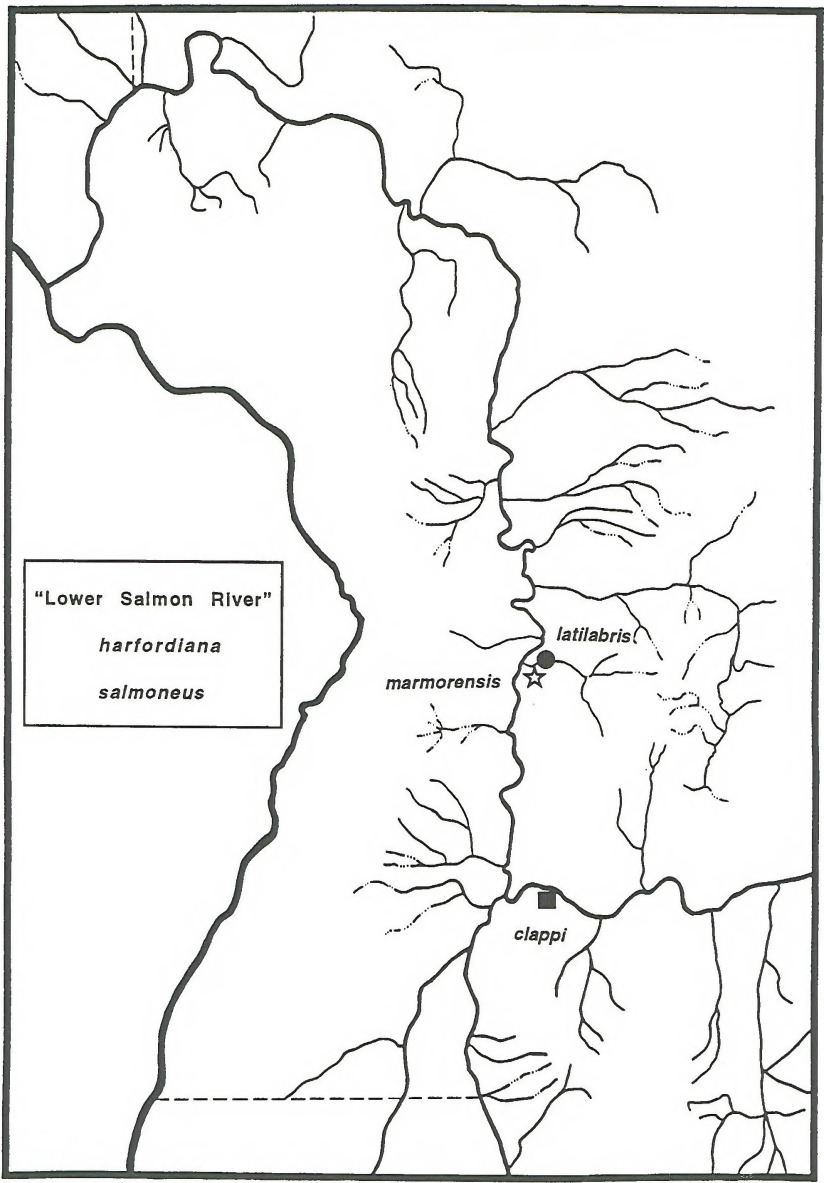


FIGURE 5. RANGES OF ENDEMIC LOWER SALMON RIVER POLYGYRID SPECIES.

Map of survey area in the Lower Salmon River Valley, showing currently known ranges for certain endemic Lower Salmon River Cryptomastix and Allogona species. Restricted ranges are characteristic of many taxa. Note absence of endemics in the Little SalmonRapid River drainages; and lack of restricted forms very far outside main Salmon River corridor, with the exception of John Day Creek. For detailed discussion of locations, see text; see also Figure 1 and Appendices A-C. 
Ranges of endemlc Oreohellx species

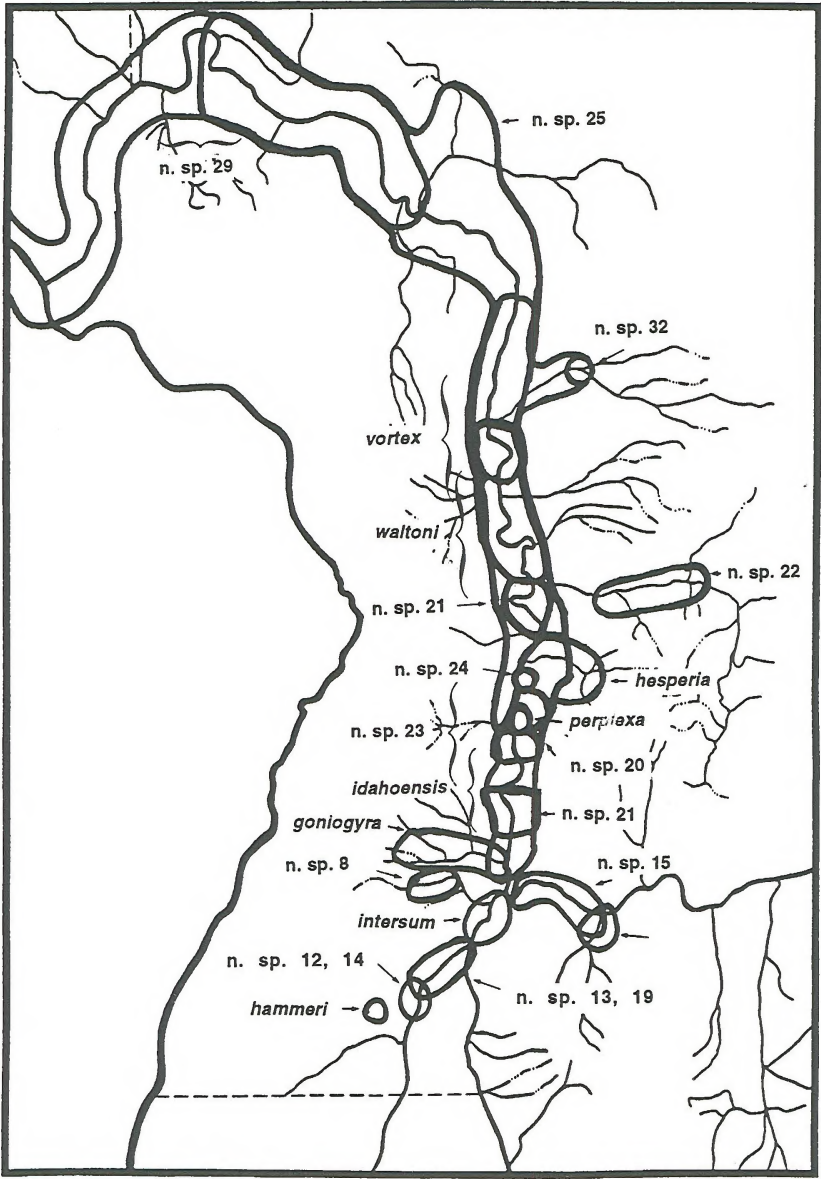




\section{FIGURE 6. LOWER SALMON RIVER LAND SNAIL BIOGEOGRAPHY.}

Generalized biogeography of Lower Salmon River land snails. The fauna is subdivided into 5 non-overlapping regions, each characterized by the presence and/or absence of certain large land taxa. Area 1 has such species as Allogona ptychophora solida; Cryptomastix populi, C.n. sp. 3, and C. n. sp. 6; and Oreohelix n. sp. 25. Area 2 has a similar fauna; but lacks C. populi and has common Oreohelix vortex. Region 3 is particularly typified by the presence of Oreohelix idahoensis idahoensis and related species, and has few Cryptomastix species (mostly C. n. sp. 5). Region 4 is characterized by the species of the Oreohelix intersum complex, and has no endemic Cryptomastix species. Area 5 is typified by Cryptomastix mullani clappi and by Oreohelix n. sp. 15 . See preceding two figures, Appendix $\mathrm{C}$, and text for detailed discussion. 
Ranges of endemic polygyrid species

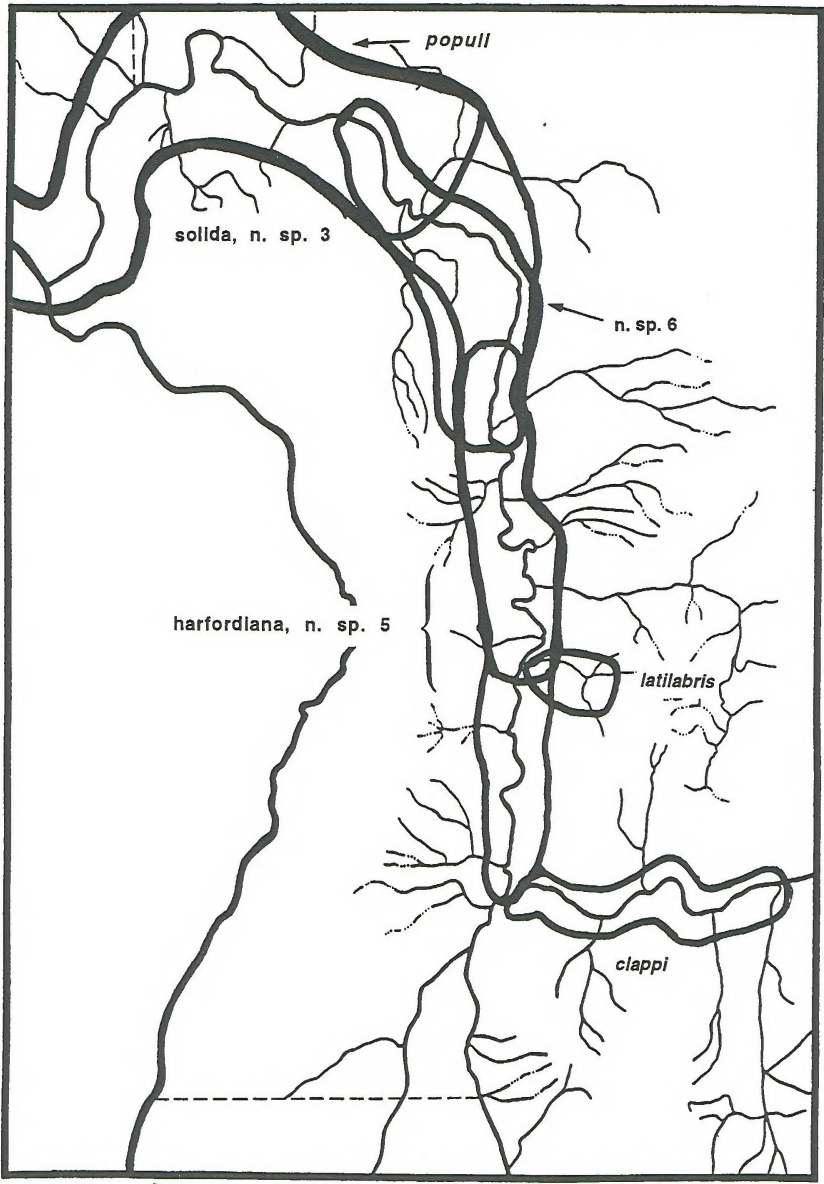




\section{FIGURE 7. SPECIES/SITE RANKINGS.}

Ranking of presently known Lower Salmon River land snail taxa based on number of occurrences (sites) with each. Ranking is from most to least frequent. All 213 sites are commonness (overestimate the number species condition, i.e. this plot may exaggerate methodological rearer large taxa. For for discussion. See Table 1 for site; and Table 4 for sites with numerous sites $(80 / 213)$. (commonness/rarity), For treatment of this data in terms of local abundance comparatively rare, $i$. Note that over half of the taxa are comparatively rare, i.e. occur at less than $5 \%$ of the sites (10 or less). 


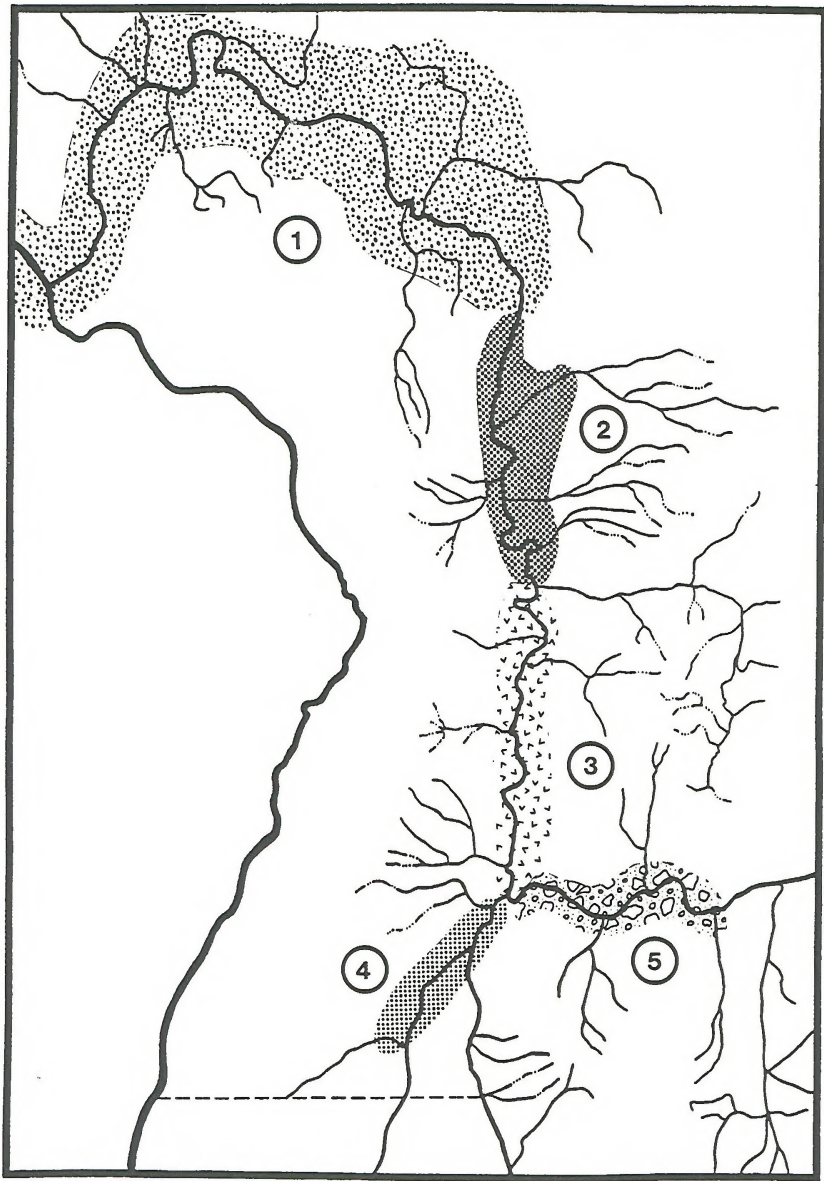




\section{FIGURE 8. LOWER SALMON RIVER LAND SNAIL DIVERSITY.}

Plot of number of sites (total 213) versus number of species-level land snail and slug taxa per site. Note relatively small proportion of sites with no land snails. Most sites, however, have only a few, mostly large taxa. This is not entirely an artifact of sampling methods. For detailed discussion, see text. 
FIGURE 7. SPECIES/SITE RANKINGS.

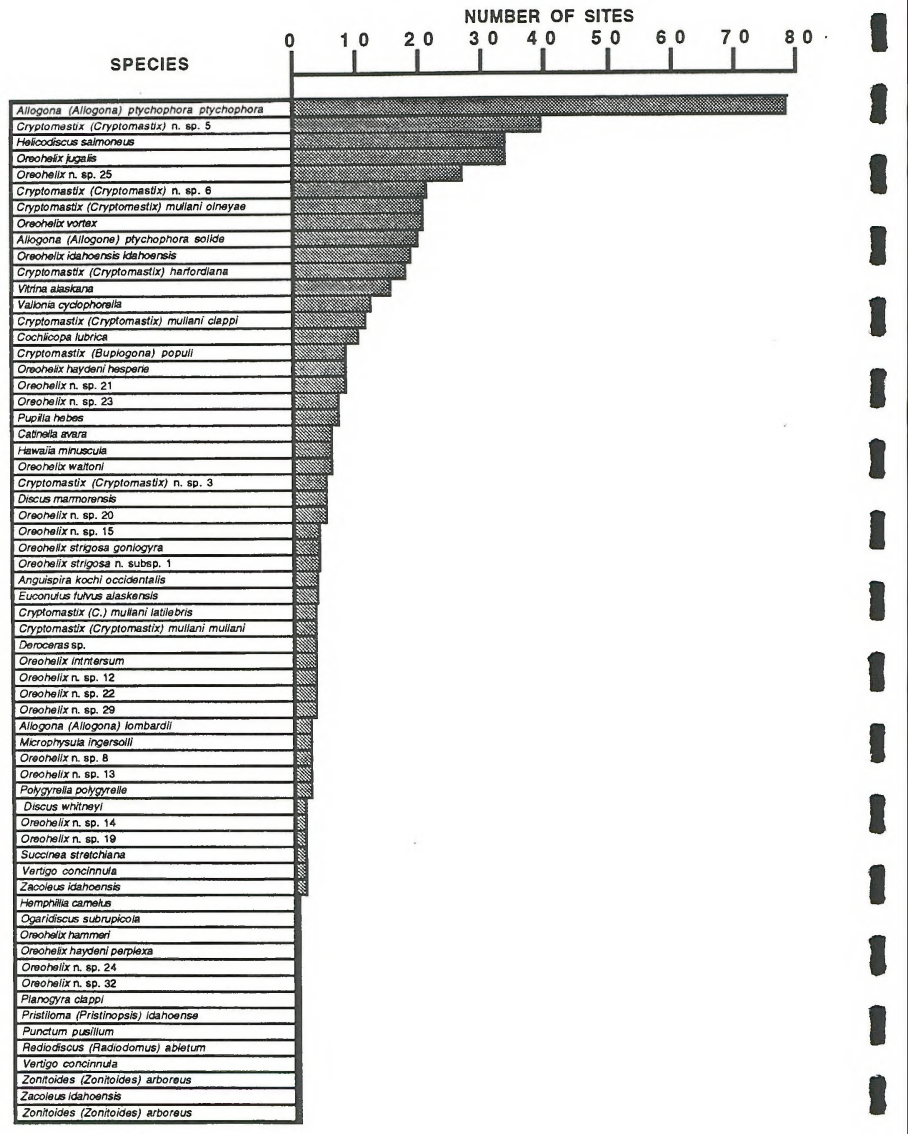




\title{
FIGURE 9. NUMBER OF SENSITIVE AND CANDIDATE LOWER SALMON RIVER LAND SNAIL SPECIES.
}

\begin{abstract}
Plots of total number of sites (out of 213) versus (A) total number of Sensitive taxa (including candidates) per site; and (B) total number of candidate taxa only per site. Note that most sites visited had at least one sensitive species-level taxon; and that sites with more than one such taxon were quite common. Less than half of the sites had any cendidate land snail taxa; and one such per site (with any) was the common case. For detailed discussion, see text.
\end{abstract}


FIGURE 8. LOWER SALMON RIVER LAND SNAIL SITE DIVERSITY

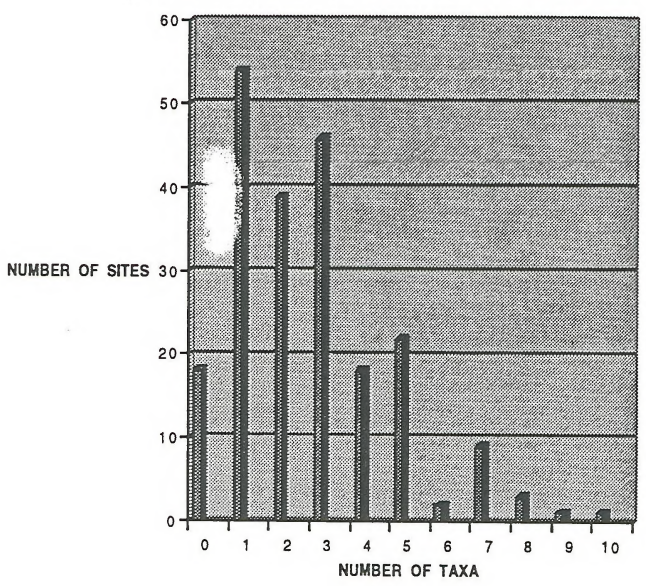




\section{FIGURE 10. STATUS OF LOWER SALMON RIVER LAND SNAILS.}

Status of Lower Salmon River land snails, as evaluated by two methods.

A, Relative proportions of endemic land snail taxa, out of a total of 61 known forms: C (cosmopolitan) $7(11 \%) ; \quad R$ (regional; mostly Washingtonian and/or Oregonian Province forms) $23(38 \%) ; \quad H$ (Hells Canyon and Lower Salmon River endemics) 4 (7\%); L (strict Lower Salmon River endemics) 27 (44\%). Note that strongly endemic taxa constitute a very high proportion of the fauna (over $51 \%$ ).

B, Local abundance of Lower Salmon River land snail taxa. A (abundant; nearly ubiquitous) $1(2 \%) ; \quad C$ (common: frequent and found at many sites, even if local only) $11(18 \%)$; UC (uncommon: infrequent at all sites or found at a moderate number of sites only, even if all of distribution local) $7(11 \%)$; $\mathrm{R}$ (rare; rare at all known sites and/or found at relatively few sites, even if local only) $11(18 \%)$; VR (very rare; found at very few sites locally) $30(49 \%) ; e$ ? (possibly extinct locally) $1(2 \%)$

See Tables 1-2 for summary listings of taxa and provincial affinities; and detailed discussion in text. 
FIGURE 9. NUMBER OF SENSITIVE AND CANDIDATE LOWER SALMON RIVER LAND SNAIL SPECIES.

A. SENSITIVE SPECIES

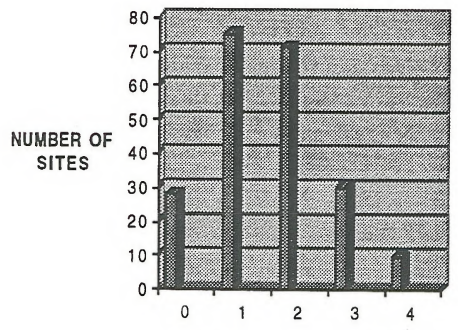

NUMBER OF SENSITIVE TAXA

B. NUMBER OF CANDIDATE SPECIES

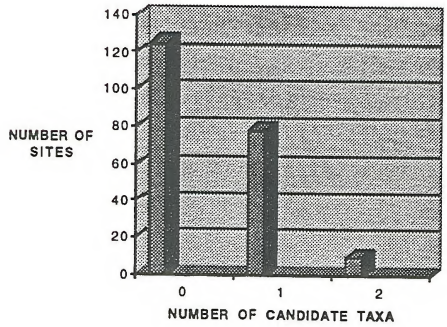




\title{
FIGURE 11. MOISTURE PREFERENCES OF LOWER SALMON RIVER LAND SNAILS.
}

\begin{abstract}
Abbreviated taxonomy on left side of figure: for full taxonomy, see Tables 1-2. Taxa are listed in alphabetical order. Moisture preferences are approximate. For convenience, they are grouped into three categories (xerophile, mesophile, notophile) which are used extensively in the text. Species with comparatively narrow geographic ranges (strict and regional endemics) shown in dark trellis pattern; species with more cosmopolitan geographic ranges shown in black. Note that endemics can cover most of range; but that most are concentrated in the xerophile third of the figure, while cosmopolitan taxa are more scattered. Note also relatively small number of local notophiles.
\end{abstract}


FIGURE 10. STATUS OF LOWER SALMON RIVER LAND SNAILS.

A. ENDEMIC STATUS

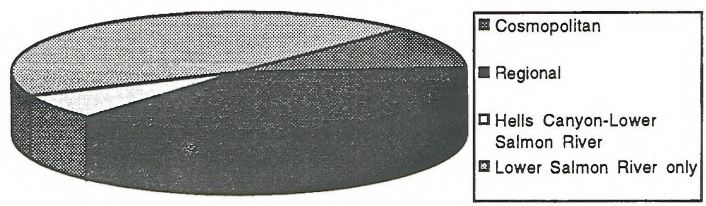

B. LOCAL STATUS

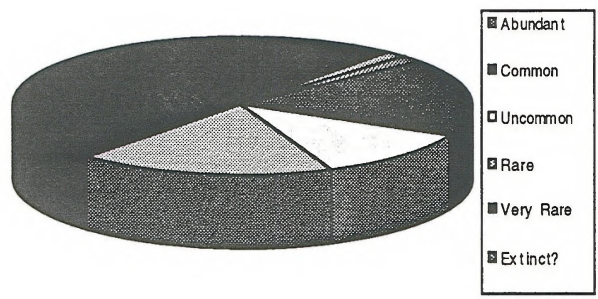




\section{FIGURE 12. ALTITUDE PREFERENCES OF LOWER SALMON RIVER LAND SNAILS.}

Abbreviated taxonomy on left side of figure: for full taxonomy, see Tables 1-2. Taxa are listed in alphabetical order. Altitude preferences are approximate. Species with comparatively narrow geographic ranges (strict and regional endemics) shown in dark trellis pattern; species with more cosmopolitan geographic ranges shown in black. Note that endemics can cover most of range; but that most are concentrated in the right two-thirds of the figure (representing low to moderate elevations), while cosmopolitan taxa are more scattered. Note also relatively small number of local hypsiphiles. This may in part be an artifact of survey scope; but not entirely. 
FIGURE 11. MOISTURE PREFERENCES OF LOWER SALMON RIVER LAND SNAILS.

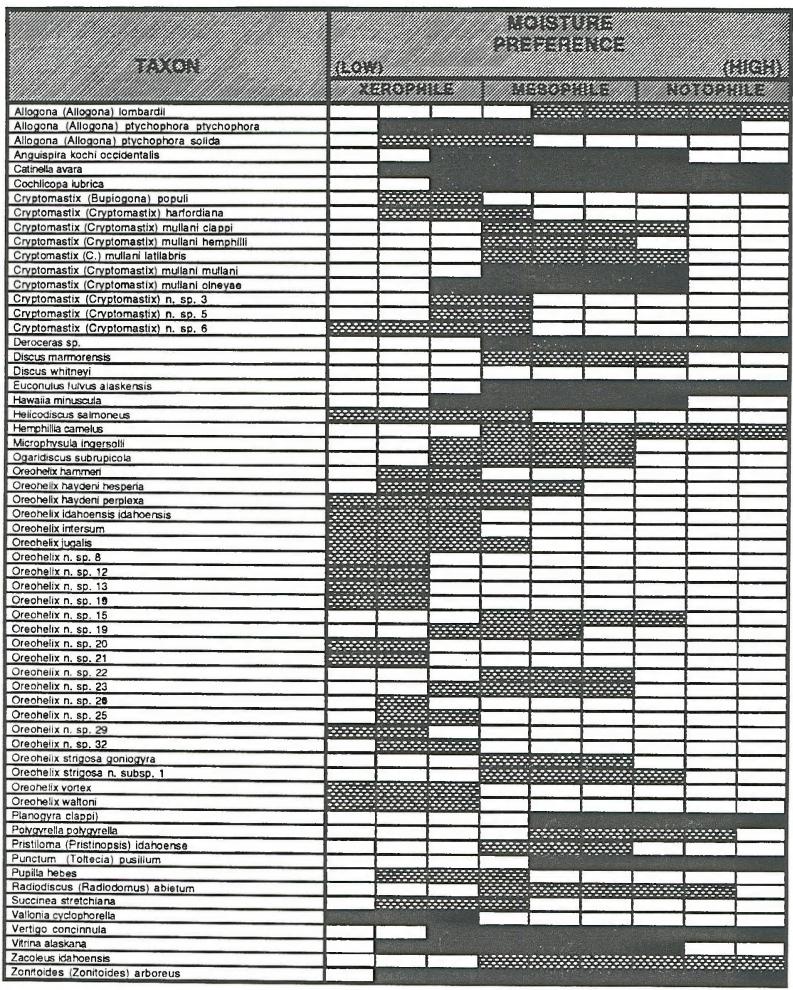



LOWER SALMON RIVER LAND SNAILS.

\begin{abstract}
Abbreviated taxonomy on left side of figure: for full taxonomy, see Tables 1-2. Taxa are listed in alphabetical order. Altitude preferences are approximate. Species with comparatively narrow geographic ranges (strict and regional endemics) shown in dark trellis pattern; species with more cosmopolitan geographic ranges shown in black. Note that endemics can cover most of range; but that most are concentrated in the right two-thirds of the figure (representing low to moderate cover; comparatively high to moderate insolation), while cosmopolitan taxa are more scattered or prefer more cover. Note also relatively small number of local taxa preferring nearly complete cover. This may in part be an artifact of survey scope and habitat availability (there are relatively few sites with nearly complete cover); but not entirely.
\end{abstract}




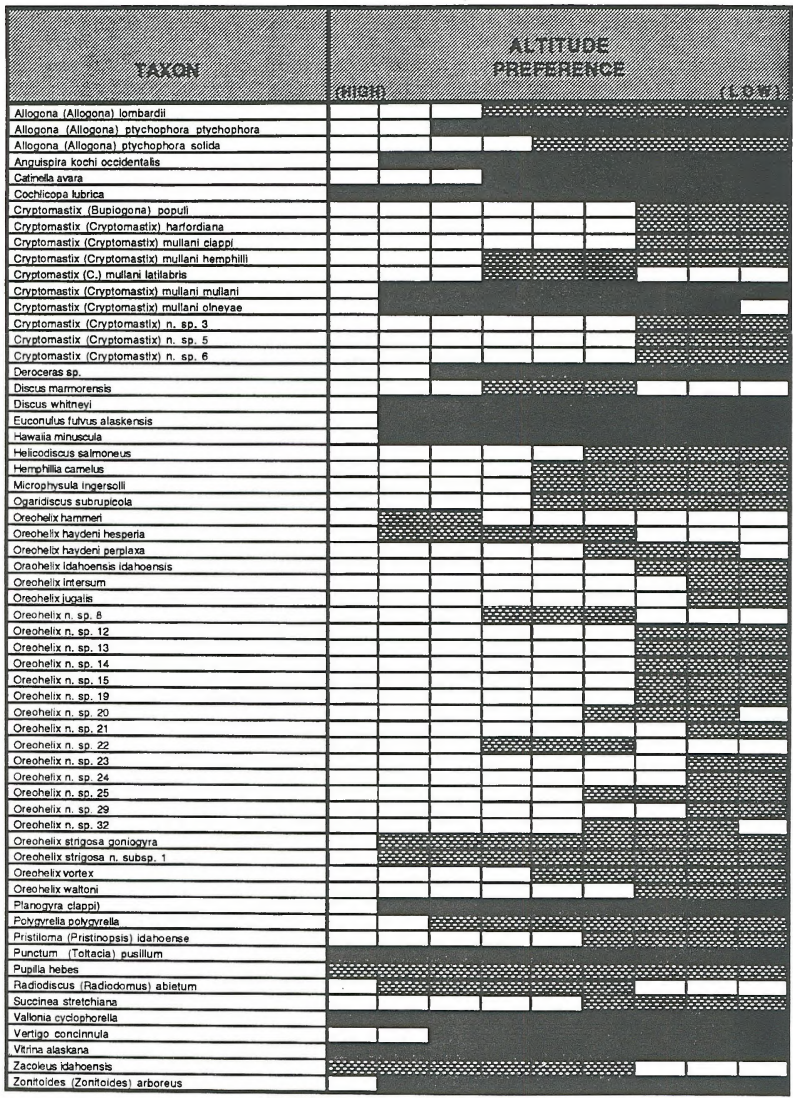


I

1

I

1

1

1

1

1

I

I

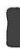

I

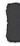

1

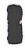

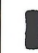

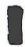

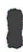

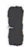




\section{3...}

Allogona (Allogona) lombardil

Allogona (Allogona) ptychophora ptychophora

Allogona (Allogona) ptychophora solida

Anguispira kochi occidentalis

Catinella avara

Cochlicopa lubrica

Cryptomastix (Bupiogona) popull

Cryptomastix (Cryptomastix) harfordiana

Cryptomastix (Cryptomastix) mullani clappi

Cryptomastix (Cryptomastix) mullani hemphilit

Cryptomastix (C.) mullani latllabris

Cryptomastix (Cryptomastix) mullani multani

Cryptomastix (Cryptomastix) mullani olnevae

Cryptomastix (Cryptomastix) n. 5 p. 3

Cryptomastix (Cryptomastix) n. sp. 5

Cryptomastix (Cryptomastix) n. sp. 6

Deroceras sp

Discus marmorensis

Discus whitneyi

Euconulus futvus alaskersis

Hawalia minuscuta

Helicodiscus salmoneus

Hemohilia camelus

Microptrysula ingersolli

Ogaridiscus subrupicola

Creohelix hammen

Oreoheirx havdeni hesperia

Oreohelix havdeni perplexa

Oreohelix idahoensis idahoensis

Oreohellx irtersum

Oreohelix jugalis

Oreohelix n. sp. 8

Oreohellix n. sp. 12

Oreohelix n. sp. 13

Oreohelix n. $5 p .14$

Oreohelix n. sp. 15

Oreohelix n. sp. 19

Oreohelix n. sp. 20

Oreohelix n. sp. 20

Oreohelix n. sp. 22

Oreohelix n. sp. 23

Oreohelixn. sp. 24

Oreohelix n. sp. 25

Oreohelix n. sp. 29

Oreohelix n. sp. 32

Oreohelix strigosa goniogyra

Oreonelix strigasa n. subsp. 1

Ore ohelix vortex

Oreohelix waltoni

Planogyra clappi\}

Polvovretila polvgrrella

Pristiloma (Pristinossis) idahos

Punctum (Tohtecia) pusillum

Pupilla hebes

Radiodiscus (Radiodomus) abiotum

Succinea stretchiana

Valonia cyclophorella

Vertigo concinnula

Vitrina ataskana

Zacoleus idahoensis

Zonitoides (Zonitoides) arboreus

\section{2,12}

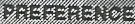

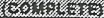

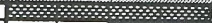
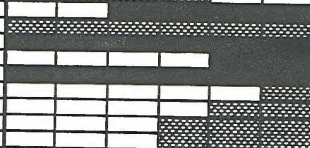

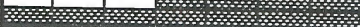

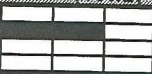

axis $x=2$
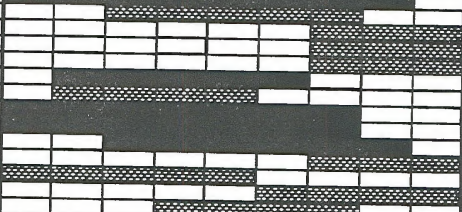

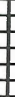
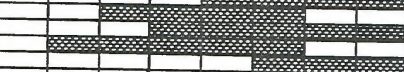

Wh⿻大从n

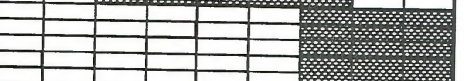

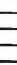
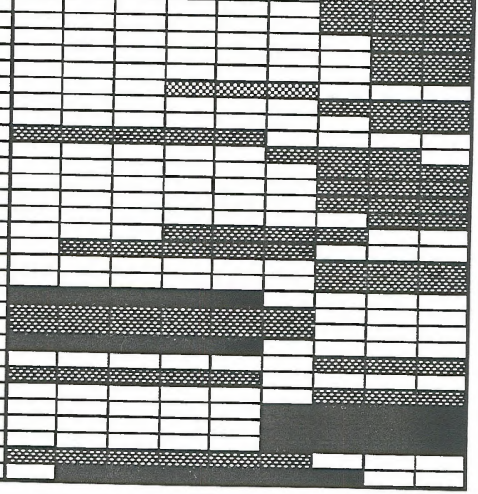


\section{APPENDICES}

APPENDIX TITLE

A.

B.

SITES

SITE MAPS

SPECIES DISTRIBUTION MAPS
PAGES

A $1-29$

B1-39

C1-62 
1

1

1

1

I

I

I

I

1

I

I

I

I

I

1

I

1

1

1 


\section{APPENDIX A. SITES.}

Legal coordinates for all localities are taken from the most current USGS $7.5^{\prime}$ series topographic map. Road names and numbers were confirmed using the Nez Perce National Forest 1990 1:126,720 map and DeLorme Mapping's Idaho Atlas and Gazetteer. Number in parentheses following locality name refers to locality number in Deixis MolluscDB ${ }^{\text {TM }}$ database. Number in brackets at the end of each entry refers to site map page number (see Appendix B).

Collector name abbreviations are as follows:

MF- Margaret Frest, Seattle, Washington

TF. Terrence Frest, Deixis Consultants, Seattle, Washington

GH- George Holm, Vancouver, British Columbia

EJ- Edward Johannes, Deixis Consultants, Seattle, Washington

RM- Robert McClure, Riggins, Idaho

SN- Steve Nelson, Seattle, Washington

SW- Steve Welty, Dubois, Wyoming

1. Riggins Bridge 1 (1296). Wh NW/4 SW/4sec. 2, T24N R1E, Riggins 1964 quad., Idaho Co. W.-facing cliff base on E. side of US95, from the Riggins bridge NE about 0.2 mile, E. side of the Salmon River, ca. RM 83.9-84.0, BLM lands. Elev. 1760'. Dry cliffs (metamorphic rock) with sporadic small talus piles; mostly grassy; scattered Celtus. Small Cryptomastix $\mathrm{n}$. $\mathrm{sp} .5$ (full ontogeny and all conditions); few dead Oreohelix idahoensis idahoensis. Snails very sporadic. Hand collected. 10/12/1993 TF, EJ! [B27]

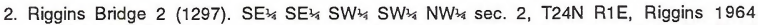
quad., Idaho Co. Small talus piles below road to gully, S. of seeps from unnamed gully, E. of US95 ca. 0.3 mile NE of Riggins Bridge, E. side of the Salmon River at RM 83.8, BLM lands. Elev. 1760'. Metamorphic rocks (low-grade schist); mostly grasses, scattered Celtus. Uncommon small Cryptomastix n. sp. 5 (all conditions); Helicodiscus salmoneus (not retained); Vallonia cyclophorella. Hand collected. Photographed. 10/12/1993 TF, EJ! [B27]

3. Riggins Bridge 3 (1298). SE年 NW/3/4 NW/3/4 NW/3 SW/4 sec. 2, T24N R1E, Riggins 1964 quad., Idaho Co. Between Salmon River (E. side) and pulloff from US95 (W. side), 0.2 mile NE of Riggins Bridge at RM 83.9, just above high water mark, BLM lands. Elev. 1720'. Boulder piles (mixed lithologies) in sandy matrix; rather dry; mostly grasses, scattered Celtus, Rhus diversiloba, Clematis. Snails very rare; small low Cryptomastix n. sp. 5 (all conditions). 10/12/1993 TF, EJ! [B27]

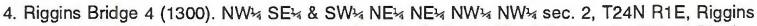
1964 quad., Idaho Co. W.-facing steep slope and short cliffs 0.7-0.8 mile NE of Riggins Bridge, E. of (above) US95 at about road mile 199.0, E. of Salmon River at RM 83.3-83.4; has traces of old pioneer road and remnants of old US95 grade, BLM lands. Elev. 1700'. Depth 2-12". Dry, short cliffs and talus, exposed bedrock (schist); mixed vegetation (grasses, Celtus, Artemisia, and Opuntia). Snails rather sparse and in all conditions; Oreohelix n. sp. 21; Cryptomastix harfordiana. Hand collected. 10/12/1993 TF, EJ! [B26]

5. South of Lightning Creek 2 (1301). Wh $\mathrm{NE}^{\frac{1}{4}} \mathrm{NE}^{\frac{1}{4}} \mathrm{SW}_{\frac{1}{4}} \mathrm{SW}^{\frac{1}{4}} \mathrm{sec}$. 35, T25N R1E, Riggins 1964 quad., Idaho Co. W.-facing steep talus 0.4 mile S. of the mouth of Lightning Creek, E. side of US95 at road mile 198.3, E. of Salmon River at RM 83.1, BLM lands. Elev. 1720'. 
Half of the site behind fence. Large schist boulders and large-scale talus; very common Celtus, Rhus diversiloba, grasses; scattered Opuntia. Moderately common Cryptomastix harfordiana (all conditions); Helicodiscus salmoneus not retained. Hand collected. Photographed. 10/12/1993 TF, EJ! [B26]

6. South of Lightning Creek 1 (1302). $E^{1 / 2} \mathrm{NE}^{\frac{1}{4}} \mathrm{SE}_{1 / 4} \mathrm{NW}_{1 / 4} \mathrm{SW}_{1 / 4}$ sec. 35, T25N R1E, Riggins 1964 quad., Idaho Co. W.-facing talus 0.25 mile S. of mouth of Lightning Creek, E. of US95 at road mile 198.5, considerably above roadway, E. side of Salmon River at RM 82.9-83.0, BLM lands. Elev. 1800-1880'. Dry steep schist talus consisting of small flat slabs; Celtus, grasses, common Artemisia, Opuntia. Oreohelix n. sp. 23; Cryptomastix harfordiana. Hand collected. 10/19/1989 TF, EJ. Uncommon Oreohelix n. sp. 23; Cryptomastix harfordiana. Hand collected. 10/2/1990 TF, GH! [B26]

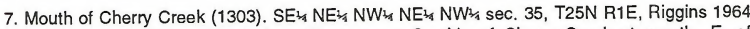
quad., Idaho Co. W. and N.-facing cliffy area on S. side of Cherry Creek at mouth, E. of US95 at road mile 199.1, E. side of Salmon River at RM 82.3, BLM lands. Elev. 1720-1740'. Steep, exposed schist bedrock, considerable soil with moss and Seligeria cover; minor Rhus diversiloba, Celtus, grasses. Uncommon Oreohelix n. sp. 21 (most dead); rare live, abundant dead Cryptomastix n. sp. 5; Helicodiscus salmoneus not retained; Vitrina alaskana; Vallonia cyclophorella. Hand collected. Photographed. 10/12/1993 TF, EJ! [B26]

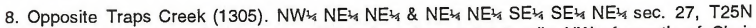
R1E, Riggins 1964 quad., Idaho Co. SW-facing slope 0.2-0.3 mile NW of mouth of Chair Creek, opposite Traps Creek, NE of US95, NE side of Salmon River at RM 81.3-81.4, BLM lands. Elev. 1740-1760'. Slope with large boulders and exposed schist bedrock, small scattered talus piles; Rhus diversiloba, common Celtus, Opuntia, grasses. Moderately common Oreohelix n. sp. 23 and Cryptomastix n. sp. 5 (full ontogeny); Helicodiscus salmoneus and Vitrina alaskana not retained. Hand collected. 10/12/1993 TF, EJ! [B26]

9. North of Fiddle Creek (1306). SE $\mathrm{SE}_{\frac{1}{4}} \mathrm{NE}_{\frac{1}{4}} \mathrm{SW}_{\frac{1}{4}} \mathrm{SW}_{\frac{1}{4}} \mathrm{NW}_{3 / 4}$ sec. 23, T25N R1E, Riggins 1964 quad., Idaho Co. N.-facing cliff, S. of US95 at road mile 201.1-201.2, N. of Fiddle Creek, S. side of Salmon River at RM 80.0-80.1. Elev. 1680'. Cliff with schist boulders and minor talus piles at base; common mosses and Seligeria. Rare recent and long-dead Oreohelix $\mathrm{n}$. $\mathrm{sp}$. 21; moderately common live Cryptomastix (weak teeth, narrow lip). Hand collected. 10/13/1993 TF, EJ! [B26]

10. Boulder piles at Salmon River RM 79.5-79.7 (lower) (1307). W1/2 $\mathrm{NE}^{\frac{1}{4}} \mathrm{SE}^{\frac{1}{4}} \mathrm{NE}^{\frac{1}{4}} \mathrm{NW}^{\frac{1}{4}}$ \&

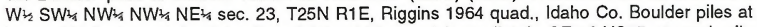
base of N.-facing road cut (partly cut into old terrace) immediately SE of US95 at road mile 201.8-202.0, N. of mine site, SE of Salmon River at RM 79.5-79.7, BLM lands. Elev. 1680'. Boulders piles (mixed lithologies) along highway derived from old terrace deposit; almost no vegetation (some grasses). Snails uncommon; Oreohelix n. sp. 23 and Cryptomastix n. sp. 5 in all conditions. Hand collected. 10/13/1993 TF, EJ! [B26]

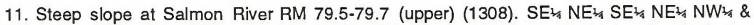
$\mathrm{SE}_{1 / 4} \mathrm{SW}_{\frac{1}{4}} \mathrm{NW}_{1 / 4} \mathrm{NW}_{1 / 4} \mathrm{NE}_{\frac{1}{4}}$ sec. 23, T25N R1E, Riggins 1964 quad., Idaho Co. N.-facing steep slope above and SE of US95 at road mile 201.8-202.0, N. of mine site, SE of Salmon River at RM 79.5-79.7, BLM lands. Elev. 1720'. Steep slope above highway cut with exposed schist bedrock and small talus piles; common Rhus diversiloba; grasses; Sorbus; some Celtus. Common Oreohelix n. sp. 23 with full ontogeny and all conditions present; Cryptomastix n. sp. 5 rather rare (all conditions); Vitrina alaskana. Hand collected. 10/13/1993 TF, EJ! [B26]

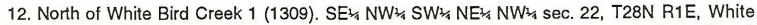
Bird 1962 quad., Idaho Co. Two small ravines to NE of Lyons Bar access road above (N. of) White Bird Creek, E. of Salmon River at RM 53.4. Elev. 1560', Two deep ravines (basalt bedrock) with small basalt talus piles at their mouths; $S$. and W.-facing; dry, open, with scattered Celtus. Moderately common Oreohelix jugalis in all conditions; very rare 
Cryptomastix mullani olneyae; long-dead Allogona ptychophora ptychophora. Hand collected. 10/13/1993 TF, EJ! [B39]

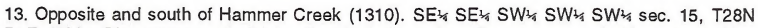
R1E, White Bird 1962 quad., Idaho Co. W.-facing talus piles on nose of ridge overlooking Salmon River (E. of) opposite and S. of mouth of Hammer Creek, along (E. side) Lyons Bar access road, approximately RM 53.1, BLM lands. Elev. 1470'. Basalt talus piles with grasses and Celtus, Ailanthus. No mollusks found. 10/13/1993 TF, EJ!

[B39]

14. Opposite Hammer Creek (1311). NW/4 SW $W_{3 / 4} N^{1 / 4} S W^{3 / 4} S W_{3 / 4}$ sec. 15, T28N R1E, White Bird 1962 quad., Idaho Co. W.-facing talus piles just S. of unnamed gully, below old pioneer road, along (E. of) Lyons Bar access road, E. side of Salmon River at RM 52.9, opposite mouth of Hammer Creek, BLM lands. Elev. 1480'. Basalt talus piles; mossy, abundant Celtus; soil mixed into talus. Oreohelix jugalis, Allogona ptychophora ptychophora, Cryptomastix n. sp. 6, and other snails hand collected. 9/30/1990 TF, GH! Rare Oreohelix jugalis and vortex; common Allogona ptychophora ptychophora; rare Cryptomastix n. sp. 6 (all conditions); Cochlicopa lubrica; Vitrina alaskana; Vallonia cyclophorella. Snails hand collected. Litter sample collected. 10/13/1993 TF, EJ!

[B39]

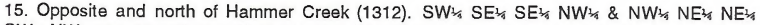
$S_{1 / 4} N_{1 / 4}$ sec. 15, T28N R1E, White Bird 1962 quad., Idaho Co. W.-facing talus piles along (E. of) Lyons Bar access road, E. side of Salmon River opposite and N. of mouth of Hammer Creek, at RM 52.3, BLM lands. Elev. 1450'. Shallow small basalt talus piles; common Rhus diversiloba, uncommon Celtus, grasses. Common Oreohelix jugalis; rare Allogona ptychophora ptychophora, Oreohelix vortex, Allogona ptychophora solida, and Cryptomastix n. sp. 5. Hand collected in all conditions. 10/13/1993 TF, EJ! [B39]

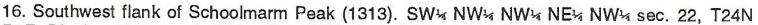
R1E, Riggins 1964 quad., Idaho Co. NW-facing cliff base on SE side of Little Salmon River; bluff 0.2 mile S. of USGS gauging station and Salmon River Road (Idaho Co. 1614); on SW flank of Schoolmarm Peak, BLM lands. Elev. 1840'. Area much modified by bulldozing; several junked cars. Schist slope with very small talus piles at base. Mostly grasses and scattered Opuntia; open and quite dry. Oreohelix intersum rare. Hand collected. 10/14/1993 TF, EJ! [B27]

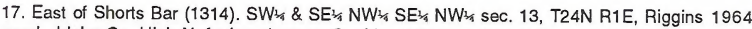
quad., Idaho Co. High N.-facing slope on S. side of Salmon River (River of No Return) at RM 88.8-89.0, E. of Shorts Bar, above Salmon River Road (Idaho Co. 1614), ca. road mile 3.03.2, BLM lands. Elev. 1800-1840'. High schist talus; well-vegetated; common mosses, Seligeria; rarer Celtus, Ailanthus, Cystopteris, Draba, Rhus diversiloba. Cryptomastix mullani clappi; Allogona ptychophora ptychophora; Oreohelix jugalis dead only; rare Oreohelix $\mathrm{n}$. sp. 15 (dead only). Hand collected. 5/31/1990 TF, EJ, SN! Oreohelix n. sp. 15 rare (all dead); Cryptomastix mullani clappi moderately common (full ontogeny); Allogona ptychophora ptychophora; Oreohelix jugalis. Hand collected. 10/14/1993 TF, EJ! [B29]

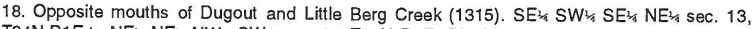
T24N R1E to $\mathrm{NE}_{\frac{1}{4}} \mathrm{NE}_{\frac{1}{4}} \mathrm{NW}_{3 / 4} \mathrm{SW}_{3 / 4}$ sec. 18, T24N R2E, Riggins 1964 quad., Idaho Co. Base of N.-facing cliffs opposite mouths of Dugout and Little Berg Creek, S. side of Salmon River (River of No Return) at RM 89.4-89.8, S. of Salmon River Road (Idaho Co. 1614), ca. road mile 3.6-4.0. Elev. 1800-1820'. Bottom of degraded schist cliffs with considerable soils; mostly open; grasses and scattered Celtus. Rare speckled Oreohelix n. sp. 18; common Allogona ptychophora ptychophora and Cryptomastix mullani clappi hand collected. 10/20/1989 TF, EJ! Very rare live Oreohelix n. sp. 18 (speckled); live Allogona ptychophora ptychophora and Cryptomastix mullani clappi. Hand collected. 10/14/1993 TF, EJ!

[B29]

19. East of the mouth of Cat Creek (1316). NW/1/4 SW/4 NE NW/4 SE $\mathrm{SW}_{1 / 4}$ sec. 20, T24N R2E, Riggins Hot Springs 1964 quad., Idaho Co. NE-facing slope on S. side of Salmon River (River of No Return) at RM 91.7, S. of Salmon River Road (Idaho Co. 1614), ca. 0.3 mile SE of 
mouth of Cat Creek, BLM lands. Elev. 1840'. Very open sandy slope with scattered talus; dry, open; scattered grasses, Celtus. Heavily grazed; common dead Cryptomastix mullani clappi, very rare live, in extremely limited areas. Hand collected. 10/14/1993 TF, EJ! [B30]

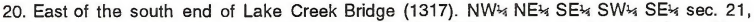
T24N R2E, Riggins Hot Springs 1964 quad., Idaho Co. Cliff base on S. side of Salmon River (River of No Return) at about RM 92.9-92.95, E. of Lake Creek Bridge on S. side of road up Lake Creek, 0.05-0.1 mile off Salmon River Road (Idaho Co. 1614), BLM lands. Elev. 1800'. Cliff and small talus piles (friable schist); abundant bryophytes; scattered Pinus ponderosa; shrubs; Draba. Oreohelix goniogyra, Allogona ptychophora ptychophora, Oreohelix n. sp. 15, and Cryptomastix mullani clappi hand collected. 8/11/1989 TF, EJ, SW! Common Oreohelix goniogyra (full ontogeny); Oreohelix n. sp. 15; Allogona ptychophora ptychophora; rarer Cryptomastix mullani clappi; collected at cliff base and within a few feet up slope; limited colony, ca. 100' long. Hand collected. 10/14/1993 TF, EJ! [B30]

21. West of the north end of Lake Creek Bridge (1318). SW/4 NE/4 NE/4 SW/4 SE/4 sec. 21, T24N R2E, Riggins Hot Springs 1964 quad., Idaho Co. S.-facing steep slope 0.1 mile W. of Lake Creek Bridge on N. side of FS9900 off Salmon River Road (Idaho Co. 1614), N. side of Salmon River (River of No Return) at RM 92.9, Nez Perce National Forest. Elev. 1840-1880'. Steep dry open slope with hornblende schist outcrop and limited talus; grasses, common Celtus, and Artemisia. Oreohelix jugalis, Allogona ptychophora ptychophora, and Cryptomastix mullani clappi hand collected. 8/11/1989 TF, EJ, SW! Scattered Oreohelix jugalis; Allogona ptychophora ptychophora; Cryptomastix mullani clappi. Hand collected. 10/14/1993 TF, EJ! [B30]

22. East of the south end of Manning Bridge (1319). NE/4 SE/4 SE $\mathrm{SW}^{\frac{1}{1 / 4}}$ sec. 20, T24N R3E, Kelly Mountain 1964 quad., Idaho Co. N.-facing cliff and talus on S. side of Salmon River Road (Idaho Co. 1614), just E. of Manning Bridge on S. side of Salmon River (River of No Return), BLM lands. Elev. 1920'. Granite cliff and thin talus; comparatively moist; Sambucus, Celtus, Pinus ponderosa, Abies, and bryophytes. Snails very rare; Allogona ptychophora ptychophora (live adults); Vitrina alaskana (not collected); Cryptomastix mullani clappi dead only. Hand collected. 10/14/1993 TF, EJ! [B10]

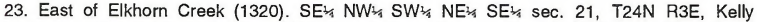
Mountain 1964 quad., Idaho Co. NW-facing shallow slope on S. side of Salmon River Road (Idaho Co. 1614), 0.4 mile E. of Elkhorn Creek, S. of Salmon River (River of No Return), BLM lands. Elev. 1920-1960'. Shallow open sandy slope; Pinus ponderosa forest with grasses and Symphoricarpus; scattered granite blocks; rather dry; impacted by forest fire. No snails seen. 10/14/1993 TF, EJ! [B10]

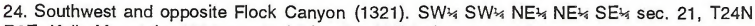
R3E, Kelly Mountain 1964 quad., Idaho Co. NW-facing steep slope on S. side of Salmon River Road (Idaho Co. 1614), E. side of unnamed creek mouth, ca. 0.6 mile E. of mouth of Elkhorn Creek, 0.5 mile SW and opposite Flock Canyon, S. of Salmon River (River of No Return), BLM lands. Elev. 2000'. Rather steep schist slope; scattered thin talus; sandy soils; Pinus ponderosa; Abies; Symphoricarpus; Ailanthus; grasses. Allogona ptychophora ptychophora and Cryptomastix mullani clappi hand collected. 10/14/1993 TF, EJ! [B10]

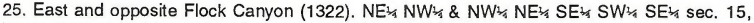
T24N R3E, Kelly Mountain 1964 quad., Idaho Co. NW-facing shallow slope on S. side of Salmon River Road (Idaho Co. 1614) at road mile 16.6, opposite but between Gasper Creek and Flock Canyon, S. of Salmon River (River of No Return), BLM lands. Elev. 1940-2000'. Moderate grassy slope with rather scattered schist talus piles with scattered boulders in open, dry Pinus ponderosa forest. Allogona ptychophora ptychophora, Vitrina alaskana, and Cryptomastix mullani clappi hand collected. 10/14/1993 TF, EJ! [B10]

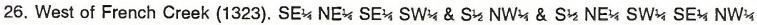
sec. 13, T24N R3E, Kelly Mountain 1964 quad., Idaho Co. NW-facing steep boulder talus on 
S. side of Salmon River Road (Idaho Co. 1614) at road mile 18.2, opposite but between Robbin Creek and Smith Canyon, about 0.5 mi. from the mouth of French Creek, S. of Salmon River (River of No Return), BLM lands. Elev. 1920-2080'. Large, open, moss covered, steep granite boulder talus. Allogona ptychophora ptychophora (rare, not collected); common Cryptomastix mullani clappi hand collected. 10/14/1993 TF, EJ! [B11]

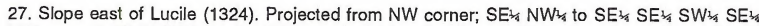
NW/3 sec. 2, T24N R1E, Lucile 1963 quad., Idaho Co. Grassy W.-facing slope above (E. of) US95 across from Lucile and S. of Sheep Gulch just N. of Lucile Caves ACEC, E. of the Salmon River at RM 77.0-77.1, BLM lands. Elev. 1720-1800'. Scattered schist boulders and mixed cobbles, small talus piles; moderately steep grassy slope with scattered Celtus, common Opuntia, rare Rhus diversiloba; sandy soil. Common but sporadic Oreohelix idahoensis idahoensis (full ontogeny); rare succineid. Colony about 0.2 mile long; extends at least 80' above road. Land snails hand collected. 10/15/1993 TF, EJ! [B17]

28. Opposite Lucile Post Office (1325). NE 1963 quad., Idaho Co. Boulders across from Lucile Post Office on E. side of Cow Creek Road (Idaho Co. 242) in Lucile, E. of Salmon River at RM 76.9. Elev. 1680'. Boulder pile and outcrops (mixed lithologies, mostly limestone) along gravel road; grasses; blackberries; much modified. Abundant Oreohelix idahoensis idahoensis (full ontogeny); possible Solem site; much modified by town encroachment. Snails hand collected. 10/15/1993 TF, EJ!

[B17]

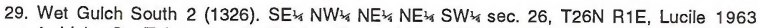
quad., Idaho Co. Talus opposite Butcher Bar and E. of US95 just beyond S. end of old US95 segment, ca. 0.3 mile S. of mouth of Wet Gulch, E. side of Salmon River at RM 74.6. Elev. 1640 '. Just S. of BLM lands. Schist talus at base of small gully; Celtus, grasses. Oreohelix n. sp. 23 (full ontogeny); very small colony. Hand collected. 10/15/1993 TF, EJ! [B15]

30. Wet Gulch South 1 (1327). Center NW/4 SE3/4 NW/3 sec. 26, T26N R1E, Lucile 1963 quad., Idaho Co. SW-facing slope 0.15 mile S. of mouth of Wet Gulch, about 0.1 mile along old US95 segment, E. of present US95 grade, E. of Salmon River at RM 74.35, BLM lands. Elev. 1880'. Very steep, open, and dry schist slope; common bedrock, rare small talus piles; scattered Celtus, common Opuntia and grasses. Very rare Oreohelix waltoni and Cryptomastix n. sp. 5 dead only. Hand collected. 10/15/1993 TF, EJ! [B15]

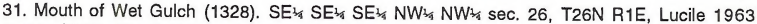
quad., Idaho Co. N.-facing slope on S. side of mouth of Wet Gulch E. of US95, ca. 20' outside of N.-S. fence, E. side of Salmon River at RM 74.2. BLM lands. Elev. 1720'. Celtus and Artemisia, Balsamorhiza, grasses, on schist talus; rather open and dry small bench. Common Oreohelix n. sp. 24 in very small area (ca. 10' x 10"). Hand collected. 10/15/1993 TF, EJ! [B15]

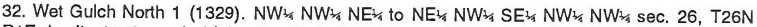
R1E, Lucile 1963 quad., Idaho Co. W.-facing slope and terrace 0.10-0.25 mile NW of mouth of Wet Gulch, E. of US95, E. side of Salmon River at RM 73.85-74.10, BLM lands. Elev. $1720-1780^{\prime}$. Schist talus and bedrock on S. end; boulder terrace to the N. Oreohelix jugalis abundant on bedrock at $\mathrm{S}$. end of site; less common above and on terrace; rare Allogona ptychophora ptychophora and succineid also found. Hand collected. 10/15/1993 TF, EJ! [B15]

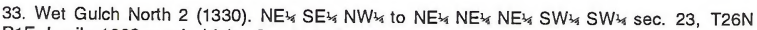
R1E, Lucile 1963 quad., Idaho Co. N.-facing steep slope on S. side of unnamed gulch, 0.3 mile N. of Wet Gulch, E. of US95, E. side of Salmon River at RM 73.7, BLM lands. Elev. $1640-1680^{\prime}$. Steep slope with mix of soil, schist talus (very minor) and boulder talus (very minor); snails in talus and high on slope; range open to grassy; common Rosa; mosses at slope base. Very rare Oreohelix haydeni hesperia, Allogona ptychophora ptychophora, and 1 recent dead Cryptomastix n. sp. 5. Hand collected. 10/15/1993 TF, EJ!

[B15] 


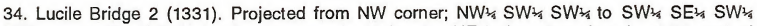
NW $1 / 4$ sec. 2, T25N R1E, Lucile 1963 quad., Idaho Co. NE-facing slope just S. of W. end of Lucile Bridge to 0.1 mile $\mathrm{S}$., colony begins ca. 20' above road off (S. of) Cow Creek Road (Idaho Co. 242), NW side of Salmon River at RM 76.9-77.0. Elev. 1640-1680'. Alluvial slope over schist bedrock; grasses, Celtus, Rhus diversiloba, and Ailanthus. Rare live and recent dead Oreohelix waltoni and Cryptomastix harfordiana hand collected. 8/11/1989 TF, EJ, SW! Uncommon recent dead and common long-dead Oreohelix waltoni; uncommon live and abundant dead Cryptomastix harfordiana. Hand collected. 6/2/1990 TF, EJ, SN! Rare live Cryptomastix harfordiana; Oreohelix waltoni long-dead only, now rare; sheep pasture. Snails hand collected. 10/15/1993 TF, EJ! [B17]

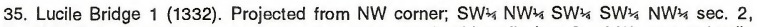
T25N R1E, Lucile 1963 quad., Idaho Co. NE-facing boulder pile just S. of W. end of Lucile Bridge (for 0.1 mile, below road off (S. of) Cow Creek Road (Idaho Co. 242), NW side of Salmon River at RM 76.9-77.0. Elev. 1580'. Boulder pile (mixed lithologies); steep; mostly open; common Rhus diversiloba, Rosa, some grasses; scattered Celtus. Oreohelix n. sp. 23 and Cryptomastix harfordiana hand collected. 6/2/1990 TF, EJ, SN! Moderately common Oreohelix n. sp. 23; rare Cryptomastix harfordiana, and Helicodiscus salmoneus. Hand collected. 10/15/1993 TF, EJ! [B17]

36. South and opposite Upper Sherwin Bar (1333). NE'/4 SE-1/4 sec. 14, T26N R1E, Lucile 1963 quad., Idaho Co. NW-facing schist cliff base, grading into talus to SW, opposite the S. end of Sherwin Bar, E. of US95 at road mile 209.0-209.2, E. side of Salmon River at about RM 71.9-72.0. Elev. 1620-1640'. BLM lands. Very dry and open steep schist slope, scattered talus, some fluvial terrace cobbles; grasses, Celtus, Balsamorhiza, common Opuntia. Oreohelix jugalis rare live and Cryptomastix n. sp. 5 dead only. Hand collected. 10/16/1993 TF, EJ! Oreohelix jugalis dead only. Hand collected. 4/26/1994 TF, EJ!

[B14]

37. Gulch opposite Upper Sherwin Bar (1334). SW $W_{1 / 4}^{1 / 4} \mathrm{NE}_{\frac{1}{4}} \mathrm{SW}_{\frac{1}{4}} \mathrm{SW}_{\frac{1}{4}} \mathrm{NW}_{\frac{1}{4}}$ sec. 13, T26N R1E, Lucile 1963 quad., Idaho Co. N. side of gulch opposite of Upper Sherwin Bar on E. side of US95 at road mile 209.3, E. side of Salmon River at RM 71.7, BLM lands. Elev. 16201640 . Schist talus with common river boulders in gulch (NE side); comparatively dry, open; grasses, rare Celtus. Cryptomastix n. sp. 5 uncommon live; Oreohelix jugalis rare; Allogona ptychophora ptychophora common dead with rare live (not retained). Hand collected. 10/16/1993 TF, EJ! [B14]

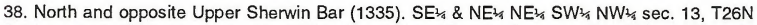
R1E, Lucile 1963 quad., Idaho Co. NW-facing schist cliff and talus opposite of Upper Sherwin Bar E. of US95 at road mile 209.5-209.7, E. side of Salmon River at RM 71.5, BLM lands. Elev. 1660'. Schist bedrock cliff and scattered small talus piles; rather dry and open; Celtus, grasses, Opuntia, Artemisia, Balsamorhiza. Moderately common Oreohelix jugalis locally (full ontogeny, mostly bandless); rare Cryptomastix. n. sp. 5; long-dead Allogona ptychophora ptychophora. Hand collected. 10/16/1993 TF, EJ! [B14]

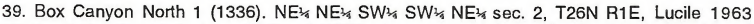
quad., Idaho Co. S.ffacing cliff N. of US95 at approximately road mile 212.0 , N. side of Salmon River at RM 68.8, N. end of Box Canyon, BLM lands. Elev. 1600'. High, nearly S.facing schist cliff with very rare small talus piles; mostly scattered grasses and Opuntia; very dry and exposed. Mostly cliff; modified extensively by road building; very rare Oreohelix waltoni live in 12' x 4' talus; very rare live and recent to long-dead Cryptomastix harfordiana; long-dead Allogona ptychophora ptychophora. Hand collected. 10/16/1993 TF, EJ!

[B14]

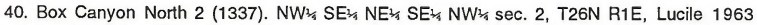
quad., Idaho Co. SW-facing gully, and upper slope on N. side of Salmon River and US95, road mile 212.2, near S. end of Blackhawk Bar, N. of Box Canyon at RM 68.5, BLM lands. Elev. 1600-1680'. Open and somewhat dry cliff, gully, and moderate slope; local bedrock exposure (schist) and small-scale talus; locally common Seligeria, some moss; Balsamorhiza; Celtus patches. Oreohelix n. sp. 21 and rare Oreohelix waltoni, very local (full ontogeny for 
both); dead Oreohelix jugalis; rare Cryptomastix harfordiana. All hand collected. 10/16/1993 TF, EJ! [B14]

41. North of Blackhawk Bar 1 (1338). SW $\frac{1 / 4}{1 / 4} \mathrm{SE}^{\frac{1}{4}} \mathrm{SW}_{\frac{1}{4}} \mathrm{SE}^{\frac{1}{4}} \mathrm{SE}_{\frac{1}{4}}$ sec. 35, T27N R1E, Slate Creek 1981 quad., Idaho Co. NW-facing cliff and gullies at road mile 213.3, N. of Blackhawk Bar, S. side of US95 and Salmon River at RM 67.0, BLM lands. Elev. 1600-1680'. Schist cliff and scattered loose rock (schist), perennially moist, mossy in some areas (abundant moss, less abundant Seligeria); common Celtus; Viola; grasses; sandy soil at base. Rare live Box Canyon Oreohelix n. sp. 21; uncommon Allogona ptychophora ptychophora; abundant Cryptomastix harfordiana; Oreohelix jugalis (very rare), and Deroceras. Hand collected. 10/16/1993 TF, EJ! [B35]

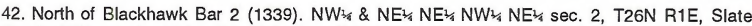
Creek 1981 quad., Idaho Co. N.-facing cliff with small reentrants, S. side of US95 between road mile 213.1-213.2, N. of Blackhawk Bar, S. side of Salmon River at RM 67.1-67.2, BLM lands. Elev. 1600-1640'. Cliff with small steep gullies; mostly exposed bedrock (schist) and sandy soil; fairly open; somewhat moist, with locally common mosses, grasses, Celtus. Uncommon Oreohelix jugalis (mostly bandless); rare slugs; dead succineid; uncommon Allogona ptychophora ptychophora; dead Cryptomastix n. sp. 5. Hand collected. 10/16/1993 TF, EJ! [B35]

43. John Day Creek 4 (1340). SE SE $^{\frac{1}{4}} \mathrm{NW}_{\frac{1}{4}} \mathrm{SE}^{\frac{1}{4}} \mathrm{SE}_{\frac{1}{4}} \mathrm{SE}^{\frac{1}{4}}$ sec. 18, T26N R2E, John Day Mtn. 1963 quad., Idaho Co. S.-facing limestone talus above 2 springs, ca. 2.7 miles up John Day Road (Idaho Co. 460) from US95, N. side of road. Elev. 2440'. Limestone talus ca. $400^{\prime}$ in length; mosses; Sambucus; grasses; little soil in talus; above 2 cold springs. Common Oreohelix haydeni hesperia (full ontogeny); uncommon Allogona ptychophora ptychophora; rare live Cryptomastix mullani latilabris, Discus marmorensis. Hand collected. 10/17/1993 TF, EJ! [B8]

44. John Day Creek 5 (1341). SE $\mathrm{SE}^{1 / 4} \mathrm{NW}_{\frac{1}{4}} \mathrm{SE}^{\frac{1}{4}} \mathrm{SE}_{\frac{14}{4}} \mathrm{SE}^{\frac{1}{4}}$ sec. 18, T26N R2E, John Day Mtn. 1963 quad., Idaho Co. Small spring originating at base of talus ca. 2.65 miles up John Day Road (Idaho Co. 460) from US95, N. side of road. Elev. 2440'. Depth 1-3". Small cold spring and spring run with limestone cobbles, scattered Rorippa; ca. 10" in width; Celtus and Sambucus leaves. Common Pristinicola hemphilli at source; badly grazed, so snails restricted to spring source. No land snails found. 10/18/1993 TF, EJ! [B8]

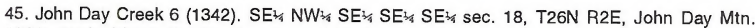
1963 quad., Idaho Co. Small spring originating at base of talus ca. 2.7 miles up John Day Road (Idaho Co. 460) from US95, N. side of road Elev. 2440'. Depth 1-3". Small cold spring and spring run with limestone cobbles, scattered Rorippa; ca. 12" in width; Celtus and deciduous leaves. Common Pristinicola hemphilli at spring source hand collected off rocks and leaves; area badly grazed. No land snails found. 10/17/1993 TF, EJ! [B8]

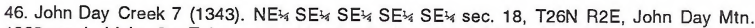
1963 quad., Idaho Co. Talus on N. side of John Day Road (Idaho Co. 460), ca. 2.8 miles up from US95 and 0.1 mile E. of two cold springs (across small gully just E. of mouth). Elev. 2440 '. Roughly 0.3 road mile NE of the type locality for Oreohelix haydeni hesperia. Thin and narrow limestone talus overshadowed by Celtus; grassy at base; bryophytes common in some areas; talus length <200'. Uncommon Discus marmorensis (half albino); rare live Allogona ptychophora ptychophora and dead Cryptomastix mullani latilabris (not retained); uncommon Oreohelix haydeni hesperia. Hand collected. 10/17/1993 TF, EJ! [B8]

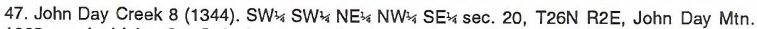
1963 quad., Idaho Co. S.-facing large talus in prominent reentrant on N. side of John Day Creek and John Day Road (Idaho Co. 460), ca. 0.75 mile SE of Trevino ranch house and opposite cabin. Elev. 2880-2920'. Large forested schist boulder talus; Pinus ponderosa, Rosa, abundant mosses, Cornus stolonifera; open in places; length ca. $750^{\prime}$. Common Discus marmorensis and Cryptomastix mullani latilabris; very rare Oreohelix haydeni hesperia 
(mostly dead); uncommon Allogona ptychophora ptychophora; rare slugs. All hand collected. 10/17/1993 TF, EJ! [B8]

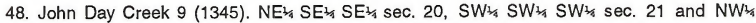
NW ${ }^{3}$ sec. 28, T26N R2E, John Day Mtn. 1963 quad., Idaho Co. Long SW-facing partly wooded slope above John Day Creek, beginning ca. 1.6 miles SE from Trevino ranch house and ending ca. 0.6 mile SE above John Day Road (Idaho Co. 460), BLM lands. Elev. 32803440 '. Open, partly wooded, moderately steep to steep slope and small cliffs, very rare rock piles; dolomitic limestone; Pinus ponderosa (scattered); grasses; Balsamorhiza. Area partly burned; moderately grazed. Oreohelix haydeni hesperia (small form?) common long-dead and quite rare live, surviving only in small groups in protected areas; uncommon long-dead Cryptomastix mullani olneyae; rare live Allogona ptychophora ptychophora. Hand collected. 10/17/1993 TF, EJ! [B8]

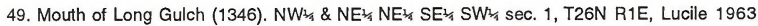
quad., Idaho Co. Mouth of Long Gulch on both sides (E. and W.-facing slopes), E. side of Salmon River, BLM lands. Elev. $1600-1640^{\prime}$. Steep slopes and thin schist talus, exposed bedrock; spring at base on W. side; mostly dry open; grasses, Balsamorhiza, Artemisia and Celtus. Oreohelix jugalis (full ontogeny) moderately common in a limited area (mostly in small gullies on both sides of Long Gulch, especially under Artemisia); rare live Allogona ptychophora ptychophora (common dead). Hand collected. Area heavily pastured. 10/16/1993 TF, EJ! [B14]

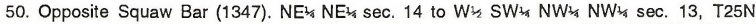
R1E, Lucile 1963 quad., Idaho Co. High, steep W.-facing slope, above (NE of) US95; E. side of Salmon River at ca. RM 78.9-79.1, opposite Squaw Bar, BLM lands. Elev. 1800-2000'. Steep slope; mostly grasses, scattered schist cobbles. No land snails seen, area heavily grazed. 10/18/1993 TF, EJ! [B17]

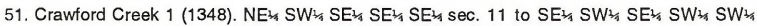
sec. 12, T25N R1E, Lucile 1963 quad., Idaho Co. N. and S.ffacing slopes along Crawford Creek above (E. of) access road, beginning ca. 0.3 road mile E. of US95. Elev. 1960-2360'. Steep slopes and stream bed; range from dry and open (grasses, Celtus, Opuntia, Balsamorhiza) to moist mossy cliff faces and shrubby slope (still mostly grasses); very common Rhus diversiloba. Very scattered Allogona ptychophora ptychophora (live); longdead Oreohelix idahoensis idahoensis; heavy grazing damage. Snails hand collected. 10/18/1993 TF, EJ! [B17]

52. Lucile Caves ACEC-Crawford Creek 2 (1349). SE $\mathrm{SW}_{3 / 4}$ \& NW $W_{\frac{1}{4}} \mathrm{NE}_{\frac{1}{4}} \mathrm{SW}_{3}$ of SW/4 sec. 12, T25N R1E, Lucile 1963 quad., Idaho Co. NW and SW-facing slopes along tributary gully on N. side of Crawford Creek, beginning ca. 0.4 road mile E. of US95 along access road, BLM lands (Lucile Caves ACEC). Elev. 2200-2600'. Relatively dry and open grassy steep slopes in tributary gully; grasses, Opuntia, Balsamorhiza, Celtus, common Rhus diversiloba; scattered schist boulders and small rock piles. Heavily grazed area. Scattered colonies of Oreohelix idahoensis idahoensis, especially on SW side; locally common where protected from grazing (very steep areas); Cryptomastix n. sp. 5. Hand collected. 10/18/1993 TF, EJ! [B17]

53. Crawford Creek 3 (1350). Center NE quad., Idaho Co. Small S.-facing talus on N. side of Crawford Creek ca. 0.25 road mile E. of US95, between two major gullies on N. side of Crawford Creek. Elev. 2020'. Small (ca. 15' length) limestone talus on N.-side of small gully; very open; grasses, Clematis, Celtus. Uncommon Oreohelix idahoensis idahoensis hand collected. 10/18/1993 TF, EJ! [B17]

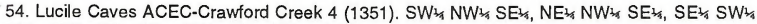
$\mathrm{NE}_{\frac{1}{4}}, \mathrm{SW}_{\frac{1}{4}} \mathrm{SE}_{\frac{1}{4}} \mathrm{NE}_{\frac{1}{4}}, \mathrm{NW}_{\frac{1}{4}} \mathrm{SE}_{\frac{1}{4}} \mathrm{NE}_{\frac{1}{4}}$ of $\mathrm{SE}_{\frac{1}{4}}$ sec. 11, T25N R1E, Lucile 1963 quad., Idaho Co. E. and W.-facing slopes in a large gully on N. side of Crawford Creek, beginning ca. 0.25 
road mile NE of US95 (E. of Salmon River), partly on BLM lands (Lucile Caves ACEC). Elev. 2000-2400'. Dry open slope along dry gully; schist boulder talus at base; grasses; Opuntia; Celtus; common Rhus diversiloba. Rare live Cryptomastix n. sp. 5, Allogona ptychophora ptychophora; scattered Oreohelix idahoensis idahoensis (some live, but most dead); hand collected. 10/18/1993 TF, EJ! [B17]

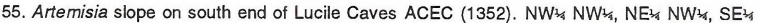

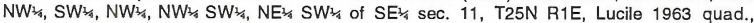
Idaho Co. Extensive steep SW-facing slope above grassy bench, S. part of BLM Lucile Caves ACEC, E. of US95 and Salmon River; length ca. 0.3 mile; width ca. 0.2 mile. Elev. 2000-2400'. Steep slope with limestone bedrock, scattered talus and boulders; grassy soil with Celtus, common large Artemisia, Opuntia, Balsamorhiza; rather dry and open. Very abundant dead Oreohelix idahoensis idahoensis; relatively common scattered live. Hand collected. Area formerly grazed; some grazing continuing. 10/18/1993 TF, EJ!

[B17]

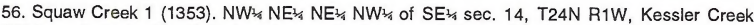
1964 quad., Idaho Co. E.-facing slope on both sides of Squaw Creek Road (FS487) 0.1 road mile W. of junction with Indian Springs Road (FS9901), E. side of Squaw Creek, ca. 1.25 road miles into Nez Perce National Forest. Elev. 3800-3820'. Limestone talus slope; Pinus ponderosa with common deciduous shrubs. Common live to long-dead Oreohelix strigosa n. subsp. 1; uncommon Cryptomastix mullani olneyae, Allogona ptychophora ptychophora and Anguispira kochi occidentalis. Hand collected. 10/19/1993 TF, EJ! [B12]

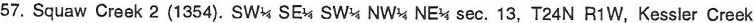
1964 quad., Idaho Co. S.-facing talus 0.5 road mile inside Nez Perce National Forest boundary, N. side of Squaw Creek Road (FS487), 0.9 road mile E. of Indian Springs Road (FS9901), N. side of Squaw Creek. Elev. 3440'. Unstable very dry basalt talus above road; mostly open, with grasses, rare Celtus and Balsamorhiza. Single long-dead specimen of Oreohelix n. sp. 8; hand collected. 10/19/1993 TF, EJ! [B12]

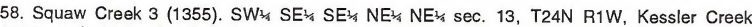
1964 quad., Idaho Co. S.-facing talus above and below Squaw Creek Road (FS487) just W. of (inside) Nez Perce National Forest boundary, 1.3 road miles E. of Indian Springs Road (FS9901), N. side of Squaw Creek. Elev. 3260'. Very dry unstable basalt talus slope with grasses, few Celtus. Long-dead specimens of new Oreohelix n. sp. 8; 1 live Allogona ptychophora ptychophora; recent dead Cryptomastix mullani olneyae. Hand collected. 10/19/1993 TF, EJ! [B12]

59. South side of the mouth of Twilegar Gulch (1356). NE $\mathrm{NE}^{\frac{1}{1 / 4}} \mathrm{SW}_{\frac{1 / 4}{4}} \mathrm{NW}^{\frac{1}{4}} \mathrm{SW}_{\frac{1}{4}}$ sec. 35 , T26N R1E, Lucile 1963 quad., Idaho Co. N.-facing schist outcrops with considerable soil on S. side of mouth of Twilegar Gulch, E. of US95 and Salmon River opposite mouth of China Creek. Elev. 1720'. Schist outcrops at mouth of gully; mossy locally; abundant grasses, common Celtus. Uncommon Oreohelix n. sp. 20; very few live; Cryptomastix n. sp. 5 live, recent and long-dead; Helicodiscus live and dead. Hand collected. 10/19/1993 TF, EJ! [B15]

60. 8.6 miles up Twilegar Gulch Road (1357). NW/3/4 SW John Day Mtn. 1963 quad., Idaho Co. N.-facing small cliffs (above road) and talus (below road) 8.4-8.6 road miles up Twilegar Gulch Road, above Wet Gulch, BLM lands. Elev. 5640'. Short cliff and talus; Pinus ponderosa forest below; cleared and burned above. Oreohelix haydenia hesperia, Anguispira kochi occidentalis, Allogona lombardii, and Cryptomastix mullani olneyae. Hand collected. 10/1/1990 TF, GH! Common Oreohelix haydeni hesperia (full ontogeny); Anguispira kochi occidentalis; Cryptomastix mullani olneyae, Allogona lombardii. Hand collected. 10/19/1993 TF, EJ!

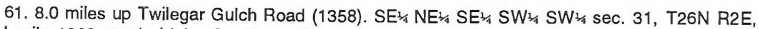
Lucile 1963 quad., Idaho Co. Slope 8.0 road miles along Twilegar Gulch Road., above Wet Gulch; collected above road. BLM lands. Elev. 5360'. Low-moderate slope and thin 
limestone talus; cleared Pinus ponderosa forest. Snails live mostly along road; dead in clear cut; Oreohelix haydeni hesperia hand collected. 10/19/1993 TF, EJ! [B16]

62. 7.6 miles up Twilegar Gulch Road (1359). SE/3 SW/3 SW/3 NW/4 SW/4 sec. 31, T26N R2E, Lucile 1963 quad., Idaho Co. N.-facing shallow limestone slope 7.6 road miles up Twilegar Gulch Road, BLM lands. Elev. 5120'. Cut-over limestone slope; Pinus ponderosa forest. Dead Oreohelix haydeni hesperia only; hand collected. 10/19/1993 TF, EJ! [B16]

63. 7.0 miles up Twilegar Gulch Road (1360). NW/3/4 $\mathrm{NW}^{\frac{3}{4}} \mathrm{SW}_{\frac{3}{4}} \mathrm{NE}^{\frac{1}{4}} \mathrm{SE}^{\frac{1}{4}} \mathrm{sec}$. 36, T26N R1E, Lucile 1963 quad., Idaho Co. N.-facing shallow slope on a low hill 7.0 road miles up Twilegar Gulch Road on N. side, Idaho State lands. Elev. 4820-4860'. Low hill in an open Pinus ponderosa forest (mostly cut-over); limestone substrate. Oreohelix haydeni hesperia, dead only (not collected). Snails essentially extinct in cut-over area. 10/19/1993 TF, EJ! [B16]

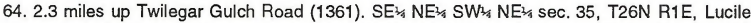
1963 quad., Idaho Co. E.-facing slope on knob 2.3 road miles up Twilegar Gulch Road on N. side, directly above Twilegar Gulch. Elev. 2600-2640'. Limestone outcrops, dry slope on an Artemisia covered knob. Oreohelix n. sp. 20 found in all conditions (mostly dead). Dead only at top of knob; live only where protected by small cliffs or talus; heavily grazed. Hand collected. 10/19/1993 TF, EJ! [B15]

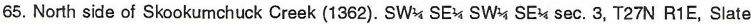
Creek 1981 quad., Idaho Co. S.-facing slope near the mouth of Skookumchuck Creek (N. side), 0.35 mile up Dairy Mountain Road (FS2025) from US95, E. of the Salmon River, BLM lands. Elev. 1580'. Dry, exposed grassy slope; replanted, probably Artemisia scrub originally; alluvial substrate. No snails found. 10/20/1993 TF, EJ!

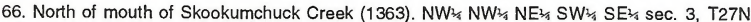
R1E, Slate Creek 1981 quad., Idaho Co. Small gully on E. side of Dairy Mountain Road (FS2025), about 0.1 road mile from US95, N. of mouth of Skookumchuck Creek, E. of the Salmon River at RM 58.1, BLM lands. Elev. 1560-1600'. Small gully collected on N. side; partly forested, with Celtus, Astragalus, Rosa; basalt bedrock with thin soil. Allogona ptychophora ptychophora, rather rare. Hand collected. 10/20/1993 TF, EJ! [B33]

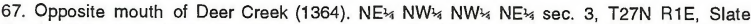
Creek 1981 quad., Idaho Co. W.-facing talus on E. side of side road to US95, E. side of Salmon River at RM 57.4, opposite mouth of Deer Creek, BLM lands. Elev. 1520-1560'. Loose open basalt talus; dry, shallow; mostly grasses, scattered Celtus and Artemisia. Oreohelix jugalis, Allogona ptychophora ptychophora, and Cryptomastix hand collected. 10/20/1993 TF, EJ! [B32]

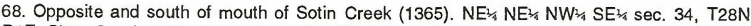
R1E, Slate Creek 1981 quad., Idaho Co. W.-facing talus opposite and S. of mouth of Sotin Creek on E. side of side road to US95, E. side of Salmon River RM 56.8, BLM lands. Elev. $1560^{\prime}$. Basalt boulder talus (dry); very little vegetation. Recent dead Cryptomastix n. sp. 5, not collected. 10/20/1993 TF, EJ!

[B32]

69. Mouth of Robbers Gulch (1366). SW $W_{1 / 4} \mathrm{NE}^{\frac{1}{4}} \mathrm{SE}^{\frac{1}{4} / 4} \mathrm{SE}^{\frac{1}{4}} \mathrm{sec}$. 14, T27N R1E, Slate Creek 1981 quad., Idaho Co. Both sides of mouth of Robbers Gulch above bridge crossing of old US95 route (N. side), N. of Salmon River at Horseshoe Bend, RM 62.9, BLM lands. Elev. 1760-1800'. Small disturbed basalt taluses, Rhus diversiloba common; some Celtus, grasses; generally very dry, open. Oreohelix vortex, sparse Cryptomastix $\mathrm{n}$. sp. 5 ; rare dead Allogona ptychophora ptychophora; area partly quarried; snails under talus in protected areas. Hand collected. 10/20/1993 TF, EJ! [B33]

70. West of Robbers Gulch (1367). N1/2 SW/3 SE-1/4 SE quad., Idaho Co. S.-facing talus 0.1 mile W. of Robbers Gulch, N. side of old US95 route, N. of Salmon River at Horseshoe Bend, RM 62.8, BLM lands. Elev. 1800'. Open dry talus basalt 
talus base in less disturbed areas in small quarry around a large Populus; understory of grasses, small Salix, little bit of Rhus diversiloba. Sparse Oreohelix vortex and Cryptomastix n. sp. 5. Hand collected. 10/20/1993 TF, EJ! [B33]

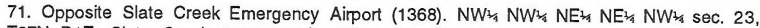
T27N R1E, Slate Creek 1981 quad., Idaho Co. W.-facing slope opposite Slate Creek Emergency Airport from US95 (along N. side of old US95 route), N. of Salmon River at Horseshoe Bend, BLM lands. Elev. 1600-1620'. Dry, open, grassy slope; alluvial substrate. No snails. 10/20/1993 TF, EJ! [B33]

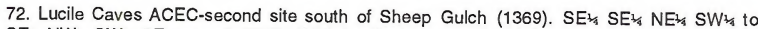
$S^{1 / 4} N_{1 / 4} S W_{1 / 4} S E_{1 / 4}$ sec. 2, T25N R1E, Lucile 1963 quad., Idaho Co. Shallow-moderately steep W.-facing slope in Lucile Caves ACEC (BLM lands), ca. $0.3 \mathrm{mi}$. S. of Lucile turnoff, above US95 (E. side). Elev. 1800-2600'. Moderately steep-shallow weathered schist slope with scattered limestone cobbles and boulders; mostly dry and open; grasses, scattered Celtus, Artemisa, Balsamorhiza, Opuntia. Very sparse live and dead Oreohelix idahoensis idahoensis hand collected; rather heavily grazed. Live material very local. 10/21/1993 TF, EJ! [B17]

73. Lucile Caves ACEC-south of Lucile Caves (1370). NE

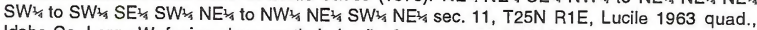
Idaho Co. Large W.-facing slope partly in Lucile Caves ACEC (BLM lands), ca. 0.7-1.1 mi. S. of Lucile turnoff and E. of US95, and S. of Lucile Caves. Elev. 1800-2600'. Steep-moderately steep slope, open, dry, and grassy, in weathered limestone; scattered outcrops and blocks. Very sparse Oreohelix idahoensis idahoensis live; common long-dead; moderately grazed. Hand collected. 10/21/1993 TF, EJ! [B17]

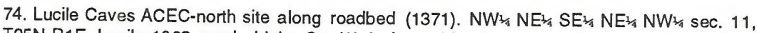
T25N R1E, Lucile 1963 quad., Idaho Co. W.-facing schist slope near N. end of old roadbed of US95, ca. $0.6 \mathrm{mi}$. S. of Lucile turnoff, Lucile Caves ACEC (BLM lands), near old mine prospect. Elev. 1720-1800'. Dry and open slope, with weathered schist outcrops; common grasses, Celtus; locally shaded, with Rubrus, Salix, etc. Oreohelix idahoensis idahoensis hand collected. 8/10/1989 TF, MF, EJ! Local but common Oreohelix idahoensis idahoensis hand collected. Litter sampled. 10/21/1993 TF, EJ! [B17]

75. Lucile Caves ACEC-second site from north on old roadbed (1372). SW/1/4 $\mathrm{NE}^{\frac{1}{4}} \mathrm{SE}^{\frac{1}{4}} \mathrm{NE}^{\frac{1}{4}}$ $\mathrm{NE}^{1 / 4}$ sec. 11, T25N R1E, Lucile 1963 quad., Idaho Co. W.-facing springy area below Lucile Caves and ca. $0.65 \mathrm{mi}$. S. of Lucile turnoff, Lucile Caves ACEC (BLM lands), ca. $0.1 \mathrm{mi}$. S. of $\mathrm{N}$. end of old US95 roadbed. Elev. 1720-1760'. Shaded, moist slope with spring runs, travertine deposition; Salix, Populus, Physocarpus, Cornus stolonifera, Sambucus. Uncommon Cryptomastix n. sp. 5 live; Oreohelix idahoensis idahoensis long-dead (not retained); Allogona ptychophora ptychophora dead only. Hand collected. 8/10/1989 TF, MF,

76. Lucile Caves ACEC-near Lucile Caves (1373). Center SW/4 SW/4 NW/4 NE-1/4 sec. 11, T25N R1E, Lucile 1963 quad., Idaho Co. Steep W.-facing travertine-covered area in vicinity of Lucile Caves and below largest spring source, ca. $0.2 \mathrm{mi}$. E. of US95 and $0.7 \mathrm{mi}$. S. of Lucile turnoff, BLM lands (Lucile Caves ACEC). Elev. 1960-2020'. Very steep, travertinecovered; open, mostly very moist; grasses, scattered bryophytes, local shrubs. Uncommon Allogona ptychophora ptychophora live; rare long-dead Oreohelix idahoensis idahoensis. Hand collected. 8/10/1989 TF, MF, EJ! [B17]
[B]

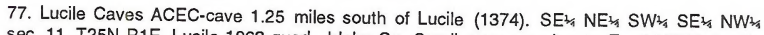
sec. 11, T25N R1E, Lucile 1963 quad., Idaho Co. Small cave opening to E. of US95, Lucile Caves ACEC (BLM lands), ca. $1.25 \mathrm{mi}$. S. of Lucile turnoff. Elev. 1680'. Small cave (former mine prospect?) in short limestone cliff; bare rock, grasses, scattered limestone cobbles and 
boulders, very limited talus. Oreohelix idahoensis idahoensis extremely local, common where found. Hand collected. 8/10/1989 TF, MF, EJ!

78. Pine Bar Campground 1 (1375). SW/3/4 SW/4 NE'/4 SE 1963 quad., Idaho Co. SW-facing basalt talus just E. of Pine Bar Campground (at end of access road) above Pine Bar Rapids, N. side of Salmon River, RM 42.7, BLM lands. Elev. 1360'. Basalt talus; mostly dry and open; Celtus, Sambucus, Opuntia, grasses. Oreohelix n. sp. 25; Cryptomastix n. sp. 6; Allogona ptychophora ptychophora (full ontogeny for all); hand collections. 10/23/1993 TF, EJ!

[B4]

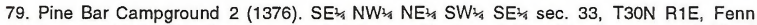
1963 quad., Idaho Co. S.-facing basalt talus on N. side of Pine Bar Campground (N. of upper access road), 0.25 mile E. of mouth of Cottonwood Gulch, N. of the Salmon River, down river from Pine Bar Rapids, RM 42.4, BLM lands. Elev. 1400'. Low, dry, and open basalt talus; snails at base; Celtus, grasses. Uncommon-locally abundant Oreohelix n. $\mathrm{sp}$. 25; Allogona ptychophora solida; Cryptomastix n. sp. 6. 10/23/1993 TF, EJ! [B4]

80. West of the mouth of Cottonwood Gulch (1377). NW/3/4 NE//4 NE T30N R1E, Fenn 1963 quad., Idaho Co. S.-facing basalt cliffs and talus 0.3 mile W. of mouth of Cottonwood Gulch, N. of access road, N. of the Salmon River down niver of Pine Bar Rapids, RM 41.9, BLM lands. Elev. $1360^{\prime}$. Steep talus in small piles at back of short basalt cliff; some rare Celtus; grasses; quite dry and open. Rare Oreohelix n. sp. 25; Allogona ptychophora ptychophora; Cryptomastix n. sp. 6. 10/23/1993 TF, EJ! [B4]

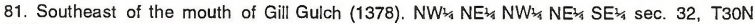
R1E, Fenn 1963 quad., Idaho Co. SW-facing small, deep and moist gully 0.5 mile SE of mouth of Gill Gulch and on N. side of access road, N. side of Salmon River at RM 41.4, BLM lands. Elev. 1440-1480'. Deep gully; basalt talus ranging from very dry-moist and mossy; Celtus; Echinopsis; grasses. Collected on both sides; rare live Oreohelix n. sp. 25; rare live Cryptomastix n. sp. 6; Allogona ptychophora solida. All hand collected. 10/23/1993 TF, EJ! [B4]

82. Murdicks Spring (1379). NW/3/4 $\mathrm{NE}^{\frac{1}{4}} \mathrm{NW}^{\frac{1}{4}} \mathrm{SE}^{\frac{1}{4}} \mathrm{NE}^{\frac{1}{4}}$ sec. 31, T3ON R1E, Fenn 1963 quad., Idaho Co. Murdicks Spring at the mouth of Pine Tree Gulch, N. of access road, N. side of Salmon River at RM 40.2. Elev. 1360'. Destroyed dry spring. Basalt talus (S.-facing) above spring covered by dead Rubrus. Spring heavily modified; Rubrus probably herbicided and partially removed. No mollusks (land or freshwater) found. 10/23/1993 TF, EJ!

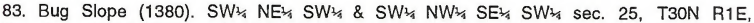
Moughmer Point 1963 quad., Idaho Co. Bug Slope (E.facing) ca. 0.4 road mile from Rocky Canyon junction N. side of access road, N. side of Salmon River at RM 38.6, BLM lands. Elev. 1200-1240'. Steep, very dry extensive basalt talus; some mosses; Celtus; Ailanthus; grasses; rare small Rhus diversiloba. Allogona ptychophora solida, Cryptomastix n. sp. 3 , and abundant dead-uncommon live Oreohelix n. sp. 25. Hand collected. 10/23/1993 TF, EJ! [B23]

84. Mouth of Maple Canyon (1381). SE $\mathrm{SE}^{\frac{1}{4}} \mathrm{NW}_{\frac{1}{4}} \mathrm{NW}_{3 / 4} \mathrm{SW}_{\frac{1}{4}} \mathrm{NW}_{3 / 4}$ sec. 26, T30N R1E, Moughmer Point 1963 quad., Idaho Co. E.-facing talus on W. side of the mouth of Maple Canyon just S. of access road, S. side of Salmon Rivern at RM 36.3, BLM lands. Elev. 1340'. Basalt talus; moist; mossy; abundant grasses; Echinopsis. Rare Allogona ptychophora solida. Hand collected. 10/23/1993 TF, EJ! [B22]

85. Mouth of Andrews Canyon (1382). N3/2 NE/4 SW/4 SE NW/4 sec. 26, T3ON R1E, Moughmer Point 1963 quad., Idaho Co. N. and S.-facing taluses at mouth of Andrews Canyon just S. of access road, S. side of Salmon River at RM 36.5, BLM lands. Elev. 1320'. Steep basalt talus on both sides of mouth of canyon; very mossy to W., dry to $E$. No live snails; very rare dead Allogona ptychophora ptychophora (not retained). Hand collection. 10/23/1993 TF, EJ! [B22] 
86. Talus northeast of Andrews Canyon (1383). $\mathrm{NE}^{\frac{1}{4}} \mathrm{NE}^{\frac{1}{4}} \mathrm{SW}_{\frac{1}{4}} \mathrm{NE}^{\frac{1}{4}} \mathrm{sec} .26, T 30 \mathrm{~N} R 1 \mathrm{E}$, Moughmer Point 1963 quad., Idaho Co. NW-facing small scattered talus along the S. side of access road, 0.4 road mile NE of the mouth of Andrews Canyon, on S. side of Salmon River at RM 36.8, BLM lands. Elev. 1320'. Shallow scanty basalt talus; mossy in places; Celtus; grasses. Very rare large Oreohelix n. sp. 29; Allogona ptychophora solida; Cryptomastix n. sp. 6 and dead only n. sp. 3. Hand collected. 10/23/1993 TF, EJ! [B22]

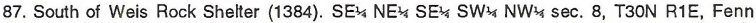
1963 quad., Idaho Co. High cliff and E.-facing talus just S. of Weis Rock Shelter, W. of Grave Creek and Grave Creek Road, 0.6 road mile up Grave Creek from its junction with Rock Creek. Elev. 1900'. Moist basalt talus (seeps were trickling down nearby cliff) with abundant mosses, Urtica and Echinopsis under locust. Abundant Cryptomastix (1 species, including rare dead-only populi); uncommon Oreohelix n. sp. 25; Allogona ptychophora solida. Hand collected. 10/23/1993 TF, EJ! [B3]

88. 1.3 miles Northeast of China Creek (1385). SE $\mathrm{SE}_{1 / 4} \mathrm{SW}_{\frac{1}{4}} \mathrm{SW}_{\frac{1 / 4}{4}} \mathrm{SE}^{\frac{1}{4}} \mathrm{SW}_{\frac{1 / 4}{4}}$ sec. 28, T31N R3W, Rattlesnake Ridge 1963 quad., Nez Perce Co. SE-facing shallow slope below Eagle Creek access road ( $E$. side), 1.3 road miles NE of mouth of China Creek, W. side of Salmon River at RM 12.5, BLM lands. Elev. 1040'. Small basalt rock piles beneath road; Celtus; open and exposed; sandy soil. Allogona ptychophora solida, Oreohelix n. sp. 29, and Cryptomastix populi. Hand collected. 10/24/1993 TF, EJ! [B25]

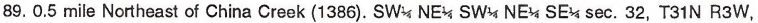
Rattlesnake Ridge 1963 quad., Nez Perce Co. Shallow slope below Eagle Creek access road (E. side), 0.5 road mile NE of mouth of China Creek, just above high water mark, W. side of Salmon River at RM 11.7, BLM lands. Elev. 1040'. Basalt talus just above high water mark; Celtus; grasses; driftwood; Rhus diversiloba; open and dry. Uncommon Oreohelix n. sp. 29; rare Allogona ptychophora solida; dead Cryptomastix populi. Hand collected. 10/24/1993 TF, EJ! [B25]

90. 0.2 mile Northeast of China Creek (1387). $W_{1 / 2} N^{2} W_{1 / 4} N^{1 / 4} N_{1 / 4} N^{1 / 4}$ sec. 5, T30N R3W, Rattlesnake Ridge 1963 quad., Nez Perce Co. E.-facing shallow slope below Eagle Creek access road ( $E$. side), 0.2 road mile NE of mouth of China Creek, just above high water mark, W. side of Salmon River at RM 11.3, BLM lands. Elev. 1040'. Small basalt rock piles; open and exposed; Celtus in vicinity; sandy soil. Cryptomastix populi, Allogona ptychophora solida, and rare Oreohelix sp. 29 hand collected. 10/24/1993 TF, EJ!

[B25]

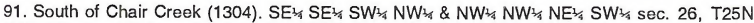
R1E, Riggins 1964 quad., Idaho Co. SW-facing talus above (NE of) US95 from the mouth of Chair Creek SE to 0.2 mile, NE side of Salmon River at RM 81.7-81.9. Elev. 1800-1820'. Large-scale schist bedrock and boulders; scattered talus piles; Rhus diversiloba, common Celtus, grasses. Land snails hand collected. 10/4/1990 TF, GH! Common large Oreohelix n. sp. 23; rarer Cryptomastix n. sp. 5. Hand collected. 10/12/1993 TF, EJ! [B26]

92. Opposite Smith Canyon (1389). SW $W_{1 / 4} \mathrm{NW}_{\frac{1 / 4}{4}} \mathrm{SE}_{\frac{1 / 4}{4}} \mathrm{SE}_{\frac{1 / 4}{4}} \mathrm{NE}_{\frac{1 / 4}{4}}$ sec. 14, T24N R3E, Kelly Mountain 1964 quad., Idaho Co. N.-facing slope opposite mouth of Smith Canyon, ca. 0.9 mile W. of French Creek, S. side of Salmon River Road (FS1614), S. of the Salmon River (River of No Return), BLM lands. Elev. 1960'. Shallow, rather dry Pinus ponderosa forest; Slope with poor understory, strongly coniferous litter; granite-derived sandy soil. No snails seen. 10/14/1993 TF, EJ!

[B11]

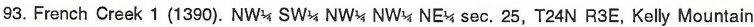
1964 quad., Idaho Co. W.-facing slope to the E. of French Creek Road (FS246), ca. 1.85 miles S. of junction with Salmon River Road, S. of the Salmon River (River of No Return), BLM lands. Elev. 2640'. Pinus ponderosa forest with scattered granite boulders; thin litter; rich bryophyte flora and moderate understory. Long dead Allogona ptychophora ptychophora seen, not collected. No snails seen in litter. 10/14/1993 TF, EJ! [B11] 
94. Race Creek 1 (1391). Center NW/3/4 SW/4 NE//4 sec. 10, T24N R1E, Riggins 1964 quad., Idaho Co. N.-facing schist talus, S. side of Race Creek just W. of mouth and 0.25 mile W., E. of horse pasture. Elev. 1800-2000'. Greenish schist talus; steep, grassy, some moss, some exposed bedrock; moist; above high water mark of creek. Oreohelix strigosa goniogyra (type locality fide Solem), moderately common; most submature. Solem collected closer to road; Baker to the W., in area now heavily pastured (snails now extinct there). Snails hand collected. 5/31/1990 TF, EJ, SN! [B27]

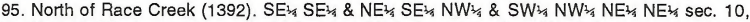
T24N R1E, Riggins 1964 quad., Idaho Co. SE-facing slope just N. of the mouth of Race Creek canyon and above (W. of) US95 for about 0.25 mile NE, W. of the Salmon River at RM 84.5-84.7. Elev. 1900-1960'. Limestone and alluvial rather shallow slope; dry, open, heavily modified; recent fire; Artemisia scrub. Recent to long-dead Cryptomastix mullani olneyae; uncommon large Oreohelix idahoensis idahoensis. Hand collected. 5/31/1990 TF, EJ, SN! [B27]

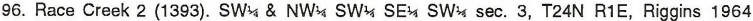
quad., Idaho Co. N. side of Race Creek Road (Idaho Co. 241); first major gully from mouth collected on E. side. Elev. 1880-2040'. Steep, open, dry gully with limestone outcrops on E. side and schist on opposite side. Artemisia scrub throughout. Small Oreohelix idahoensis idahoensis colony; snails mostly around limestone outcrops; schist on opposite side of gully. Hand collected. 10/19/1989 TF, MF, EJ! [B27]

97. Northwest-facing slope at Salmon River RM 79.6-79.8 (1394). SW sec. 23, T25N R1E, Riggins 1964 quad., Idaho Co. N. to NW-facing slope above present gold mine and $1 / 8$ mile to NE above US95 (SE of), opposite RM 79.6-79.8, E. of Salmon River, BLM lands. Elev. 1760-1800'. Grassy, rocky, rather open steep slope with a weak talus. Cryptomastix n. sp. 5 and Oreohelix n. sp. 23 hand collected. 8/10/89 TF, MF, EJ! Common large Oreohelix n. sp. 23; rarer Cryptomastix n. sp. 5. Both hand collected. 5/31/1990 TF, EJ, SN! [B26]

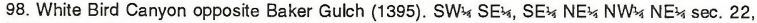
T28N R1E, White Bird 1962 quad., Idaho Co. SE-facing talus on NW side of White Bird Creek, SW of the mouth of Baker Gulch. Elev. 1600-1640'. Partly grassy, mostly dry, open, Artemisia scrub hillside with basalt taluses. Basalt talus partly damaged by old road and by grazing. Common Oreohelix n. sp. 25, less common Oreohelix vortex, Cryptomastix mullani olneyae, and Allogona ptychophora ptychophora. All hand collected. 9/30/1990 TF, EJ! [B39]

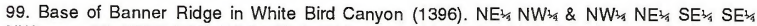
$\mathrm{NW}_{3 \frac{1}{4}}$ sec. 22, T28N R1E, White Bird 1962 quad., Idaho Co. N.-facing slope at the base of Banner Ridge in White Bird Canyon just S. of White Bird Road, ca. 0.28 mile E. of mouth of White Bird Creek, and 0.2 road miles from Lyons Bar turnoff. Elev. 1480-1500'. Wooded slope with exposed basalt bedrock; small talus piles; moist, small seeps; Salix, Cornus stolonifera, some common forbs, and Urtica. Oreohelix n. sp. 25, Allogona ptychophora ptychophora, and rare dead Oreohelix waltoni. Hand collected. 8/11/1989 TF, EJ, SW! Abundant Oreohelix n. sp. 25, common Polygyrella, Allogona ptychophora ptychophora, rare dead Oreohelix waltoni. Hand collected. 10/21/1989 TF, EJ! Site almost totally destroyed by road widening. A few surviving Oreohelix n. sp. 25 and Allogona ptychophora ptychophora locally; no Oreohelix waltoni seen. 10/12/1993 TF, EJ!

[B39]

100. Talus North of Copperville (1397). NW 21, T28N R1E, White Bird 1962 quad., Idaho Co. E.-facing prominent talus above Hammer Creek Road, on N. edge of Copperville, W. of the Salmon River at about RM 53.2; collected $\mathrm{N}$. for ca. $800^{\prime}$. Elev. $1560-1600$ '. Base of very steep and large open basalt talus; abundant lichens, moss, some Seligeria; Celtus at base. Cryptomastix n. sp. 5, Allogona ptychophora 
solida and Oreohelix jugalis in limited area on E. side of talus at base. 10/5/1990 TF, GH! [B39]

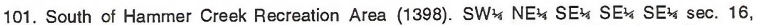
T28N R1E, White Bird 1962 quad., Idaho Co. Gully and E.-facing talus just above Hammer Creek Road, ca. 0.25 road mile S. of turnoff to Hammer Creek Recreation Area, W. of the Salmon River at RM 53.0. Elev. 1600-1640'. Gully and steep, unstable, open basalt talus; seepy at base with common nettles. Road cuts into talus; basalt talus over alluvial/fluvial terrace. Allogona ptychophora solida and Cryptomastix n. sp. 5 hand collected. 10/21/1989 TF, EJ!

[B39]

102. Opposite White Bird Elementary School (1399). SW/4 SW/4 SE//4 NW/4 sec. 14, T28N R1E, White Bird 1962 quad., Idaho Co. E.-facing talus and outcrops directly opposite White Bird Elementary School. Elev. 1600-1640'. Basalt talus and outcrops; range from open to tree-covered (deciduous); common nettles. Cryptomastix mullani olneyae, Oreohelix vortex, Oreohelix n. sp. 25, Allogona ptychophora ptychophora, and Polygyrella polygyrella. Hand collected. 8/11/1989 TF, EJ, SW. Oreohelix n. sp. 25, Cryptomastix mullani olneyae, Allogona ptychophora ptychophora, Oreohelix vortex, and Polygyrella hand collected. 10/21/1989 TF, EJ! Abundant Oreohelix n. sp. 25; common Cryptomastix mullani olneyae, Allogona ptychophora ptychophora; rare Oreohelix vortex; some Polygyrella polygyrella. Hand collected. 6/1/1990 TF, EJ, SN! Oreohelix n. sp. 25 abundant; common Cryptomastix mullani olneyae, Allogona ptychophora ptychophora; uncommon Oreohelix vortex; some Polygyrella polygyrella. Hand collected. 6/17/1993 TF, EJ! [B39]

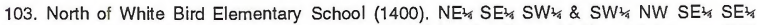
NW' sec. 14, T28N R1E, White Bird 1962 quad., Idaho Co. Steep bluff and talus, ca. 400' NNW of White Bird Elementary School and W. of old US95. Elev. 1600'. Shallow mossy (somewhat trashy) basalt talus at base of steep bluff; partly forested, moist; common Urtica, deciduous trees, raspberries. Presumed Oreohelix vortex site of Berry; claimed type locality. Allogona ptychophora ptychophora, Cryptomastix mullani olneyae, Oreohelix vortex; rarer Oreohelix n. sp. 25, and Polygyrella polygyrella. Hand collected. 6/17/1993 TF, EJ! Common Cryptomastix mullani olneyae, Oreohelix vortex, rarer Oreohelix n. sp. 25, and Polygyrella polygyrella. Hand collected. 10/13/1993 TF, EJ!

[B39]

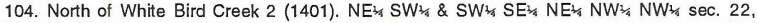
T28N R1E, White Bird 1962 quad., Idaho Co. SW-facing steep talus slope E. of Lyons Bar access road, ca. 0.4 mile N. of mouth of White Bird Creek, E. side of Salmon River. Elev. 1480-1520'. Steep basalt talus slope; Artemisia scrub with rare Celtus; talus mostly open. Common Oreohelix jugalis and Cryptomastix n. sp. 6 hand collected. 9/30/1990 TF, GH! [B39]

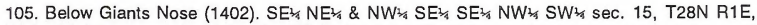
White Bird 1962 quad., Idaho Co. W.-facing talus E. of Lyons Bar access road at base of Giants Nose, E. side of Salmon River at RM 52.7. Elev. 1440'. Dry, open, partly steep basalt talus; grassy; surrounding vegetation Artemisia scrub. Common Oreohelix jugalis. Hand collected. 9/30/1990 TF, GH! [B39]

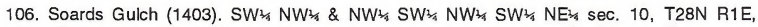
White Bird 1962 quad., Idaho Co. Taluses (N.- and S.-facing) to the E. of Lyons Bar access road on both sides of Soards Gulch, above (E. of) Salmon River at RM 51.3, BLM lands. Elev. 1480-1500'. Metamorphic-granodiorite talus; thin, low, dry, open; grasses, Artemisia scrub above; scattered Celtus, common Rhus diversiloba locally. Abundant Oreohelix vortex, small Cryptomastix harfordiana; Allogona ptychophora ptychophora and some Oreohelix jugalis. Hand collected. 6/1/1990 TF, EJ, SN! [B38]

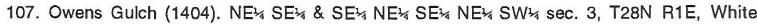
Bird 1962 quad., Idaho Co. W.-facing talus to the E. of Lyons Bar access road on N. side of Owens Gulch, E. of Salmon River at RM 50.5, BLM lands. Elev. 1480'. Schistose phyllite, 
shallow talus; part washout from gulch, part glacial-accentuated talus; open, dry; grasses, scattered Celtus, Rhus diversiloba; Artemisia scrub above. Common Cryptomastix harfordiana, Oreohelix n. sp. 25, and Allogona ptychophora ptychophora. Hand collected. $6 / 1 / 1990 \mathrm{TF}, \mathrm{EJ}, \mathrm{SN!}$ [B38]

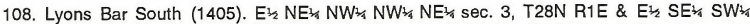
SW/4 SE⿺辶 sec. 34, T29N R1E, White Bird 1962 quad., Idaho Co. W.-facing shallow talus, ca. 0.2 mile S. of S. end, Lyons Bar, above (E. of) Lyons Bar access road, E. of Salmon River at RM 49.8, BLM lands. Elev. 1440-1480'. Shallow metasedimentary talus; dry, open; some grasses, Rhus diversiloba, Celtus. Oreohelix n. sp. 25, Cryptomastix harfordiana, and Allogona ptychophora ptychophora hand collected. 9/30/1990 TF, GH!

[B38]

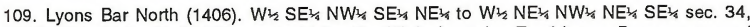
T29N R1E, White Bird 1962 quad., Idaho Co. W.-facing talus E. of Lyons Bar access road from Lyons Bar, N. almost to Shut-in Canyon (0.3 miles), E. of Salmon River, RM 49.0-49.3, BLM lands. Elev. 1480-1520'. Red phyllite outcrops and talus; varies from open to forested; dry to N., moist to S.; Celtus, shrubs. Common odd bandless Oreohelix vortex?; Oreohelix jugalis; Cryptomastix n. sp. 5 and Allogona ptychophora ptychophora. Hand collected. $6 / 1 / 1990$ TF, EJ, SN! Common odd bandless Oreohelix vortex?; Oreohelix jugalis; Cryptomastix n. sp. 5 and Allogona ptychophora ptychophora. Hand collected. 9/30/1990 TF, GH! [B38]

110. Squaw Creek 9 (1407). Center $W_{1 / 2} N^{1 / 4} N_{1 / 4} S^{1 / 4} N_{1 / 4}^{1 / 4}$ sec. 21, T24N R1E, Riggins 1964 quad., Idaho Co. S.-facing talus 0.2 mile up Seven Devils Road (FS517) from junction with US95 on N. side; above irrigation channel, W. of Little Salmon River. Elev. 1860'. Very dry, open basalt talus and alluvium; talus in minor gullies; Artemisia scrub with scattered grasses; very local mosses and Seligeria. Oreohelix intersum hand collected. 10/3/1990 TF, GH! Rare Oreohelix intersum (medium-sized form). Hand collected. 5/31/1990 TF, EJ, SN! [B28]

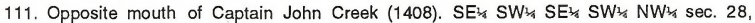
T24N R1E, Riggins 1964 quad., Idaho Co. E.-facing talus W. of US95, ca. road mile 192.9 and opposite mouth of Captain John Creek, W. of Little Salmon River at RM 2.6. Elev. 1940'. Edge (outside) of BLM lands. Moderate-scale basalt talus at base of series of small gullies; mostly open talus but common moss and Seligeria, Rhus diversiloba, lichens. Oreohelix intersum hand collected. 10/2/1990 TF, GH! Uncommon typical (medium-sized) Oreohelix intersum. Hand collected. 5/31/1990 TF, EJ, SN!

[B28]

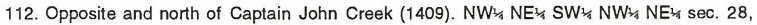
T24N R1E, Riggins 1964 quad., Idaho Co. S.-facing talus N. of US95 at road mile 192.4, base of steep slope and above irrigation channel near pump house, opposite and $\mathrm{N}$. of Captain John Creek, W. of Little Salmon River at RM 2.1. Elev. 1880'. Large-scale basalt talus; grassy; mostly open; occasional Rhus diversiloba. Oreohelix intersum (medium-sized) uncommon. Collected by hand, 5/31/1990 TF, EJ, SN!

[B28]

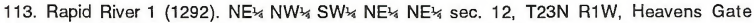
1979 quad., Idaho Co. S.-facing hillside on N. side of Rapid River at lower trail gate, near (SW of) Rapid River Hatchery (Idaho Power), Rapid River Wild and Scenic River. Elev. 2220'. Rocky, steep grassy slope. Most liths limestone, cobble-sized. Scattered Celtus, most cover grass. Slope rather dry and exposed. Large Oreohelix n. sp. 12. Snails locally common. 10/2/1990 TF, GH! Oreohelix n. sp. 12; most 2/3 grown; rare just-hatched juveniles. Snails locally common. 10/11/1993 TF, EJ!

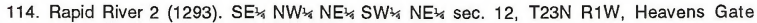
1979 quad., Idaho Co. S.-facing hillside on N. side of Rapid River ca. 0.25 miles SW of lower trail gate, above and below lower trail (not shown on USGS map) near its western terminus and below upper trail (113), Nez Perce National Forest (Rapid River Wild and Scenic River). Elev. 2220'. Rocky, steep grassy slope at base of rock cliff. Most liths limestone, cobble- 
sized. Scattered Celtus, Astragalus, Artemisia; but most cover grass. Slope rather dry and exposed. Two Oreohelix n. sp. 12 and n. sp. 14, Cryptomastix mullani olneyae, and Allogona ptychophora ptychophora hand collected. 10/2/1990 TF, GH! Snails in scattered colonies in most favorable locations. Collected from base of floodplain to cliff base. Two Oreohelix $\mathrm{n}$. $\mathrm{sp}$. (12 \& 14), both in intersum group. Larger with fine ribs, large umbilicus. Smaller almost flat, with produced keel, basal angulation, coarse ribs. Also odd Cryptomastix, Euconulus fulvus subsp., Allogona ptychophora ptychophora. Most submature; some fresh hatched juveniles. 10/11/1993 TF, EJ! [B5]

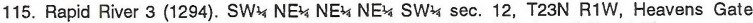
1979 quad., Idaho Co. E.-facing slope above F. S. trail on W. side of Rapid River, ca. 0.1 mile N. of Thorn Gulch, Nez Perce National Forest (Rapid River Wild and Scenic River). Elev. 2220'. Open, rather dry, steep grassy slope with scattered Celtus and Artemisia. Scattered talus patches. Most liths limestone, cobble-sized. Quite dry except very locally. Snails rare; 2 Oreohelix present, one small, keeled (n. sp. 14); second n. sp. 12 (looks more like classic intersum). Hand collected. 10/11/1993 TF, EJ! [B5]

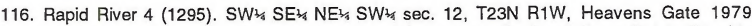
quad., Idaho Co. N. and S. sides of unnamed gulch ca. 0.1 mile S. of Thorn Gulch, W. side of Rapid River above F. S. trail, Nez Perce National Forest (Rapid River Wild and Scenic River). Elev. 2280'. Range from mossy, partly forested talus slopes to dry, grassy, rocky open hillside. Lithology metasedimentary. Snails scattered, locally common. Oreohelix $\mathrm{n}$. $\mathrm{sp} .12$ mostly in drier areas; Cryptomastix (odd morph.) mostly in wetter areas, associated with rare (and dead) Allogona ptychophora ptychophora. Most snails subadult; a few fresh juveniles. 10/11/1993 TF, EJ! [B5]

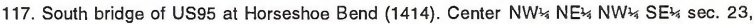
T27N R1E, Slate Creek 1981 quad., Idaho Co. SE-facing boulder pile beneath S. bridge of US95 (road mile 216.5) at Horseshoe Bend on N. side of the Salmon River at RM 64.3. Elev. $1560^{\prime}$. Boulder pile (fluvial, mixed lithologies) over basalt bedrock; open, dry; some grasses; above high water mark. Uncommon Oreohelix jugalis; common dead only on outcrop to SW. Hand collected. 10/28/1989 TF, MF, EJ!

118. Opposite Cooper Bar (1410). $W_{1 / 2}^{1 / 2 E^{1 / 4}} \mathrm{SE}_{1 / 4}^{1 / 4 W^{1 / 4}} \mathrm{SW}_{3 / 4}$ sec. 26, T28N R1E, Slate Creek 1981 quad., Idaho Co. W. to N.-facing shallow talus on S. side of mouth of small gully on $E$. side of US95, opposite Cooper Bar, E. of Salmon River, RM 55.8, BLM lands. Elev. 15201560 . Basalt talus slope at mouth of small gully, very little vegetation; some moss; open and comparatively dry. Common small Cryptomastix n. sp. 5 and Oreohelix vortex in talus. Hand collected. 10/5/1990 TF, GH! [B32]

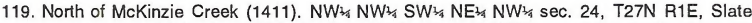
Creek 1981 quad., Idaho Co. SW-facing basalt talus on old US95, ca. 0.2 mile N. of mouth of McKinzie Creek, NE of the Salmon River at Horseshoe Bend, RM 63.3-63.4. Elev. 1560'. Rather thin basalt talus; mostly dry, open; grasses. Moderately common Oreohelix vortex; partly disturbed by road building and road closure (bulldozing). Land snails hand collected. 10/5/1990 TF, GH! [B33]

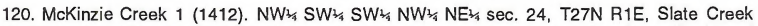
1981 quad., Idaho Co. S.-facing talus ca. 0.2 mile up McKinzie Creek Road, on N. side of creek, N. of the Horseshoe Bend of the Salmon River. Elev. 1720-1760'. Low, open basalt talus; common Celtus; some Rhus diversiloba; generally dry. Moderately common Oreohelix vortex; rarer Allogona ptychophora ptychophora and Cryptomastix n. sp. 5. Hand collected. 10/5/1990 TF, GH! [B33]

121. South of McKinzie Creek (1413). $W_{1 / 2} S_{1 / 4} S_{1 / 4} S^{1 / 4} N_{1 / 4}$ sec. 24, T27N R1E, Slate Creek 1981 quad., Idaho Co. W.-facing talus above (SE of) old US95, ca. 0.3 mile S. of McKinzie Creek and 0.1 mile N. of the mouth of Slippy Creek, SE side of the Salmon River at Horseshoe Bend, RM 63.5, BLM lands. Elev. 1600-1620'. Dry, open basalt talus with almost 
no vegetation. Limited talus; most bladed smooth. Uncommon Oreohelix vortex and Cryptomastix n. sp. 5 in remaining talus. Hand collected. 10/5/1990 TF, GH! [B33]

122. Opposite Russell Bar 1 (1415). SE $E_{1 / 4}^{1 / 4 E^{1 / 4}} S_{W_{1 / 4}} S_{W_{1 / 4}} N_{W_{1 / 4}}$ sec. 23, T27N R1E, Slate Creek 1981 quad., Idaho Co. N.-facing slope ca. 0.5 mile W. of US95 bridge on S. side of Horseshoe Bend Road, opposite E. end of Russell Bar, S. side of Salmon River, RM 61.8. Elev. 1640-1680'. Moist partly wooded slope on W. side of gully. No land snails found. 8/10/1989 TF, MF, EJ! [B33]

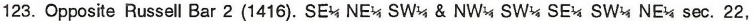
T27N R1E, Slate Creek 1981 quad., Idaho Co. N.-facing slope ca, 1.2 miles W. of US95 bridge on S. side of Horseshoe Bend Road, opposite center of Russell Bar, S. side of Salmon River at RM 61.4-61.5, BLM lands. Elev. 1640-1680'. Moderate slope, mostly grassy; on basalt; rather moist. Area heavily grazed. No snails despite moisture. Hand collection attempted. 8/10/1989 TF, MF, EJ! [B33]

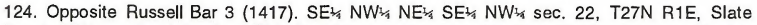
Creek 1981 quad., Idaho Co. NE-facing slope ca. 1.6 miles W. from US95 bridge on S. side of Horseshoe Bend Road, opposite W. end of Russell Bar, S. side of Salmon River RM 61.2, BLM lands. Elev. 1520'. Rocky (basalt) slope and short cliff; very moist and mossy. Road construction impact. No snails. Hand collection attempted. 8/10/1989 TF, MF, EJ! [B33]

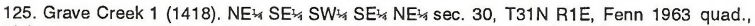
Idaho Co. S.-facing talus at first (upper most) crossing of Grave Creek by Grave Creek Road, W. of road and N. side of creek. Elev. 3080-3120'. Basalt talus; rather dry except basally; scattered Celtus and forbs locally. Uncommon Cryptomastix populi; one Oreohelix n. sp. 25? (immature); Allogona ptychophora solida. Hand collected. 4/24/1994 TF, EJ! [B3]

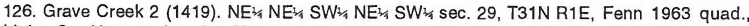
Idaho Co. Unnamed spring N. of Grave Creek, N. side of Grave Creek Road, just over 0.3 road mile W. of Hanley Gulch, N. of Grave Creek. Elev. 2920'. Depth 0-2". Spring not indicated on USGS map. Common Rorippa, mosses in spring runs; several coalescing spring runs with basalt cobbles; grassy and seepy, with Equisetum stands; at sources, Angelica and Celtus. Allogona ptychophora solida, Cryptomastix mullani olneyae, and Vertigo concinnula hand collected. 10/23/1990 TF! Common Allogona ptychophora solida; common Cryptomastix mullani olneyae; 1 Deroceras sp. Physella and sphaeriids in spring. 4/24/1994 TF, EJ! [B3]

127. Hammer Creek Recreation Area. (1471). Center NW/1/4 NW/4 SW/4 sec. 15, T28N R1E, White Bird 1982 quad., Idaho Co. Boulder piles and small talus to W. of Hammer Creek Recreation Area (BLM) access road, ca. 0.2 mi. N. of junction with Hammer Creek Road and $0.1 \mathrm{mi}$. W. of boat launch, W. of Salmon River at RM 52.7. Elev, 1480'. Boulder piles and small-scale talus of mixed lithologies; local bryophytes, Prunus, Populus, Salix, grasses; locally well-shaded. Uncommon Allogona ptychophora ptychophora and Oreohelix jugalis; very rare Cryptomastix n. sp. 6 . Hand collected. Partly destroyed by R.A. modification; some taluses above-high-water-mark talus. 10/22/1993 TF, EJ!

[B39]

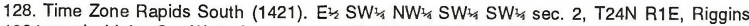
1964 quad., Idaho Co. W.-facing slope on E. side of Salmon River S. of Time Zone Rapids at RM 84.2, BLM lands. Elev. 1720-1740'. Scattered garnet and hornblende schist talus with rare Cystopteris fragilis, some Celtus, rare Lupinus, and mosses. Cryptomastix n. sp. 5 rare scattered in individual taluses. Heavily pastured; probably very dry. Hand collected. 4/25/1994 TF, EJ! [B27]

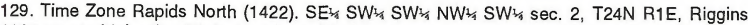
1964 quad., Idaho Co. W.-facing slope, E. side of Salmon River N. of Time Zone Rapids just E. of Riggins Bridge (US95), RM 84.1, BLM lands. Elev. 1720-1800'. Scattered garnet and hornblende schist taluses, rather shallow with Celtus, Cystopteris fragilis, Lupinus. Live 
Cryptomastix n. sp. 5, two long dead Oreohelix idahoensis idahoensis. Hand collected. 4/25/1994 TF, EJ! [B27]

130. Opposite Lightning Creek South (1423). NW/3 SW/4 NW/3 SW/4 sec. 35, T25N R1E, Riggins 1964 quad., Idaho Co. E.-facing talus at mouth and S. of prominent gully on W. side of Salmon River at about RM 83.0, opposite and south of Lightning Creek, BLM lands. Elev. $1760^{\prime}$. Shallow schist (with quartz and tourmaline) talus with abundant Rhus diversiloba, some Celtus, grasses. Pinus ponderosa forest above and below with scattered boulders. Probably very dry in summer. Site grazed. Uncommon Oreohelix n. sp. 21 and Cryptomastix harfordiana. Hand collection. 4/25/1994 TF, EJ!

[B26]

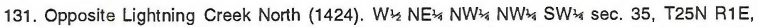
Riggins 1964 quad., Idaho Co. E.-facing talus below S. major gully almost directly opposite Lightning Creek on W. side of Salmon River at RM 82.9, BLM lands. Elev. 1760'. Dry schist talus, rather shallow, with abundant Rhus diversiloba; open Pinus ponderosa forest. Rare Oreohelix n. sp. 21 and Allogona ptychophora ptychophora; common Cryptomastix harfordiana. Hand collected. 4/25/1994 TF, EJ, RM! [B26]

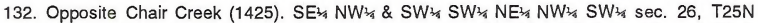
R1E, Riggins 1964 quad., Idaho Co. NE-facing taluses on W. side of Salmon River at Chair Creek Rapids, RM 81.8-81.9, opposite Chair Creek, BLM lands. Elev. 1760-1800'. Thin schist talus; fairly mossy; common Rhus diversiloba, moderately common Celtus, Cystopteris; fairly open. Oreohelix n. sp. 23, Allogona ptychophora ptychophora, and Cryptomastix harfordiana hand collected. 4/25/1994 TF, EJ! [B26]

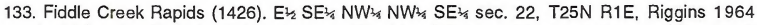
quad., Idaho Co. E.-facing talus slope on W. side of Salmon River between Ladder Creek and Clarks Creek at Fiddle Creek Rapids, RM 80.5, BLM lands. Elev. 1680'. Large schist boulder talus with Rhus diversiloba, Celtus, Cystopteris, and rare Seligeria; probably rather dry. Uncommon Allogona ptychophora solida; Cryptomastix n. sp. 5; Helicodiscus salmoneus. Hand collected. 4/25/1994 TF, EJ! [B26]

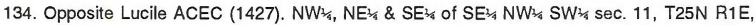
Lucile 1963 quad., Idaho Co. NE-facing limestone slope on W. side of Salmon River opposite BLM ACEC, RM 78.2, BLM lands. Elev. 1640-1680'. Blue limestone boulders piles at and above high water level with Celtus, Artemisia, mosses, grasses; small limestone basal talus and scattered small rock piles with Artemisia. Oreohelix jugalis on lower slope above high-water mark, Oreohelix n. sp. 20 found higher up. Cryptomastix n. sp. 5 in talus to midheight (rare). Hand collected. 4/25/1994 TF, EJ, RM! [B17]

135. Upper Butcher Bar (1428). W/2 SW/4 NW/4 NW/3/4 NW/4 sec. 35, T26N R1E, Lucile 1963 quad., Idaho Co. E.-facing hillside on W. side of Salmon River at Upper Butcher Bar, RM 75.3, BLM lands. Elev. 1680'. Dry exposed hillside, mixed phyllite and limestone with schist to the N.; Artemisia, rare Opuntia; grasses. Uncommon Oreohelix waltoni in small rock piles; Oreohelix jugalis uncommon on lower slope. Hand collected. 4/26/1994 TF, EJ, RM! [B15]

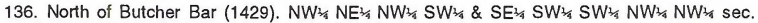
26, T26N R1E, Lucile 1963 quad., Idaho Co. NE-facing slope on W. side of Salmon River, N. of Butcher Bar, opposite Wet Gulch, RM 74.1-74.2, BLM lands. Elev. 1600-1680'. Rocky slope (schistose metasedimentary lithology) with small talus piles; Artemisia, Balsamorhiza, Opuntia, Seligeria, and Cystopteris on N. side. Oreohelix waltoni found higher up the hill in small draw; Oreohelix jugalis, Cryptomastix harfordiana, and rare Helicodiscus salmoneus throughout the site. Hand collected. 4/26/1994 TF, EJ, RM!

[B15]

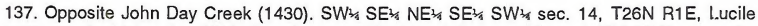
1963 quad., Idaho Co. SE-facing slope on W. side of Salmon River at RM 72.5, opposite John Day Creek.. Elev. 1640-1680'. Slope with pegmatite bedrock; fair amount of Artemisia 
with Seligeria, Opuntia, sparse grasses; dry, very open. Common Oreohelix jugalis, rare Cryptomastix n. sp. 6. Hand collected. Heavily grazed. 4/26/1994 TF, EJ, RM!

138. Below Upper Sherwin Bar (1431). SW $W_{\frac{1}{4}} \mathrm{SW}_{\frac{3}{4}} \mathrm{NW}_{3} \mathrm{NE}_{\frac{1}{4}} \mathrm{NW}_{\frac{1}{4}}$ sec. 13, T26N R1E, Lucile 1963 quad., Idaho Co. SE-facing slope and cliffs on W. side of Salmon River at RM 71.3, ca. 0.25 mile below (S. of) Upper Sherwin Bar. BLM lands. Elev. 1600-1680'. Pegmatite outcrops and thin talus; rather dry; talus with Celtus, Opuntia; some Seligeria. Live-dead Oreohelix jugalis and long-dead Cryptomastix n. sp. 6. Hand collected. 4/26/1994 TF, EJ!

[B14]

139. Opposite Blackhawk Bar (1432). NE $\mathrm{NE}^{\frac{1}{4} / 4} \mathrm{NW}_{\frac{1}{4}} \mathrm{SW}_{\frac{1}{4}} \mathrm{NW}_{1 / 4}$ sec. 2, T26N R1E, Lucile 1963 quad., Idaho Co. NE-facing slope on W. side of Salmon River, opposite Blackhawk Bar, RM 68.3. Elev. 1560'. Metasedimentary shallow talus, mostly large; Seligeria, Cheilanthes, and Cystopteris. Abundant Allogona ptychophora ptychophora (small); some Cryptomastix n. sp. 6; 1 specimen of Oreohelix jugalis. Hand collected. 4/26/1994 TF, EJ! [B14]

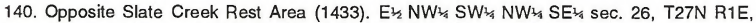
Slate Creek 1981 quad., Idaho Co. E.-facing talus slope on W. side of Salmon River, opposite Slate Creek rest area, RM 65.4, BLM lands. Elev. 1560'. Rather dry and steep basalt talus with Artemisia. Cryptomastix n. sp. 6 and Oreohelix vortex. Hand collected. 4/26/1994 TF, EJ! [B35]

141. Above mouth of Sotin Creek (1434). SE $\mathrm{NE}^{1 / 4} \mathrm{SW}_{\frac{1}{4}} \mathrm{SW}_{1 / 4} \mathrm{NE}_{1 / 4}$ sec. 34, T28N R1E, Slate Creek 1981 quad., Idaho Co. SE-facing slope on W. side of Salmon River above mouth of Sotin Creek, RM 56.8, BLM lands. Elev. 1480'. Steep basalt talus with common Celtus; dry, mostly large cobbles, composite, unstable locally. Uncommon Oreohelix $\mathrm{n}$. $\mathrm{sp}$. 25; Allogona ptychophora ptychophora; Cryptomastix n. sp. 6; Helicodiscus salmoneus; Pupilla hebes; Vallonia; Cochlicopa lubrica generally beneath Celtus in small stable taluses only. Hand collected. 4/26/1994 TF, EJ!

[B32]

142. Northwest of Bracket Gulch (1526). NE/4/4 SW/4 NW/4 NW/4 sec. 27, T28N R1E, Slate Creek 1981 quad., Idaho Co. NE-facing slope, ca. 0.6 mile NW of Bracket Gulch, and above Pittsburg Landing Road (FS493), W. side of Salmon River above mouth of Sotin Creek, ca. RM 54.5, BLM lands. Elev. 1440-1460'. Grassy open slope; dry, scattered Rubus, Celtus, Prunus, grasses; alluvial substrate. Dead Allogona ptychophora ptychophora only; not collected. Impacted by road building. 4/27/1994 TF, EJ!

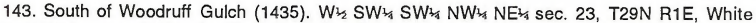
Bird 1962 quad., Idaho Co. W.-facing talus slope S. of Woodruff Gulch on E. side of Salmon River, RM 46.7, BLM lands. Elev. 1460-1480'. Basalt (red) talus slope; thin, dry; Rosa, Rubrus, Rhus diversiloba, Opuntia, and Artemisia. Oreohelix vortex and Cryptomastix harfordiana abundant; Pupilla hebes; Allogona ptychophora ptychophora; Helicodiscus salmoneus. Hand collected. 4/27/1994 TF, EJ!

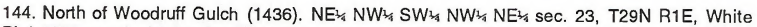
Bird 1962 quad., Idaho Co. W.-facing slope and cliffs N. of Woodruff Gulch on E. side of Salmon River, RM 46.6, BLM lands. Elev. 1440'. Exposed red basalt knobs and thin talus; dry, open, grassy, moist at base; Rhus diversiloba, Celtus, and Artemisia. Oreohelix jugalis and Cryptomastix n. sp. 6 uncommon; rare Allogona ptychophora ptychophora. Hand collected. 4/27/1994 TF, EJ, RM! [B37]

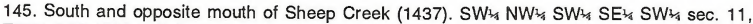
T29N R1E, White Bird 1962 quad., Idaho Co. NE-facing taluses opposite of and 0.25 mile S. of mouth of Sheep Gulch on SW side of Salmon River, RM 45.2, BLM lands. Elev. 1480'. Red rhyolitic basalt taluses about $80^{\prime}$ above river with Rhus diversiloba; diverse bryophyte flora; Sorbus; Artemisia. Uncommon Oreohelix n. sp. 25; common Cryptomastix n. sp. 6 and Allogona ptychophora ptychophora. Hand collected. 4/27/1994 TF, EJ!

[B37] 


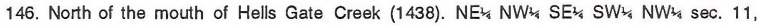
T29N R1E, Fenn 1963 quad., Idaho Co. E.- and NE-facing talus slope below (N. of) mouth of Hells Gate Creek on W. side of Salmon River, RM 43.2, BLM lands. Elev. 1640'. Metamorphic basalt talus, common Rhus diversiloba; Artemisia; Seligeria; Cystopteris; dry, exposed. Oreohelix jugalis, Oreohelix n. sp. 25, Cryptomastix n. sp. 6, Allogona ptychophora ptychophora, and abundant Helicodiscus salmoneus. Hand collected. 4/27/1994 TF, EJ! [B4]

147. Below and east of Devils Garden (1439). $\mathrm{SE}^{\frac{1}{4}} \mathrm{NW}_{1 / 4} \mathrm{NE}_{\frac{1}{4}} \mathrm{SE}_{\frac{1}{4}} \mathrm{NW}_{3 / 4}$ sec. 31, T30N R1E, Moughmer Point 1963 quad., Idaho Co. N.-facing talus slope on S. side of Salmon River below and E. of Devils Garden, RM 39.8, BLM lands. Elev. 1340'. Moist basalt talus with Rhus diversiloba; Celtus; Prunus; bryophytes; probably dry in summer. Allogona ptychophora solida, Oreohelix n. sp. 25, Cryptomastix n. sp. 3, 6, and olneyae. Hand collected. 4/27/1994 TF, EJ! [B23]

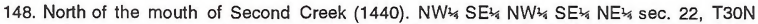
R1W, Moughmer Point 1963 quad., Idaho Co. E.-facing talus slope N. (downstream) of the mouth of Second Creek on W. side of Salmon River at RM 35.3, BLM lands. Elev. 1280'. Dry large cobble-boulder taluses with Rhus diversiloba, some mosses, Seligeria, large Artemisia. Uncommon Oreohelix n. sp. 25, common Allogona ptychophora solida; uncommon Cryptomastix olneyae and n. sp. 6. Hand collected. 4/27/1994 TF, EJ!

[B22]

149. Below Packers Creek (1441). NW/4 NW/4 NW/4 NW/4 NE $W_{1 / 4}^{1 / 4}$ sec. 10, T30N R1W, Moughmer Point 1963 quad., Idaho Co. W.-facing talus slope on E. side of Salmon River at RM 32.8, ca. 0.5 mile downstream from mouth of Packer Creek, BLM lands. Elev. 1280'. Steep basalt talus slope; common Celtus, scattered Balsamorhiza, Rhus diversiloba, Sorbus; rather dry and open, but some Seligeria, mosses, Cystopteris. Common Cryptomastix populi; rare Oreohelix n. sp. 25; rare Allogona ptychophora ptychophora. Hand collected. 4/27/1994 TF, EJ!

[B21]

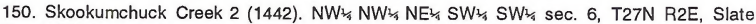
Creek 1981 quad,, Idaho Co. S.-facing talus on N. side of Skookumchuck Creek, N. side of Dairy Mountain Road (FS2025), ca. 0.3 mile SE of Dairy Mountain Road turnoff (junction with Delmadge Ridge Road). Elev. 2040'. Comparatively dry basalt talus, but abundant Rhus diversiloba and scattered Celtus, Prunus, grasses, other shrubs. Abundant Oreohelix n. sp. 25; common Cryptomastix n. sp. 5; uncommon Oreohelix n. sp. 32; uncommon Allogona ptychophora ptychophora. Hand collected. 4/24/1994 TF, EJ! [B34]

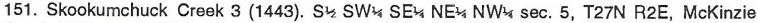
Creek 1963 quad., Idaho Co. S.-facing talus on N. side of Skookumchuck Creek, N. side of Delmadge Ridge Road (FS2025), 1.0-1.3 miles from Dairy Mountain Road turnoff (junction with Dairy Mountain Road) just before stiff sharp turn in road. Elev. 2400'. Very steep basalt talus with Celtus locally. Common Oreohelix n. sp. 25; uncommon Allogona ptychophora ptychophora; common Cryptomastix n. sp. 6. Hand collected. 4/25/1994 TF, EJ! [B18]

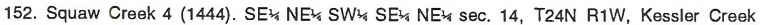
1964 quad., Idaho Co. SE-facing talus N. of Squaw Creek Road (FS487) 0.1 mile E. of junction with Indian Springs Road (FS9901), N. of Squaw Creek, Nez Perce National Forest. Elev. 3800'. Forested (Pinus ponderosa, second growth). Limestone substrate. Uncommon large Oreohelix strigosa n. subsp. 1; rare Allogona ptychophora ptychophora, Cryptomastix mullani mullani. Hand collection. 4/26/1994 TF, EJ! [B12]

153. Squaw Creek 5 (1445). Center NW3 sec. 18, T24N R1E, Kessler Creek 1964 quad., Idaho Co. SE-facing talus slope above Squaw Creek Road (FS487), ca. 2.0 miles E. of intersection with Indian Springs Road (FS9901), N. of Squaw Creek, BLM lands. Elev. 3080'. Steep unstable basalt talus; rather open, dry; some grasses, Sorbus, rare Celtus. No land snails seen. 4/26/1994 TF, EJ!

[B12] 


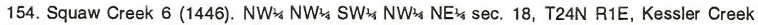
1964 quad., Idaho Co. SE-facing talus slope above Squaw Creek Road (FS487), ca. 2.0 miles E. of intersection with Indian Springs (FS9901), N. of Squaw Creek, partly or entirely on BLM lands. Elev. 3040'. Steep unstable basalt talus; rather open, dry; some grasses, Sorbus, rare Celtus. No land snails seen. 4/26/1994 TF, EJ! [B12]

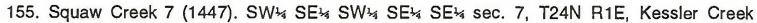
1964 quad., Idaho Co. SE-facing shallow slope on N. side of Squaw Creek Road (FS487), ca. 2.8 miles from junction with Indian Springs Road (FS9901), N. of Squaw Creek. Elev. $2880^{\prime}$. Open dry grassy slope with scattered small basalt talus piles; abundant grasses, some Celtus. No land snails seen. 4/26/1994 TF, EJ! [B12]

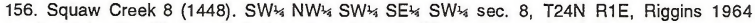
quad., Idaho Co. Shallow S.-facing slope 0.8 mile W. up Squaw Creek Road (FS487) from Seven Devils Road (FS517) turnoff, N. side, N. of Squaw Creek. Elev. 2760'. Open shallow dry grassy slope with small basalt taluses in scattered piles; abundant grasses, rare Celtus, some Rhus diversiloba. Oreohelix n. sp. 8 very rare live, rare dead; Cryptomastix mullani olneyae. Hand collected. 4/26/1994 TF, EJ! [B28]

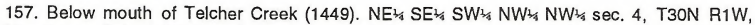
Moughmer Point 1963 quad., Idaho Co. SW-facing talus slope below mouth of Telcher Creek on NE side of Salmon River at RM 31.1, BLM lands. Elev. 1200-1240'. Metasedimentary (nephrite) shallow taluses, fairly exposed; common Prunus, Celtus, Rhus diversiloba, and Rosa. Cryptomastix populi, Allogona ptychophora solida, and Oreohelix n. sp. 25. Hand collected. 4/28/1994 TF, EJ! [B21]

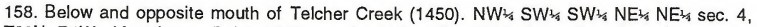
T30N R1W, Moughmer Point 1963 quad., Idaho Co. NE-facing talus slope below and opposite mouth of Telcher Creek on W. side of unnamed gully, S. side of Salmon River at RM 30.8, BLM lands. Elev. 1240-1280'. Nephrite talus with large cobble-boulders. Largely exposed and open, but common Celtus and bryophytes, ninebark, Prunus locally. Common Cryptomastix populi; very rare Oreohelix n. sp. 25 (not collected); common Allogona ptychophora solida; Helicodiscus salmoneus; rare Euconulus fulvus alaskensis; Cryptomastix n. sp. 6. Hand collected. 4/28/1994 TF, EJ! [B21]

159. Below mouth of Mahoney Creek (1527). NW' $\mathrm{SE}_{1 / 4} \mathrm{SW}_{\frac{1 / 4}{4}} \mathrm{SE}_{\frac{1 / 4}{4}} \mathrm{NW}_{\frac{1}{1 / 4}}$ sec. 1, T3ON R2W, Boles 1963 quad., Idaho Co. NE-facing talus on S. side of Salmon River, ca. 0.3 mile above and opposite White House Bar and 0.2 mile below mouth of Mahoney Creek, RM 28.2, BLM lands. Elev. 1320-1360'. Phyllite-nephrite, large cobble-boulder talus; collected in moist mossy, shaded over with Prunus, ninebark, Celtus, diverse bryophytes. Common Allogona ptychophora solida; uncommon Oreohelix n. sp. 25; common Helicodiscus salmoneus; Cryptomastix populi; rare Cryptomastix n. sp. 3. Hand collected. 4/28/1994 TF, EJ! [B2]

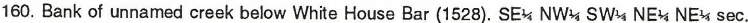
2, T30N R2W, Boles 1963 quad., Idaho Co. Bank of unnamed creek (W. side) just above mouth of canyon, below (W. of) White House Bar, N. side of Salmon River at RM 27.5, BLM lands. Elev. 1240'. Moist permanent creek with Cornus stolonifera; bryophytes; common Celtus; small metasedimentary talus piles. Abundant Cryptomastix populi; common 3toothed flat Cryptomastix n. sp. 3; uncommon Oreohelix n. sp. 25; uncommon Allogona ptychophora solida. Hand collected. 4/28/1994 TF, EJ!

161. Slope above Snow Hole Rapids (1529). N1/2 NE $\mathrm{NE}_{1 / 4}^{1 / 4} \mathrm{SE}_{1 / 4} \mathrm{SE}_{1 / 4}$ sec. 20, T31N R2W, Westlake 1979 quad., Idaho Co. S.-facing slope at mouth of unnamed gully above Snow Hole Rapids, N. side of Salmon River at RM 23.4-23.5, BLM lands. Elev. 1240'. Dry open basalt talus surrounded by granite bedrock; uncommon Rhus diversiloba; Celtus. Common Cryptomastix populi, 3-toothed Cryptomastix n. sp. 3; uncommon Allogona ptychophora ptychophora; rare Oreohelix n. sp. 25. Hand collected. 4/28/1994 TF, EJ! [B36] 


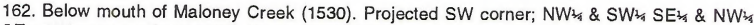
SE $\frac{1 / 4}{4}$ SW sec. 7, T31N R2W, Hoover Point 1967 quad., Lewis Co. S.-facing slope on N. side of Salmon River below (W. of) mouth of Maloney Creek at RM 19.9. Elev. 1200'. Open, heavily grazed granite (hornblende, quartz, feldspar) boulder slope; Artemisia and grasses. Uncommon live Oreohelix; dead Cryptomastix only; long-dead Allogona ptychophora ptychophora (not retained). Hand collected. 4/28/1994 TF, EJ!

[B7]

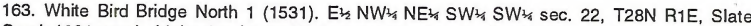
Creek 1981 quad., Idaho Co. Large W.-facing talus slope to $E$. of White Bird Road on E. side of Salmon River, ca. 0.25 mile N. of White Bird Bridge at RM 54.2. Elev. 1680-1720'. Largescale basalt talus slope; dry, open: scattered Celtus, grasses at base; cobble-boulder sized rocks. Moderately common large typical Oreohelix jugalis. Hand collected, 10/21/1989 TF, EJ, SW! Half of the talus has been mined for road material. Shovel present on the site. No Oreohelix jugalis collected. 6/1/1990 TF, EJ, SN! Oreohelix jugalis colony now extinct. Talus completely removed by mining for road material. 10/30/1990 TF, EJ!

164. Skookumchuck Creek 1 (1532). $\mathrm{SE}^{\frac{1}{4}} \mathrm{SE}_{\frac{1}{4}} \mathrm{NW}_{\frac{1}{4}} \mathrm{SE}_{\frac{1}{4}} \mathrm{SE}_{\frac{1}{1 / 4}}$ sec. 1, T27N R1E, Slate Creek 1981 quad., Idaho Co. S.-facing talus to $E$. of prominent unnamed gully on N. side of Dairy Mountain Road (FS2025), ca. 3.0 road miles E. from US95 on Dairy Mountain Road (ca. 2.5 miles from mouth of Skookumchuck Creek) Elev. 2000'. Moderate-sized basalt talus; rather open and dry, but common Rhus diversiloba, grasses, scattered Celtus; Sambucus at base. Abundant Oreohelix vortex. Hand collected. 9/30/1990 TF, GH!

[B34]

165. North of Blackhawk Bar 3 (1533). Center SE $\frac{1 / 4}{4} \mathrm{SE}^{\frac{1}{4}} \mathrm{SE}^{\frac{1}{4} / 4}$ sec. 35, T27N R1E, Slate Creek 1981 quad., Idaho Co. W.-facing cliff and prominent small and steep gully to SE of US95, ca. 9.0 miles N. of Riggins, S. side of the Salmon River at RM 66.9. Elev. 1600-1680'. Mossy schist cliffs and small-scale talus; abundant mosses, some Prunus, Celtus, Cystopteris, grasses. Common small Cryptomastix harfordiana; rarer Allogona ptychophora (not collected); dead Oreohelix n. sp. 21. Hand collected. 10/4/1990 TF, GH!

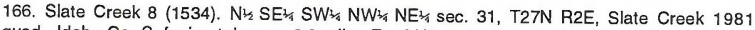
quad., Idaho Co. S.-facing talus ca. 2.0 miles E. of US95 on Slate Creek Road (FS354) (N. of road), N. of Slate Creek. Elev. 1760-1800'. Very dry open, badly pastured shallow red basalt talus; scattered grasses; locally common Celtus. Dead Oreohelix vortex (long-dead) not collected. Extinct colony. 6/2/1990 TF, EJ, SN! [B35]

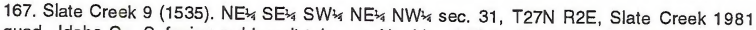
quad., Idaho Co. S.-facing red basalt talus on N. side of Slate Creek Road (FS354), ca. 1.7 miles E. of US95, N. of Slate Creek. Elev. 1720'. Very dry pastured thin red basalt talus, very shallow; common grasses, Balsamorhiza, Artemesia clumps. Very badly pastured; extinct Oreohelix vortex colony (specimens not retained). 6/2/1990 TF, EJ, SN!

[B35]

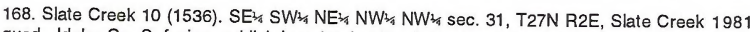
quad., Idaho Co. S.-facing reddish basalt talus N. of Slate Creek Road (FS354), ca. 1.5 miles E. from US95, N. of Slate Creek. Elev. 1680-1720'. Pastured shallow, open and dry grassy reddish basalt talus slope, with common grasses, Artemesia, scattered Celtus, Balsamorhiza. Very badly pastured; extinct Oreohelix vortex colony with long-dead shells only not retained. 6/2/1990 TF, EJ, SN! [B35]

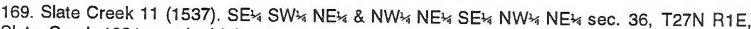
Slate Creek 1981 quad., Idaho Co. S.-facing shallow talus above (N. of) Slate Creek Road (FS354), ca. 1.1 miles E. of US95, N. of Slate Creek. Elev. 1640-1680'. Shallow vescicular basalt (with greenish agate) talus slope; some soil in talus; common Celtus, grasses, some other forbs. Shallow dry talus; extinct Oreohelix vortex colony (shells not retained). 6/2/1990 TF, EJ, SN! [B35] 


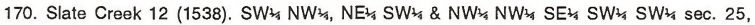
T27N R1E, Slate Creek 1981 quad., Idaho Co. S.-facing slope ca. 0.2-0.3 mile E. off current US95 on old US95 cutoff on N. side, W. of Slate Creek Road (FS354) junction, N. of Slate Creek. Elev. 1640'. Mostly vegetated (grasses, Celtus) shallow-moderately steep dry and open grassy slope with scattered basalt alluvial cobbles. Perhaps too dry and modified by road building. No land snails seen. 6/2/1990 TF, EJ, SN!

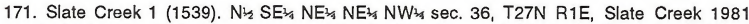
quad., Idaho Co. S.-facing slope ca. 0.7 mile E. off current US95 on Slate Creek Road (FS354) on N. side of road, N. of Slate Creek. Elev. 1600-1640'. Steep vesicular (green agate) basalt talus with admixed soil; common Celtus; some Sorbus; grasses; locally shaded. Common Oreohelix vortex locally; rarer Helicodiscus salmoneus; uncommon Cryptomastix mullani olneyae. Hand collected. 6/2/1990 TF, EJ, SN!

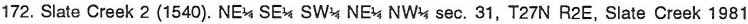
quad., Idaho Co. Talus below Slate Creek Road (FS354), ca. 1.3 road miles E. of US95. Elev. 1680'. Cobble-sized reddish basalt talus with admixed soil; rather open and dry, with little cover other than grasses at top; abundant vegetation at base (edge of floodplain); common Rhus diversiloba, Celtus, forbs. Common Oreohelix vortex; Helicodiscus salmoneus and Allogona ptychophora ptychophora uncommon. Hand collected. 6/2/1990 TF, EJ, SN! [B35]

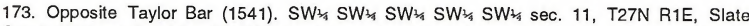
Creek 1981 quad., Idaho Co. W.-facing talus on S. side of unnamed gully opposite of Taylor Bar at the S. end of Campbell Flat, E. side of US95, E. of Salmon River, ca. RM 59.6. Elev. $1560^{\prime}$. Low, small-scale basalt talus, mostly open and grassy. Cryptomastix harfordiana hand collected. 10/5/1990 TF, GH! [B33]

174. North end of Campbell Flat (1542). NE药 SW Creek 1981 quad., Idaho Co. W.-facing talus across from N. end of Campbell Flat on E. side of US95, E. of Salmon River at RM 58.9. Elev. 1540'. Moderately low basalt talus, rather open and dry except at base (grasses, mosses). Oreohelix jugalis, Allogona ptychophora ptychophora, and a few Cryptomastix n. sp. 5 hand collected. 10/5/1990 TF, GH!

[B33]

175. Slate Creek 4 (1543). $\mathrm{N}_{1 / 2} \mathrm{SW}_{\frac{1}{4}}$ \& $\mathrm{N}_{1 / 2} \mathrm{SE}_{\frac{1}{4}} \mathrm{NE}_{\frac{1}{4}} \mathrm{SW}_{\frac{1}{4}} \mathrm{SE}_{\frac{1}{4}}$ sec. 33, T27N R2E, McKinzie Creek 1963 quad., Idaho Co. S.-facing talus above (N. of) Slate Creek Road (FS354), ca. 4.0 mile E. of US95. Elev. 2000'. Rather open schist talus; varies from boulder-cobbles, very open to partly shaded; Celtus, Artemisia, Prunus, Sorbus. Abundant Discus marmorensis; common Oreohelix n. sp. 22; less common Allogona ptychophora ptychophora. Hand collected. 10/4/1990 TF, GH! Oreohelix n. sp. 22, Discus marmorensis, Cryptomastix mullani olneyae, and Allogona ptychophora ptychophora hand collected. 6/17 1993 TF, EJ!

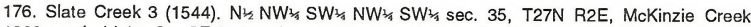
1963 quad., Idaho Co. SE-facing slope below (S. of) Slate Creek Road (FS354) to flood plain of Slate Creek, ca. 5.7 miles from (E. of) US95, Nez Perce National Forest. Elev. 2280'. Wooded steep schist and limestone slope (Pinus ponderosa forest), deep soil, moist. Uncommon Oreohelix strigosa n. subsp. 1, Oreohelix n. sp. 22; Allogona lombardii and ptychophora ptychophora; rare Discus marmorensis; Anguispira kochi occidentalis; Cryptomastix mullani olneyae. hand collected. 6/1/1990 TF, EJ, SN! Rare Oreohelix strigosa n. subsp. 1, Oreohelix n. sp. 22; Allogona lombardii; uncommon Discus marmorensis; Cryptomastix mullani olneyae; Allogona ptychophora ptychophora. Hand collected. 10/4/1990 TF, EJ! [B19]

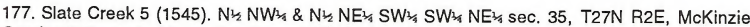
Creek 1963 quad., Idaho Co. S.- and SE-facing slope N. of Slate Creek Road (FS354), ca. 6.2-6.7 miles from US95, Nez Perce National Forest. Elev. 2440'. Very steep and moist wooded limestone slope in Pinus ponderosa forest; abundant forbs, mosses; deciduous understory. Common Oreohelix n. sp. 22; Allogona lombardii rare; Oreohelix strigosa n. 
subsp. 1; very rare Hemphillia sp.; uncommon Discus marmorensis; Cryptomastix mullani olneyae; common Allogona ptychophora ptychophora and large Anguispira kochi occidentalis. Hand collected. 6/1/1990 TF, EJ, SN! Abundant Oreohelix n. sp. 22; rare Allogona lombardii; Oreohelix strigosa n. subsp. 1; very rare Hemphillia sp.; Cryptomastix mullani olneyae; uncommon Discus marmorensis; common Allogona ptychophora ptychophora; abundant large Anguispira kochi occidentalis. Hand collected. Site threatened by limestone quarry (Suzie Q). 10/4/1990 TF, GH! [B19]

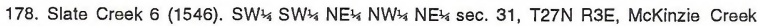
1963 quad., Idaho Co. S.-facing steep slope above (N. of) Slate Creek Road (FS354), ca. 8.7 miles E. from US95 and 0.3 mile W. of North Fork Campground, Nez Perce National Forest. Elev. 2800'. Steep, wooded limestone knob, N. of Slate Creek Road; Pinus ponderosa forest with Linnaea, Cornus canadensis, other forbs. Oreohelix n. sp. 22; Cryptomastix mullani olneyae; Discus marmorensis; Allogona ptychophora ptychophora. Hand collected. 6/1/1990 TF, EJ, SN! Common Oreohelix n. sp. 22; rare Discus marmorensis; Cryptomastix sp., Allogona ptychophora ptychophora, and Anguispira kochi occidentalis hand collected. 10/4/1990 TF, GH! Oreohelix n. sp. 22, Discus marmorensis; Cryptomastix mullani olneyae, Anguispira kochi occidentalis, and Allogona ptychophora ptychophora hand collected. 6/17/1993 TF, EJ!

[B20]

179. Papoose Creek 1 (1547). NW/4 NW/1/4 NW/4 NW/1/4 sec. 25, T24N R1W, Kessler Creek 1964 quad., Idaho Co. Dominantly S.-facing low limestone knob at mouth of gully and base of Papoose Saddle, 5.8 miles NW of US95 on Seven Devils Road (FS517) or about 3.2 miles from Squaw Creek Road junction (FS487), on NW side of road, above Papoose Creek, Nez Perce National Forest. Elev. 4200-4240'. Cut-over low limestone knob in Pinus ponderosa forest; mossy, moist understory with abundant forbs, including Viola. Thin litter (cut over) and rocky soil; common large Oreohelix strigosa n. subsp. 1; uncommon Allogona ptychophora ptychophora; rare Cryptomastix mullani olneyae. Hand collected. 4/25/1994 TF, EJ! [B13]

180. Papoose Creek 3 (1549). W W/ NW/3 SW/4 sec. 27, T24N R1W, Kessler Creek 1964 quad., Idaho Co. Seven Devils Road (FS517), ca. road mile 9.5-10.0 E. from US95, on N. side of road and McClinery Ridge, Nez Perce National Forest. Elev. 5880-5960'. Moist Pinus ponderosa forest (common bryophytes); but very open; logging debris, Rubrus common. Large Oreohelix strigosa n. subsp. 1 rare; very rare Radiodiscus abietum; mostly logged and open. Hand collected. 10/2/1990 TF, GH! [B13]

181. Kessler Creek 1 (1550). NW1/4 SE SW/4 $^{\frac{1}{1 / 4}}$ sec. 36, T25N R1W, Kessler Creek 1964 quad., Idaho Co. Predominantly on S.-facing slope (partly on N.-facing slope) 2.3 miles up Kessler Creek Road (FS410), off Race Creek Road, on limestone knob on both sides of Kessler Creek and road, Nez Perce National Forest. Elev. 4000-4200'. Pinus ponderosa forest (partly logged), on limestone knob surrounded by basalt (E.) and schist (W.) on both sides of road and flanking Kessler Creek floodplain. Abundant large Oreohelix strigosa goniogyra or related species, on limestone only, mostly in unlogged area. Hand collected. 10/2/1990 TF, GH! [B12]

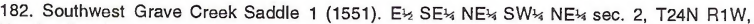
Kessler Creek 1964 quad., Idaho Co. Predominantly S.-facing open area on Grave Creek Road (FS2052), ca. 2.5 miles W. of origin, near crossing of Grave Creek Trail, SW ca. 0.5 mile from Grave Creek Saddle, high above Grave Creek on N. side, Nez Perce National Forest. Elev. 4680'. Schist outcrops; open Pinus ponderosa forest. Oreohelix strigosa goniogyra only live near road (abundant) and outcrops. Millions of dead shells in adjacent logged areas; none live there. Hand collected. 10/3/1990 TF, GH! [B12]

183. Southwest Grave Creek Saddle 2 (1552). SW $W_{1 / 4} N^{1 / 4} N^{1 / 4} W_{1 / 4} N^{1 / 4}$ sec. 2, T24N R1W, Kessler Creek 1964 quad., Idaho Co. Mostly SW-facing schist outcrops along Grave Creek Road (FS2052), W. of Grave Creek Trail, ca. 0.7 mi. SW of Grave Creek Saddle, ca. 2.8 miles from Kessler Creek Road, high above Grave Creek on N. side, Nez Perce National Forest. Elev. 4720'. Schist outcrops, formerly moist Pinus ponderosa forest (now logged). 
Common Oreohelix strigosa goniogyra along road on outcrops; dead shells only in logged and burned areas. Hand collected. 10/3/1990 TF, GH!

[B12]

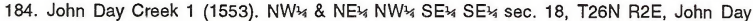
Mtn. 1963 quad., Idaho Co. NW-S.-facing talus 2.7 miles up John Day Creek Road E. from US95; prominent limestone outcrop to $\mathrm{N}$. of road Elev. 2560-2680'. Type locality for Oreohelix haydeni hesperia. Large, mostly open limestone talus (cobble-sized) and outcrops just E. of gully; common grasses, Celtus; soil common in talus. Very common live and dead shells of Oreohelix haydeni hesperia. Hand collected. 8/11/1989 TF, EJ, SW! Oreohelix haydeni hesperia and Allogona ptychophora ptychophora hand collected. 5/31/1990.

[B8]

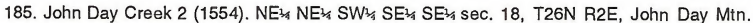
1963 quad., Idaho Co. SE-facing gully about 2.6 miles up John Day Creek Road from US95, on N. side of road and creek. Elev. 2560-2680'. Type locality of Cryptomastix mullani latilabris. Limestone cobble-gravel talus in gully; mostly Celtus scrub; dry, leaf-covered. Uncommon live Cryptomastix mullani latilabris, common Oreohelix haydeni hesperia, Pristiloma, etc. Hand and litter sampled. 8/11/1989 TF, EJ, SW! Cryptomastix mullani latilabris and Oreohelix haydeni hesperia hand collected. 10/1/1990 TF! Oreohelix haydeni hesperia and Cryptomastix mullani latilabris hand collected. 10/17/1993 TF, EJ!

[B8]

186. John Day Creek 3 (1555). Center NW'/4 SE SW/4 sec. 18, T26N R2E, Lucile 1963 quad., Idaho Co. S.-facing talus 1.95 miles up John Day Creek Road from US95, on N. side of road, ca. 0.1 mile from cluster of houses. Elev. 2240-2280'. Type locality of Oreohelix waltoni. Low basalt talus, badly pastured below, with common Celtus, grasses; mostly open and dry, cut by cow paths. No Oreohelix waltoni found in lower talus. 8/11/1989 TF, EJ, SW! Oreohelix jugalis rare in base; Allogona ptychophora ptychophora uncommon; heavily pastured; no Oreohelix waltoni obvious. Hand collected. 6/1/1990 TF, EJ, SN! Lower talus examined, no Oreohelix waltoni. 10/3/1990 TF! Oreohelix jugalis rare in base to upper talus; Allogona ptychophora ptychophora uncommon; rare live (juveniles only, not retained) and dead Oreohelix waltoni in upper talus; Cryptomastix mullani latilabris. Hand collected. 10/17/1993 TF, EJ! [B14]

187. Box Canyon (1556). SE $\mathrm{SE}^{\frac{1}{4}} \mathrm{SE}^{\frac{1 / 4}{4}} \mathrm{SW}^{\frac{1}{4}} \mathrm{SE}^{\frac{1}{4}} \mathrm{NE}^{1 / 4} \mathrm{sec}$. 2, T26N R1E, Lucile 1963 quad., Idaho Co. SW-facing small seep in gully in Box Canyon, N. of US95 at road mile 211.7, N. side of Salmon River, RM 69.05, BLM lands. Elev. 1800-1840'. Shallow seepy area with common Celtus below, dry and open above, surrounded by cliffs NW and SW; metasedimentary rocks, schist. Common Oreohelix waltoni, Oreohelix n. sp. 21 locally in small area; common Pupilla hebes, Vallonia cylophorella, etc. in litter; uncommon Cryptomastix harfordiana; most of the talus removed by road construction. Hand and litter sampled. 6/1/1990 TF, EJ, SN!

[B14]

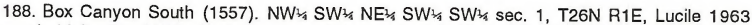
quad., Idaho Co. SW-facing very steep cliff opposite RM 69.4, NE side of Salmon River near geological marker, NE of US95, BLM lands. Elev. 1600'. Small very steep gully in metasedimentary cliff face, very open and dry, very limited talus; grasses only. Very rare Oreohelix n. sp. 21 and Cryptomastix n. sp. 5; most talus removed by road building. Hand collected. 8/11/1989 TF, EJ, SW! [B14]

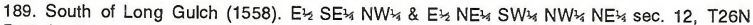
R1E, Lucile 1963 quad., Idaho Co. W.-facing slope on old US95 cutoff ca. 0.4 mile S. of Long Gulch and 0.2 mile N. of present US95; approximately RM 69.9. Elev. 1640'. Alluvium over granite; sandy, mostly grasses; some Celtus, Artemisia, Balsamorhiza; thin, dry soil. No land snails seen. 6/1/1990 TF, EJ, SN!

[B14]

190. Opposite John Day Bar (1559). Center NW/4 NW/4 NE'/4 sec. 23, T26N R1E, Lucile 1963 quad., Idaho Co. W.-facing slope to E. of US95 and ca. 0.2 mile S. of mouth of John Day Creek, opposite John Day Bar on E. side of Salmon River at RM 72.8. Elev. 1600-1680'. 
Celtus stand in alluvium, shaded and moist. Common Allogona ptychophora ptychophora; uncommon Oreohelix jugalis. Hand collected. 8/11/1989 TF, EJ, SW! [B14]

191. South of Rice Creek Bridge (1560). Es/2 NW/3/4 NW/4 NW/1/4 SW/4 sec. 25, T30N R1W, Moughmer Point 1963 quad., Idaho Co. Level area ca. 0.1 mile S. of Rice Creek Bridge on E. side of Rice Creek Road, E. of Salmon River, RM 37.6. Elev. 1320'. Bridge also called Boles Bridge. Nearly level grassy area and shallow basalt talus below (W. of road; mostly grasses, scattered basalt boulders. Common Oreohelix n. sp. 25, Cryptomastix n. sp. 3, and Allogona ptychophora ptychophora. Hand collected. 9/29/1990 TF, GH!

192. Berg Bar South (1561). NW/4 NW/3/4 SW/4 SE//4 sec. 18, T24N R2E, Riggins 1964 quad., Idaho Co. N.-facing steep hillside on S. end of Berg Bar and W. of shallow knob, S. side of French Creek Road (Idaho Co. 1614), S. side of Salmon River (River of No Return), RM 90.1. Elev. 1800-1840'. Grassy slope developed on schist talus. Moderately common Oreohelix n. sp. 15; uncommon Allogona ptychophora ptychophora (not collected) and Cryptomastix mullani clappi. Hand collected. 5/31/1990 TF, EJ, SN! Rare Oreohelix n. sp. 15, rare live Cryptomastix mullani clappi, and Allogona ptychophora ptychophora. Hand collected. 10/3/1990 TF, GH! [B29]

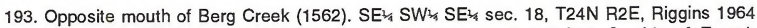
quad., Idaho Co. N.-facing spring slope to E. of campground and bar, S. side of French Creek Road (Idaho Co. 1614) at road mile 4.1-4.3, on E. side of low knob, S. side of Salmon River (River of No Return), RM 90.3-90.5. Elev. 1800-1840'. Partly consolidated schist talus; very moist with weakly distinct springs; grasses, deciduous trees, good understory; local landslides. Oreohelix n. sp. 15 uncommon live; dead only Cryptomastix mullani clappi (not retained). Hand collected. No aquatic mollusks found in the springs. 8/11/1989 TF, EJ, SW! Oreohelix n. sp. 15; Cryptomastix mullani clappi, dead (not retained); uncommon Allogona ptychophora ptychophora (not retained). Hand collected. 5/31/1990 TF, EJ, SN!

[B29]

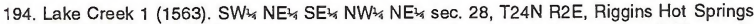
1964 quad., Idaho Co. N.-facing slope approximately 0.4 mile S. of Lake Creek Bridge to S. up Lake Creek. Elev. 2000'. Partly wooded slope with large granite and metasedimentary boulders. Single Oreohelix n. sp. 15; Allogona ptychophora rare; 1 odd small Oreohelix sp.; rare Cryptomastix mullani clappi. Hand collected. 10/3/1990 TF, GH! [B30]

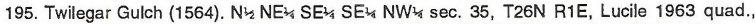
Idaho Co. Ca. 0.6 mile up Twilegar Gulch Road E. from US95, in main gully for Twilegar Gulch. Elev. 1960-2040'. Oreohelix haydeni perplexa type locality. Exposed limestone outcrops and small talus piles in Artemisia scrub, Twilegar Gulch below prominent limestone ledges and exposures. Oreohelix haydeni perplexa live only in small area on S. side of main gulch and surrounding Artemisia scrub; dead over much of $\mathrm{SE}^{-3} \mathrm{sec}$. 35. Abundant dead, rare live Oreohelix haydeni perplexa; Cryptomastix n. sp. 5. Hand collected. 8/10/1989 TF, EJ, SW! Oreohelix haydeni perplexa and live Cryptomastix n. sp. 5 hand collected. 6/1/1990 TF, EJ, SN! Oreohelix haydeni perplexa rarely live, most dead; one sclariform. Hand collected. 10/1/1990 TF, GH! [B15]

196. West side of White Bird Creek bridge (1420). N $\mathrm{N}_{2} \mathrm{NW}_{1 / 4} \mathrm{NW}_{3 / 4} \mathrm{SW}_{1 / 4} \mathrm{NE}^{\frac{1}{4}} \mathrm{sec}$. 22, T28N R1E, White Bird 1982 quad., Idaho Co. S.-facing talus slope and exposures above White Bird Creek just W. of bridge and above Lyons Bar access road. Elev. 520'. Basalt exposures and small talus piles; mostly grasses with scattered Celtus; mostly open and dry. Uncommon Oreohelix vortex; grazing impact. Hand collected. 10/5/1990 TF, GH! [B39]

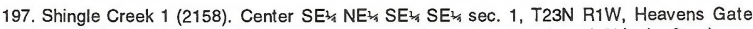
1979 quad. Idaho Co. N.-facing basalt outcrops and forest on S. side of Shingle Creek, ca. $0.2 \mathrm{mi}$. NW of mouth and $0.1 \mathrm{mi}$. from old DeVaney Place (now owned by State of Idaho). Elev. 2280'. Basalt cliff, rare talus, and forested outcrops; fairly well-shaded but disturbed forest with common deciduous understory plants. Collected along ca. 300' of road. Common small Oreohelix n. sp. 19, abundant Cryptomastix mullani olneyae; common Allogona 
ptychophora ptychophora. Hand collected. 5/31/1990 TF, EJ, SN! Abundant Cryptomastix mullani olneyae; common Allogona ptychophora ptychophora and Oreohelix jugalis. Hand collected. 10/3/1990 TF, GH! [B5]

198. East-facing slope at mouth of Rapid River (2159). SE1/4 NE1/4 SE T24N R1E, Pollock 1979 quad., Idaho Co. Steep S. and E.facing slope above junction (NW) of Rapid River Road (FS2114) and US95 near mouth of Rapid River. Elev. 2000-2040'. Sandy, exposed slope with basalt outcrop, alluvium; mostly grasses, with scattered Celtus; mostly dry and open, but seepy in spring. Common local Oreohelix n. sp. 19; rare dead Allogona ptychophora ptychophora (not retained). Site has been grazed. Hand collected. 5/31/1990 TF, EJ, SN! [B24]

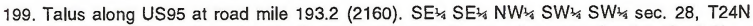
R1E, Riggins 1964 quad., Idaho Co. E.-facing talus on S. side of unnamed gulch N. of Alum Gulch, W. of US95 at road mile 193.2; opposite Little Salmon River at RM 3.0. Elev. 1920'. Basalt cobble-boulder talus with Rhus diversiloba, Sorbus; grasses at base and sides; rare Seligeria, bryophytes. Uncommon large Oreohelix n. sp. 13; heavily grazed; most talus mined for road fill. Snails hand collected. 10/20/1989 TF, EJ! [B28]

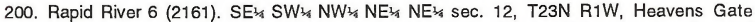
1979 quad., Idaho Co. E.-facing gully on trail switchback, ca. $0.1 \mathrm{mi}$. W. from gate in back of Rapid River Fish Hatchery (upstream), Nez Perce National Forest (Rapid River Wild and Scenic River). Elev. 2240-2280'. Open, dry, grassy; scattered Celtus and wood debris; mostly weathered bluish schist, limestone pebbles and cobbles. Very common large Oreohelix $\mathrm{n}$. sp. 13; site formerly grazed. Snails hand collected. 10/2/1990 TF, GH!

201. Rapid River 7 (2162). SE-1/4 SW 1979 quad., Idaho Co. Shallow S.-facing shallow gully ca. 0.2 mi. W. of gate in back of Rapid River Hatchery (upstream) and ca. 120' above Rapid River, Nez Perce National Forest (Rapid River Wild and Scenic River). Elev. 2320'. Grassy gully with common Celtus and large wood and metal debris; scattered schist with common limestone cobbles; rather open and dry. Grazed; locally abundant large Oreohelix n. sp. 13. Hand collected. 10/2/1990 TF, GH! [B5]

202. Sheep Gulch-lowermost 1.0 mile (2163). Projected from SE corner; N1/2 NE⿺辶/ SW/4 to $\mathrm{NW}^{\frac{1}{4}} \mathrm{NE}^{\frac{1}{4}} \mathrm{SE}_{1 / 4} \mathrm{NE}_{\frac{1}{1 / 4}} \mathrm{SE}_{1 / 4}$ sec. 2, T25N R1E, Lucile 1963 quad., Idaho Co. N.-facing steep limestone slope on S. side of Sheep Gulch, ca. 0.7-1.0 mi. E. from US95. Elev. 2120-2200'. Steep limestone slope and slope base; mostly open, dry, with grasses; weathered blue schist below; limestone outcrops above. Rare live and dead Oreohelix idahoensis idahoensis in 0.70.9 mi. from US95; Oreohelix n. sp. 20 in next 0.1 mi. All hand collected. 10/1/1990 TF, GH! [B17]

203. Lower site of unnamed gulch between Sheep and Twiligar Gulch (2164). NW/4 SW $\mathrm{SW}_{3 / 4} \mathrm{NW}_{3 / 4} \mathrm{SE}_{1 / 4}$ sec. 35, T26N R1E, Lucile 1963 quad., Idaho Co. Small N.-S. gully on N. side of unnamed gulch between Sheep and Twiligar Gulch, ca. $1.2 \mathrm{rd}$. mi. from US95, before 1 st road crossing of gulch. Elev. 2080-2100'. Small-scale limestone outcrops and very minor talus, mostly E.-facing; grasses, Artemesia, scattered Celtus, Opuntia; open and dry. Uncommon Oreohelix n. sp. 20; live only in rocky areas; long-dead shells for considerable area but this now heavily grazed. Snails hand collected. 10/1/1990 TF, GH! [B15]

204. Upper site of unnamed gulch between Sheep and Twilegar Gulch (2165). SW $\mathrm{NW}_{1 / 4} \mathrm{SE}^{\frac{1}{4}} \mathrm{SE}_{\frac{1}{4}}$ sec. 35, T26N R1E, Lucile 1963 quad., Idaho Co. Head of S. branch of unnamed gulch between Sheep and Twiligar Gulch, starting at 2nd road crossing of gulch (highest), ca. $2.0 \mathrm{rd}$. mi. from US95. Elev. 2360-2580'. Steep slope with mixed deeply weathered schist and limestone bedrock exposure; very open and dry; mostly grasses, small Artemesia. Oreohelix n. sp. 20 long dead only; not collected; large area walked in detail without in finding live specimens; heavily grazed. 10/1/1990 TF, GH! [B15]
[B. 


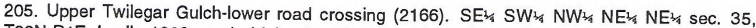
T26N R1E, Lucile 1963 quad., Idaho Co. First (lower) road crossing of upper Twilegar Gulch, ca. 2.5 mi. off US95. Elev. 2680'. Mostly W.-facing, shallow gullies with limestone cobbles, boulders; some alluvium; mostly open, dry, grasses. No mollusks; heavily grazed. 10/1/1990 TF, GH!

[B15]

206. Upper Twilegar Gulch-upper road crossing (2167). NW/1/4 NW/3/4 SW/4 NW/3/4 NW/3 sec. 36 , T26N R1E, Lucile 1963 quad., Idaho Co. Upper Twilegar Gulch at upper road crossing, ca. $3.4 \mathrm{mi}$. off US95, State of Idaho lands. Elev. 3000'. Mostly W.-facing limestone slope and minor talus; open, grassy, dry; some Celtus, Artemesia. Rare Oreohelix n. sp. 20; grazed. Hand collected. 10/1/1990 TF, GH!

[B15]

207. Lucile Caves ACEC-North of mouth of Crawford Creek (2168). NE//4 SE1/4 SW/1/4 to NW/3/4 $\mathrm{SE}_{1 / 4} \mathrm{SE}_{1 / 4} \mathrm{SW}_{3 / 4} \mathrm{SE}^{\frac{1}{4}}$ sec. 11, T25N R1E, Lucile 1963 quad., Idaho Co. Just E. of US95 and $0.1 \mathrm{mi}$. NW of Crawford Creek, beginning near cliff base and extending $0.2 \mathrm{mi}$. E., Lucile Caves ACEC (BLM lands). Elev. 1680-1800'. Limestone cliff base (W.-facing), partly shaded and wooded, to shallow, rather open and dry limestone outcrop with Sorbus; Artemesia, and grasses. Common but very local Oreohelix idahoensis idahoensis. Hand collected. 10/1/1990 TF, GH! [B17]

208. Lucile Caves ACEC-1.4 miles south of Lucile (2169). E⿰氵 $\mathrm{SE}^{\frac{1}{4}} \mathrm{NW}^{\frac{1}{4}} \mathrm{NE}^{\frac{1}{4}} \mathrm{SW}_{\frac{1}{4}} \mathrm{sec} .11$, T25N R1E, Lucile 1963 quad., Idaho Co. Short limestone cliff E. of US95 and $1.4 \mathrm{mi}$. S. of Lucile turnoff, Lucile Caves ACEC (BLM lands). Elev. 1720-1760'. Short limestone cliff with minor talus; mostly bedrock, dry, grassy, open; some Sorbus, Rubus, Rhus diversiloba. Common long-dead and recently dead Oreohelix idahoensis idahoensis. 8/10/1989 TF, MF, EJ! [B17]

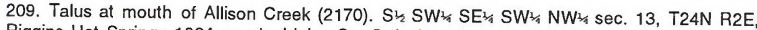
Riggins Hot Springs 1964 quad., Idaho Co. S.-facing, dry, open granite talus on N. side of Allison Creek and FS221, ca. 0.2 mi. NW of Allison Creek Campground. Elev. 1940-2000'. Dry, open granite outcrops and talus with grasses, uncommon Celtus and Opuntia. Rare Oreohelix jugalis hand collected. 10/3/1990 TF, GH! [B31]

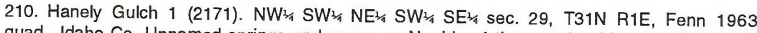
quad., Idaho Co. Unnamed springs and seeps on N. side of the mouth of Hanley Gulch, NE side of Grave Creek Road. Elev. 2840'. Depth 0-2". Small cold springs and seeps, varies from open to Rorippa covered with scattered Mimulus. Spring not indicated on USGS map. Allogona ptychophora ptychophora and Vertigo concinnula hand collected off vegetation in seeps. 9/29/1990 TF, GH! Rare Allogona ptychophora solida, Allogona ptychophora ptychophora, Cryptomastix mullani mullani, and Deroceras sp. on vegetation in seeps. Physella in seeps and springs. All hand collected. 4/24/1994 TF, EJ! [B3]

211. Springs northeast of French Creek (1472). Center SW Kelly Mountain 1964 quad., Idaho Co. Unnamed springs northeast of the town of French Creek, S. side of the Salmon River (River of No Return) and French Creek Road (Idaho 1614). Elev. 1960-1980'. Two small cold springs and associated seeps; N.-facing, partly wooded, grasses and bryophytes locally; mostly muddy substrate. Springs not shown on USGS map. Cryptomastix mullani clappi hand collected. 8/10/1989 TF, EJ! [B11]

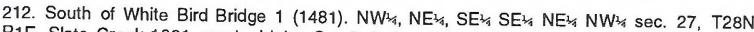
R1E, Slate Creek 1981 quad., Idaho Co. S.-facing Artemisia slope and red basalt talus in small ravine on $\mathrm{N}$. side of road to White Bird, ca. 0.5 mile S. of White Bird Bridge, $\mathrm{W}$. of US95, S. side of Salmon River at RM 54.9, BLM lands. Elev. 1560'. Dry Artemisia scrub; red pumicy basalt. Dry and heavily grazed. No land snails found. 10/22/1993 TF, EJ! S
[B32]

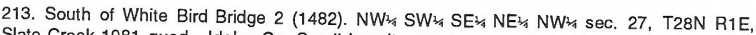
Slate Creek 1981 quad., Idaho Co. Small basalt promontory and flanking ravines below (S. 
side of) road to White Bird, ca. 0.4 mile S. of White Bird Bridge, W. of US95, S. side of Salmon River at RM 54.8, BLM lands. Elev. 1520'. Rocky (basalt) open ridge and steep ravines, mostly S.-facing; Artemisia scrub, some Celtus, Rhus in ravines. Rare live and longdead Oreohelix jugalis. Hand collected. 10/22/1993 TF, EJ! [B32]

Southeastern slope of Mount Sampson (2157). NE//4 sec. 22, T23N R1W, Heavens Gate 1979 quad., Idaho Co. Loose rock of a knife-edge rock outcrop on the southeastern slope of Mount Sampson, Seven Devils Mountains, Nez Perce National Forest. Elev. ca. 5500'. Carinate form in broken limestone outcrop. Pseudotsuga menziesii, Pinus ponderosa, Balsamorhiza, Physocarpus capitatus, Mertensia platyphylla, glacier lily. Oreohelix hammeri type locality. Most found on east slope. Found with estivation membrane, without and crawling mostly under rocks (not deep). 7/1982 William P. Hammer! [B6] 


\section{APPENDIX B. SITE MAPS.}

Maps of localities visited during this survey. Base map derived from appropriate USCS $7.5^{\prime}$ topographic series and at same scale $(1: 24,000)$. For overall view, compare with with Figure 1. Black dots (or star in the case of Oreohelix hammeri, not collected but occurring in the area) indicate site locations: for details see Appendix A. For species maps, see Appendix C. For site listing by taxon, see Table 4.

\begin{tabular}{|c|c|c|}
\hline QUADRANGLE & SITES & MAP \\
\hline Boles & $159 \quad 160$ & B2 \\
\hline Fenn & $\begin{array}{llll}87 & 125 & 126 & 210\end{array}$ & B3 \\
\hline Fenn & $78-82 \quad 146$ & B4 \\
\hline Heavens Gate & $113-116 \quad 197 \quad 200 \quad 201$ & B5 \\
\hline Heavens Gate & O. hammeri type locality (unnumbered) & B6 \\
\hline Hoover Point & 162 & B7 \\
\hline John Day Mtn. & $43-48 \quad 184 \quad 185$ & B8 \\
\hline John Day Mtn. & 60 & $\mathrm{Bg}$ \\
\hline Kelly Mountain & $22-25$ & B10 \\
\hline Kelly Mountain & $\begin{array}{llll}26 & 92 & 93 & 211\end{array}$ & B11 \\
\hline Kessler Creek & $\begin{array}{llll}56 & 57 & 152-155 & 181-183\end{array}$ & B 12 \\
\hline Kelssler Creek & $179 \quad 180$ & B13 \\
\hline Lucile & $36-40 \quad 49 \quad 137-139 \quad 186-190$ & B14 \\
\hline Lucile & $\begin{array}{lllllll}29-33 & 59 & 64 & 135 & 136 & 195 & 203-206\end{array}$ & B15 \\
\hline Lucile & 61.63 & B16 \\
\hline Lucile & $\begin{array}{llllllllll}27 & 28 & 34 & 35 & 50-55 & 72-77 & 134 & 202 & 207 & 208\end{array}$ & B17 \\
\hline McKinzie & 151 & B18 \\
\hline McKinzie & $175-177$ & B19 \\
\hline McKinzie & 178 & $\mathrm{~B} 20$ \\
\hline Moughmer Point & $\begin{array}{lll}149 & 157 \quad 158\end{array}$ & B21 \\
\hline Moughmer Point & $84-86148$ & $\mathrm{~B} 22$ \\
\hline Moughmer Point & $\begin{array}{lll}83 & 147 & 191\end{array}$ & $\mathrm{~B} 23$ \\
\hline Pollock & 198 & $\mathrm{~B} 24$ \\
\hline Rattlesnake Point & 88.90 & B25 \\
\hline Riggins & 4-11 $91 \quad 97 \quad 130-133$ & B26 \\
\hline Riggins & $\begin{array}{lllll}1-3 & 16 & 94-96 & 128 & 129\end{array}$ & $\mathrm{~B} 27$ \\
\hline Riggins & $110-112 \quad 156 \quad 199$ & $\mathrm{~B} 28$ \\
\hline Riggins & $\begin{array}{llll}17 & 18 & 192 & 193\end{array}$ & B29 \\
\hline Riggins Hot Springs & $19-21 \quad 194$ & B30 \\
\hline Riggins Hot Springs & 209 & B31 \\
\hline Slate Creek & $\begin{array}{llllllll}67 & 68 & 118 & 141 & 142 & 163 & 212 & 213\end{array}$ & B32 \\
\hline Slate Creek & $\begin{array}{lllll}65-71 & 117 & 119-124 & 173 & 174\end{array}$ & B33 \\
\hline Slate Creek & 150164 & B34 \\
\hline Slate Creek & $\begin{array}{llll}41 & 42 & 140 & 165-172\end{array}$ & B35 \\
\hline Westlake & 161 & B36 \\
\hline White Bird & $143-145$ & B37 \\
\hline White Bird & $106-109$ & B38 \\
\hline White Bird & $12-15 \quad 98-105 \quad 127 \quad 196$ & B39 \\
\hline
\end{tabular}




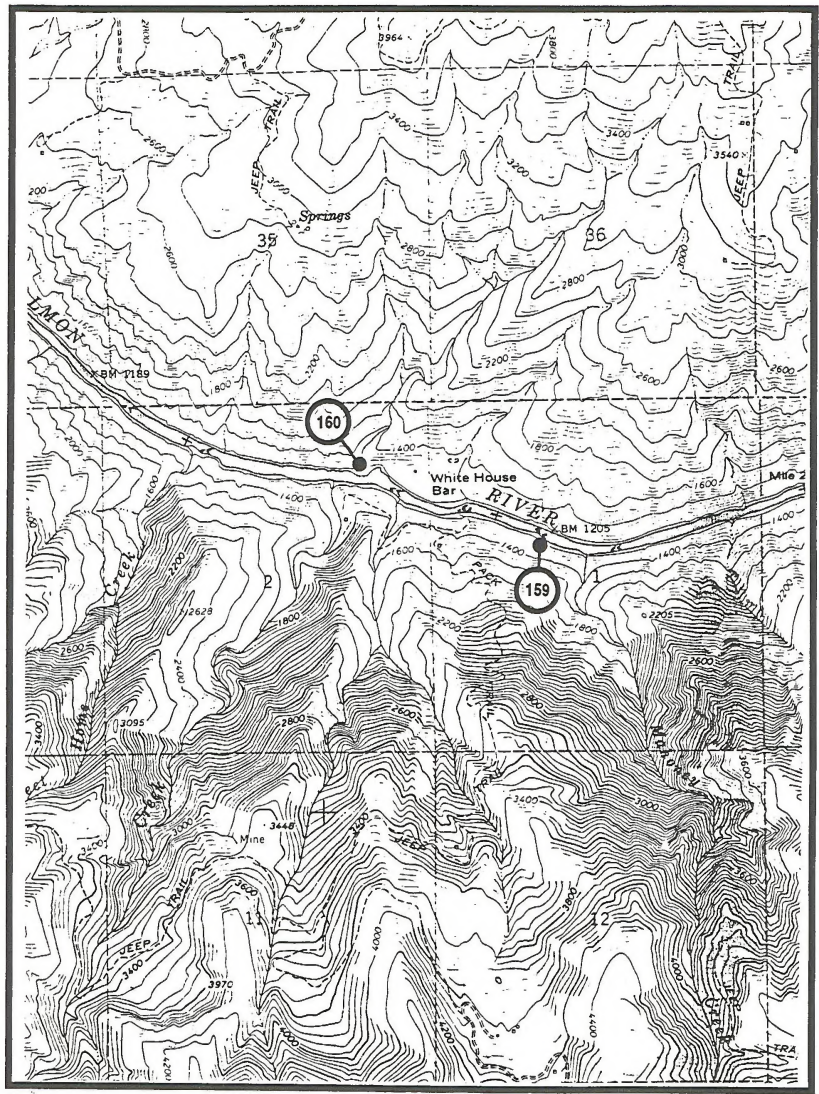

BOLES QUADRANGLE, IDAHO CO., ID

SITES 159,160 


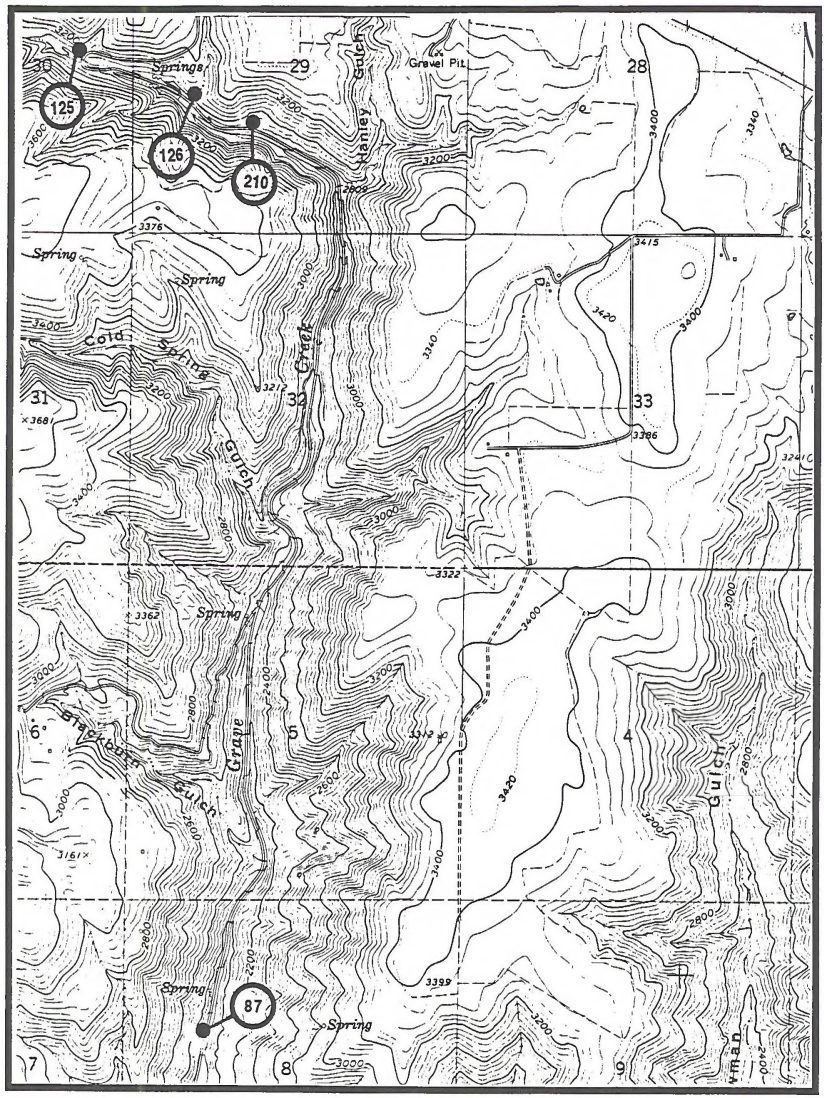

FENN QUADRANGLE, IDAHO CO., ID

SITES $87,125,126,210$ 


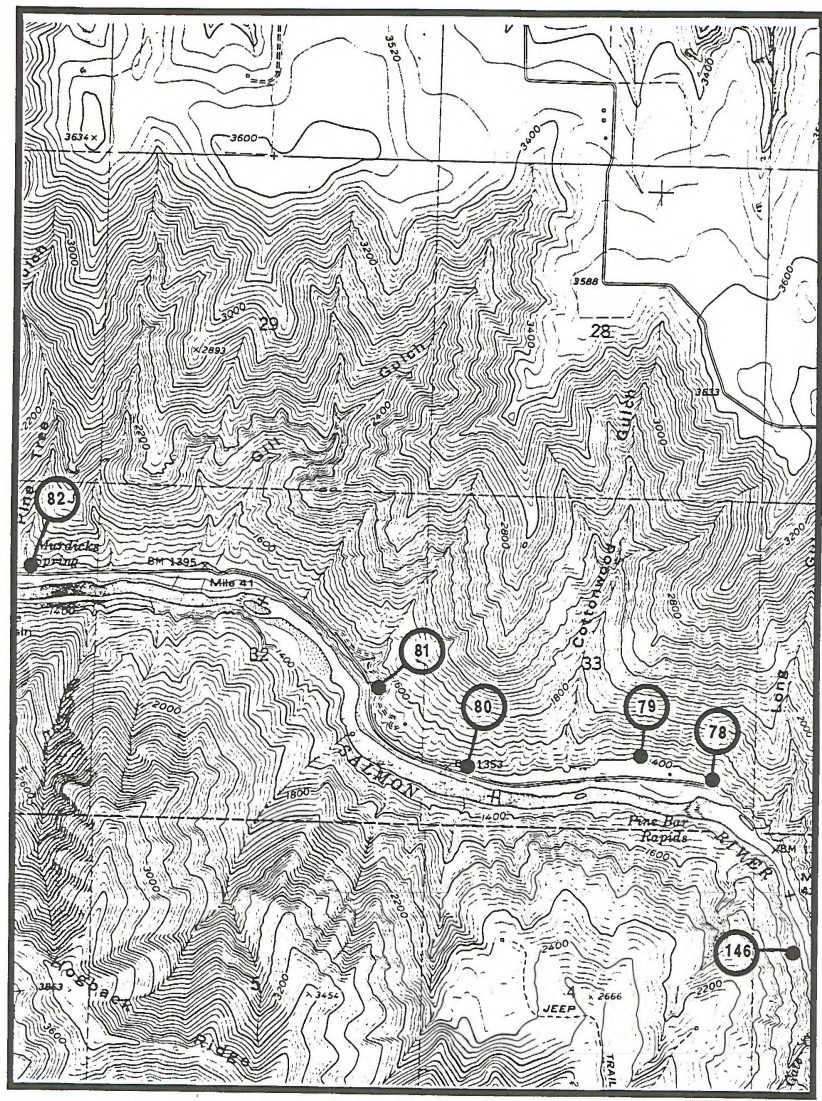

FENN QUADRANGLE, IDAHO CO., ID

SITES $78,79,80,81,82,146$ 


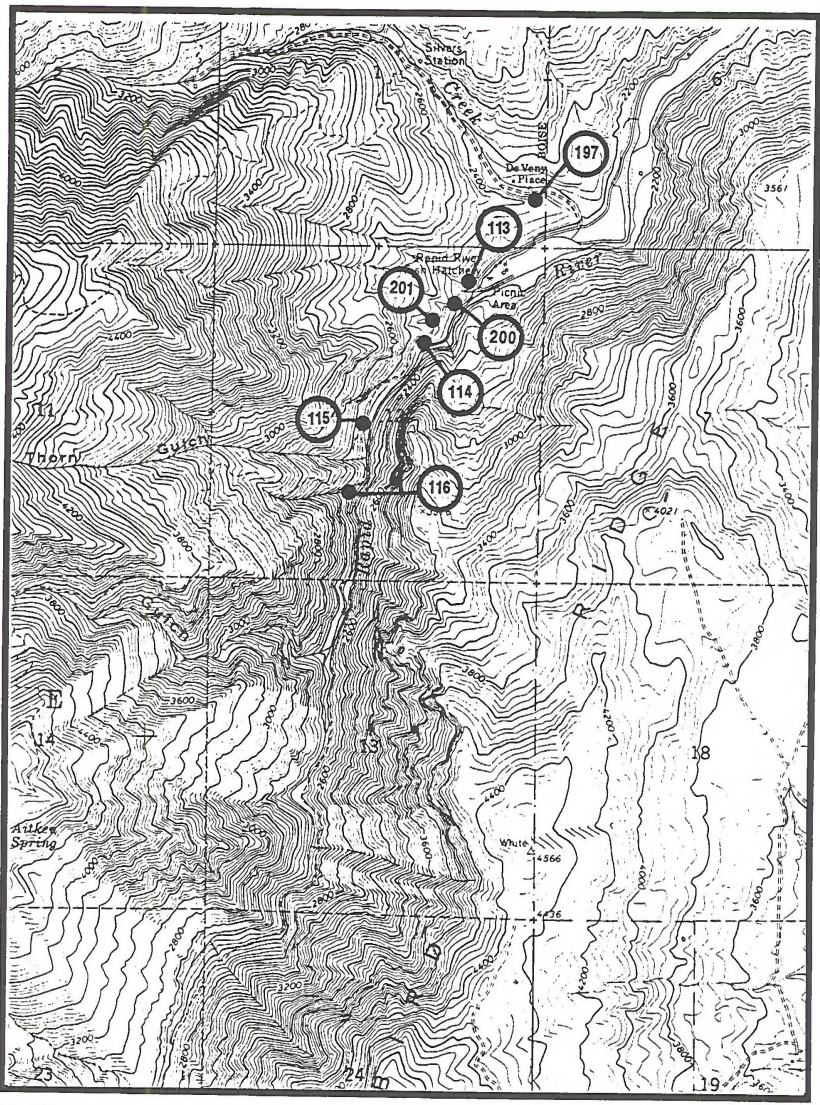

HEAVENS GATE QUADRANGLE, IDAHO CO., ID

SITES 113, 114, 115, 116, 197, 200, 201 


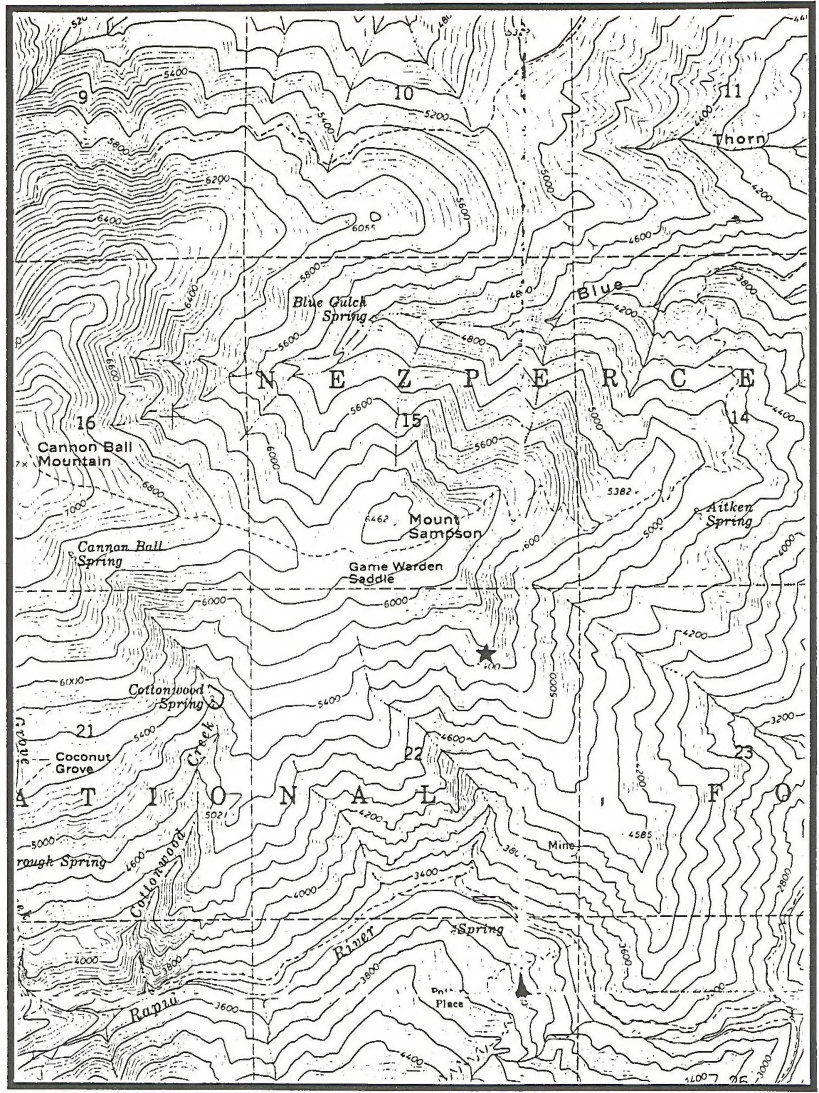

HEAVENS GATE QUADRANGLE, IDAHO CO., ID TYPE AND ONLY LOCALITY FOR OREOHELIX HAMMERI 


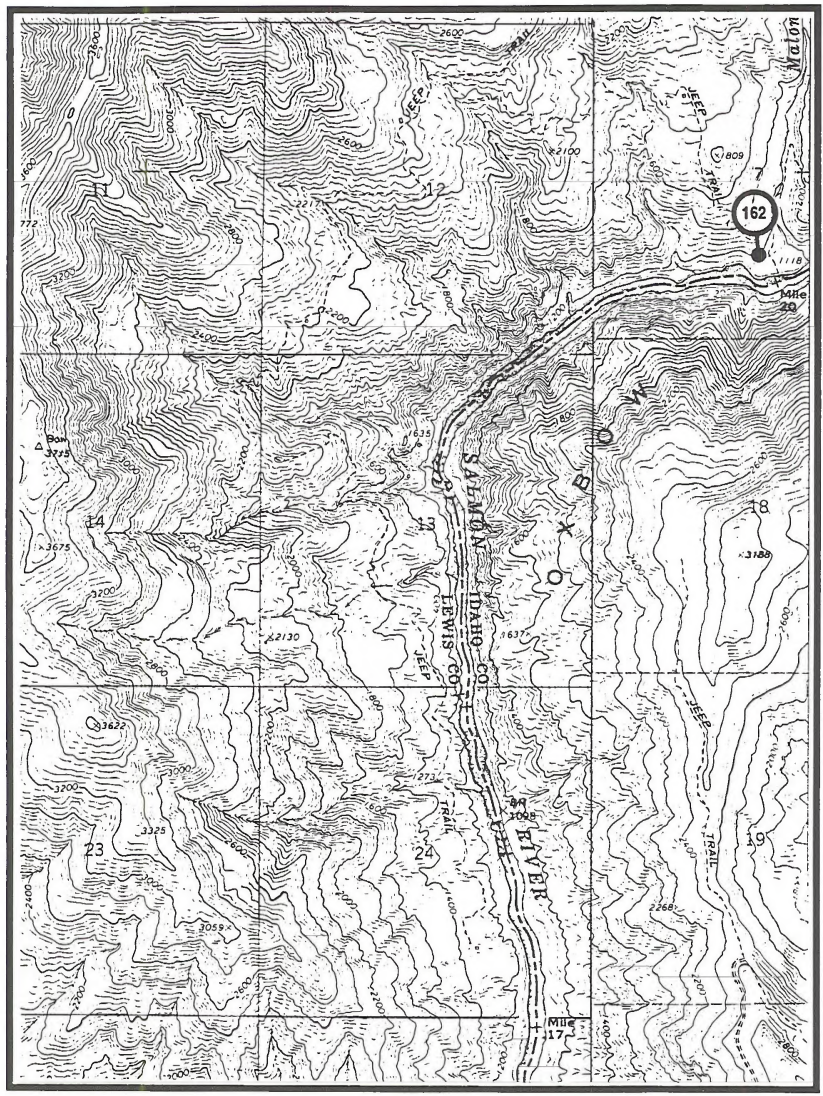

HOOVER POINT QUADRANGLE, LEWIS CO., ID

SITE 162 


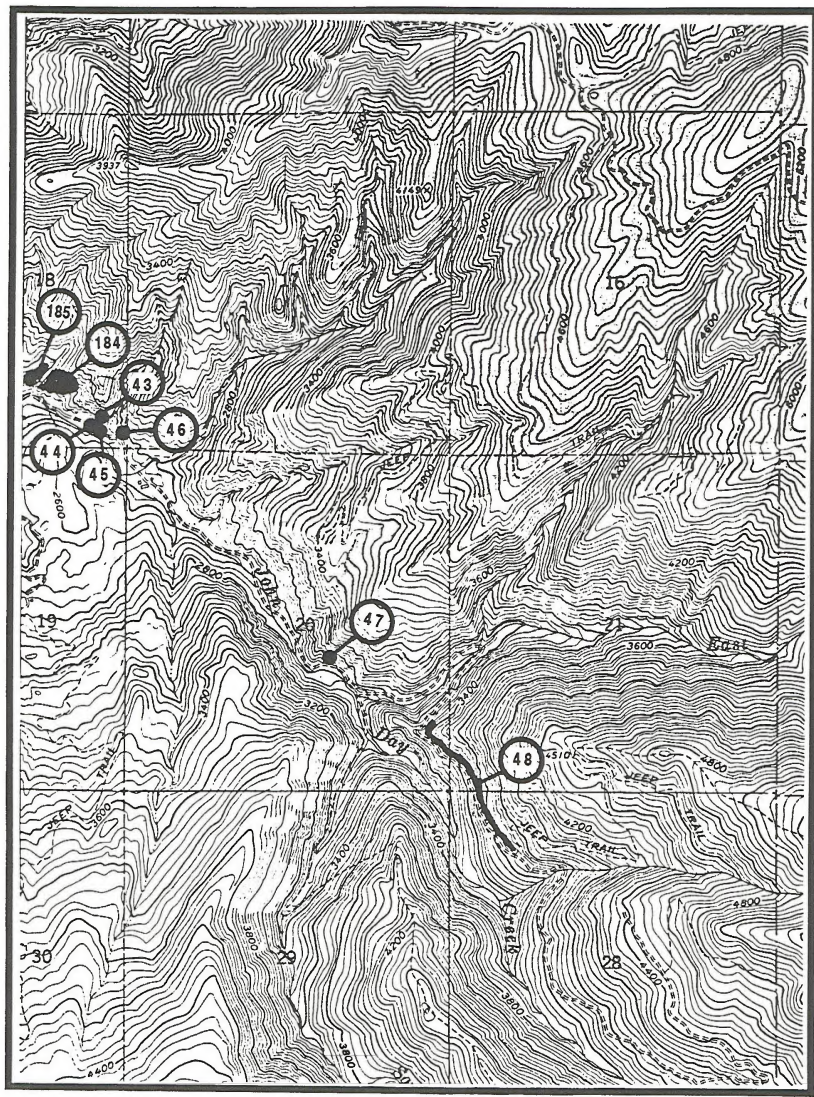

JOHN DAY MTN. QUADRANGLE, IDAHO CO., ID

SITES $43,44,45,46,47,48,184,185$ 


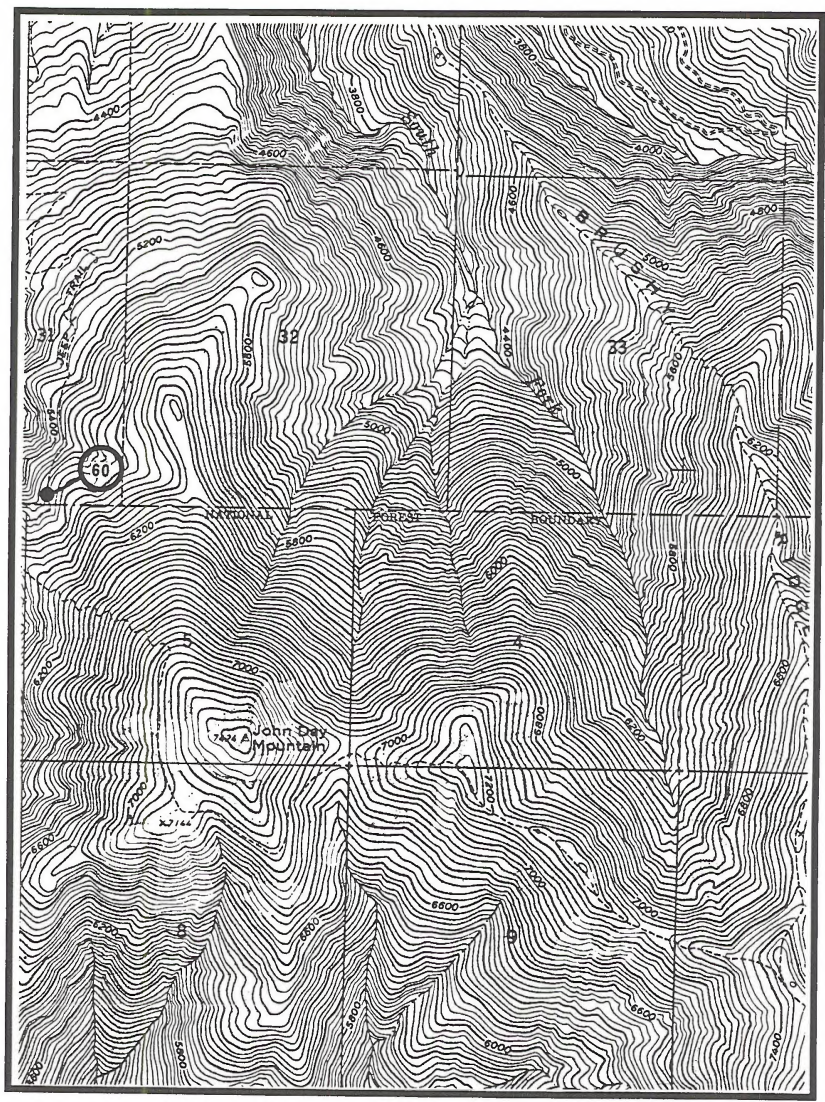

JOHN DAY MTN. QUADRANGLE, IDAHO CO., ID

SITE 60 


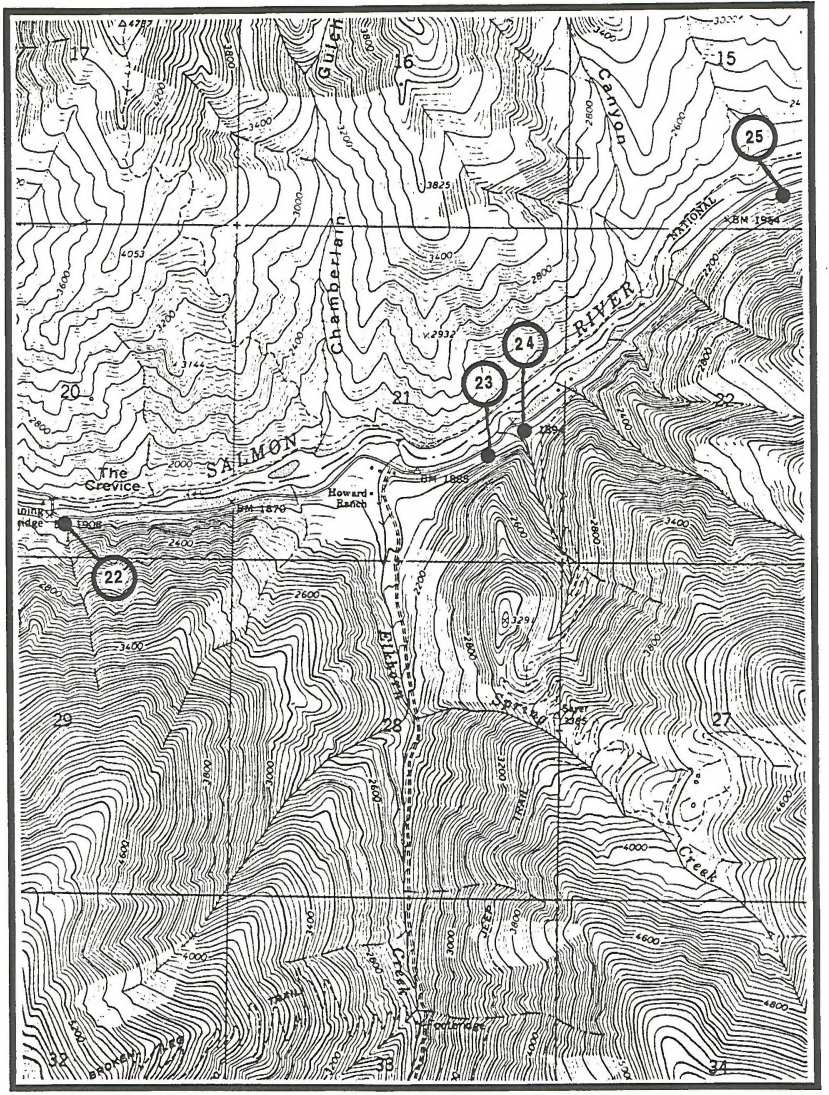

KELLY MOUNTAIN QUADRANGLE, IDAHO CO., ID

SITES 22, 23, 24, 25 
B11

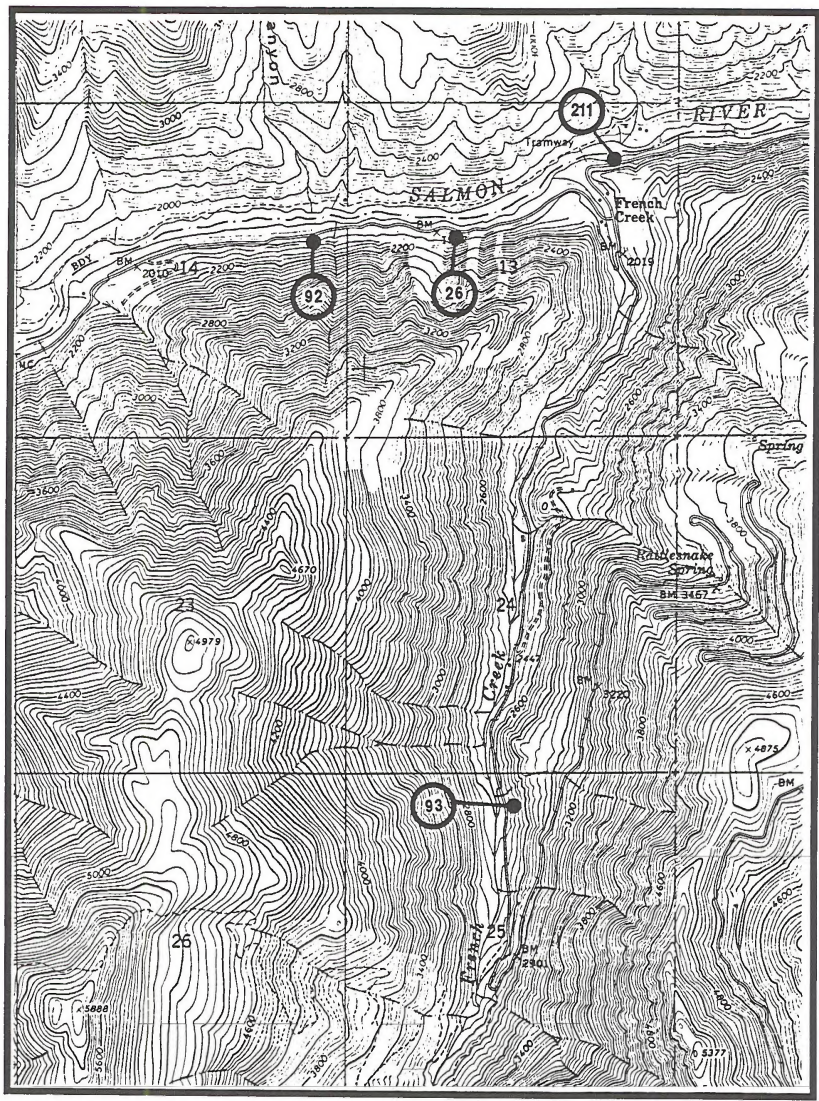

KELLY MOUNTAIN QUADRANGLE, IDAHO CO., ID

SITES 26, 92, 93, 211 


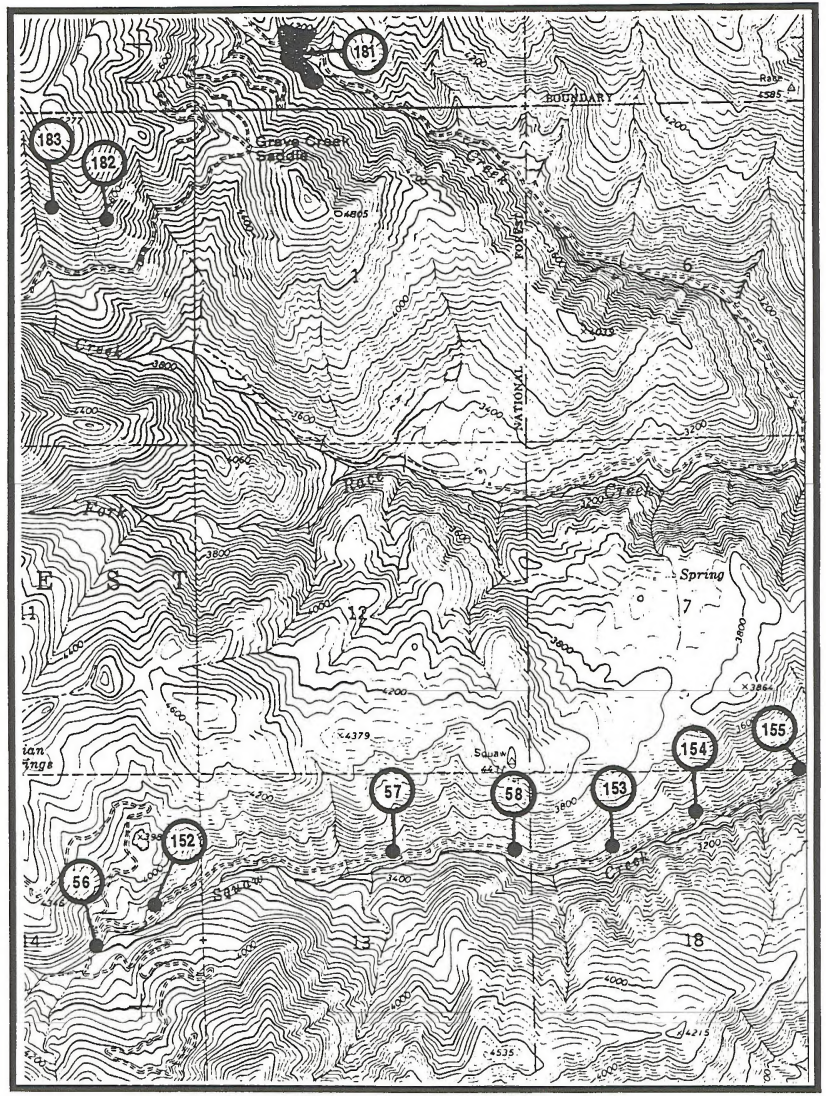

KESSLER CREEK QUADRANGLE, IDAHO CO., ID

SITES $56,57,58,152,153,154,155,181,182,183$ 
B 13

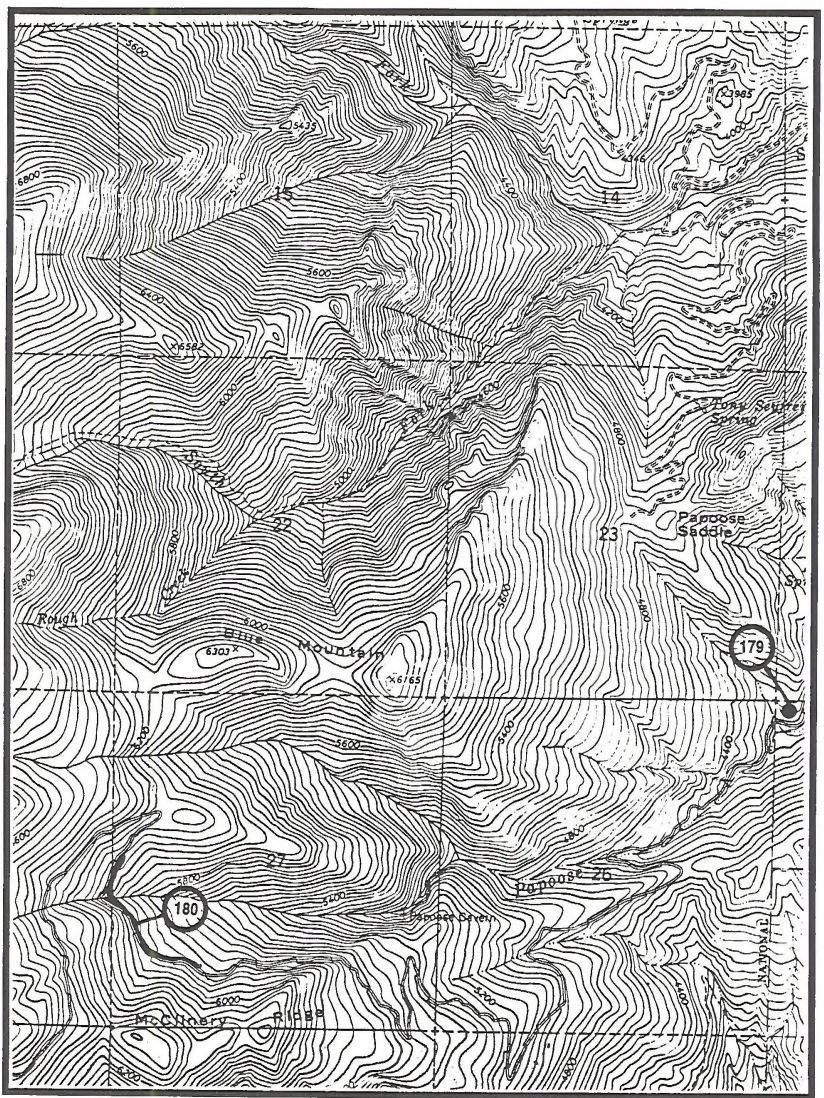

KESSLER CREEK QUADRANGLE, IDAHO CO., ID

SITES 179,180 
B14

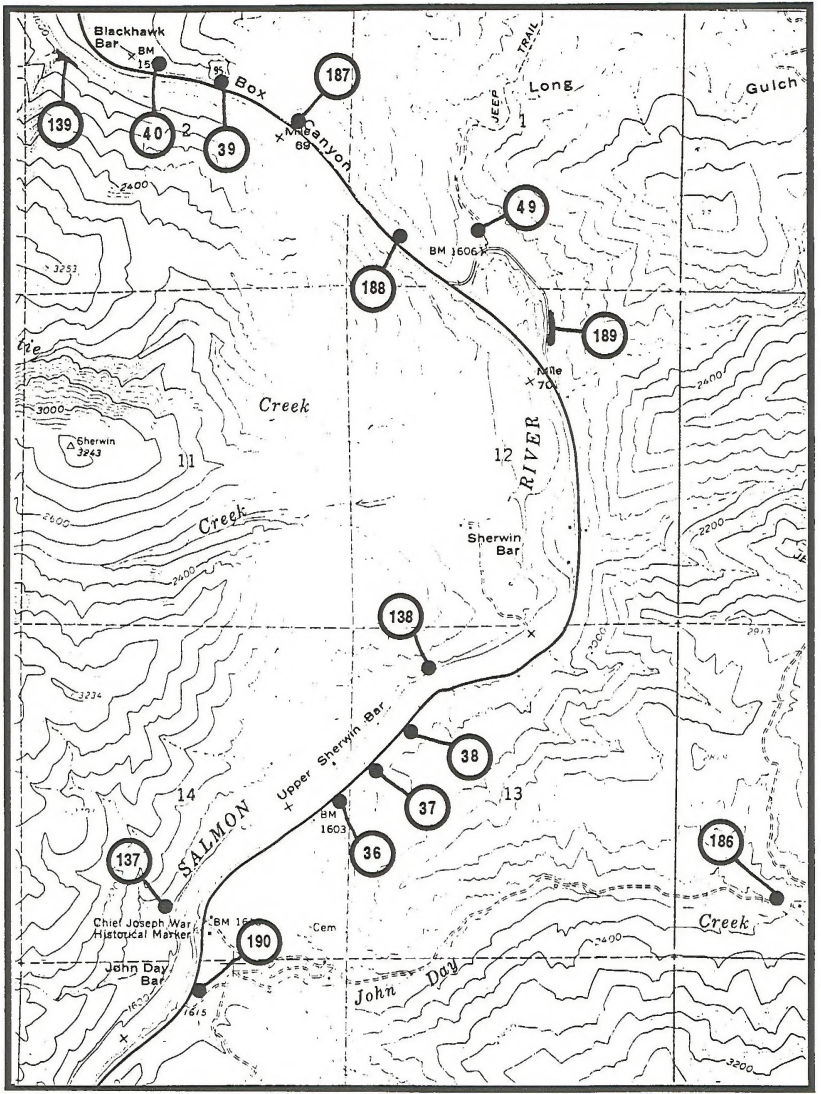

LUCILE QUADRANGLE, IDAHO CO., ID

SITES $36,37,38,39,40,49,137,138,139,186,187,188,189,190$ 
B15

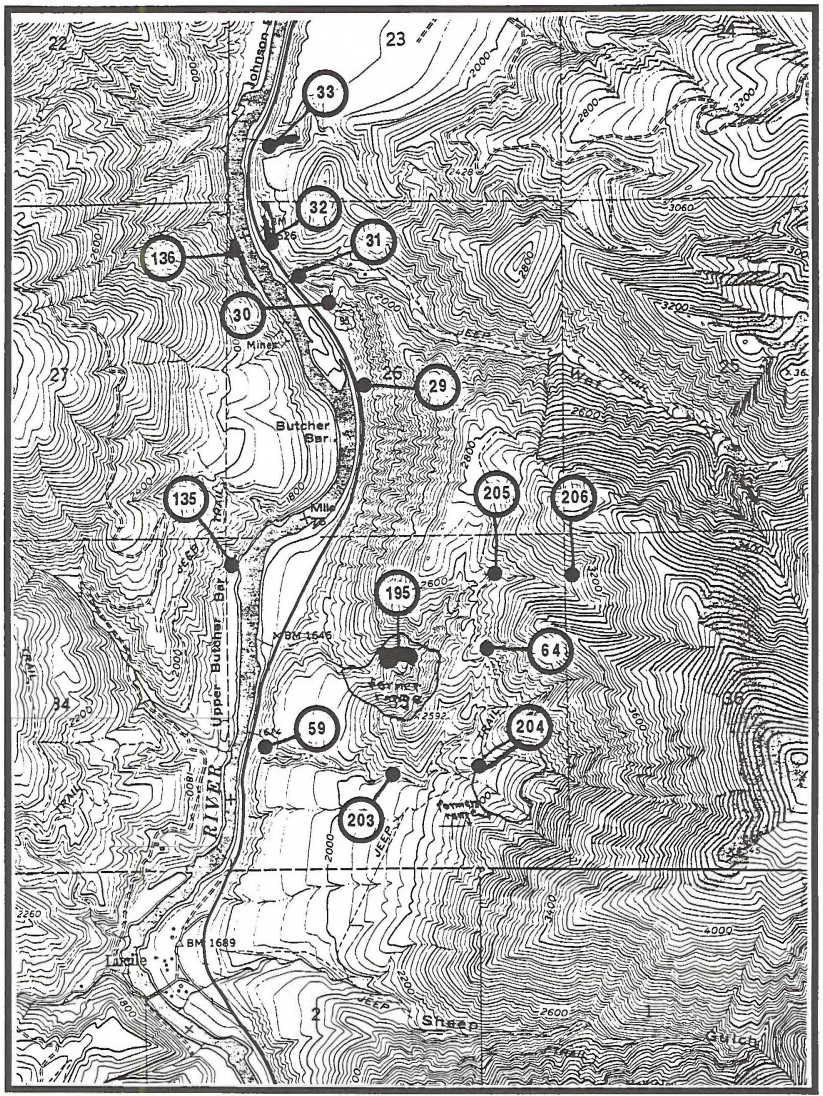

LUCILE QUADRANGLE, IDAHO CO., ID

SITES 29, 30, 31, 32, 33, 59, 64, 135, 136, 195, 203, 204, 205, 206 
B16

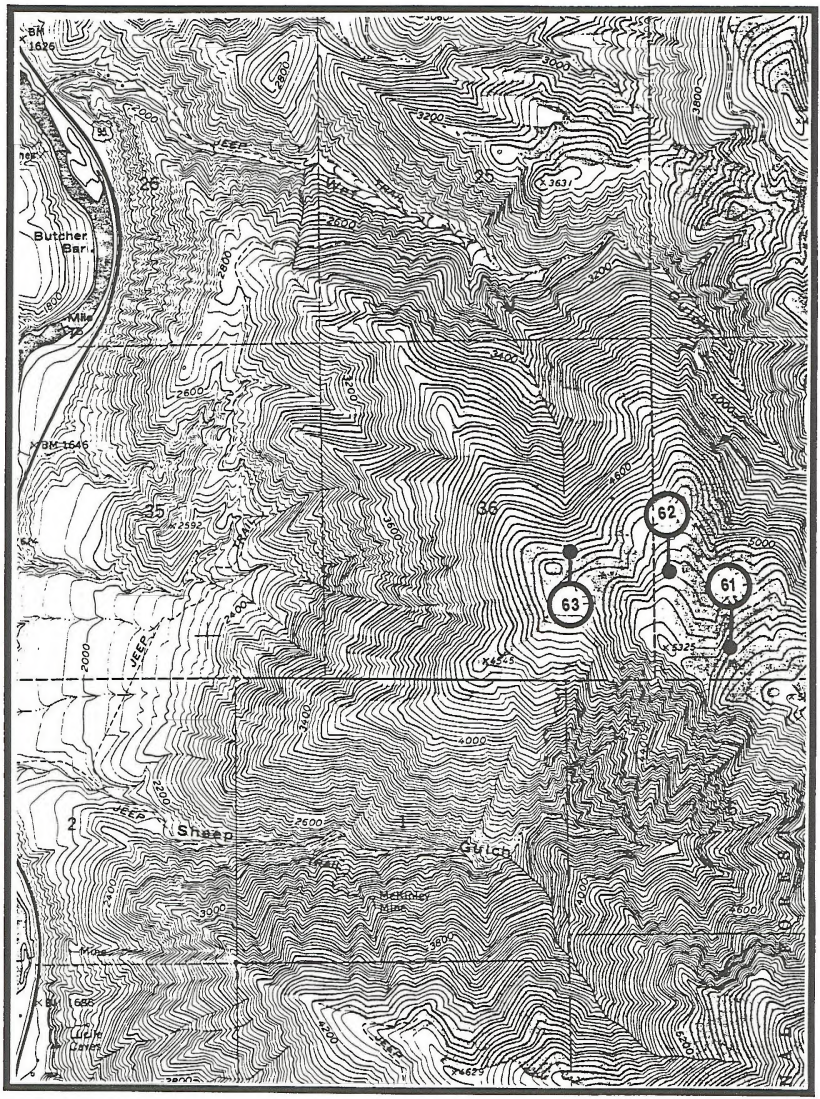

LUCILE QUADRANGLE, IDAHO CO., ID

SITES $61,62,63$ 


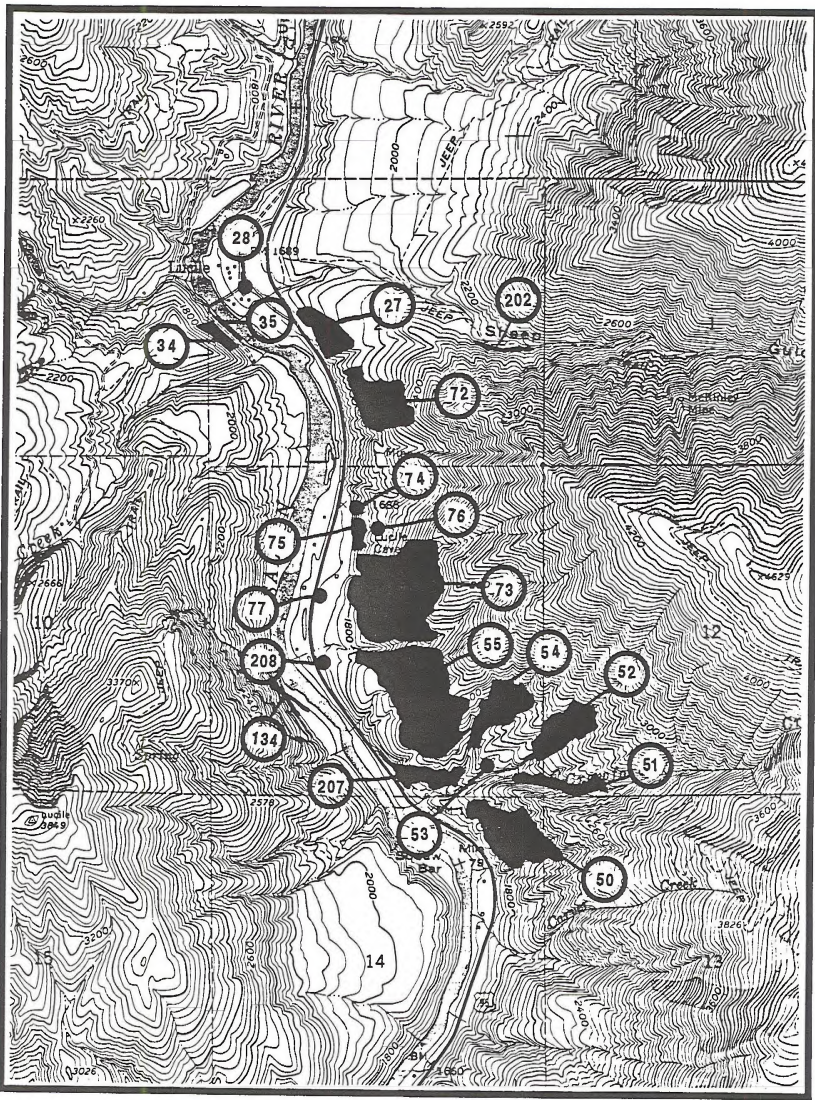

LUCILE QUADRANGLE, IDAHO CO., ID

SITES $27,28,34,35,50,51,52,53,54,55,72,73,74,75,76,77,134$, $202,207,208$ 


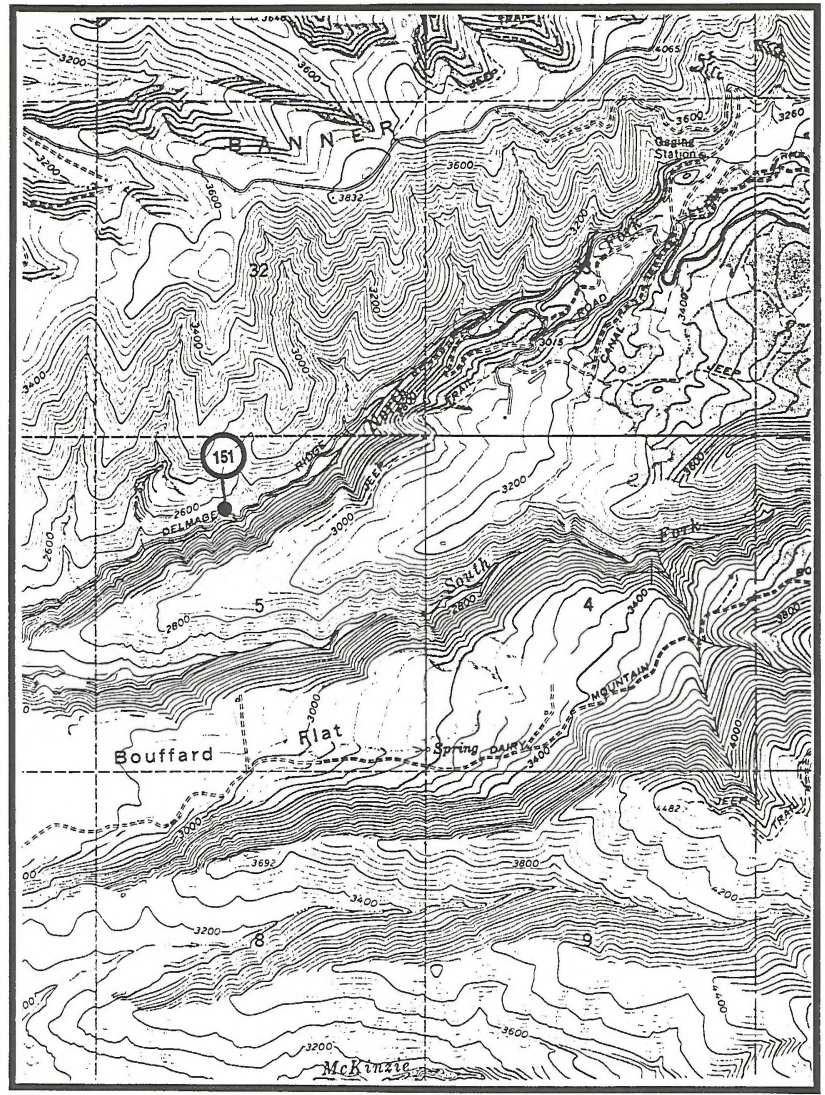




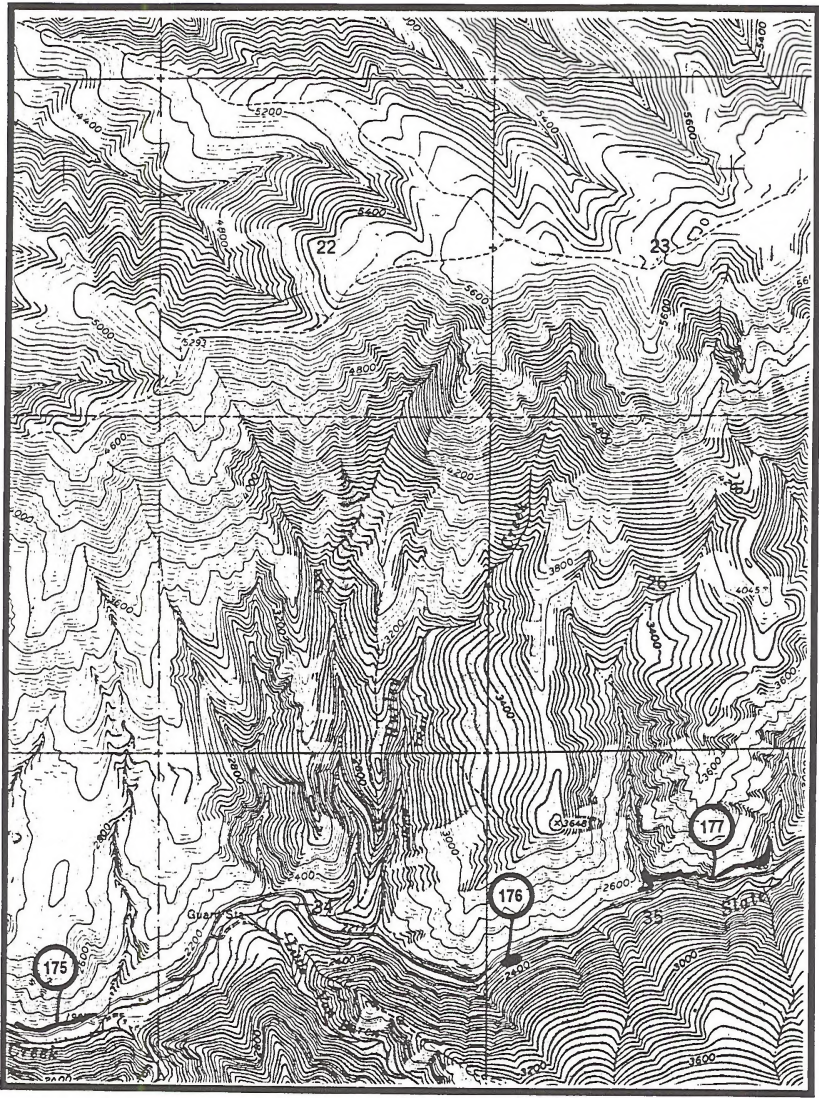

MC KINZIE QUADRANGLE, IDAHO CO., ID

SITES 175, 176, 177 


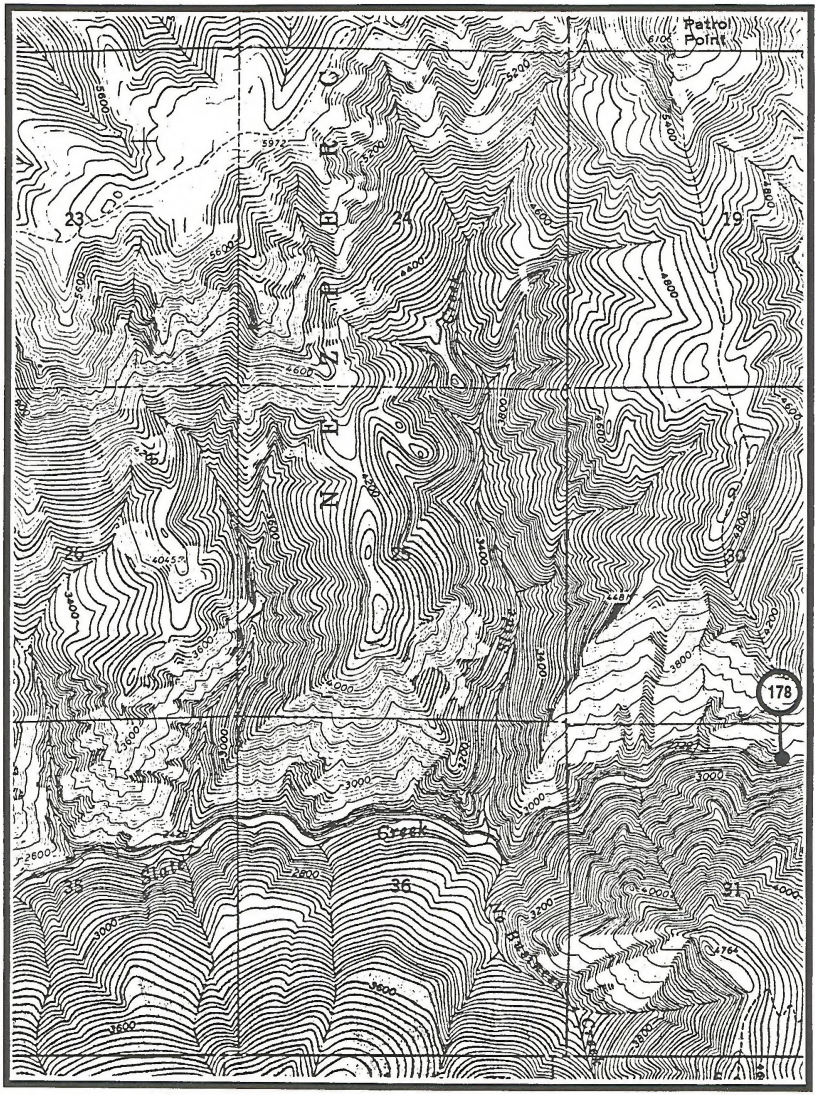

MC KINZIE QUADRANGLE, IDAHO CO., ID SITE 178 


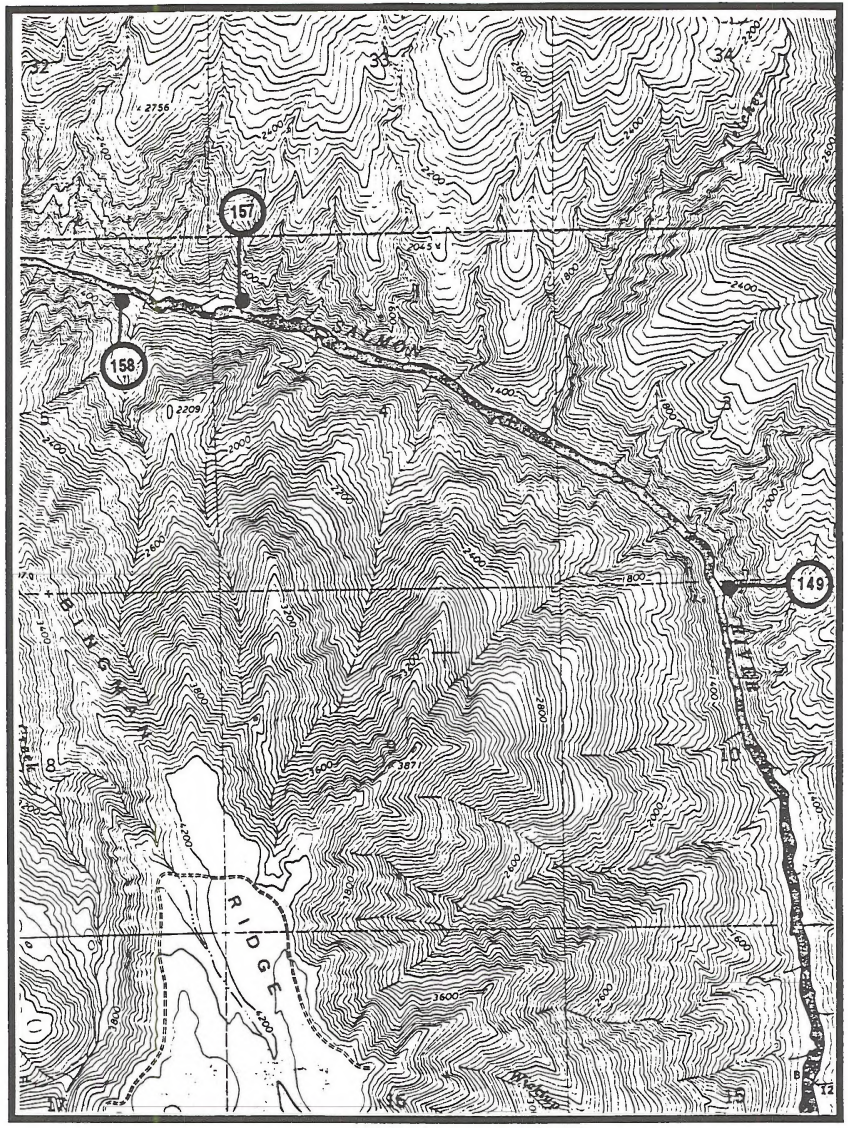

MOUGHMER POINT QUADRANGLE, IDAHO CO., ID

SITES 149, 157, 158 


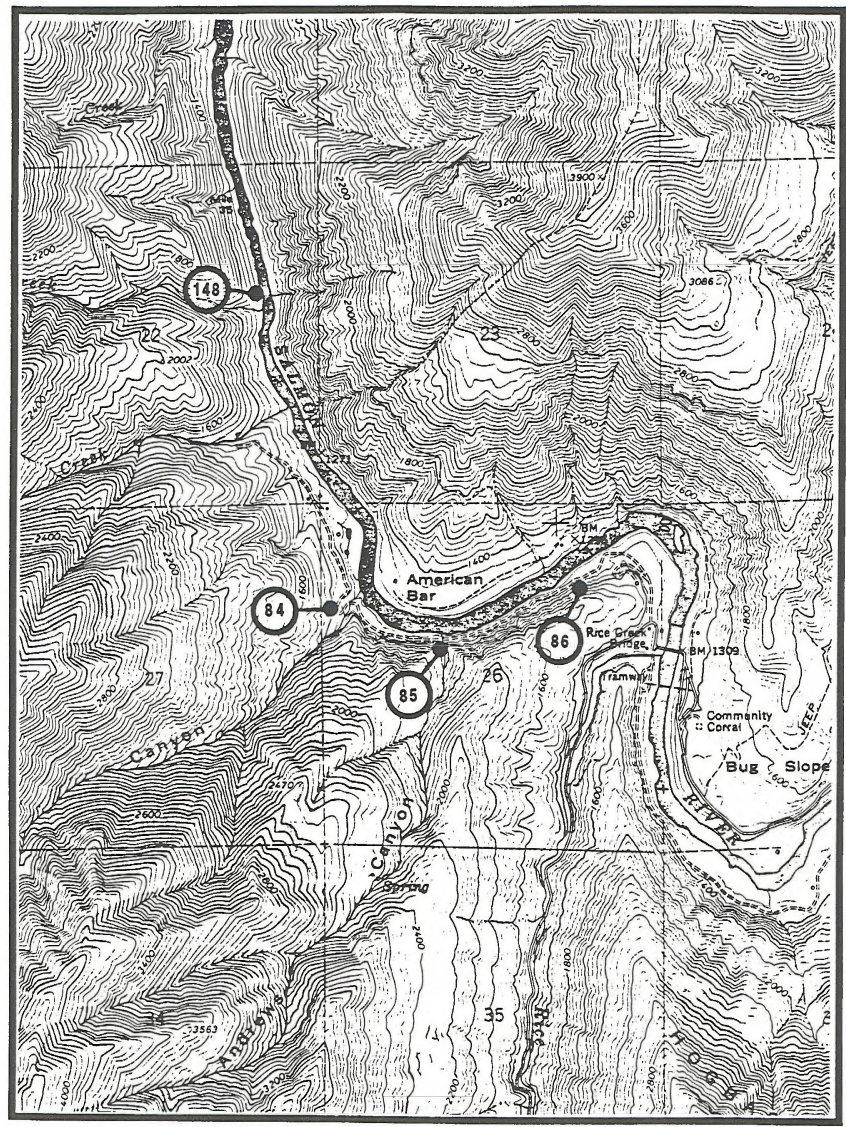

MOUGHMER POINT QUADRANGLE, IDAHO CO., ID

SITES $84,85,86,148$ 


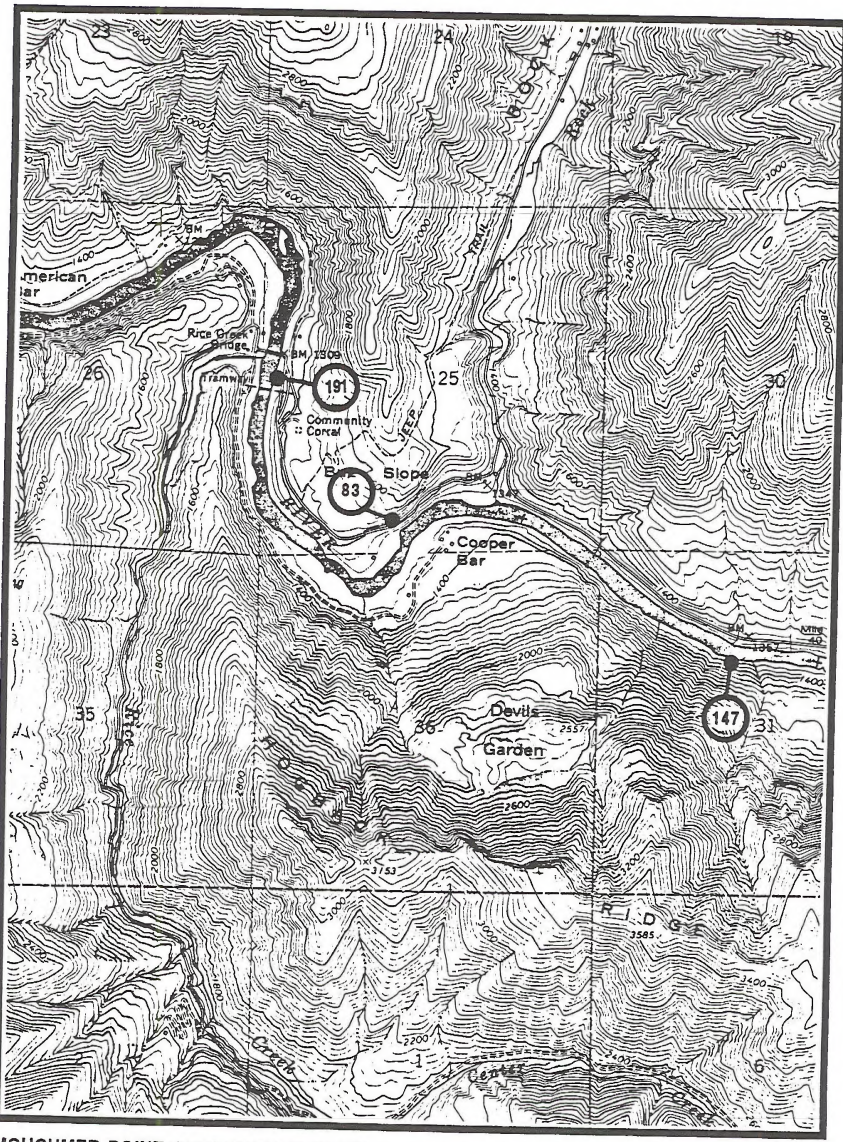

MOUGHMER POINT QUADRANGLE, IDAHO CO., ID

SITES $83,147,191$ 
B 24

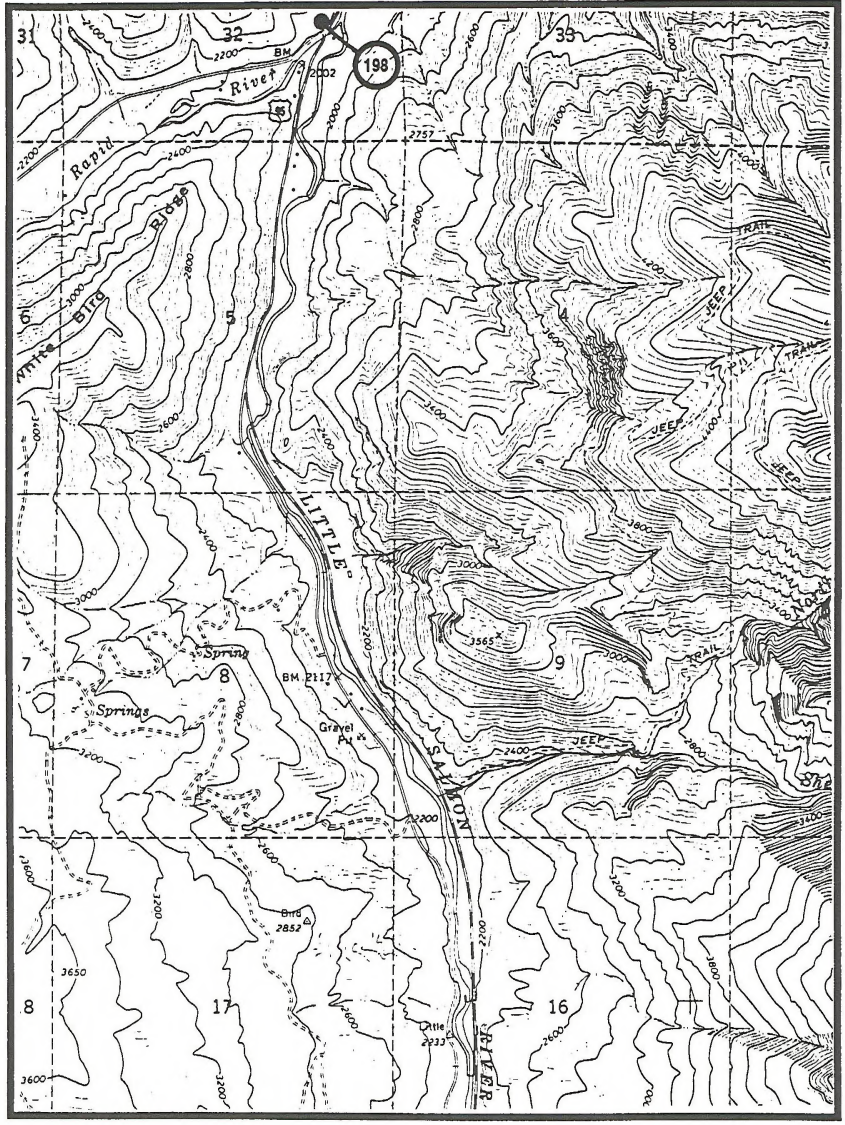

POLLOCK QUADRANGLE, IDAHO CO., ID

SITE 198 


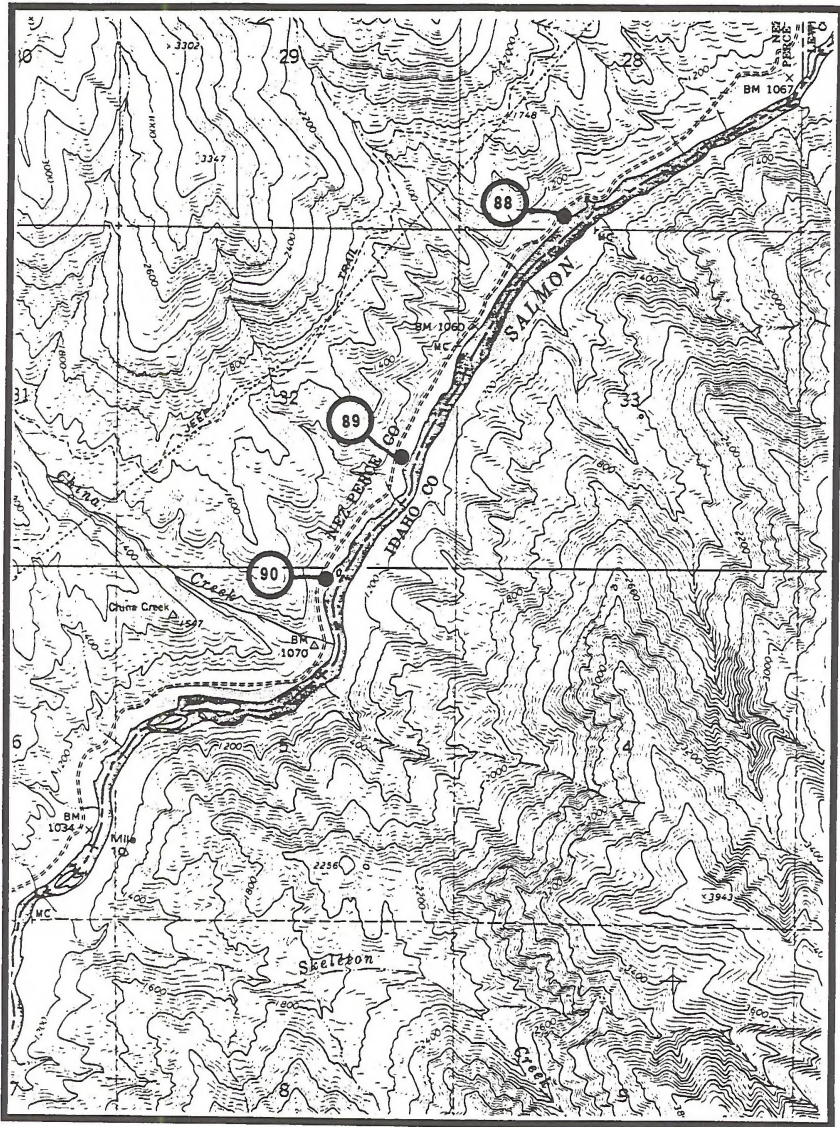

RATTLESNAKE RIDGE QUADRANGLE, NEZ PERCE CO., ID

SITES $88,89,90$ 


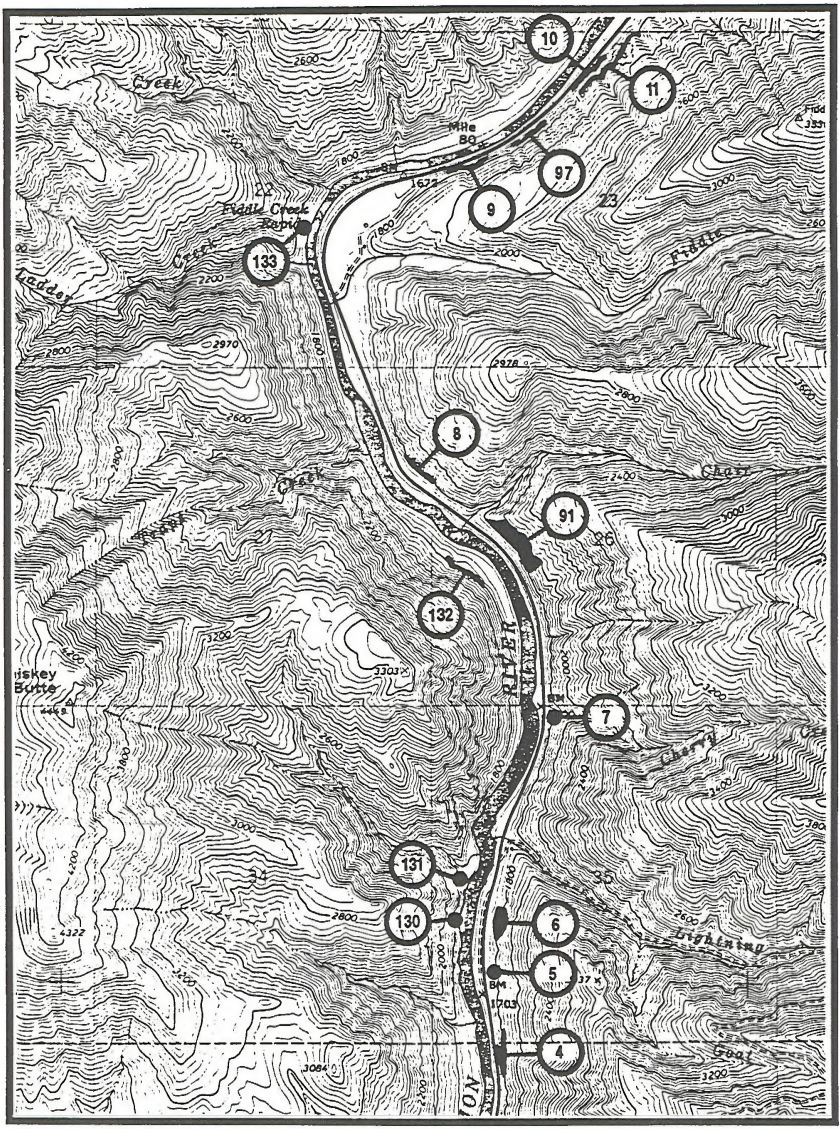

RIGGINS QUADRANGLE, IDAHO CO., ID

SITES $4,5,6,7,8,9,10,11,91,97,130,131,132,133$ 


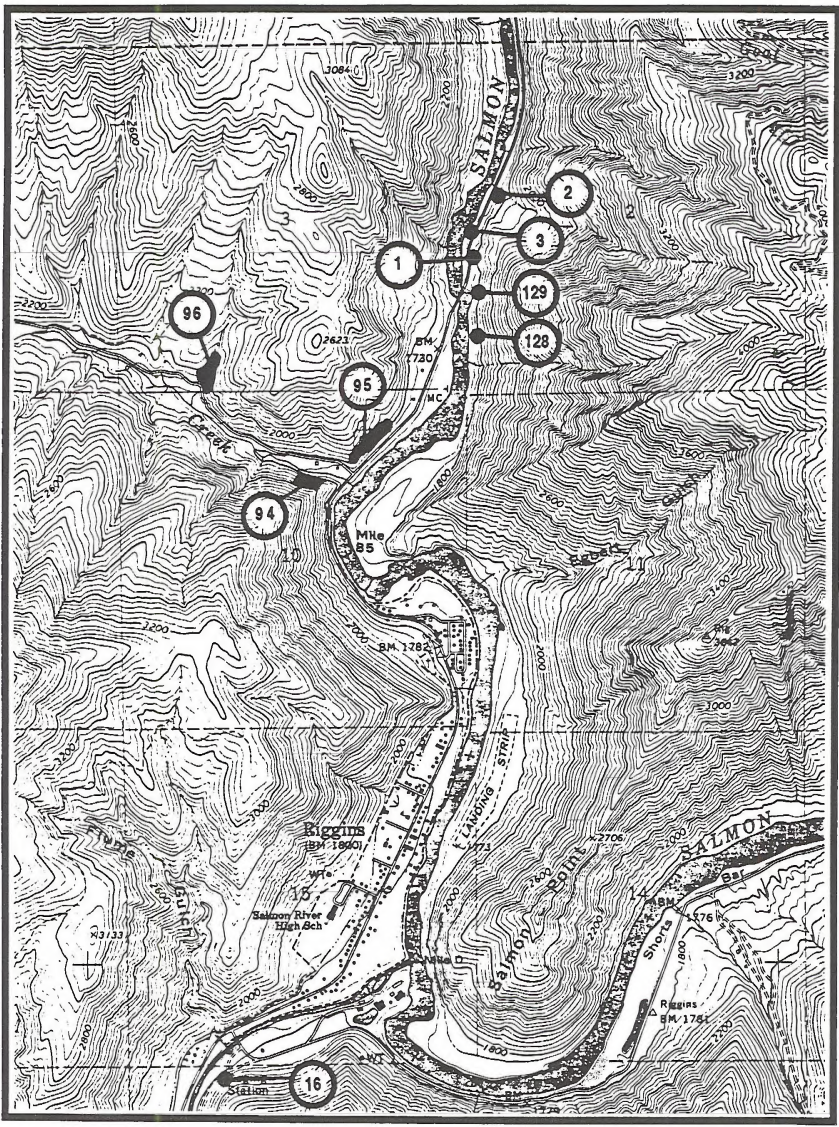

RIGGINS QUADRANGLE, IDAHO CO., ID

SITES 1, 2, 3, 16, 94, 95, 96, 128, 129 


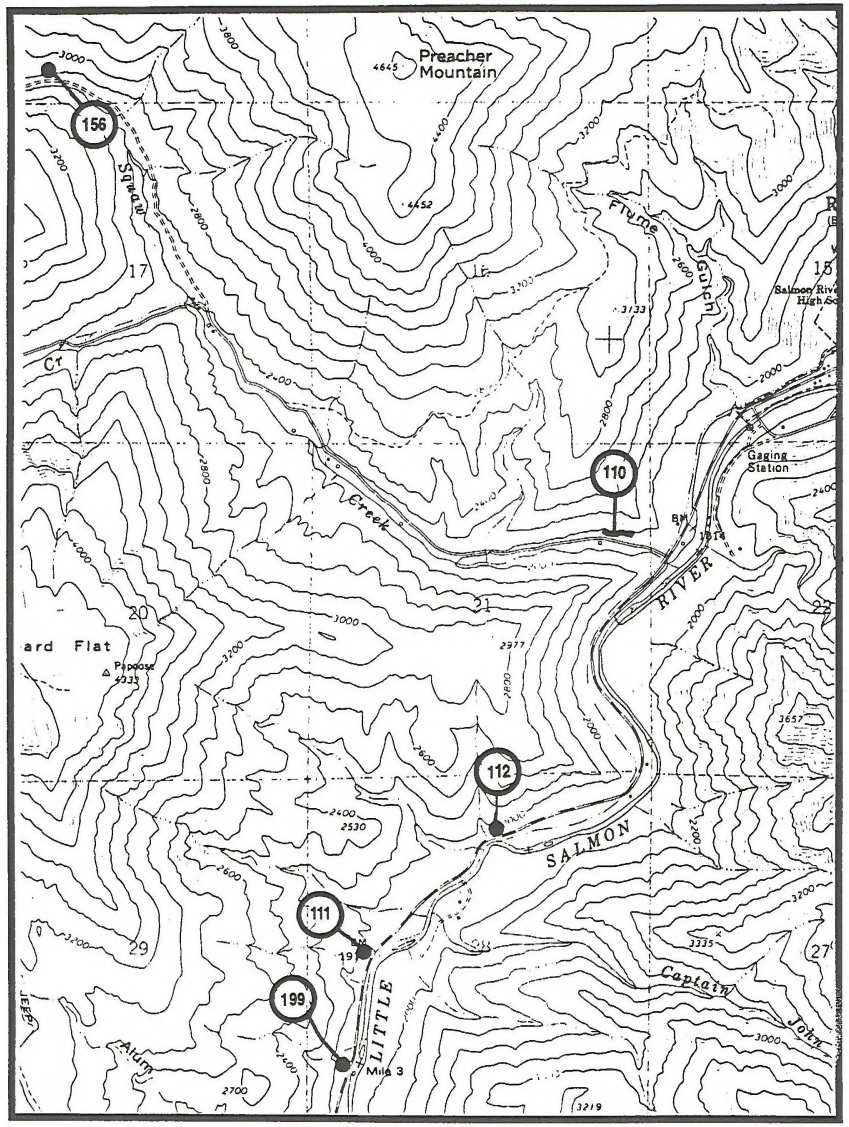

RIGGINS QUADRANGLE, IDAHO CO., ID

SITES 110, 111, 112, 156, 199 


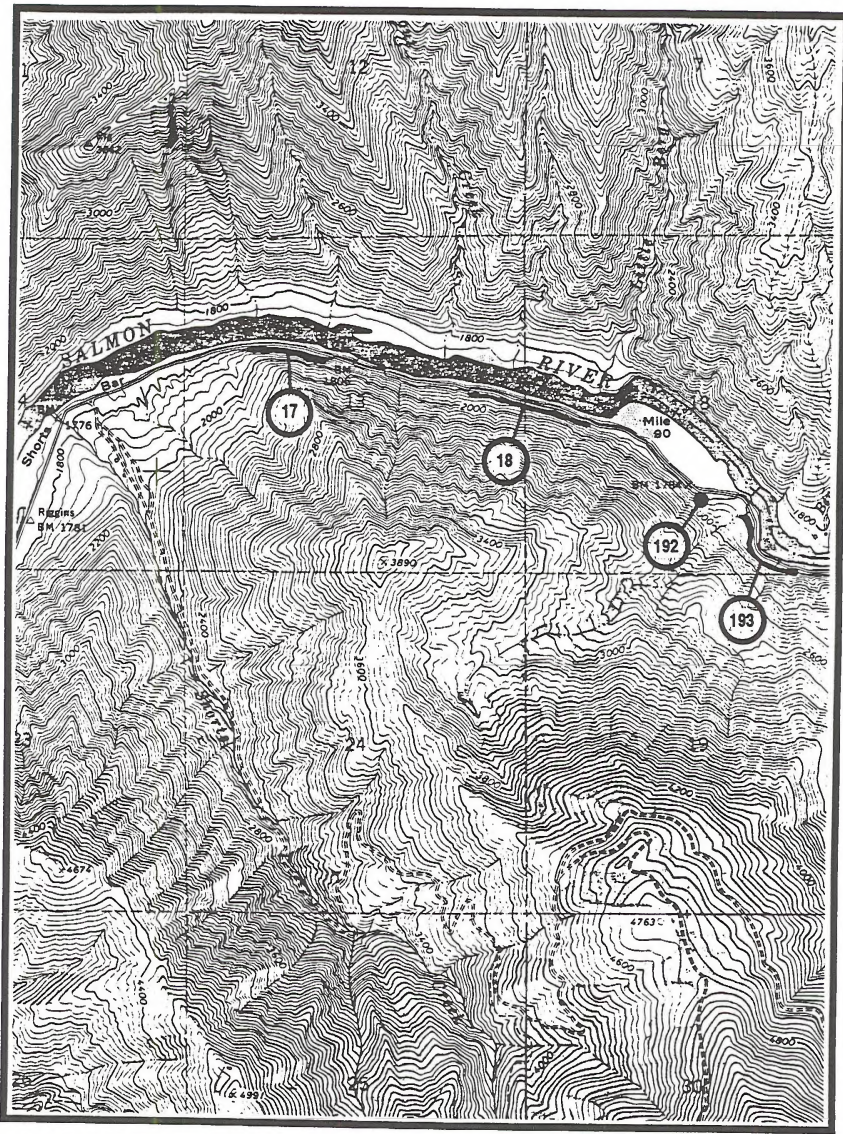

RIGGINS QUADRANGLE, IDAHO CO., ID

SITES $17,18,192,193$ 


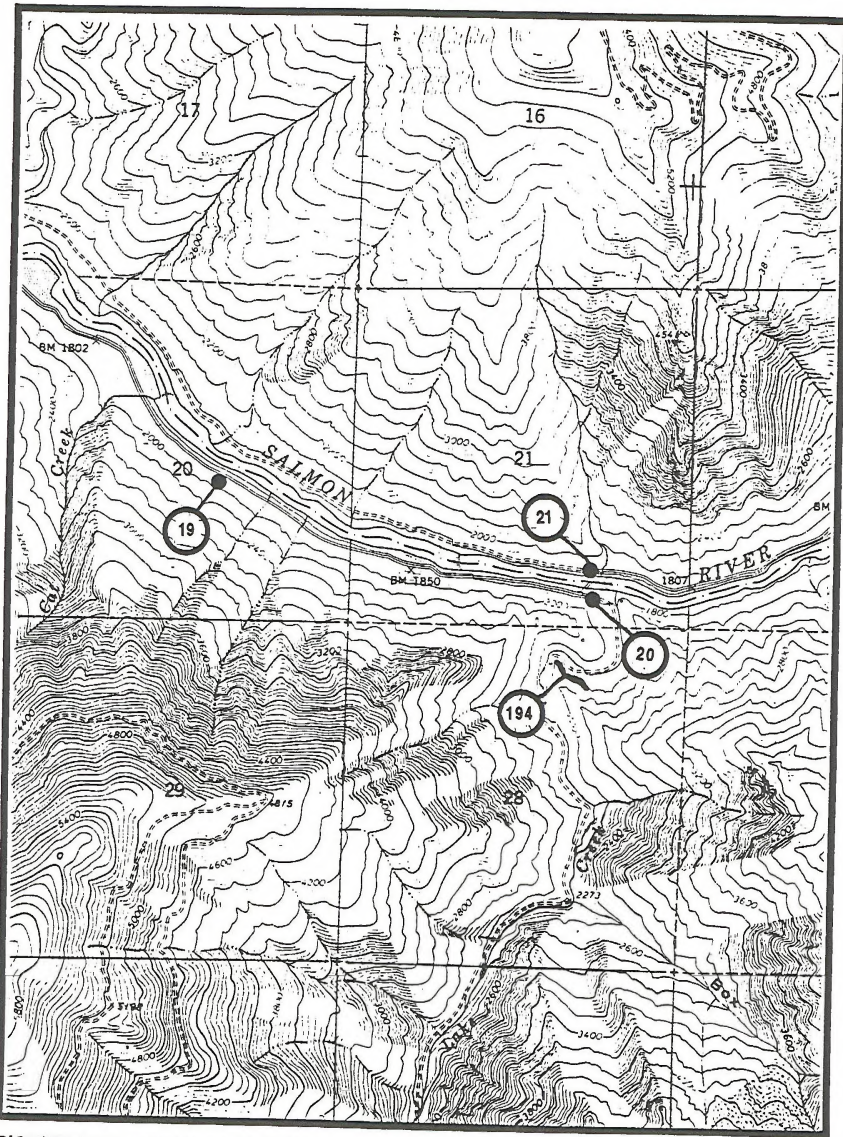

RIGGINS HOT SPRINGS QUADRANGLE, IDAHO CO., ID

SITES 19, 20, 21, 194 


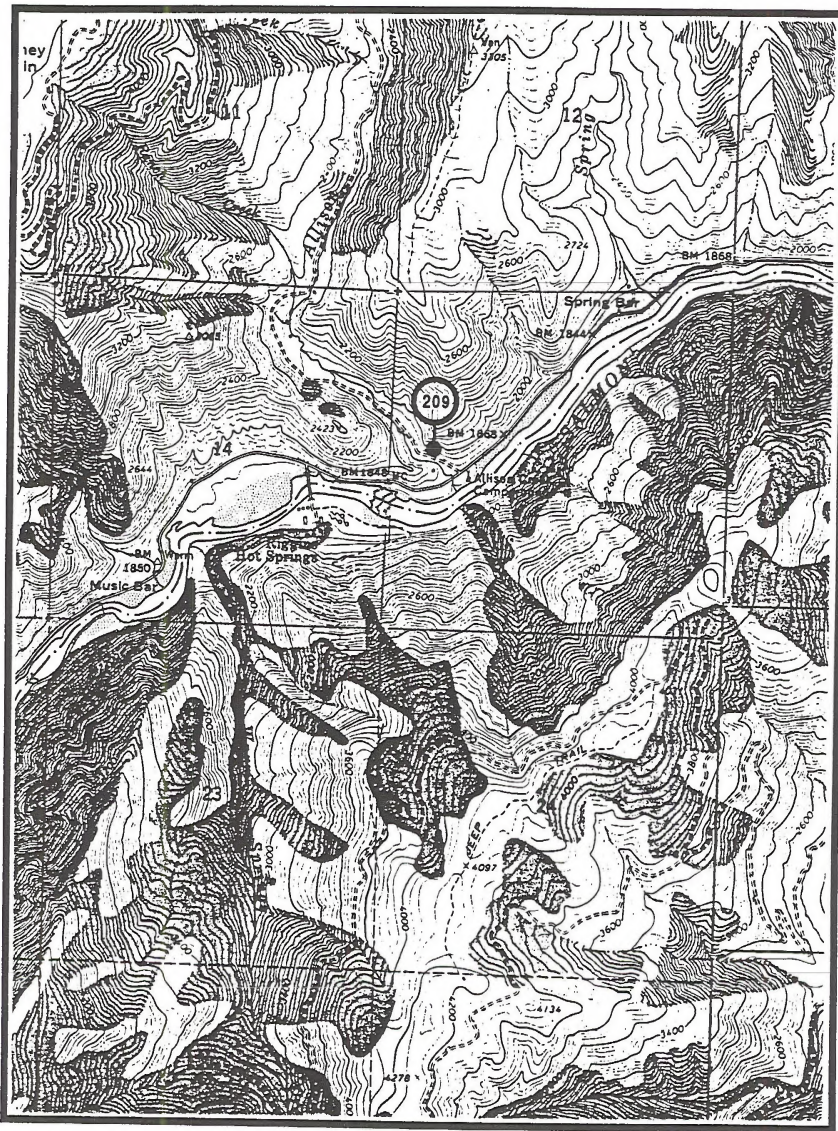

RIGGINS HOT SPRINGS QUADRANGLE, IDAHO CO., ID

SITE 209 
B 32

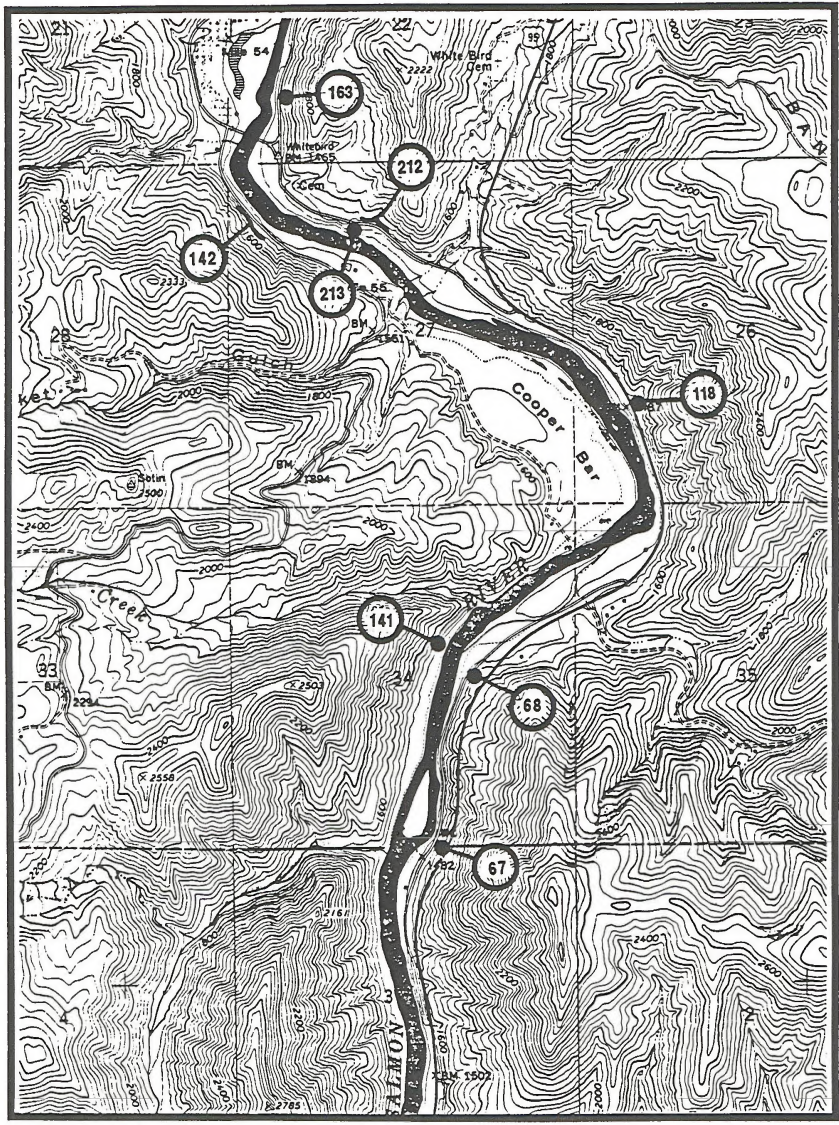

SLATE CREEK QUADRANGLE, IDAHO CO., ID

SITES $67,68,118,141,142,163,212,213$ 
B 33

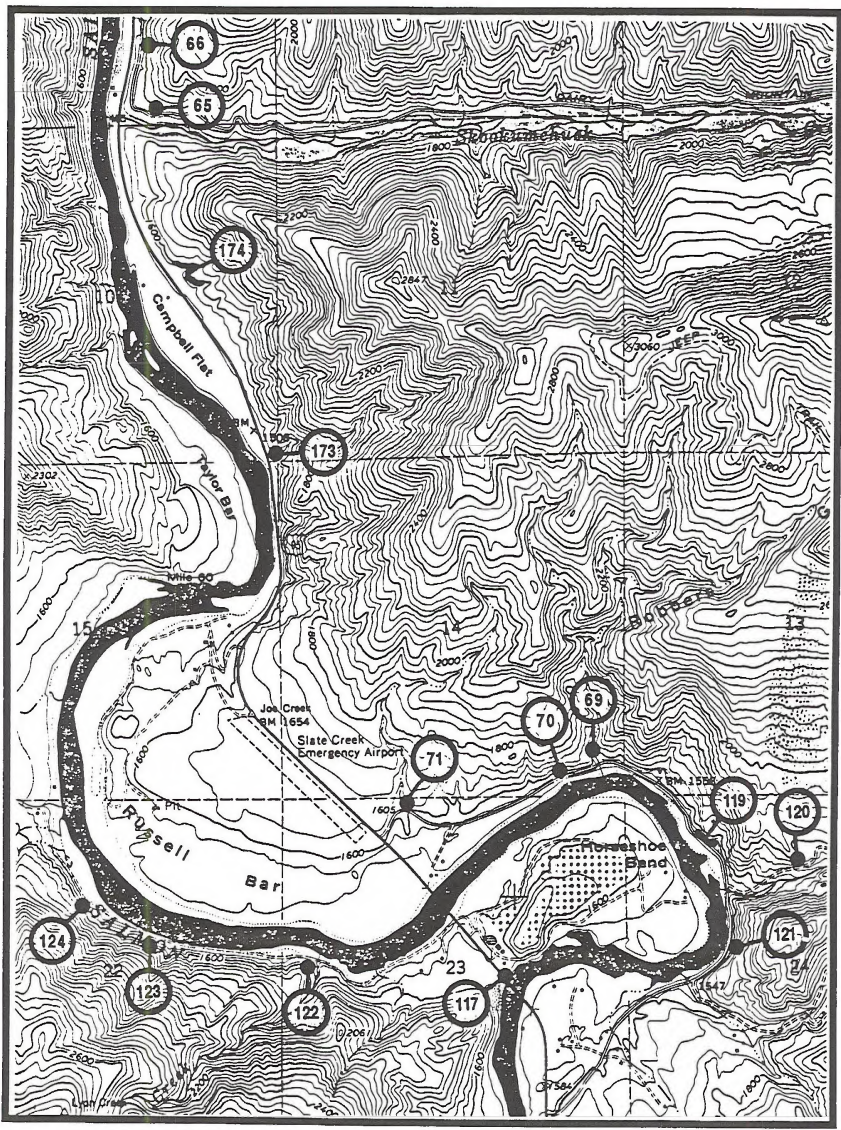

SLATE CREEK QUADRANGLE, IDAHO CO., ID

SITES $65,66,69,70,71,117,119,120,121,122,123,124,173,174$ 


\section{B 34}

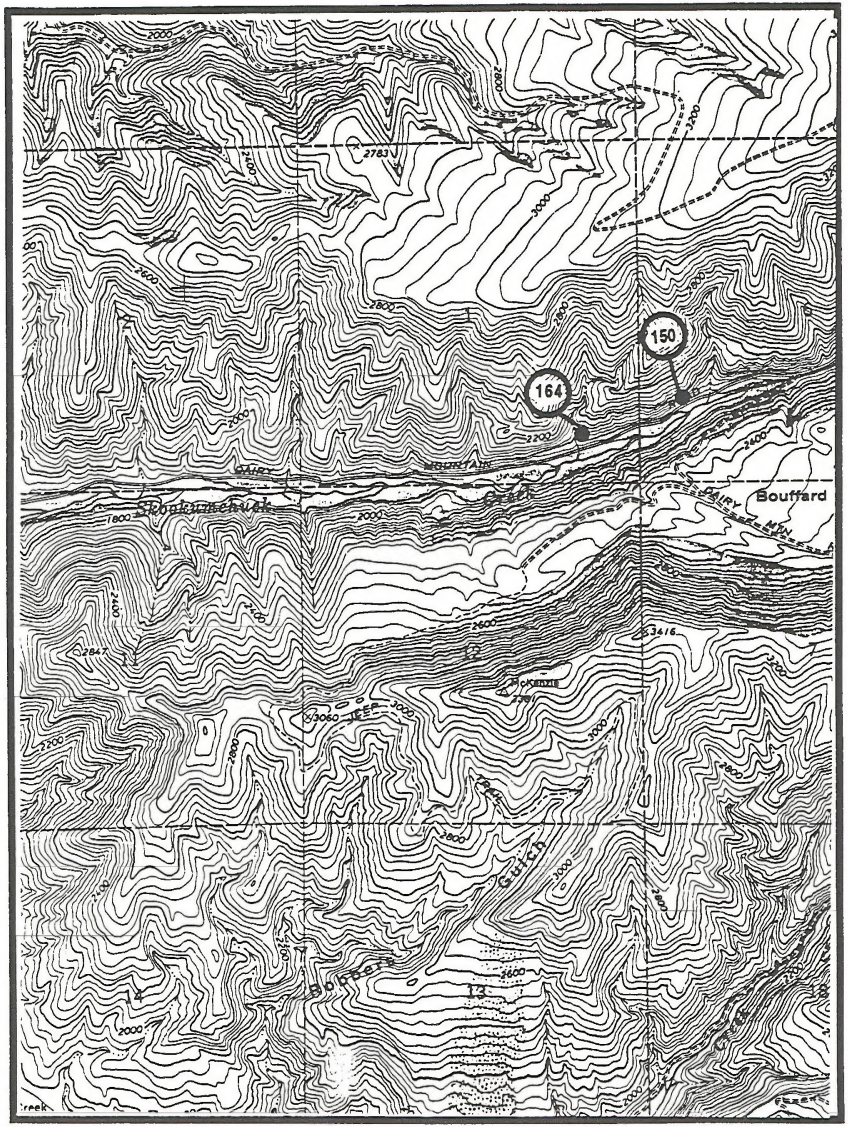

SLATE CREEK QUADRANGLE, IDAHO CO., ID

SITES 150, 164 


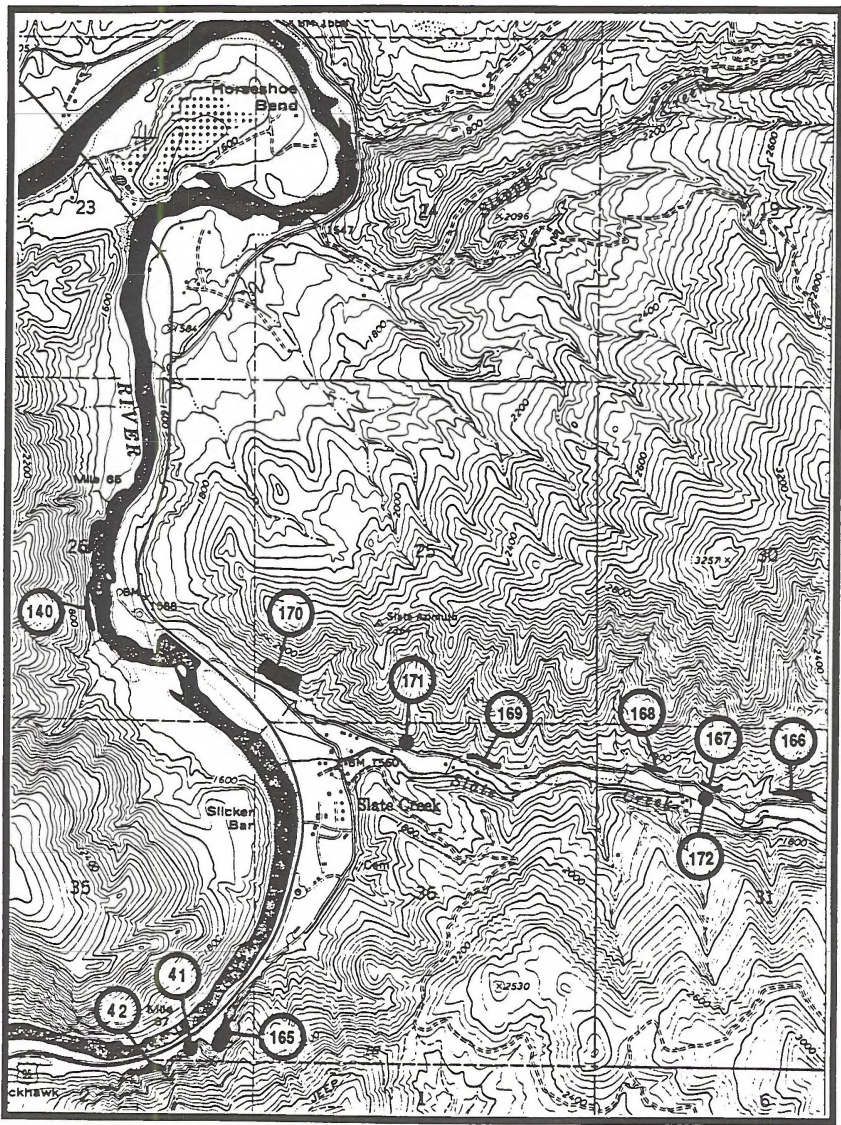

SLATE CREEK QUADRANGLE, IDAHO CO., ID

SITES $41,42,140,165,166,167,168,169,170,171,172$ 


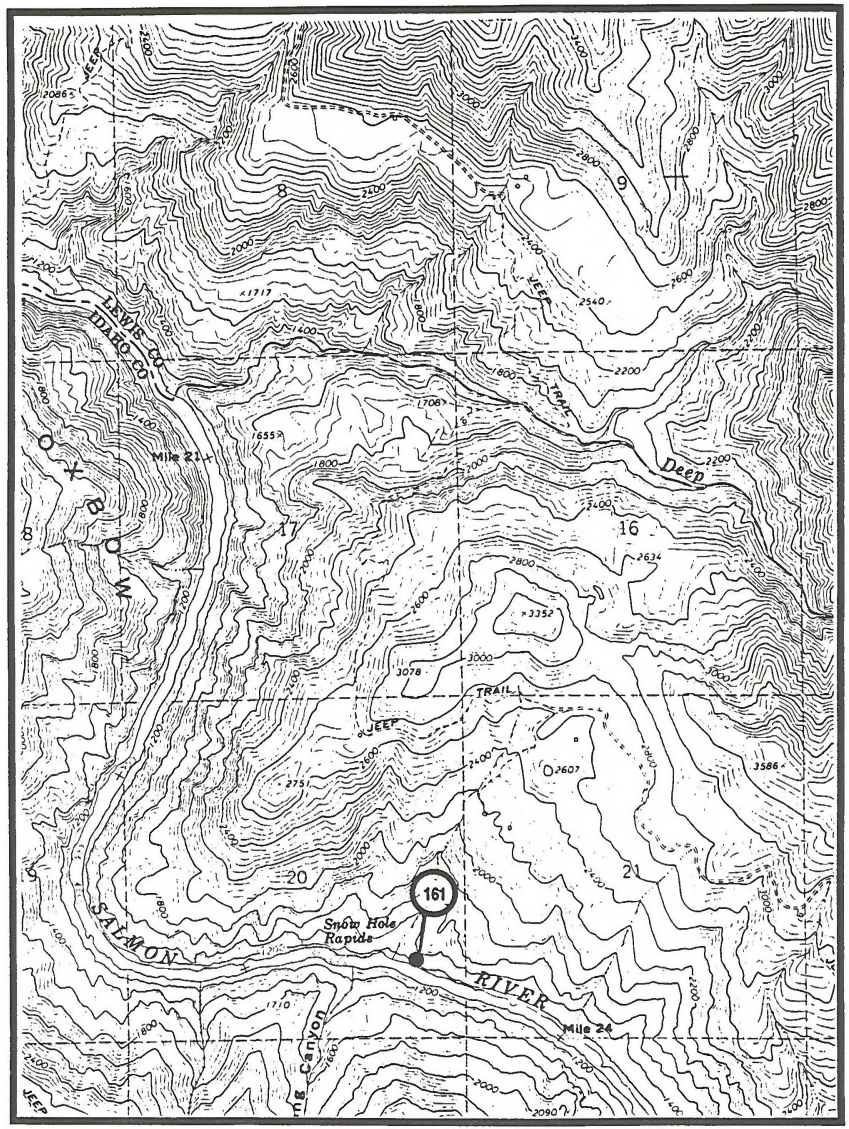

WESTLAKE QUADRANGLE, IDAHO CO., ID 


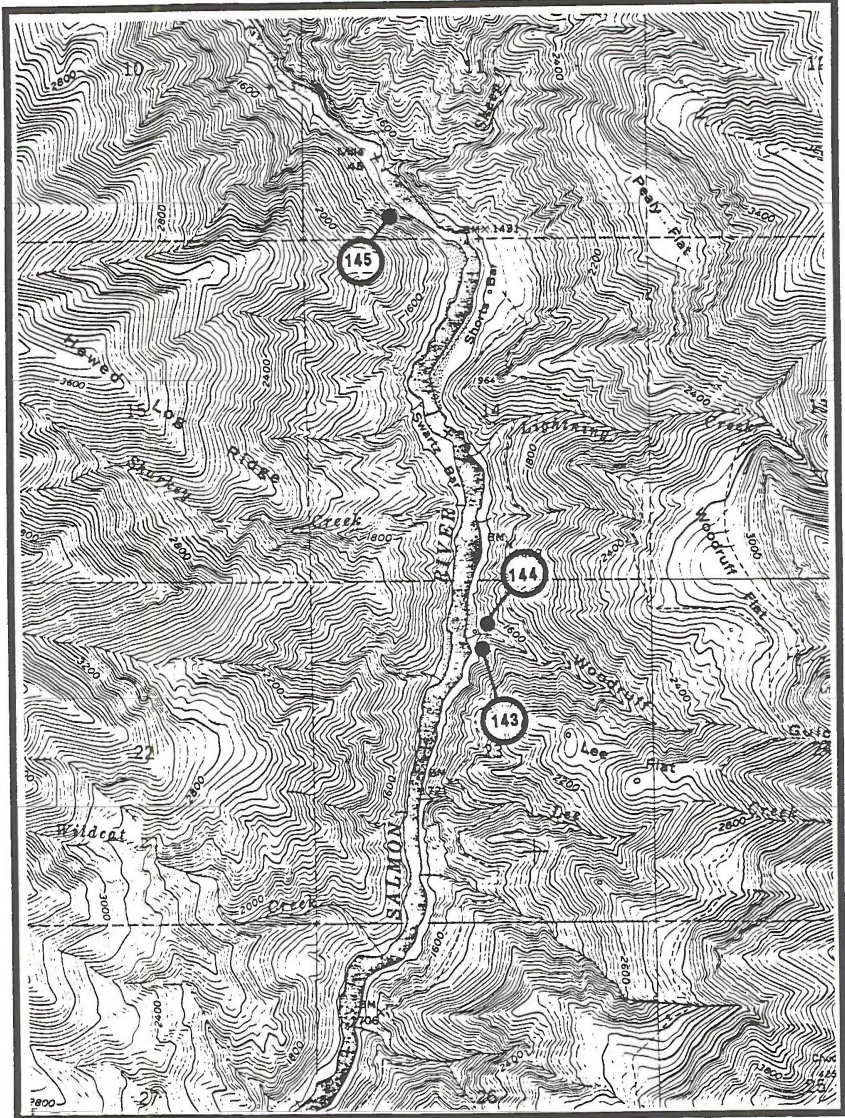

WHITE BIRD QUADRANGLE, IDAHO CO., ID

SITES $143,144,145$ 
B 38

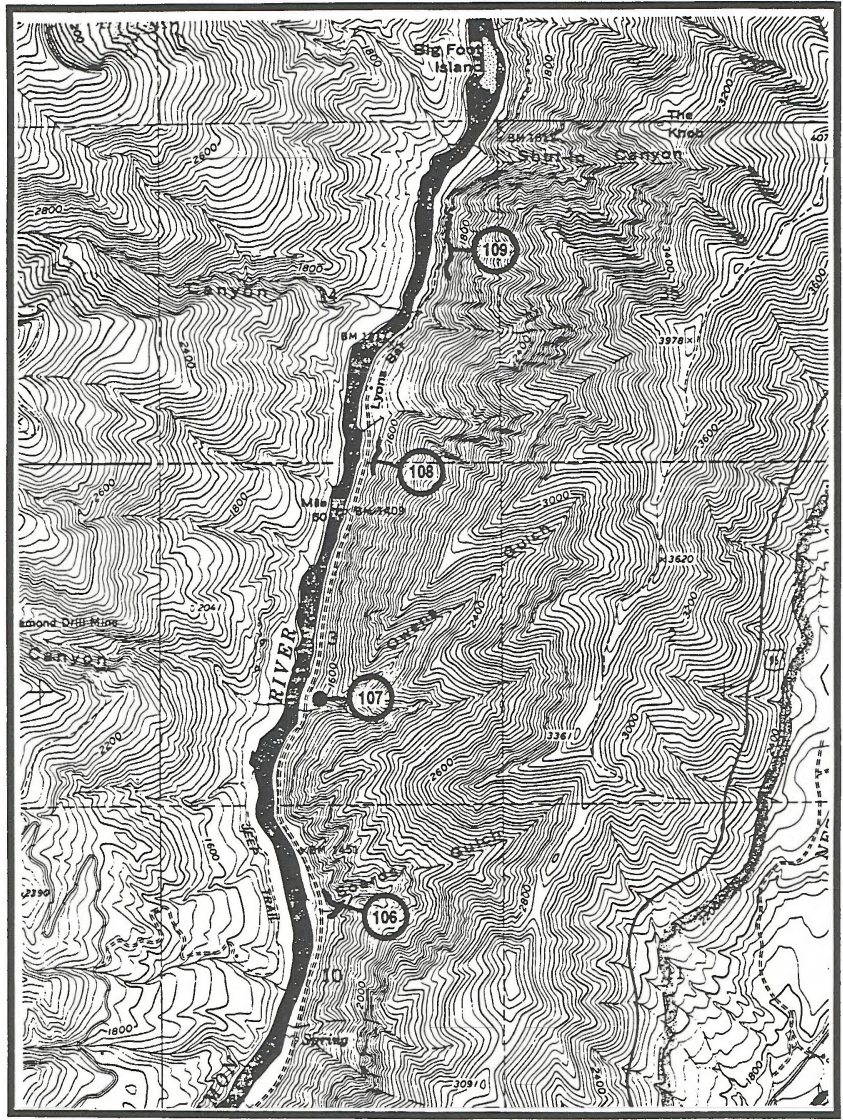

WHITE BIRD QUADRANGLE, IDAHO CO., ID

SITES 106, 107, 108, 109 


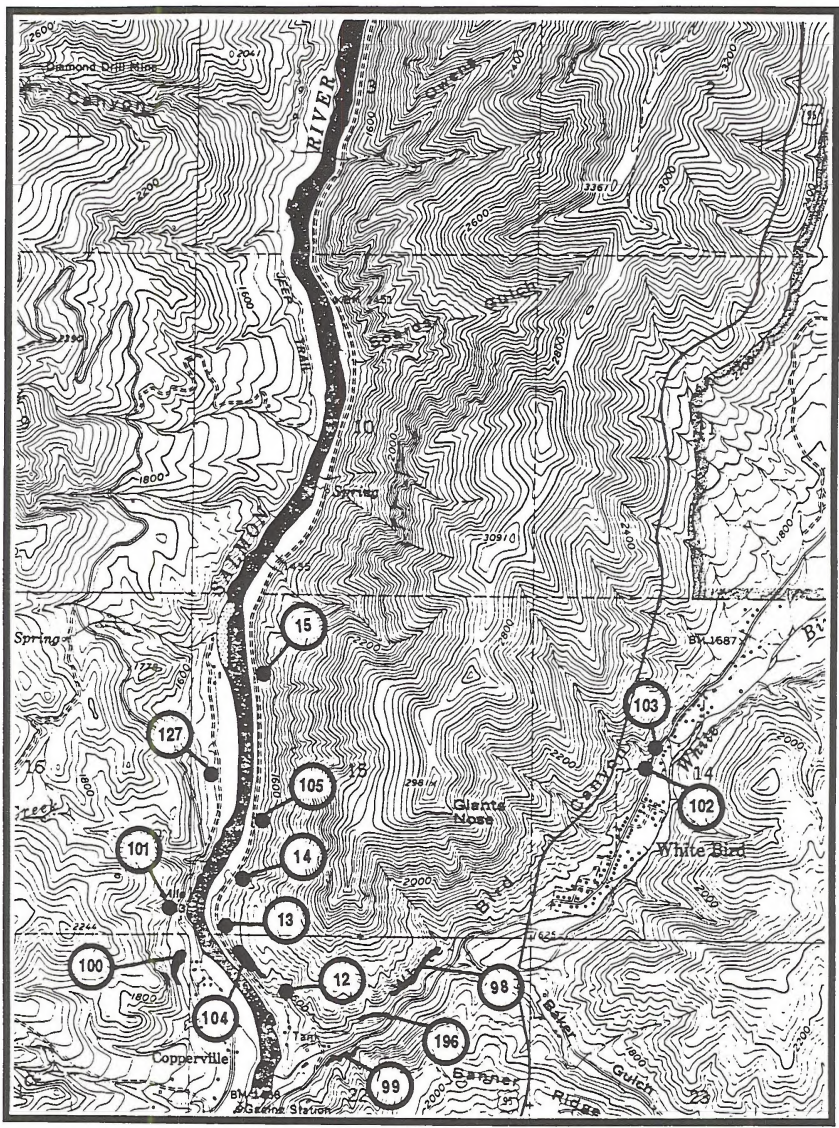

WHITE BIRD QUADRANGLE, IDAHO CO., ID

SITES 12, 13, 14, 15, 98, 99, 100, 101, 102, 103, 104, 105, 127, 196 
I

I

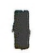

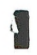

1

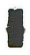

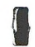

I

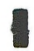

I

I

I

I

I

1

I

I

1 


\section{APPENDIX C. SPECIES DISTRIBUTION MAPS.}

Maps of distribution of each terrestrial mollusk species collected during this survey. Base map should be compared with Figure 1 (same scale). Black dots (or star in the case of Oreohelix hammeri, not collected but occurring in the area) indicate site locations: for details see Appendix A. Dots may represent more than one closely-spaced site. For site maps, see Appendix B. For site listing by taxon, see Table 4.

\section{SPECIES}

Allogona (Allogona) lombardii Smith, 1943.

Allogona (Allogona) ptychophora ptychophora (Brown, 1870).

Allogona (Allogona) ptychophora solida Vanatta, 1924.

Anguispira kochi occidentalis (Von Martens, 1882).

Catinella avara (Say, 1824).

Cochlicopa lubrica (Müller, 1774)...

Cryptomastix (Bupiogona) populi (Vanatta, 1924)

Cryptomastix (Cryptomastix) harfordiana (Binney, 1878).

Cryptomastix (Cryptomastix) mullani clappi (Hemphill, 1897).

Cryptomastix (C.) mullani latilabris (Pilsbry, 1940).

Cryptomastix (Cryptomastix) mullani mullani (Bland \& Cooper, 1861)..

Cryptomastix (Cryptomastix) mullani olneyae (Pilsbry, 1891)

Cryptomastix (Cryptomastix) n. sp. 3

Cryptomastix (Cryptomastix) n. sp. 5

Cryptomastix (Cryptomastix) n. sp. 6.

Deroceras sp.

Discus marmorensis Baker, 1932

Discus whitneyi (Newcomb, 1864)

Euconulus fulvus alaskensis Pilsbry, 1906.

Hawaiia minuscula (Binney, 1840).

Helicodiscus salmoneus Binney, 1886

Hemphillia camelus Pilsbry \& Vanatta, 1897.

Microphysula ingersolli (Bland, 1874)

Ogaridiscus subrupicola (Dall, 1877).

Oreohelix hammeri Fairbanks, 1984

Oreohelix haydeni hesperia Pilsbry, 1939

Oreohelix haydeni perplexa Pilsbry, 1939

Oreohelix idahoensis idahoensis (Newcomb, 1866)

Oreohelix intersum (Hemphill, 1890).

Oreohelix jugalis (Hemphill, 1890).

Oreohelix n. sp. 8.

Oreohelix n. sp. 12

Oreohelix n. sp. 13

Oreohelix n. sp. 14

Oreohelix n. sp. 15

Oreohelix n. sp. 19

Oreohelix n. sp. 20

Oreohelix n. sp. 21

Oreohelix n. sp. 22

\section{MAP}

C3

$\mathrm{C} 4$

$\mathrm{C} 5$

C6

$\mathrm{C} 7$

$\mathrm{C} 8$

C9

C10

C11

$\mathrm{C} 12$

$\mathrm{C}_{13}$

C14

C15

C16

C17

$\mathrm{C} 18$

C19

$\mathrm{C} 20$

C21

C22

C23

C24

C25

C26

C27

C28

C29

С30

C31

C32

C33

C34

C35

C36

C37

C38

C39

C40

C41 


\section{APPENDIX C. SPECIES DISTRIBUTION MAPS. (cont.)}

\section{SPECIES}

MAP

Oreohelix n. sp. 23.

$\mathrm{C} 42$

Oreohelix

n. sp. 24 .

$\mathrm{C} 43$

Oreohelix

n. sp. 25.

$\mathrm{C} 44$

Oreohelix

n. $s p .29$

$\mathrm{C} 45$

Oreohelix n. sp. 32.

C46

Oreohelix strigosa goniogyra Pilsbry, 1934

$\mathrm{C} 47$

Oreohelix strigosa n. subsp. 1

$\mathrm{C} 48$

Oreohelix vortex Berry, 1932

$\mathrm{C} 49$

Oreohelix waltoni Solem, 1975.

C50

Planogyra clappi (Pilsbry, 1898)

C51

Polygyrella polygyrella (Bland \& Cooper, 1861)............................... C52

Pristiloma (Pristinopsis) idahoense (Pilsbry, 1902).......................... C53

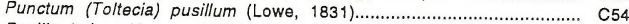

Pupilla hebes (Ancey, 1881).................................................... C55

Radiodiscus (Radiodomus) abietum Baker, 1930............................. C56

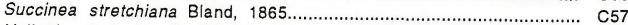

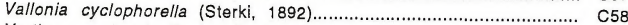

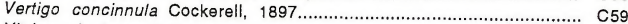

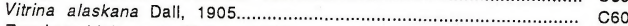

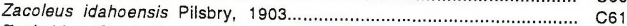

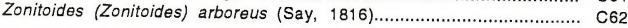


Allogona (Allogona) lombardll Smlth, 1943

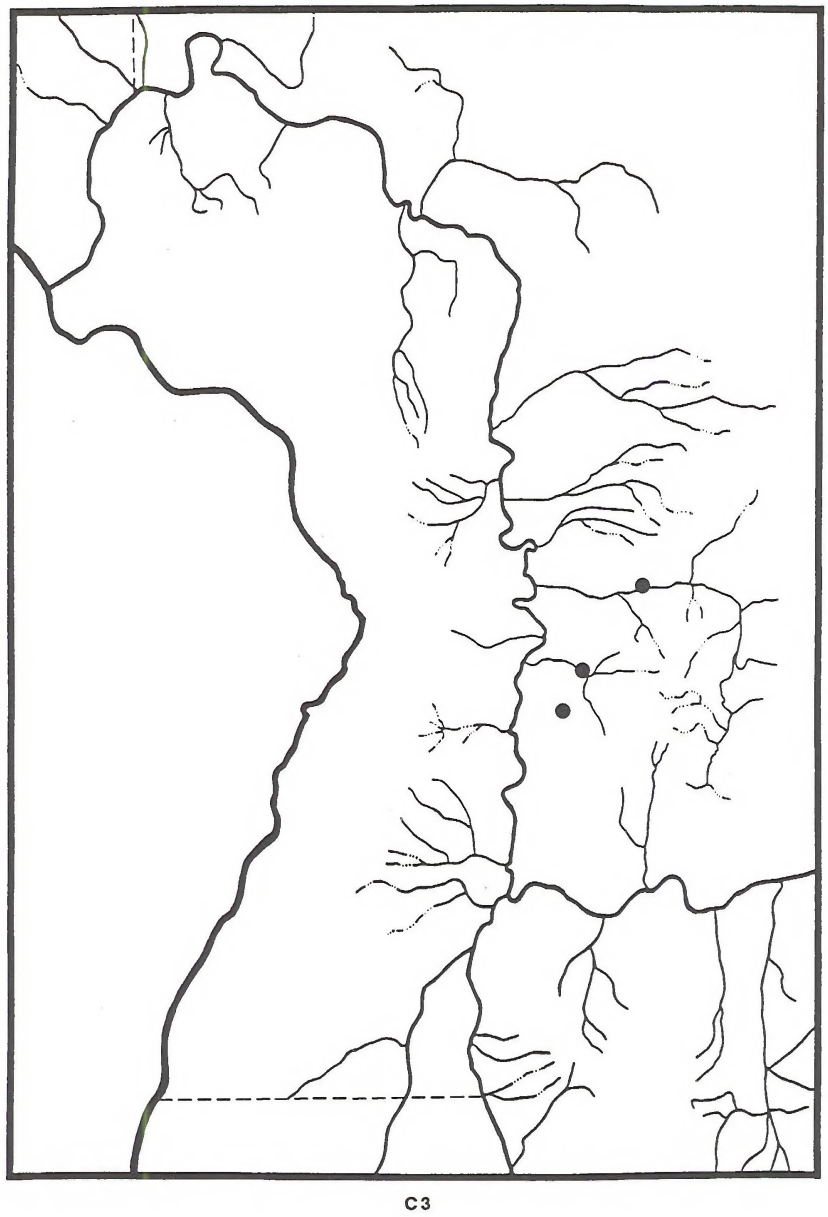


Allogona (Allogona) ptychophora ptychophora (Brown, 1870)

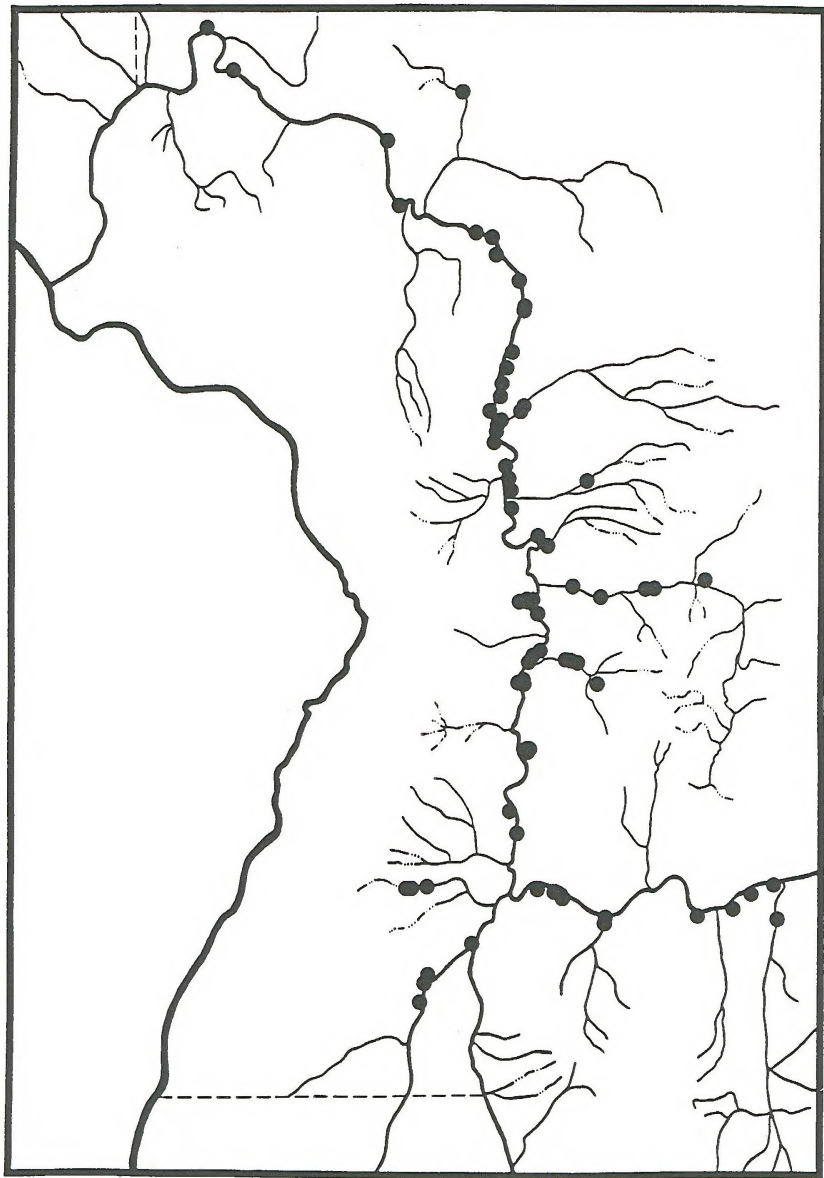


Allogona (Allogona) ptychophora sollda Vanatta, 1924

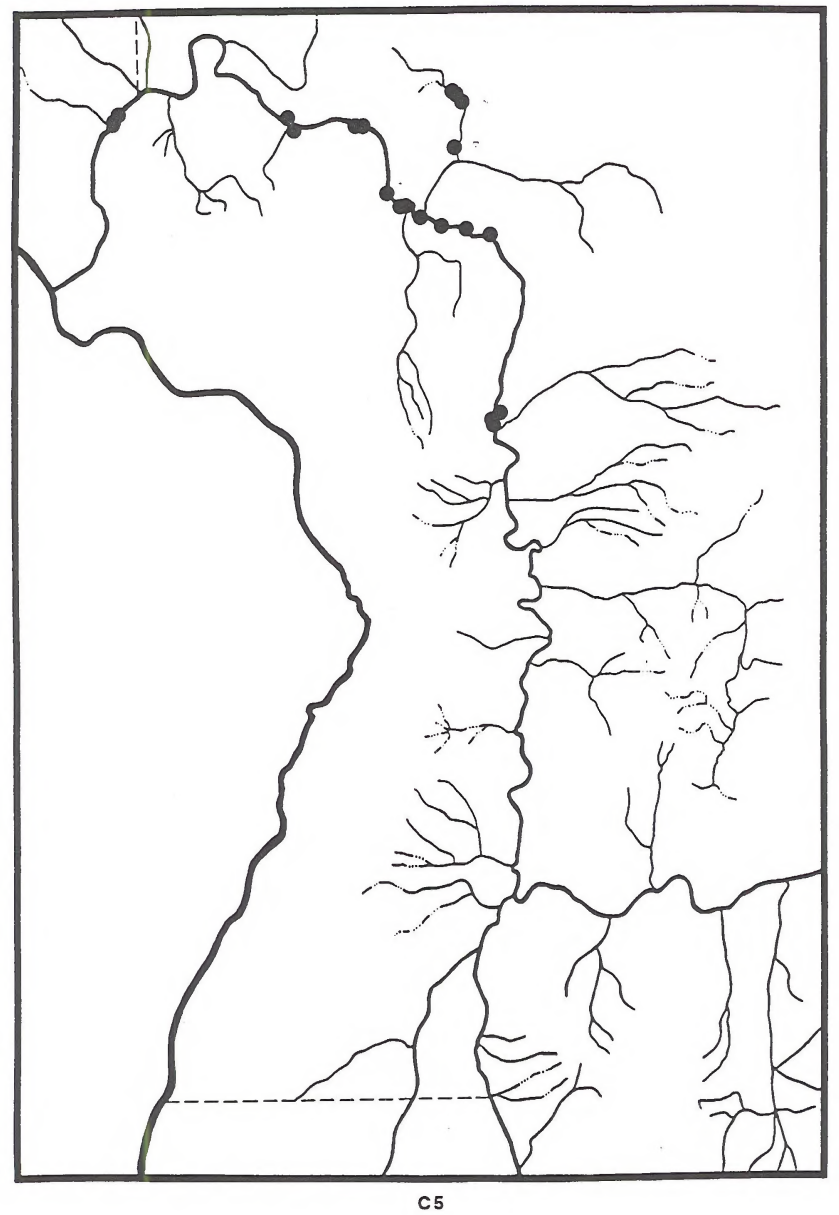


Anguispira kochi occidentalis (Von Martens, 1882)

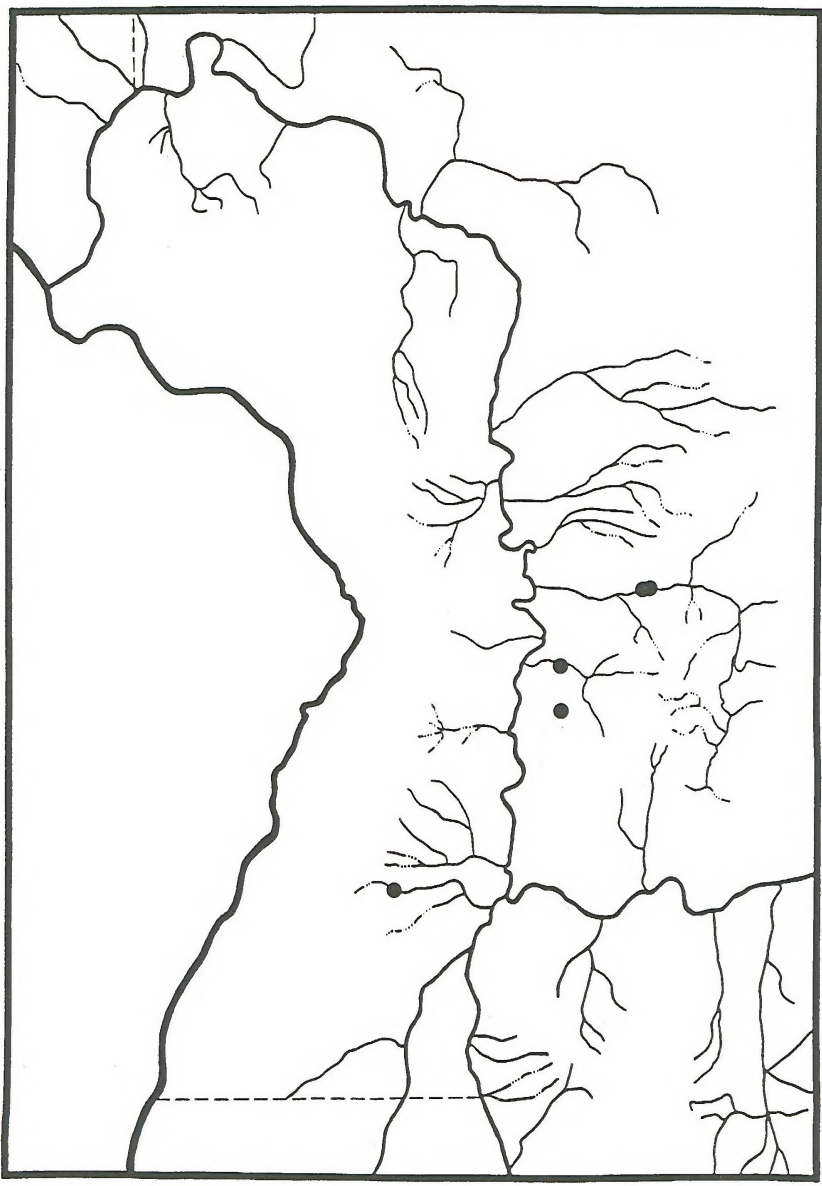

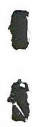

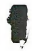

1

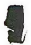

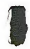

I

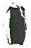

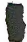

1

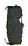

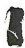

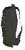

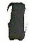

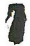

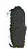

C6 
Catinella avara (Say, 1824)

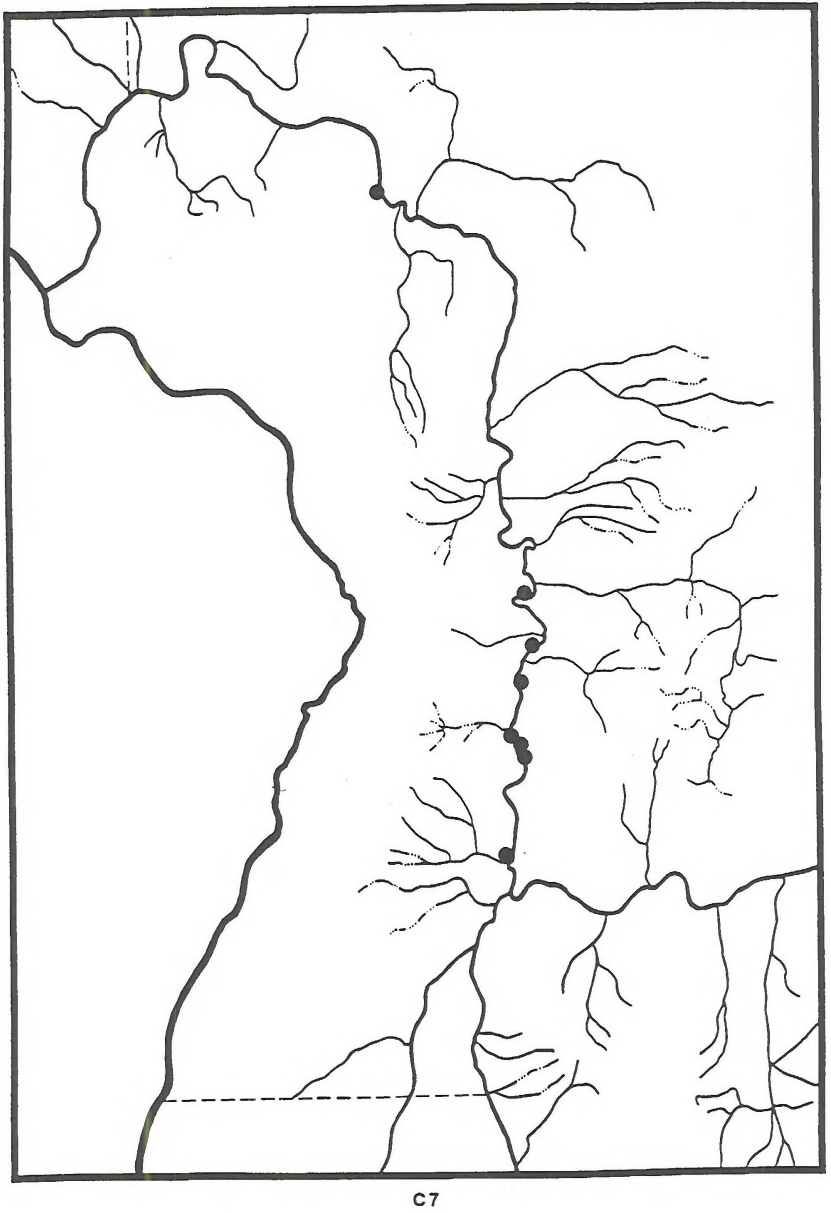


Cochlicopa lubrica (Müller, 1774)

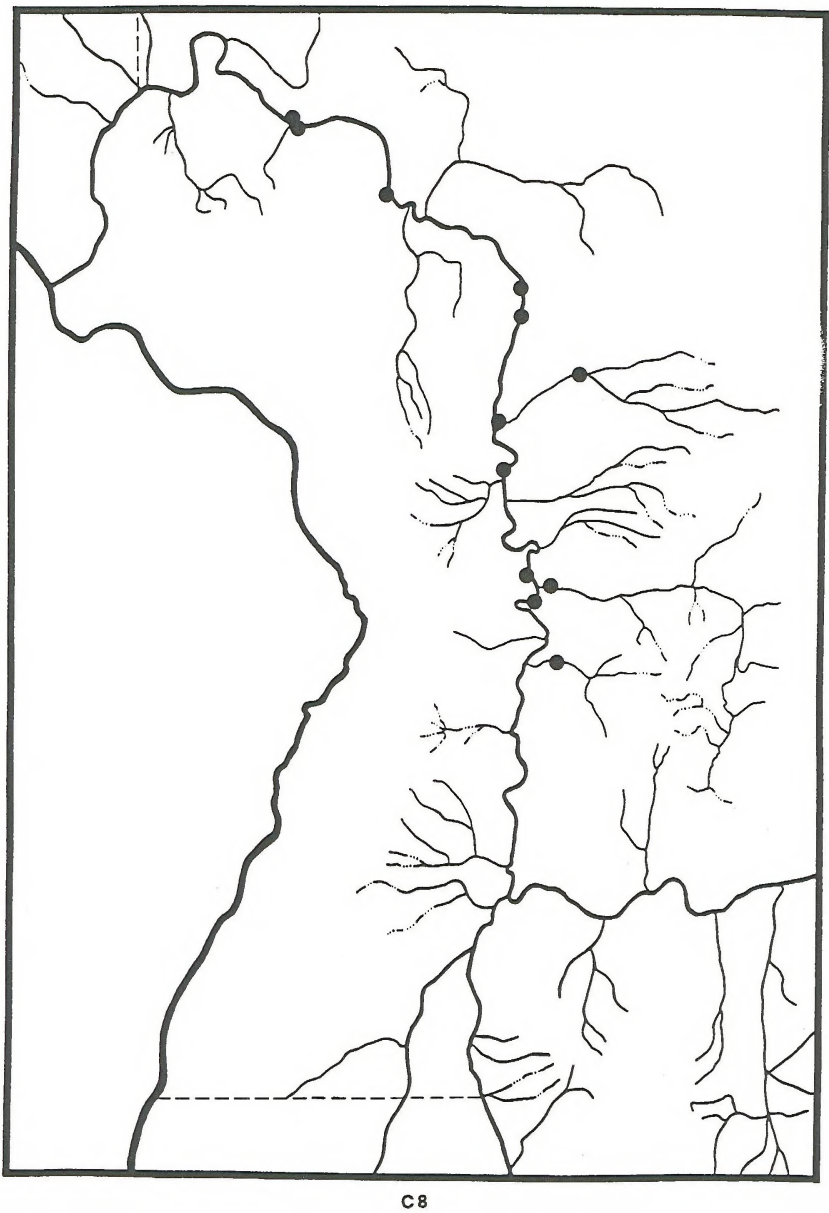

1
1
1
1
1
1
1
1
1
1
1
1
1
1 
Cryptomastlx (Buplogona) popull (Vanatta, 1924)

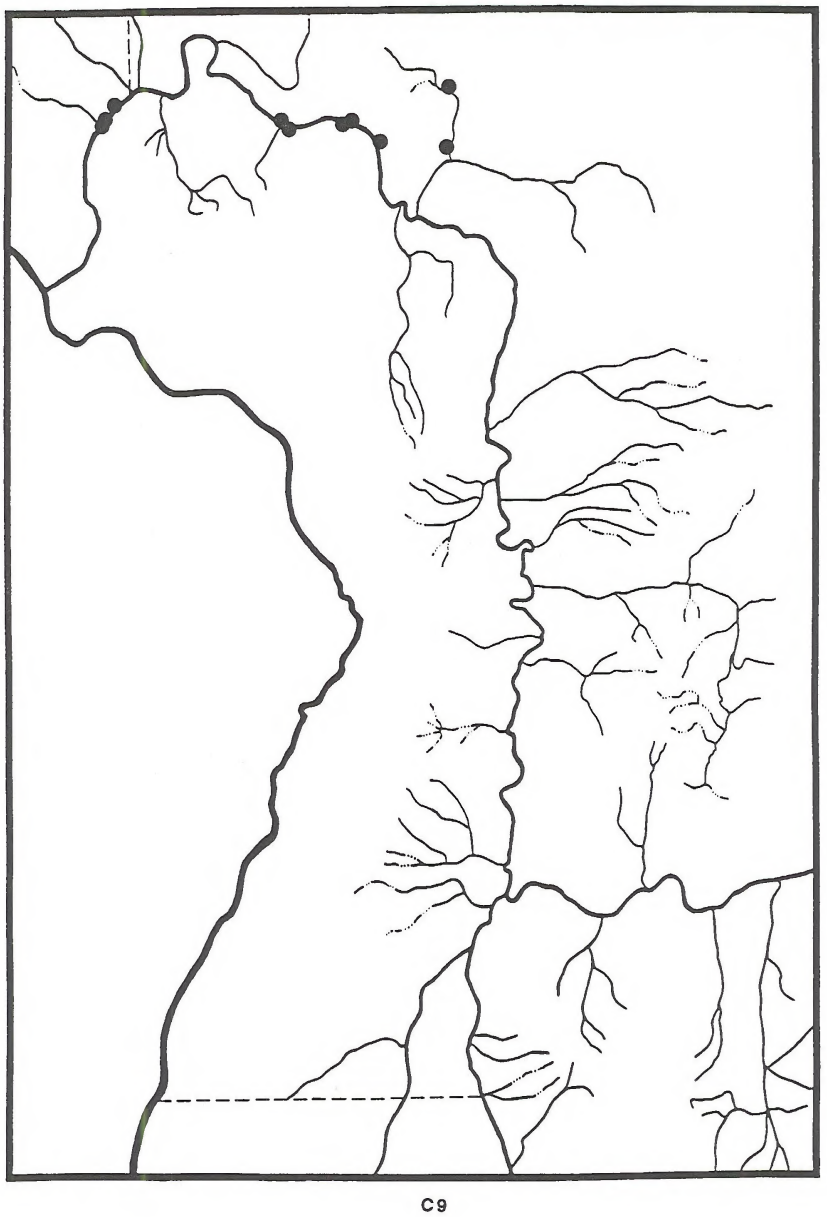


Cryptomastlx (Cryptomast/x) harfordlana (BInney, 1878)

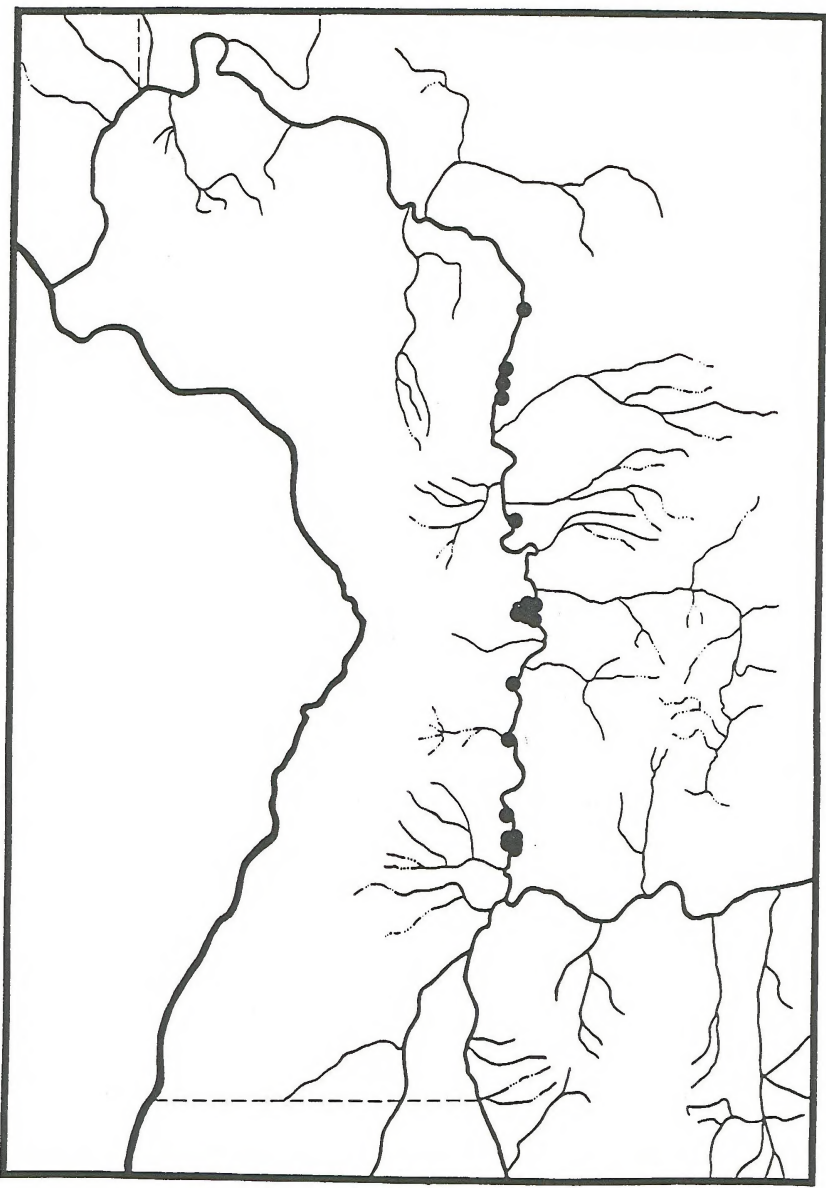

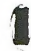

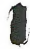

1

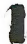

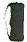

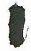

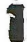

I

I

I

I

I

।

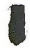

I

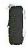

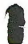

C10 


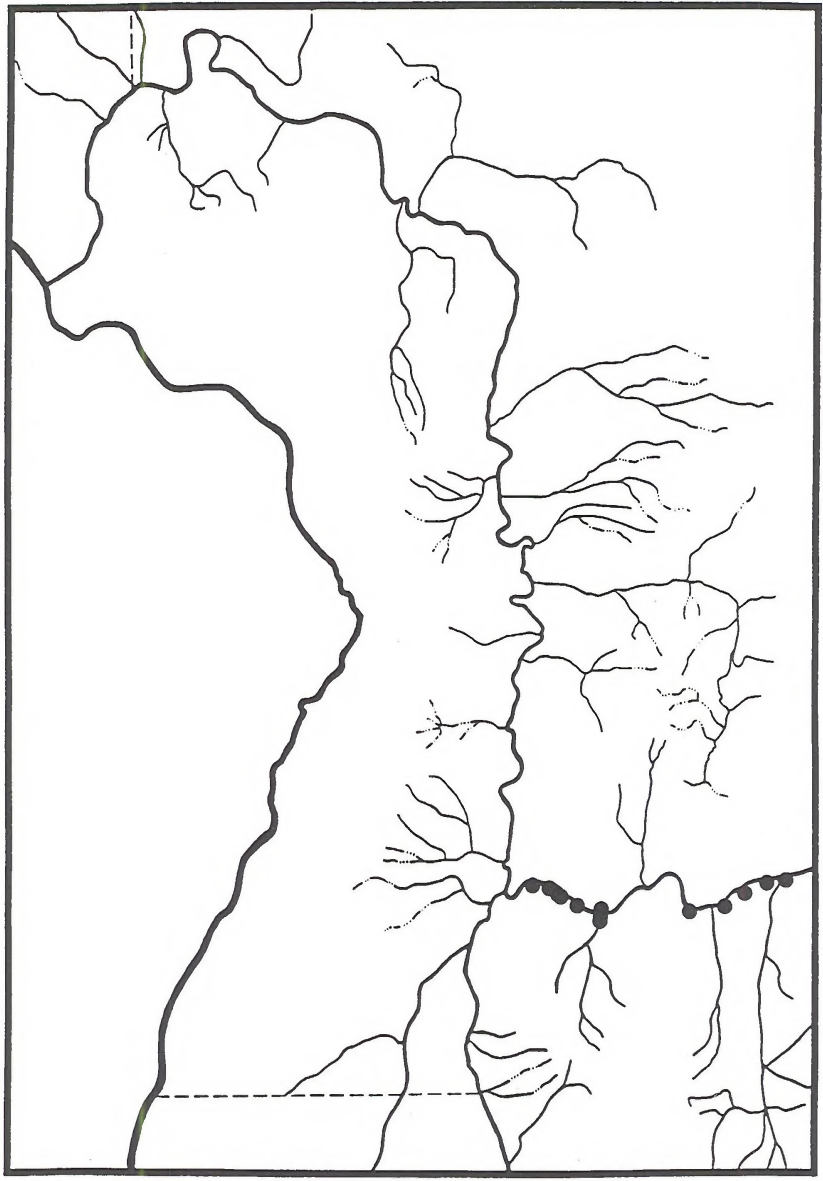


Cryptomastix (Cryptomastix) mullani latilabris (Pilsbry, 1940)

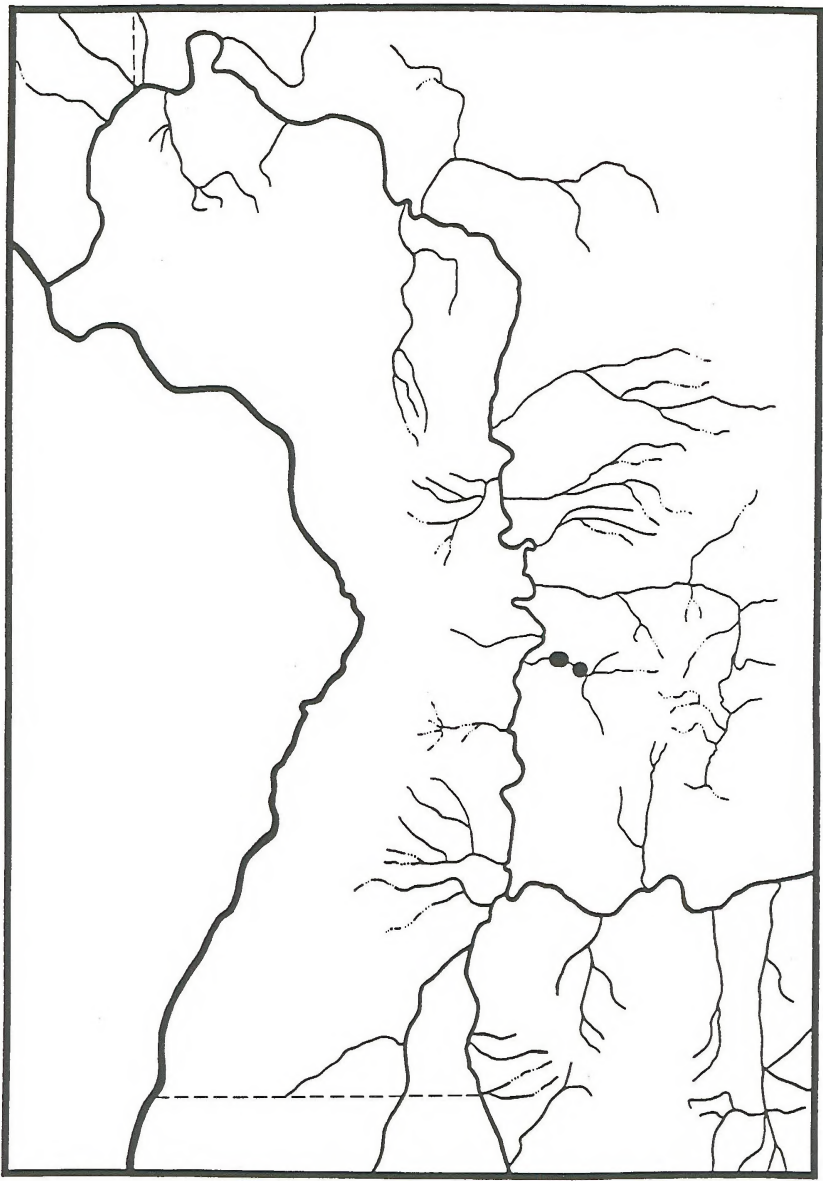


Cryptomastlx (Cryptomastlx) mullani mullanl (Bland \& Cooper, 1861)

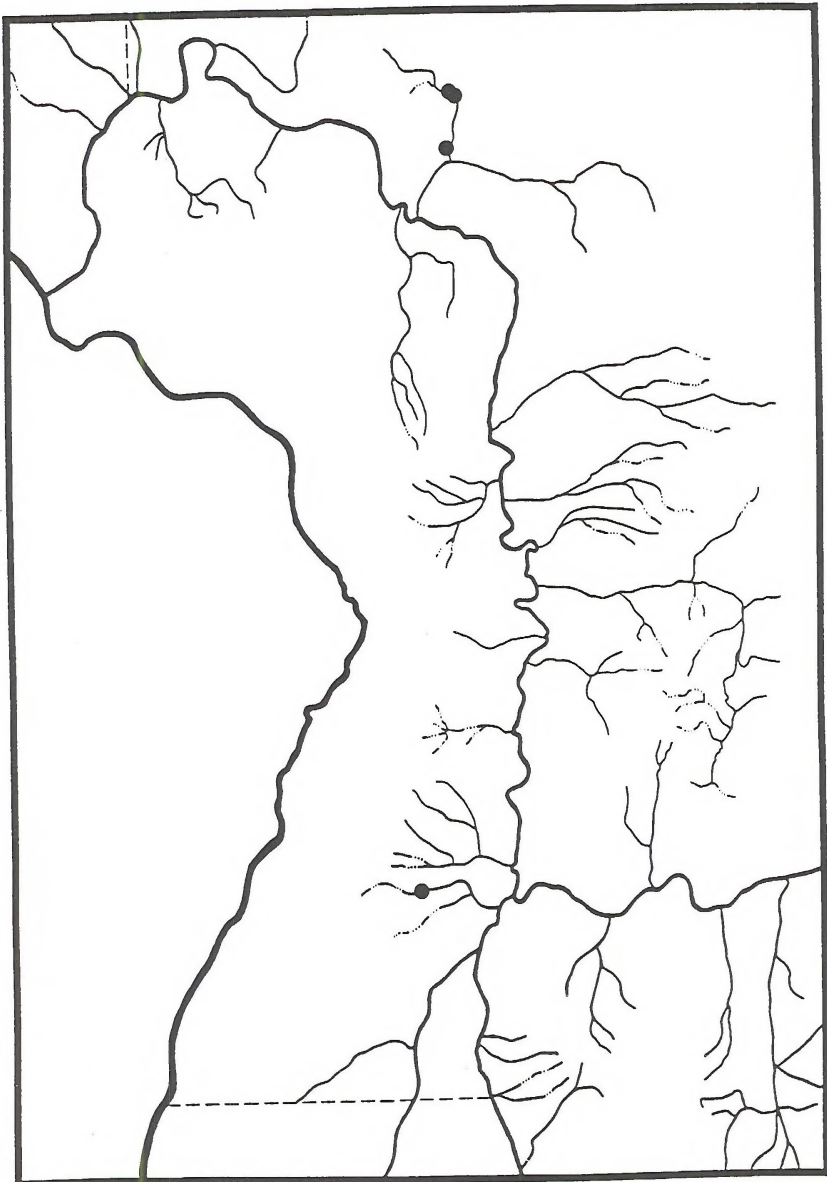

C13 


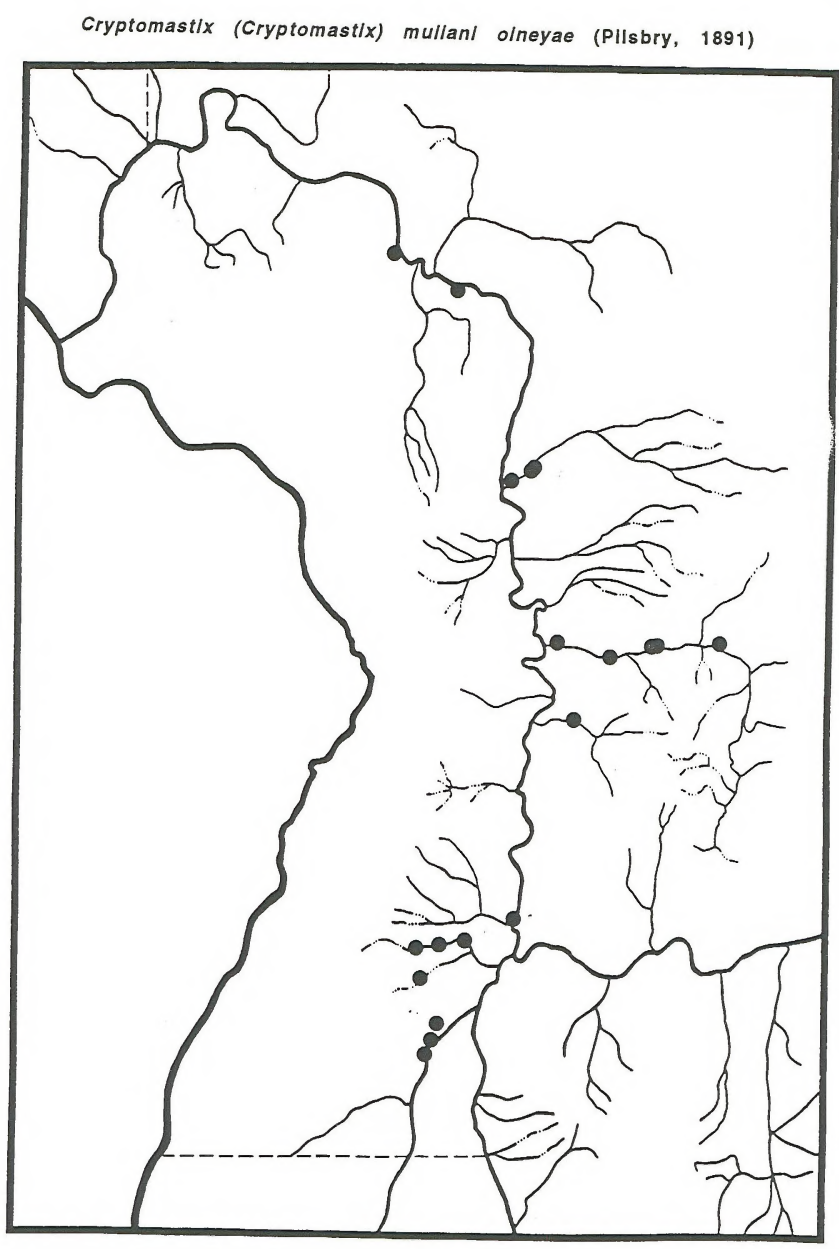

1

1

1

1

1

1

1

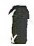

I

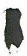

I

I

I

I

I

I

I

C14 
Cryptomastix (Cryptomastix) n. sp. 3

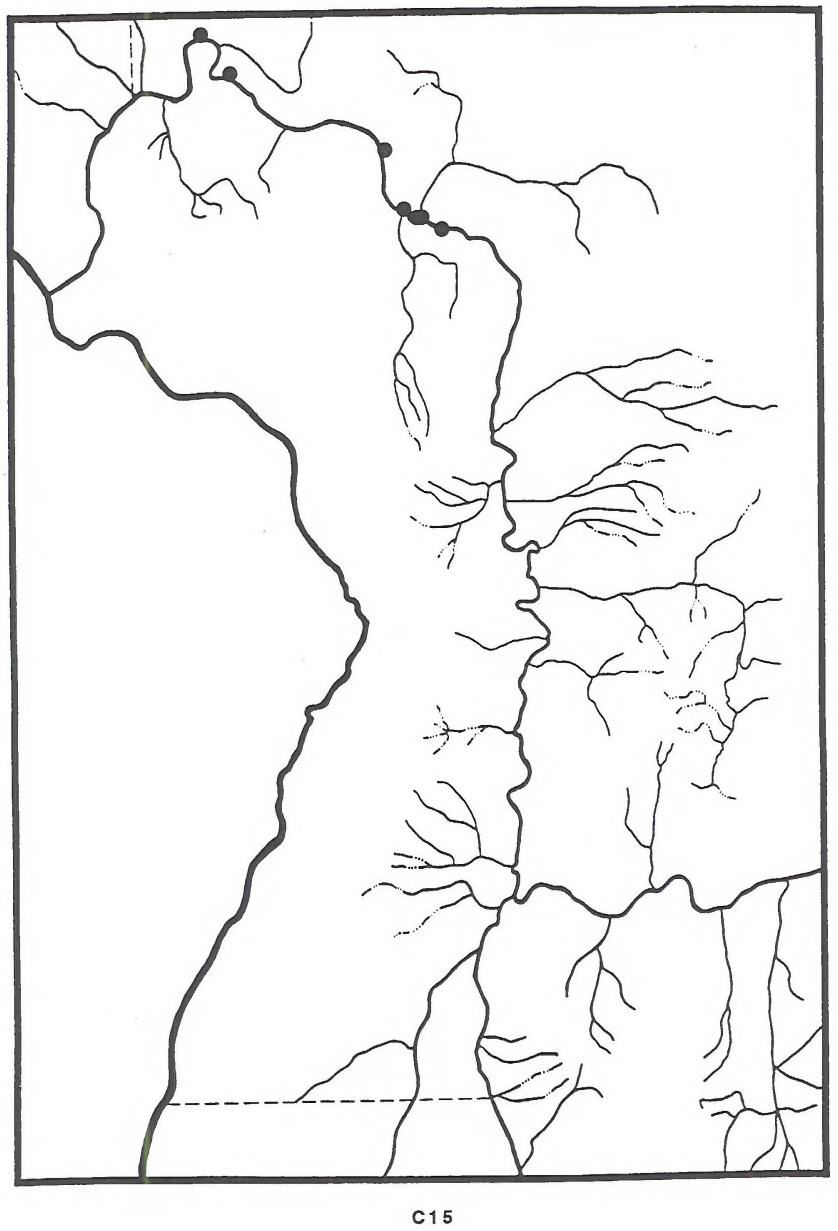


Cryptomastix (Cryptomastix) n. sp. 5

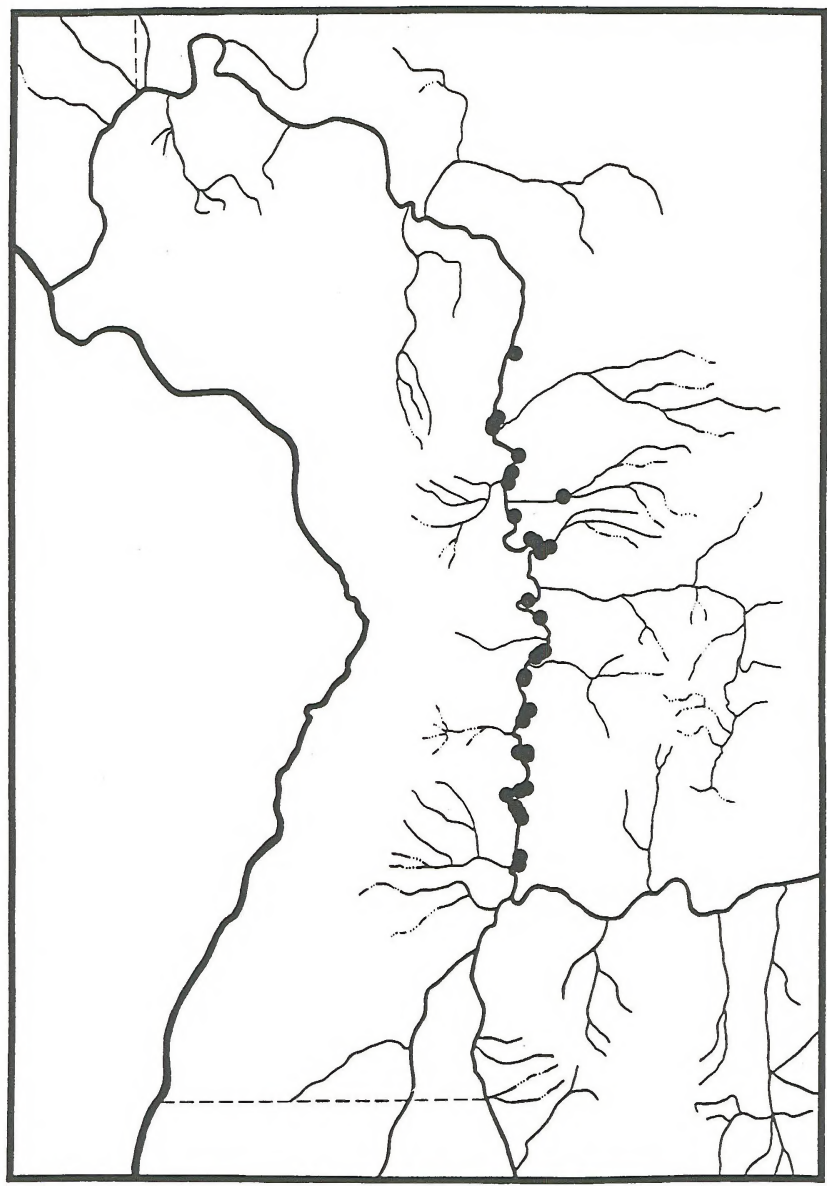

1

i

I

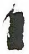

I

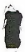

I

I

I

I

I

i

I

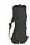

C16 


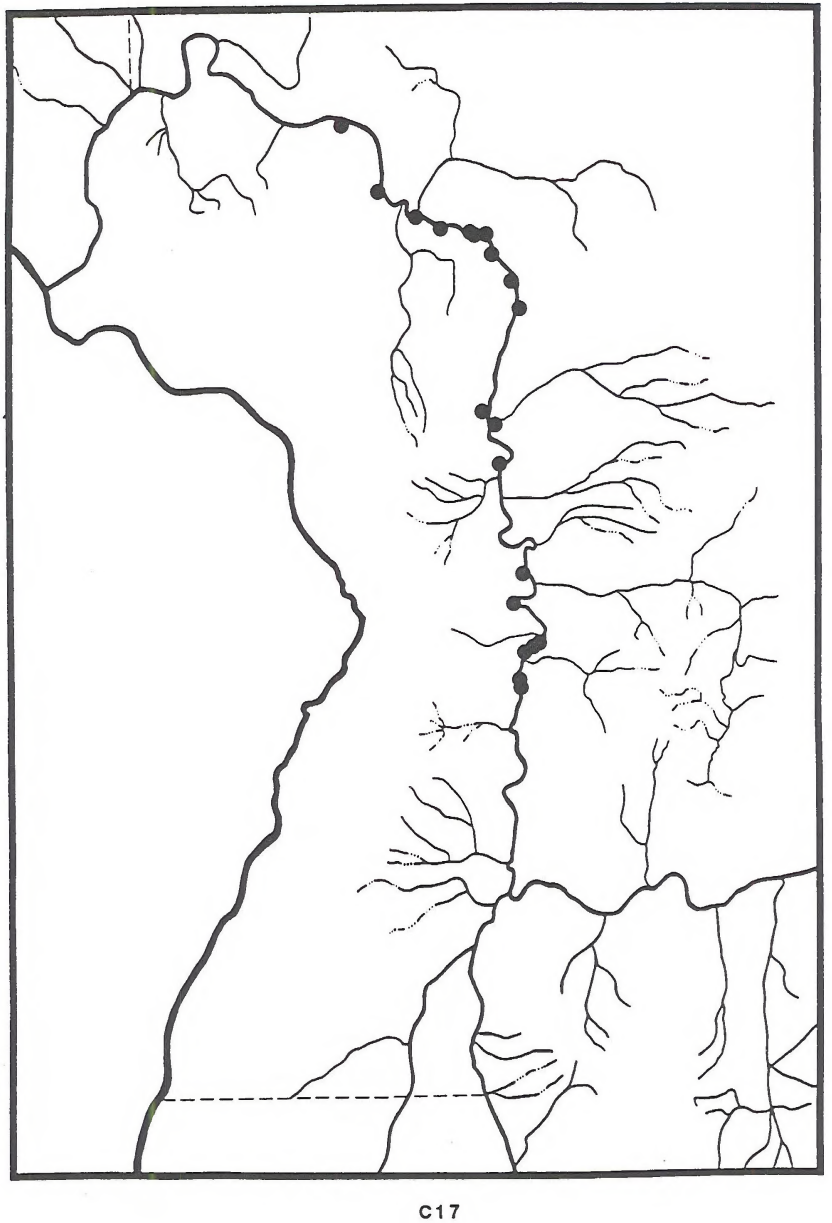


Deroceras sp.

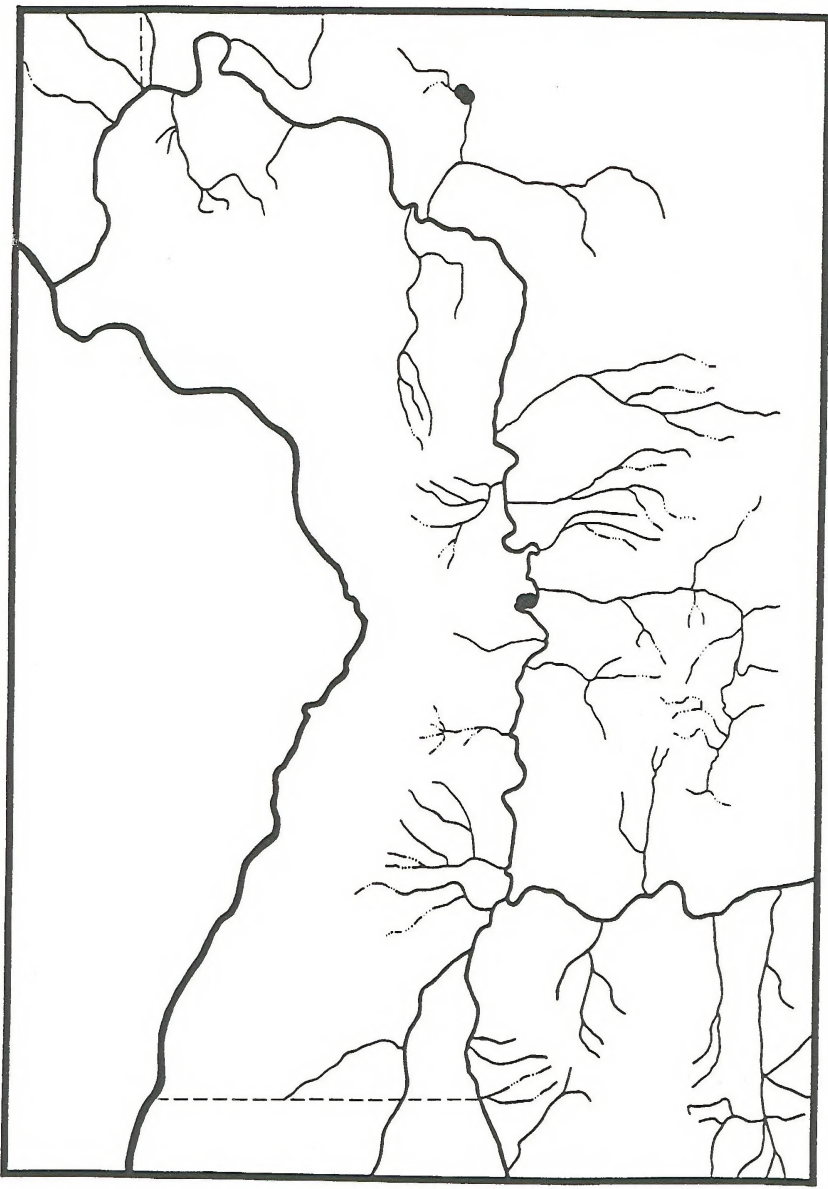

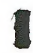

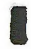

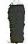

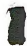

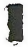

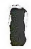

1

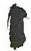

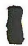

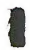

I

I

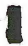

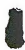

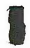

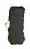

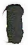

C18 


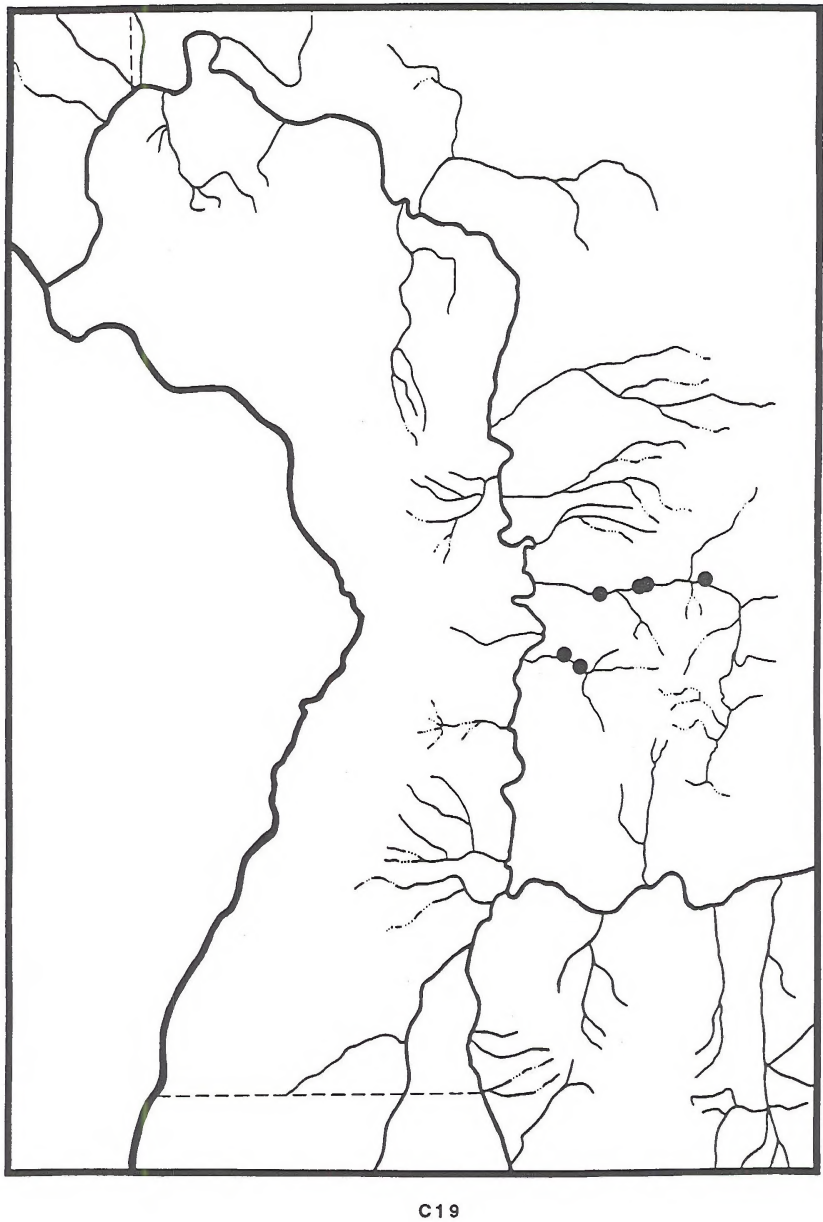


Dlscus whltneyl (Newcomb, 1864)

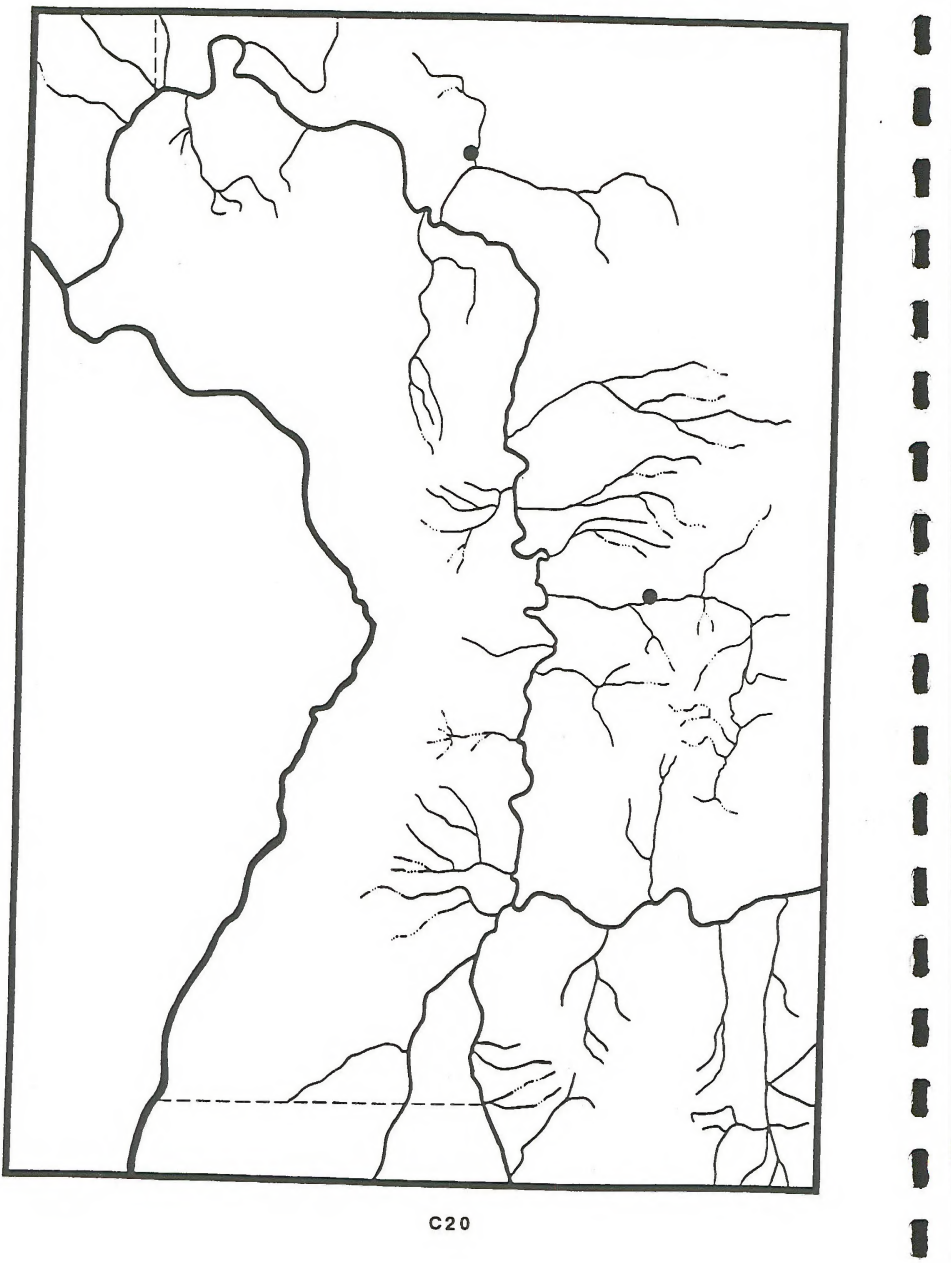


Euconulus fulvus alaskensis Plisbry, 1906

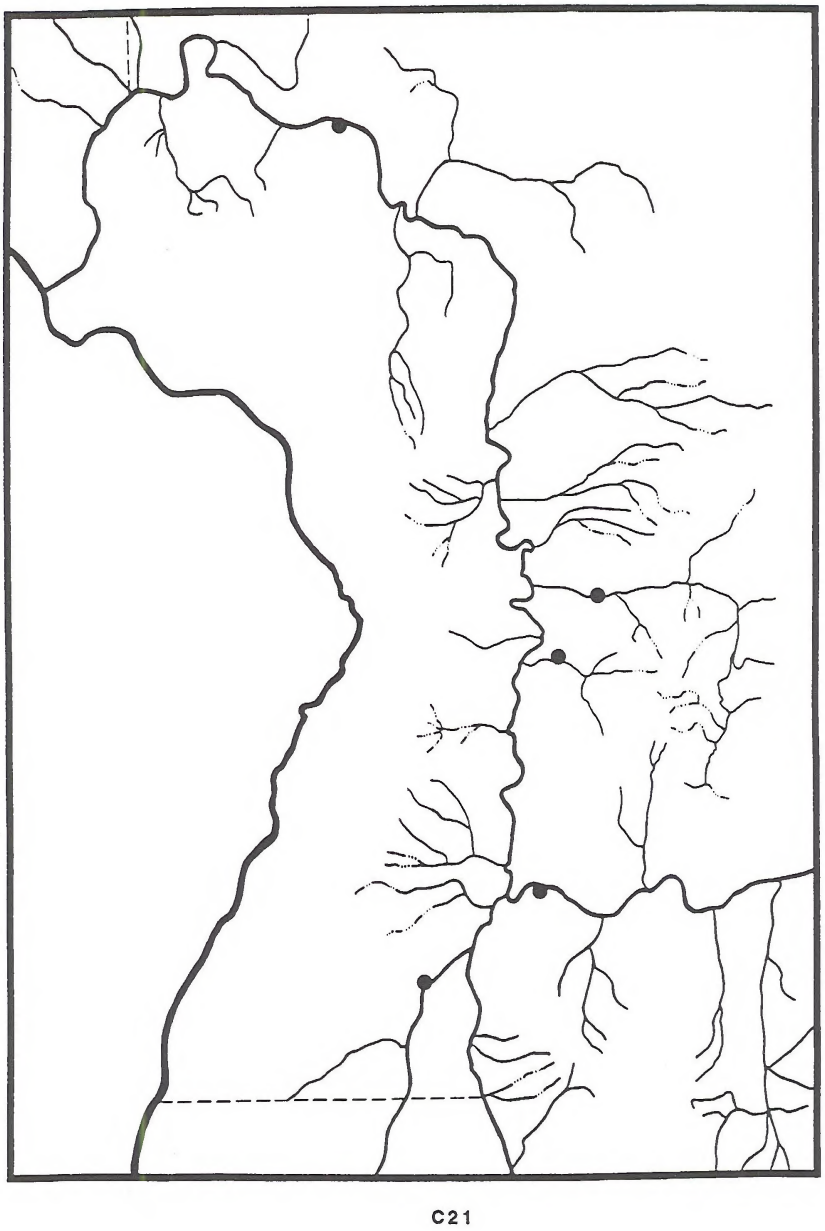




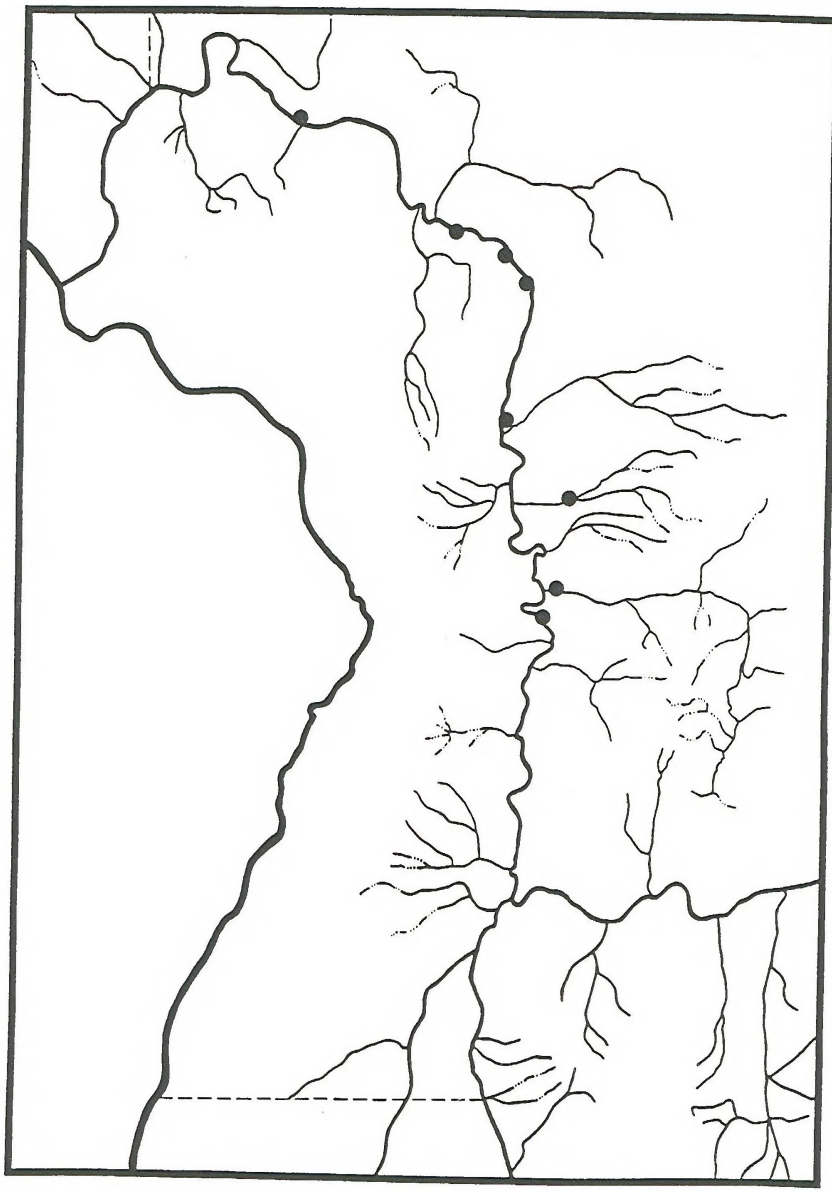


Hellcodiscus salmoneus Binney, 1886

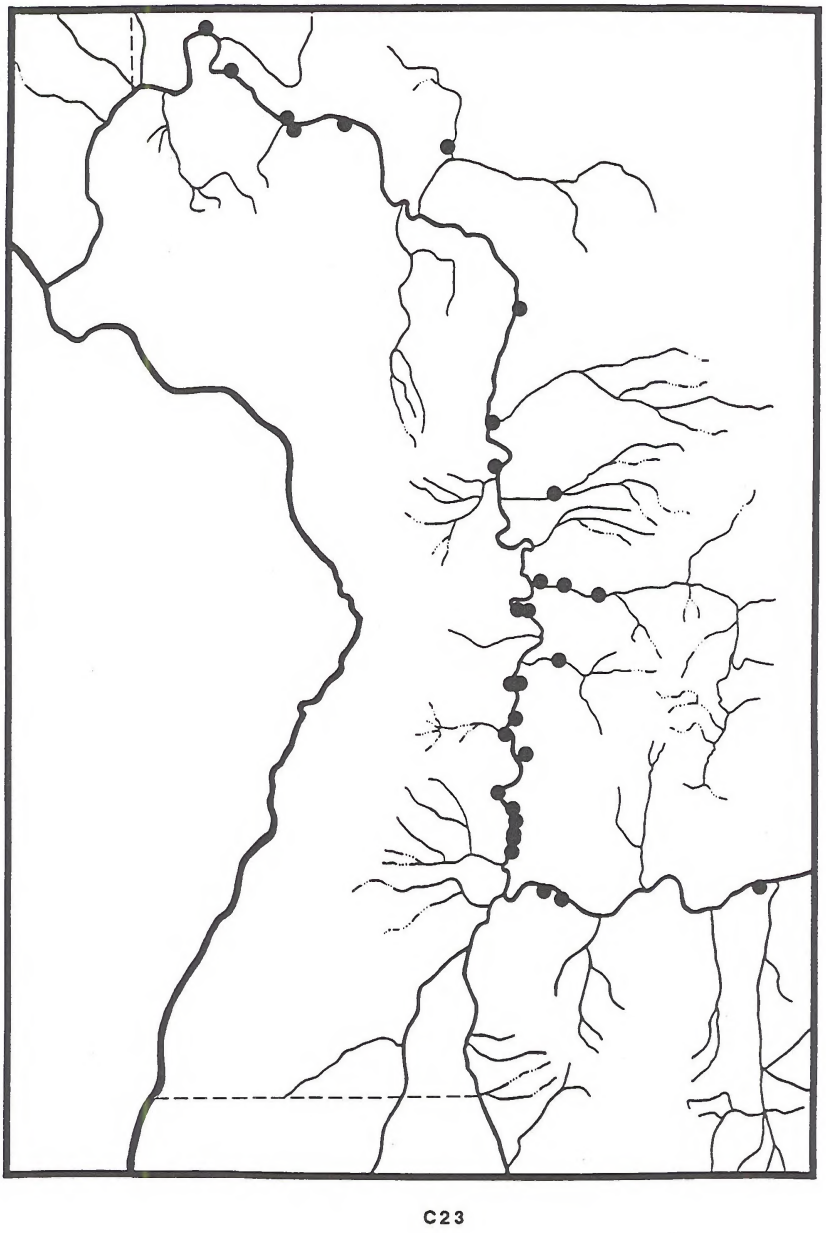


Hemphillia camelus Pilsbry \& Vanatta, 1897

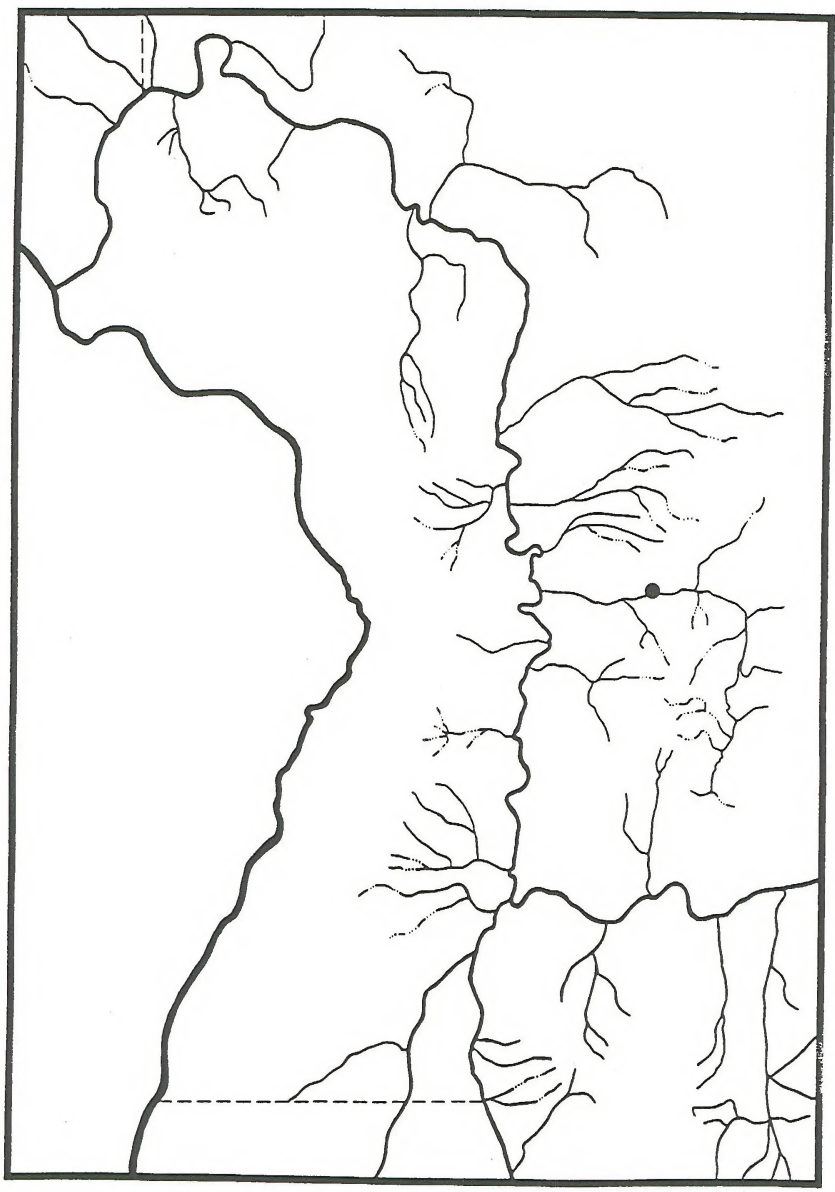

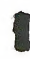

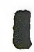

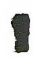

1

1

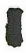

1

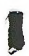

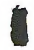

I

I

I

I

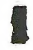

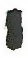

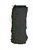

C2 4 
Mlcrophysula Ingersolll (Bland, 1874)

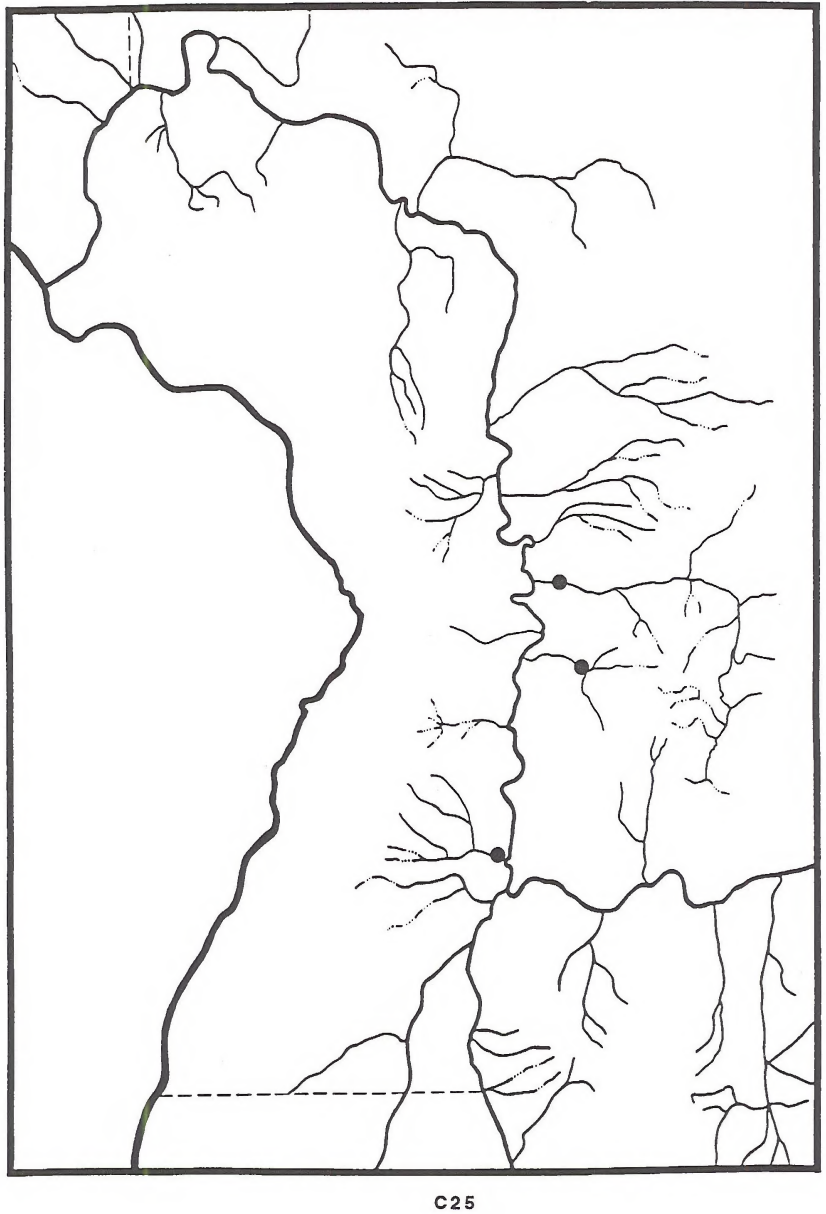


Ogaridiscus subrupicola (Dall, 1877)

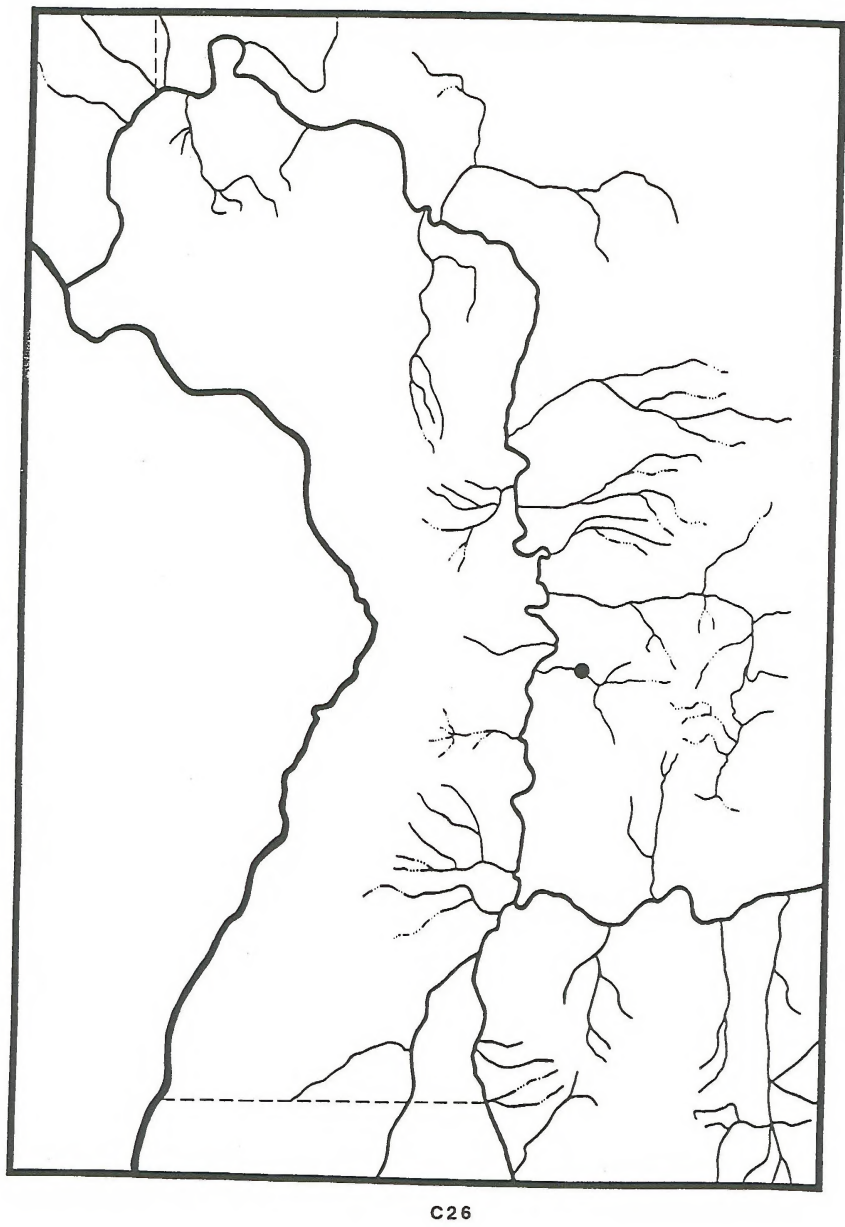

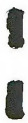

1

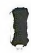

1

I

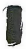

I

I

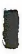

I

I 


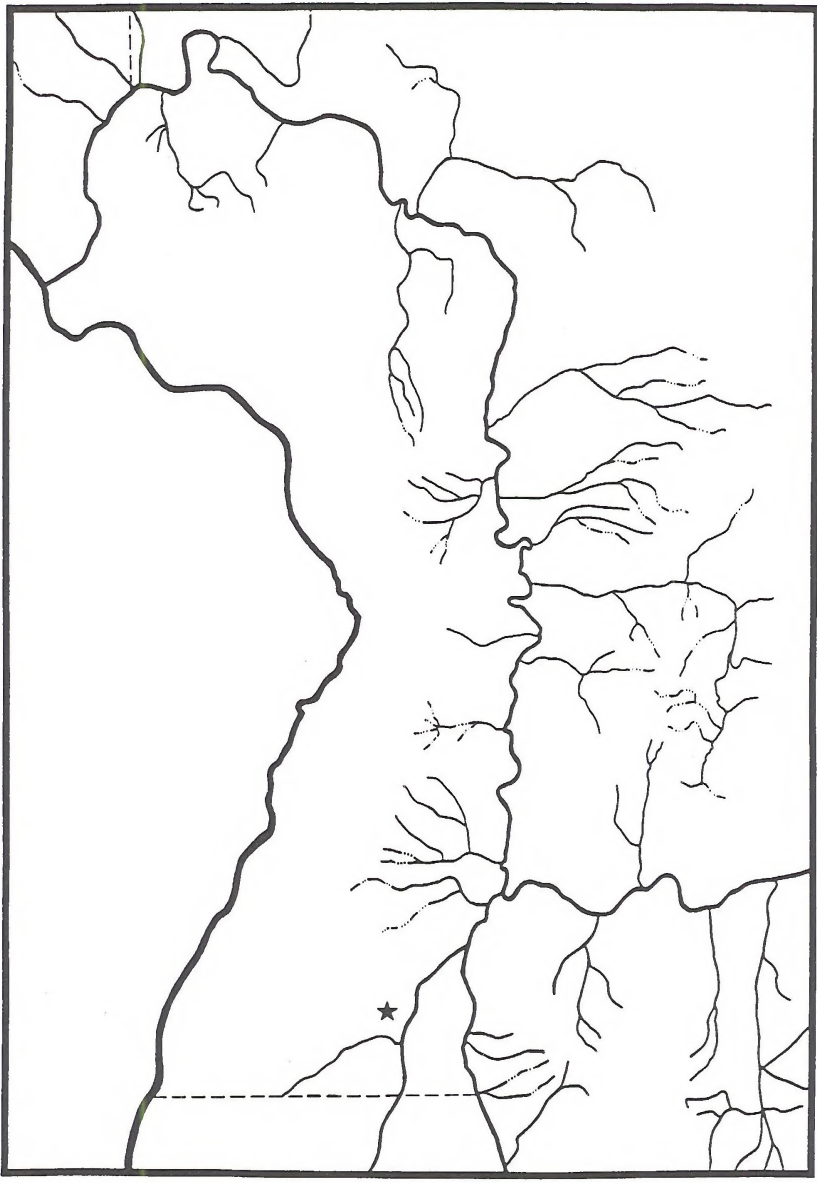


Oreohelix haydeni hesperia Pilsbry, 1939

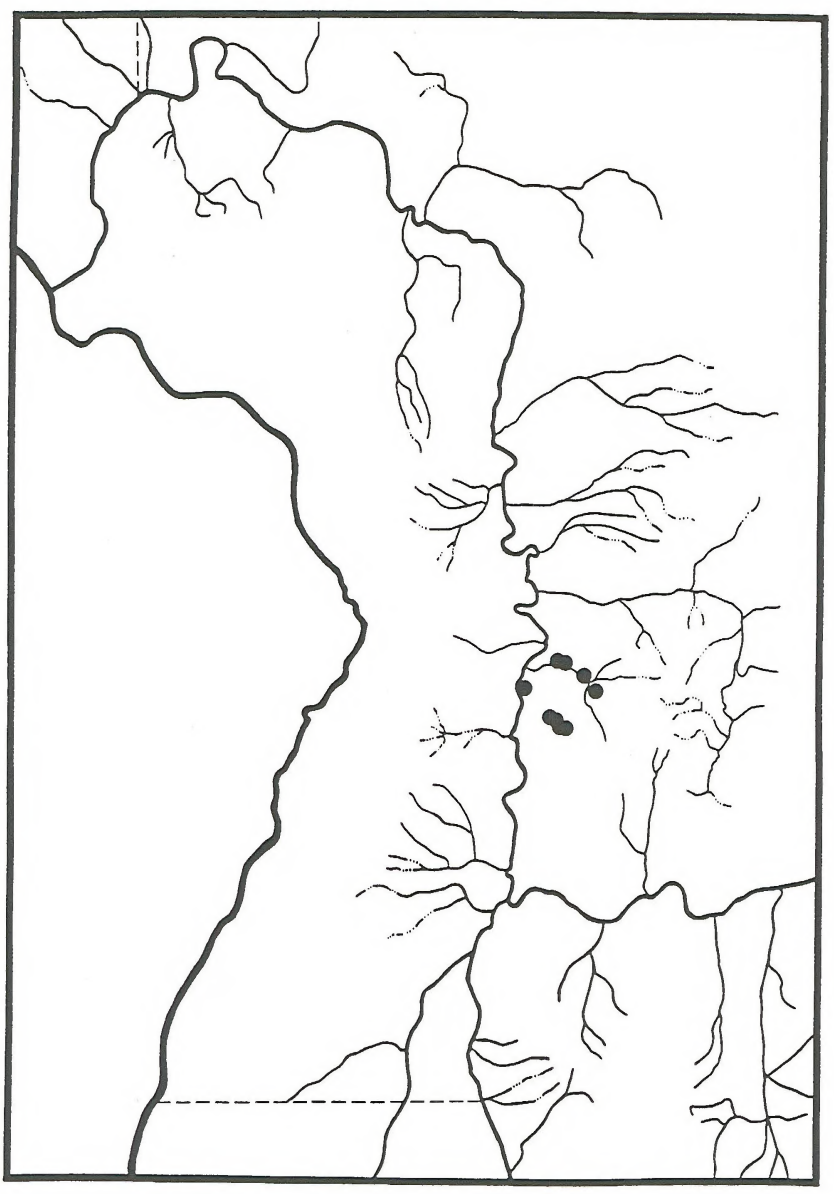

C2 8 


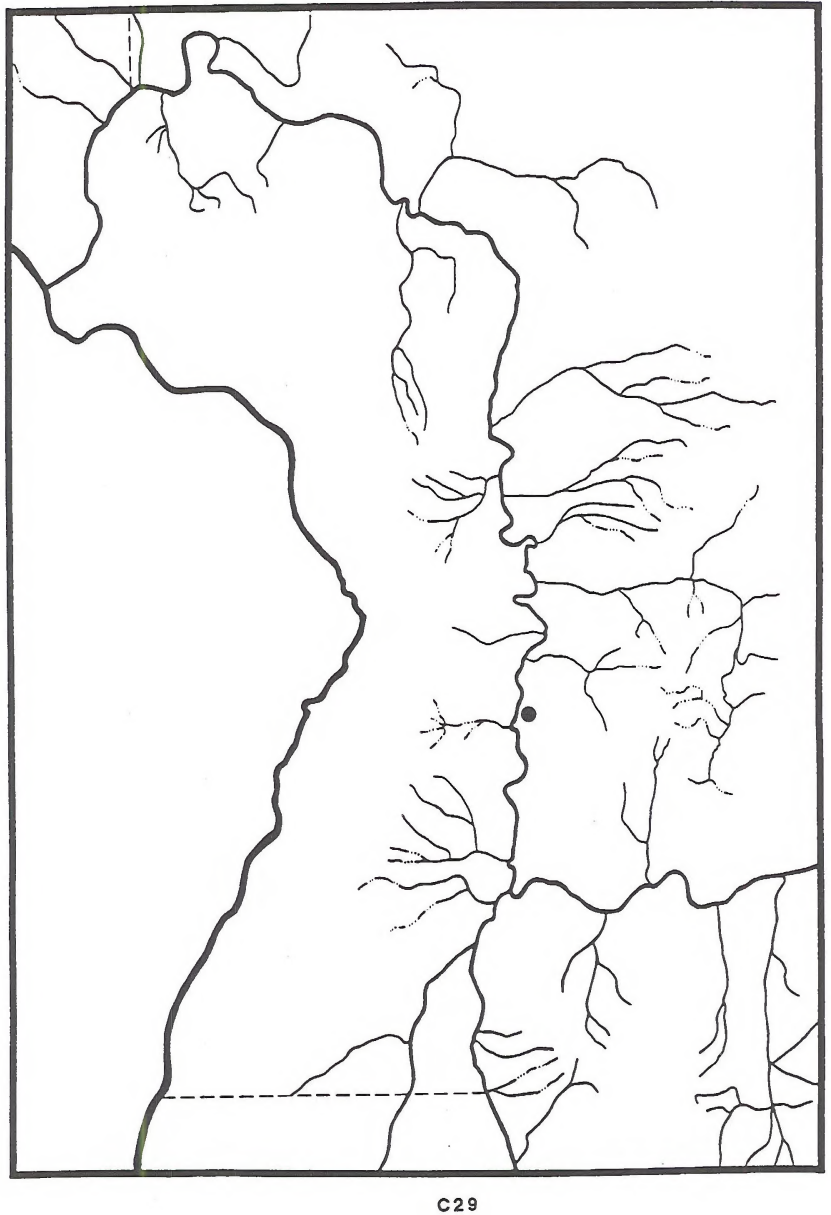


Oreohelix idahoensis idahoensis (Newcomb, 1866)

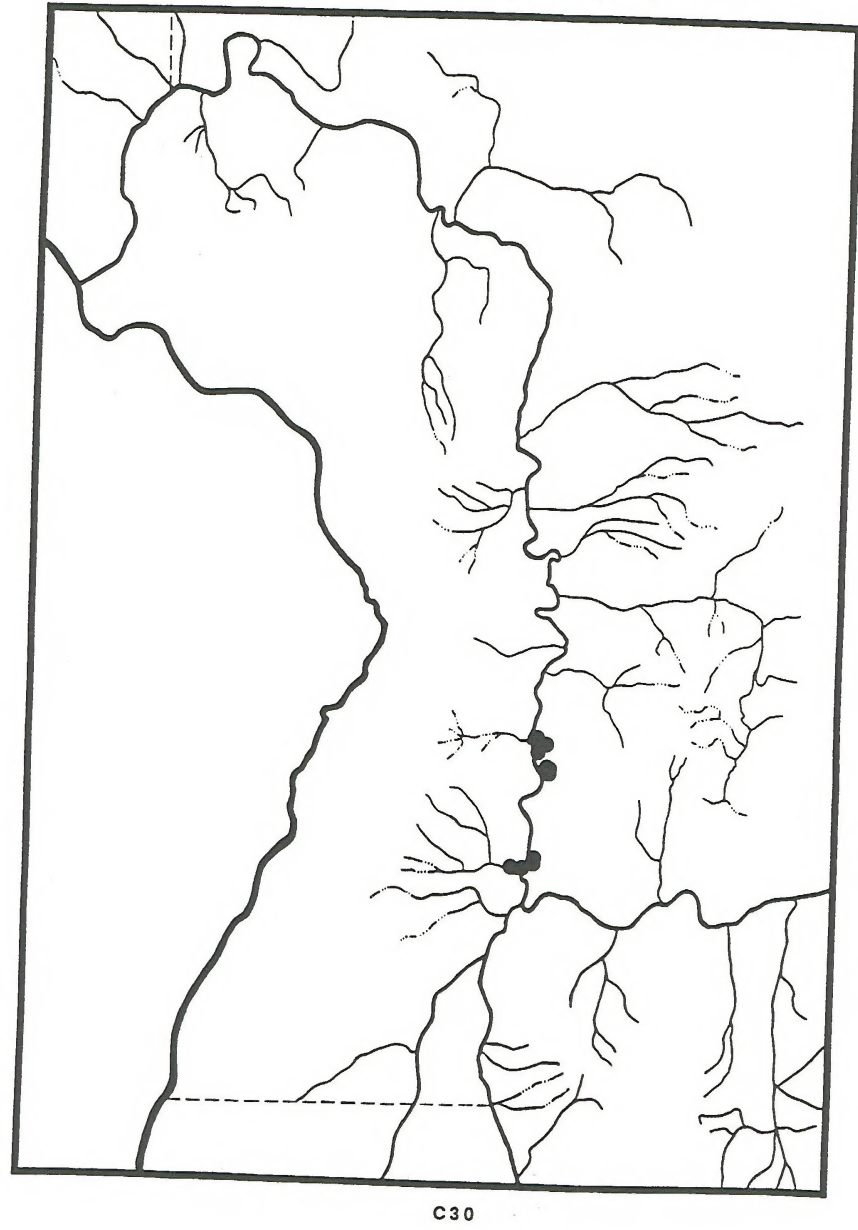

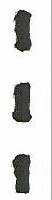

1

I

I

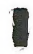

I

I

I

I

I

I

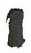

I

I

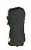

C30 
Oreohelix intersum (Hemphill, 1890)

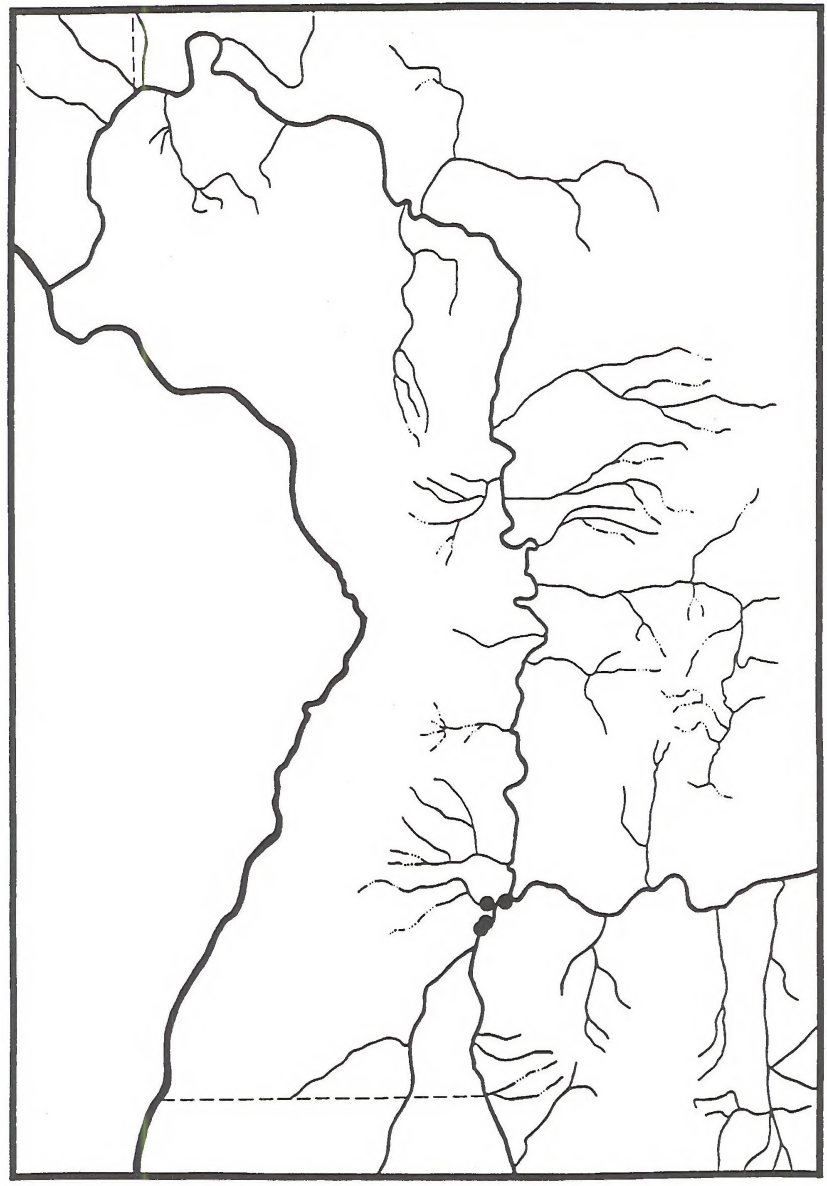

C31 
Oreohelix jugalis (Hemphill, 1890)

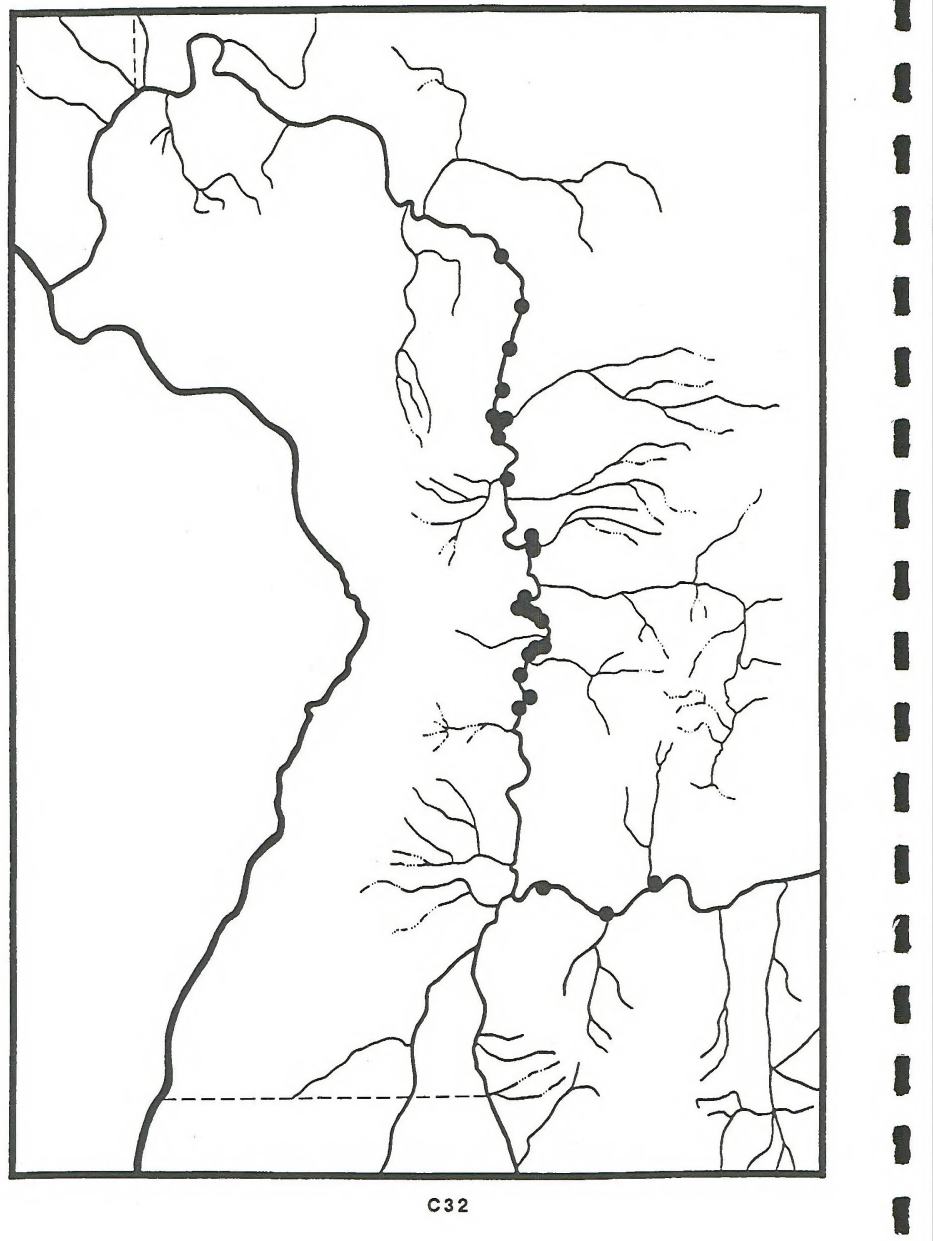


Oreohelix n. sp. 8

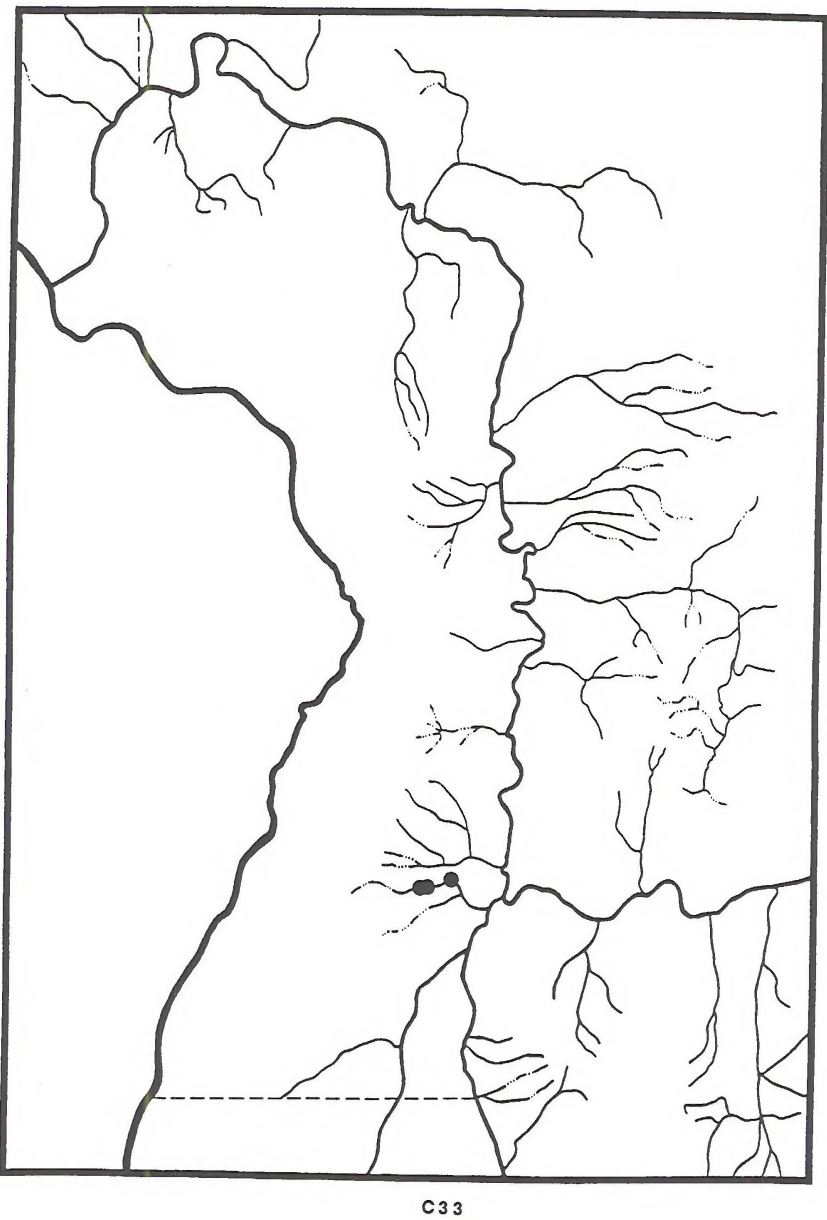


Oreohelix n. sp. 12

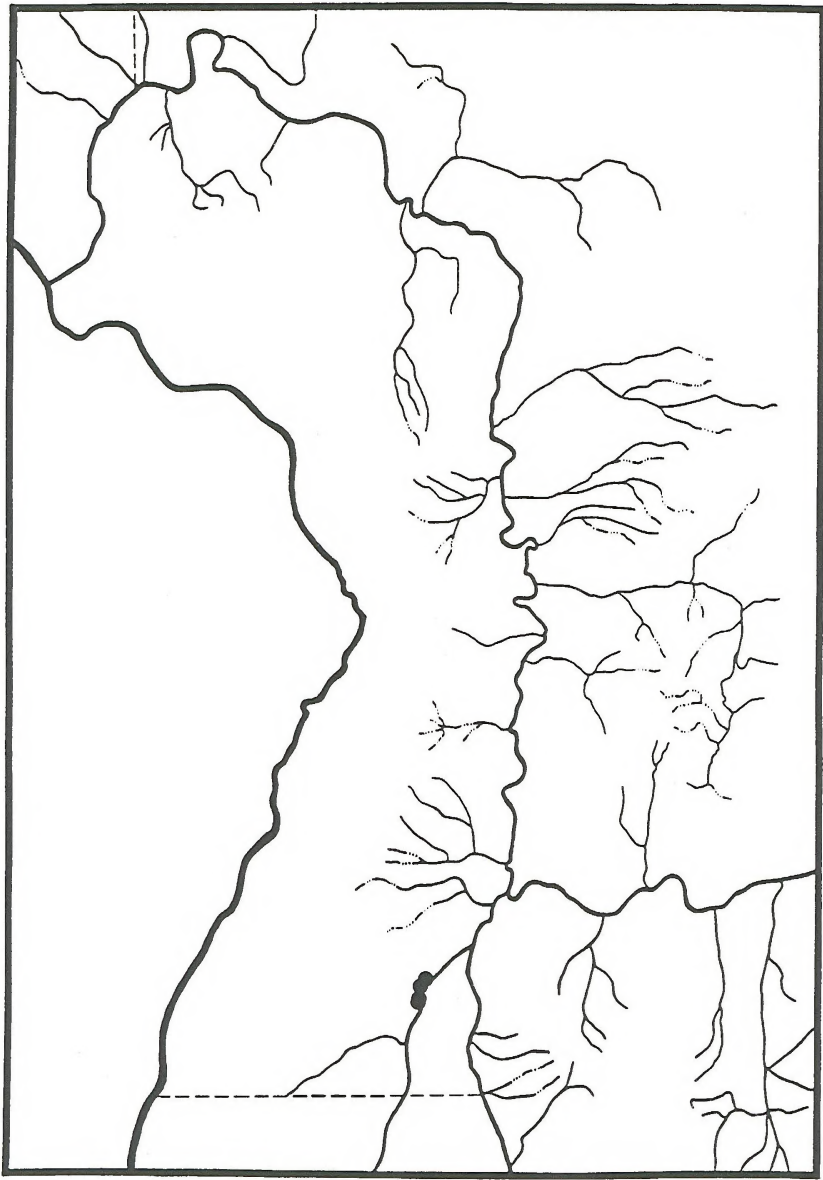


Oreohelix n. sp. 13

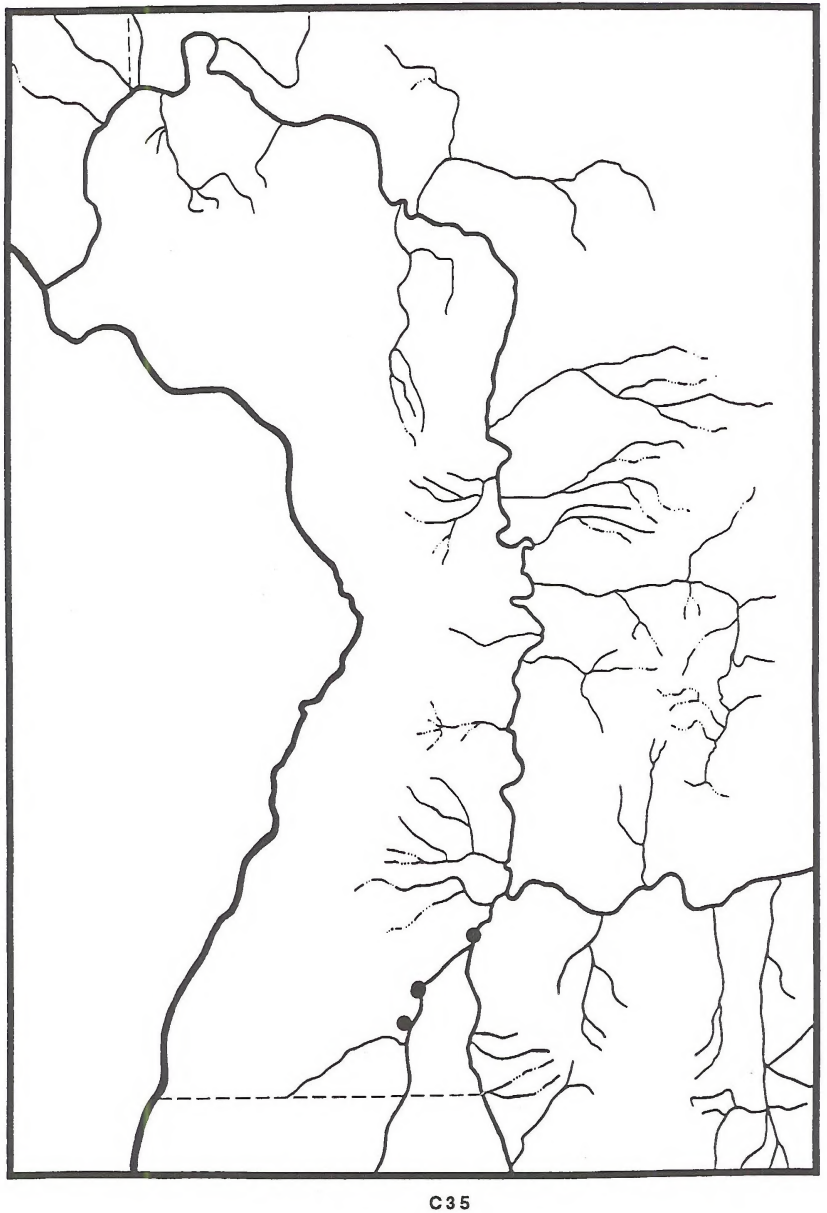


Oreohelix n. sp. 14

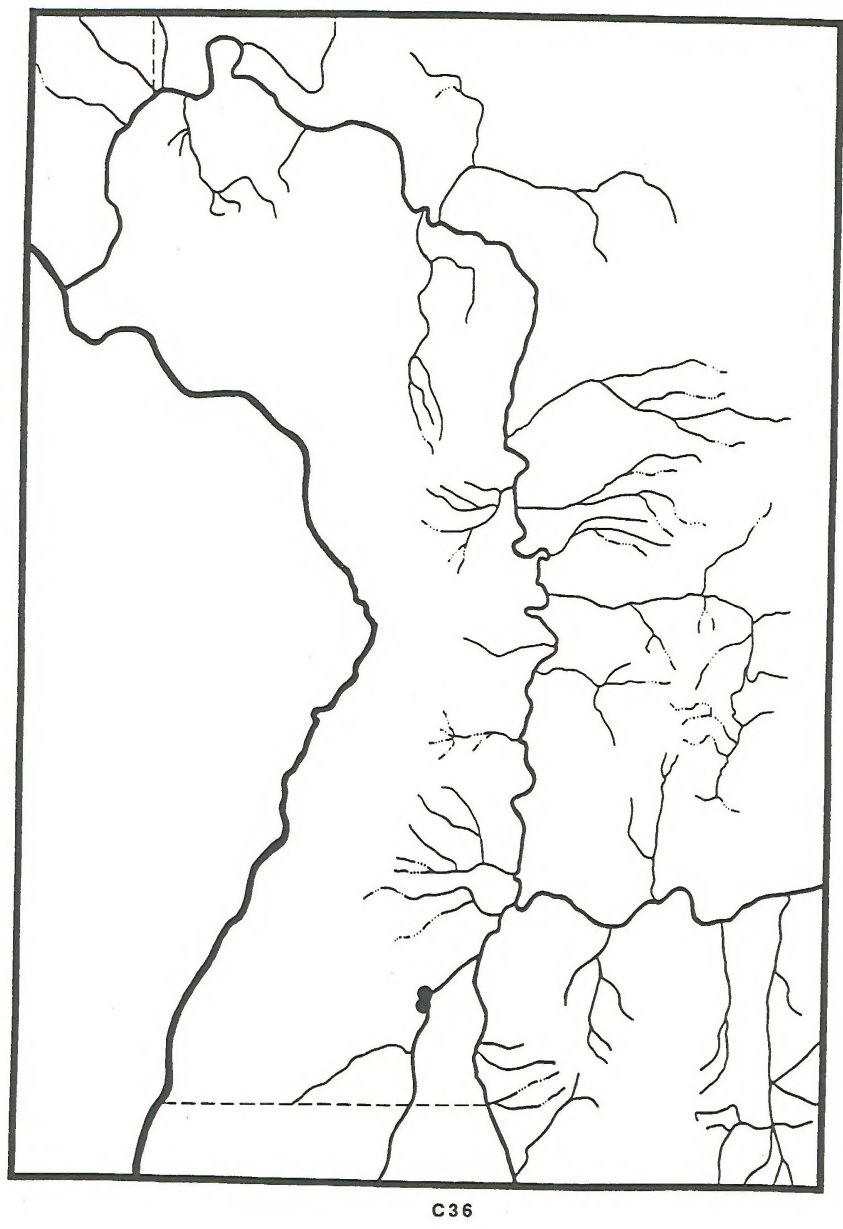


Oreohelix n. sp. 15

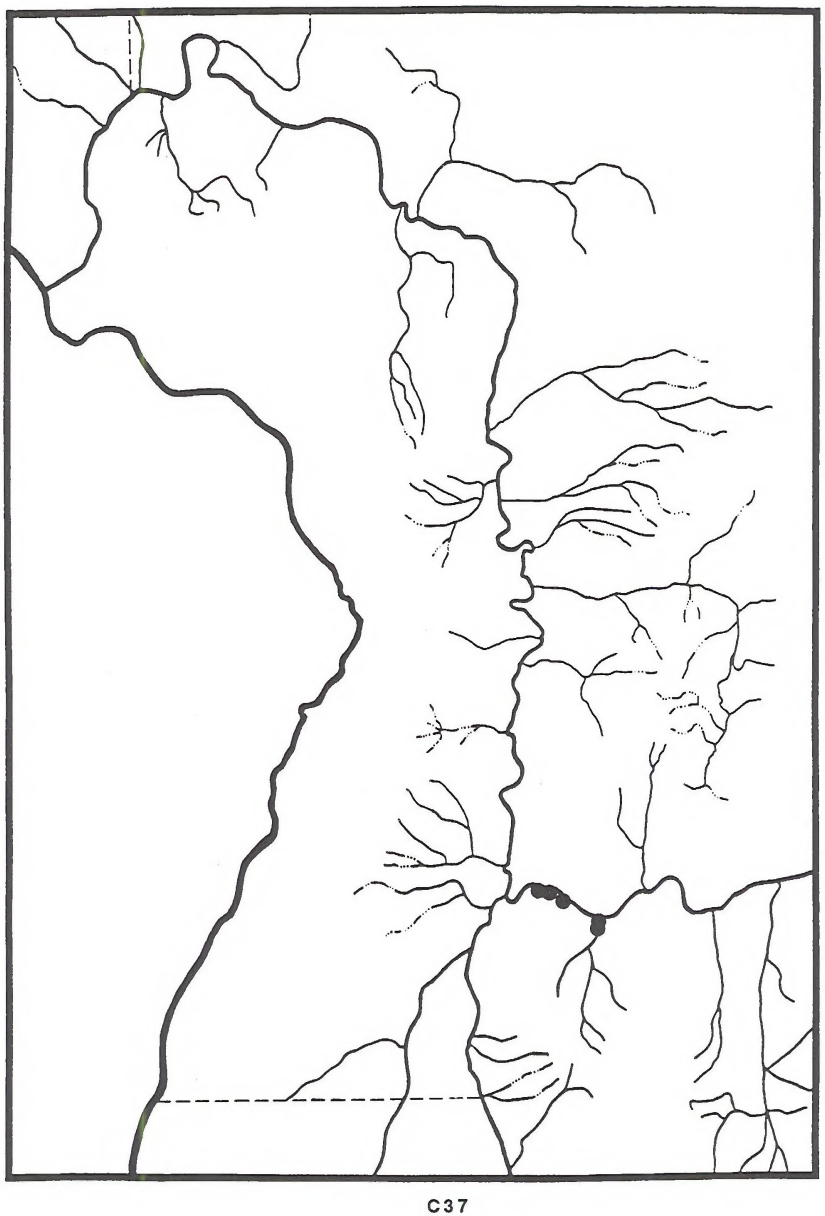


Oreohelix n. sp. 19

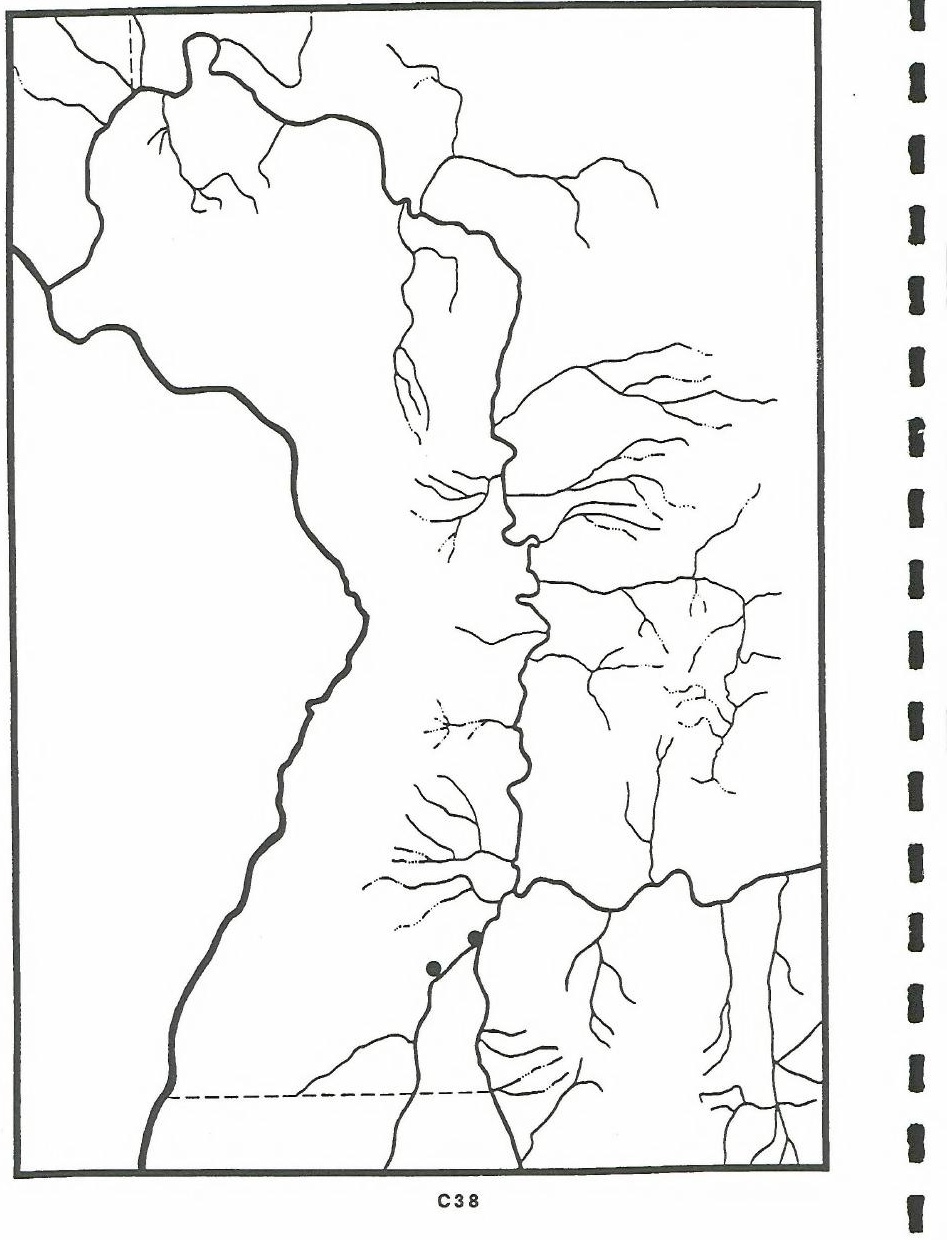


Oreohelix n. sp. 20

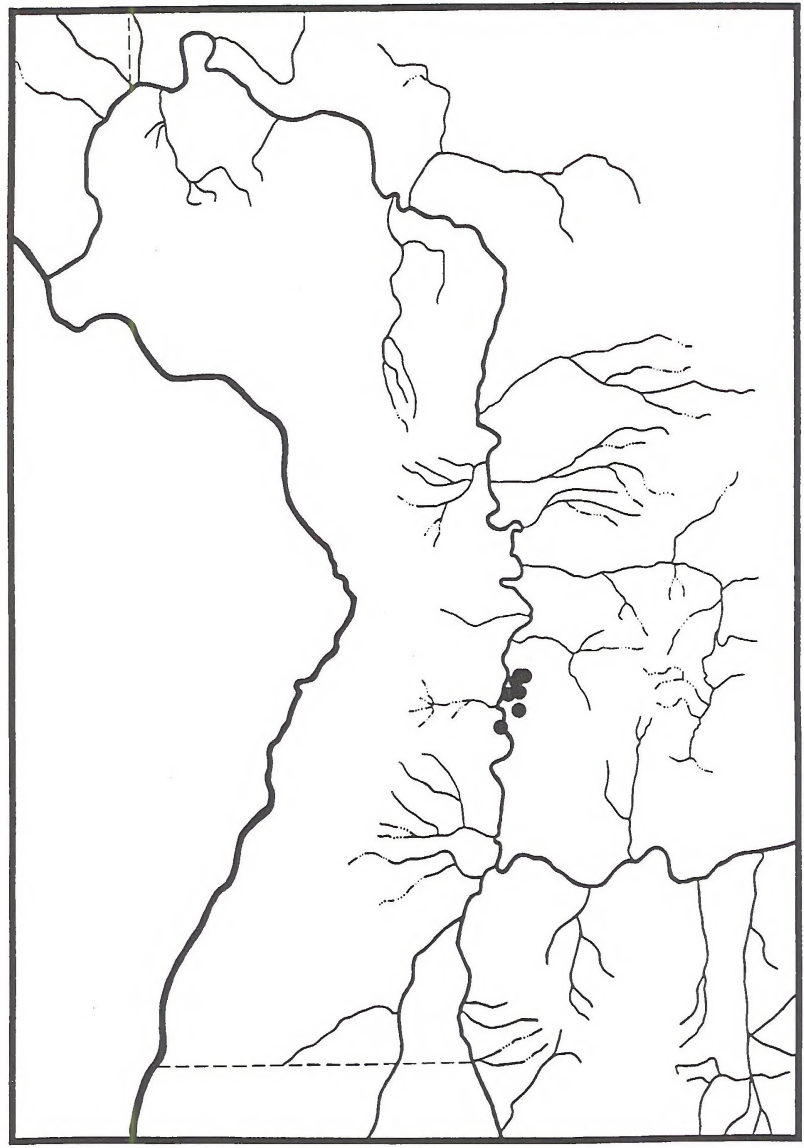

C 39 
Oreohelix n. sp. 21

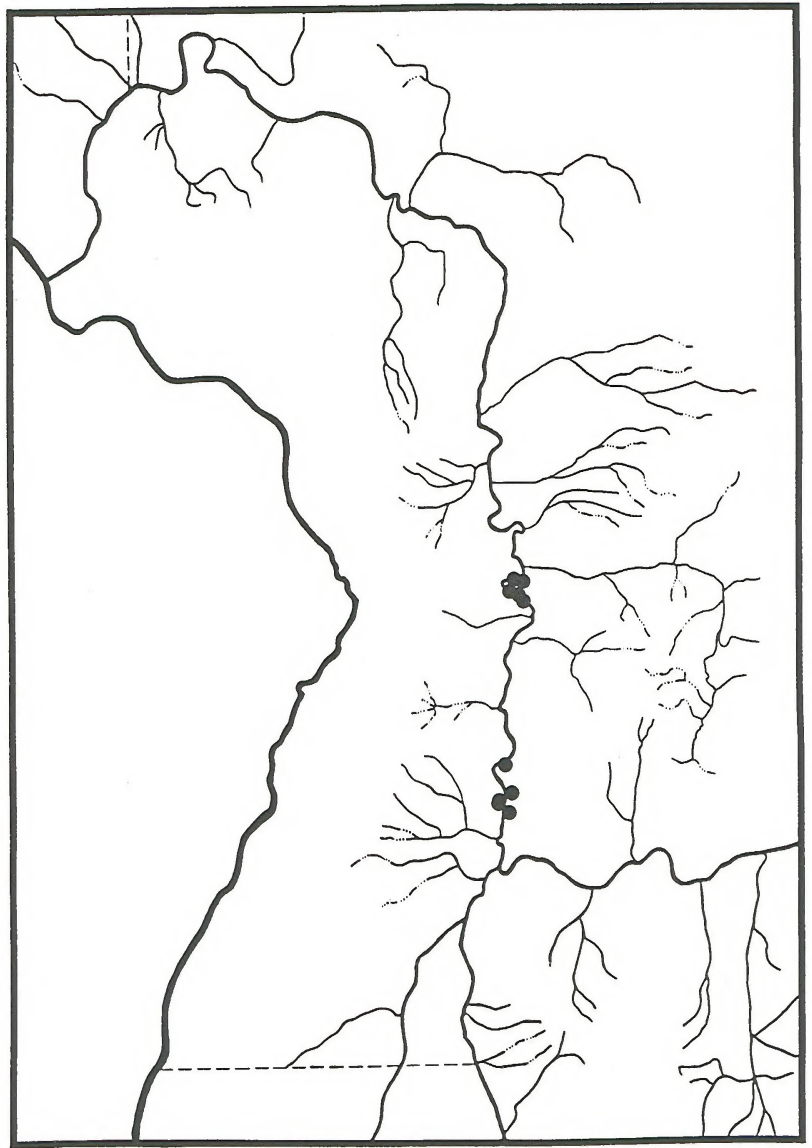

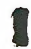

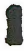

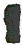

1

1

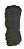

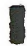

I

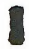

I

I

I

I

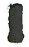

I

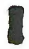

C 40 


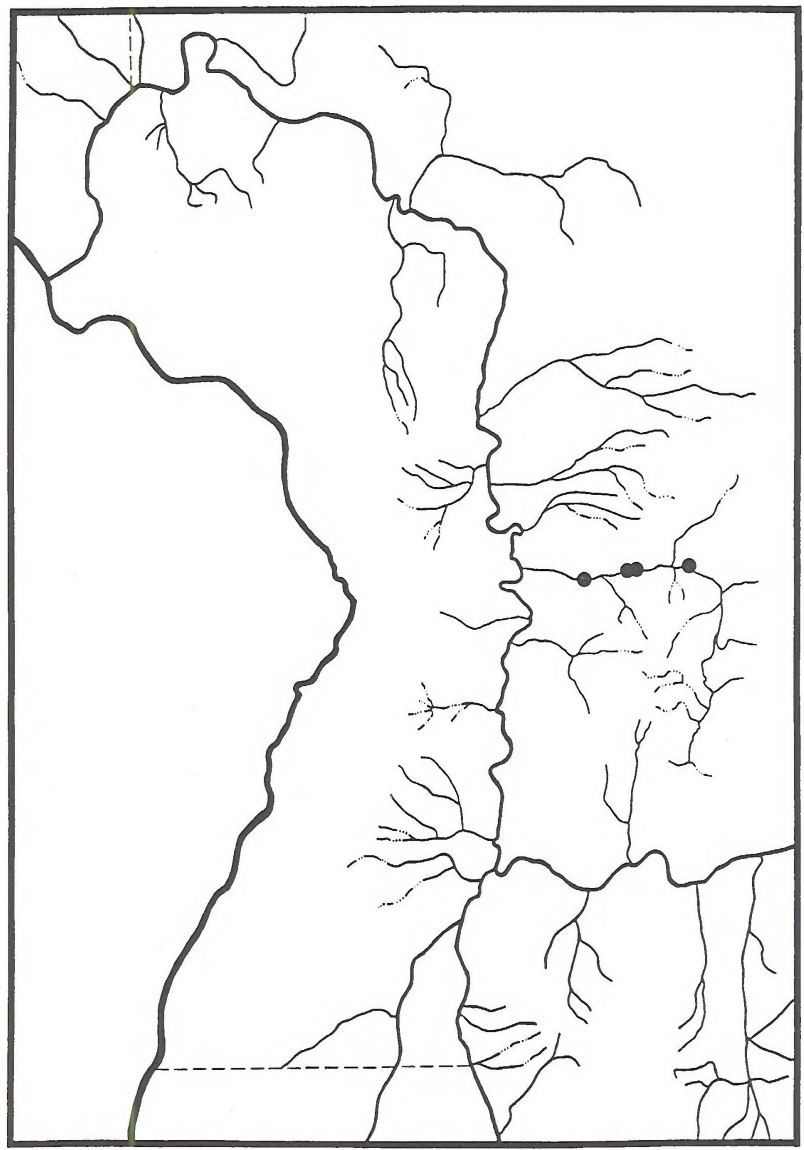


Oreohelix n. sp. 23

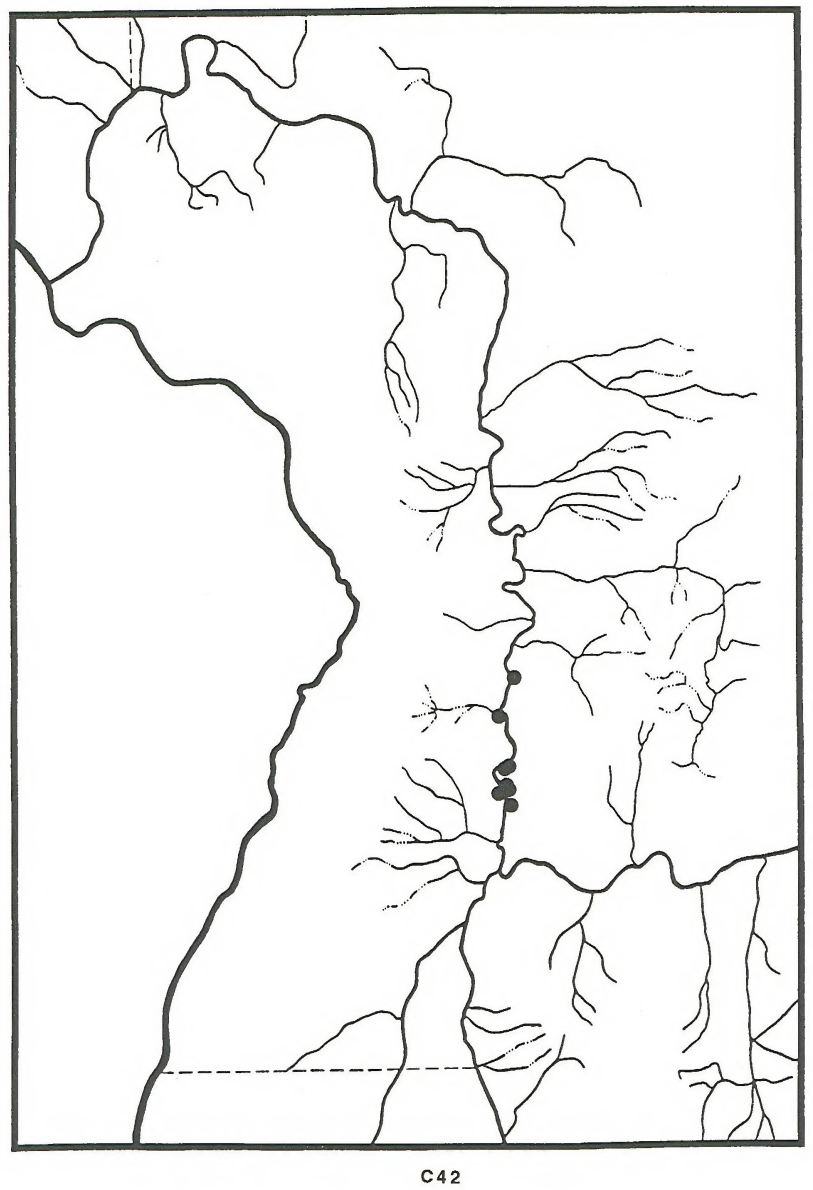

I

1

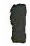

I

I

8

I

I

I

I

I

I

I

I

I

I

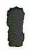


Oreohelix n. sp. 24

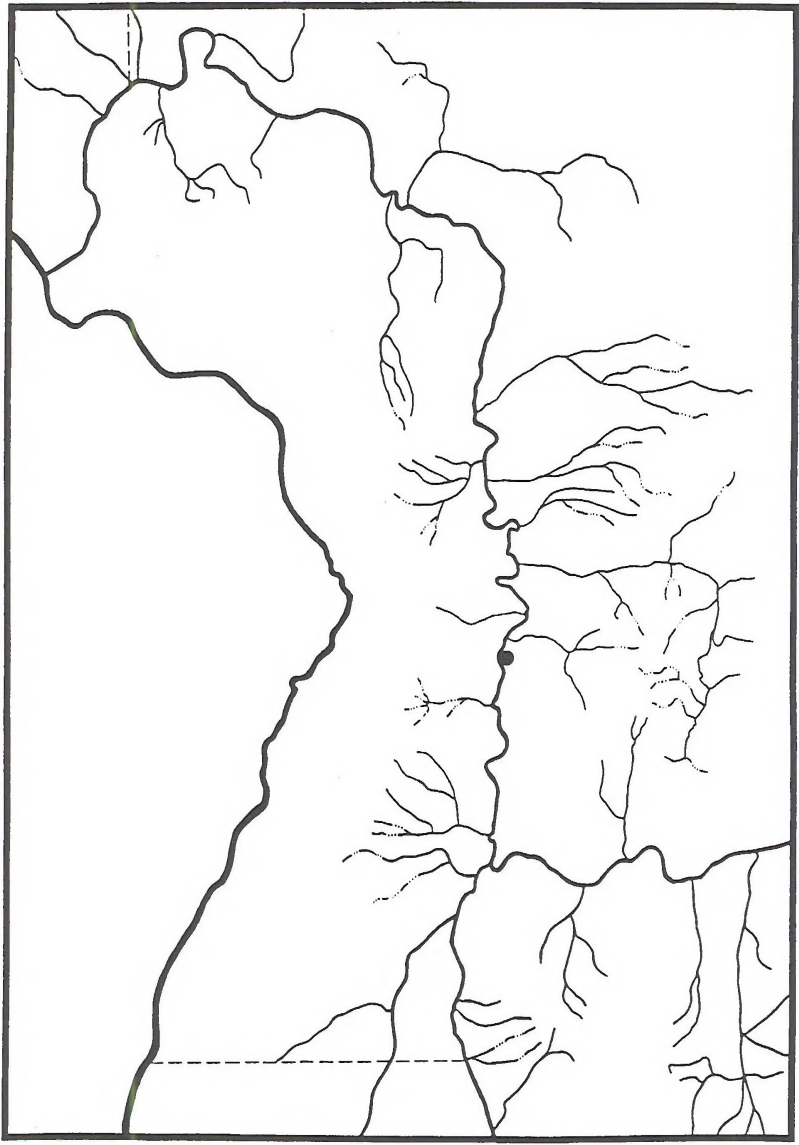

C 43 
Oreohelix n. sp. 25

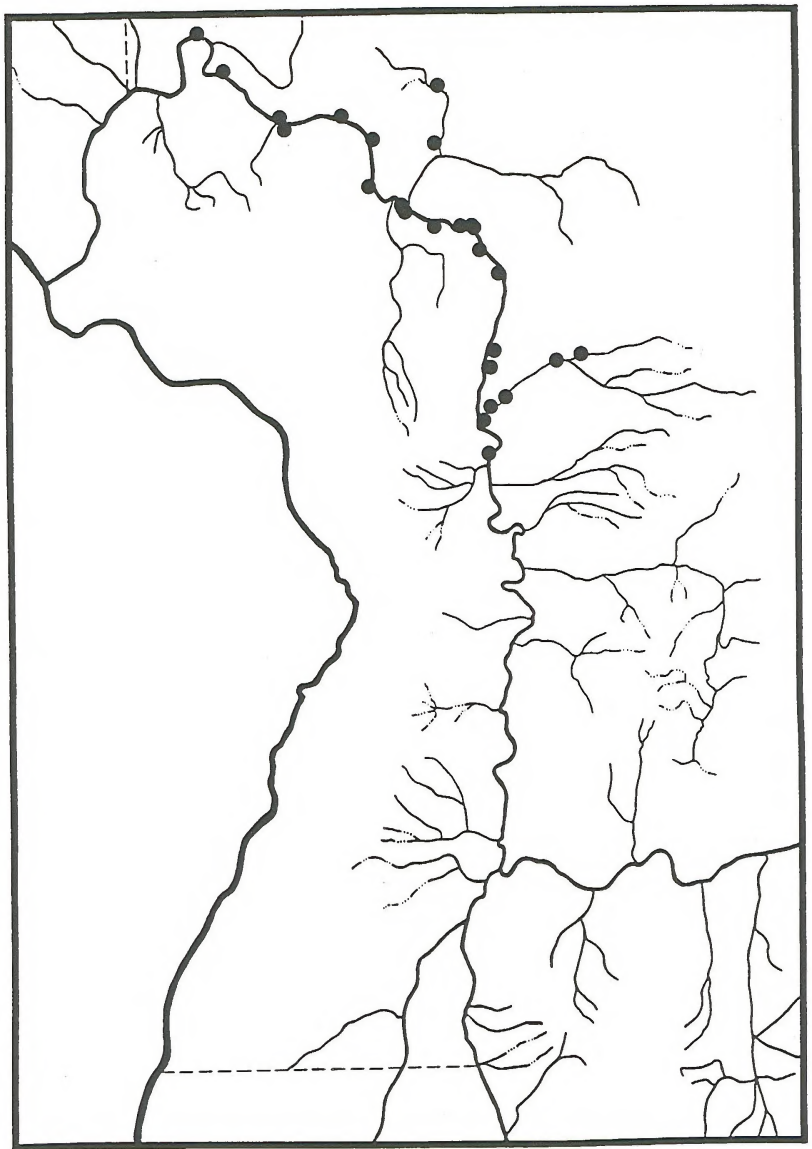

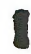

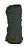

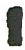

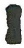

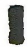

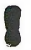

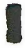

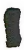

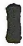

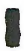

I

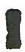

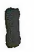

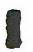

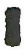

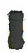

C 44 


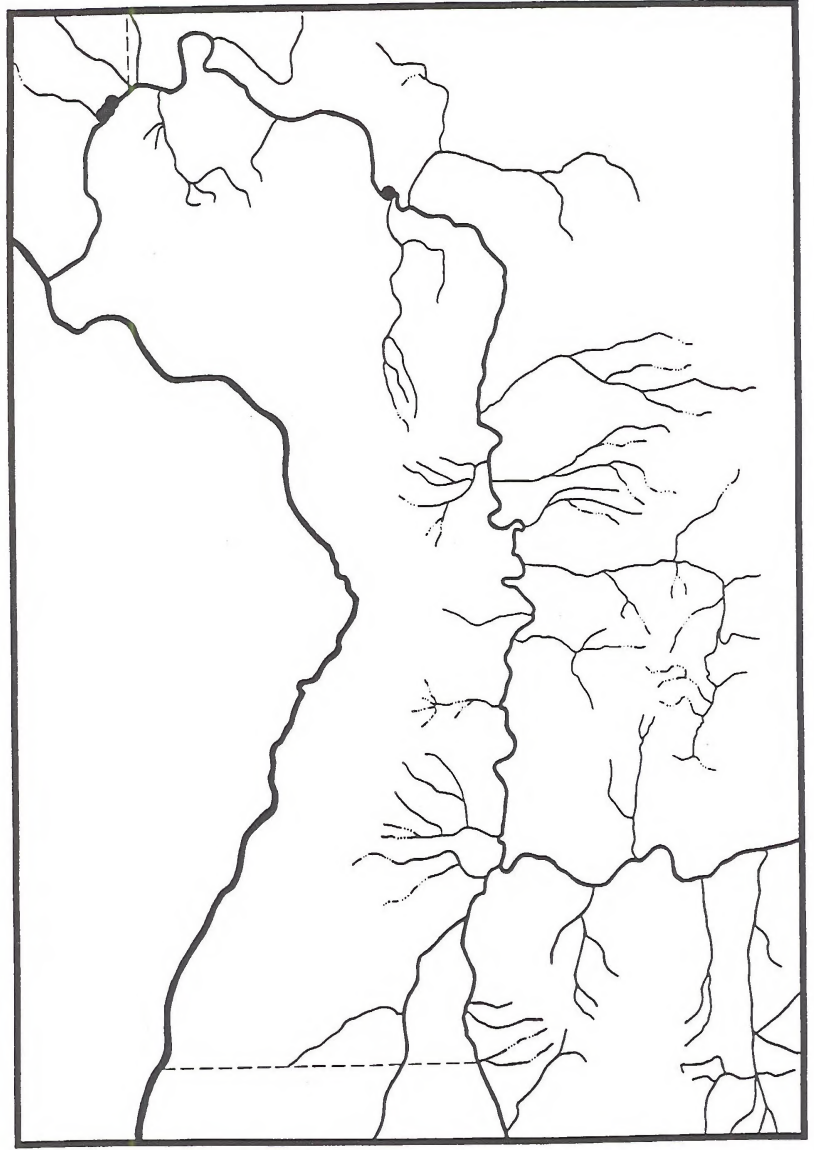

C 45 
Oreohelix n. sp. 32

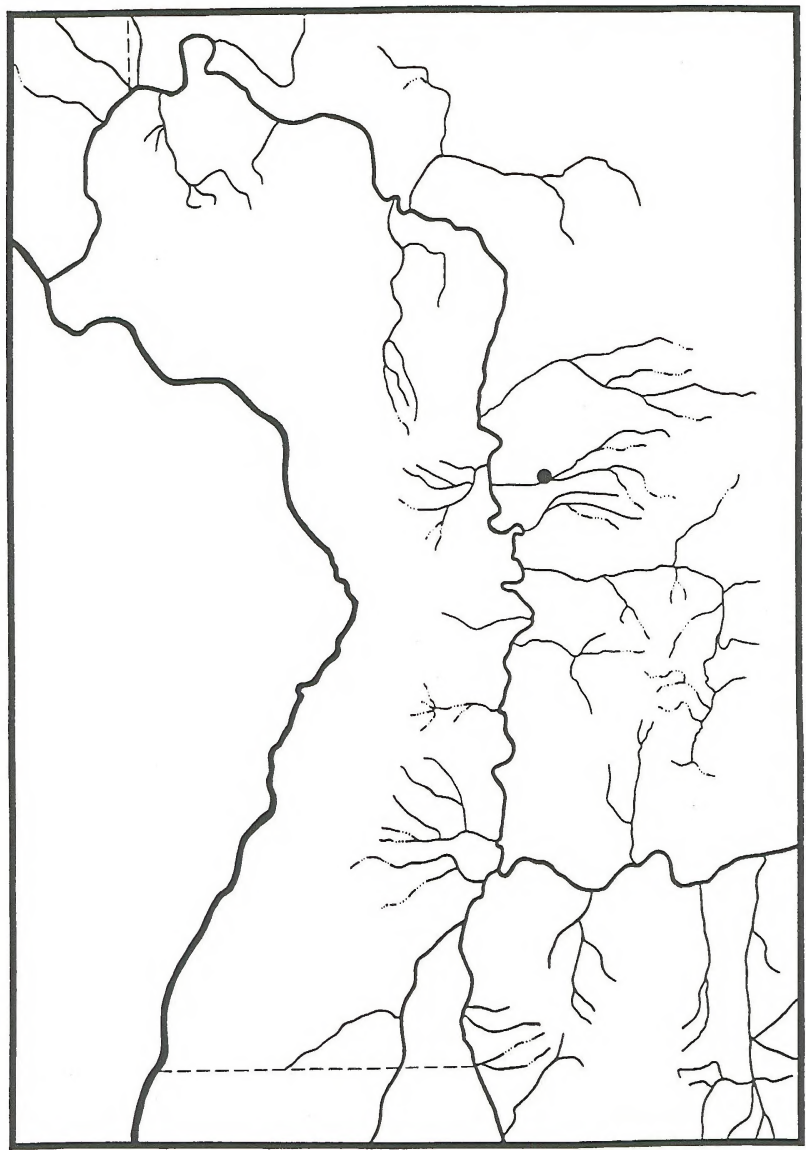

I

I

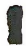

I

I

8

I

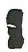

I

I

I

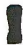

I

I

I

I

C 46 


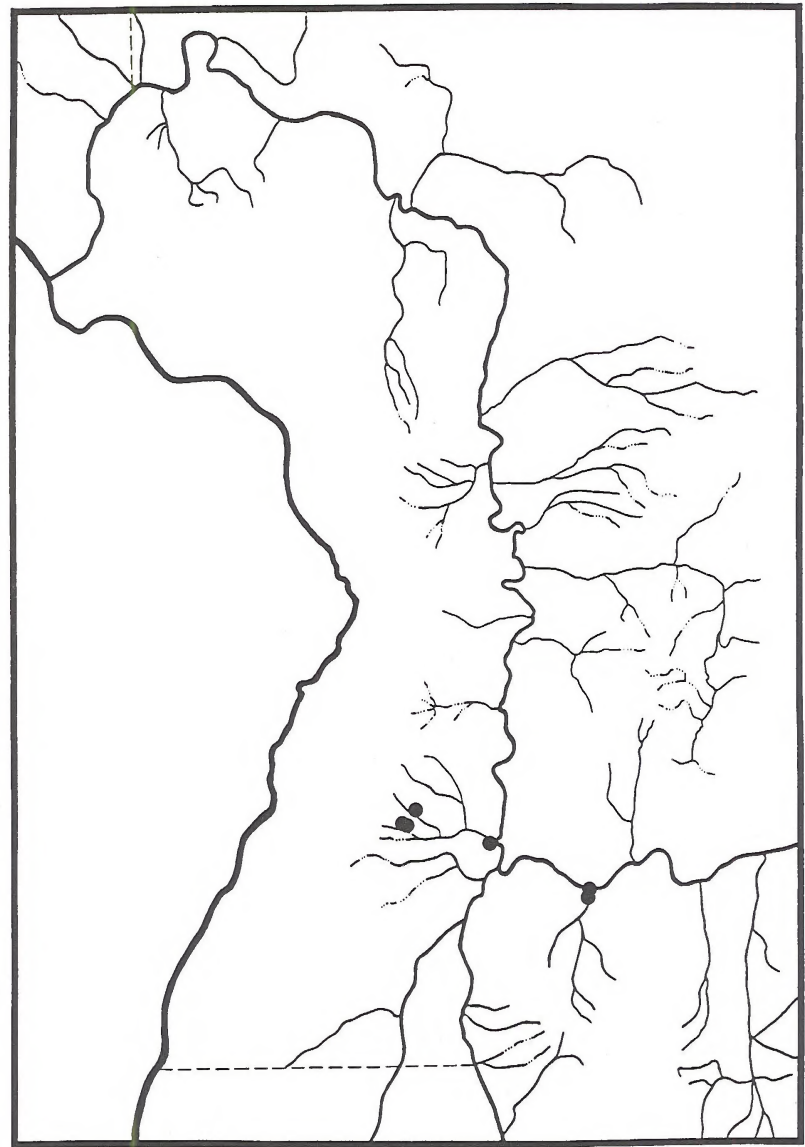


Oreohelix strigosa n. subsp. 1

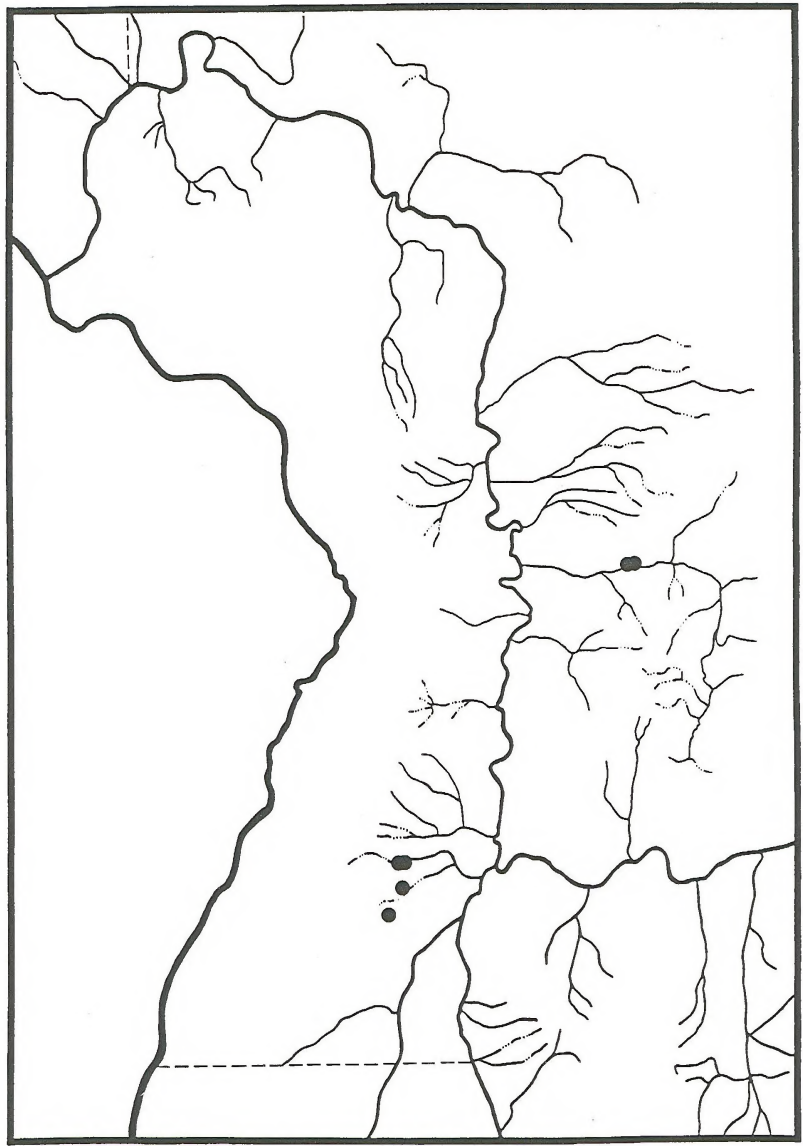

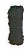

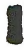

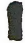

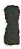

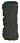

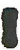

I

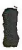

I

I 


\section{Oreohelix vortex Berry, 1932}

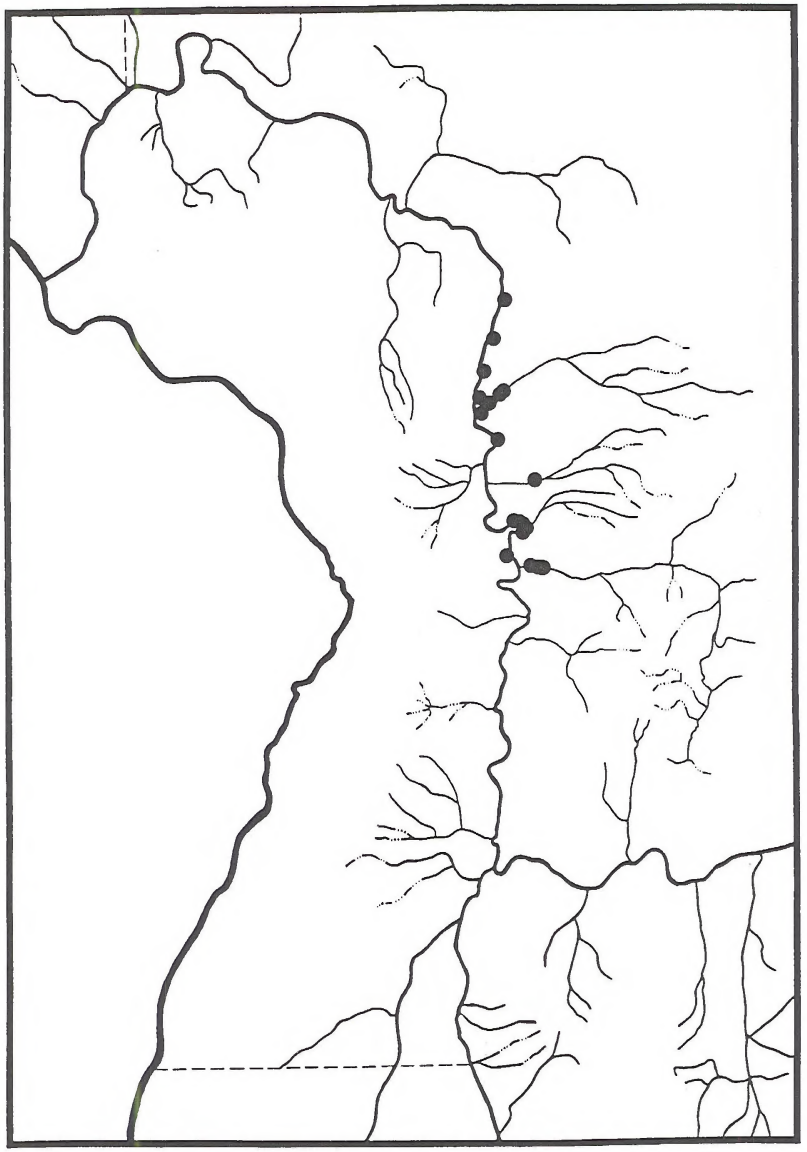

C 49 
Oreohelix waltoni Solem, 1975

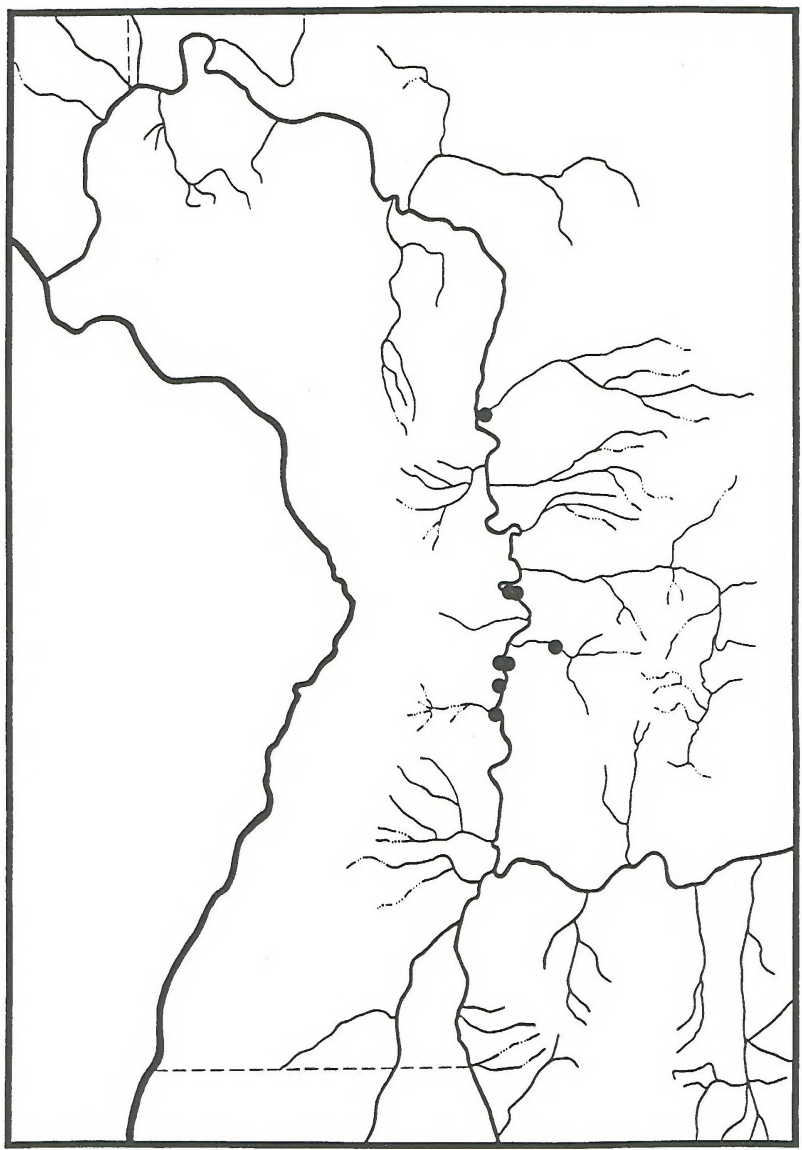

C 50 
Planogyra clappi (Pilsbry, 1898)

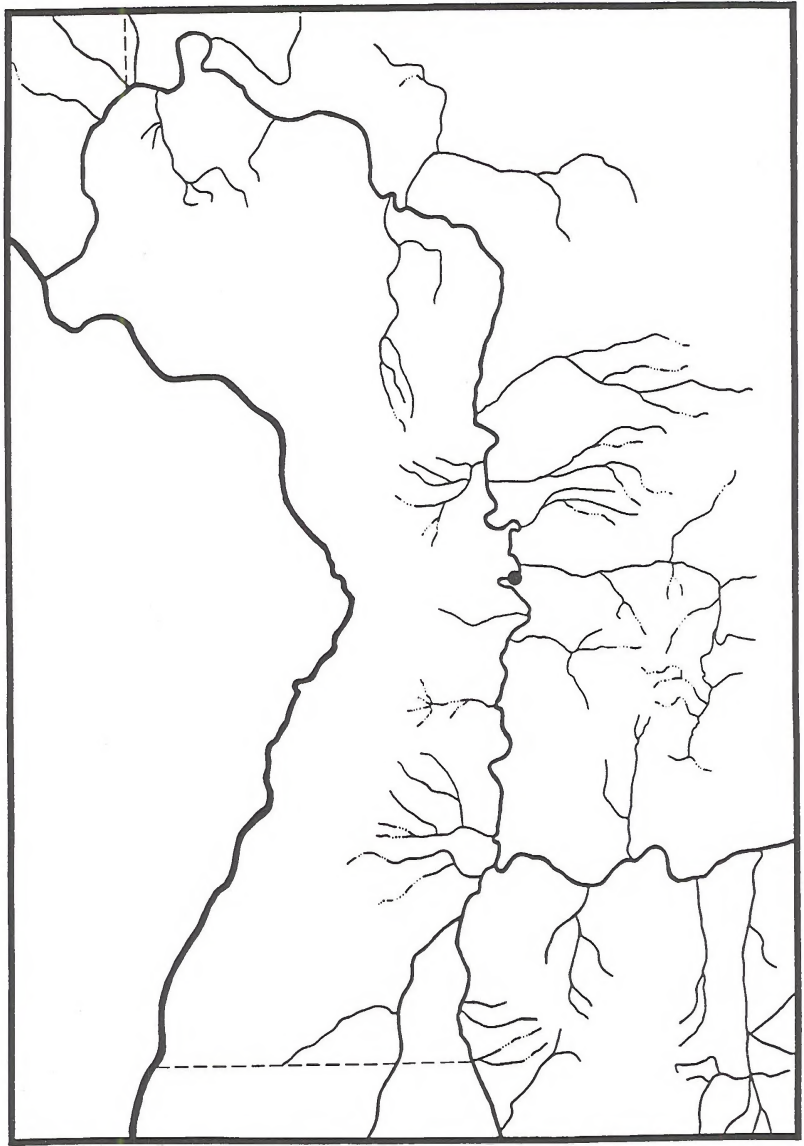

C51 
Polygyrella polygyrella (Bland \& Cooper, 1861)

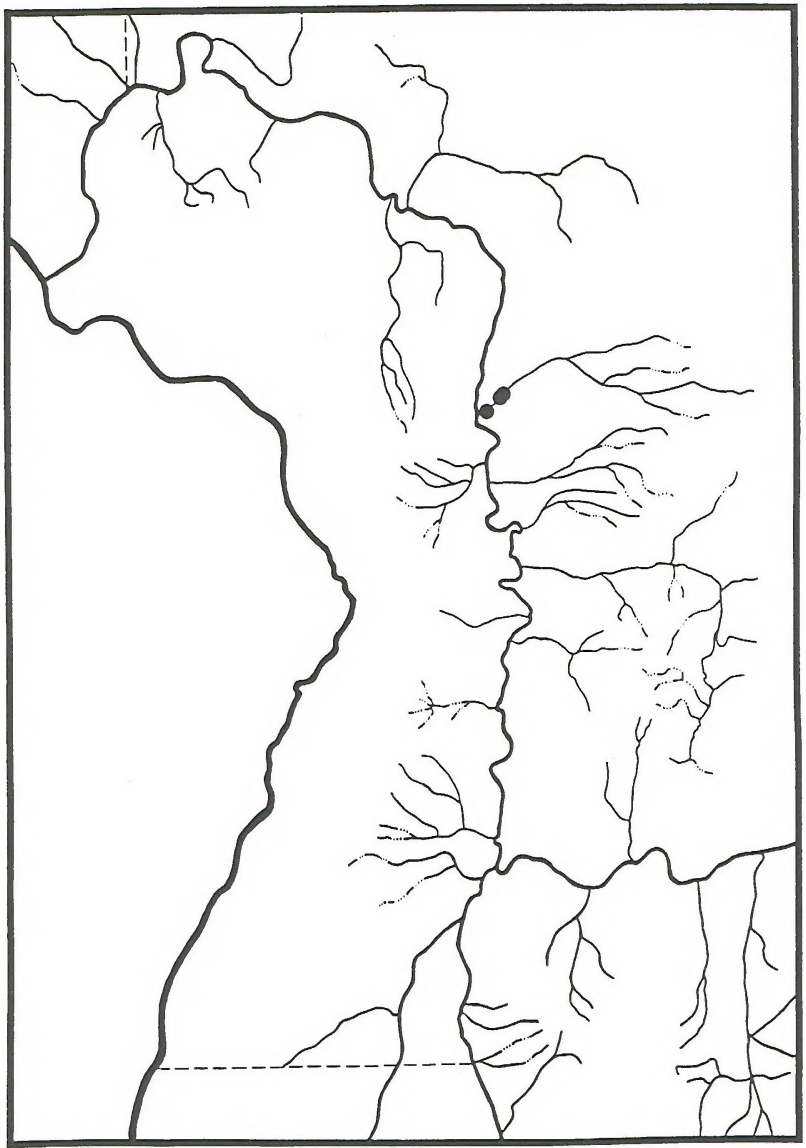

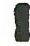

I

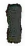

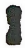

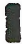

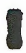

I

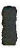

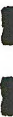




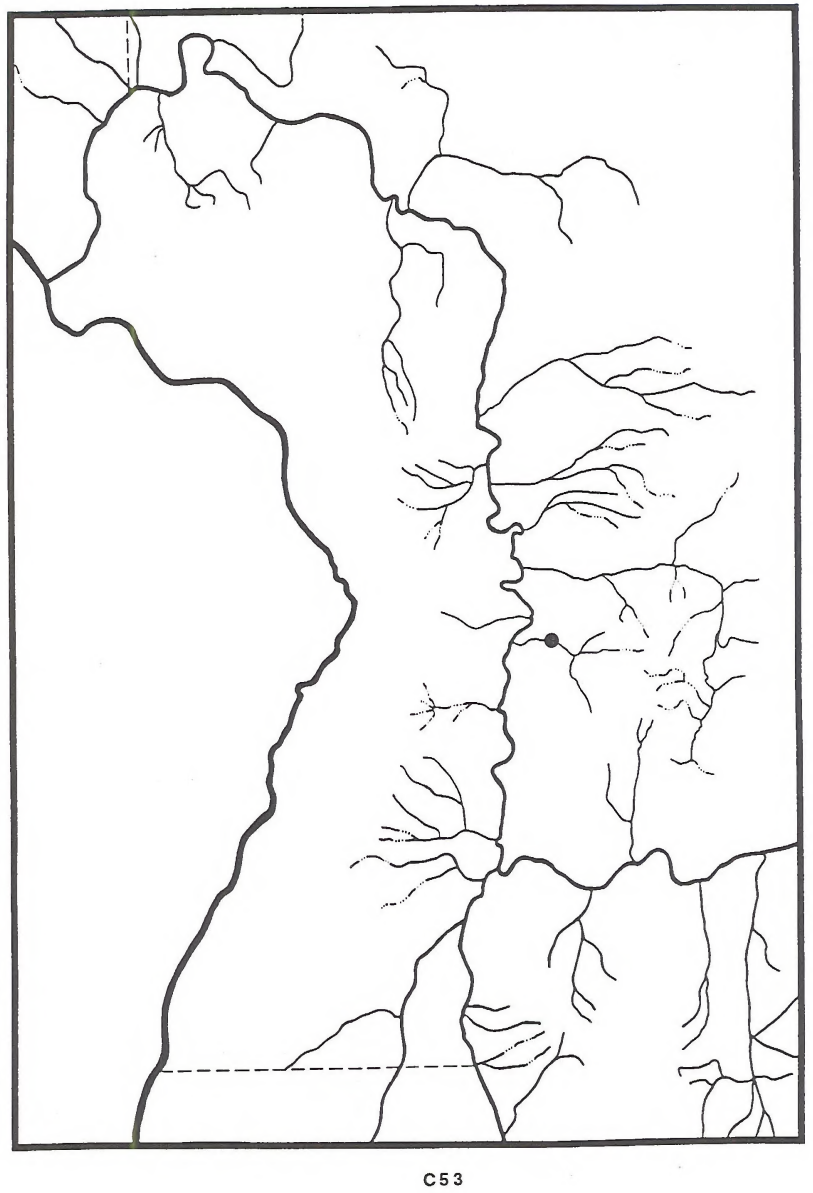


Punctum pusillum (Lowe, 1831)

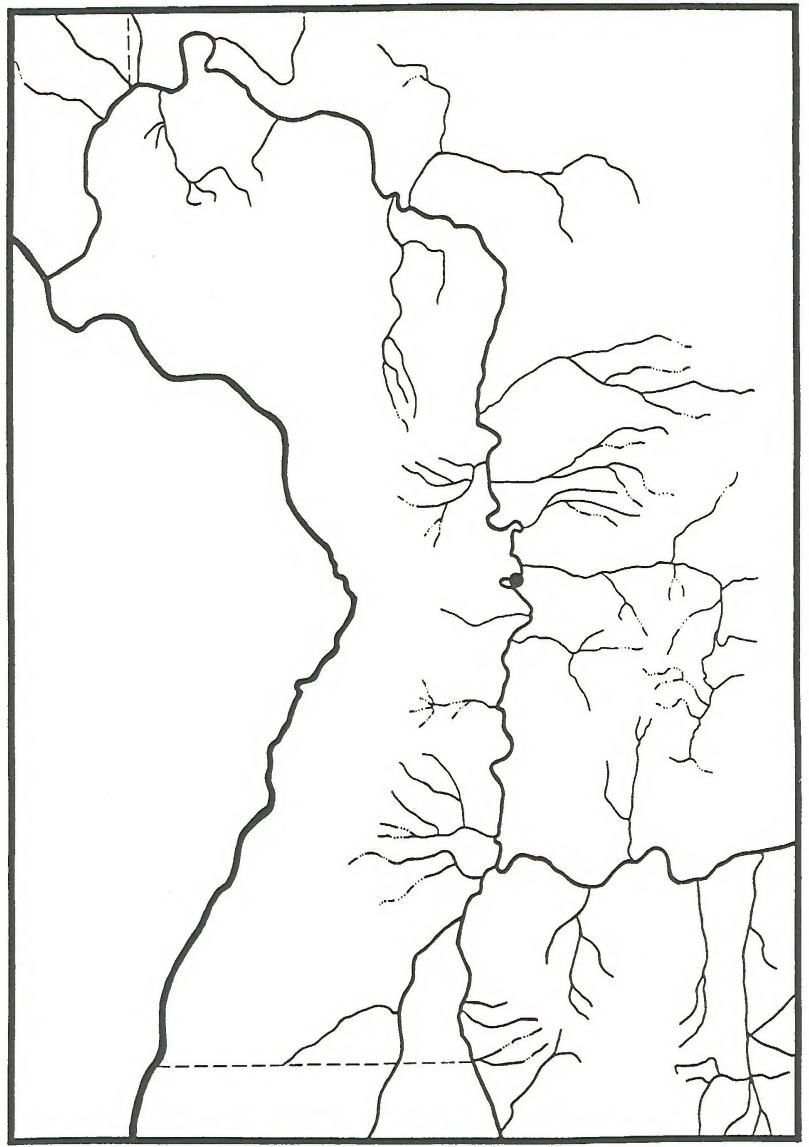


Pupilla hebes (Ancey, 1881)

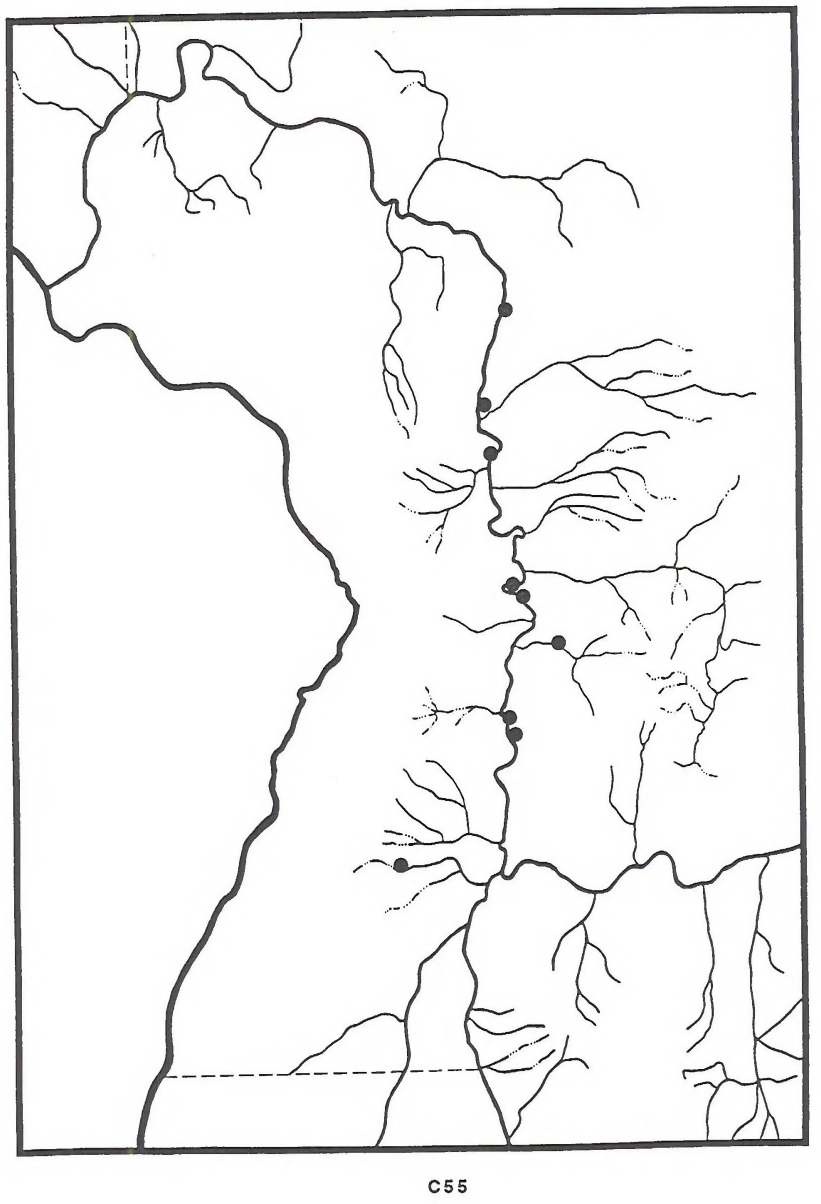




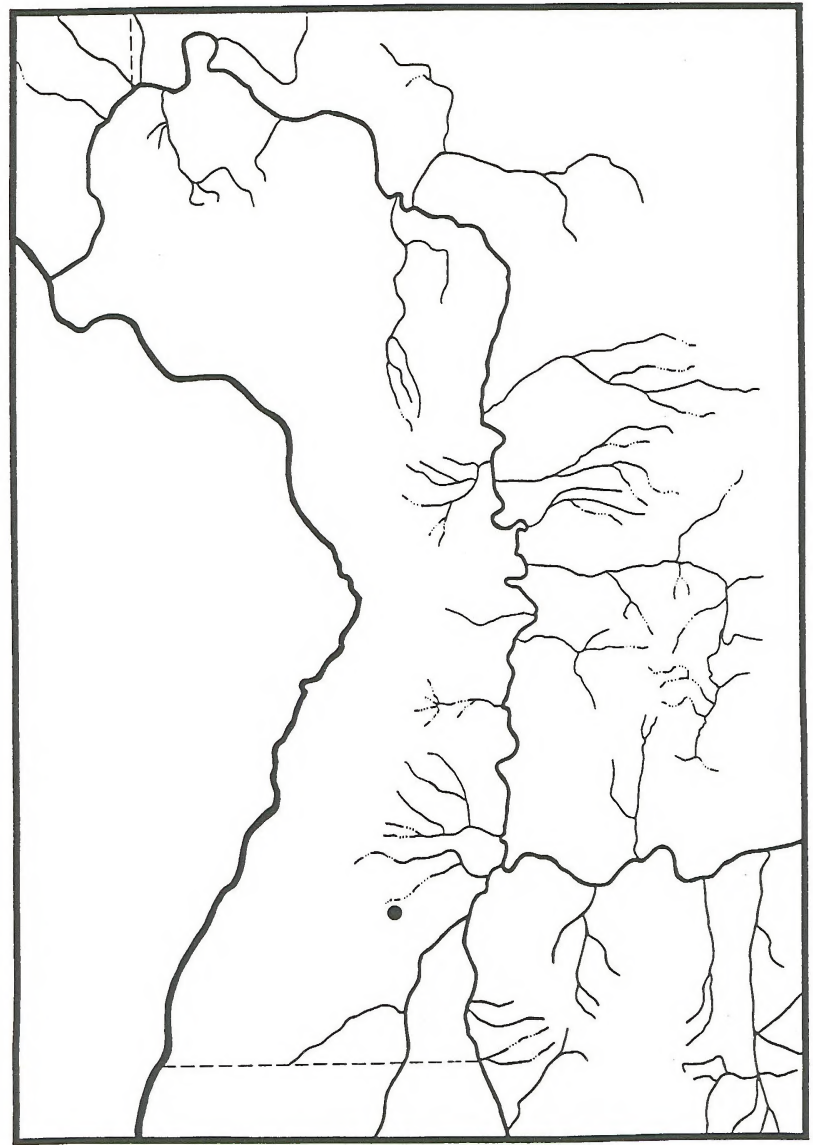

C5 6 


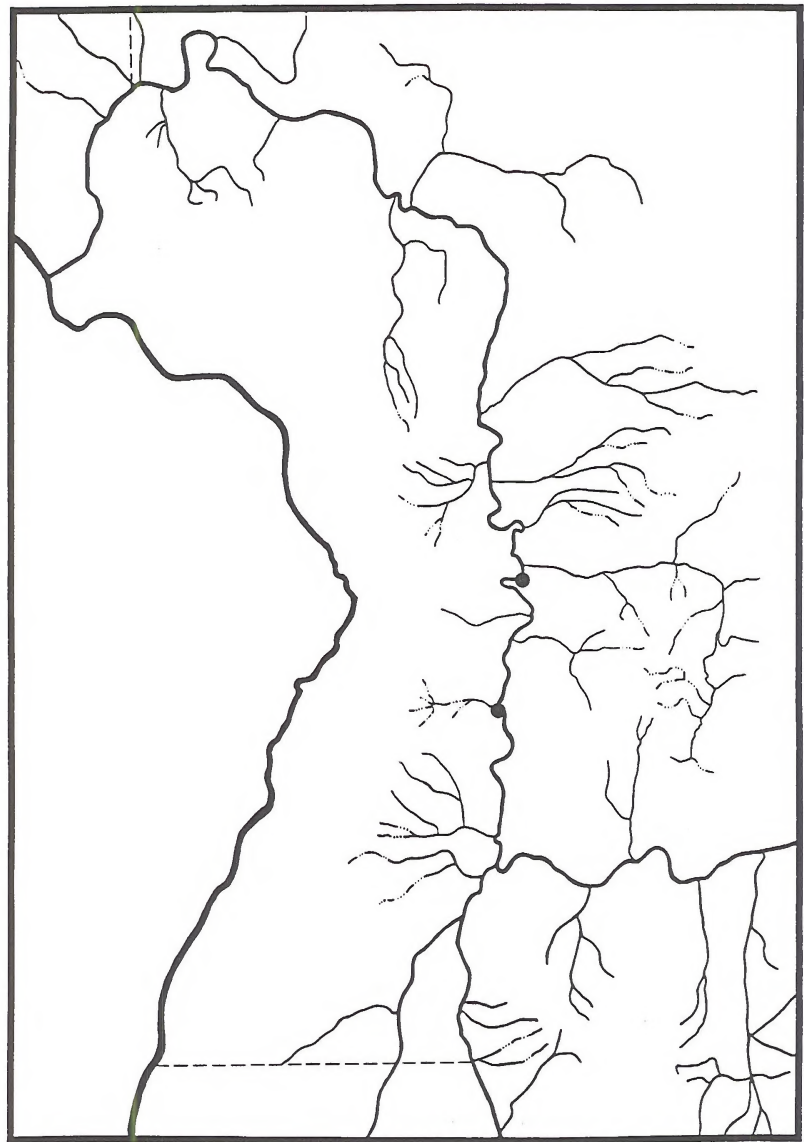

C 57 
Vallonia cyclophorella (Sterki, 1892)

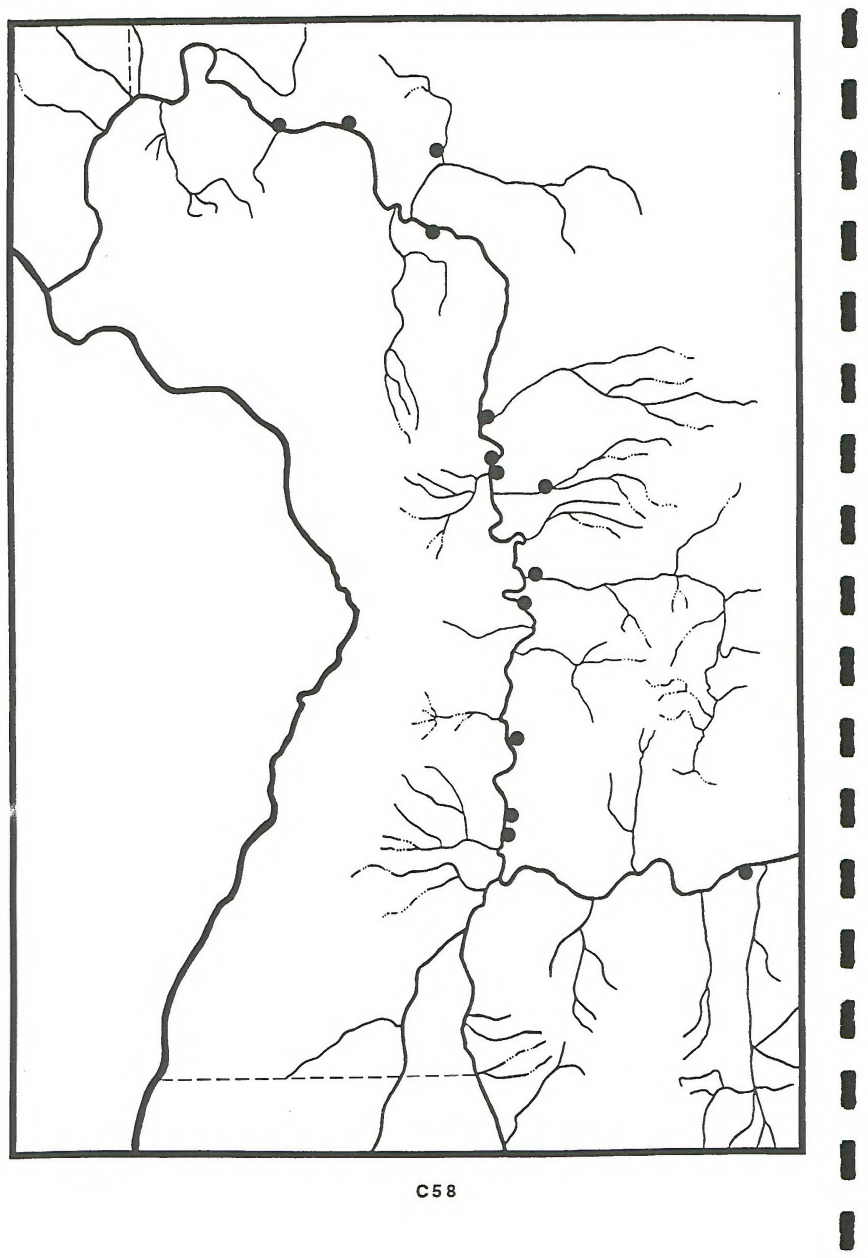


Vertigo concinnula Cockerell, 1897

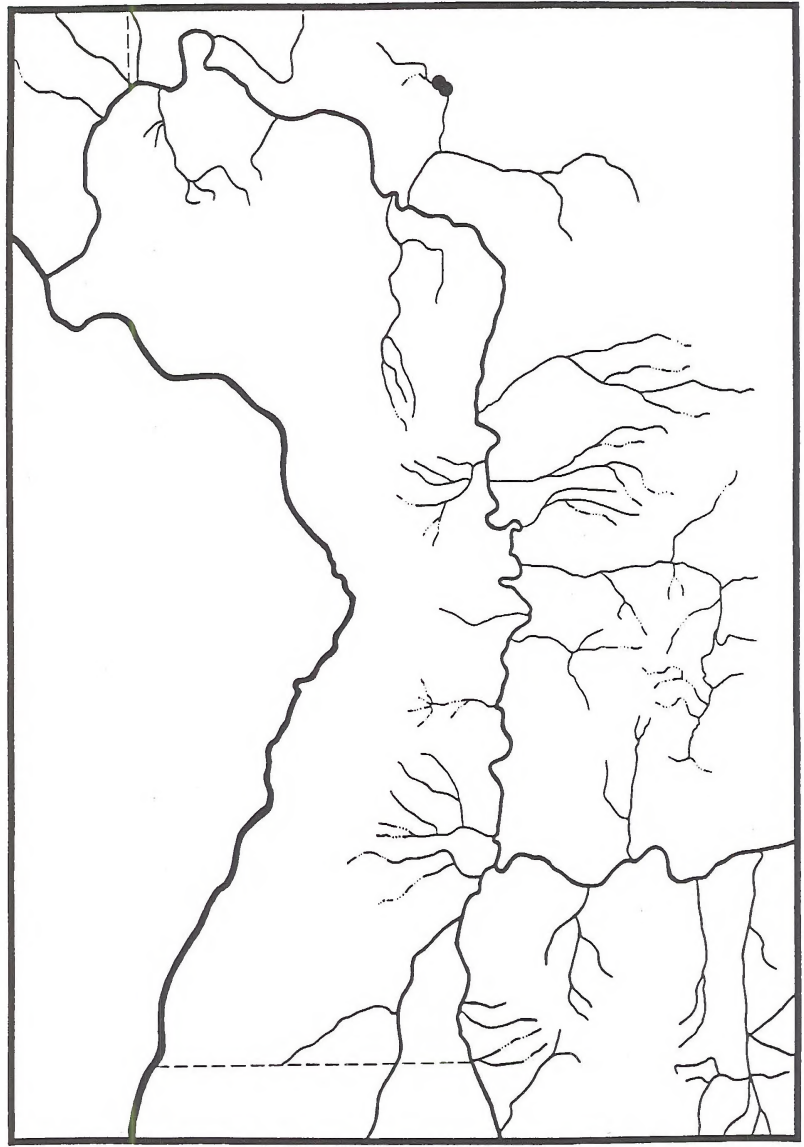

C59 
Vitrina alaskana Dall, 1905

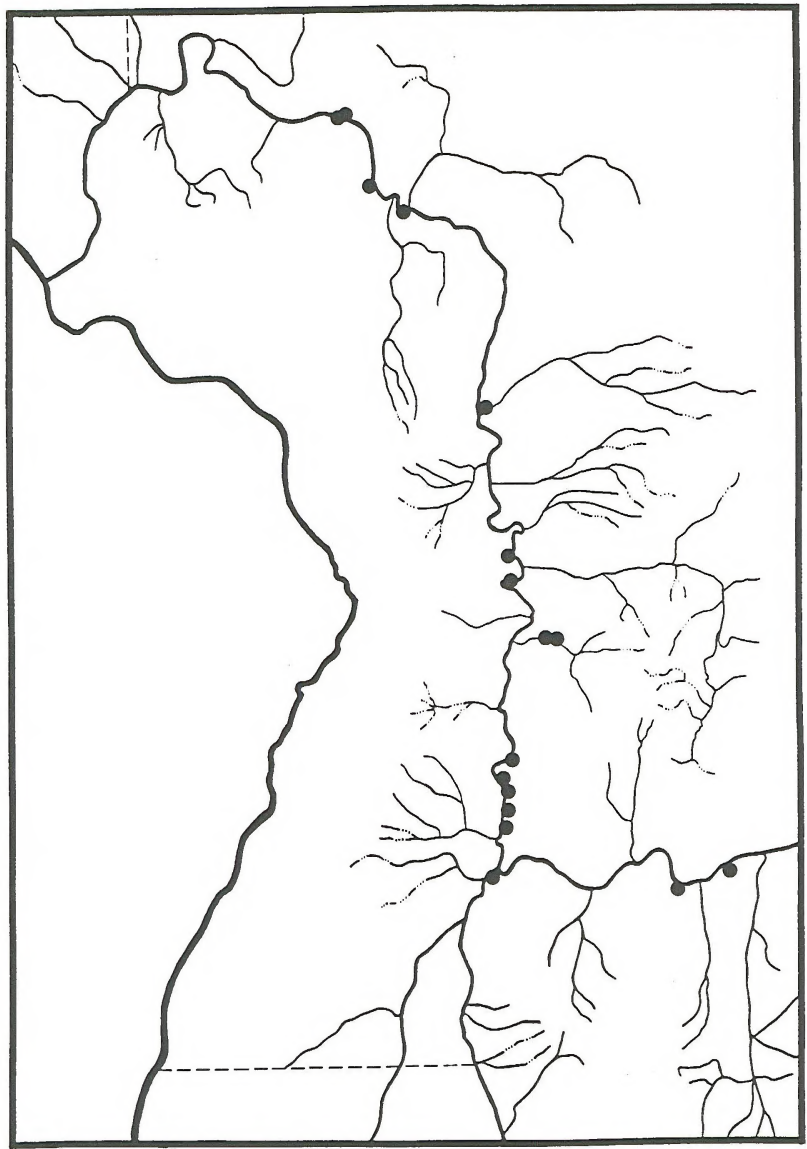

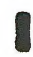

I

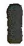

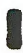

I

I

I

. 


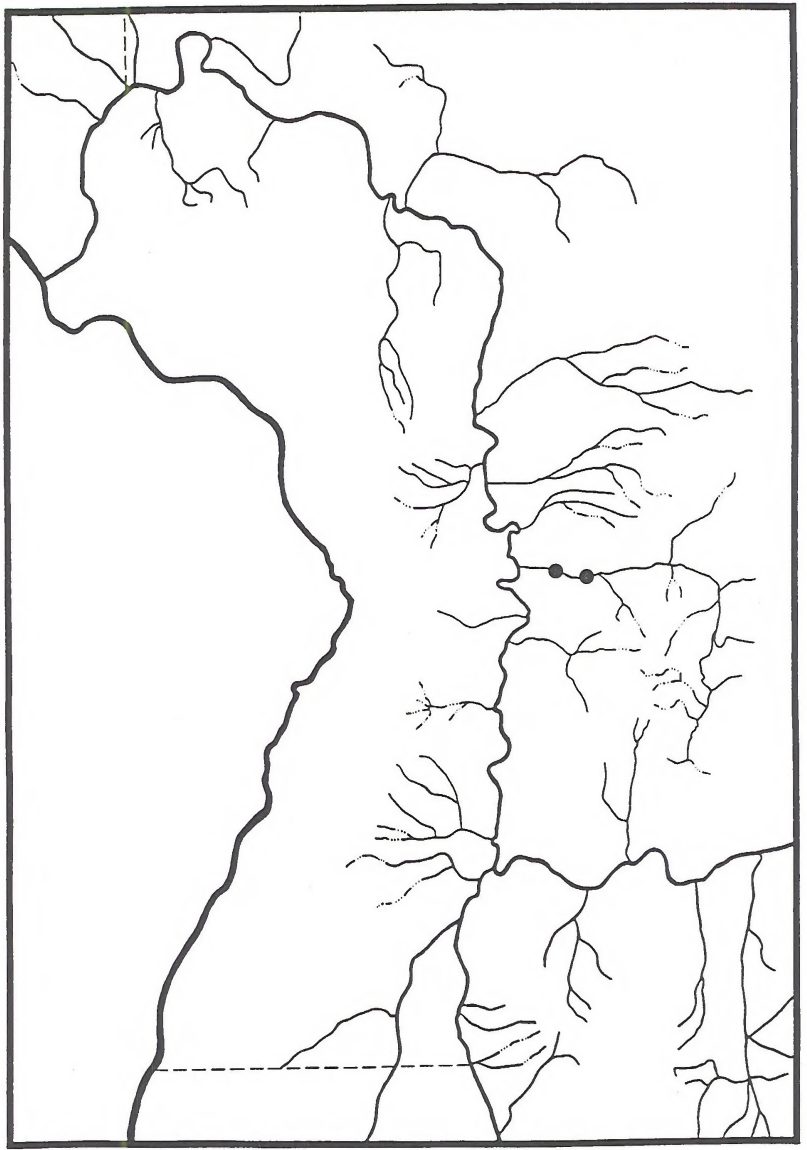


Zonitoides (Zonitoides) arboreus (Say, 1816)

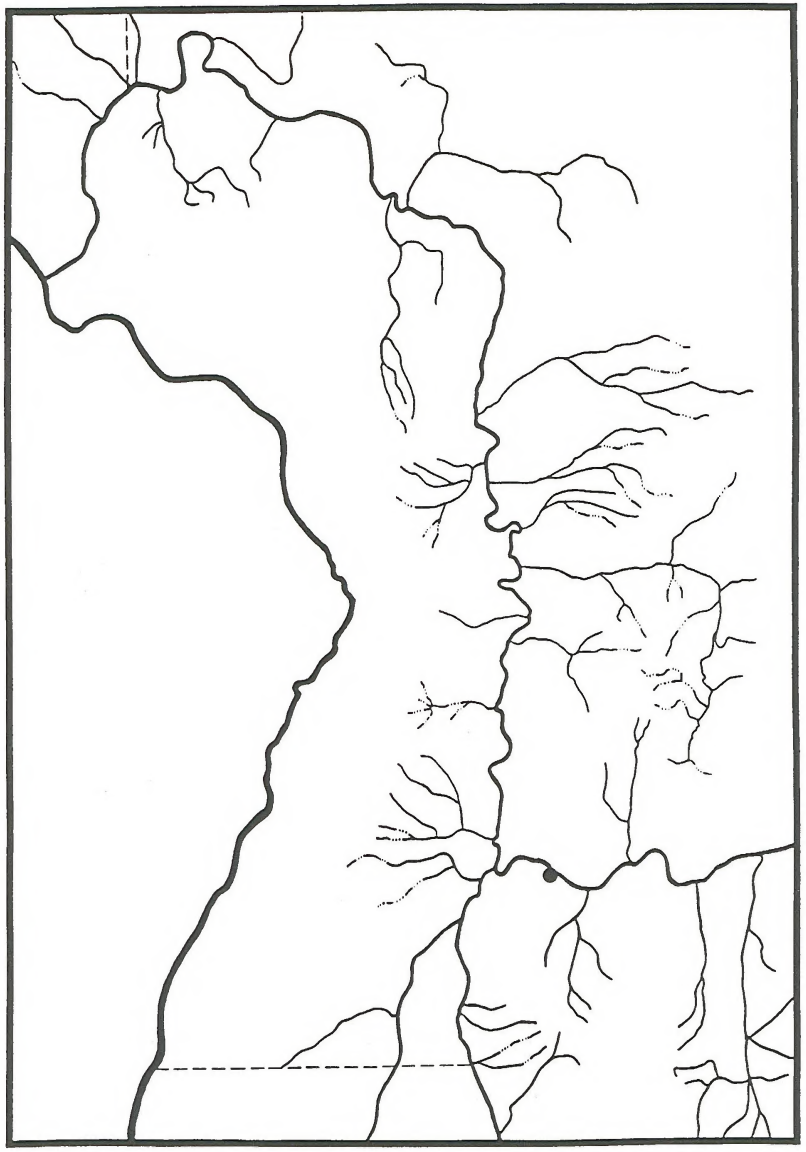

I

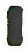

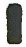

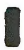

,

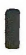

I

I

I

I

I

I

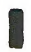

I

I

I

C62 

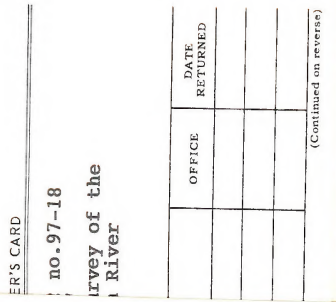

QL 84.2 . . 352 no.97-18 88055407 Land snail survey of the lower Salmon River

BLIVI LISMAM BLDG 50, ST-150A DENVER FEDERAL CENTER P.O. BOX 25047 DENVER, COLORADO 80225 


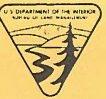

Bureau of Land Management Idaho State Office

1387 S. Vinnell Way

Boise, Idaho 83709

BLM/ID/PT-98/002+1150 